\title{
GREENLANDIC ICE ARCHIVES OF NORTH ATLANTIC COMMON ERA CLIMATE
}

\author{
by
}

\author{
Matthew B. Osman \\ B.A., Augustana College (2014)
}

Submitted in partial fulfillment of the requirements for the degree of

Doctor of Philosophy

at the

\section{MASSACHUSETTS INSTITUTE OF TECHNOLOGY \\ and the \\ WOODS HOLE OCEANOGRAPHIC INSTITUTION}

\begin{abstract}
September 2019
C2019 Matthew B. Osman. All rights reserved.

The author hereby grants to MIT and WHOI permission to reproduce and to distribute publicly paper and electronic copies of this thesis document in whole or in part in any medium now known or hereafter created.
\end{abstract}

Author

Joint Program in Oceanography/Applied Ocean Science \& Engineering Massachusetts Institute of Technology \& Woods Hole Oceanographic Institution August 16, 2019

Certified by.

Dr. Sarah B. Das

Associate Scientist with Tenure in Geology \& Geophysics

Woods Hole Oceanographic Institution Thesis Supervisor

Accepted by

Prof. Oliver Jagoutz Associate Professor of Geology Massachusetts Institute of Technology Chair, Joint Committee for Marine Geology \& Geophysics 


\title{
GREENLANDIC ICE ARCHIVES OF NORTH ATLANTIC COMMON ERA CLIMATE
}

by

\begin{abstract}
Matthew B. Osman
Submitted to the MIT-WHOI Joint Program in Oceanography and Applied Ocean Science and Engineering on August 16, 2019, in Partial Fulfilment of the Requirements for the Degree of

Doctor of Philosophy.
\end{abstract}

The Common Era (A.D. 1- present) represents a crucial period for climatic studies, documenting the timespan over which human activities have become an increasingly domineering force in shaping Earth's landscape, climate, and ecology. Direct, quantifiable records of climatic phenomena are severely limited over much of the Common Era, necessitating high-resolution, naturally-derived proxies to extend climatic insights beyond the satellite and instrumental era, particularly across remote high-latitude and maritime regions of the North Atlantic. Here, I use modern, data-driven and physically-based modeling approaches to gain new insights into North Atlantic climate variability from the Greenlandic ice core archive. First, I investigate the climatic fidelity of ice core glaciochemical climate proxies at the microphysical-scale. I show that several soluble chemical species - key among them methanesulfonic acid (MSA) - undergo rapid vertical migration through a super-cooled liquidadvection process along ice crystal grain-boundaries. I demonstrate that significant multi-year MSA changes occur only under low snow-accumulation and high-impurity-content conditions, thus mitigating the phenomenon over much of Greenland. Building upon these findings, I then investigate the cause of declining 19th and 20th-century MSA concentrations across the interior Greenland Ice Sheet. My results illustrate that Greenlandic MSA records provide a new proxy for North Atlantic planktonic biomass changes, illuminating a $10 \pm 7 \%$ decline in marine productivity over the Industrialera. I next present a new climate record from a previously-unexplored coastal ice cap in west-central Greenland. Using a physically-constrained ice cap flowline inversion model, I identify marked centennial-scale changes in coastal precipitation during the last millennium, including a $\sim 40 \%$ increase in coastal precipitation since the industrial-onset. These changes are drastically larger than those observed from inland Greenland records, revealing enhanced sensitivity in west Greenlandic hydroclimates to regional Atlantic and Arctic-wide temperature variability. Finally, leveraging a compilation of nearly 30 annual-resolution Greenland water-isotope records, I isolate coherent signatures of atmospheric circulation variability to reconstruct changes in the North Atlantic eddydriven jet-stream over the last millennium, exposing progressively enhanced variability during the past two-centuries consistent with amplified Arctic thermal-wind forcing. This thesis thus illuminates new Common Era climatic and ecologic changes, and expands the scope of the Greenlandic ice archive as proxies of the coupled North Atlantic climate system.

Thesis Supervisor: Dr. Sarah B. Das

Title: Associate Scientist with Tenure in Geology \& Geophysics

Woods Hole Oceanographic Institution 


\section{Acknowledgements}

Above all, my dearest appreciation goes to Ally Frickman: if not for your patience, love, support, and the innumerable sacrifices over these last five years, I likely would not be writing these words of acknowledgement now. Thank you so very much.

To my parents, Paul and Pauline ("P\&P”): Dad, thanks for showing me, by example, the value of hard work, and for dragging my brothers and me to all those National Parks, museums, historic battlefields, and abandoned quarries during my childhood instead of to Disneyland (despite our constant urging). The wide diversity of questions this thesis aims to address is, in no small part, a testimony to the infectious-curiosity you instilled in me from a young age. And, Mom, thank you for your selflessness, for the countless hours you've spent listening, and for being a constant beacon of positivity.

To my advisor, Sarah Das: thank you for teaching me how to ask the right questions, and how to seek out the tough answers. Thanks for being a constant source of levelheadedness, and thanks especially for your patience: I'm well aware that for every "good" idea I've had these past five years, you've heard me out on at least 10 bad ones! And, lastly, thanks for always believing in me.

To all members of the greater "Das glaciology lab" family (Laura Stevens, Luke Trusel, Alison Criscitiello, and Maya Bhatia): thank you for your mentorship, friendship, and thoughtful critique. Thank you each for setting the bar high.

To my dissertation committee (Olivier Marchal, Sloan Coats, Joe McConnell, David McGee, and Alan Condron): thanks for the support, camaraderie, and the knowledge you've each passed on.

To Matt Evans and Joe McConnell, and members of your respective labs: My sincerest appreciation for the fantastic ice core chemistry measurements. It's been a true pleasure working with both of you.

To my officemates at WHOI and MIT (Nathan Mollica and the 54-1320 crew: Martin Wolf, Charles Gertler, Maria Zawadowicz, Sarvesh Garimella, Cuiqi Zhang, Lesly Franco): Simply stated, I couldn't have been luckier to have each of you by my side throughout these last five years.

To Dan Cziczo: thanks for introducing me to the hidden world of teeny-tiny airborne particles, and for accepting me with open arms into your MIT family. It made all the difference.

To members of my WHOI G\&G softball squad: Keep your heads up. Despite our overwhelmingly poor $\sim 5-35$ record, you're all still winners in my mind.

To Dave Pruitt: thanks for giving me a chance during my formative teenage years, and for teaching me the value of self-discipline and perseverance. These tools have come in handy far beyond the bandstand we once shared.

To Michael Wolf and Jeff Strasser: thanks for being the mentors I needed throughout college, and for recognizing - and fostering - something in me early on that I certainly never saw in myself. You both planted the seed that has, in part, blossomed into this thesis. 
To my various funders: scientific research - especially the polar variety - is wicked expensive, and this dissertation wouldn't have been possible without the big-bucks graciously provided by the U.S. Department of Defense Office of Naval Research (National Defense Science and Engineering Graduate fellowship), the National Science Foundation's Office of Polar Programs (1205196, 1418256), as well as generous support from the Woods Hole Oceanographic Institution. An Ocean Outlook Fellowship from the Bjerknes Centre (Bergen, Norway) bred much creativity, and is also much-appreciated.

And finally, to all my friends in the MIT Joint Program and beyond: you know who you are! Thanks for the laughs, knowledge, adventures, good-ideas, bad-ideas, brutal-honesty, compassionatedishonesty, and ceaseless support. You all mean the world to me, truly.

Sincerely,

Matt 


\section{Contents}

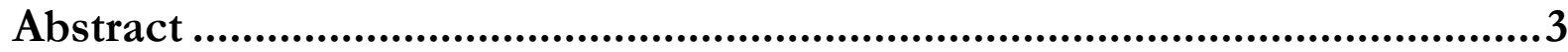

Acknowledgements..................................................................................... 4

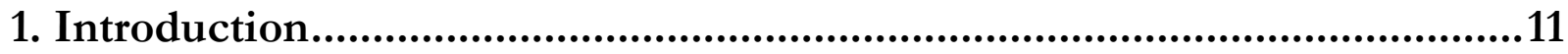

1.1 Ice core science: concepts, approaches, and complications ............................................. 13

1.2 A guiding philosophy on ice core proxy development...................................................... 16

1.3 The Disko Bay ice core project...................................................................................... 18

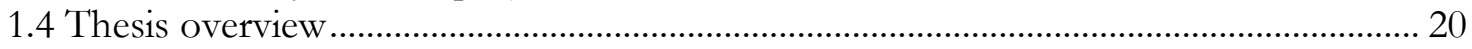

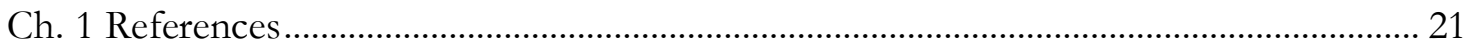

\section{Methanesulfonic acid (MSA) migration in polar ice: data synthesis and}

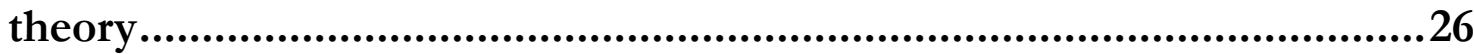

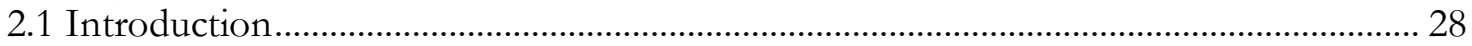

2.2 MSA migration in ice cores …………………………………………………….... 30

2.2.1 Snow accumulation ..................................................................................... 31

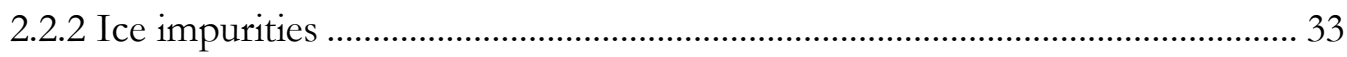

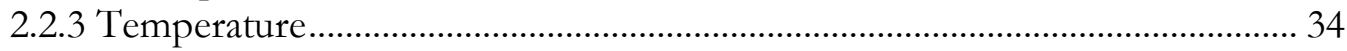

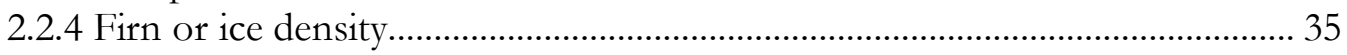

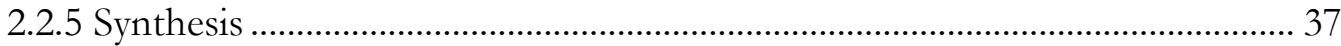

2.3 A case study: the DIV2010 MSA record ............................................................................ 37

2.3.1 Identification of DIV2010 migration zones............................................................ 38

2.3.2 Cross-correlation analysis................................................................................... 39

2.4 Towards a mechanistic understanding of MSA migration.................................................. 39

2.4.1 The impurity transport model of Rempel et al. (2002) ..................................... 40

2.4.2 Physico-chemical parameters of MSA migration …………………………..... 42

2.4.2.1 Grain boundary diffusivity of $\mathrm{MS}^{-}$and $\mathrm{Na}^{+}$.................................... 42

2.4.2.2 Liquidus relationships for relavent sea-salt species .......................... 43

2.4.3 A simplified model of MSA migration................................................................ 45

2.4.4 Assessment of MS diffusivity ………………………………………………. 49

2.5 Paleoclimate implications............................................................................................... 50

2.5.1 Revisiting the effect of temperature on grain boundary migration................... 51

2.5.2 Vertical extent of MSA migration.................................................................. 52

2.5.3 Revisiting the combined influence of snow accumulation and $\left[\mathrm{Na}^{+}\right]$............ 54

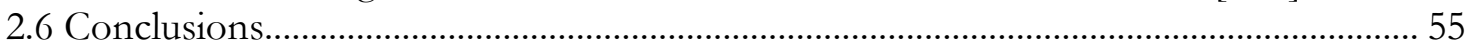

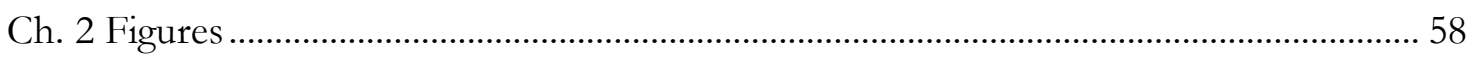

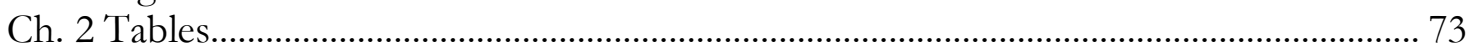

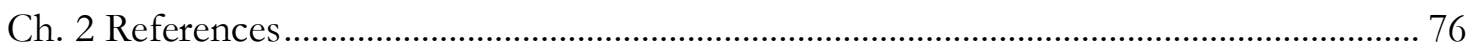

3. Industrial-era decline of subarctic Atlantic productivity .............................82

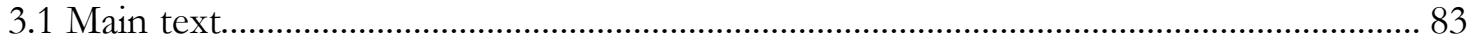

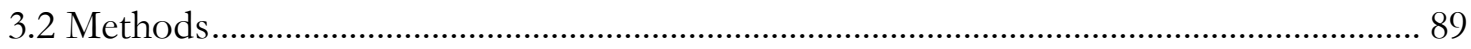

3.2.1 [MSA] record collection, analysis, and preprocessing....................................... 89 
3.2.2 Extraction of [MSA]-PC1 and uncertainty estimation....................................... 90

3.2.3 Attribution of probable MSA source regions .................................................... 92

3.2.4 Correlation analysis of subarctic Atlantic $\left[\mathrm{DMS}_{\mathrm{sw}}\right]$ to satellite NPP.............. 94

3.2.5 Processing of Continuous Phytoplankton Recorder (CPR) survey data........ 95

3.2.6 Time series statistical significance testing .......................................................... 97

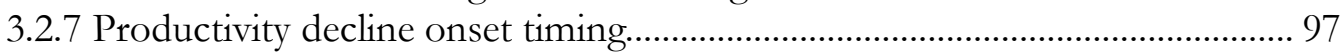

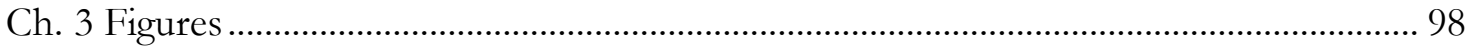

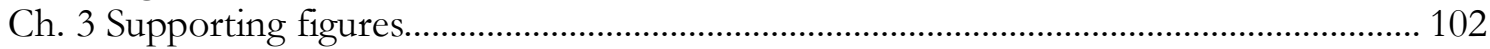

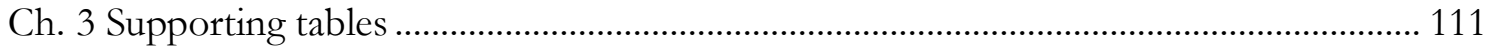

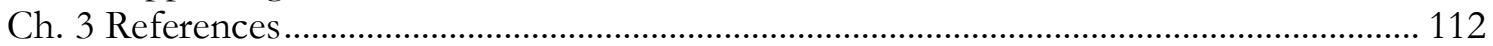

\section{Enhanced coastal west Greenland hydroclimate variability during the}

Common Era..................................................................................117

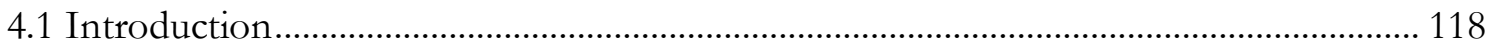

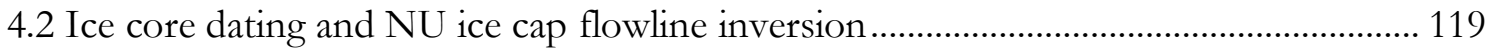

4.3 Enhanced CWG hydroclimate variability during the last millennium ............................ 122

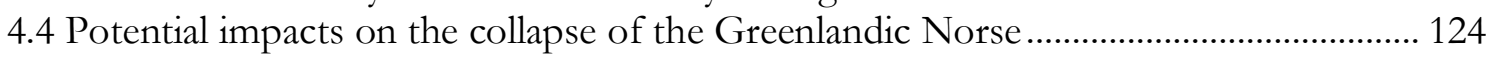

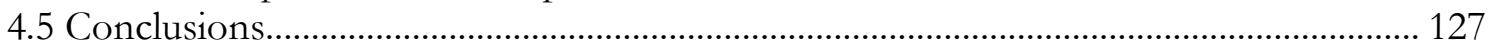

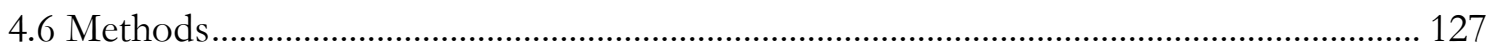

4.6.1 Ice core drilling, processing, and dating........................................................... 127

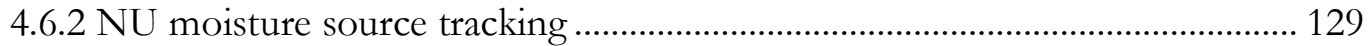

4.6.3 NU ice cap glacier flowline inversion framework ........................................... 129

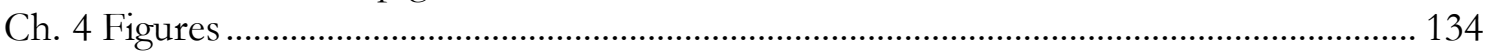

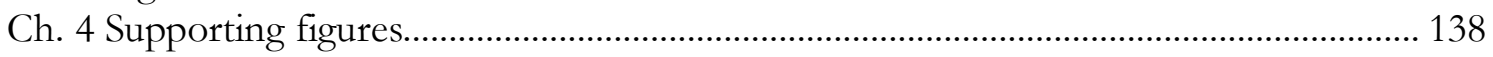

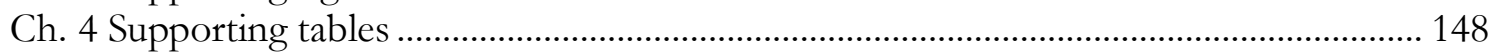

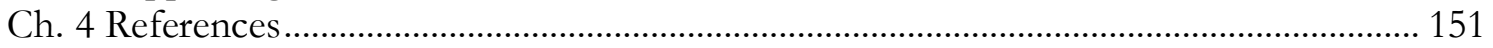

\section{Enhanced North Atlantic jet-stream variability coeval with Arctic warming}

during the last millennium ..............................................................157

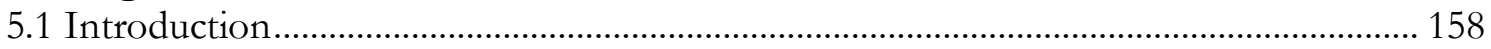

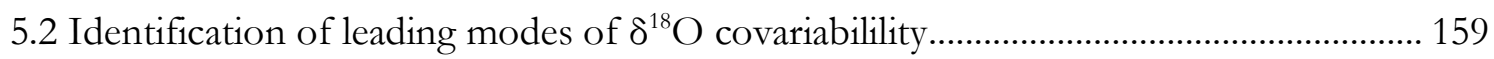

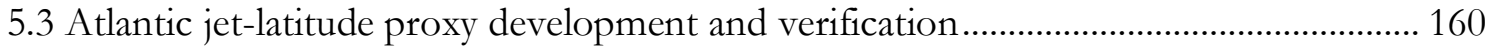

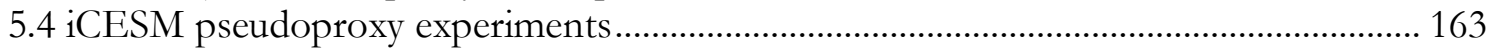

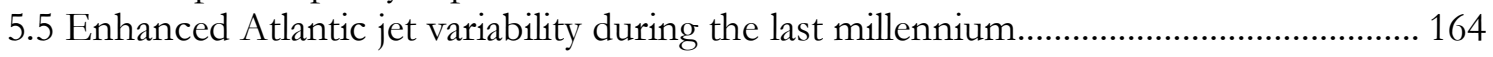

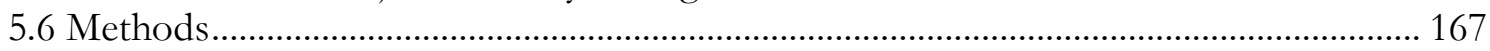

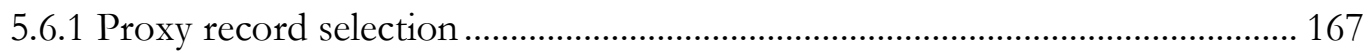

5.6.2 Probabilistic Principal Component Analysis (pPCA) and missing data

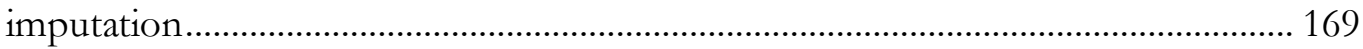

5.6.3 $\delta^{18} \mathrm{O}-\mathrm{PC} 1$ and -PC2 signal extraction and uncertainty attribution.................. 170

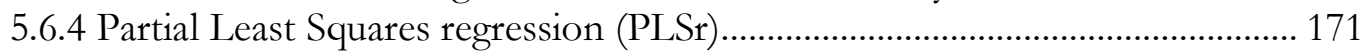

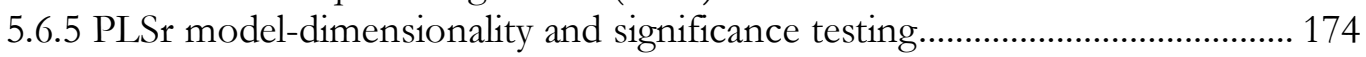

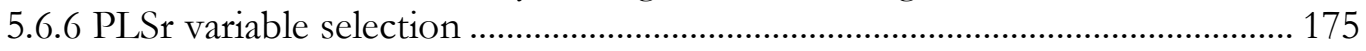

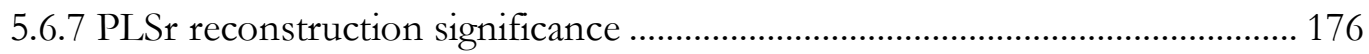

5.6.8 Time series correlation statistical significance testing ....................................... 177

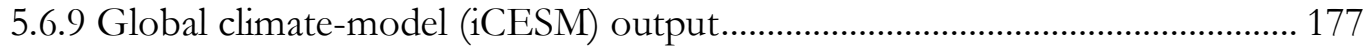

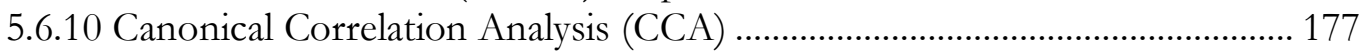

5.6.11 iCESM pseudoproxy experiments .................................................................... 178 


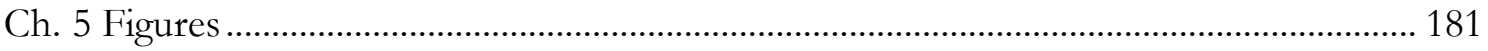

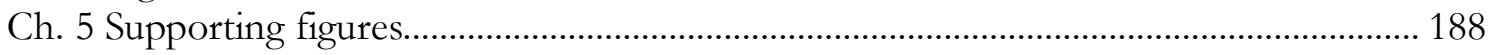

Ch. 5 Supporting tables …………………………………………………………... 198

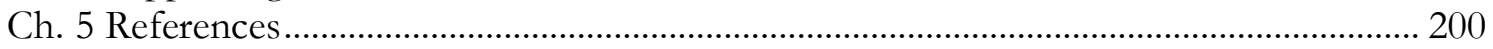

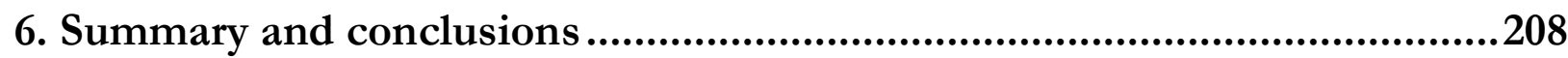

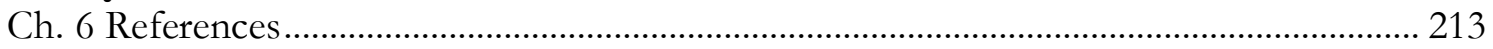

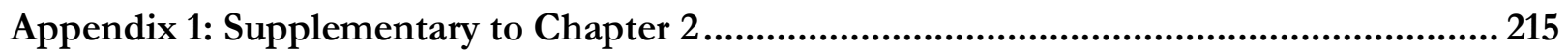

A1.1 Defining the shallowest depth of MSA migration .................................................... 215

A1.2 Calculation of the slopes and liquidus curves ............................................................. 215

A1.3 Discretization of the MSA migration models ............................................................... 216

A1.3.1 Linearized model...…………………………………………………………..... 216

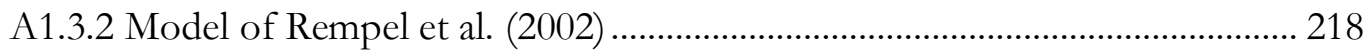

A1.3.3 Modeling MSA migration at DIV2010 …………………………………….... 220

A1.3.4 Sensitivity experiments with the RWW model .............................................. 221

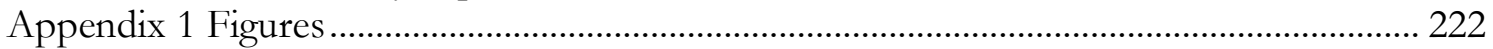

Appendix 1 Tables …………………………………………………………………… 228

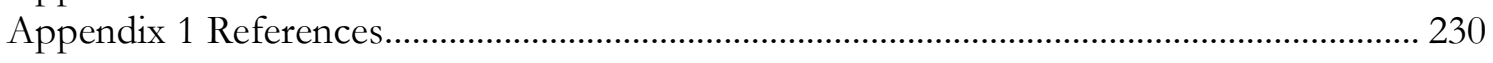

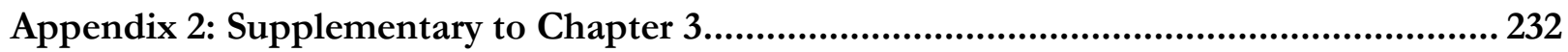

A2.1 Marine airmass source and covariation in Greenland [MSA] records......................... 232

A2.1.1 Site-wise marine airmass source attribution .................................................. 232

A2.1.2 Exploratory principal component analysis of Greenland [MSA] records... 233

A2.1.3 Spatiotemporal stability of marine-airmass trajectories \& Arctic influence 234

A2.2 Comparison of data-infilling methodologies for [MSA]-PC1 computation................ 235

A2.3 Satellite-derived net primary productivity and temporal trends (A.D. 1998-2016) .... 236

A2.4 Processing of Continuous Plankton Recorder (CPR) survey data .............................. 238

A2.4.1 Record availability by standard CPR region: summer vs. annual.................. 238

A2.4.2 Comparison of methods for determining CPR temporal variation.............. 239

A2.5 Comparison of [MSA]-PC1 to regional sea-ice behavior................................................ 240

A2.6 NOAA Global Surface Seawater DMS Database measurements................................... 242

A2.7 Defining the subarctic Atlantic "warming hole" and AMOC index .............................. 242

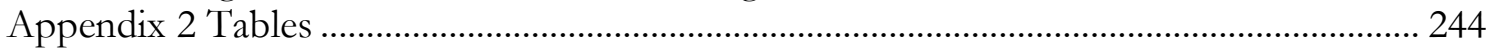

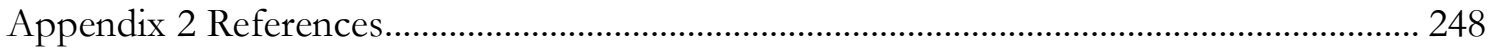

Appendix 3: Disko Bay ice core array data..................................................................... 252

A3.1 Greenland Central (GC) ice core [MSA] measurements (A.D. 1821 - 2013) ............. 252

A3.2 Nuussuaq (NU) ice core accumulation history (A.D. 79 - 2015) ................................. 252

A3.3 NU ice core mean-annual $\delta^{18}$ O (A.D. 1001 - 2000) .................................................... 253

Appendix 4: Trusel et al. (2018) - Nonlinear rise in Greenland runoff in response to postindustrial Arctic warming .......................................................................................... 259 


\section{Introduction}

The Common Era (A.D. 1 - present) represents a critical period for paleoclimatic studies, documenting the span of time over which human activities have become an increasingly domineering force in shaping Earth's landscape, climate, and ecology. Direct, quantifiable observations of climatic phenomena are severely limited over much the Common Era, however, extending only a matter of a few decades (i.e., the satellite-era onset c. A.D. 1979) for most locations on Earth or, where instrumental-meteorological measurements exist, centuries at most. Provided robust calibrations can be developed, natural-derived proxies of climate provide key insights into climate variability extending well beyond the satellite and instrumental era. Such reconstructions, in turn, grant key spatiotemporal context towards the rapidity and magnitude of observed climate changes over recent decades, as well as insights into projected future responses to contemporary anthropogenic forcing. Here, I focus on the Common Era-history of climate variability across the North Atlantic sector, broadly defined as comprising the maritime region bounded by the North American eastern seaboard, the European western seaboard, and all associated landmasses therein.

Contemporary societal interest in the North Atlantic is propelled by the diversity, complexity, and interconnectedness of the region's integrated ocean-atmosphere-ice components, and its direct influence on continental North American and European weather and climate, ecosystems, economics, transport/commerce, and habitability more broadly (e.g., Serreze and Barry, 2005). Significant shifts in the North Atlantic mean climatic state have punctuated the last two millennia, including those of purported warmth: e.g., the Roman Climatic Optimum (c. 250 B.C. - A.D. 400; e.g., Bianchi and McCave, 1999), the Medieval Warm Period (c. A.D. 950 - 1300; Jones and Mann, 2004; Mann et al., 2009), and contemporary post-industrial era warming (c. 1850 -; Abram et al., 2016); as well as those of relative cooling: e.g., the Dark Ages Cold Period (c. A.D. 400 and 750; Helama et al., 2017) and Little Ice Age (c. A.D. 1400 - 1850; Jones and Mann, 2004; Mann et al., 2009). Such periods are thought to have played an important role in the rise and fall of various North American and European civilizations throughout the Common Era (Fagan, 2004; Büntgen et al., 2011; Zhang et al., 2011; McCormick et al., 2012; Moffa-Sanchez et al., 2017), and potentially preconditioned events of major historical significance including, e.g., European exploration and discovery (Ogilvie et al., 2000) and periods of plague (e.g., the Black Death, c. 14th century; Schmid et al., 2015; Yue and Lee, 2018), megadrought (Haug et al., 2003; Cook et al., 2015), and famine (Lima et al., 2014). 
Given the region's marine-dominated, high-latitude, and thereby remote nature, climatic proxies reflecting North Atlantic climatic conditions have remained largely confined to ocean- and terrestrial-derived sediment records (Sundqvist et al., 2014; Armand et al., 2016; Moffa-Sanchez et al., 2019). However, because sediment records are typically of low-resolution and (or) imprecisely dated, the sediment archive has collectively struggled to constrain high-resolution (annual to multi-decadalscale) and spatially-coherent mechanisms of climate variability over the Common Era. To combat these uncertainties, this thesis is centered on the application and advancement of Greenlandic ice cores as high-resolution proxies of North Atlantic Common Era climate.

While archives of past climate from polar ice sheets have long provided fantastic, relatively unperturbed insights into the past composition and physical state of the atmosphere, this thesis premises that these records have thus far remained underutilized to their full potential. Since the original, pioneering studies conducted upon the Camp Century, Greenland ice core by Willi Dansgaard and colleagues in the 1960's (Dansgaard et al., 1969), technological advancements have significantly expanded our ability to extract and analyze polar ice cores. Such advancements have elevated the Greenlandic ice core archive during recent decades as one the most most-spatially pervasive, highest resolution, and analytically expansive terrestrial proxy archives across the northern Atlantic sector (Jouzel, 2013). Yet, whereas any one given ice core might typically entrain upwards of two-dozen or more uniquely-measured physical and chemical parameters - each reflecting, in turn, some otherwise unique aspect of the climate system - only a small fraction of these parameters is typically explored or climatically interpreted (at least, in the peer-reviewed canon). Encouragingly, in tandem with these technological advances, the 21 st century has seen a pervasive push towards an increasingly "open" and transparent scientific process, predicated in part upon a growing number of user-friendly and reputable online scientific repositories for data- and code-distribution (e.g., Emile-Geay et al., 2013; McKay and Kaufman, 2014; McKay and Emile-Geay, 2016). Such resources have made a previouslyunprecedented amount of ice core paleoclimate data now publicly-available for scientific analysis. Taking advantage of this online data-deluge (though, admittedly, still a fair-bit of data-nagging from collaborators), I illustrate herein how modern data-oriented perspectives (e.g., Faghmous and Kumar, 2017), in tandem with theoretical and (or) physically-based modeling approaches, can be used to extract new insights across ice core records, hence revealing a host of otherwise "uncommon" Common Era climatic changes.

In the following subsections, I pave the way for this thesis' research chapters by briefly laying out [1.1] several fundamental concepts, approaches, and assumptions native to ice core science; [1.2] 
a synopsis of climate-proxy development and guiding philosophies this thesis entails therein; [1.3] an overview of a new coastal Greenland ice core project on which this thesis is - in part - prefaced, and; [1.4] a brief road map of the research Chapters [2-5] to come.

\subsection{Ice core science: concepts, approaches, and complications}

An understanding of the research findings presented in Chapters [2-5] necessitates the reader possesses a foundational grasp of the key analysis techniques and assumptions underlying modern ice core science. While a full treatment is well-beyond the scope of this introduction, I present here a brief overview - well-referenced for the interested reader's convenience - of several aspects mostrelevant to this thesis.

In the broadest sense, an ice core comprises a contiguous (e.g., meter-by-meter) cylindrical tube of snow and ice drilled vertically from the surface of an ice cap, ice sheet, or glacier. Ice core locations are generally targeted at high-elevation, interior ice sheet sites (as opposed to its peripheries) where more snowfall accumulates each winter than is melted away in the summer (i.e., the so-called "accumulation zone"); indeed, it is this simple condition that even permits the growth (or, at the least, continued existence) of an ice cap or ice sheet at all, and a history of past snowfall to be preserved year-after-year (Cuffey and Patterson, 2010). The annual snowfall that is conserved in an ice core stacked annually, year-by-year, moving progressively older in time with increasing depth from the surface - contains an abundance of information relevant to climatic studies (Alley, 2000). Physical properties of an ice core include grain size and orientation (e.g., Gow et al., 1997; Weikusat et al., 2017), temperature (e.g., Dahl-Jensen et al., 1998), density, annual layer thickness or, relatedly, accumulation rate (e.g., Meese et al., 1994; Andersen et al., 2006), electrical conductivity (e.g., Taylor et al., 1993), and melt layer thickness (e.g., Trusel et al., 2018), each of which can be quantifiably measured along an ice column and interpreted in the context of past climatic changes. Similarly, analysis of the ice core's chemical properties, including direct measurements of past atmospheric gases entrained within ice air-bubbles (e.g., Petit et al., 1999); the stable isotopic content of the snow and ice (e.g., Dansgaard et al., 1964, 1969); windblown impurities such as dust (e.g., Fuhrer et al., 1999), microbes (Knowlton et al., 2013), and soot (McConnell et al., 2007); soluble ions (Legrand and Mayewski, 1997); as well as trace metal elemental-concentrations (together comprising an ice core record's "glaciochemistry"), can now be conducted efficiently (using continuous flow-analysis 
techniques, e.g., McConnell et al., 2002), at ultra-high analytical precision (i.e., parts per billion to trillion precision for ions and elemental concentrations; McConnell et al., 2002; Maselli et al., 2017) and at high depth-resolution (generally around one-two centimeters per sample for non-gaseous measurements).

A fundamental aspect of any ice core climatic record is the establishment of its age-to-depth relationship, i.e., its "chronology". The amount of snowfall an ice core site receives on a year to year basis, and depth-resolution at which measurements are made, together precondition the age-resolution of that ice core record's climatic insights. Ice cores constituting high accumulation-rates and high depth-resolved chemical measurements allow for subseasonal-scale temporal insights, thus permitting "annual layer counting" to be conducted on the seasonal peaks and troughs exhibited by most chemical parameters (e.g., Vinther et al., 2006). Intermittent volcanic (Sigl et al., 2015; Toohey and Sigl, 2017), radiogenic (e.g., Arienzo et al., 2017), and metallic (e.g., McConnell et al., 2018) depositional "horizons" assist in synchronizing layer-counts to well-dated historical events during the Common Era, allowing internally-consistent "checks" to be made on the downcore accuracy of annual layer counting. Typically, age-resolution decreases in ice cores as depth increases, as annual layers progressively thin due to compaction, vertical strain and horizontal flow (Alley et al., 1998; Cuffey and Patterson). While interior sites in Greenland permit precise annual layer counting well beyond the Common Era (Vinther et al., 2006), due to generally-high snow accumulation rates (i.e., $\sim 0.1$ to 1 meters of water equivalent; Box et al., 2013) and a sufficiently thick ice sheet ( 3 kilometers at Summit, Greenland), on smaller (and thinner) near coastal and (or) alpine ice caps enhanced vertical strain can cause severe thinning of annual layers at much shallower depths (e.g., Kekonen et al., 2005). At such sites, annual dating of ice cores must often rely more-intensively on the use of idealized glacial flow models, ideally tuned to independently-identified depth-age constraints (e.g., volcanic horizons) determined from chemical measurements (e.g., Fudge et al., 2014). In Chapter [4] of this dissertation I provide an example of such a model, in order to date a new ice core from a small, coastal west Greenland ice cap.

A particularly unique aspect of any ice core glaciochemical record is the spatially-integrated insights it entails. Nearly all microscopic particles (i.e., aerosols) and molecular compounds emitted to the atmosphere can be quantifiably measured in trace concentrations (either directly or indirectly) along an ice column, provided such particles are windblown and deposited atop the Greenland Ice Sheet (e.g., Legrand and Mayewski, 1997; Alley, 2000). These spatially-remote signals serve as a virtue for the inference of past climatic change, though they come with several non-negligible caveats. To 
the first-order, ice core records of aerosol deposition provide a view into past aerosol provenance or emissions changes, both of which may be of climatic or ecologic value. More often, however, this naïve view is complicated by the fact that any ice core record inherently comprises an integrated history of several other - often competing - underlying factors, none of which should be presumed a priori as stationary through time. Such factors include $i$. changes in that site's representative atmospheric circulation patterns, $i i$. shifting emissions source(s) and atmospheric residence time of the specific aerosol in question, as well as iii. time-dependent changes/trends in precipitation and (or) airmass particle scavenging (Legrand and Mayewski, 1997; Cuffey and Patterson, 2010). To address such problems head-on, in Chapters [3] and [4] I illustrate how state-of-the-art "back-trajectory" atmospheric models can be employed to probabilistically discriminate between ice core aerosolemissions and moisture uptake sources across the Greenland Ice Sheet.

In addition to these potential "pre-depositional" complications, myriad "post-depositional" processes acting near the surface of an ice sheet can impact the climatic-integrity of ice core glaciochemical signals. The collective impact of such processes - which include wind scouring, snow redistribution, sublimation, melt, photolysis, and molecular diffusion - prove challenging to quantify and hence potentially correct for (Wolff, 1996). Further, whereas each might be viewed as broadlydependent upon site-specific quantities such as elevation, temperature, distance-to-coast, windiness, and accumulation rate, recent studies have also shown that considerable variability in glaciochemical signals can occur only meters apart (Wolff et al., 2005). In my interpretation, such studies suggest that, collectively, near-surface post-depositional processes might be viewed as a Markovian (i.e., random) process that effectively adds "noise" to an otherwise meaningful climatic signal. Considerable effort is thus made in this thesis to compile multiple, temporally-overlapping records from across the Greenland Ice Sheet whenever possible (e.g., Chapters 2, 4 and 5), in order to extract (in a statistical sense) climatic signals from the noise.

As concerning, it is often assumed that glaciochemical signals measured deeper in the ice core column have not significantly moved relative to the surrounding ice in which they were originally deposited. Yet, such assumptions have proved contrary to both observations (e.g., Curran et al., 2002) and theoretical considerations (Rempel et al., 2001, 2002), both of which indicate the potential for significant vertical migration of soluble (i.e., ionic) impurities at the liquid interface of individual ice grains. Such post-depositional migration is a critical problem for paleoclimate reconstructions using ice cores, given that the phenomenon can obscure potentially-useful climatic information embedded across (originally-deposited) chemical features. In Chapter [2] of this thesis, I employ a joint 
observational and theoretical approach to explore the potential implications of such (often-erroneous) assumptions. In particular, I hone in on a specific, and widely-measured, glaciochemical species methanesulfonic acid, or MSA - whose interpretation in the climatic literature has been largely hindered by such migratory processes.

\subsection{A guiding philosophy on proxy development}

Having established the basis for several of the fundamental assumptions and complications unique to ice core science, I now provide an overview and guiding philosophy on Common Era ice core proxy development. This subsection is most relevant to Chapters [3], [4], and [5] (see also Appendix 3).

I begin with the following proposition: that all quantitative measurements of weather and climate are proxies. This proposition is, in fact, intuitive; a mercury thermometer is premised on an empirical relationship between temperature and the density (or volume) of liquid mercury. It is predicated on our understanding that as a thermometer is heated, the density of the mercury contained within it will near-linearly decrease, expand, and rise up the glass tube, hence giving us a temperature measurement. The relationship between mercury density and temperature is so well-constrained that in our day-to-day lives we tend to unequivocally view such measurements as truth. Yet, because the density of mercury is only a proxy of temperature, the actual quantity we care about, such measurements are nonetheless subject to small uncertainties, stemming in turn from underlying (and otherwise uncontrollable) circumstances which render the mercury-thermometer/temperature relationship imperfect. Indeed, even our most advanced meteorological measurements, such as

inferences of global surface temperature based on the intensity of upwelling radiative "proxies" measured by Earth-orbiting satellites, comprise functionally similar relationships and underlying uncertainties.

Likewise, natural proxies from ice cores provide "real" measurements of climate. What's different from the above examples, however, are the $i$. governing physical processes that ultimately link a measured ice core signal to a climatic variable, $i i$. the degree of confidence to which one can assume time-stationarity in those processes, and $i i$. the rather-implicit acknowledgement that in the natural world there are typically many uncontrollable (that is, "random") underlying processes that make the association between proxy and climate imperfect. At its core, this proxy-climate relationship is quite simple: 


$$
y_{s, t}=A\left(x_{t}\right)+b+\epsilon_{t}
$$

where $y_{s, t}$ represents the climate signal at time $t, x$ an ice core proxy measurement, $b$ a bias term (systematic offset-adjustment), and $A$ the (linear or nonlinear) operator transforming $x$ into $y$. The error term $\epsilon$ implies $A(x)$ will never perfectly match $y_{s}{ }^{1}$. That is,

$$
y_{a, t}=A\left(x_{t}\right)+b
$$

where $y_{a}$ denotes a close approximation of $y_{s}$, such that $y_{s}-y_{a}=\epsilon$ for all $t$.

In practice, $y_{s}$ will represent a physical quantity for which robust meteorological measurements exist, notwithstanding (perhaps disingenuously) my prior argument that such a quantity is itself also a proxy and hence subject to its own (typically small) uncertainties. Generally, the observed climate variable $y_{s}$ extends only a few decades or centuries, at most, from present into the past. Thus, one ultimately aims to "calibrate" (i.e., invert Eq. (1.2) to determine some optimal $A$ ) using the period of common temporal overlap between proxy (i.e., $x$ ) and a climate "observation" (i.e., $y_{s}$ ), thereby allowing quantitation ("reconstruction") of $y_{s}$ from $x$ beyond the calibration period. In doing so, one often assumes time stationarity in $A$.

While Eq. (1.2) presumes a statistically "robust" relationship between $x$ and $y_{s}$ during the overlapping calibration interval (as, for example, determined by rejection of a null hypothesis under some prespecified $p$-value criterion), this thesis holds that such statistical coherence is by itself not wholly-sufficient when developing an ice core climate proxy. Instead, this thesis aims for a more holistic approach, tuned to the unique challenges that ice core proxies so often present (see also, Sect. 1.1). Specifically, in developing quantitative ice core proxies of Common Era climatic change, this thesis endeavors - whenever possible - to:

1. integrate ice core signals across several modern targets, e.g., reanalysis, satellite, and station-based instrumental observations (Chapters [3-5]);

2. incorporate physicochemical models of glaciologically-relevant processes, i.e., so called ice core "proxy-systems-modeling" (Chapters $[2,4])$;

\footnotetext{
${ }^{1}$ Note that Eq. (1.1) is inverse to the real-world functional assignment, $x\left(y_{s}\right)=B\left(y_{s}\right)+f+\delta$

which states that $X$ is in fact governed by a changing climate (albeit imperfectly, as implied by the noise term $\delta$ ). Note $B$ represents a new linear or nonlinear operator transforming $y$ into $x$. The bias term is here represented by $f$.
} 
3. generate quantifiable inferences into the underlying atmospheric circulatory conditions that measured ice core signals are often predicated upon (Chapters [3-4]); and

4. develop improved insights into underlying physical linkages between ice core proxies and climate using state-of-the-art global climate model simulations (Ch. [3,5]).

In striving to meet these conditions, this thesis thus attempts to generate past reconstructions of climatic and ecologic variability that are both statistically-sound and mechanistically-grounded.

\subsection{The Disko Bay ice core project}

The North Atlantic's terrestrial-based cryosphere (ice-sheets, glaciers, permafrost) is currently undergoing particularly rapid change. Since the early 1990's, estimates of Greenland Ice Sheet contribution to sea level rise has accelerated from near zero to a current mass imbalance of $\sim 225 \mathrm{Gt}$ $\mathrm{yr}^{-1}$ (Vaughan et al., 2013). Correspondingly, over the past decade it has become increasingly clear that much of this imbalance is attributable to variable oceanographic processes occurring at the ocean-ice interface. Recent studies have highlighted the coupled impacts of melt-inducing North Atlantic seasurface temperatures (Holland et al., 2008; Straneo and Heimbach, 2013) as well as the diminished stabilizing effects of declining sea-ice extent (Carr et al., 2013) on Greenland Ice Sheet's numerous marine-terminating outlet glaciers. These changes have also contributed to the enhancement of sensible and latent heat-fluxes from the ocean to the atmosphere, facilitating increases in temperature and humidity over the Greenland Ice Sheet and, hence, negative surface mass balance changes (Liu et al., 2016; Stroeve et al., 2017).

Prior to the satellite-era observations, our understanding of climate and coupled oceanographic-cryospheric variability in the northern North Atlantic diminishes markedly. To extend this limited period of observations and to place satellite observations within a longer-term context, we $^{2}$ ventured in Spring of 2014 and 2015 to several previously unexplored ice caps situated within coastal west Greenland's Disko Bay - a region typified in recent decades by particularly intense outlet glacier thinning (Moon et al., 2012) and declining sea-ice concentration (Walsh et al., 2017) - with the goal of acquiring new ice core records of coastal climate- and cryospheric-variability spanning the preceding centuries to millennia. From these field campaigns, we successfully recovered a highresolution, intermediate depth $(\sim 140 \mathrm{~m})$ ice core record from a small ice cap perched atop the

\footnotetext{
2014 Disko Bay field team: Sarah Das (WHOI), Benjamin Smith (UW-APL), Matt Evans (Wheaton College), Ashley York (Clark University), Laura Stevens (WHOI), Matt Bingham (Milton Academy)

2015 Disko Bay field team: Sarah Das, Matt Osman (MIT-WHOI), Luke Trusel (WHOI), Mike Waszkiewicz (IDDO)
} 
Nuussuaq Peninsula, west Greenland $\left(70.49^{\circ} \mathrm{N}, 52.26^{\circ} \mathrm{W}\right)$. This core, the "NU" record, represents the most-coastal ice core to date along the west Greenland margin (e.g., Trusel et al., 2018), thus offering a unique chance to study Baffin Bay sea-surface variability and west Greenlandic ocean-ice coupling over the Common Era. Additionally, a complimentary intermediate depth core was recovered from a site further inland $\left(68.91^{\circ} \mathrm{N},-43.39^{\circ} \mathrm{E}, 2400 \mathrm{~m}\right)$ on the Greenland Ice Sheet, the "GC" ice core, strategically placed to $i$. serve as an intermediary between our coastal NU record and pre-existing interior-Greenland Ice Sheet ice core records, while also $\ddot{i}$. robustly capturing summertime melt (Trusel et al., 2018) and glaciochemical trends (Osman et al., 2019) over recent centuries ${ }^{3}$.

The acquisition, processing, analysis, and dating of the NU and GC records represent a "tangible" contribution from this thesis to the paleoclimatic research communities. Therein, aspects of the analysis and interpretation of the "Disko Bay ice core array" are included in in nearly all subsequent chapters (i.e., void Chapter [2]), though are highlighted most-explicitly in Chapter [4]. All novel measurements produced by and climatically interpreted within this thesis are provided in Appendix 3. Additionally, Appendix 4 includes a study by Trusel et al. (2018), that examines the annual surface-runoff contribution from the Greenland Ice Sheet over the last three and a half centuries using melt layer stratigraphic measurements developed using the Disko Bay array. In Trusel et al. (2018), we show that the onset of anomalous Greenland Ice Sheet surface melting and runoff is consistent with Industrial-era Arctic warming (c. mid-19th c.), but has only emerged above natural variability during the most-recent two to three decades. Further, because Greenland Ice Sheet melting exhibits a strongly-nonlinear response to summertime surface warming, we illustrate that increasing temperatures over the 21 st century will have detrimental consequences on future melt-runoff and sealevel rise. I played a key role in this study, with contributions that included developing the statistical model and numerical code used for reconstructing past Greenland runoff, conducting the spectral and statistical analyses, as well as assisting in the overall design and writing of the manuscript. Additionally, Trusel et al. (2018) carefully describes the annual-dating of the GC and NU records, which I also led; the dating of these records underlies results presented in Chapters [3], [4], and [5] of this dissertation, though it is not explicitly described within these chapters.

\footnotetext{
${ }^{3}$ Note that a third coastal ice core site, situated on the low-elevation Disko Island Ice Cap $\left(69.66^{\circ} \mathrm{N},-52.74^{\circ} \mathrm{E}, 1250 \mathrm{~m}\right)$, was also targeted. However, intense melting and polythermal ice conditions discovered during ice core drilling efforts in Spring 2015 precluded the retrieval of a multicentury-scale ice core record from this site. While two adjacent $\sim 20 \mathrm{~m}$ cores were successfully recovered, neither record yielded insights extending beyond the satellite era (c. 1979). As such, neither record is included within this dissertation.
} 


\subsection{Thesis overview}

This thesis makes use of over half a century's worth of careful analytical measurements conducted upon Greenlandic ice (Jouzel, 2013), and thus embodies the collective efforts of hundreds of individuals before me. Through the analysis of these Greenlandic ice core records and those newlydeveloped herein, I attempt here to break new ground in our understanding of North Atlantic climate variability over the Common Era, and significantly expand the scope of the Greenlandic ice archive as proxies of the coupled North Atlantic climate system. The subsequent chapters are broadly laid out as follows:

In Chapter [2], I investigate the fidelity of ice core glaciochemical climate proxies at the microphysical-scale. I compile the largest spatiotemporal array of polar ice core glaciochemistry to date, and develop empirical and theoretical models to explore the post-depositional transport of routinely-analyzed soluble, marine-derived chemical species in cold, polar ice. Building on this glaciochemical database, in Chapter [3], I investigate the cause of declining MSA concentrations spanning the 19th and 20th centuries across the Greenland Ice Sheet, allowing me to develop the first area-integrated constraints on North Atlantic marine productivity variability over the pre- to postIndustrial-era transition. In Chapter [4], I present an observationally constrained glacier-flowline inversion method, which permits both a precise and physically-constrained dating of the NU coastal ice core record while also, incidentally, recovering the NU ice cap's accumulation history. Using this record, I then develop new insights into centennial-scale coastal west Greenland hydroclimate variability and its drivers during the Common Era, with new implications for understanding the mysterious $14^{\text {th }}-15^{\text {th }}$ century disappearance of Greenlandic Norse "Vikings". Finally, in Chapter [5], I present a compilation of nearly 30 high-resolution Greenland water-isotope records - the largest array of ice core water-isotope records ever compiled - in order to extract coherent signatures of atmospheric circulation variability and reconstruct last millennium changes in the North Atlantic jet stream. In Chapter [6], I conclude with a recapitulation of this thesis' research findings and provide a brief discourse on future research directions. 


\section{Ch. 1 References}

Alley, R. B. (2000). Ice-core evidence of abrupt climate changes. Proceedings of the National Academy of Sciences, 97(4), 1331 LP - 1334. https://doi.org/10.1073/pnas.97.4.1331

Andersen, K. K., Ditlevsen, P. D., Rasmussen, S. O., Clausen, H. B., Vinther, B. M., Johnsen, S. J., \& Steffensen, J. P. (2006). Retrieving a common accumulation record from Greenland ice cores for the past 1800 years. Journal of Geophysical Research Atmospheres, 111(15). https://doi.org/10.1029/2005JD006765

Arienzo, M. M., McConnell, J. R., Chellman, N., Criscitiello, A. S., Curran, M., Fritzsche, D., ... Steffensen, J. P. (2016). A Method for Continuous 239Pu Determinations in Arctic and Antarctic Ice Cores. Environmental Science \& Technology, 50(13), 7066-7073. https://doi.org/10.1021/acs.est.6b01108

Armand, L., Ferry, A., \& Leventer, A. (2017, February 28). Advances in palaeo sea ice estimation. Sea Ice, pp. 600-629. https://doi.org/doi:10.1002/9781118778371.ch26

Barnola, J. M., Raynaud, D., Korotkevich, Y. S., \& Lorius, C. (1987). Vostok ice core provides 160,000-year record of atmospheric CO2. Nature, 329(6138), 408-414. https://doi.org/10.1038/329408a0

Bianchi, G. G., \& McCave, I. N. (1999). Holocene periodicity in North Atlantic climate and deep-ocean flow south of Iceland. Nature, 397(6719), 515-517. https://doi.org/10.1038/17362

Bond, G. C., Showers, W., Elliot, M., Evans, M., Lotti, R., Hajdas, I., ... Johnson, S. (1999, January 1). The North Atlantic's 1-2 Kyr Climate Rhythm: Relation to Heinrich Events, Dansgaard/Oeschger Cycles and the Little Ice Age. Mechanisms of Global Climate Change at Millennial Time Scales, pp. 35-58. https://doi.org/doi:10.1029/GM112p0035

Box, J. E., Cressie, N., Bromwich, D. H., Jung, J.-H., van den Broeke, M., van Angelen, J. H., ... McConnell, J. R. (2012). Greenland Ice Sheet Mass Balance Reconstruction. Part I: Net Snow Accumulation (16002009). Journal of Climate, 26(11), 3919-3934. https:/ /doi.org/10.1175/JCLI-D-12-00373.1

Büntgen, U., Tegel, W., Nicolussi, K., McCormick, M., Frank, D., Trouet, V., ... Esper, J. (2011). 2500 Years of European Climate Variability and Human Susceptibility. Science, 331(6017), 578 LP - 582. https://doi.org/10.1126/science.1197175

Carr, J. R., Vieli, A., \& Stokes, C. (2013). Influence of sea ice decline, atmospheric warming, and glacier width on marine-terminating outlet glacier behavior in northwest Greenland at seasonal to interannual timescales. Journal of Geophysical Research: Earth Surface, 118(3), 1210-1226. https://doi.org/10.1002/jgrf.20088

Cook, E. R., Seager, R., Kushnir, Y., Briffa, K. R., Büntgen, U., Frank, D., ... Zang, C. (2015). Old World megadroughts and pluvials during the Common Era. Science Advances, 1(10), e1500561. https://doi.org/10.1126/sciadv.1500561

Cuffey, K.M. and W.S.B. Paterson. 2010. The physics of glaciers. Fourth edition. Amsterdam, etc., Academic Press. 704pp. ISBN-10: 0-123694-61-2, ISBN-13: 978-0-123-69461-4.

Curran, M. A. J., Palmer, A. S., van Ommen, T. D., Morgan, V. I., Phillips, K. L., McMorrow, A. J., \& Mayewski, P. A. (2002). Post-depositional movement of methanesulphonic acid at Law Dome, Antarctica, and the influence of accumulation rate. Annals of Glaciology, 35, 333-339. https://doi.org/DOI: $10.3189 / 172756402781816528$

Dahl-Jensen, D., Mosegaard, K., Gundestrup, N., Clow, G. D., Johnsen, S. J., Hansen, A. W., \& Balling, N. (1998). Past Temperatures Directly from the Greenland Ice Sheet. Science, 282(5387), 268 LP - 271. https://doi.org/10.1126/science.282.5387.268

Dansgaard, W. (1964). Stable isotopes in precipitation. Tellus, 16(4), 436-468. https://doi.org/10.1111/j.21533490.1964.tb00181.x 
Dansgaard, W., Johnsen, S. J., Møller, J., \& Langway, C. C. (1969). One Thousand Centuries of Climatic Record from Camp Century on the Greenland Ice Sheet. Science, 166(3903), 377 LP - 380. https://doi.org/10.1126/science.166.3903.377

Emile-Geay, J., \& Eshleman, J. A. (2013). Toward a semantic web of paleoclimatology. Geochemistry, Geophysics, Geosystems, 14(2), 457-469. https://doi.org/10.1002/ggge.20067

Faghmous, J. H., \& Kumar, V. (2014). A Big Data Guide to Understanding Climate Change: The Case for Theory-Guided Data Science. Big Data, 2(3), 155-163. https://doi.org/10.1089/big.2014.0026

Fudge, T. J., Waddington, E. D., Conway, H., Lundin, J. M. D., \& Taylor, K. (2014). Interpolation methods for Antarctic ice-core timescales: application to Byrd, Siple Dome and Law Dome ice cores. Clim. Past, 10(3), 1195-1209. https://doi.org/10.5194/cp-10-1195-2014

Fuhrer, K., Wolff, E. W., \& Johnsen, S. J. (1999). Timescales for dust variability in the Greenland Ice Core Project (GRIP) ice core in the last 100,000 years. Journal of Geophysical Research: Atmospheres, 104(D24), 31043-31052. https://doi.org/10.1029/1999JD900929

Gow, A. J., Meese, D. A., Alley, R. B., Fitzpatrick, J. J., Anandakrishnan, S., Woods, G. A., \& Elder, B. C. (1997). Physical and structural properties of the Greenland Ice Sheet Project 2 ice core: A review. Journal of Geophysical Research: Oceans, 102(C12), 26559-26575. https://doi.org/10.1029/97JC00165

Helama, S., Jones, P. D., \& Briffa, K. R. (2017). Dark Ages Cold Period: A literature review and directions for future research. The Holocene, 27(10), 1600-1606. https://doi.org/10.1177/0959683617693898

Holland, D. M., Thomas, R. H., de Young, B., Ribergaard, M. H., \& Lyberth, B. (2008). Acceleration of Jakobshavn Isbræ triggered by warm subsurface ocean waters. Nature Geoscience, 1, 659. Retrieved from https://doi.org/10.1038/ngeo316

Ilka, W., Daniela, J., Tobias, B., Jan, E., H., F. S., Frank, W., ... Thomas, K. (2017). Physical analysis of an Antarctic ice core-towards an integration of micro- and macrodynamics of polar ice*. Philosophical Transactions of the Royal Society A: Mathematical, Physical and Engineering Sciences, 375(2086), 20150347. https://doi.org/10.1098/rsta.2015.0347

Jones, P. D., \& Mann, M. E. (2004). Climate over past millennia. Reviews of Geophysics, 42(2). https://doi.org/10.1029/2003RG000143

Kekonen, T., Moore, J., Perämäki, P., Mulvaney, R., Isaksson, E., Pohjola, V., \& van de Wal, R. S. W. (2005). The 800 year long ion record from the Lomonosovfonna (Svalbard) ice core. Journal of Geophysical Research: Atmospheres, 110(D7). https://doi.org/10.1029/2004JD005223

Knowlton, C., Veerapaneni, R., D’Elia, T., \& Rogers, S. O. (2013). Microbial analyses of ancient ice core sections from greenland and antarctica. Biology, 2(1), 206-232. https://doi.org/10.3390/biology2010206

Legrand, M., \& Mayewski, P. (1997). Glaciochemistry of polar ice cores: A review. Revienss of Geophysics, 35(3), 219-243. https://doi.org/10.1029/96RG03527

Lima, M. (2014). Climate change and the population collapse during the "Great Famine" in pre-industrial Europe. Ecology and Evolution, 4(3), 284-291. https://doi.org/10.1002/ece3.936

Liu, J., Chen, Z., Francis, J., Song, M., Mote, T., and Hu, Y. (2016). Has Arctic sea ice loss contributed to increased surface melting of the Greenland Ice Sheet? J. Climate, 29, 3373-3386. https://doi.org/10.1175/JCLI-D-15-0391.1.

Lozier, M. S., Li, F., Bacon, S., Bahr, F., Bower, A. S., Cunningham, S. A., .. Zhao, J. (2019). A sea change in our view of overturning in the subpolar North Atlantic. Science, 363(6426), 516 LP - 521. https://doi.org/10.1126/science.aau6592 
Maselli, O. J., Chellman, N. J., Grieman, M., Layman, L., McConnell, J. R., Pasteris, D., ... Sigl, M. (2017). Sea ice and pollution-modulated changes in Greenland ice core methanesulfonate and bromine. Climate of the Past, 13(1), 39-59. https://doi.org/10.5194/cp-13-39-2017

McConnell, J. R., Edwards, R., Kok, G. L., Flanner, M. G., Zender, C. S., Saltzman, E. S., ... Kahl, J. D. W. (2007). 20th-Century Industrial Black Carbon Emissions Altered Arctic Climate Forcing. Science, 317(5843), 1381-1384. https://doi.org/10.1126/science.1144856

McConnell, J. R., Lamorey, G. W., Lambert, S. W., \& Taylor, K. C. (2002). Continuous Ice-Core Chemical Analyses Using Inductively Coupled Plasma Mass Spectrometry. Environmental Science \& Technology, 36(1), 7-11. https://doi.org/10.1021/es011088z

McConnell, J. R., Wilson, A. I., Stohl, A., Arienzo, M. M., Chellman, N. J., Eckhardt, S., ... Steffensen, J. P. (2018). Lead pollution recorded in Greenland ice indicates European emissions tracked plagues, wars, and imperial expansion during antiquity. Proceedings of the National Academy of Sciences, 115(22), 5726 LP - 5731. https://doi.org/10.1073/pnas.1721818115

McCormick, M., Büntgen, U., Cane, M. A., Cook, E. R., Harper, K., Huybers, P., ... Tegel, W. (2012). Climate Change during and after the Roman Empire: Reconstructing the Past from Scientific and Historical Evidence. The Journal of Interdisciplinary History, 43(2), 169-220. Retrieved from http://www.jstor.org/stable/41678664

McKay, N. P., \& Emile-Geay, J. (2016). Technical note: The Linked Paleo Data framework - a common tongue for paleoclimatology. Clim. Past, 12(4), 1093-1100. https://doi.org/10.5194/cp-12-1093-2016

Meese, D. A., Gow, A. J., Grootes, P., Stuiver, M., Mayewski, P. A., Zielinski, G. A., ... Waddington, E. D. (1994). The Accumulation Record from the GISP2 Core as an Indicator of Climate Change Throughout the Holocene. Science, 266(5191), 1680 LP - 1682. https://doi.org/10.1126/science.266.5191.1680

Moffa-Sánchez, P., Moreno-Chamarro, E., Reynolds, D. J., Ortega, P., Cunningham, L., Swingedouw, D., ... Yeager, S. (2019). Variability in the northern North Atlantic and Arctic oceans across the last two millennia: A review. Paleoceanography and Paleoclimatology, O(ja). https://doi.org/10.1029/2018PA003508

Moffa-Sánchez, P., \& Hall, I. R. (2017). North Atlantic variability and its links to European climate over the last 3000 years. Nature Communications, 8(1), 1726. https://doi.org/10.1038/s41467-017-01884-8

Moon, T., Joughin, I., Smith, B., \& Howat, I. (2012). 21st-Century Evolution of Greenland Outlet Glacier Velocities. Science, 336(6081), 576 LP - 578. https://doi.org/10.1126/science.1219985

Ogilvie, A. E. J., Barlow, L. K., \& Jennings, A. E. (2000). North Atlantic climate c.ad 1000: Millennial reflections on the Viking discoveries of Iceland, Greenland and North America. Weather, 55(2), 34-45. https://doi.org/10.1002/j.1477-8696.2000.tb04028.x

Osman, M. B., Das, S. B., Trusel, L. D., Evans, M. J., Fischer, H., Grieman, M. M., ... Saltzman, E. S. (2019). Industrial-era decline in subarctic Atlantic productivity. Nature, 569(7757). https://doi.org/10.1038/s41586-019-1181-8

Rahmstorf, S., Box, J. E., Feulner, G., Mann, M. E., Robinson, A., Rutherford, S., \& Schaffernicht, E. J. (2015). Exceptional twentieth-century slowdown in Atlantic Ocean overturning circulation. Nature Climate Change, 5, 475. Retrieved from https://doi.org/10.1038/nclimate2554

Rempel, A. W., Waddington, E. D., Wettlaufer, J. S., \& Worster, M. G. (2001). Possible displacement of the climate signal in ancient ice by premelting and anomalous diffusion. Nature, 411(6837), 568-571. https://doi.org/10.1038/35079043

Rempel, A. W., Wettlaufer, J. S., \& Waddington, E. D. (2002). Anomalous diffusion of multiple impurity species: Predicted implications for the ice core climate records. Journal of Geophysical Research: Solid Earth, 107(B12), ECV 3-1-ECV 3-12. https://doi.org/10.1029/2002JB001857 
Schmid, B. V, Büntgen, U., Easterday, W. R., Ginzler, C., Walløe, L., Bramanti, B., \& Stenseth, N. C. (2015). Climate-driven introduction of the Black Death and successive plague reintroductions into Europe. Proceedings of the National Academy of Sciences, 112(10), 3020 LP - 3025. https://doi.org/10.1073/pnas.1412887112

Sigl, M., Winstrup, M., McConnell, J. R., Welten, K. C., Plunkett, G., Ludlow, F., ... Woodruff, T. E. (2015). Timing and climate forcing of volcanic eruptions for the past 2,500 years. Nature, 523, 543. Retrieved from https://doi.org/10.1038/nature14565

Srokosz, M. A., \& Bryden, H. L. (2015). Observing the Atlantic Meridional Overturning Circulation yields a decade of inevitable surprises. Science, 348(6241), 1255575. https://doi.org/10.1126/science.1255575

Straneo, F., \& Heimbach, P. (2013). North Atlantic warming and the retreat of Greenland's outlet glaciers. Nature, 504(7478), 36-43. Retrieved from http://dx.doi.org/10.1038/nature12854

Sundqvist, H. S., Kaufman, D. S., McKay, N. P., Balascio, N. L., Briner, J. P., Cwynar, L. C., ... Viau, A. E. (2014). Arctic Holocene proxy climate database \&ndash; new approaches to assessing geochronological accuracy and encoding climate variables. Clim. Past, 10(4), 1605-1631. https://doi.org/10.5194/cp-10$1605-2014$

Taylor, K. C., Hammer, C. U., Alley, R. B., Clausen, H. B., Dahl-Jensen, D., Gow, A. J., .. Waddington, E. D. (1993). Electrical conductivity measurements from the GISP2 and GRIP Greenland ice cores. Nature, 366(6455), 549-552. https://doi.org/10.1038/366549a0

Thornalley, D. J. R., Oppo, D. W., Ortega, P., Robson, J. I., Brierley, C. M., Davis, R., ... Keigwin, L. D. (2018). Anomalously weak Labrador Sea convection and Atlantic overturning during the past 150 years. Nature, 556(7700), 227-230. https://doi.org/10.1038/s41586-018-0007-4

Toohey, M., \& Sigl, M. (2017). Volcanic stratospheric sulfur injections and aerosol optical depth from 500 BCE to 1900 CE. Earth Syst. Sci. Data, 9(2), 809-831. https://doi.org/10.5194/essd-9-809-2017

Trusel, L. D., Das, S. B., Osman, M. B., Evans, M. J., Smith, B. E., Fettweis, X., ... van den Broeke, M. R. (2018). Nonlinear rise in Greenland runoff in response to post-industrial Arctic warming. Nature, 564(7734), 104-108. https://doi.org/10.1038/s41586-018-0752-4

Vaughan, D., Comiso, J. C., Allison, I., Carrasco, J., Kaser, G., Kwok, R., ... Zhang, T. (2013). Observations: Cryosphere. Climate Change 2013: The Physical Science Basis. In Observations: Cryosphere. in Climate Change 2013: The Physical Science Basis.

Vinther, B. M., Clausen, H. B., Johnsen, S. J., Rasmussen, S. O., Andersen, K. K., Buchardt, S. L., ... Heinemeier, J. (2006). A synchronized dating of three Greenland ice cores throughout the Holocene. Journal of Geophysical Research: Atmospheres, 111(D13). https:// doi.org/10.1029/2005JD006921

Walsh, J. E., Fetterer, F., Scott Stewart, J., \& Chapman, W. L. (2017). A database for depicting Arctic sea ice variations back to 1850. Geographical Review, 107(1), 89-107. https://doi.org/10.1111/j.19310846.2016.12195.x

Weller, G. (2007). M.C. Serreze and R.G. Barry. 2005. The arctic climate system. Cambridge, Cambridge University Press. 385pp. ISBN 052181418 9, hardback. f80. Joumal of Glaciology, 53(182), 519. https://doi.org/DOI: 10.3189/S002214300020124X

Wolff, E. (1996). Chemical Exchange Between the Atmosphere and Polar Snow. https://doi.org/10.1007/978-3-64261171-1

Yue, R. P. H., \& Lee, H. F. (2018). Climate change and plague history in Europe. Science China Earth Sciences, 61(2), 163-177. https://doi.org/10.1007/s11430-017-9127-x 
Zhang, D. D., Lee, H. F., Wang, C., Li, B., Zhang, J., Pei, Q., \& Chen, J. (2011). Climate change and large-scale human population collapses in the pre-industrial era. Global Ecology and Biogeography, 20(4), 520-531. https://doi.org/10.1111/j.1466-8238.2010.00625.x 


\title{
2. Methanesulfonic acid (MSA) migration in polar ice: Data synthesis and theory
}

This chapter was originally published as: Osman, M., Das, S. B., Marchal, O., and Evans, M. J. (2017). Methanesulfonic acid (MSA) migration in polar ice: data synthesis and theory, The Cryosphere, 11, 24392462, https://doi.org/10.5194/tc-11-2439-2017. Used with permission as granted in the original copyright agreement.

\begin{abstract}
Methanesulfonic acid (MSA; $\left.\mathrm{CH}_{3} \mathrm{SO}_{3} \mathrm{H}\right)$ in polar ice is a unique proxy of marine primary productivity, synoptic atmospheric transport, and regional sea ice behavior. However, MSA can be mobile within the firn and ice matrix, a post-depositional process that is well known but poorly understood and documented, leading to uncertainties in the integrity of the MSA paleoclimatic signal. Here, we use a compilation of 22 ice core MSA records from Greenland and Antarctica and a model of soluble impurity transport in order to comprehensively investigate the vertical migration of MSA from summer layers, where MSA is originally deposited, to adjacent winter layers in polar ice.

We find that the shallowest depths of MSA migration in our compilation vary over a wide range ( $\sim 2 \mathrm{~m}$ to $400 \mathrm{~m}$ ), and are positively correlated with snow accumulation rate and negatively correlated with ice concentration of $\mathrm{Na}^{+}$(typically the most abundant cationic sea salt). Although the considered soluble impurity transport model provides a useful mechanistic framework for studying MSA migration, it remains limited by inadequate constraints on key physico-chemical parameters, most notably, the diffusion coefficient of MSA in cold ice $\left(D_{M S}\right)$. We derive a simplified version of the model, which includes $D_{M S}$ as the sole parameter, in order to illuminate aspects of the migration process. Using this model, we show that the progressive phase alignment of MSA and $\mathrm{Na}^{+}$ concentration peaks observed along a high-resolution West Antarctic core is most consistent with 10${ }^{12} \mathrm{~m}^{2} \mathrm{~s}^{-1}<D_{M S}<10^{-11} \mathrm{~m}^{2} \mathrm{~s}^{-1}$, one order of magnitude greater than $D_{M S}$ values previously estimated from laboratory studies. More generally, our data synthesis and model results suggest that (i) MSA migration may be fairly ubiquitous, particularly at coastal and (or) high accumulation regions across Greenland and Antarctica, and (ii) can significantly change annual and multi-year MSA concentration averages. Thus, in most cases, caution should be exercised when interpreting polar ice core MSA
\end{abstract}


records, although records that have undergone severe migration could still be useful for inferring decadal and lower-frequency climate variability. 


\subsection{Introduction}

Measurements of soluble impurity species in polar ice cores provide important high-resolution proxies of past climatic phenomena, including past changes in sea-ice extent, marine and terrestrial productivity, volcanism, biomass burning, atmospheric cycling, and anthropogenic pollution (e.g., Legrand and Mayewski, 1997). A foundational premise, however, is that these species undergo negligible post-depositional redistribution in the ice column, an assumption unsupported by numerous ice core records from Greenland and Antarctica. Processes acting within the upper firn layer, including wind pumping, diffusion, photolysis, volatility, sublimation, and melt (Wolff et al., 1996), can affect the stability of chemical species soon after deposition and undermine the climatic interpretation of these records down-core (Wagnon et al. 1999, Weller et al. 2004). Deeper in the ice column, both observation (e.g., Barnes et al., 2003b) and theory (Nye, 1991; Rempel et al. 2001, 2002) indicate the potential for solid and liquid-state chemical migration, impacting the stability of chemical species much later after deposition. In this study, we focus on one species particularly susceptible to vertical migration in polar ice, methanesulfonic acid, or MSA $\left(\mathrm{CH}_{3} \mathrm{SO}_{3} \mathrm{H}\right.$; Pasteur and Mulvaney, 2000).

The processes leading to the production, transport, and deposition of MSA onto an ice sheet are complex (e.g., Abram, 2013). The progenitor compound of MSA, dimethylsulfoniopropionate, or $\left.\operatorname{DMSP}\left(\left(\mathrm{CH}_{3}\right)_{2} \mathrm{~S}^{+} \mathrm{CH}_{2} \mathrm{CH}_{2} \mathrm{COO}\right)^{-}\right)$, is produced by certain marine algae as an osmotic regulator (Dickson and Kirst, 1986). Planktonic life cycle processes ultimately release DMSP to the water column, whereupon the ensuing bacterial-mediated cleavage of the compound promotes the formation of dimethylsulfide, or DMS ((CH3) $\left.)_{2} \mathrm{~S}\right)$, a highly-insoluble gaseous compound (Yoch, 2002). Once freed to the atmosphere, DMS is rapidly photo-oxidized (Saltzman et al., 1983), branching to form either non-sea salt sulfate (nssSO ${ }^{-2}$ ), or, to a lesser extent, MSA. Unlike $\mathrm{nssSO}_{4}^{-2}$, however, DMS production appears to be the exclusive source of MSA (Abram, 2013).

Early studies on DMS and DMSP production in the Southern Ocean (Curran and Jones, 2000) and in Arctic waters (Leck and Persson, 1996) reported the greatest fluxes of DMS near the marginal sea ice zone at the onset of spring - summer decay (Turner et al., 1995; Curran et al., 1998). Since concentrations of atmospheric MSA rapidly decrease with increasing altitude and distance from their marine source (the mean atmospheric lifetime of MSA is estimated to about 7 days; Hezel et al. 2011), deposition of MSA at coastal ice sheet localities near-ubiquitously exhibits well-defined annual peaks during the late-spring to summer months. Conversely, the relatively low wintertime MSA deposition may be jointly attributed to (1) limited marine productivity during polar darkness, (2) increased 
wintertime sea ice extent and, accordingly, atmospheric transport distances, and (or) (3) diminished atmospheric $\mathrm{OH}$ radical concentrations, the primary oxidant of airborne DMS (Jourdain and Legrand, 2001). The strong seasonality and unique marine source of MSA in ice cores have led to its predominant use as a high-resolution proxy for past sea-ice cover (e.g., Welch et al., 1993; Abram et al., 2013).

Mulvaney et al. (1992) appear to be the first authors to report migration of MSA in polar ice, using data from Dolleman Plateau, Antarctica Peninsula. In the shallow portions of the Dolleman Plateau core, concentrations of MSA exhibited well-defined summer maxima, as expected. With increasing depth in the ice column, however, a distinctive shift to predominantly winter [MS] maxima was found (hereafter, MSA is denoted as $\mathrm{MS}^{-}$when referring to its anionic form, $\mathrm{CH}_{3} \mathrm{SO}_{3}^{-}$, as measured by ion chromatography). Concluding that a change in the seasonality of peak MSA production and (or) deposition was unlikely, the authors postulated this shift to result from post-depositional vertical migration. Since then, numerous ice core studies from both Antarctica and Greenland have reported the migration phenomenon over a wide range of depths, temperatures, and ionic concentrations in the ice column (Table 2-1 and references therein).

Despite the importance of [MS] records in paleoclimatic studies, there have been few systematic evaluations of the environmental and (or) chemical conditions promoting MSA migration from summer-to-winter layers in polar ice. Furthermore, aspects of this migration process exhibit behavior distinct from other post-depositional processes, and are important to understand mechanistically. First, the [MS] maxima that are formed in winter are converse to what would be expected from typical (Fickian) diffusion, which would instead weaken the amplitude of summertime [MS] peaks. Second, MSA movement has been reported to occur in the up-core direction (Curran et al., 2002), ruling out gravitational forcing as the sole mechanism for migration. These observations, corroborated by evidence for highly concentrated regions of sulfuric acid at the interface of individual ice crystals (Mulvaney et al. 1988), led to speculation that liquid migration of soluble impurities could occur along the boundaries of individual ice crystals, likely along concentration gradients (Mulvaney et al. 1992). However, critical questions remain. For example, why should MSA in particular exhibit migration, while associated soluble impurities and acids (e.g., nssSO ${ }_{4}^{2-}$ ) do not (Pasteur et al., 1999)? How could diffusion result in clearly defined concentration maxima in winter layers? Could the "trapping" of migrating MSA in the adjacent winter layer stem any subsequent "spillover" of MSA into an adjacent annual layer, as assumed in prior studies (e.g., Kreutz et al. 1998; Pasteur and Mulvaney, 2000; Becagli et al. 2009; Thomas and Abram, 2016)? Clearly, investigating the 
mechanisms(s) responsible for MSA migration in polar ice is necessary if we are to answer these questions and build confidence in the use of [MS] in polar ice as a paleoclimatic indicator.

The overarching goal of this study is to develop a better understanding of the environmental and physico-chemical processes that are conducive to MSA migration in cold, polar ice, in order to improve the interpretation of ice-core [MS $]$ records. This paper is organized as follows. In Section 2.2, we consider published [MS] and ancillary measurements from a variety of Greenlandic and Antarctic ice cores in an effort to identify site-specific factors that influence MSA migration. In Section 2.3, we present observations from the high-resolution, precisely dated DIV2010 ice core (West Antarctica) as a case study for MSA migration. In Section 2.4, we summarize our current understanding of the physico-chemical processes leading to MSA migration, utilizing an existing model describing soluble impurity transport along ice grain boundaries (Rempel et al., 2002). We derive a simplified version of this model to illuminate these processes, and to test the ability of different values of MSA diffusivity to reproduce the down-core change in phase relationship between the concentrations of MSA (deposited primarily in summer) and $\mathrm{Na}^{+}$(deposited primarily in winter) observed along the DIV2010 core. In Section 2.5, we assess the integrity of the DIV2010 [MS] record, and discuss the broader implications of our results for the interpretation of [MS] records across a wide range of polar conditions. Section 2.6 concludes with an overview of our results and suggestions for future research.

\subsection{MSA migration in ice cores}

In this section, we use observations to evaluate the relative importance of site-specific variables on MSA migration in polar ice. We compiled 22 ice core [MS'] records originating from 20 sites in Greenland and Antarctica (see Appendix 2), taken from both the literature and unpublished datasets (Table 2-1). The following criteria are adopted for selection of the records: (1) high temporal resolution and dating accuracy (annually resolved and dating uncertainty $<3 \mathrm{yr}$ ); (2) multi-decadal record length (20 yr minimum); and (3) documented changes in seasonality in the [MS] record and (or) an explicit mention of MSA migration from summer-to-winter layers. Post-depositional surficial losses of MSA may occur via gaseous diffusion in the top 1-2 meters of the firn at low accumulation sites (Wagnon et al., 1999, Delmas et al., 2003, Weller et al., 2004). As a result, we exclude records from sites where annual mean accumulation rate is less than $100 \mathrm{~kg} \mathrm{~m}^{-2} \mathrm{yr}^{-1}$, and assume that vertical redistribution of MSA via gas-phase diffusion (Kuo et al., 2011) is negligible at all considered sites and depths. Also 
excluded are records from sites subject to moderate to severe melt, which, through percolation, can also rapidly redistribute $\mathrm{MS}^{-}$along the firn (Moore et al., 2005).

Of the 20 sites, thirteen indicate MSA migration, five do not indicate migration, and at two sites migration is deemed unclear at the deepest depths sampled (Fig. 2-1). The sites and records cover a wide range of climatologic and glaciological conditions, as represented by annual mean surface air temperature, annual mean accumulation rate, distance inland, and impurity concentrations in the ice (Table 2-1 and Figure 2-1). Figure 2-1a illustrates the range of annual mean accumulation rates $(\dot{b})$ and annual mean surface air temperatures (SAT) of all sites. A strong, nonlinear relationship is apparent between both variables, as expected (Cuffey and Patterson, 2010). Similarly, for the 14 sites where glaciochemical data are available (Table 2-1), Figures 2-1b and 2-1c show, respectively, the depthaveraged concentrations of $\mathrm{Na}^{+} \overline{\mathrm{Na}^{+}}$; an ionic species whose relevance we expound upon in Sect. 2.2.2) and $\mathrm{MS}^{-}\left(\overline{M S^{-}}\right)$, taken here as rough measures of winter and summer deposition, respectively, across sites. While impurity deposition largely covaries with distance inland (Fig. 2-1b and 2-1c), with higher $\overline{\mathrm{Na}^{+}}$and $\overline{\mathrm{MS}^{-}}$at sites nearer to the coast, this pattern does not always hold true, likely due to effects associated with seasonal atmospheric transport and (or) local differences in the production of the progenitor aerosols of both ions (Iizuka et al., 2016). There is also a notable geographic difference: Greenland values of $\overline{\mathrm{Na}^{+}}$and $\overline{\mathrm{MS}^{-}}$(observed at the high-elevation, inland Summit2010 and D4 sites) are lower than those reported for all Antarctic ice cores. In the following sub-sections, we explore in detail the effects of snow accumulation, ice impurity concentration, surface air temperature, and ice density on MSA migration.

\subsubsection{Snow accumulation}

Previous work has suggested that high snow accumulation acts as the primary deterrent for MSA migration (Pasteur and Mulvaney, 2000), a result of either (i) the longer distance required for an ion to travel from the summer to winter layer, (ii) the corresponding suppression of summer-winter layer ionic concentration gradients at higher accumulation sites, or (iii) both (Curran et al., 2002). General support for this suggestion is illustrated in Figure 2-1a, showing that sites with $\dot{b}>0.45 \mathrm{~m} \mathrm{w}$. eq. $\mathrm{yr}^{-1}$ (meter of water equivalent per year) appear less likely to exhibit clear signs of MSA migration than sites with lower accumulation rates. This consideration, however, does not take into account the depth required for migration to occur. As such, we consider below whether MSA migration invariably occurs across the full range of accumulation rates, given sufficient depth within the firn column. 
At low-to-moderate accumulation rate sites $\left(\dot{b}=0.1-0.45 \mathrm{~m}\right.$ w. eq. $\left.\mathrm{yr}^{-1}\right)$, MSA migration seems to universally occur, with the shallowest reported depths of migration showing a positive relationship with accumulation rate (Table 2-1 and Fig. 2-2). Data from sites characterized by moderately high accumulation rates $\left(\dot{b}=0.45-0.65 \mathrm{~m}\right.$ w. eq. $\left.\mathrm{yr}^{-1}\right)$ are not as straightforward to interpret. For example, in the Dome Summit South (DSS; Law Dome, Antarctica) and Dyer Plateau ice cores, signs of MSA migration were noted in the original studies. At DSS $\left(\dot{b}=0.64 \mathrm{~m}\right.$ w.eq. $\left.\mathrm{yr}^{-1}\right)$, moderate indications of [MS $]$ annual maxima extending into adjacent autumn layers were reported at depths deeper than about 40-50 m (Curran et al., 2002). Similarly, at Dyer Plateau ( $\dot{b}=0.48 \mathrm{~m}$ w.eq. $\mathrm{yr}^{-1}$ ) [MS $]$ showed suppressed, localized maxima in both winter and summer layers throughout a core section from $\sim 51-54 \mathrm{~m}$ depth, indicating, perhaps, initial or transitory stages of migration (Pasteur and Mulvaney, 2002). On the other hand, two [MS] records at sites characterized by annual mean accumulation rates similar to DSS and Dyer, the 2 Barrell $\left(\dot{b}=0.51 \mathrm{~m}\right.$ w.eq. $\left.\mathrm{yr}^{-1}\right)$ and WHG ice cores ( $\dot{b}=0.61 \mathrm{~m}$ w.eq. $\left.\mathrm{yr}^{-1}\right)$, respectively, showed no signs of migration. However, neither WHG nor the 2Barrell records extend as deep as their counterparts, suggesting WHG and 2Barrell may be of insufficient length and thus may also show migration at similar depths. Finally, of the four sites characterized by high accumulation rates $\left(>0.65 \mathrm{~m}\right.$ w. eq. $\left.\mathrm{yr}^{-1}\right)$, three $[\mathrm{MS}$ ] records, the Gomez $(\dot{b}=$ $0.88 \mathrm{~m}$. w.eq. $\left.\mathrm{yr}^{-1}\right)$, Beethoven $\left(\dot{b}=1.2 \mathrm{~m}\right.$. w.eq. $\left.\mathrm{yr}^{-1}\right)$, and DE08 $\left(\dot{b}=1.27 \mathrm{~m}\right.$. w.eq. $\left.\mathrm{yr}^{-1}\right)$ ice cores, did not present signs of migration. The exception is the highest accumulation site, Bruce Plateau $(\dot{b}=1.98$ $\mathrm{m}$. w.eq. $\mathrm{yr}^{-1}$ ), where clear evidence of summer-to-winter migration was reported at $\sim 395 \mathrm{~m}$ depth (Porter et al., 2016). Notably, Bruce Plateau is also the deepest drilled record among the high accumulation rate sites of our compilation.

We use these observations to determine the relationship between $\dot{b}$ and the depth of first occurrence of MSA migration, $z_{f o}$, defined as the shallowest reported depth where [MS-] consistently shows its annual maximum in winter (see Appendix 2 for details about the estimation of $z_{f o}$ for each site). We first consider just Antarctic sites reporting MSA migration (Fig. 2-2a). A least squares fit of a power law of $z_{f o}$ against $\dot{b}$, with the intercept fixed to the origin, yields $r^{2}=0.99$ (Fig. 2-2a). To ensure that the fit is not dominated by the data pair with the highest $\dot{b}$ value (Bruce Plateau), $z_{f o}$ is regressed against $\dot{b}$ using only those records with accumulation rates $<0.45 \mathrm{~m} \mathrm{w}$. eq. $\mathrm{yr}^{-1}$, which yields $\mathrm{r}^{2}=0.82$ (Fig. 2-2b). Remarkably, extension of the latter fit to the Bruce Plateau data point produces a value of $z_{f o}$ that is within $\sim 15 \mathrm{~m}$ of the reported value (Fig. $2-2 \mathrm{a}$ ). The ability of the power law to 
describe the data in both scenarios suggests that, at least at Antarctic sites, the annual mean rate of snow accumulation has a strong (non-linear) influence on the shallowest depth of MSA migration in the ice column.

Applying this power law to the five sites where MSA migration was not observed or reported (Fig. 2-1), we find that three of these sites did not reach the predicted $z_{f o}$. The exceptions are (i) the WHG core, where little information on MSA migration in the deepest portions of the core is provided in the original study (Sinclair et al., 2014), and (ii) the Law Dome DE08 core, where the largest depth reported by Curran et al. (2002) remains within $\sim 15 \mathrm{~m}$ of the predicted $z_{f o}$. These results suggest that MSA migration may be more general than commonly thought and that records for which MSA migration was not reported either may have not reached the requisite depth, or they do not have the necessary resolution, required to observe the phenomenon. The two high elevation records from inland Greenland, which have low overall impurity concentration relative to the coastal Antarctic records, appear anomalous (Fig. 2-2a). This anomaly may result from the effect of ice impurities - in particular cationic sea salts - on MSA migration, a point we investigate in more detail below.

\subsubsection{Ice impurities}

Earlier studies hypothesized that the presence of well-defined [MS] peaks in winter layers reflects interaction with sea salts, which are preferentially deposited during winter months at most coastal locations (Legrand and Mayewski, 1997). The attributed mechanism, first hypothesized by Mulvaney et al. (1992) and echoed by subsequent studies (Wolff et al., 1996; Kreutz et al., 1998, Pasteur and Mulvaney, 2000; Curran et al., 2002), posits that a MSA molecule rejected to and dissolved in the under-cooled liquid veins present at the interface of ice grains (Mulvaney et al., 1988) would be transported by diffusion along a concentration gradient. This mechanism could transport MS in either the down or up gradient direction and would not necessarily conform to the concentration gradient measured on bulk ice samples (Sect. 2.4). Mulvaney et al. (1992) further proposed that upon contact with a cation, the precipitation of a stable cation salt through a metathesis reaction could effectively remove MS- from solution, thus sequestering the resultant precipitate in the winter layer.

Here we evaluate whether observations support this mechanism, by comparing $z_{f o}$ to the bulk concentrations of winter-deposited cations at sites showing evidence of MSA migration. Our evaluation is premised by the notion that higher ionic concentrations have greater ability to regulate the chemical composition of liquid veins, when in situ temperatures exceed the eutectic temperatures 
of the dominant progenitor salt species of those ions (Nye et al., 1991; Sect. 2.4). We constrain our analysis to the relationship between MSA and $\mathrm{Na}^{+}$for the following reasons. First, at coastal localities, the most abundant winter-maximum cation is typically $\mathrm{Na}^{+}$, though the relative abundance of $\mathrm{Mg}^{2+}$, $\mathrm{Ca}^{2+}$, and $\mathrm{K}^{+}$may vary from site to site (Legrand and Mayewski, 1997). Second, past studies have noted that MSA concentration peaks tend to coincide with $\mathrm{Na}^{+}$concentration peaks down-core (Pasteur and Mulvaney, 2000; Kreutz et al., 1998). Finally, $\mathrm{Na}^{+}$is considered to be relatively nonreactive within the ice column (Barnes et al., 2003a,b; Legrand and Mayewski, 1997), while less abundant cations, such as $\mathrm{Mg}^{2+}$, appear to be more susceptible to post-depositional effects (Kreutz et al., 1998; Wolff et al., 1996).

In Figure 2-3, $z_{f o}$ is plotted against the core-averaged concentration of $\mathrm{Na}^{+}\left(\overline{\mathrm{Na}^{+}}\right)$for the eleven sites where $\left[\mathrm{Na}^{+}\right]$data are available. These sites have comparable annual mean accumulation rates, within $0.13-0.42 \mathrm{~m}$ w. eq. $\mathrm{yr}^{-1}$, so that the effect of $\overline{\mathrm{Na}^{+}}$on MSA migration could be isolated with some confidence. We find that as $\overline{\mathrm{Na}^{+}}$decreases, MSA migration tends to be observed at greater depths in the firn or ice column (Fig. 2-3). The depth $z_{f o}$ appears to be particularly sensitive to $\overline{N a^{+}}$ for low concentrations of $\overline{\mathrm{Na}^{+}}$, as can be seen most prominently for the two Greenland cores showing migration, D4 and Summit2010. This result conforms to the suggestion that, as the concentration of $\mathrm{Na}^{+}$is reduced, the concentration gradient of $\mathrm{MS}^{-}$existing in the liquid vein network between the winter and summer layers is also reduced, thereby decreasing the rate at which MSA migration occurs. Another possibility is that the reduction of $\left[\mathrm{Na}^{+}\right]$closes off the liquid vein network within winter layers, inhibiting the vertical transport of ions along grain boundaries, although data are lacking to explore this further.

\subsubsection{Temperature}

Temperature may influence MSA migration in at least two ways. First, the rate of diffusion of MSalong grain boundaries may depend on temperature, with higher rates occurring at warmer site, as suggested by Pasteur et al. (1999). Such dependence would imply that sites characterized by lower in situ temperatures would tend to exhibit larger values of $z_{f o}$. Second, the precipitation of an MS-sea salt from solution may be required to sequester MS- in the winter layer, as proposed by Mulvaney et al. (1992). If effective, the formation of winter-layer [MS'] annual maxima would be inhibited at sites where in situ temperature exceeds the eutectic temperature(s) of the dominant precipitated $\mathrm{MS}^{-}$-sea salt(s). We can test both of the foregoing thermal influences with the available observations. However, 
due to a lack of firn temperature profiles, we substitute the more widely available annual mean surface air temperature (SAT) as a surrogate for in situ temperature. This approach appears justified, as vertical thermal gradients in polar ice sheets are typically small below $10 \mathrm{~m}$, and their magnitude dictated primarily by local annual mean SAT (Cuffey and Patterson, 2010). We note that deeper in the ice, thermal gradients could be important (Rempel et al., 2001), particularly near the bedrock due to geothermal fluxes and (or) frictional heat dissipation, but we do not consider those cases here.

As a rough test of a thermal influence on MSA diffusivity, we regress $Z_{f o}$ against SAT (not shown). Unlike the relationships between $z_{f o}$ and $\dot{b}$ or $\left[\mathrm{Na}^{+}\right]$, no significant relationship between $z_{f o}$ and SAT is observed. Likewise, no significant relationship is found between the $Z_{f o}$ residuals of the

relationship between $z_{f o}$ and $\dot{b}$ (arguably, the best predictor for $z_{f o}$ ) and SAT (also not shown). These results suggest that temperature has a negligible influence on MSA migration, at least for the sites considered (Table 2-1).

Similarly, available observations do not indicate that sites reporting MSA migration can be discriminated on the basis of SAT. Although sites presenting no evidence for MSA migration tend to experience high SAT $\left(-19^{\circ} \mathrm{C}\right.$ to $-12.5^{\circ} \mathrm{C}$, Fig. 2-1a), two sites where MSA migration has been reported are also characterized by equal or higher SAT. We interpret this observation as an artifact of the strong relationship between SAT and accumulation rate in polar regions (Figure 2-1), whereupon $\dot{b}$ is deemed to be the most relevant variable in driving $Z_{f o}$ (Sect. 2.1). This conclusion, in turn, indicates that either precipitating $\mathrm{MS}^{-}$-salts may not drive MSA migration (Mulvaney et al., 1992), or the eutectic temperature(s) of the dominant $\mathrm{MS}^{-}$-sea salt(s) is (are) less than $-29.5^{\circ} \mathrm{C}$, the lowest $\mathrm{SAT}$ reported in Table 2-1. We return to this discussion in Section 2.5.1, after incorporating recent estimates of the eutectic temperatures of the dominant $\mathrm{MS}^{-}$-sea salts.

\subsubsection{Firn or ice density}

The mechanism of MSA migration described above, involving diffusion along liquid grain boundaries, relies on the assumption that the ice grains are sufficiently well compacted to form interconnected premelted veins between the summer and winter layers. This mechanism seems to imply there should be a relationship between the onset of MSA migration and ice density $(\rho)$, yet to our knowledge such possible relationship has not been investigated. Here, we consider the firn or ice densities $\left(\rho_{f o}\right)$ 
observed at the shallowest depth of MSA migration, $z_{f o}$, again using our compilation of Greenland and Antarctic data.

In Figure $2-4, z_{f o}$ is plotted against $\rho_{f o}$ for the seven sites where available data permit (Table 1). A weighted least squares fit to the data, with the weighting provided by the errors in the $Z_{f o}$ estimates, shows a positive relationship between $z_{f o}$ and $\rho_{f o}(p<0.01)$, as expected. Data for low accumulation Berkner Island sites, where annual mean $\dot{b}=0.18-0.22 \mathrm{~m}$ w.eq. $\mathrm{yr}^{-1}$, indicate the occurrence of MSA migration at densities exceeding about 515-560 $\mathrm{kg} \mathrm{m}^{-3}$ (Wagenbach et al., 1994), while higher accumulation sites, including THW2010, Ferrigno, and DIV2010 $(\dot{b}=0.28-0.41 \mathrm{~m}$ w.eq. $\mathrm{yr}^{-1}$ ) show values of $\rho_{f o}$ values in the range of $610-650 \mathrm{~kg} \mathrm{~m}^{-3}$. The highest values of $\rho_{f o}$ values, in the range $710-760 \mathrm{~kg} \mathrm{~m}^{-3}$, are found for the Greenland cores, D4 and Summit2010.

Interestingly, the firn or ice densities at the shallowest depths of MSA migration $(\sim 500$ to $\sim 800 \mathrm{~kg} \mathrm{~m}^{-3}$, Fig. 2-4), are all comparable to or higher than the critical value of $550 \mathrm{~kg} \mathrm{~m}^{-3}$ that corresponds to the theoretical closest random packing of spherical ice grains (Benson, 1962). Densities greater than $550 \mathrm{~kg} \mathrm{~m}^{-3}$ can be achieved only by bond formation, or sintering, at the contact of individual grains (Cuffey and Patterson, 2010). Persistent vertical transport of under-cooled liquid at the grain boundaries (Mulvaney et al., 1992) requires reaching or exceeding this effective critical density. The compiled data also indicate that the critical density for MSA migration may vary between sites (Fig. 2-4), which might be due to variability in grain shape, grain size, and (or) impurity content. For example, firn samples with densities of 350-400 $\mathrm{kg} \mathrm{m}^{-3}$ can typically be cut into blocks (Cuffey and Patterson, 2010), which suggests that bond formation in the upper firnpack can begin at densities below $550 \mathrm{~kg} \mathrm{~m}^{-3}$. Furthermore, at the lowest accumulation sites, Byrd Station, Siple Dome, and the Filchner-Ronne Ice Shelf, MSA migration was reported in the shallowest $\sim 5 \mathrm{~m}$ of the firn $\left(z_{f o}=2.6\right.$, 2, and 3-4 m, respectively). Although density data are not available for these specific records, this observation suggests that MSA migration may begin at bulk densities substantially lower than $550 \mathrm{~kg}$ $\mathrm{m}^{-3}$, perhaps through high-density microlayers, such as wind-blown crusts, features commonly found at lower accumulation sites (Cuffey and Patterson, 2010). While more data are needed, available evidence presented here supports the notion that a density of at least $500 \mathrm{~kg} \mathrm{~m}^{-3}$, comparable to the theoretical value of $550 \mathrm{~kg} \mathrm{~m}^{-3}$, is needed for MSA migration. 


\subsubsection{Synthesis}

Our data analysis suggests that the annual mean rate of snow accumulation appears to have a strong influence on the shallowest depth at which MSA migration is observed. The concentration of $\mathrm{Na}^{+}$in the ice or firn appears to also be an important factor, especially at sites characterized by low $\overline{N a^{+}}$. Annual mean SAT appears to play a less important role in determining $z_{f o}$, at least in the SAT range where data are available $\left(-29.5^{\circ} \mathrm{C}\right.$ to $\left.-12.5^{\circ} \mathrm{C}\right)$. Lastly, the onset of migration appears to be associated with a critical density near 450-550 $\mathrm{kg} \mathrm{m}^{-3}$, though this may not hold true for all low accumulation sites. Overall, our analysis suggests that MSA migration may be more common than usually thought, and that existing [MS] records not exhibiting evidence for migration may not be deep enough, or have the necessary (sub-annual) resolution, to observe the phenomenon.

The shallowest depth of MSA migration $\left(z_{f o}\right)$ appears most readily predictable from $\dot{b}$ in coastal Antarctica. This result appears in part attributable to the comparably higher concentrations of $\mathrm{Na}^{+}$in the coastal Antarctic cores than in the two Greenland cores showing evidence of migration (Table 2-1). The joint effect of annual mean accumulation rate and depth-averaged $\mathrm{Na}^{+}$concentration on the shallowest depth of MSA migration is illustrated in Figure 2-5, which shows MSA migration tends to occur deeper in the firn or ice column for larger values of $\dot{b}$ and lower values of $\overline{N^{+}}$. Notably, Antarctic sites with comparably low concentrations of $\mathrm{Na}^{+}$tend to occur further inland and at higher elevations, and thus also tend to have lower accumulation rates than considered in this study

(i.e., $\dot{b}<0.1 \mathrm{~m}$. w.eq. $\mathrm{yr}^{-1}$ ). Greenland, in contrast, experiences comparably large accumulation rates even at its highest-altitude, inland locations (e.g., Summit). For a recent overview of Greenland-wide $\left[\mathrm{Na}^{+}\right]$deposition, see Rhodes et al. (2017).

\subsection{A case study: the DIV2010 MSA record}

In this section, we use a well-dated multi-century ice core record from DIV2010, an intermediate accumulation rate site in coastal West Antarctica (Table 2-1), to document in detail the phenomenon of MSA migration. Prior studies have investigated aspects of the DIV2010 core, including variability in accumulation (Medley et al., 2013; Medley et al., 2014) and chemical composition (Criscitiello et al., 2013; Criscitiello et al., 2014; Pasteris et al., 2014). As this is the first report of the DIV2010 [MS] record below the zone of MSA migration, however, we describe the record in more detail here. 
Inorganic salt ions (e.g., $\mathrm{Na}^{+}$) and $\mathrm{MS}^{-}$were measured on discrete samples at a constant sampling interval $\Delta z=5 \mathrm{~cm}$ using standard suppressed ion chromatography methods (Curran and Palmer, 2001). The age-depth relationship of the core was established independently by identifying summer maxima in three parameters - $[\mathrm{nssS}],\left[\mathrm{H}_{2} \mathrm{O}_{2}\right]$, and $\delta^{18} \mathrm{O}-$ measured at $\sim 2 \mathrm{~cm}$ resolution (Pasteris et al., 2014). Here, we examine data from the top $60.4 \mathrm{~m}$ of DIV2010 (AD 1905-2010) covering the zone of progressive migration of MSA. Dating uncertainty over this depth interval is estimated to be less than $1 \mathrm{yr}$ based on tie points to well known volcanic events (Pasteris et al., 2014), and the sampling frequency ( $\sim 10-15$ samples per year) allows for seasonally resolved records throughout this depth interval (Criscitiello et al., 2013; Criscitiello, 2014). At a depth $60.4 \mathrm{~m}$ in the core, annual layer thinning estimated using a thinning model assuming frozen basal conditions and a linear vertical strain rate (Nye, 1963) is considerably less than the distance required for a chemical species to migrate from the summer to the winter layer $(\sim 30 \mathrm{~cm})$. As a result, no correction for thinning is applied.

The migration of MSA from summer to winter layers in the DIV2010 ice core appears to be progressive. To document this progression and contrast the behavior of $\mathrm{Na}^{+}$and $\mathrm{MS}^{-}$, the month of the annual maximum of [MS] (m) and the month of the annual maximum of $\left[\mathrm{Na}^{+}\right]\left(\mathrm{m}_{\mathrm{Na}+}\right)$ are each plotted versus age (Fig. 2-6). The month of the annual maximum of [MS'] tends to change down-core from summer to predominantly winter, as revealed by the significant linear trend of $\mathrm{m}_{\mathrm{MS}}$-between $\mathrm{AD}$ 1905-1999 ( $\mathrm{r}=0.75 ; \mathrm{p}<0.001)$. In contrast, $\left[\mathrm{Na}^{+}\right]$consistently shows maxima in the winter layers, i.e., $\mathrm{m}_{\mathrm{Na}}$ - portrays no significant trend over this period $(\mathrm{r}=0.09, \mathrm{p}=0.41)$. Similarly, $\left[\mathrm{nssSO}_{4}{ }^{2-}\right.$ ] displays its annual maximum consistently in the summer layers during this period (not shown). Note that no significant decrease in annual mean [MS'] is found deeper than $10 \mathrm{~m}$, suggesting post-depositional losses are negligible at the DIV2010 core site.

\subsubsection{Identification of DIV2010 migration zones}

Notwithstanding the progressive nature of MSA migration in the DIV2010 core, we identify three distinct zones in the [MS] record for this core (Fig. 2-7). First, a shallow zone is defined as the depth interval where density is less than $550 \mathrm{~kg} \mathrm{~m}^{-3}$; at DIV2010, this depth occurs at approximately $9.1 \mathrm{~m}$ (Medley et al., 2014). The upper $9.1 \mathrm{~m}$ of the core appears to contain the original (unaltered by migration) [MS'] variations, to the extent that annual maxima of [MS'] are found in the summer layers and are out of phase with winter $\left[\mathrm{Na}^{+}\right]$maxima. Second, a transition zone is defined further down-core, where the [MS] record exhibits no consistent seasonality. Finally, a deep zone is defined as the deepest 
portion of the record considered, where $[\mathrm{MS}]$ and $\left[\mathrm{Na}^{+}\right]$annual maxima appear to be broadly in phase (Fig. 2-7). In order to facilitate our analysis, we linearly interpolated the [MS-] record onto a monthly scale, with the three zones defined to entail an equal number of data points $(n=132$ months, or 11 years).

To better reveal the variable phase relationship between $[\mathrm{MS}]$ and $\left[\mathrm{Na}^{+}\right]$in the shallow, transition, and deep zones, monthly mean values of $[\mathrm{MS}]$ and $\left[\mathrm{Na}^{+}\right]$are calculated and the standard error of the monthly means are computed for each zone (Fig. 2-8). In all three zones, $\mathrm{Na}^{+}$shows concentration maxima in winter, albeit with broad variation between April and September. In contrast, MS- exhibits concentration maxima during summer (January) in the shallow zone, but during winter (broadly, May to August) in the deep zone. In the transition zone, the monthly mean [MS] are not significantly different between summer (DJF) and winter (JJA), though local maxima in both spring (MAM) and fall (SON) are apparent.

\subsubsection{Cross-correlation analysis}

Cross-correlation coefficients are calculated to quantify the amount of linear relationship between the monthly mean $[\mathrm{MS}]$ and $\left[\mathrm{Na}^{+}\right]$at different lags in the three zones. Due to the finite length of the records, only the coefficients from lag 1 to lag 24 (2 yr) are calculated (Fig. 2-9). In the shallow zone, [MS] and $\left[\mathrm{Na}^{+}\right]$show a negative correlation at lag 0 and a positive correlation at lag 6 (i.e., 6 months); both correlations appear significant at the 5\% level compared to two uncorrelated series (Chatfield, 1996). These results reflect MSA and $\mathrm{Na}^{+}$being deposited primarily during summer and winter, respectively. In contrast, in the transition zone and more prominently in the deep zone, the [MS] and $\left[\mathrm{Na}^{+}\right]$records show a positive correlation at lag 0 and a negative correlation at lag 6 ; in the deep zone the correlations at lags 0 and 6 are both significant at the 5\% level. The positive correlation at zero lag in the transition and deep zones indicates that positive deviations in [MS] tend to coincide with positive deviations in $\left[\mathrm{Na}^{+}\right]$. The distinct phase relationships between the two species in the shallow and deep zones are consistent with MSA migration.

\subsection{Towards a mechanistic understanding of MSA migration}

In this section, we discuss the physico-chemical processes that may be responsible for MSA migration using an existing model of soluble impurity transport. We then derive a linearized version of the model in order to further illuminate the processes that lead to the movement of MSA from summer to winter 
layers.

\subsubsection{The impurity transport model of Rempel et al. (2002)}

The physical mechanisms responsible for the presence of a liquid phase in ice cores, even well below the freezing point of pure water, are well documented (e.g., Nye et al. 1973, Nye 1991) and attributed to two distinct physical processes. The first relates to the fact that the atomic radii of most impurity species (not including requisitely-small ionic species, e.g., $\mathrm{F}^{-}, \mathrm{Cl}^{-}$, and $\mathrm{NH}_{4}^{+}$; Wolff, 1996) possess a misfit strain energy that inhibits their incorporation into the tightly packed, crystalline ice lattice. During densification, these impurities are thus preferentially expelled to the boundaries of individual grains of ice. This process has been observed using optical measurements (Mulvaney et al., 1988; Bartels-Rauch et al., 2014). As the concentration of impurities at the grain boundary is increased, the local equilibrium temperature is decreased, depressing the freezing point of the water-impurity mixture. At temperatures greater than a system's eutectic point, premelted aqueous solutions are assumed to exist at equilibrium as interconnected, submicron veins at the grain boundaries. The second process responsible for the presence of a liquid phase in polar ice pertains to the interstitial curvature occurring at the interface of three (i.e., triple junctures) or four (i.e., nodes) ice grains. Known as the Gibbs-Thompson effect, this thermodynamic phenomenon is related to the deviation in chemical potential of a vapor surrounding a curved surface from that of the same vapor at equilibrium with a flat liquid surface. In effect, it allows smaller (more curved) ice grains of a given composition to melt at lower temperatures than larger (less curved) ice grains of the same composition (Wettlaufer and Worster, 2006).

Importantly, both of the foregoing processes should respond collaterally to a temperature change, although they may not have the same importance in the maintenance of a liquid phase: scaling arguments suggest that the curvature effect required to reach a given volume of premelted liquid is negligible in ice sheets in comparison to the effect of impurity-driven under-cooling (Rempel et al., 2001). Focusing on the first process, Rempel et al. (2002) developed an elegant model describing the movement of soluble impurities along crystal grain boundaries. They considered impurity migration due to (1) temperature gradients (Rempel et al. 2001), which vary gradually downcore (typically $<1^{\circ} \mathrm{C}$ per $100 \mathrm{~m}$ in ice sheet interiors; Cuffey and Patterson, 2010), and (2) impurity concentration gradients, which are characterized by length scales typically on the order of centimeters (Rempel et al. 2002). They derived the following impurity migration equation, referred to below as the RWW model: 


$$
\frac{\partial}{\partial t} c_{B, k}=-\nabla \cdot\left(v+v_{k}\right) c_{B, k}
$$

where,

$$
v_{k}=D_{k} \frac{\nabla T}{\left(T_{m}-T\right)}+D_{k} \frac{\sum \Gamma_{i} \nabla \mathrm{c}_{B, i}-\frac{\nabla c_{B, k}}{c_{B, k}} \sum \Gamma_{i} \mathrm{c}_{B, i}}{\sum \Gamma_{i} \mathrm{c}_{B, i}}
$$

Here $c_{B, k}$ is the bulk concentration of the $\mathrm{k}^{\text {th }}$ impurity species, i.e., the mass of the $\mathrm{k}^{\text {th }}$ impurity species per unit ice volume as measured during standard chemical analyses, $t$ is time, and $v_{k}$ is an effective velocity of the $\mathrm{k}^{\text {th }}$ impurity species relative to the surrounding ice. The ice velocity, $v$, would arise, e.g., from a vertical strain rate and appears to have a small influence on MSA transport on time scales of years to decades (Nye, 1963). As a result, it is systematically neglected in this paper (see also, Rempel et al., 2002).

As indicated by (2.2), the relative velocity $v_{k}$ has two distinct contributions. The first is due to the motion of molecules in the liquid along a temperature gradient and leads to solute transport, even in the absence of concentration gradients. It is proportional to the diffusivity of the $\mathrm{k}^{\text {th }}$ impurity in the liquid, $D_{k}$, and inversely proportional to the difference $T_{m}-T$ between the melting point of pure ice $\left(T_{m}\right)$ and the temperature of the liquid $(T)$. The second contribution to $v_{k}$ arises from the concentration gradients of all solutes present in the liquid veins, including the $\mathrm{k}^{\text {th }}$ impurity. As with the first contribution, it is proportional to the diffusivity of the $\mathrm{k}^{\text {th }}$ impurity in the liquid, but it would occur in the absence of a temperature gradient. It also depends on the slope of the liquidus curve, $\Gamma_{i}$, of the various solutes that are present in the liquid veins. Scaling arguments suggest that $v_{k}$ is often well approximated by the second contribution in (2.2), at least in portions of the ice column where temperature gradients are small (Rempel et al. 2002). The small effect of the first contribution on MSA migration is further supported by observations made in Section 2.2.3.

A binary mixture provides the simplest context to discuss the mechanisms of MSA migration in the RWW model. In a mixture comprising $\mathrm{MS}^{-}$and $\mathrm{Na}^{+}$, equations (2.1-2.2) reduce to (for negligible $v)$

$$
\frac{\partial}{\partial t} c_{M S A}=-\nabla \cdot\left(v_{M S} c_{M S}\right),
$$




$$
\frac{\partial}{\partial t} c_{N a}=-\nabla \cdot\left(v_{N a} c_{N a}\right)
$$

where,

$$
\begin{aligned}
& v_{M S A}=\frac{D_{M S} \Gamma_{N a}}{\Gamma_{M S} \mathrm{c}_{M S}+\Gamma_{N a} c_{N a}}\left(\nabla c_{N a}-\frac{c_{N a}}{c_{M S}} \nabla c_{M S}\right), \\
& v_{N a}=\frac{D_{N a} \Gamma_{M S}}{\Gamma_{M S} \mathrm{c}_{M S}+\Gamma_{N a} c_{N a}}\left(\nabla c_{M S}-\frac{c_{M S}}{c_{N a}} \nabla c_{N a}\right) .
\end{aligned}
$$

In this case, the model implicitly assumes that an appreciable amount of the MSA and $\mathrm{Na}^{+}-$ containing impurities are rejected from the crystalline lattice of individual ice grains during firnification. The postulated expulsion would concentrate impurities at the grain boundaries, depressing the freezing point of the inter-granular medium to form sub-micron, under-cooled liquid veins. In general, higher impurity concentrations would lead to higher abundance of premelt liquid. Thus, more premelt liquid is predicted to occur in winter layers, where $\left[\mathrm{Na}^{+}\right]$is typically maximum, than in summer layers, where the comparatively low (bulk) concentration of MSA shows a maximum. The ensuing network of liquid veins would allow the ionic impurities to diffuse under their own concentration gradients, such that a large proportion of the MS-from the MS-rich summer layer migrates to the MS-poor winter layer. Conversely, a comparatively small proportion of $\mathrm{Na}^{+}$migrates to the summer layer, because the $\mathrm{Na}^{+}$concentration difference between the summer and winter layers is reduced by the larger amount of premelt liquid in the winter layer than in the summer layer. The net result of the different transport rates of $\mathrm{MS}^{-}$and $\mathrm{Na}^{+}$is that variations in [MS] ultimately become in phase with variations of $\left[\mathrm{Na}^{+}\right]$(Fig. 2-10).

\subsubsection{Physico-chemical parameters of MSA migration}

The RWW model as applied to the system containing $\mathrm{MS}^{-}$and $\mathrm{Na}^{+}$(equations 2.3-2.4) includes four parameters: the slopes of the liquidus curve for relevant $\mathrm{MS}^{-}$- and $\mathrm{Na}^{+}$-containing soluble impurity species $\left(\Gamma_{M S}\right.$ and $\left.\Gamma_{N a}\right)$, and the grain-boundary diffusivities of $\mathrm{MS}^{-}$and $\mathrm{Na}^{+}\left(D_{M S}\right.$ and $\left.D_{N a}\right)$. Below, we review the existing literature on each of these quantities.

\subsubsection{Grain boundary diffusivity of $\mathrm{MS}^{-}$and $\mathrm{Na}^{+}$}

We first consider the grain boundary diffusion coefficient of $\mathrm{MS}^{-}, D_{M S}$. Lacking empirical 
constraints, Rempel et al. (2002) approximated the diffusivity for ionic constituents in equation (2.2) as one-third the molecular diffusivity of a bulk liquid (i.e., $D_{M S}=5 \cdot 10^{-10} \mathrm{~m}^{2} \mathrm{~s}^{-1}$ ), scaled so as to account for the random orientation of premelted liquid veins in the ice (Lemlich, 1978). Smith et al. (2004) reported a value of $D_{M S}=2 \cdot 10^{-13} \mathrm{~m}^{2} \mathrm{~s}^{-1}$ for solid ice, estimated by measuring variations in [MS] across horizontal sections of an ice core from Law Dome, Antarctica following nearly 15 years of freezer storage at $-20^{\circ} \mathrm{C}$. Using similar ice substrate and experimental set up, Roberts et al. (2009) revised this estimate to $\left(4.1 \cdot 10^{-13} \pm 2.5 \cdot 10^{-14}\right) \mathrm{m}^{2} \mathrm{~s}^{-1}$ at $-20^{\circ} \mathrm{C}$, which was interpreted by the authors to represent diffusive losses of volatile MSA occurring during extended periods of freezer storage. Notably, this estimate is 1-3 orders of magnitude larger than that reported for solid-state diffusion of $\mathrm{HCl}$ (Thibert and Dominé, 1997), $\mathrm{HNO}_{3}$ (Thibert and Dominé, 1998), $\mathrm{HCHO}$ (Barret et al., 2011), and deuteriorated water ( $\mathrm{Lu}$ et al., 2009) determined in single ice crystals, despite the molecular radius of MSA greatly exceeding that of each of these species (Roberts et al., 2009). In fact, subsequent studies have contended that the $D_{M S}$ estimate of Roberts et al. (2009) is unlikely to represent pure solid-state diffusion of MSA in firn or ice, and suggested that at least some of the storage-based losses of MSA occurred via liquid transport along grain boundaries (McNeil et al., 2012; Bartels-Rausch et al., 2014). We thus consider the two values of $D_{M S}$ as suggested by Rempel et al. (2002) and Roberts et al. (2009) as potential extrema

Although the grain boundary diffusion coefficient for $\mathrm{Na}^{+}, D_{\mathrm{Na}}$, is also under-constrained, empirical evidence supports a relative immobility of $\mathrm{Na}^{+}$in polar ice. For example, Barnes et al. (2003a) noted no detectable changes in the amplitude of $\left[\mathrm{Na}^{+}\right]$peaks over the past $\sim 11,000$ years (top $350 \mathrm{~m}$ ) in the low-accumulation Dome C ice core record (East Antarctica), while the amplitudes of both $\mathrm{Cl}^{-}$ ] and $\left[\mathrm{SO}_{4}{ }^{2-}\right]$ peaks were found to change over the same period. Furthermore, optical measurements at Dome $\mathrm{C}$ suggest a predisposition for $\mathrm{Na}^{+}$to be situated at grain boundaries and for $\mathrm{Cl}^{-}$to be located preferentially within the crystalline structure (Barnes et al., 2003b). The importance of these findings is twofold: (i) $\mathrm{Na}^{+}$appears to be situated in the requisite location to favor the presence of premelt liquid at the grain boundaries, enabling MS migration as envisioned in the RWW model to occur; and (ii) $\mathrm{Na}^{+}$shows greatly reduced mobility relatively to $\mathrm{MS}^{-}$(or similar sulfur-based acidic species).

\subsubsection{Liquidus relationships for relevant sea-salt species}

The slopes of the liquidus curves, $\Gamma_{M S}$ and $\Gamma_{N a}$, represent linear approximations of the undercooling as a function of impurity concentration in the liquid phase present near the grain boundaries, $c$, i.e., $T_{m}-T=\Gamma c$, where $T$ is the in situ temperature and $T_{m}$ is the melting point for pure ice (see 
Appendix 2, Fig. A1-2). Knowledge of $\Gamma$ requires knowledge of the dominant precursor (bonded) molecular state(s) of the $\mathrm{MS}^{-}$and $\mathrm{Na}^{+}$ions present in the ice (thus, $\Gamma_{M S}$ and $\Gamma_{N a}$ should be viewed as shorthand notations for $\Gamma_{M S *}$ and $\Gamma_{N a *}$, where * represents some unknown cationic - anionic pair). Unfortunately, such data remain sparse beyond those reported in a few notable studies (e.g., Barnes et al., 2003b, Sakurai et al., 2010, Iizuka et al., 2016).

It is generally assumed that all measured MS present in polar firn or ice samples derives solely from MSA (Sakurai et al., 2010). In the binary system MSA- $\mathrm{H}_{2} \mathrm{O}$, MSA reaches its eutectic temperature at $-75^{\circ} \mathrm{C}$ (Stephen and Stephen, 1963). Thus, any MSA molecules expelled to and concentrated at grain boundaries are expected to exist in liquid solution with $\mathrm{H}_{2} \mathrm{O}$. By contrast, $\mathrm{Na}^{+}$in polar ice may have a number of precursors. For coastal ice cores, however, it seems reasonable to expect that the majority of $\mathrm{Na}^{+}$is deposited either as $\mathrm{NaCl}$ derived primarily from sea spray during storm activity (Legrand and Mayewski, 1997), or as sodium-sulfate salts such as mirabilite, $\mathrm{Na}_{2} \mathrm{SO}_{4} \cdot 10 \mathrm{H}_{2} \mathrm{O}$, derived from brine rejection in sea-ice or from atmospheric sea-salt sulfatization (Rankin et al., 2002; Iizuka et al., 2016). While the $\mathrm{NaCl}-\mathrm{H}_{2} \mathrm{O}$ system reaches its eutectic at $-21.3^{\circ} \mathrm{C}$ (Stephen and Stephen, 1963), the eutectic of the $\mathrm{Na}_{2} \mathrm{SO}_{4}-\mathrm{H}_{2} \mathrm{O}$ system is $-1.6^{\circ} \mathrm{C}$ (Hougen et al., 1954), suggesting that $\mathrm{Na}^{+}$deposited as $\mathrm{Na}_{2} \mathrm{SO}_{4}$ should be relatively immobile at most polar ice core sites. Consequentially, the majority of $\mathrm{Na}^{+}$relevant to grain boundary migration is likely derived from $\mathrm{NaCl}$. At DIV2010, for example, the molar ratio $\mathrm{Cl}: \mathrm{Na}$ in the top $60.4 \mathrm{~m}$ of the core averages 1.806 , similar to the mean molar ratio $\mathrm{Cl}: \mathrm{Na}=1.8$ used for seawater (e.g., Chesselet, et al., 1972). This indicates a primary marine source of $\mathrm{NaCl}$ aerosols at DIV2010, as both brine rejection and sea salt sulfatization in the atmosphere would tend to produce an offset in the amount of $\mathrm{Cl}^{-}$deposited (Iizuka et al., 2016).

Although the annual mean surface air temperature at most sites showing MSA migration is observed to be well below $-21.3^{\circ} \mathrm{C}$ (Sect. 2.2.3), the upper firn $(<10-20 \mathrm{~m}$ ) undergoes seasonal temperature fluctuations that may exceed this value during summer months (Cuffey and Paterson, 2010), thereby providing a potential mechanism to temporarily free $\mathrm{Na}^{+}$from its bonded state with $\mathrm{Cl}^{-}$. When premelted liquid solutions containing $\mathrm{Na}^{+}$and $\mathrm{Cl}^{-}$refreeze, $\mathrm{Cl}^{-}$may thus be preferentially allocated within the ice structure (Tokumasu et al., 2015; Barnes et al., 2003b).

With $\mathrm{Na}^{+}$and $\mathrm{MS}^{-}$both situated at the grain boundaries, the resulting binary system is the sodium-salt of $\mathrm{MS}, \mathrm{CH}_{3} \mathrm{SO}_{3} \mathrm{Na} \cdot n \mathrm{H}_{2} \mathrm{O}$, and water (Mulvaney et al., 1992). Recent experimental data indicate that the eutectic temperature for the $\mathrm{CH}_{3} \mathrm{SO}_{3} \mathrm{Na} \cdot n \mathrm{H}_{2} \mathrm{O}-\mathrm{H}_{2} \mathrm{O}$ system occurs at approximately $-29.3^{\circ} \mathrm{C}$ (Sakurai et al., 2010). For comparison, the eutectics for the binary systems $\mathrm{Ca}\left(\mathrm{CH}_{3} \mathrm{SO}_{3}\right)_{2} \cdot n \mathrm{H}_{2} \mathrm{O}$ 
$-\mathrm{H}_{2} \mathrm{O}$ and $\mathrm{Mg}\left(\mathrm{CH}_{3} \mathrm{SO}_{3}\right)_{2} \cdot n \mathrm{H}_{2} \mathrm{O}-\mathrm{H}_{2} \mathrm{O}$ amount to $-32.6^{\circ} \mathrm{C}$ and $-5.0^{\circ} \mathrm{C}$, respectively (Sakurai et al., 2010). Table 2-2 lists the slopes of the liquidus curves for these MS-salts in addition to those for alternative relevant sea salts containing $\mathrm{Ca}^{2+}$ and $\mathrm{Mg}^{2+}$, and $\mathrm{SO}_{4}^{2-}$ (see also Sect. A1.2 in Appendix 2). For the system $\mathrm{CH}_{3} \mathrm{SO}_{3} \mathrm{Na} \cdot n \mathrm{H}_{2} \mathrm{O}-\mathrm{H}_{2} \mathrm{O}$ the slope amounts to $6.5 \mathrm{~K} \mathrm{M}^{-1}$.

\subsubsection{A simplified model of MSA migration}

Although the RWW model provides significant insight into the mechanisms of MSA migration, the system of non-linear partial different equations $(2.1 \mathrm{a}-\mathrm{b})$ or $(2.3 \mathrm{a}-\mathrm{b})$ does not permit a straightforward analysis (e.g., no closed form solution of these equations with general initial and boundary conditions is available to our knowledge). In this section, we develop a linearized version of the model for the binary system comprising $\mathrm{CH}_{3} \mathrm{SO}_{3} \mathrm{Na}$ and $\mathrm{H}_{2} \mathrm{O}$ (eqs. 2.3-2.4) in order to further our understanding of MSA migration. Of course, the insight to be gained is only as reliable as the assumptions upon which the linearized model relies.

Consider the governing equations (2.3a-b), making it explicit that concentration gradients are strictly vertical,

$$
\begin{gathered}
\frac{\partial c_{M S}}{\partial t}=-\frac{\partial}{\partial z}\left(w_{M S} c_{M S}\right), \\
\frac{\partial c_{N a}}{\partial t}=-\frac{\partial}{\partial z}\left(w_{N a} c_{N a}\right),
\end{gathered}
$$

where,

$$
\begin{aligned}
& w_{M S}=D_{M S} \frac{\Gamma_{N a}}{\Gamma_{N a} c_{N a}+\Gamma_{M S} c_{M S}}\left(\frac{\partial c_{N a}}{\partial z}-\frac{c_{N a}}{c_{M S}} \frac{\partial c_{M S}}{\partial z}\right), \\
& w_{N a}=D_{N a} \frac{\Gamma_{M S}}{\Gamma_{N a} c_{N a}+\Gamma_{M S} c_{M S}}\left(\frac{\partial c_{M S}}{\partial z}-\frac{c_{M S}}{c_{N a}} \frac{\partial c_{N a}}{\partial z}\right),
\end{aligned}
$$

Here, $w_{M S}$ and $w_{N a}$ are the vertical components of $\mathrm{MS}^{-}$and $\mathrm{Na}^{+}$migration velocity, respectively, and $z$ is depth. Three assumptions are made (see also Rempel et al., 2002). First, the slope of the liquidus curve is taken to be the same for the two ionic species, i.e., $\Gamma_{N a}=\Gamma_{M S}$ (Sect. 2.4.2.2). This assumption appears plausible if the $\mathrm{MS}^{-}$-salt species $\mathrm{CH}_{3} \mathrm{SO}_{3} \mathrm{Na} \cdot n \mathrm{H}_{2} \mathrm{O}$ dominates in the premelt liquid present near the grain boundaries. With this assumption, the slopes of the liquidus curves cancel out in the 
defining relationships for $w_{M S}$ and $w_{N a}(2.7 \mathrm{a}-\mathrm{b})$. Second, the concentration of $\mathrm{MS}^{-}$is taken to be much smaller than the concentration of $\mathrm{Na}^{+}$in the liquid veins, i.e., $c_{M S} \ll c_{N a}$. This assumption is generally supported by $[\mathrm{MS}]$ and $\left[\mathrm{Na}^{+}\right]$measurements on ice core samples originating from most coastal sites (Sect. 2.2.3; Table 2-1). Under the two assumptions above, relation (2.7a) becomes

$$
w_{M S}=D_{M S}\left(1+0\left[\frac{c_{M S}}{c_{N a}}\right]\right)\left(\frac{1}{c_{N a}} \frac{\partial c_{N a}}{\partial z}-\frac{1}{c_{M S}} \frac{\partial c_{M S}}{\partial z}\right)
$$

upon expansion of the denominator in a Taylor series. Thus, to the first order in $c_{M S} / c_{N a}$, the speed of MS- migration can be approximated as

$$
w_{M S}=D_{M S}\left(\frac{1}{c_{N a}} \frac{\partial c_{N a}}{\partial z}-\frac{1}{c_{M S}} \frac{\partial c_{M S}}{\partial z}\right) .
$$

A similar development for $w_{N a}$ leads to

$$
w_{N a}=D_{N a}\left(\frac{1}{c_{M S}} \frac{\partial c_{M S}}{\partial z}-\frac{1}{c_{N a}} \frac{\partial c_{N a}}{\partial z}\right) \frac{c_{M S}}{c_{N a}},
$$

which is also first order in $c_{M S} / c_{N a}$. The ratio of the migration speeds for the two ionic species is thus

$$
\frac{w_{N a}}{w_{M S}}=\left(\frac{D_{N a}}{D_{M S}}\right) \frac{c_{M S}}{c_{N a}}
$$

If $D_{M S}$ is comparable to or higher than $D_{N a}$, then $\mathrm{Na}^{+}$would migrate much more slowly than MS - In this case, $\mathrm{Na}^{+}$would be quasi immobile and its concentration at a given depth would vary only slowly with time (compared to MS'). This consideration suggests the following, third assumption. The concentration of $\mathrm{Na}^{+}$at a given depth in the ice column and at a given time is decomposed into a mean value, $\bar{c}_{N a}(z)$, and a fluctuation, $c_{N a}^{\prime}(z, t)$,

$$
c_{N a}(z, t)=\bar{c}_{N a}(z)+c_{N a}^{\prime}(z, t) .
$$


Assuming that $c_{N a}^{\prime}(z, t) \ll \bar{c}_{N a}(z)$, as suggested by the relatively small mobility of $\mathrm{Na}^{+}$, the vertical speed of $\mathrm{MS}^{-}$migration along the ice column can be further approximated as

$$
w_{M S}=D_{M S}\left(\frac{1}{\bar{c}_{N a}} \frac{\partial \bar{c}_{N a}}{\partial z}-\frac{1}{c_{M S}} \frac{\partial c_{M S}}{\partial z}\right)
$$

The insertion of (12) into (6a) yields

$$
\frac{\partial c_{M S}}{\partial t}+\frac{\partial}{\partial z}\left(w_{*} c_{M S}\right)=\frac{\partial}{\partial z}\left(D_{M S} \frac{\partial c_{M S}}{\partial z}\right)
$$

where $w_{*}$ is an effective velocity of $\mathrm{MS}^{-}$induced by vertical gradients in $\left[\mathrm{Na}^{+}\right]$,

$$
W_{*}=\frac{D_{M S}}{\bar{c}_{N a}} \frac{\partial \bar{c}_{N a}}{\partial z}
$$

Thus, under the three stated assumptions, MSA migration can be described by a single, linear partial differential equation (eq. 2.13) with the MS $^{-}$diffusivity as a single parameter. In this model (eq. 2.13), MSA migration arises from two fundamental processes: (1) the convergence or divergence of MSdriven by $\mathrm{Na}^{+}$concentration gradients and (2) the diffusion of $\mathrm{MS}^{-}$along its own concentration gradient. Albeit physically distinct, both processes depend on the diffusivity of $\mathrm{MS}^{-}$in the intergranular liquid.

It is instructive to consider the character of the steady state distribution of [MS-] according to the linearized model. With the tendency term $\partial c_{M S} / \partial t$ set to zero, equation (2.13) reduces to

$$
\frac{\partial}{\partial z}\left(\frac{c_{M S}}{\bar{c}_{N a}} D_{M S} \frac{\partial \bar{c}_{N a}}{\partial z}\right)=\frac{\partial}{\partial z}\left(D_{M S} \frac{\partial c_{M S}}{\partial z}\right)
$$

given the defining relation for $w_{*}$ (eq. 2.14). If $D_{M S}$ is uniform along the ice column $\left(\partial D_{M S} / \partial z=0\right)$, and at depths where $\mathrm{Na}^{+}$shows an extremum $\left(\partial \bar{c}_{N a} / \partial z=0\right)$, equation (2.15) becomes

$$
\frac{c_{M S}}{\bar{c}_{N a}} \frac{\partial^{2} \bar{c}_{N a}}{\partial z^{2}}=\frac{\partial^{2} c_{M S}}{\partial z^{2}}
$$


Since concentrations are positive quantities, the concentration ratio on the left-hand side of eq. (2.16) is always positive, implying that the two second-order derivatives should always have the same sign. Thus, minima (maxima) of $\mathrm{MS}^{-}$concentration will coincide with minima (maxima) of $\mathrm{Na}^{+}$ concentration. The [MS $]$ profile, regardless of its initial (i.e., unaltered) character, will evolve so as to become eventually in phase with the $\left[\mathrm{Na}^{+}\right]$profile. Figure 2-10 illustrates this evolution of the [MS] profile to steady state as simulated by the linearized model and compares it with the evolution simulated with the RWW model (see Appendix A1.3 for details about the numerical solutions of these two models).

The following example illuminates the respective roles of the effective velocity, $w_{*}$, and of the diffusivity, $D_{M S}$, in the MSA migration process. Consider a locally Gaussian profile of $\left[\mathrm{Na}^{+}\right]$,

$$
\bar{c}_{N a} \propto \exp \left(-\left[z-z_{0}\right]^{2} / 2 \sigma^{2}\right),
$$

where $z_{0}$ is the depth at which $\left[\mathrm{Na}^{+}\right]$is maximum and $\sigma$ describes the spread of $\mathrm{Na}^{+}$on each side of the maximum (Fig. 2-11). In this case, the effective velocity $w_{*}=-D_{M S-}\left(z-z_{0}\right) / \sigma^{2}$ is positive above $z_{0}$ and negative below $z_{0}$, and the migration equation (2.13) becomes

$$
\frac{\partial c_{M S}}{\partial t}-\frac{D_{M S}}{\sigma^{2}}\left(z-z_{0}\right) \frac{\partial c_{M S}}{\partial z}=D_{M S} \frac{\partial^{2} c_{M S}}{\partial z^{2}}+\frac{D_{M S}}{\sigma^{2}} c_{M S},
$$

where it has been again assumed that $D_{M S}$ is vertically uniform. Interestingly, the migration equation (2.18) has the familiar form of an advection-diffusion-reaction equation. The $2^{\text {nd }}$ term on the left-hand side corresponds to downward advection of $\mathrm{MS}^{-}$above $z_{0}$ and to upward advection of MS below $z_{0}$, i.e., it tends to accumulate $\mathrm{MS}^{-}$at $z_{0}$. On the right hand side, the $1^{\text {st }}$ term represents Fickian diffusion, and the $2^{\text {nd }}$ term is a "reaction" term that stems from the vertical variation of $w_{*}$. The second term is always positive, effectively leading to MS production throughout the ice column at a rate proportional to the amount of MS - initially present. As time progresses, all [MS-] maxima that may be present in the ice section where $\left[\mathrm{Na}^{+}\right]$is distributed according to (2.17) will be gradually shifted toward $z=z_{0}$. At steady state, the [MS'] profile will be maintained by a balance between $\mathrm{MS}^{-}$advection to the $[\mathrm{MS}]$ maximum and effective production on the one hand, and the diffusion of $\mathrm{MS}^{-}$away from the [MS] maximum on the other hand (Fig. 2-11). 


\subsubsection{Assessment of $\mathrm{MS}^{-}$diffusivity}

We next aim to constrain a range of values for MS $^{-}$diffusivity along ice grain boundaries consistent with observed $\mathrm{MS}^{-}$concentrations in polar ice. To this end, the simplified model of MSA migration (eq. 2.13), which includes $D_{M S}$ as the sole parameter, is solved for different values of $D_{M S}$ and model results are compared with data from the DIV2010 ice core.

The model is solved numerically using finite differences (Appendix A1.3; Figures A1-5 and A1-6). The model domain, with an upper boundary is situated at $z=9.1 \mathrm{~m}$ and a lower boundary at $z=60.4 \mathrm{~m}$, is intended to represent the present-day shallow zone at the DIV2010 site. The model grid has a uniform spacing $(\Delta z=0.05 \mathrm{~m})$, with grid points coinciding with the sampling depths of the DIV2010 core. The grid cell interfaces coincide with the upper and lower boundaries of the domain. With this configuration of the grid, the boundary conditions of the model consist of a vanishing flux of $\mathrm{MS}^{-}$prescribed at the upper and lower boundaries of the domain:

$$
w_{*} c_{M S}-D_{M S} \frac{\partial c_{M S}}{\partial z}=0, \quad \text { at } z=9.1 \mathrm{~m} \text { and } 60.4 \mathrm{~m} .
$$

The initial conditions of the model consist of an idealized [MS] profile obtained by linearly interpolating, at the model grid points, the (unaltered) monthly mean [MS'] values for the shallow zone (Fig. 2-5). The vertical profile of $\left[\mathrm{Na}^{+}\right]$, which determines the effective velocity of $\mathrm{MS}^{-}\left(w_{*}\right)$, is directly derived from the measured profile of $\left[\mathrm{Na}^{+}\right]$in the shallow zone (since model grid points coincide with sampling depths, no interpolation is necessary).

The model is integrated over a time interval that approximates the time it would take for the shallow zone to be buried by a layer of equal thickness through surface accumulation (see Appendix A1-4 for details). This final time, denoted as $t_{f}$, is taken as $95 \mathrm{yr}$, based on the difference between the ages of the sample at $z=9.1 \mathrm{~m}$ and $60.4 \mathrm{~m}$. At the end of the model integration $\left(t=t_{f}\right)$, the crosscorrelation between the $[\mathrm{MS}]$ and $\left[\mathrm{Na}^{+}\right]$profiles simulated by the model between $\mathrm{z}=9.1$ and $60.4 \mathrm{~m}$ is calculated and compared to the cross-correlation between the measured $\left[\mathrm{Na}^{+}\right]$and $[\mathrm{MS}]$ profiles over the same depth interval. This procedure is repeated for four different values of $D_{M S}, 10^{-10}, 10^{-11}$, $10^{-12}$, and $10^{-13} \mathrm{~m}^{2} \mathrm{~s}^{-1}$, encompassing the values assumed or suggested in prior studies (e.g., Rempel et al., 2002; Roberts et al., 2009). A "good" value of $D_{M S}$ is expected to lead to a "good" agreement between the simulated and observed cross-correlations, at least at small lags. 


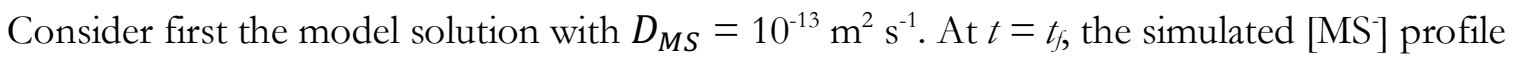
has not significantly deviated from its initial profile, which is negatively correlated at zero lag with the $\left[\mathrm{Na}^{+}\right]$profile (Fig. 2-12a). This result suggests that the value of $D_{M S}=10^{-13} \mathrm{~m}^{2} \mathrm{~s}^{-1}$ is too small to account for the down-core change in phase relationship between $\left[\mathrm{Na}^{+}\right]$and [MS] observed at DIV2010. For $10^{-12} \mathrm{~m}^{2} \mathrm{~s}^{-1}<D_{M S}<10^{-11} \mathrm{~m}^{2} \mathrm{~s}^{-1}$, the simulated cross-correlation at zero lag between $\left[\mathrm{Na}^{+}\right]$and [MS] switches from negative to positive. For values of $D_{M S} \geq 10^{-11} \mathrm{~m}^{2} \mathrm{~s}^{-1}$, it is positive but much stronger than observed, suggesting that these values may be too large. Thus, $D_{M S}$ values that best explain DIV2010 data would be in the range from $10^{-12}$ to $10^{-11} \mathrm{~m}^{2} \mathrm{~s}^{-1}$, i.e., greater than the value of $\left(4.1 \cdot 10^{-}\right.$ $\left.{ }^{13} \pm 2.5 \cdot 10^{-14}\right) \mathrm{m}^{2} \mathrm{~s}^{-1}$ reported by Roberts et al., (2009) and lower than the value of $5 \cdot 10^{-10} \mathrm{~m}^{2} \mathrm{~s}^{-1}$ assumed by Rempel et al. (2002). We stress that this result is immune to potential dating errors in the sense that the cross-correlation coefficients are calculated for different vertical spacings along the core, not for different time lags; calculating cross-correlations at different time lags leads to a similar result (Fig. 212b; see also Fig.'s A1-5 and A1-6 in Appendix 2).

While the $D_{M S}$ range estimated by a comparison to DIV2010 data is instructive, we note it is not necessarily universal, as diffusivities in polar ice are expected to vary in response to multiple glaciological factors. For example, the experimental results of Kim et al. (2008) show that the diffusion coefficients of ions in under-cooled mixtures are a function of both ionic concentration and temperature. Additionally, physical properties of the firn and ice, including porosity, grain-boundary density, and crystal size, may affect the partitioning of chemical impurities between the liquid premelt and the ice lattice (Dominé et al., 2008; Spaulding et al., 2011), thereby affecting the amount of impurities subjected to anomalous diffusion as well as the interconnectivity of the liquid premelt/vein network. While the RWW model can account for this partitioning (Rempel et al., 2002), the proportions of total $\mathrm{MS}^{-}$and $\mathrm{Na}^{+}$that are present in liquid form remain poorly constrained (Sakurai et al., 2010). Even at a given site, seasonal and interannual variations in impurity concentrations may lead to down-core changes in $D_{M S}$. Finally, $D_{M S}$ does not take into account whether MS migration is dominated by diffusion at two-grain boundaries, or at triple junctures and node networks (Wettlaufer and Worster, 2006, Riche et al., 2012). As a result of all these complicating factors, $D_{M S}$, as defined in the RWW model and constrained here, should probably be viewed as an effective diffusivity.

\subsection{Paleoclimatic implications}




\subsubsection{Revisiting the effect of temperature on grain boundary migration}

In section 2.2.3, we tested the hypothesis that post-depositional formation of winter [MS] maxima occurs solely as a result of the precipitation of $\mathrm{MS}^{-}$-salts from their grain boundary solutions in seasalt rich winter layers (Mulvaney et al., 1992; Wolff et al., 1996; Kreutz et al., 1998, Pasteur and Mulvaney, 2000; Curran et al., 2002). This hypothesis, denoted below as the "Mulvaney model", suggests that MS in under-cooled solutions should migrate along its concentration gradient via Fickian diffusion until reaching $\mathrm{Na}^{+}$-rich layers, where crystallization of $\mathrm{CH}_{3} \mathrm{SO}_{3} \mathrm{Na}$ removes $\mathrm{MS}^{-}$from the premelt solution, thereby perpetuating a [MS] gradient between summer and winter layers in the residual premelt. Importantly, it suggests MSA migration would be inhibited at sites where in situ temperatures are greater than the eutectic temperature of the binary system $\mathrm{CH}_{3} \mathrm{SO}_{3} \mathrm{Na}^{\cdot} n \mathrm{H}_{2} \mathrm{O}-\mathrm{H}_{2} \mathrm{O}$ $\left(-29.3^{\circ} \mathrm{C}\right)$, since $\mathrm{CH}_{3} \mathrm{SO}_{3} \mathrm{Na}$ would not be precipitated from the premelt liquid. However, such an inhibition is not apparent in our data compilation (Sect. 2.3).

The RWW model (Sect. 2.4) is fundamentally different than the Mulvaney model. The RWW model does not represent crystallization and metathetic removal of constituents from the liquid phase (Sect. 2.2). Rather, in the RWW model, MS is implicitly assumed to remain dissolved in the premelt liquid following migration from the summer to winter layers, provided in situ temperatures exceed the eutectic temperature of the binary system $\mathrm{CH}_{3} \mathrm{SO}_{3} \mathrm{Na} \cdot n \mathrm{H}_{2} \mathrm{O}-\mathrm{H}_{2} \mathrm{O}$.

The foregoing assumption can be evaluated using our data compilation. At 19 of the 20 sites considered (Table 2-1), the ice temperature as estimated from the annual mean SAT exceeds the eutectic temperature of the binary system $\mathrm{CH}_{3} \mathrm{SO}_{3} \mathrm{Na} \cdot n \mathrm{H}_{2} \mathrm{O}-\mathrm{H}_{2} \mathrm{O}$, suggesting MSA migration could occur according to the RWW model at these sites. The only site where ice temperature is estimated to be less than $-29.3^{\circ} \mathrm{C}$ is the Summit2010 record from Greenland (Maseli et al., 2017), where MSA migration is also observed but not predicted to occur based on this model. We offer a few explanations for this sole discrepancy. First, ice temperatures may depart significantly from annual mean SAT. The annual mean SAT at Summit is $-29.5^{\circ} \mathrm{C}$ (Giese et al., 2015), just below but very close to the eutectic temperature for the system $\mathrm{CH}_{3} \mathrm{SO}_{3} \mathrm{Na}^{*} n \mathrm{H}_{2} \mathrm{O}-\mathrm{H}_{2} \mathrm{O}$. It is therefore conceivable that ice temperatures may in fact slightly exceed the eutectic temperature of this system, at least along some portions of the ice column and (or) during some time intervals in the past. Another possibility is that the $\mathrm{Ca}^{2+}$ salt of MS, $\mathrm{Ca}\left(\mathrm{CH}_{3} \mathrm{SO}_{3}\right)_{2}$, a component of the system $\mathrm{Ca}\left(\mathrm{CH}_{3} \mathrm{SO}_{3}\right)_{2} \cdot n \mathrm{H}_{2} \mathrm{O}-\mathrm{H}_{2} \mathrm{O}$ with a lower eutectic of $32.6^{\circ} \mathrm{C}$, may be more efficient than the $\mathrm{Na}^{+}$salt of $\mathrm{MS}^{-}, \mathrm{CH}_{3} \mathrm{SO}_{3} \mathrm{Na}$, in driving MSA migration at 
Summit2010, given the much higher abundances of $\mathrm{Ca}^{2+}$ in inland Greenland ice compared to coastal Antarctica (Iizuka et al., 2008).

A currently poorly constrained situation arises for sites characterized by in situ temperatures less than $\sim-30^{\circ} \mathrm{C}$ and greater than $-75^{\circ} \mathrm{C}$ (Table 2-2) In this temperature regime, MSA remains in solution while $\mathrm{Na}^{+}$is presumably immobile, either as solid state $\mathrm{NaCl}, \mathrm{CH}_{3} \mathrm{SO}_{3} \mathrm{Na}$, or $\mathrm{Na}_{2} \mathrm{SO}_{4}\left(\mathrm{~T}^{2}\right.$ able 2-2). MSA migration as envisioned in the Mulvaney model, but not in the RWW model, may operate under such conditions. On the other hand, the Mulvaney model may not apply should summer concentrations of $\mathrm{Na}^{+}$be high enough to sequester a large fraction of the $\left[\mathrm{MS}\right.$ ] as $\mathrm{CH}_{3} \mathrm{SO}_{3} \mathrm{Na}$ (s) in summer layers. This sequestration process appears supported by the lack of discernable MSA migration in the subannually-resolved portion (i.e., down to $\sim 10.5 \mathrm{~m}$ ) of the [MS] record from South Pole (SP-95), where annual mean SAT is $-51^{\circ} \mathrm{C}$ (Meyerson et al., 2002). While SP-95 is not considered

in our data compilation due to the site's low $\dot{b}\left(0.08 \mathrm{~m}\right.$ w.eq. $\left.\mathrm{yr}^{-1}\right)$, the lack of clear MSA migration at SP-95 departs from the expected relationship found between $\dot{b}$ and $z_{f o}$ in Antarctica (Sect. 2.2.1; Fig. 2-2). This observation leads us to speculate that MS at SP-95 may be immobilized in the summer layers through a metathesis reaction with $\mathrm{Na}^{+}$allocated to the grain boundaries.

In sum, we propose that MSA migration operates at most sites through anomalous diffusion as described in the RWW model. This migration process would occur if in situ temperatures exceed the relevant eutectic temperatures, so that MS can be present in solution in the presence of $\mathrm{Na}^{+}$and $\mathrm{Ca}^{2+}$ situated at the grain boundaries. The relevant eutectic temperatures are inferred here to range from $-29.3^{\circ} \mathrm{C}$ to $-32.6^{\circ} \mathrm{C}$, depending on the binary system considered (Sakurai et al., 2010). Importantly, most coastal ice core locations, despite their paleoclimatic significance, are susceptible to MSA migration given their relatively high SAT (Table 2-1), although high accumulation rates will mitigate this phenomenon to some degree (Sect. 2.2.1). One coastal region of exception may be northeastern Greenland, where relatively cold conditions (SAT of approximately -30 to $33^{\circ} \mathrm{C}$; Weißbach et al., 2016) may keep the ice below the eutectic temperature of the primary $\mathrm{MS}^{-}{ }^{-}$salts.

\subsubsection{Vertical extent of MSA migration}

A reigning question in the use of [MS] in polar ice as a paleoclimate proxy is the extent of MSA migration along the core. Past studies have circumvented this potential issue by assuming either that (1) MSA migration is confined within an annual layer (Kreutz et al., 1998; Curran et al., 2003; Thomas and Abram, 2016), or (2) multi-year averages of [MS-] are largely unaffected by migration (Wolff et al., 
1996). While (2) appears a more conservative approach, the requisite averaging period, and thus the maximum resolution that can be achieved in a paleoclimatic reconstruction given MSA migration, remains unknown. In this section, we examine assumptions (1-2) using DIV2010 data and the linearized model of MSA migration.

In an effort to account for a range of initial (i.e., unperturbed) [MS'] profiles in the shallow zone of DIV2010 (Sect. 2.3.1), a large number $(10,000)$ of numerical experiments of MSA migration are conducted. The initial [MS'] profile of a given experiment is obtained by adding, to the monthly mean [MS] values observed in the shallow zone, a normal noise with a mean of zero and a variance equal to that of the mean monthly values in the shallow zone. If a negative concentration value arises in the initial profile, the procedure is repeated until all values in the profile are positive. Using this approach, inter-annual variability in the initial [MS'] profile is emulated, such that no two years should contain the same mean [MS] in a given experiment, nor should a given year display the same mean [MS ] for different experiments. In contrast, all experiments rely on the same $\left[\mathrm{Na}^{+}\right]$profile measured at DIV2010. Given the uncertainties in MS diffusivity (Sect. 2.4.4), two sets of experiments are considered: a first set with $D_{M S}=10^{-12} \mathrm{~m}^{2} \mathrm{~s}^{-1}$ and a second with $D_{M S}=10^{-11} \mathrm{~m}^{2} \mathrm{~s}^{-1}$ (so that $2 \times 10,000$ $=20,000$ experiments are actually performed). For all experiments, the model is subjected to a condition of no MS- flux at both the upper and lower boundaries of the domain, and is integrated for $t=t_{f}=95 \mathrm{yr}$ (Sect. 2.4.4).

Figure 2-13a shows (i) the $\left[\mathrm{Na}^{+}\right]$profile observed at DIV2010 and used to constrain the effective velocities $w_{*}$ in the model, and (ii) the annual mean [MS] profiles simulated by the model at $t=t_{f}$ For $D_{M S}=10^{-11} \mathrm{~m}^{2} \mathrm{~s}^{-1}$, the changes in annual mean [MS $]$ relative to the initial [MS] profile are much larger than for $D_{M S}=10^{-12} \mathrm{~m}^{2} \mathrm{~s}^{-1}$ (Fig. 2-13b), particularly prior to $\mathrm{AD} 1975$ ( $t=25 \mathrm{yrs}$ ). In some sections of the simulated profiles, dramatic positive or negative changes in annual mean [MS] occur, depending on the magnitude of the local $\left[\mathrm{Na}^{+}\right]$gradients. In some individual years (e.g., AD 1954), relative changes in the annual mean [MS] reach 60 to $100 \%$, clearly negating the assumption (1) above, that MSA migration is confined within an annual layer.

Given this finding, we next explore assumption (2) that multi-year averages of [MS'] data could be used to accurately reflect the original (i.e., unaltered) multi-year mean [MS'] signal. To this end, we average the simulated [MS $]$ profiles at $t=t_{f}$ in different time intervals ranging from 3 to 15 years and compare the final (altered) averages to the initial (unaltered) averages (Fig. 2-13c). As expected, the difference between the final and initial averages of [MS] decreases as the averaging period increases. Interestingly, the difference shows only modest reduction as the averaging period increases from 7 to 
15 years.

In sum, while our results may pertain only to DIV2010 and rely on a series of modelling assumptions (Sect. 2.4.3), two points appear worthy of note. First, for [MS'] records showing evidence of MSA migration, the assumption that MSA remained confined within annual layers may not be generally valid, given in particular the high inter-annual variability in the concentrations of $\mathrm{Na}^{+}$and other major impurities potentially conducive to MSA migration, which is typical of most ice cores originating from coastal sites (Legrand and Mayewski, 1997). High inter-annual variability in $\left[\mathrm{Na}^{+}\right]$, for example, corresponds to large vertical $\left[\mathrm{Na}^{+}\right]$gradients along the core, which tend to increase MSA migration. Second, at least for [MS'] records exhibiting severe MSA migration such as at DIV2010, averaging the data over a time period of approximately ten years may constitute a reasonable compromise between accuracy and temporal resolution for paleoclimatic reconstruction.

\subsubsection{Revisiting the combined influence of snow accumulation and $\left[\mathrm{Na}^{+}\right]$on MSA migration}

In Section 2.2, we provided empirical evidence that two local factors appear to influence the shallowest depth of MSA migration in polar ice cores: annual mean accumulation rate $(\dot{b})$ and core-averaged $\mathrm{Na}^{+}$ concentration. Here, we assess whether the ability to predict $z_{f o}$ from these two factors is also mechanistically grounded. Since the linearized model is not valid for small values of $\left[\mathrm{Na}^{+}\right] /\left[\mathrm{MS}^{-}\right]$, the original model of Rempel et al. (2002) is used in an effort to produce results of more general validity.

We first simulate, for a range of layer thicknesses and layer-averaged $\left[\mathrm{Na}^{+}\right]$values, the time it takes for a [MS] maximum present in the annual layer and initially out of phase with the $\left[\mathrm{Na}^{+}\right]$ maximum in the layer $\left(\varphi=180^{\circ}\right)$, to align with the $\left[\mathrm{Na}^{+}\right]$maximum in the layer $\left(\varphi=0^{\circ}\right)$. Given the asymptotic nature of the concentration evolutions simulated by the model, we approximate this time as the time at which the phase difference between the $[\mathrm{MS}]$ and $\left[\mathrm{Na}^{+}\right]$maxima drops to $\varphi<20^{\circ}$. Experiments are conducted for different extents of the model domain, to represent different values of annual layer thicknesses $(\lambda)$. For each experiment, the initial $[\mathrm{MS}]$ and $\left[\mathrm{Na}^{+}\right]$profiles in the layer are sinusoidal functions of depth, with (i) a period set equal to the layer thickness, (ii) a [MS-] maximum present in the middle of the layer, and (iii) two $\left[\mathrm{Na}^{+}\right]$maxima present at the top and bottom of the layer (see Sect. A1.5 in the Appendix for details). The model is subjected to a condition of no flux both at the top and at the bottom of the layer. The model parameters are set to $\Gamma_{M S}=\Gamma_{N a}=6.5 \mathrm{~K}$ $\mathrm{mol}^{-1}$ and $D_{M S}=D_{N a}=10^{-11} \mathrm{~m}^{2} \mathrm{~s}^{-1}$ or $10^{-12} \mathrm{~m}^{2} \mathrm{~s}^{-1}$. 
The time required for approximate phase alignment $\left(\varphi<20^{\circ}\right)$ of the simulated $[\mathrm{MS}]$ and $\left[\mathrm{Na}^{+}\right]$ profiles is shown for two different values of $\lambda$ and a range of layer-averaged $\left[\mathrm{Na}^{+}\right]$values (Fig. 2-14a); this time is referred to as $t_{\varphi}$ below. It is seen that $t_{\varphi}$ increases with $\lambda$ and decreases with layeraveraged $\left[\mathrm{Na}^{+}\right]$. Similar results are displayed in Figure 2-14b in a form that is reminiscent of Figure 25 (linear scales) and Figure 2-14c (logarithmic scales), which both show the combined effect of annual mean accumulation and core-averaged $\left[\mathrm{Na}^{+}\right]\left(\overline{\mathrm{Na}^{+}}\right)$on the shallowest depths of MSA migration $\left(\mathrm{Z}_{f 0}\right)$ in our data compilation. To the extent that $\lambda$ increases with $\dot{b}$, the model results appear to be qualitatively consistent with the data, thereby providing a theoretical basis to the notion that $\dot{b}$ and $\left[\mathrm{Na}^{+}\right]$could be used to predict $Z_{f 0}$.

The nonlinear relationship found between $z_{f 0}$ and $\dot{b}$ (Sect. 2.2) is also worth further exploration. Results from the RWW model can be well-approximated by the power law $t_{\varphi} \propto \lambda^{2}$ (Fig. 2-15), which is reminiscent of the power law relationship $z_{f o} \propto \lambda^{1.77}$ derived from our data compilation (Fig. 2-2). The observed variation of the shallowest depth of MSA migration with accumulation rate would thus reflect the mere fact that, similar to Fickian diffusion with constant diffusivity, the time scale for anomalous diffusion $\left(t_{\varphi}\right)$ varies quadratically with the thickness over which the diffusion takes place $(\lambda)$. Both current observations and the present set of experiments with the RWW model suggest that [MS] records from ice cores characterized by high accumulation and low core-averaged $\left[\mathrm{Na}^{+}\right]$should undergo relatively small alteration by MSA migration.

\subsection{Conclusions}

Polar ice core records of methanesulfonic acid have been used to draw inferences about oceanic and atmospheric processes at polar latitudes on a range of time scales. However, both observation and theory suggest that MSA is mobile in the ice column, leading to uncertainties about its integrity as an indicator of past climatic conditions. Here, we synthesize existing data from a range of polar environments and consider an impurity transport model to study MSA migration in polar ice. Emphasis is placed on (i) the environmental conditions that favor MSA migration and (ii) a better understanding of the physico-chemical processes causing the movement of MSA in polar firn and ice.

Our analysis shows that the shallowest depth at which MSA migration occurs in coastal ice cores varies with annual mean accumulation rate. In Antarctica in particular, a power law characterizes this relationship accurately. It suggests that the absence of MSA migration observed in some ice cores 
from high accumulation sites stems from the fact that chemical measurements for these cores have been conducted on samples that are not deep enough to have undergone migration. Thus, MSA migration in polar ice may be more general than commonly thought. Annual mean surface air temperature and the concentration of the dominant cation sea salt, $\mathrm{Na}^{+}$, appear to be less influential than accumulation rate under most circumstances, at least at most coastal Antarctic sites and in the temperature range from $-29.5^{\circ} \mathrm{C}$ to $-12.5^{\circ} \mathrm{C}$. A notable exception is for inland Greenland sites, where MSA migration tends to occur deeper in the core than would be predicted from surface accumulation alone, an offset hypothesized to stem from extremely low concentrations of marine-derived impurities relative to most coastal Antarctic sites. Our analysis further suggests that MSA migration generally takes place once firn or ice density reaches a critical value near $550 \mathrm{~kg} \mathrm{~m}^{-3}$, which corresponds to the tightest packing of spherical ice grains in the firn and enabling the formation of premelted liquid veins at grain boundaries. However, at some low accumulation sites $\left(\dot{b}=0.1-0.2 \mathrm{~m}\right.$ w. eq. $\left.\mathrm{yr}^{-1}\right)$, MSA migration is observed at depths where bulk density is likely to be less than $550 \mathrm{~kg} \mathrm{~m}^{-3}$. This result suggests that small-scale variability in ice density is important and (or) that other factors may also determine the onset of MSA along the firn or ice column.

New high-resolution data from the West Antarctic DIV2010 ice core shows annual [MS] maxima gradually shifting down-core from austral summer, when MSA deposition is high, to austral winter, when MSA deposition is low and $\mathrm{Na}^{+}$deposition is high. As a result, a down-core change in the phase relationship between $[\mathrm{MS}]$ and $\left[\mathrm{Na}^{+}\right]$is observed, whereby $[\mathrm{MS}]$ and $\left[\mathrm{Na}^{+}\right]$are negatively correlated at zero lag in the upper part of the core and positively correlated at zero lag in the lower part of the core, providing evidence of the progressive nature of MSA migration.

A linearized version of the impurity transport model of Rempel et al. (2002) is derived for the binary system $\mathrm{CH}_{3} \mathrm{SO}_{3} \mathrm{Na} \cdot n \mathrm{H}_{2} \mathrm{O}-\mathrm{H}_{2} \mathrm{O}$ in order to further understanding of the MSA migration phenomenon in polar ice. In this linearized model, MS transport is governed by a single linear partial differential equation with $\mathrm{MS}^{-}$diffusivity in the under-cooled liquid $\left(D_{M S}\right)$ as the sole parameter. In this model, MSA migration arises from two transport processes: (1) the convergence or divergence of $\mathrm{MS}^{-}$driven by $\left.\mathrm{Na}^{+}\right]$gradients and (2) the diffusion of $\mathrm{MS}^{-}$along its own concentration gradient. Analysis of this model shows that $\left[\mathrm{MS}^{-}\right]$maxima (minima) are bound to coincide with $\left[\mathrm{Na}^{+}\right]$maxima (minima) along the ice column, regardless of the timing of MSA deposition maxima. The model, therefore, provides a mechanistic explanation for the tendency for MSA, deposited mainly during summer, to present concentration peaks in winter layers in the deepest part of polar ice cores. 
Finally, we use the linearized MSA migration model and the DIV2010 data to gain insight into two poorly constrained yet critically important aspects of MSA migration. First, we evaluate different values of MS- diffusivities in polar ice. We find that $D_{M S}$ values in the range from $10^{-12}$ to $10^{-11} \mathrm{~m}^{2} \mathrm{~s}^{-1}$ lead to the most accurate simulations of the down-core change in the phase relationship between [MS] and $\left[\mathrm{Na}^{+}\right]$observed at DIV2010. Second, using this range of values, we apply the model to determine the extent to which MSA migration has altered the original [MS] record for DIV2010. We estimate the errors incurred by averaging [MS] data over annual (and multi-year) intervals, an approach often adopted to reduce the effect of migration on the interpretation of [MS] records. We find that MSA migration may have lead to significant changes in the annual and multi-year [MS] averages at DIV2010. This result suggests that [MS] records severely perturbed by MSA migration may best be used to infer decadal and lower-frequency climate variability, though a range of [MS-] records and a better constrained model are needed to investigate this further.

The migration of MSA in cold, polar ice is a fascinating but challenging phenomenon. This paper covers many, but not all, of its observational and theoretical aspects. For example, contentions of MSA migrating away from regions of high acidity in the core, as caused by the deposition of compounds of volcanic origin (Curran et al., 2002; Delmas et al., 2003), are not explored here. While the model of Rempel et al. (2002) provides an important mechanistic framework for understanding MSA migration in polar ice and perhaps for ultimately correcting its effects for paleoclimatic reconstruction, its usefulness remains limited by uncertainties about key physico-chemical parameters. These include most notably the diffusivities of the relevant migrating species in under-cooled liquid, the slope of the liquidus curves for relevant, interacting species, and the partitioning of impurities between the ice lattice and the surface of the ice grains. Laboratory studies under a range of controlled conditions would help constrain these parameters, improve our understanding of MSA migration in polar ice, and make full use of the paleoclimatic potential of this compound. 


\section{Ch. 2 Figures}
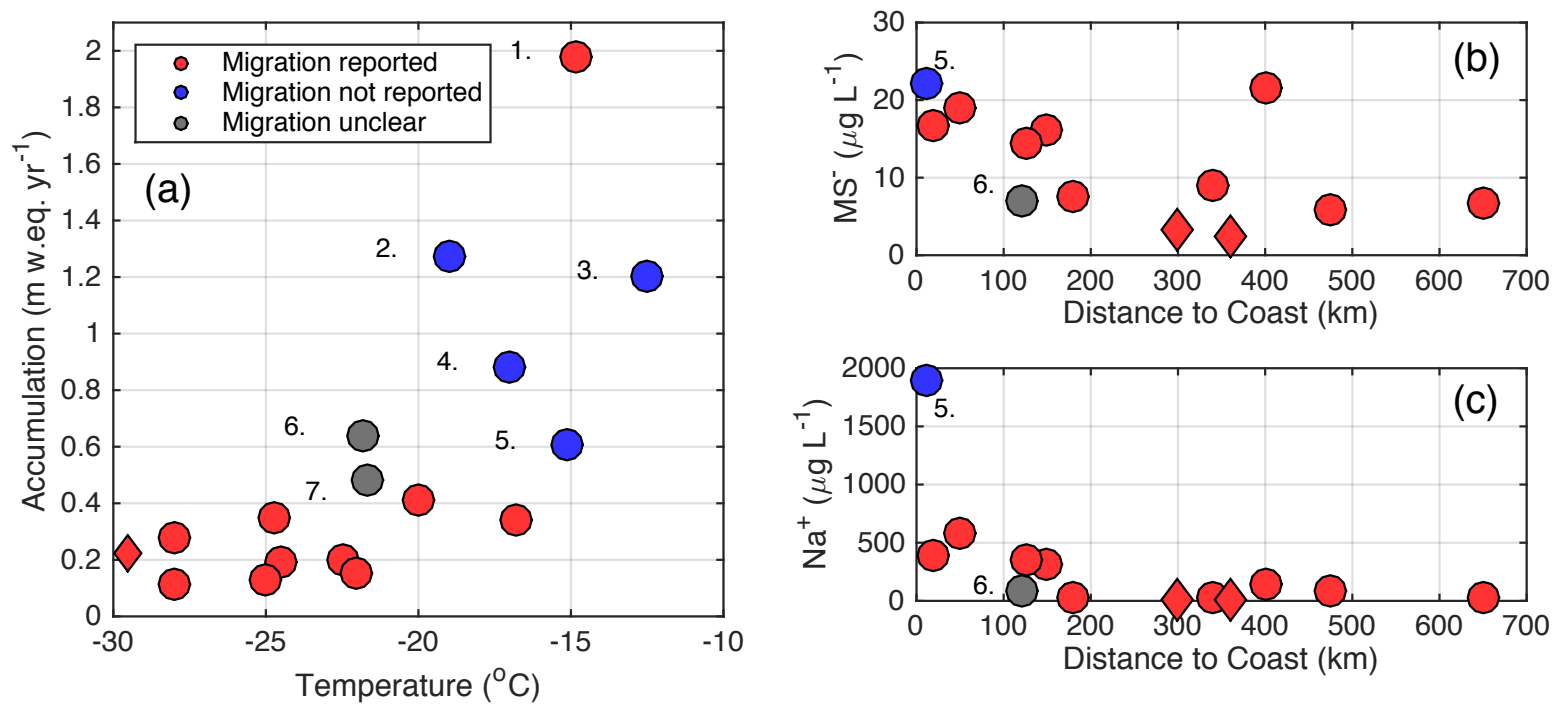

Figure 2-1: Compilation of data for Antarctic (circles) and Greenland (diamonds) ice cores for which [MS-] records meet the criteria of this study. (a) Annual mean accumulation rate versus annual mean surface air temperature. (b) Core-averaged [MS-] versus distance to the coast. (c) Core-averaged $\left[\mathrm{Na}^{+}\right]$versus distance to the coast. The colors indicate whether MSA migration has been reported, deemed as unclear, or not reported in the original publications. The numbers indicate ice core sites with $\dot{b}>0.45 \mathrm{~m} \mathrm{w}$. eq. $\mathrm{yr}^{-1}: 1$. Bruce Plateau (length of record: $448 \mathrm{~m}$ ), 2. DS08-Law Dome (196 m, corresponding to a time span of $145 \mathrm{yr}$ ), 3. Beethoven Plateau (47 m, 28 yr), 4. Gomez Nunutak (56 m, 42 yr), 5. WHG-Victoria Land (106 m, 130 yr), 6. DSS-Law Dome (124 m, 156 yr), 7. Dyer Plateau (80 m, 103 yr). 

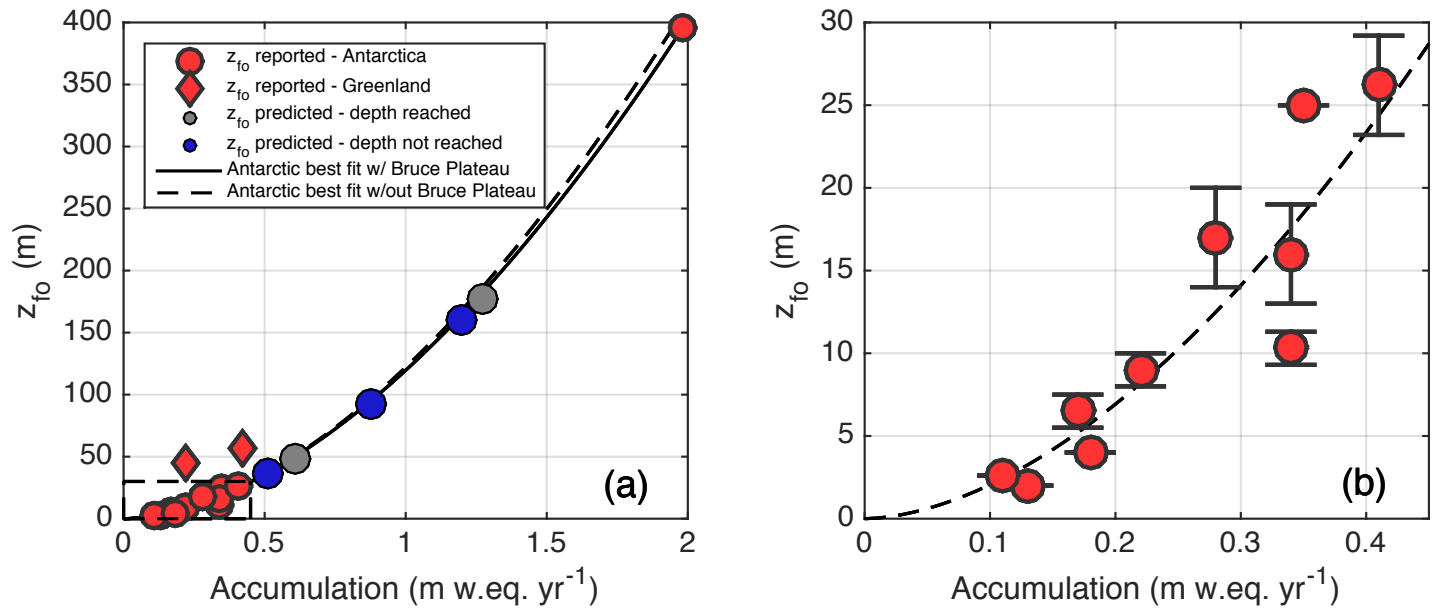

Figure 2-2: (a) Shallowest depth of MSA migration, $z_{f o}$, versus annual mean accumulation rate $(\dot{b})$ for Antarctic (circles) and Greenland sites (diamonds). The dashed line is the least-squares fit $z_{f o}=125 \cdot \dot{b}^{1.77}$ through the Antarctic data with $\dot{b}<0.45 \mathrm{~m}$. w .eq. $\mathrm{yr}^{-1}\left(\mathrm{n}=10 ; \mathrm{r}^{2}=0.82\right)$ and used to predict $z_{f o}$ at sites where MSA migration was not reported (grey and blue). At 2 of these sites (WHG and DE08; grey), maximum sampling depth exceeds the predicted $z_{f o}$. The solid black line is the fit when including the Bruce Plateau data $\left(\dot{b}=1.98 \mathrm{~m}\right.$. w .eq. $\left.\mathrm{yr}^{-1}\right)$. (b) Expanded view of panel (a) (rectangle bounded with dashed lines). Error estimates for $Z_{f o}$ are generally crude (Appendix A1.1). Some are based on unit conversion from $\mathrm{m} w$. eq. to $\mathrm{m}$ using a firn densification model (Harron and Langway, 1980) constrained by site diagnostic observations (Table 1) and an assumed surface snow density range of $300-400 \mathrm{~kg} \mathrm{~m}^{-3}$. The dashed line is the same as in panel (a). 


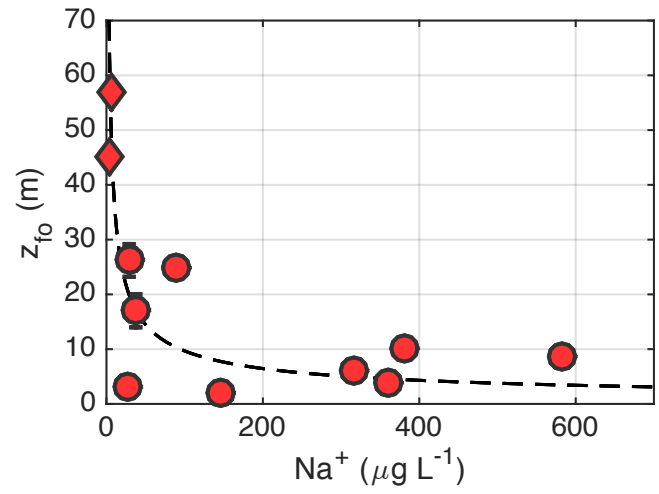

Figure 2-3. Shallowest depth of MSA migration versus core-averaged $\left[\mathrm{Na}^{+}\right]$for different core sites in Antarctica (circles) and Greenland (diamonds). The dashed line is the least-squares fit $Z_{f o}=142 \cdot\left[\mathrm{Na}^{+}\right]^{-0.58}$ through all the data $\left(n=11, \mathrm{r}^{2}=0.85\right)$. 


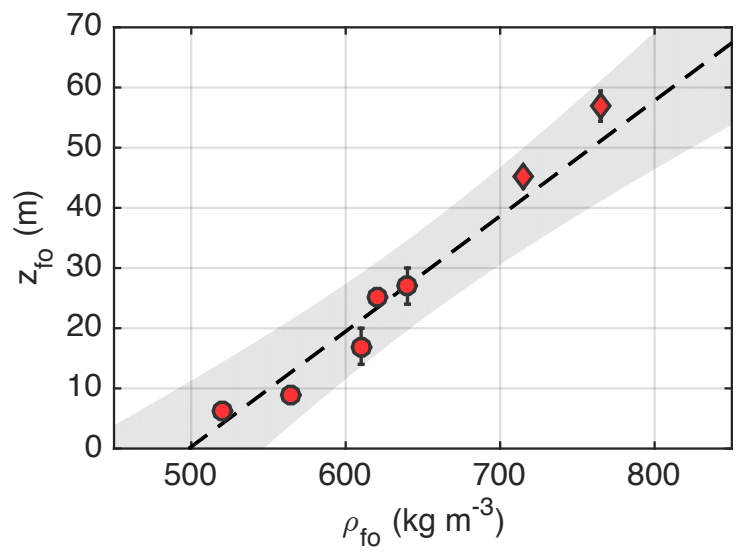

Figure 2-4. Shallowest depth of MSA migration versus firn or ice density for different core sites in Antarctica (circles) and Greenland (diamonds). The vertical bars are error estimates (Appendix 2.1), the dashed line is the weighted least-squares fit $z_{f o}=-95.6+0.192 \rho$ through the data $\left(\mathrm{n}=7 ; \mathrm{r}^{2}=0.89\right)$, with the weighting provided by the $z_{f o}$ error estimates, and the shaded region is the region of $95 \%$ confidence. 


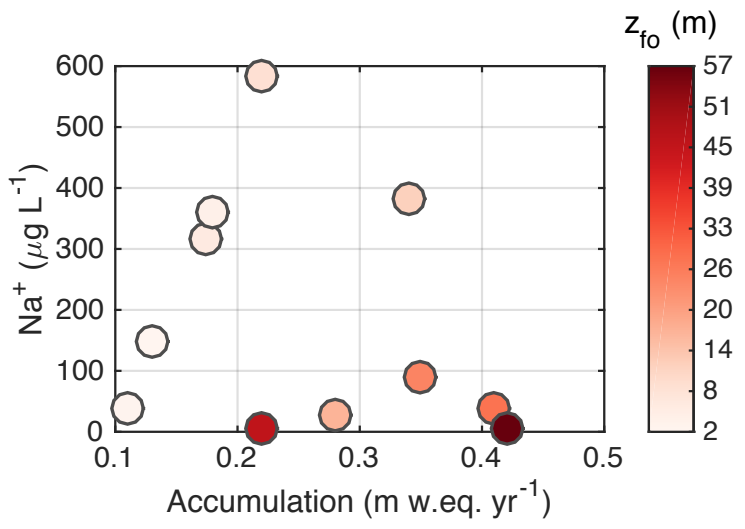

Figure 2-5. Core-averaged $\left[\mathrm{Na}^{+}\right]$versus annual mean accumulation rate for different core sites in Antarctica and Greenland. The different colors correspond to different values of the shallowest depth of MSA migration. 


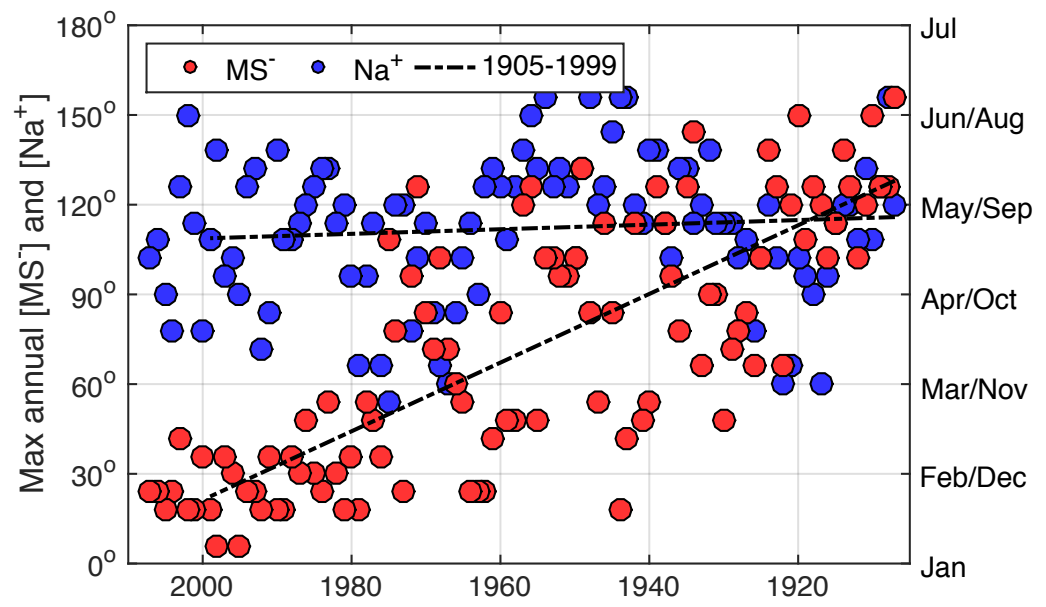

Figure 2-6: Timing of annual maximum of [MS] (red) and annual maximum of $\left[\mathrm{Na}^{+}\right]$(blue) versus calendar age (year AD) for the DIV2010 core. No obvious predisposition for migration in the up or down-core direction is observed in DIV2010. As such, the timing of annual maximum [MS] and annual maximum $\left[\mathrm{Na}^{+}\right]$are defined in terms of the number of degrees out of phase of January $1^{\text {st }}\left(0^{\circ}\right)$, where $180^{\circ}$ indicates an annual maximum on July $1^{\text {st. }}$ The two dashed lines are the least-squares fits for [MS-] and $\left[\mathrm{Na}^{+}\right]$over the period AD 1999-1905, corresponding to depths below which $\rho=550 \mathrm{~kg} \mathrm{~m}^{-3}$. The fit is highly significant for [MS-] ( $\mathrm{n}=95, \mathrm{r}=0.75$, $\mathrm{p}<0.0001)$ and not significant for $\left[\mathrm{Na}^{+}\right](\mathrm{n}=95, \mathrm{r}=0.09, \mathrm{p}=0.41)$. 


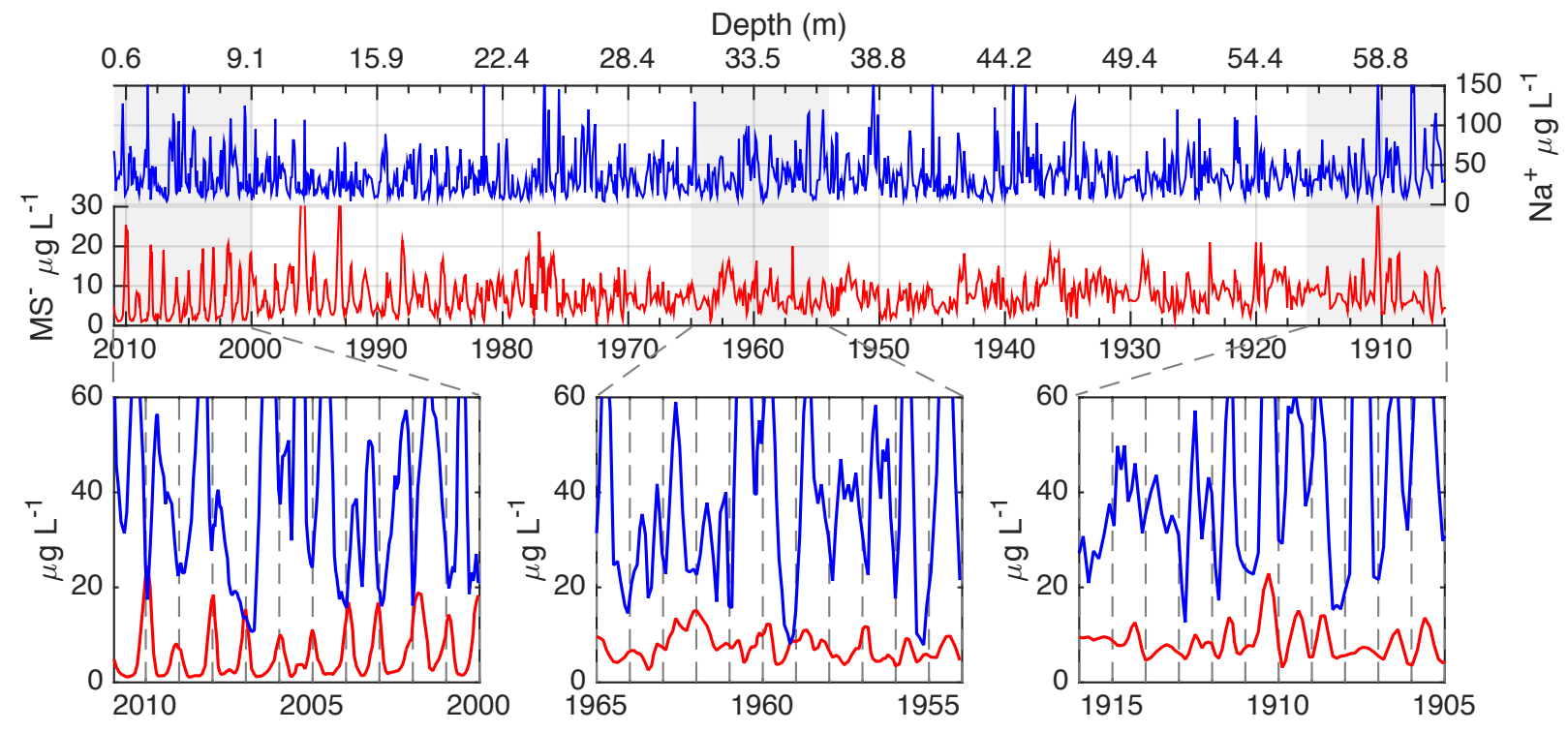

Figure 2-7: Records of [MS] (red) and $\left[\mathrm{Na}^{+}\right]$(blue) from the DIV2010 ice core. Upper panel: the entire record considered in this study, with a depth scale at the top and a time scale (year AD) at the bottom (raw data). Bottom panels: 11-yr long portions of the records within the shallow zone (left), the transition zone (middle), and the deep zone (right). Three-point running averages are displayed for each zone. Dashed vertical lines denote January $1^{\text {st }}$ of each year. 

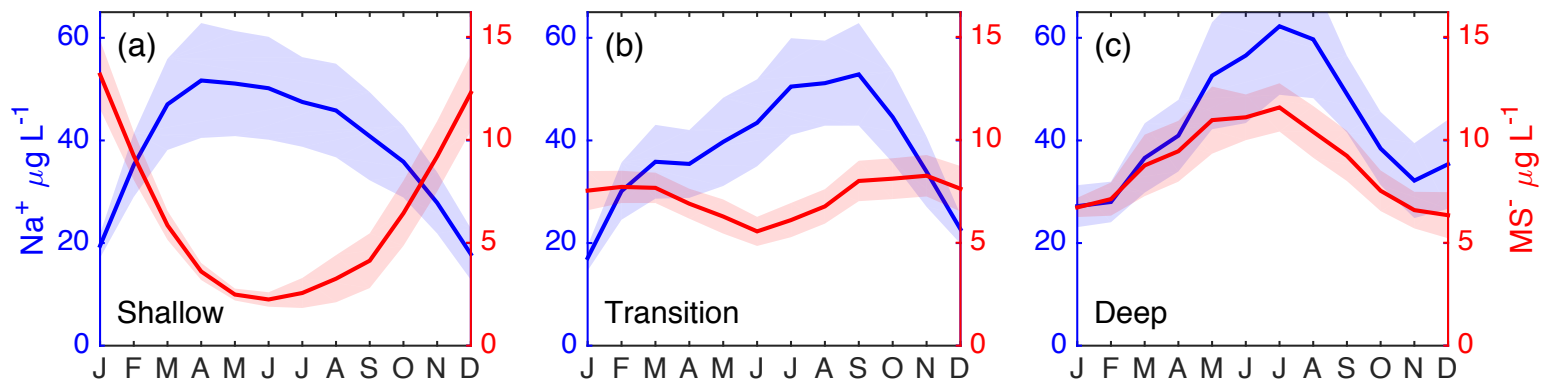

Figure 2-8: Monthly mean concentration of $\mathrm{Na}^{+}$and MS- in the shallow (a), transition (b), and deep (c) zones of DIV2010. The shaded regions indicate \pm 1 standard error of the mean. 

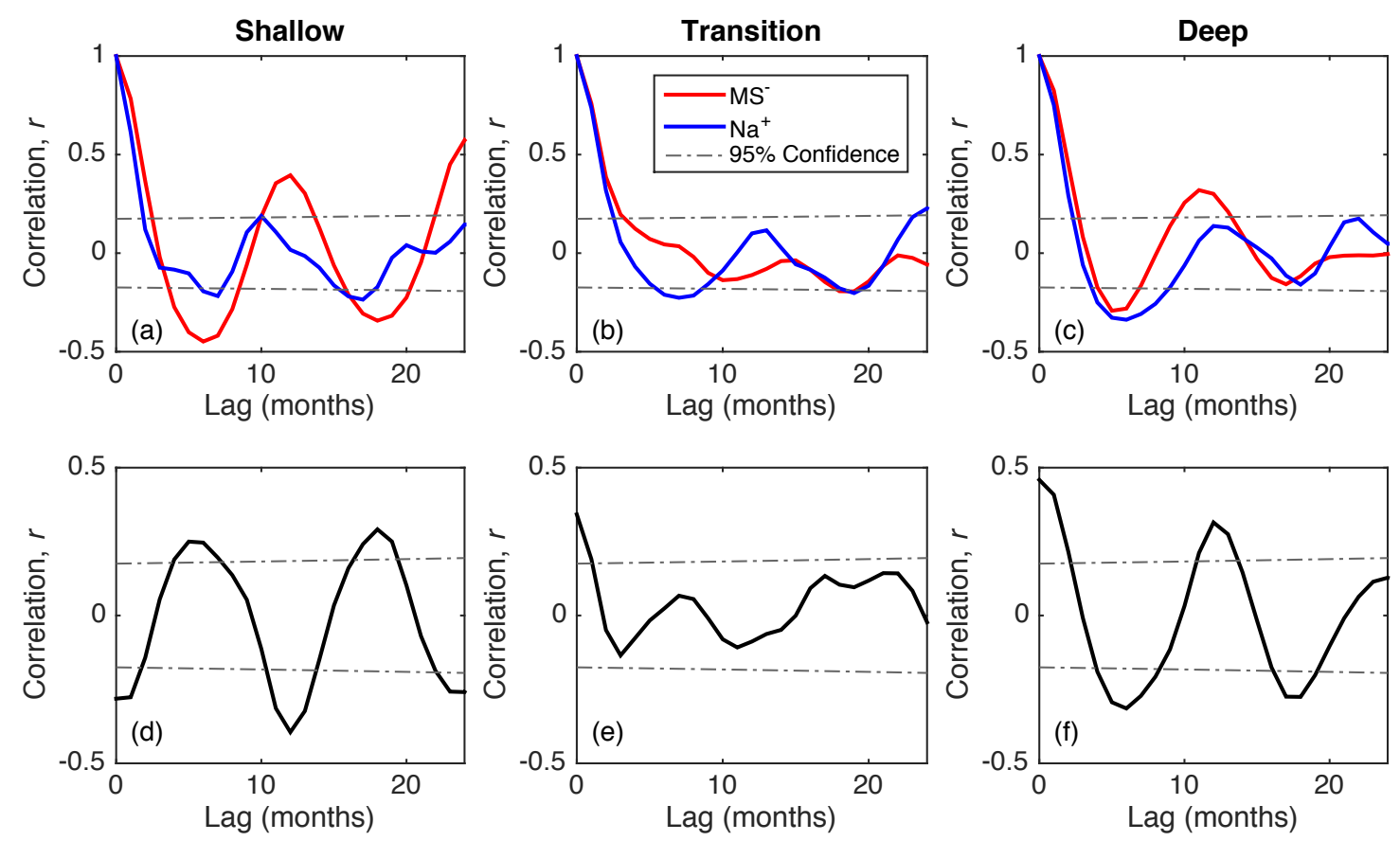

Figure 2-9: (a-c) Correlograms of [MS] and $\left[\mathrm{Na}^{+}\right]$in the three zones of the DIV2010 ice core. The horizontal dashed lines show the $95 \%$ confidence interval for a time series with no autocorrelation (white sequence). (df) Cross-correlation between [MS-] and $\left[\mathrm{Na}^{+}\right]$in the three zones of the DIV2010 ice core. The horizontal dashed lines show the $95 \%$ confidence interval for two uncorrelated time series. 

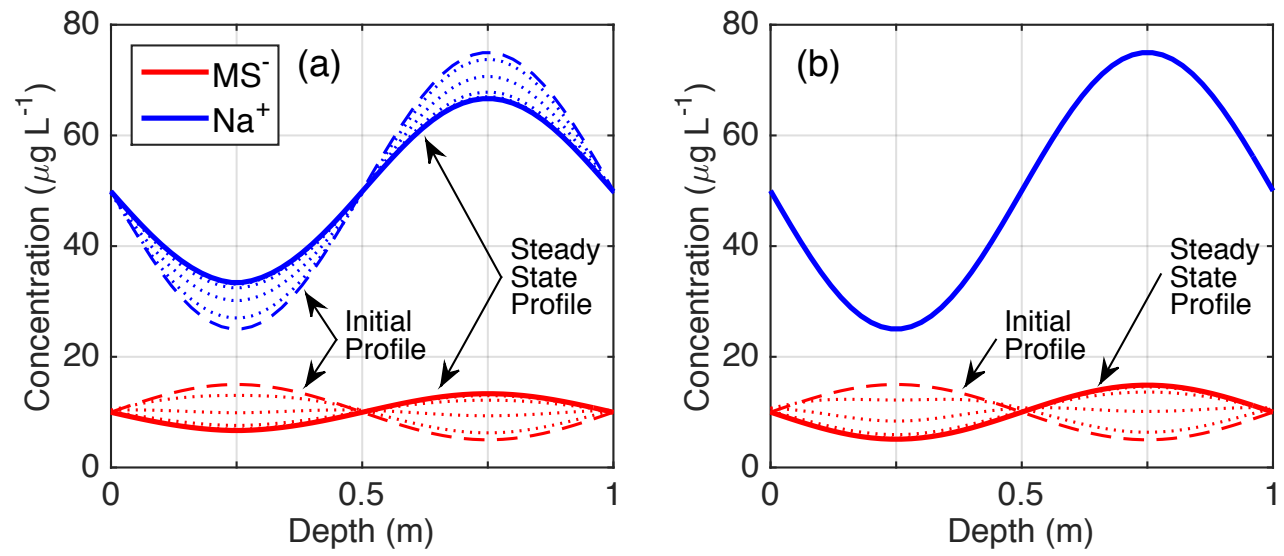

Figure 2-10: Comparison between the RWW model and the linearized model. (a) Profiles of [MS-] and $\left[\mathrm{Na}^{+}\right]$ simulated by the RWW model with $D_{M S}=D_{N a}=10^{-11} \mathrm{~m}^{2} \mathrm{~s}^{-1}$ and $\Gamma_{M S}=\Gamma_{M S}=6.5 \mathrm{~K} \mathrm{M}^{-1}$. (b) Profiles of [MS] simulated by the linearized model with an effective velocity based on the $\left[\mathrm{Na}^{+}\right]$profile shown in the panel and with $D_{M S}=10^{-11} \mathrm{~m}^{2} \mathrm{~s}^{-1}$ (see text and Appendix 2 for details). 


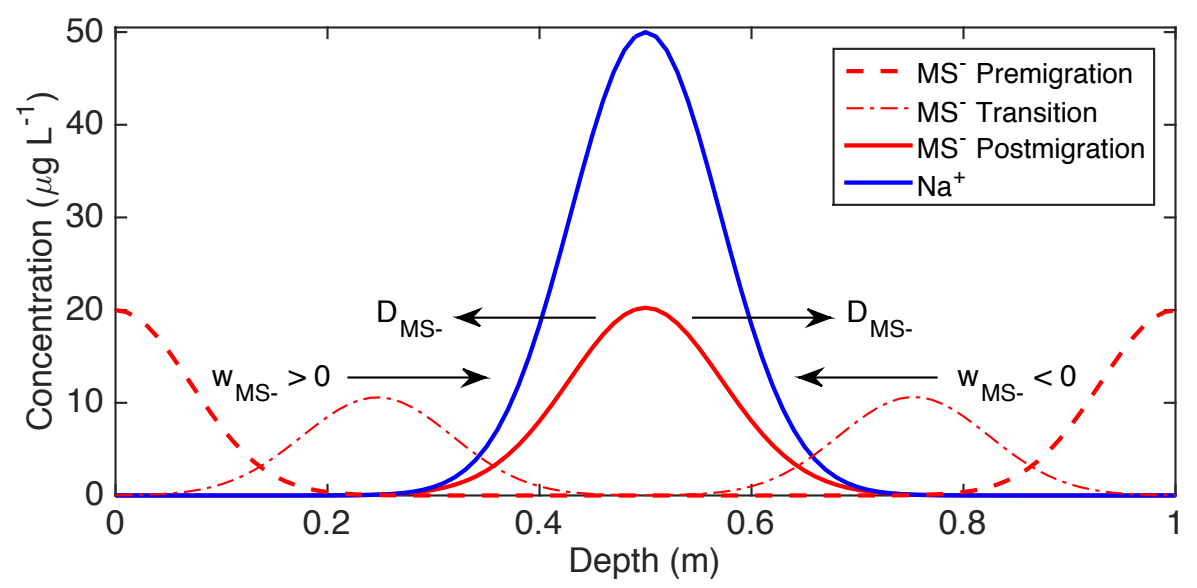

Figure 2-11: Evolution of [MS-] simulated by the linearized model assuming (i) an effective velocity based on a Gaussian profile of $\left[\mathrm{Na}^{+}\right]$(blue) and (ii) $D_{M S}=10^{-11} \mathrm{~m}^{2} \mathrm{~s}^{-1}$. The dashed, dotted-dashed, and solid red lines show, respectively, the initial, transient, and steady state profiles of [MS]. The different symbols and arrow show the two transport processes affecting the steady-state profile of [MS-]: MS- convergence toward the [ $\mathrm{Na}^{+}$] maximum, and MS- diffusion away from the $\left[\mathrm{Na}^{+}\right]$maximum (see text and Appendix 2 for details). 

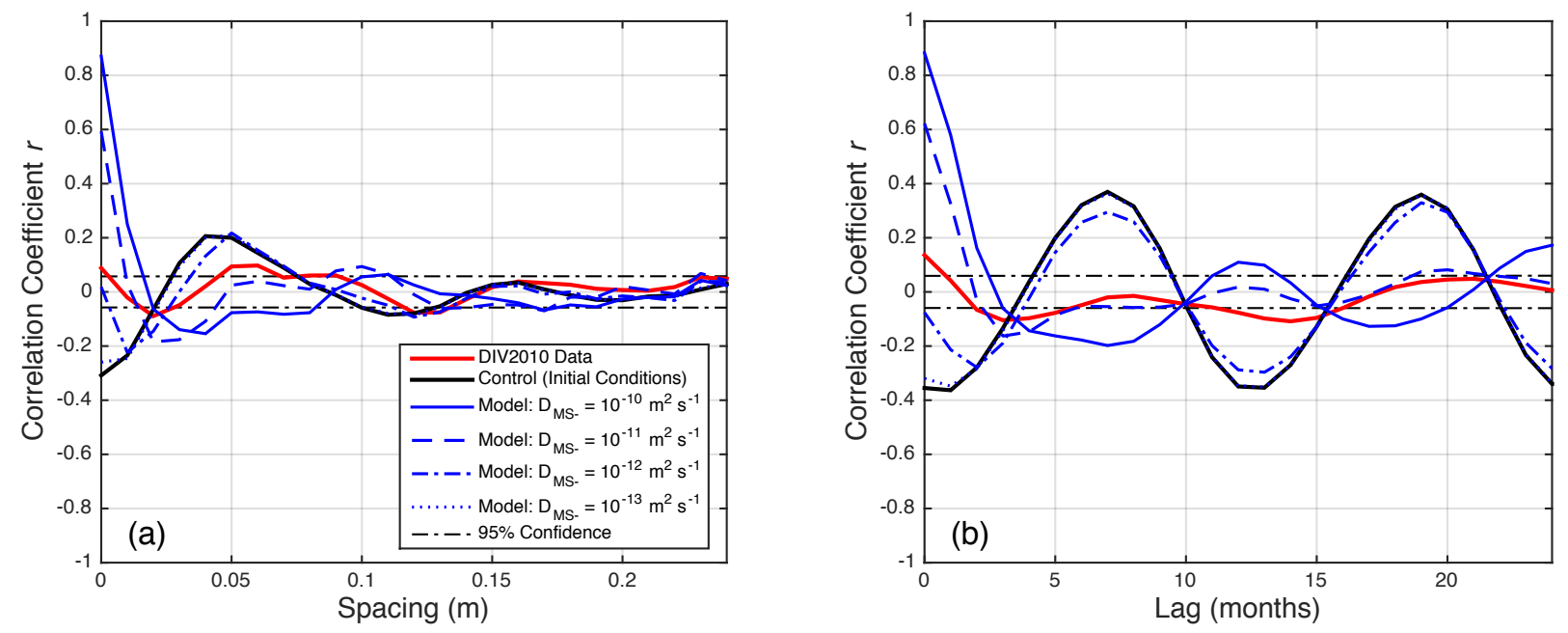

Figure 2-12: Cross-correlation between $\left[\mathrm{Na}^{+}\right]$and [MS] at different vertical spacings (a) and different time lags (b). In each panel, the red line shows the cross-correlations calculated from the DIV2010 data below the shallow zone $(\mathrm{z}>9.1 \mathrm{~m})$, the blue lines show the cross-correlations calculated from the linearized model for different values of $D_{M S}$, the solid black line shows the cross-correlations corresponding to the initial conditions of the model, and the horizontal dashed lines show the $95 \%$ confidence interval for two uncorrelated time series (see text and Appendix 2 for details). 

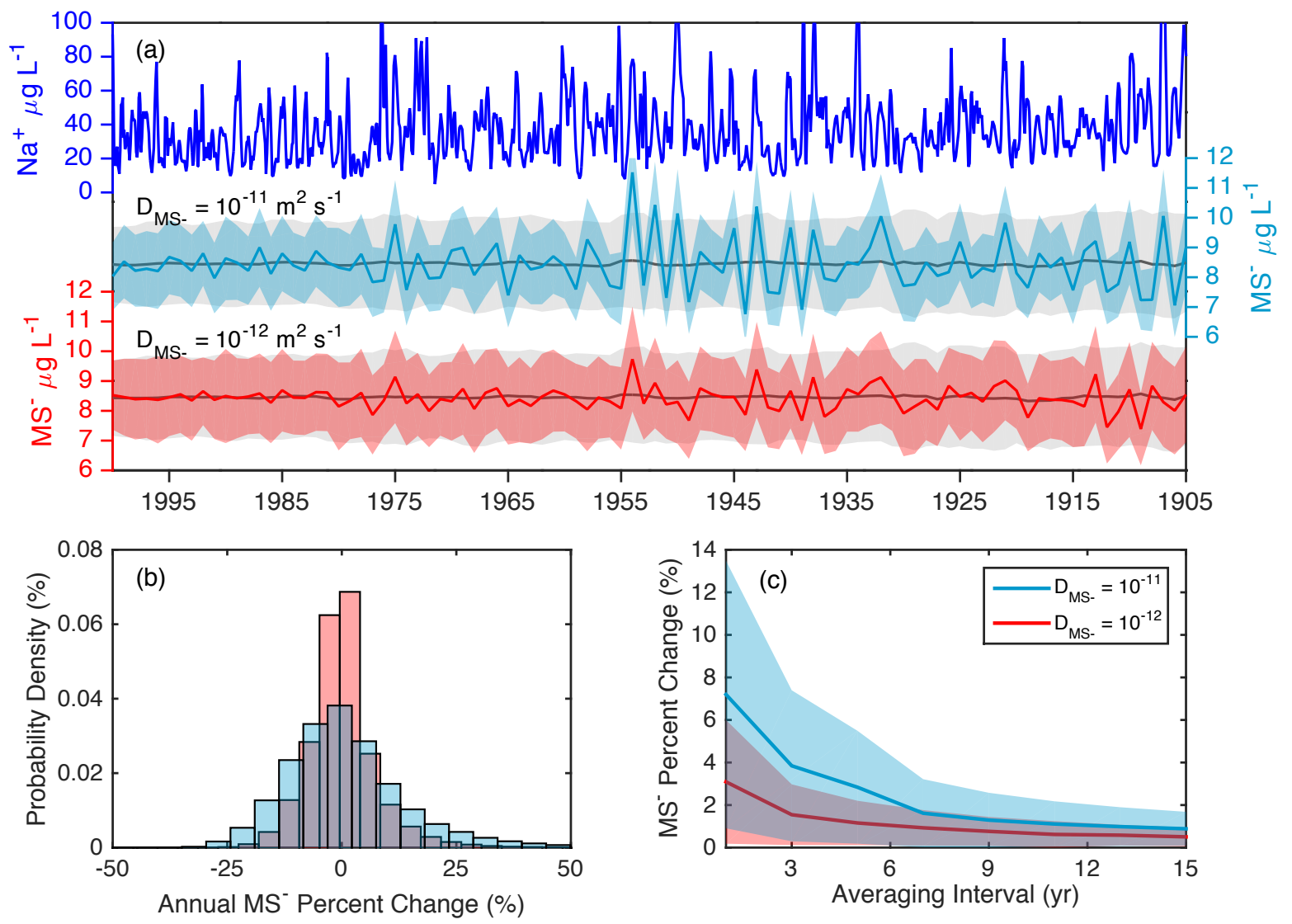

Figure 2-13: Extent of MSA migration in the DIV2010 ice core as estimated from the linearized model. Panel (a), top: DIV2010 $\left[\mathrm{Na}^{+}\right]$record (5-point smoothed). Panel (a), middle: (i) Annual means of [MS] (black line) and standard deviations of [MS-], $\sigma$ (gray band, representing $\pm 1 \sigma$ about the means) for the initial conditions (ICs) of the model experiments, and (ii) annual means of [MS-] (blue line) and standard deviations of [MS-] (blue band) for the terminal conditions (TCs, $\sim 95 \mathrm{yr}$ ) of the model experiments for $D_{M S}=10^{-11} \mathrm{~m}^{2} \mathrm{~s}^{-1}$. Panel (a), bottom: Same as panel (a), middle, but for $D_{M S}=10^{-12} \mathrm{~m}^{2} \mathrm{~s}^{-1}$. Panel (b): Probability density of the absolute difference between the annual mean [MS] for the ICs and TCs, normalized to the annual mean [MS] of the ICs, for all model experiments with $D_{M S}=10^{-11} \mathrm{~m}^{2} \mathrm{~s}^{-1}$ (blue) and $10^{-12} \mathrm{~m}^{2} \mathrm{~s}^{-1}$ (red). Panel (c): Absolute difference between the annual mean [MS] for the ICs and TCs, normalized to the annual mean [MS-] of the ICs, for all model experiments with $D_{M S}=10^{-11} \mathrm{~m}^{2} \mathrm{~s}^{-1}$ (blue) and $10^{-12} \mathrm{~m}^{2} \mathrm{~s}^{-1}$ (red), as a function of the data averaging interval. The shaded regions illustrate the dispersion ( \pm 1 standard deviation) of the normalized absolute differences among the model experiments. 

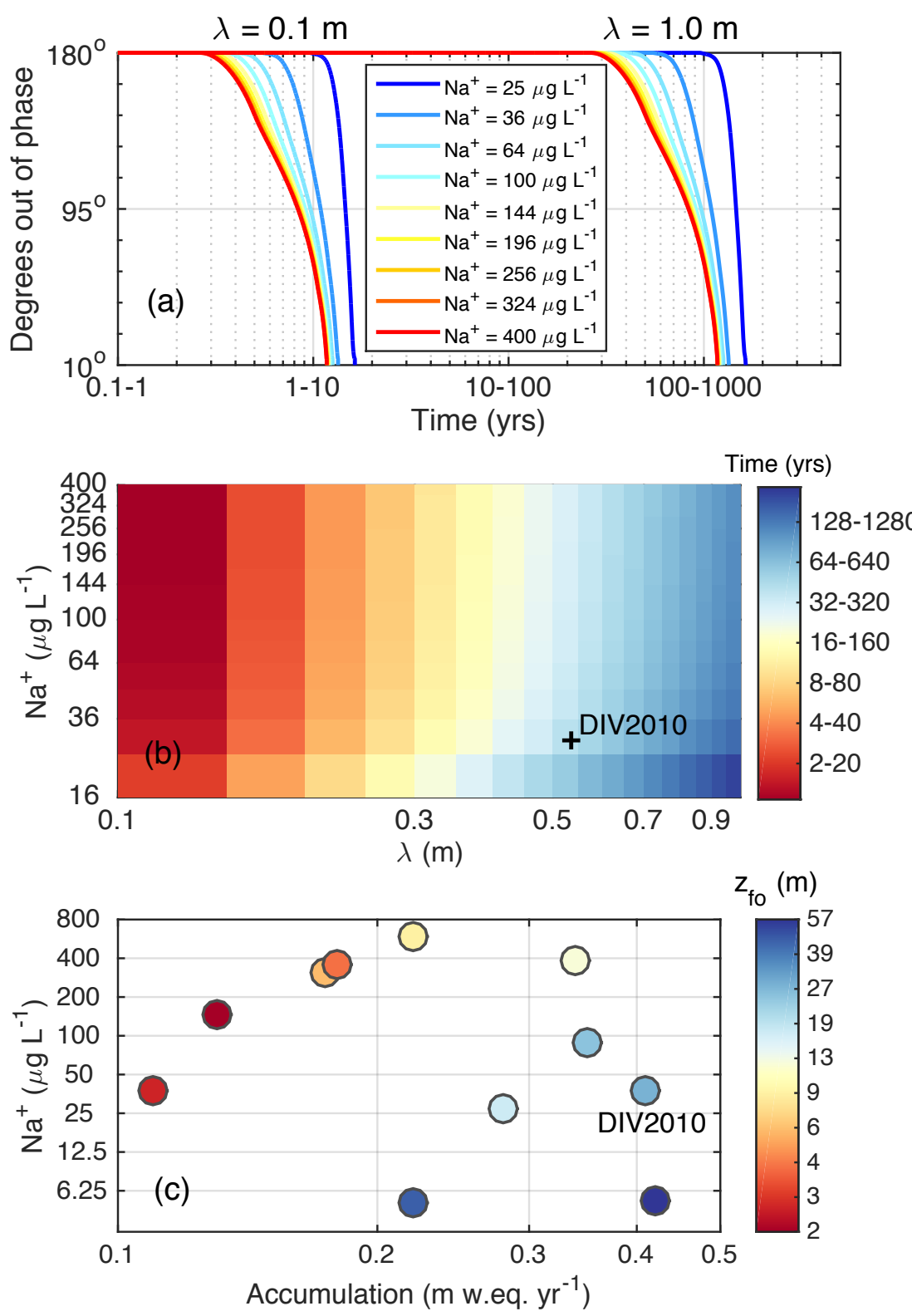

Figure 2-14: (a) Evolution of the phase difference between [MS-] and $\left[\mathrm{Na}^{+}\right]$maxima for (i) two different extents of the model domain or "annual layer thickness" (0.1 and $1 \mathrm{~m})$ and (ii) different layer averages of $\left[\mathrm{Na}^{+}\right](25-$ $400 \mu \mathrm{g} \mathrm{L}{ }^{-1}$ ), as calculated from the RWW model. Note the two different scales along the horizontal axis: the scale from 0.1 to $100 \mathrm{yr}$ applies to model results with $D_{M S}=10^{-11} \mathrm{~m}^{2} \mathrm{~s}^{-1}$, and the scale from 1 to $1,000 \mathrm{yr}$ applies to model results with $D_{M S}=10^{-12} \mathrm{~m}^{2} \mathrm{~s}^{-1}$. (b) Time required for approximate alignment of [MS] and $\left[\mathrm{Na}^{+}\right]$ maxima for different values of "annual layer thickness" and different layer averages of $\left[\mathrm{Na}^{+}\right]$, as calculated from the RWW model. Conditions for the DIV2010 core site are indicated by the cross. (c) Shallowest depth of MSA migration for different values of annual mean accumulation rate and different core averages of $\left[\mathrm{Na}^{+}\right]$according to our data compilation, with DIV2010 denoted. Note the logarithmic scales in all panels. 


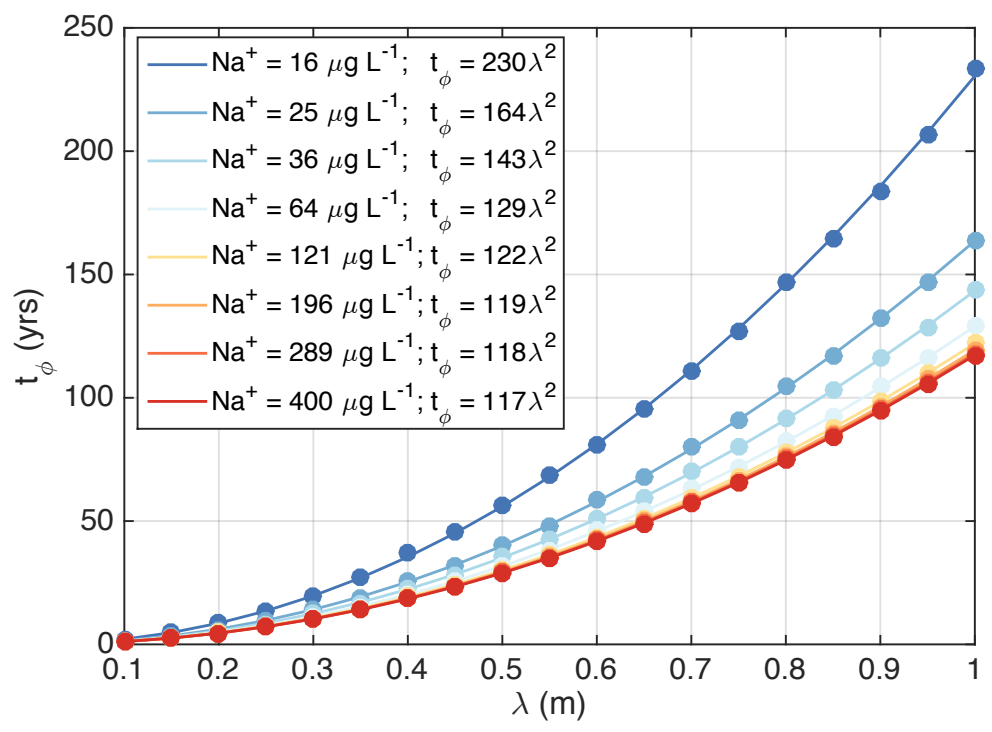

Figure 2-15: The time required for approximate alignment of $[\mathrm{MS}]$ and $\left[\mathrm{Na}^{+}\right]$maxima $\left(t_{\varphi}\right)$ as a function of annual layer thickness $(\lambda)$ for different layer averages of $\left[\mathrm{Na}^{+}\right]$and $D_{M S}=10^{-11} \mathrm{~m}^{2} \mathrm{~s}^{-1}$. The various curves are the least-squares power law fit $t_{\varphi}=a \lambda^{e}$. The exponent $e$ is estimated to about 2 for all values of layer-averaged $\left[\mathrm{Na}^{+}\right]$(note that the least squares power law fit for $D_{M S}=10^{-12} \mathrm{~m}^{2} \mathrm{~s}^{-1}$, not shown, yields a value of $a$ that is a factor of 10 higher than for $D_{M S}=10^{-11} \mathrm{~m}^{2} \mathrm{~s}^{-1}$ ). 


\section{Ch. 2 Tables}

Table 2-1. Ice core sites where MSA migration (or lack thereof) has been reported (" $\sim$ " denotes unavailable data and "n/a" denotes a non-applicable field).

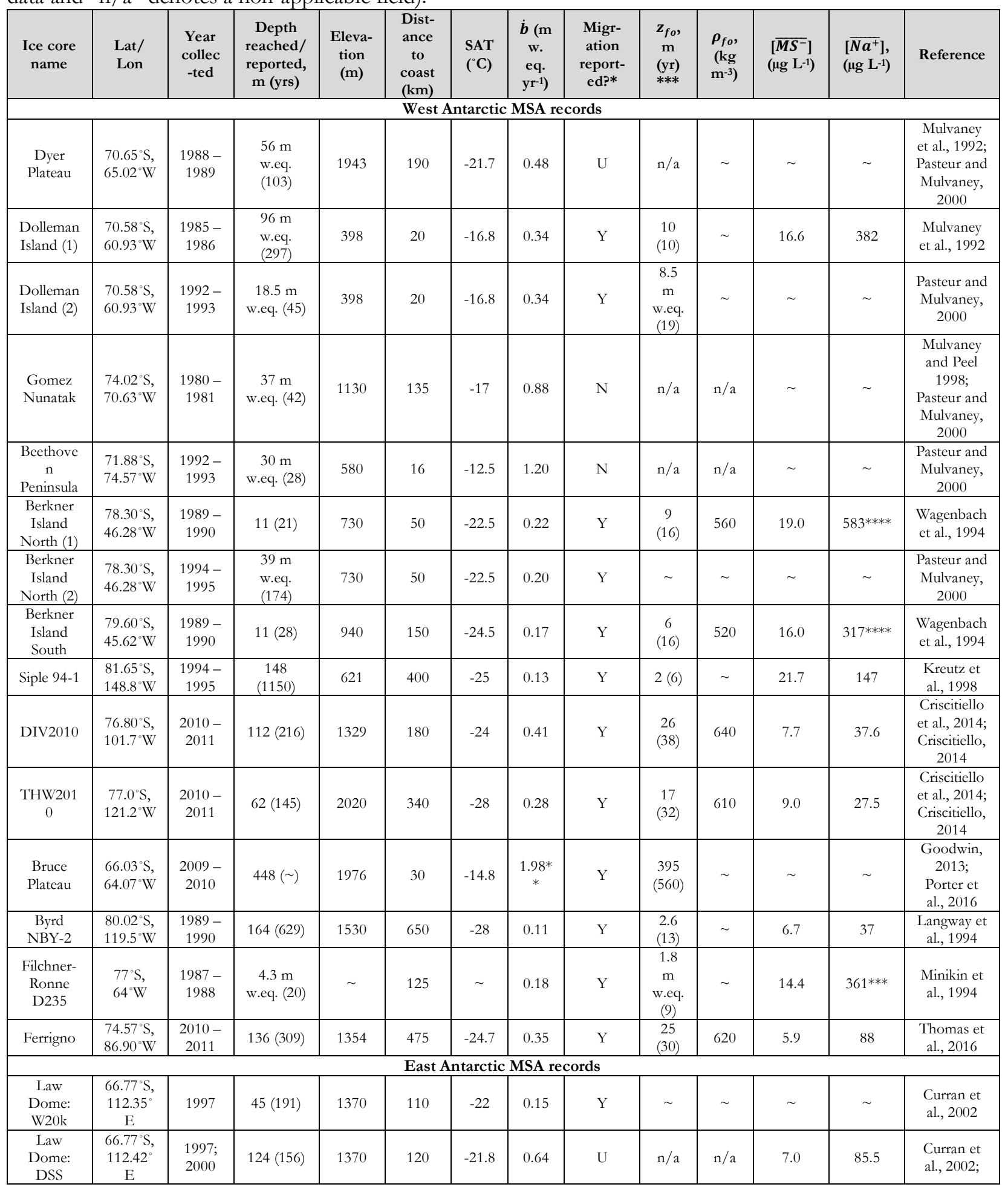




\begin{tabular}{|c|c|c|c|c|c|c|c|c|c|c|c|c|c|}
\hline & & & & & & & & & & & & & $\begin{array}{c}\text { Curran et } \\
\text { al., } 2003\end{array}$ \\
\hline $\begin{array}{c}\text { Law } \\
\text { Dome: } \\
\text { DE08 }\end{array}$ & $\begin{array}{c}66.72^{\circ} \mathrm{S} \\
113.18^{\circ} \\
\mathrm{E}\end{array}$ & 1986 & $196(145)$ & $\sim$ & 100 & -19 & 1.27 & $\mathrm{~N}$ & $\mathrm{n} / \mathrm{a}$ & $\mathrm{n} / \mathrm{a}$ & $\sim$ & $\sim$ & $\begin{array}{l}\text { Curran et } \\
\text { al., } 2002\end{array}$ \\
\hline $\begin{array}{l}\text { WHG - } \\
\text { Victoria } \\
\text { Land }\end{array}$ & $\begin{array}{c}72.90^{\circ} \mathrm{S} \\
169.08^{\circ} \\
\mathrm{E}\end{array}$ & 2006 & $105(130)$ & 400 & 12 & -15 & 0.61 & $\mathrm{~N}$ & $\mathrm{n} / \mathrm{a}$ & $\mathrm{n} / \mathrm{a}$ & 22 & 1901 & $\begin{array}{c}\text { Sinclair et } \\
\text { al., 2012; } \\
\text { Sinclair et } \\
\text { al., } 2014\end{array}$ \\
\hline \multicolumn{14}{|c|}{ Greenland MSA records } \\
\hline $\begin{array}{c}\text { Summit2 } \\
010\end{array}$ & $\begin{array}{l}72.33^{\circ} \mathrm{N} \\
38.28^{\circ} \mathrm{W}\end{array}$ & 2010 & $87(268)$ & 3213 & 360 & -29.5 & 0.22 & $\mathrm{Y}$ & $\begin{array}{l}43.7- \\
46.9 \\
(120- \\
130)\end{array}$ & $\begin{array}{l}710- \\
720\end{array}$ & 3.4 & $5.1^{* * * * * *}$ & $\begin{array}{l}\text { Maselli et } \\
\text { al., } 2017\end{array}$ \\
\hline D4 & $\begin{array}{l}71.4^{\circ} \mathrm{N} \\
44.0^{\circ} \mathrm{W}\end{array}$ & 2004 & $145(270)$ & 2710 & 300 & $\sim$ & 0.42 & Y & $\begin{array}{l}54.3- \\
59.4 \\
(90- \\
100)\end{array}$ & $\begin{array}{l}760- \\
770\end{array}$ & 2.5 & $5.3^{* * * *}$ & $\begin{array}{c}\text { MSA data } \\
\text { unpublishe } \\
\text { d }\end{array}$ \\
\hline 2Barrell & $\begin{array}{l}76.94^{\circ} \mathrm{N} \\
63.15^{\circ} \mathrm{W}\end{array}$ & 2011 & $21.3(21)$ & 1685 & 100 & $\sim$ & 0.51 & $\mathrm{~N}$ & $\mathrm{n} / \mathrm{a}$ & $\mathrm{n} / \mathrm{a}$ & $\sim$ & $\sim$ & $\begin{array}{l}\text { Osterberg } \\
\text { et al., } 2015\end{array}$ \\
\hline
\end{tabular}

$* \mathrm{Y}=\mathrm{Yes} ; \mathrm{N}=\mathrm{No} ; \mathrm{U}=$ Unclear

** Bruce Plateau annual mean accumulation rate appears to be highly variable over the core-depth; listed value represents the AD 1750-2010 estimate (Goodwin, 2013).

*** See Section A1.1 and Table A1-1 in the Appendix for more information on how $\mathbf{z}_{\boldsymbol{f o}}$ is defined at each site.

**** $\left[\overline{\mathrm{Na}^{+}}\right]$estimated using the reported site value for $\left[\overline{\mathrm{Cl}^{-}}\right]$, and converted assuming a site-ratio $\left[\overline{\mathrm{Cl}^{-}}\right] /\left[\overline{\mathrm{Na}^{+}}\right]=1.8$, the mean seawater ratio (e.g., Chesselet et. al, 1972)..

***** $[\overline{\mathrm{Na}}]$ measurements made using continuous-flow inductively coupled plasma mass spectrometry (ICP-MS), as opposed to $\left[\overline{\mathrm{Na}^{+}}\right]$measurements made using ion chromatography (IC). As ICP-MS measures both the soluble and insoluble mass content, $[\overline{\mathrm{Na}}]$ values are likely slightly higher than IC-based estimates of $\left[\overline{\mathrm{Na}^{+}}\right]$. 
Table 2-2. Slopes of the liquidus curves $(\Gamma)$ estimated for various binary mixtures composed of impurity species of likely relevance and water. All values listed in columns prior to the $\Gamma$ column are required for calculation of $\Gamma$ (see Sect. A1.1 in the Appendix).

\begin{tabular}{|c|c|c|c|c|c|c|}
\hline Species & $\begin{array}{l}\text { Mol. } \\
\text { mass (g } \\
\text { mol-1) }^{-1}\end{array}$ & $\begin{array}{c}\text { Eutectic } \\
\text { temperature } \\
\left({ }^{\circ} \mathrm{C} \text {; binary }\right. \\
\left.\text { with } \mathrm{H}_{2} \mathrm{O}\right)\end{array}$ & $\begin{array}{c}\text { Eutectic } \\
\text { composition } \\
(w \mathrm{t} \% \text {; binary } \\
\left.\text { with } \mathrm{H}_{2} \mathrm{O}\right)\end{array}$ & $\begin{array}{c}\text { Density at } \\
\text { eutectic }\left(g \mathrm{~mL}^{-1} ;\right. \\
*=\text { approximated })\end{array}$ & $\Gamma\left(\mathbf{K ~ M}^{-1}\right)$ & Reference \\
\hline $\mathrm{CH}_{3} \mathrm{SO}_{3} \mathrm{H}$ & 96.11 & -75.0 & 51.1 & 1.20 & 11.7 & $\begin{array}{l}\text { Stephen and } \\
\text { Stephen, } 1963\end{array}$ \\
\hline $\mathrm{Na}\left(\mathrm{CH}_{3} \mathrm{SO}_{3}\right)$ & 119.11 & -29.3 & 47 & $1.15^{*}$ & 6.5 & Sakurai et al., 2010 \\
\hline $\mathrm{Mg}\left(\mathrm{CH}_{3} \mathrm{SO}_{3}\right)_{2}$ & 214.50 & -5.0 & 14.2 & $1.15^{*}$ & 6.6 & Sakurai et al., 2010 \\
\hline $\mathrm{Ca}\left(\mathrm{CH}_{3} \mathrm{SO}_{3}\right)_{2}$ & 230.27 & -32.6 & 47 & $1.20 *$ & 12.9 & Sakurai et al., 2010 \\
\hline $\mathrm{NaCl}$ & 58.44 & -21.3 & 23.3 & 1.16 & 4.6 & $\begin{array}{c}\text { Stephen and } \\
\text { Stephen, } 1963\end{array}$ \\
\hline $\mathrm{MgCl}_{2}$ & 95.21 & -33.0 & 21.6 & 1.13 & 12.9 & $\begin{array}{l}\text { Stephen and } \\
\text { Stephen, } 1963\end{array}$ \\
\hline $\mathrm{CaCl}_{2}$ & 110.98 & -51.0 & 30 & 1.19 & 15.9 & $\begin{array}{c}\text { Stephen and } \\
\text { Stephen, } 1963\end{array}$ \\
\hline $\mathrm{H}_{2} \mathrm{SO}_{4}$ & 98.08 & -62.0 & 35.6 & 1.19 & 14.3 & $\begin{array}{c}\text { Hornung et al., } \\
1956\end{array}$ \\
\hline $\mathrm{Na}_{2} \mathrm{SO}_{4}$ & 142.04 & -1.6 & 4.0 & 1.12 & 5.5 & Hougen et al., 1954 \\
\hline $\mathrm{MgSO}_{4}$ & 120.37 & -3.6 & 17.3 & 1.22 & 2.3 & Marion et al., 1999 \\
\hline $\mathrm{CaSO}_{4}$ & 136.14 & -0.7 & 18.0 & 1.23 & 0.4 & Rolnick, 1954 \\
\hline
\end{tabular}




\section{Ch. 2 References}

Abram, N. J., Wolff, E. W., and Curran, M. A. J. (2013). A review of sea ice proxy information from polar ice cores. Quat. Sci. Rev., 79, 168-183, doi:10.1016/j.quascirev.2013.01.011

Barnes, P. R. F., Wolff, E. W., Mader, H. M., Udisti, R., Castellano, E., and Röthlisberger, R. (2003). Evolution of chemical peak shapes in the Dome C, Antarctica, ice core. J. Geophys. Res., 108, 4126, doi:10.1029/2002JD002538

Barnes, P. R. F., Wolff, E. W., Mallard, D. C., Mader, H. M. (2003). SEM Studies of the Morphology and Chemistry of Polar Ice, Microscopy Research and Technique, 62, 62-69

Barret, M., Houdier, S., and Domine, F. (2011). Thermodynamics of the formaldehyde - water and formaldehyde - ice systems for atmospheric applications, J. Phys. Chem. A, 115, 307-317, doi:10.1021/jp108907u

Bartels-Rausch, T., Jacobi, H. W., Kahan, T. F., Thomas, J. L., Thomson, E. S., Abbatt, J. P. D., Ammann, M., Blackford, J. R., Bluhm, H., Boxe, C., Domine, F., Frey, M. M., Gladich, I., Guzman, M. I., Heger, D., Huthwelker, Th., Klan. P., Kuhs W. F., Maus, S., Moussa, S. G., McNeill, V. F., Newberg, J. T., Pettersson, J. B. C., Roeselova, M., and Sodeau, J. R. (2014). A review of air-ice chemical and physical interactions (AICI): Liquids, quasi-liquids, and solids in snow, Atmos. Chem. Phys., 14(3), 1587-1633, doi:10.5194/acp14-1587-2014

Becagli, S., Castellano, E., Cerri, O., Curran, M., Frezzotti, M., Marino, F., Morganti, A., Proposito, M., Severi, M., Traversi, R., Udisti, R. (2009). Methanesulphonic acid (MSA) stratigraphy from a Talos Dome ice core as a tool in depicting sea ice changes and southern atmospheric circulation over the previous 140 years, Atmos. Environ., 43(5), 1051-1058, doi:10.1016/j.atmosenv.2008.11.015

Benson, C. S.: Stratigraphic studies in the snow and firn of the Greenland ice sheet (1962). SIPRE Res. Rep. 70, 76-83

Chatfield, C. (1996). The analysis of time series: an introduction. Texts in statistical science. Chapman and Hall/CRC, Boca Raton.

Chesselet, R., Morelli, J., and Buat-Menard, P. (1972). Variations in ionic ratios between reference sea water and marine aerosols, J. Geophys. Res., 77(27), 5116-5131, doi:10.1029/JC077i027p05116

Criscitiello, A. S., Das, S. B., Evans, M. J., Frey, K. E., Conway, H., Joughin, I., Medley, B., and Steig, E. J. (2013). Ice sheet record of recent sea-ice behavior and polynya variability in the Amundsen Sea, West Antarctica, J. Geophys. Res. Ocean., 118(1), 118-130, doi:10.1029/2012JC008077

Criscitiello, A. S., Das, S. B., Karnauskas, K. B., Evans, M. J., Frey, K. E., Joughin, I., Steig, E. J., Mcconnell, J. R., and Medley, B. (2014). Tropical pacific influence on the source and transport of marine aerosols to West antarctica, J. Clim., 27(3), 1343-1363, doi:10.1175/JCLI-D-13-00148.1

Criscitiello, A. S. (2014). Amundsen Sea sea-ice variability, atmospheric circulation, and spatial variations in snow isotopic composition from new West Antarctic firn cores. Ph.D. Thesis. The Massachusetts Institute of Technology - Woods Hole Oceanographic Institution Joint Program in Oceanography/Applied Science and Engineering, MA, USA, 242 pp.

Cuffey, K.M., and Paterson, W. S. B. (2010). The Physics of Glaciers, 3 ${ }^{\text {rd }}$ Ed. Burlington, MA: ButterworthHeinemann/Elsevier.

Curran, M. A. J., and Jones, G. B. (2000). Dimethylsulfide in the Southern Ocean: Seasonality and flux, J. Geophys. Res., 105(D16), 20451-20459 
Curran, M. A. J., and Palmer, A. S. (2001). Suppressed ion chromatography methods for the routine determination of ultra low level anions and cations in ice cores, Journal of Chromatography A, 919(1), 1071132.

Curran, M. A. J., Palmer, A. S., van Ommen, T. D., Morgan, V., Phillips, K. L., McMorrow, A. J., and Mayewski, P. (2002). Post-depositional methanesulphonic acid movement on Law Dome and the effect of accumulation rate, Annals of Glaciology, 35, 333-339

Curran, M. A. J., van Ommen, T. D., Morgan, V. I., Phillips, K. L., and Palmer, A. S. (2003). Ice core evidence for Antarctic sea ice decline since the 1950s., Science, 302(5648), 1203-1206, doi:10.1126/science.1087888

Delmas, R. J., Wagnon, P., Goto-Azuma, K., Kamiyama, K., and Watanabe, O. (2003). Evidence for the loss of snow-deposited MSA to the interstitial gaseous phase in central Antarctic firn, Tellus, Ser. B Chem. Phys. Meteorol., 55(1), 71-79, doi:10.1034/j.1600-0889.2003.00032.x

Dickson, D. M. and Kirst, G. O. (1986). $\beta$-dimethylsulphoniopropionate, glycine betaine and homarine in the osmoacclimation of Platymonas subcordiformis. Planta, 167, 536-543

Domine, F., Albert, M., Huthwelker, T., Jacobi, H.-W., Kokhanovsky, A. A., Lehning, M., Picard, G., and Simpson, W. R. (2008). Snow physics as relevant to snow photochemistry, Atmos. Chem. Phys., 8, 171-208, https://doi.org/10.5194/acp-8-171-2008

Giese, A. L., and Hawley, R. L. (2015). Reconstructing thermal properties of firn at Summit, Greenland, from a temperature profile time series, J. of Glaciol., 61(227), 503-510, doi:10.3189/2015JoG14J204

Goodwin, B. P. (2013). Recent Environmental Changes on the Antarctic Peninsula as Recorded in an Ice Core from the Bruce Plateau, Ph. D. Thesis, The Ohio State University, OH, USA, 247 pp.

Herron, M. M., Langway Jr, C. C. (1980). Firn densication: An empirical model. J. Glaciology, 25, 373-385.

Hezel, P., Alexander, J. B., Bitz, C. M., Steig, E. J., Holmes, C. D., Yang, X., and Sciare, J. (2011). Modeled methanesulfonic acid (MSA) deposition in Antarctica and its relationship to sea ice, J. Geophys. Res. Atmos., 116(23), 1-18, doi:10.1029/2011JD016383

Hornung, E. W., Brackett, T. E., and Giauque, W. F. (1956). The Low Temperature Heat Capacity and Entropy of Sulfuric Acid Hemihexahydrate. Some Observations on Sulfuric Acid "Octahydrate", J. Am. Chem. Soc., 78 (22), 5747-5751, doi:10.1021/ja01603a009

Hougen, O.A., Watson, K.W., Ragtz, R.A. (1954). Chemical Process Principles (2nd Ed.), Wiley, New York, NY

Iizuka, Y., Horikawa, S., Sakurai, T., Johnson, S., Dahl-Jensen, D., Steffensen, J.P., and Hondoh, T., A. (2008). relationship between ion balance and the chemical compounds of salt inclusions found in the Greenland Ice Core Project and Dome Fuji ice cores, J. Geophys. Res., 113, 1-11, doi:10.1029/2007JD009018

Iizuka, Y., Ohno, H., Uemura, R., Suzuki, T., Oyabu, I., Hoshina, Y., Fukui, K., Hirabayashi, M. (2016). Spatial distributions of soluble salts in surface snow of East Antarctica, Tellus B, 68, 29285, http://dx.doi.org/10.3402/tellusb.v68.29285

Jourdain, B., and Legrand, M. (2001). Seasonal variations of dimethyl sulfide, dimethyl sulfoxide, sulfur dioxide, methanesulfonate, and non-sea-salt sulfate aerosols at Dumont d'Urville (December 1998 - July 1999), J. Geophys. Res., 106, 14,391-14,408, doi:10.1029/2000JD900841

Kim, J. S., and Yethiraj, A. (2008). A Diffusive Anomaly of Water in Aqueous Sodium Chloride Solution at Low Temperatures, J. Phys. Chem. B, 112, 1729-1735, DOI:10.1021/jp076710+

Kreutz, K. J., Mayewski, P. A., Whitlow, S. I., and Twickler, M. S. (1998). Limited migration of soluble ionic species in a Siple Dome, Antarctica, ice core, Ann. Glaciol., 27, 371-377

Kumar, P. (2006). Breakdown of the Stokes-Einstein relation in supercooled water, PNAS, 103(35), 1295512956, doi: $10.1073 /$ pnas.0605880103 
Kuo, M. H., Moussa, S. G., and McNeill, V. F. (2011). Modeling interfacial liquid layers on environmental ices, Atmos. Chem. Phys., 11, 9971-9982, https://doi.org/10.5194/acp-11-9971-2011

Langway, C.C., Jr., Osada, K., Clausen, H. B., Hammer, C.U, Shoji, H., and Mitani, A. (1994). New chemical stratigraphy over the last millennium for Byrd Station, Antarctica, Tellus, 46B, 40-51

Leck, C. and Persson, C. (1996). Seasonal and short-term variability in dimethyl sulfide, sulfur dioxide and biogenic sulfur and sea salt aerosol particles in the Arctic marine boundary layer during summer and autumn. Tellus, 48B(2), 272-299

Legrand, M., and Mayewski, P. (1997). Glaciochemistry of polar ice cores: A review, Rev. Geophys., 35(3), 219_ 243, doi:10.1029/96RG03527

Lemlich, R. (1978). A theory for the limiting conductivity of polyhedral foam at low density. J. Colloid Interface Sci. 64, 107-110

Lu, H., McCartney, S. A., and Sadtchenko, V. (2009). H/D exchange kinetics in pure and HCl doped polycrystalline ice at temperatures near its melting point: Structure, chemical transport, and phase transitions at grain boundaries, J. Chem. Phys., 130, 054501-054511, doi:10.1063/1.3039077

Marion, G. M., Farren, R. E. (1998). Mineral solubilities in the Na-K-Mg-Ca-Cl-SO4-H2O system: a reevaluation of the sulfate chemistry in the Spencer-Møller-Weare model, Geochim. Cosmochim. Acta, 63(9), $1305-1318$.

Maselli, O. J., Chellman, N. J., Grieman, M., Layman, L., McConnell, J. R., Pasteris, D., Rhodes, R. H., Saltzman, E., and Sigl, M. (2017). Sea ice and pollution-modulated changes in Greenland ice core methanesulfonate and bromine, Clim. Past., 13, 39-59, doi:10.5194/cp-2016-49.

McNeill, V. F., Grannas, A. M., Abbatt, J. P. D., Ammann, M., Ariya, P., Bartels-Rausch, T., Domine, F., Donaldson, D. J., Guzman, M. I., Heger, D., Kahan, T. F., Klan, P., Masclin, S., Toubin, C., and Voisin, D. (2012). Organics in environmental ices: Sources, chemistry, and impacts, Atmos. Chem. Phys., 12(20), 9653-9678, doi:10.5194/acp-12-9653-2012

Medley, B., Joughin, I., Smith, B. E., Das, S. B., Steig, E. J., Conway, H., Gogineni, S., Lewis, C., Criscitiello, A. S., McConnell, J. R., van den Broeke, M. R., Lenaerts, J. T. M., Bromwich, D. H., Nicolas, J. P., and Leuschen, C. (2014). Constraining the recent mass balance of Pine Island and Thwaites glaciers, West Antarctica, with airborne observations of snow accumulation, The Cryosphere, 8, 1375-1392, doi:10.5194/tc-8-1375-2014

Medley, B., Joughin, I., Das, S. B., Steig, E. J., Conway, H., Gogineni, S., Criscitiello, A. S., McConnell, J. R., Smith, B. E., van den Broeke, M. R., Lenaerts, J. T. M., Bromwich, D. H., and Nicolas, J. P. (2013). Airborne-radar and ice-core observations of annual snow accumulation over Thwaites Glacier, West Antarctica confirm the spatiotemporal variability of global and regional atmospheric models, Geophys. Res. Lett., 40, 3649-3654

Meyerson, E. A., Mayewski, P. A., Kreutz, K. J., Meeker, L. D., Whitlow, S. I., and Twickler, M. S. (2002). The polar expression of ENSO and sea-ice variability as recorded in a South Pole ice core, Ann. Glaciol., 35, 430-436, doi:10.3189/172756402781817149

Minikin, A., Wagenbach, D., Graf, W., and Kipfstuhl, J. (1994). Spatial and seasonal variations of the snow chemistry at the Filchner-Ronne Ice Shelf, Antarctica, J. Geophys. R., 20, 283-290

Moore, J. C., Grinsted, A., Kekonen, T., and Pohjola, V. (2005). Separation of melting and environmental signals in an ice core with seasonal melt, Geophys. Res. Lett., 32, L10501, doi: 101029/2005GL023039

Mulvaney, R., Wolff, E. W., and Oates, K. (1998). Sulphuric acid at grain boundaries in Antarctic ice, Nature, $331,247-249$

Mulvaney, R., and Peel, D. A. (1988). Anions and cations in ice cores from Dolleman Island and the Palmer Island plateau, Antarctic Peninsula, Ann. Glaciol., 10, 121-125 
Mulvaney, R., Pasteur, E. C., Peel, D. A., Saltzman, E. S., and Whung, P. Y. (1992). The ratio of MSA to nonsea-salt sulphate in Antarctic Peninsula ice cores, Tellus B, 44(4), doi:10.3402/tellusb.v44i4.15457

Nye, J. F. (1963). Correction factor for accumulation measured by the thickness of the annual layers in an ice sheet. J. Glaciol., 4(36), 785-788

Nye, J. F., and Frank, F. C. (1973). Hydrology of the intergranular veins in a temperate glacier, in International Association of Scientific Hydrology, Pub. 95 (Symposium at Cambridge 1969: Hydrology of Glaciers), pp. 157-161

Nye, J. F. (1991). Thermal behaviour of glacier and laboratory ice. J. Glaciol., 37 (127), 401-413

Osterberg, E. C., Hawley, R. L., Wong, G., Kopec, B., Ferris, D., and Howley, J. (2015). Coastal ice-core record of recent northwest Greenland temperature and sea-ice concentration, J. Glaciol., 61(230), 1137-1146, doi:10.3189/2015JoG15J054.

Pasteris, D. R., Mcconnell, J. R., Das, S. B., Criscitiello, A. S., Evans, M. J., Maselli, O. J., Sigl, M., and Layman, L. (2014). Seasonally resolved ice core records from West Antarctic indicate a sea ice source of sea-salt aerosol and a biomass burning source of ammonium, J. Geophys. Res. Atmos., 119(3), 9168-9182, doi:10.1002/2013JD020720.

Pasteur, E. C., and Mulvaney, R. (2000). Migration of methane sulphonate in Antarctic firn and ice, J. Geophys. Res., 105, 11525-11534, doi:10.1029/2000JD900006

Pasteur, E. C., and Mulvaney, R. (1999). Laboratory study of the migration of methane sulphonate in firn, J. Glaciol., 45(150), 214-218, doi:doi:10.3189/002214399793377202.

Porter, S. E., Parkinson, C. L., and Mosley-Thompson, E. (2016). Bellinghausen Sea ice extent recorded in an Antarctic Peninsula ice core, J. Geophys. Res. Atmos., 121, 13886-13900, doi:10.1002/2016JD025626.

Rankin, A. M., Wolff, E. W., and Martin, S. (2002). Frost flowers - implications for tropospheric chemistry and ice core interpretation, J. Geophys. Res., 107(D23), 4683, doi:10.1029/2002JD002492

Rempel, A. W., Waddington, E. D., Wettlaufer, J. S., and Worster, M. G. (2001). Possible displacement of the climate signal in ancient ice by premelting and anomalous diffusion., Nature, 411, 568-571, doi:10.1038/35079043.

Rempel, A. W., Wettlaufer, J. S., and Waddington, E. D. (2002). Anomalous diffusion of multiple impurity species: Predicted implications for the ice core climate records, J. Geophys. Res., 107, 1-12, doi:10.1029/2002JB001857

Riche, F., Bartels-Rausch, T., Schreiber, S., Ammann, M., and Schneebeli, M. (2012). Temporal evolution of surface and grain boundary area in artificial ice beads and implications for snow chemistry, J. Glaciol., 58, 815-817, doi:10.3189/2012JoG12J058

Roberts, J. L., van Ommen, T. D., Curran, M. A. J., and Vance, T. R. (2009). Methanesulphonic acid loss during ice-core storage: Recommendations based on a new diffusion coefficient, J. Glaciol., 55(193), 784-788, doi:10.3189/002214309790152474

Rolnick, L. S. (1954). The stability of gypsum and anhydrite in the geologic environment, Ph.D. Thesis, Massachusetts Institute of Technology, MA, USA, 147 pp.

Sakurai, T., Ohno, H., Genceli, F. E., Horikawa, S., Iizuka, Y., Uchida, T., and Hondoh, T. (2010). Magnesium methanesulfonate salt found in the Dome Fuji (Antarctica) ice core, J. Glaciol., 56(199), 837-842, doi:10.3189/002214310794457335

Saltzman, E. S., Savoie, D. L., Zika, R. G., and Prospero, J. M. (1983). Methane sulfonic acid in the marine atmosphere, J. Geophys. Res., 88, 10,897-10,902

Sinclair, K. E., Bertler, N. A. N., and van Ommen, T. D. (2012). Twentieth-century surface temperature trends in the western Ross Sea, Antarctica: Evidence from a high-resolution ice core, J. Clim., 25(10), 3629-3636, 
doi:10.1175/JCLI-D-11-00496.1.

Sinclair, K. E., Bertler, N. A. N., Bowen, M.M., and Arrigo, K. R. (2014). Twentieth century sea-ice trends in the Ross Sea from a high-resolution, coastal ice-core record, Geophys. Res. Lett., 41, 3510-3516, doi:10.1002/2014GL059821.

Smith, B. T., van Ommen, T. D., and Curran, M. A. J. (2004). Methanesulphonic acid movement in solid ice cores, Ann. Glaciol., 39, 540-544, doi:10.3189/172756404781814645

Spaulding, N.E., Meese, D.A., and Baker, I. (2011). Advanced microstructural characterization of four East Antarctic firn/ice cores. J. Glaciol., 57(205), 796-810

Stephen, H. and Stephen, T. (1963). Solubilities of Inorganic and Organic Compounds. Vol. (1), Oxford, Pergamun Press.

Thibert, E., and Dominé, F. (1997). Thermodynamics and Kinetics of the Solid Solution of $\mathrm{HCl}$ in Ice, J. of Phys. Chem. B, 101(18), 3554-3565, doi: 10.1021/jp962115o.

Thibert, E., and Dominé, F. (1998). Thermodynamics and Kinetics of the Solid Solution of $\mathrm{HNO}_{3}$ in Ice, J. of Phys. Chem. B, 102 (22), 4432-4439, doi: 10.1021/jp980569a.

Thomas, E. R., and Abram, N. (2016). Ice core reconstruction of sea ice change in the Amundsen-Ross Seas since 1702 AD, Geophys. Res. Lett., 43, doi:10.1002/2016GL068130.

Turner, S. M., Nightingale, P. D., Broadgate, W., and Liss, P. S. (1995). The distribution of dimethylsulfide and dimethylsulphoniopropionate in Antarctic waters and ice, Deep Sea Res., Part II, 42, 1059-1080

Wagenbach, D., Graf, W., Minikin, A., Trefzer, U., Kipestuhl, J., Oerter, H., and Blindow, N. (1994). Reconnaissance of chemical and isotopic firn properties on top of Berkner Island, Antarctica, Ann. Glaciol., 20, 307-312.

Wagnon, P., Delmas, R. J. and Legrand M. (1999). Loss of volatile acid species from upper firn layers at Vostok, Antarctica, J. Geophys. Res., 104(D3), 3423, doi:10.1029/98JD02855

Weißbach, S., Wegner, A., Opel, T., Oerter, H., Vinther, B. M., and Kipfsuhl, S. (2016). Spatial and temporal oxygen isotope variability in northern Greenland - implications for a new climate record over the past millennium, Clim. Past, 12, 171-188, doi:10.5194/cp-12-171-2016

Welch, K. A., Mayewski, P. A., and Whitlow, S. I. (1993). Methanesulfonic acid in coastal Antarctic snow related to sea-ice extent, Geophys. Res. Lett., 20(6), 443-446, doi:10.1029/93GL00499

Weller, R. (2004). Postdepositional losses of methane sulfonate, nitrate, and chloride at the European Project for Ice Coring in Antarctica deep-drilling site in Dronning Maud Land, Antarctica, J. Geophys. Res., 109(D7), 1-9, doi:10.1029/2003JD004189, 2004.

Wettlaufer, J. S., and Worster M. G. (2006). Premelting Dynamics, Annu. Rev. Fluid Mech., 38(1), 427-452, doi:10.1146/annurev.fluid.37.061903.175758

Wolff, E.W. (1996). Location movement and reactions of impurities in solid ice, in Chemical Exchange Between the Atmosphere and Polar Snow, NATO ASI Ser., Ser. 1, Global Environmental Change, vol. 43, pp 541-560, edited by E.W.Wolff and R.C. Bales, Springer-Verlag, New York

Yoch, D. C. (2002). Dimethylsulfoniopropionate: Its Sources, Role in the Marine Food Web, and Biological Degradation to Dimethylsulfide, Society, 68 (12), 5804-5815, doi:10.1128/AEM.68.12.5804 


\title{
3. Industrial-era decline of subarctic Atlantic productivity
}

This chapter was originally published as: Osman, M. B., Das, S. B., Trusel, L. D., Evans, M. J., Fischer, H., Grieman, M. M., Kipfstuhl, S., McConnell, J. R., Saltzman, E. S. (2019). Industrial-era decline in subarctic Atlantic productivity. Nature, 569(7757). https://doi.org/10.1038/s41586-019-1181-8. Used with permission as granted in the original copyright agreement.

\begin{abstract}
Marine phytoplankton play a critical role in modulating marine-based food webs, fishery yields, and the global drawdown of atmospheric $\mathrm{CO}_{2}$. Due to sparse measurements prior to $21^{\text {st }}$ century satellite monitoring, however, little is known of the long-term response of planktonic stocks to climate forcing. Here we produce the first continuous, multi-century record of subarctic Atlantic marine productivity, showing a marked $10 \pm 7 \%$ decline has occurred across this highly-productive ocean basin over the last two centuries. We support this conclusion through the application of a novel marine-productivity proxy, established using a unique signal of planktonic-derived aerosol commonly identified across an array of Greenlandic ice cores. Utilizing contemporaneous satellite-era observations, we demonstrate this signal's use as a robust and high-resolution proxy for spatially-integrated marine productivity variations. We show that the initiation of declining subarctic Atlantic productivity broadly coincides with the onset of Arctic surface warming, and that productivity strongly covaries with regional seasurface temperatures and basin-wide gyre circulation strength over recent decades. Taken together, our results suggest the industrial-era productivity decline may be evidence of the predicted collapse of northern Atlantic planktonic stocks in response to a weakened Atlantic Meridional Overturning Circulation (AMOC). Continued AMOC weakening, as projected for the $21^{\text {st }}$ century, may therefore result in further productivity declines across this globally-relevant region.
\end{abstract}




\subsection{Main text}

The subarctic Atlantic $\left(50-65^{\circ} \mathrm{N}, 60-10^{\circ} \mathrm{W}\right)$ comprises one of the world's most biologically productive seasonal phytoplankton blooms (Sverdrop et al., 1953; Boyce et al., 2010; Behrenfeld et al., 1997, 2014; Barton et al., 2016). Bloom magnitude varies annually, in response to controls such as the timing and abundance of light and nutrients in the upper ocean (Sverdrop et al., 1953; Behrenfeld et al., 1997), and predator-prey coupling dynamics (Behrenfeld et al., 1997, 2014). These biophysical controls, in turn, vary in response to underlying physical drivers that are sensitive to long-term changes in upperocean climatic forcing, such as the mixed layer depth (MLD), sea-surface temperature (SST), baroclinicity, and wind.

Over the preceding $\sim 200$ years (i.e. the industrial-era) the northern Atlantic has undergone numerous climatic perturbations outside the range of naturally forced variability, resulting in widespread surface warming (Abram et al., 2016), AMOC slowdown (Rahmstorf et al., 2015; Caesar et al., 2018; Thornalley et al., 2018), sea ice decline (Kinnard et al., 2011), and accelerating Greenland Ice Sheet (GrIS) runoff (Trusel et al., 2018). Contemporaneous estimates of primary productivity are less well resolved. Satellite-derived planktonic biomass concentrations, extending back only to late1997 (and intermittently to 1979; Behrenfeld et al., 1997; Boyce et al., 2010), do not reveal significant decadal-scale trends, but rather, modest productivity variability over the first two decades of $21^{\text {st }}$ century monitoring (Fig.'s S3-1 and S3-2; Appendix 2). Earlier spatiotemporally sparse sources, including ship-based ocean color (Behrenfeld et al., 1997; Boyce et al., 2010) and planktonic abundance observations (Hátún et al., 2009; Fig. S3-3; Appendix 2), however, hint at a longer-term, $20^{\text {th }}$ century decline. To date, no spatially-reconciled, temporally-resolved reconstruction of basin-scale primary productivity exists over the pre- to post-industrial transition. This limits our ability to quantify climatic impacts on subarctic Atlantic ecosystems, and contextualize model-based predictions of future ecologic responses to anthropogenic forcing (Moore et al., 2018).

Here we use records of a marine-derived biogenic aerosol (methanesulfonic acid concentration, [MSA]) from GrIS ice cores to reconstruct annual subarctic Atlantic productivity variability over the preceding $\sim$ two and a half centuries. At high latitudes, MSA is solely produced as an oxidative byproduct from oceanic dimethylsulfide (DMS) emissions (Legrand et al., 1997). DMS, in turn, is linked to several planktonic life-cycle processes involving dinoflagellate, haptophyte (including coccolithophores) and, to a lesser extent, diatom, chrysophyte, and prasinophyte assemblages (Stefels et al., 2007). Notwithstanding uncertainties in the long-term feedbacks between 
DMS emissions and climate (Charlson et al., 1987), we demonstrate that GrIS-[MSA] records provide a first order proxy for regional ocean-atmosphere fluxes of DMS (Legrand et al., 1997; Section 3.2.4), which are tightly coupled to changes in nearby marine productivity (Polashenski et al., 2018).

Although interior Greenlandic ice core [MSA] records are known to undergo post-depositional vertical migration (Osman et al., 2019), we assume hereafter that potential migration-based "skewing" of the original [MSA]-signal can be largely minimized by combining (e.g., time-averaging) several GrIS[MSA] records. Several considerations underlie this assumption. First, MSA migration directionality is not systematic, and may occur in either the (atmosphere-oriented) up or down direction depending primarily on local cationic soluble impurity concentration gradients (Osman et al., 2017). Moreover, MSA migration is known to be largely mitigated at ice core sites comprising relatively high annual snow-accumulation rates and low cationic-impurity concentrations, conditions which typify much of the GrIS interior. Finally, despite contentions of post-depositional volatile losses of MSA have been reported at high-acidity and low accumulation sites in Antarctica (nominally, $<0.10 \mathrm{~kg} \mathrm{~m}^{-2} \mathrm{yr}^{-1}$; Weller et al., 2004), such losses are likely largely inhibited across the GrIS, where relatively high accumulation rates, as well as low acidity summertime layers, prevail (Table S3-1).

Provided these considerations, we combine 12 high-resolution [MSA] records (Section 3.2.1) to examine the covariation of [MSA] across the GrIS (Table S3-1). To physically constrain potential DMS emission source regions across the 12 ice core sites, we conduct daily atmospheric backtrajectory analyses during the time of MSA summertime maximum, June-July-August (JJA; Table S31), over a multi-decadal time-frame (AD 1948-2013; Section 3.2.3). A conspicuous multi-century decline in [MSA] is evident in nearly all records (Fig. 3-1a), irrespective of their GrIS locations and primary summertime airmass-trajectory pathways - trending from predominantly southeasterlydominated (Irminger Sea origin) atmospheric influence at southern-situated GrIS sites to southwesterly-dominated (Labrador Sea origin) influence at northern-situated sites (Fig. 3-1b; Fig.'s S3-4 and S3-5). Moreover, when averaging the 12 records into either Irminger Sea- $(n=7$ sites; Fig. 3-1b) or Labrador Sea-dominated constituents ( $n=5$ sites), we find significant GrIS-[MSA] covariation down to annual-timescales ( $p<0.0001$; Fig. S3-6; Appendix 2).

This strong coherence we observe between GrIS-[MSA] records suggests that time-variability of MSA deposition across the GrIS is dominated by a common, large-scale mode of North Atlantic DMS production and emissions. Using a probabilistic principal component analysis (PCA) methodology, we extract this common signal of GrIS-[MSA] variability over the period A.D. 17672013 (Section 3.2.2). The leading principal component, [MSA]-PC1, robustly captures the multi- 
century decline in industrial-era [MSA] observed across the individual records, while significantly $(p=$ 0.002) explaining nearly half of the GrIS-[MSA] variability (median/mode at $\sim 44 \%$; Fig. 3-2a). Correlation of the [MSA] records to the resultant [MSA]-PC1 signal furthermore reveals each record to be significantly and positively related ( $\phi<0.1$; Section 3.2.2; Table S3-1), with centrally-situated GrIS sites exhibiting the strongest covariation with [MSA]-PC1 (Fig. 3-2a). Exploiting this spatialloading pattern, we statistically-composite the 12 sites' back-trajectory results (Section 3.2.3; Fig.'s S34 and S3-5; Appendix 2) underscoring the west-central to northeastern (NE) subarctic Atlantic basin as the most probable source of GrIS-deposited MSA (Fig. 3-2b,c). Significantly, this MSA source region, centered over the highly-productive (Hátún et al., 2009, Behrenfeld et al., 2014) and climatically-sensitive (Hátún et al., 2005; Rahmstorf et al., 2015; Abram et al., 2016; Caesar et al., 2018; Thornalley et al., 2018) Irminger and Labrador Seas proximal to the upwind Greenland coast, overlaps with the greatest Atlantic-sector surface JJA DMS seawater concentrations (Lana et al., 2011), [DMS $\left.S_{\mathrm{sw}}\right]$ (and, relatedly, DMS-emissions; Fig 3-3a).

Strong spatial coherence further exists between summertime $\left[\mathrm{DMS}_{\mathrm{sw}}\right]$ and satellite-derived estimates of net primary productivity (NPP) from the chlorophyll- $\alpha$ (Chl- $\alpha)$ dependent Vertically Generalized Production Model (VGPM; Behrenfeld et al., 1997; Appendix 2) across the northern Atlantic sector, despite differences in the collection and spatial scalability of these two data sources (Appendix 2; Fig. 3-3a). The observed similarity suggests that past variations in northern Atlantic DMS production, as inferred from [MSA]-PC1, also provide a signal of past productivity variations across this sector, given time-averaged scalability in the ocean-atmosphere emission rate of DMS to DMS $_{\text {sw }}$ production (Lana et al., 2011). Indeed, correlation of VGPM-derived NPP against [DMS sw] measurements from the NOAA Global Surface Seawater DMS Database (Lana et al., 2011; Section 3.2.4) supports a strong spatiotemporal association $(r=0.75 ; p<0.0001)$ between subarctic Atlantic productivity and the magnitude of DMS production (Fig. 3-3b), a relationship well above globallyintegrated values (Fig. S3-7c; Appendix 2). A similar regression analysis against independently-derived counts of DMS-producing diatom, dinoflagellate, and coccolithophore relative abundance from the Continuous Plankton Recorder (CPR) ship-survey (Section 3.2.5) also yields significant relationships with $\left[\mathrm{DMS}_{\mathrm{sw}}\right]$ in all three functional groups $(\not<0.005$; Fig. S3-7d,e,f), implying that variations in DMS production and emissions across the subarctic Atlantic are well representative of contemporaneous broad-scale changes in planktonic biomass and productivity.

The above back-trajectory and correlation analyses are connected through an empirical orthogonal function (EOF) analysis of satellite NPP, which reveals the leading mode of summertime 
and annual NPP-variability (NPP-PC1; 20\% and 24\% explained-variance, respectively) to be closelyaligned with [MSA]-PC1 over multiannual timescales (Fig. 3-3d), while also remaining notably consistent with spatially-integrated summertime and annual NPP yields $(r=0.75$ and 0.91 , respectively; Fig. S3-2). This latter similarity is underscored in Figure 3-3c by the broadly-coherent loading pattern of NPP-PC1 (EOF1), spatially-linking marine productivity across a broad portion of the Irminger, Labrador, as well as western-Icelandic Seas (Fig. 3-3c). Importantly, the analysis also reveals the extrema of NPP-EOF1 to directly overlie the [MSA]-PC1 airmass density maxima and altitude minima of Figures 3-2b and 3-2c, respectively. Provided moderate stability in the spatial character of productivity variability during the past (and the underlying phytoplankton assemblages comprising it), this independently confirms that DMS-emissions from this region, once converted to MSA in the atmosphere and deposited atop the GrIS, are ideally suited for reconstructing broad-scale subarctic Atlantic productivity variations.

Results from our combined back-trajectory (Fig. 3-2b,c), correlation (Fig. 3-3b; Fig. S3-7), and EOF (Fig. 3-3c) analyses support our use of the [MSA]-PC1 signal (Fig. 3-2a) as an index for past marine productivity variations across the subarctic Atlantic basin. Our ice core-based productivity index is remarkably consistent with the $20^{\text {th }}$ century decline in (basin-scale) North Atlantic planktonic stocks previously reported by Boyce et al. (2010; $p<0.001$; Fig. S3-8a), as well as broadly congruent with several CPR-based indices of subarctic Atlantic planktonic abundance (Fig. 3-4a; Section 3.2.4; Fig. S3-3). Notably, all records show a pronounced decline over the second half of the $20^{\text {th }}$ century, followed by recent intermittent (likely natural-decadal) productivity variability that has so-far characterized the contemporary satellite-era (Fig. 3-4a; Fig. S3-2). Moreover, our new multi-century productivity record significantly extends prior spatiotemporally-limited ship-based observations beyond the mid-20 ${ }^{\text {th }}$ century (Boyce et al., 2010), suggesting the $20^{\text {th }}$ century decline is part of a much longer-term trend.

The additional temporal context of our productivity index allows us to investigate subarctic Atlantic productivity responses to changes in atmospheric and oceanic forcing over recent decades, here characterized by indices of the North Atlantic Oscillation (Jones et al., 1997; Ortega et al., 2015; NAO) and Subpolar Gyre (SPG) circulation strength (Hátún et al., 2005). Using correlation analysis (Fig. S3-8a; Section 3.2.6), we find the NAO is only weakly related to our reconstructed bioproductivity variations while, in contrast, SPG strength indicates significant negative influence over decadal timescales as previously indicated from sparse ship-based color data (Hátún et al., 2009). Modeling studies suggest that during weakened (Born et al., 2013; Sgubin et al., 2017) and (or) 
contracted (Hátún et al., 2005) SPG states, wintertime MLD's deepen across the central-NE subarctic Atlantic and shoal across the Labrador Seas (Born et al., 2013). Thus, in addition to its first-order inverse effect on NE Atlantic SST variability (Hátún et al., 2005; Fig. 3-4a), this could explain how a weak SPG, by enhancing wintertime deep-water nutrient replenishment to the euphotic zone (Sverdrop et al., 1953; Schmittner et al., 2005; Barton et al., 2016; Moore et al., 2018) or by delaying the seasonal-onset of predatorial grazing cycles (Behrenfeld et al., 2014) across the ecologicallyproductive central-NE Atlantic (Hátún et al., 2009; Fig. 3-3a), could lead to increases in NPP as observed by our results.

Differential change-point analysis (Abram et al., 2016; Trusel et al., 2018) of our [MSA]-PC1 record suggests declining subarctic Atlantic productivity began in A.D. $1816 \pm 11$ years (Fig. 3-4a; Section 3.2.7), broadly consistent with the onset of regional surface temperature warming (Abram et al., 2016). Applying a calibration derived from the relationship between [MSA]-PC1 and the leading mode of $21^{\text {st }}$ century satellite NPP (Fig. 3-3d; Fig. S3-2), we calculate an estimated $\sim 10 \pm 7 \%$ decline $( \pm 2 \sigma$; Fig. 3-4b) in contemporary subarctic Atlantic NPP yields since the industrial-era onset. Despite the uncertainties of this estimate, arising from the short time-span of satellite NPP estimation (Fig. 34a) and limited GrIS-[MSA] data-availability during this period (Fig. 3-3d; Section 3.2.2), the onset of declining subarctic Atlantic productivity appears temporally-consistent with the $(\sim 15 \%)$ decline in industrial-era Atlantic thermohaline overturning strength (i.e., AMOC) recently inferred from Labrador and Irminger basin marine sediments (Thornalley et al., 2018). We similarly observe strong multidecadal- to centennial-scale correspondence $(p<0.001)$ between our productivity index and a separate, high-resolution terrestrial proxy-based reconstruction (Rahmstorf et al., 2015) of AMOC predicated upon NE Atlantic upper ocean heating anomalies (Fig. 3-4a; Fig. S3-9; Appendix 2). These results, suggesting a positive relationship between productivity, subarctic Atlantic SSTs and large-scale thermohaline variability across decadal-scale and longer timescales, contrast model-based contentions of a positive (i.e., reinforcing) influence of SPG-circulation strength on both subarctic Atlantic overturning (Sgubin et al., 2017) and, by extension, productivity.

The strong observed coherence between productivity and AMOC strength, moreover, supports a previous model-based hypothesis (Schmittner et al., 2005) that a sustained, industrial-era slowdown of AMOC (Rahmstorf et al., 2015; Caesar et al., 2018; Thornalley et al., 2018) would lead to dramatically reduced planktonic yields across the northern Atlantic. In particular, both [MSA]-PC1 and AMOC exhibit corresponding multicentury-scale (Rahmstorf et al., 2015; Thornalley et al., 2018) lows during the 1980's to 1990's. This time period coincides with a massive accumulation of freshwater 
$\left(\sim 15,000 \mathrm{~km}^{3}\right.$ from 1965-1990) into the subarctic Atlantic basin following the Great Salinity Anomaly of the late-1960's (Curry and Muritzen, 2005; Fig. 3-4a). According to the relationships illuminated by our results, the decrease in upper-ocean densities associated with this event, hypothesized to have weakened deep-water formation across the Labrador and Irminger Seas (Rahmstorf et al., 2015; Curry et al., 2005) may also have led to a diminishing of northern Atlantic planktonic stocks, presumably either through long-term shoaling of wintertime MLDs and the gradual diminishing of euphotic nutrient concentrations (Schmittner et al., 2005; Barton et al., 2016; Moore et al., 2018), or through first-order thermal influences (Barton et al., 2016; Behrenfeld et al., 1997). Further, the onset of industrial-era Arctic sea ice decline and elevated GrIS runoff, commencing several decades after our productivity decline and accelerating into present (Kinnard et al., 2011; Trusel et al., 2018), suggests that a long-term freshening of NE subarctic Atlantic surface waters - similarly implicated in driving the industrial-era AMOC decline (Barton et al., 2016; Rahmstorf et al., 2015; Caesar et al., 2018; Thornalley et al., 2018) - may have contributed in sustaining the industrial-era productivity decline over the late $19^{\text {th }}$ and $20^{\text {th }}$ centuries. Clearly, more work is needed to understand these complex relationships.

Our ice core-based index of subarctic Atlantic bioproductivity highlights the sensitivity of marine-based autotrophic-ecosystems to industrial-era forcing and provides context for projected future ecologic changes (Rahmstorf et al., 2015). Although previous ship-based (Boyce et al., 2010; Hátún et al., 2009) and satellite-derived reconstructions suggested an early $21^{\text {st }}$ century reversal in the $20^{\text {th }}$ century subarctic Atlantic productivity decline (Fig. 3-4a), results from our [MSA]-PC1 proxy show the decline on which this intermittent $21^{\text {st }}$ century increase is superimposed is much longer than previously observed (Boyce et al., 2010), and may still be ongoing. Monitoring of the AMOC at $26.5^{\circ} \mathrm{N}$ since 2004 has shown a decade-long decline in meridional heat transport, decreasing as much as 10 times faster than model-predicted slowdowns (Srokrosz et al., 2015). Given the multiyear time-lag required of Atlantic-wide mixing (Sverdrop et al., 1953; Hátún et al., 2005), as well as the ongoing, nonlinear rise in Greenland runoff (Trusel et al., 2018) believed to contribute to subarctic Atlantic freshening and AMOC slowdown over multidecadal to centennial timescales (Rahmstorf et al., 2015; Bakker et al., 2016; Thornalley et al., 2018), we speculate declining subarctic Atlantic productivity will characterize the coming decades with important implications on future atmospheric carbon drawdown (Takahashi et al., 2009) and northern Atlantic fisheries (Stock et al., 2017). 


\subsection{Methods}

\subsection{1 [MSA] record collection, analysis, and preprocessing}

Twelve methanesulfonic acid (MSA; $\mathrm{CH}_{3} \mathrm{SO}_{3} \mathrm{H}$ ) concentration ([MSA]) ice core records were compiled from sites situated on the Greenland Ice Sheet (GrIS; $n=12$ records). MSA is measured at trace concentrations in polar ice via its constituent anion, methanesulfonate $\left(\mathrm{MS}^{-} ; \mathrm{CH}_{3} \mathrm{SO}_{3}^{-}\right.$; Whung et al., 1994; Saltzman et al., 1997). The five previously published [MSA] records used in this compilation were measured using either conventional ion-chromatography (IC) techniques (20D, Whung et al., 1994; NGRIP, Andersen et al., 2004; GRIP93a, Legrand et al.,1997) or electrospray ionization with triple quadrupole mass spectrometry (ESI-MS-MS; Summit2010 and TUNU; Maselli et al., 2017). Specific details on the measurement techniques can be found in the original studies (Table S3-1). Six out of seven of the remaining (previously unpublished) [MSA] records were measured using IC. Measurement of MS in the GC record (Trusel et al., 2018) was conducted at Wheaton College (MA, USA) with analytical and core-sampling procedures identical to those described in Criscitiellio et al. (2013). Records derived from the Northern Greenland Traverse (NGT-B16, -B18, -B20, -B21, and-B26) were analyzed at the Alfred-Wegener-Institute following the methodology of Fischer et al. (1998). The remaining unpublished [MSA] record, D4, was also analyzed via ESI-MS-MS at the Desert Research Institute following Maselli et al. (2017).

Records were selected with the criterion that the records must i) be of moderate to high temporal resolution (measured at $\leq 3$ years sample ${ }^{-1}$; note $10 / 12$ records exist at $\leq 1$ year resolution; Fig. 3-1a), ii) be well-dated ( $<5$ year estimated uncertainty at the deepest portions of the records presented), and iii) represent $>100$ years of continuous length within the period A.D. 1767-2013. Aspects of all ice cores have been previously published, such that information on each ice core's dating methodology can be found within references listed in Table S3-1. Prior to analysis of the [MSA] records, each was linearly interpolated to a resolution of one year. The period of common overlap for all 12 records is A.D. 1821 - 1985. It is assumed that dating uncertainties amongst records are approximately normally distributed, such that dating inconsistencies are effectively averaged out during dimensional reduction.

Note that a decision was made not to analyze MSA fluxes. This was due primarily to the lack of high-resolution accumulation data for all 12 sites. However, recent century-scale reconstructions of GrIS accumulation rate, derived from both inland (Andersen et al., 2006; Mernild et al., 2014) and near-coastal (Mosley-Thompson et al., 2005) ice cores, do not generally support evidence for 
spatiotemporally-synchronous shifts in accumulation across Greenland, nor to our knowledge regional multicentury accumulation increases necessary to promote (via dilution) the multi-century decreases in the [MSA] records presented here. Similarly, although MSA is highly hygroscopic and thus generally believed to be primarily wet-deposited on the GrIS (Whung et al., 1994), due to the lack of highresolution accumulation data we are inhibited from quantitatively discerning the precise partitioning of [MSA] between wet and dry deposition at most (11/12, void 20D) sites. Nonetheless, our necessary assumption of negligible long-term changes in MSA depositional partitioning when spatially-averaged across the GrIS appears valid, given in particular the strong temporal covariation in [MSA] across differing GrIS moisture source regions (Fig. S3-6; Table S3-1).

\subsubsection{Extraction of [MSA]-PC1 and uncertainty estimation}

We used an Empirical Orthogonal Function- (EOF) based data infilling routine (Beckers and Rixon, 2003) to infill missing values in the [MSA] records prior to signal extraction. In our study, missing values occur at the extremities of the records, and thus represent records that either i) were collected prior to A.D. 2013, or ii) did not extend as deep as A.D. 1767. Under the criterion that the oldest PC1 age (i.e., A.D. 1767) represents the oldest age where $>75 \%$ of Greenlandic [MSA] records remain, $<8 \%$ of data points amongst the 12 records required infilling. For the more recent portion of the PC1 series, we relaxed our $75 \%$ record-retention criterion to enable greater temporal-overlap with satellite observations (c. 1998). While this relaxation did, in general, invoke a trade-off with declining precision

in the [MSA] signal extraction for satellite-interval years (as encapsulated by slightly enlarged [MSA]PC1 confidence interval widths; Fig.'s 3-2a and 3-3d), we nonetheless expect our PC1 extraction to be robust given the strong satellite-era coverage of the Summit2010 record, the largest variancecontributor to [MSA]-PC1 (Table 1).

The EOF data infilling procedure (Beckers and Rixon, 2003) accounts for covariability between, as well as autocovariance within, individual MSA records, such that strong covariability between two records during a period of common overlap should result in imputed values of comparable covariance between the two records, should one of the records require infilling during a time period where data exists in the other. By such, the autocovariance structure of imputed values within that record should jointly reflect the autocovariance of that record's measured (that is, nonmissing) values. The data infilling procedure (Beckers and Rixon, 2003) was conducted as follows: all records were standardized to unit variance and centered to mean zero over their period of common overlap, 1821 - 1985 A.D. Missing values were set to zero (an unbiased apriori value), and the resultant 
matrix decomposed into left (temporal EOFs) and right (spatial EOFs) singular vectors using the method of Singular Value Decomposition (SVD). The missing (zero) values were then recovered by replacing the zero values with infilled values of the reconstructed [MSA] data matrix, following truncation of both EOF vector spaces. The number of EOFs retained for data infilling was obtained using a Monte Carlo cross-validation approach, whereby 5\% of the [MSA] data points were withheld at random and iteratively reconstructed with a progressively less truncated EOF vector space until a specified convergence criterion was met (RMSE $<10^{-8}$; Beckers and Rixon, 2003).

We tested the sensitivity of the cross-validation procedure across a large number of data infilling procedures using the [MSA] Greenlandic array, and found that EOF-based data infilling (Beckers and Rixon, 2003) routinely and robustly reproduced much of the low frequency variance of the [MSA] dataset across separate tests. However, slight variations in the magnitude of imputed values could occur between tests, an expected result due to the finite size of the [MSA] dataset used for cross validation. More specifically, variations in the optimal number of EOFs retained for the imputation of missing values could lead to small differences in the fraction of the original variance restored in the imputed [MSA] values between tests. In our case, the number of retained EOF's varied most often between $2-4$, representing $\sim 50-65 \%$ of the [MSA] variance. Since the amount of variance restored back into the imputed data will always be less than the original data, a method was required to restore remaining variance. To do so, we adopted an approach similar to Kinnard et al. (2011), whereby for each test we divided the infilled [MSA] data matrix into "signal" and "noise" components. The signal represents the "retained" [MSA] data matrix, constructed by applying the inverse EOF transform to the [MSA] dataset using only as many EOF's as was determined to optimally construct the imputed values. Conversely, the noise represents the "residual" [MSA] data matrix constructed by applying the inverse EOF transform with the remaining EOF's. We applied the method of Cholesky factorization to the noise component of each record, in order to produce pseudo-random noise vectors, i.e., randomized vectors with autocorrelation identical to each record's noise component, that could be added back to the imputed values in sequence and restore variance to the solution. In practice, our pseudo-random variance-restoration routine encourages enlarged uncertainty attribution in portions of the [MSA]-PC1 record requiring data-infilling (i.e., its extremities; see Figures 3-2a and 3-3d).

We incorporated a probabilistic principal component analysis in order to reduce "noise" amongst the 12 [MSA] records and better extract a meaningful mode of common variability, as well as to provide insight into the spatial distribution of homogenous [MSA] signals across the GrIS (e.g., Fig. 3-1c; Fig. S3-3; Appendix 2). Extraction of the Greenlandic [MSA]-PC1 signal, including 
estimation of its confidence intervals, was conducted via the following procedure: i) The [MSA] dataset, $\boldsymbol{X}_{i}$, was centered to mean zero and standardized to unit variance, with missing values in $\boldsymbol{X}_{\boldsymbol{i}}$ set to 0. ii) Missing values in $\boldsymbol{X}_{\boldsymbol{i}}$ were statistically infilled following Beckers and Rixon (2003), with pseudorandom variance restoration in the imputed values enforced. iii) Step 2) was repeated for an additional 99 realizations ( $n=100$ realizations total), with each $\boldsymbol{X}_{i}=\boldsymbol{X}_{1}, \boldsymbol{X}_{2}, \ldots \boldsymbol{X}_{n}$ stored for later use. iv) For each $i=1,2, \ldots n$ imputed [MSA] datasets, $j=1,2, \ldots n$ surrogate [MSA] datasets of equal dimension were created using uniform-random sampling with replacement of the [MSA] records (i.e., a "bootstrap" approach; Babamoradi et al., 2013). v) PCA was performed on each $\boldsymbol{X}_{i, j}\left(n^{2}=10^{4}\right)$ surrogate [MSA] dataset, transformed using orthogonal Procrustes rotation in order to correct for (Eigen-transform) rotational ambiguity (Babamoradi et al., 2013), and the PC1 extracted and stored. vi) The confidence intervals were computed using the $2.5^{\text {th }}-97.5^{\text {th }}$ percentiles of the PC1 distribution (representing all $n^{2}$ tests). The "best-fit" PC1 signal represents the median fit (50 percentile) of the distribution. For a comparison with alternate methods of missing data estimation and [MSA]-PC1 extraction, the reader is referred to Appendix 2.

\subsubsection{Attribution of probable MSA source regions}

Changes in atmospheric circulation and windiness can affect aerosol transport and deposition across the GrIS, impacting the fidelity of ice core climate records across various timescales (Saltzman et al., 1997; Maselli et al., 2017; Sinclair et al., 2013; Schlosser et al., 2008; Scarchilli et al., 2011; Sharma et al., 2012; Hezel et al., 2011). Heterogeneous signals existing across our 12 GrIS-[MSA] records, due to localized productivity and (or) atmospheric variations that are particularly salient across interannual to subdecadal timescales (Sinclair et al., 2013; Schlosser et al., 2008; Scarchilli et al., 2011) are largely suppressed by dimensional reduction of the 12 [MSA] records into [MSA]-PC1 (Fig. S3-3) and through multiyear smoothing of the PC1-series thereafter (i.e., 5-year smoothing; Fig. 3-2d; Fig. S3-7).

Over longer, multidecadal to centennial timescales, current evidence (Jones et al., 1997; Ortega et al., 2015) does not generally support significant shifts in recent internally-driven, regional loweratmospheric dynamics, suggesting the primary emission source should underlie the most probable ("mean state") trajectory pathway taken by low-lying Greenland-bound air parcels when integrated across several decades (see also Appendix 2). To support this latter suggestion, we used the National Oceanic and Atmospheric Administration (NOAA) Air Resources Laboratory's Hybrid Single-Particle Lagrangian Integrated Trajectory (HYSPLIT) model, version 4.9 (Stein et al., 2015) to enable estimates

of probable marine source regions of MSA at each site. HYSPLIT employs a joint Lagrangian-Eulerian 
approach, in which numerical singularities, or atmospheric "particles", are subjected to a time-variant, spatially fixed 3-dimensional gridded wind field across a time-invariant land-surface field, and tracked backwards in time at hourly-time steps.

Particle trajectories were forced atmospheric wind data from the National Centers for Environmental Protection and Atmospheric Research (NCEP/NCAR) global atmospheric reanalysis dataset $^{51}$, gridded at $2.5^{\circ} \times 2.5^{\circ}$ resolution over 17 pressure levels $(1000,925,850,700,600,500,400$, 300, 250, 200, 150, 100, 70, 50, 30, 20, and $10 \mathrm{hPa}$ ). The HYSPLIT model forced using the NCEP/NCAR wind-reanalysis has been shown to provide comparable results to HYSPLIT trajectories forced using higher-resolution (e.g., $1^{\circ}$-gridded) wind reanalysis products from the European Centre for Medium-Range Weather Forecasts (Sinclair et al., 2013).

Since position errors of an individual air mass back-trajectory are estimated to upwards of $30 \%$ of distance travelled (Schlosser et al., 2008; Scarchilli et al., 2011) a probabilistic approach was taken here, in which a large-number of trajectories were computed and integrated into "airmass transport density maps". In order to focus on low elevation air masses $(\sim 0-1000 \mathrm{~m})$, which are assumed to be more representative of regional marine-derived moisture and aerosol sources, all particle backtrajectories were initialized from a height of 500 meters above ground level and released daily during the months June-July-August from A.D. 1948-2013. In total, 6,121 trajectories were released above each ice core site (i.e., 73,452 total), and tracked hourly for 7 days prior to the particle release date, coinciding with the approximate atmospheric lifetime of MSA (Hezel et al., 2011). At the end of each model trajectory simulation, all hourly trajectory locations situated over ocean were summed in discrete $1^{\circ} \times 1^{\circ}$ bins and area-normalized to produce the marine-airmass transport density grids, nominally representing the relative probability that any given trajectory endpoint would be situated over a given grid-cell at any point along a trajectory. Due to the inherent concentric partitioning of trajectory end-points around the trajectory release point, each grid-cell within the transport density grid was then normalized by its inverse radial distance from the trajectory release point to remove its central tendency (Criscitiello et al., 2016). Finally, all airmass transport density grids were normalized on a $0-1$ (least to most probable) relative scale. In addition, the median particle trajectory height for each grid box was computed, in order to target regions consisting of predominantly low-lying oceanic airmasses, and thus those originating within the marine boundary layer.

In order to achieve an airmass transport density (and median atmospheric elevation) grid statistically representative of the [MSA]-PC1 series, we composited the 12 sites airmass transport density grids (and median atmospheric elevation grids) into a single map. This was achieved by 
weighting the 12 individual airmass transport density grids (and median atmospheric elevation grids) by each site's squared correlation (i.e., fraction of variance shared) with the [MSA]-PC1 signal over the common-overlap period A.D. 1821-1985 (Table S3-1) prior to compositing. Note that the inferred source region, situated over the central-NE subarctic Atlantic in the vicinity of the Irminger and Icelandic Basins (Fig. 3-2c,d), is also considerably removed from the summertime sea ice marginal front where GrIS-deposited MSA origination has previously been attributed (Maselli et al., 2017). For a more in-depth analysis of the possible maritime source regions of Greenlandic MSA on a per-site basis, the reader is referred to Appendix 2 (see also Fig. S3-5).

\subsubsection{Correlation analysis of subarctic Atlantic [DMS $\left.\mathrm{Dw}_{\mathrm{sw}}\right]$ to satellite NPP}

We compared surface seawater DMS concentrations $\left(\left[\mathrm{DMS}_{\mathrm{Sw}}\right]\right)$ to satellite derived net primary productivity (NPP) estimates (Fig. 3-2b) using measurements of [DMS $\mathrm{Dw}_{\mathrm{sw}}$ compiled within the NOAA Global Surface Seawater DMS Database (Kettle et al., 1999; Lana et al., 2011) for the period Jan 1 1998 to Dec 31 2016. This period was chosen in order to overlap with ocean color measurements from leading satellite sensors (e.g., SeaWIFS: late 1997 - 2009, and MODIS-AQUA: mid 2002 present; Appendix 2). It is important to note that no quality control on the $\left[\mathrm{DMS}_{\mathrm{SW}}\right]$ measurements compiled in the database currently exist, due to the lack of $\left[\mathrm{DMS}_{\mathrm{sw}}\right]$ measurement protocols, or intercalibration methodologies (Lana et al., 2011). Rather, in order to remove anomalous [DMS $\left.S_{\mathrm{sw}}\right]$ values, measurements representing the middle $95 \%$ of concentrations were retained for analysis. This resulted in 30,047 measurements. As $\left[\mathrm{DMS}_{\mathrm{sw}}\right]$ values archived within the database are most often clustered in space and time, values were binned monthly at $1^{\circ} \times 1^{\circ}$ gridded resolution, log transformed to achieve normality and heteroscedasticity, and averaged. This procedure resulted in a reduction from 30,047 global measurements to 3045 unique global data points, a much smaller subset of which $(n=224)$ derives from the subarctic Atlantic $\left(50-65^{\circ} \mathrm{N} ; 60-10^{\circ} \mathrm{W}\right.$ ). We then upscaled (via 2-dimensional linear interpolation) the $1 / 6^{\circ} \times 1 / 6^{\circ}$ gridded estimates of log-transformed ocean Net Primary Productivity (NPP), taken from the popular Vertically Generalized Production Model (VGPM; Behrenfeld et al., 1997), onto a centered $1^{\circ} \times 1^{\circ}$ spatial grid. All unique $\left[\mathrm{DMS}_{\mathrm{sw}}\right]$ data points were regressed against the corresponding (log-transformed and standardized) NPP $1^{\circ} \times 1^{\circ} \times 1$-month grid point using ordinary least squares. For $\left[\mathrm{DMS}_{\mathrm{sw}}\right]$ grid points in the subarctic Atlantic with more than one observation $(n=186$ out of 224 total measurements), linear regression analysis was conducted via weighted least squares (WLS; where weights represent the inverse standard error of each average $\left[\mathrm{DMS}_{\mathrm{sw}}\right]$ value measured within a given $1^{\circ} \times 1^{\circ} \times 1$-month bin) against the corresponding NPP value. An analysis of the 
relationship between global vs. subarctic Atlantic $\left[\mathrm{DMS}_{\mathrm{Sw}}\right]$ and NPP can be found in Fig. S3-6 (see also Appendix 2).

\subsubsection{Processing of Continuous Phytoplankton Recorder (CPR) survey data}

For inferences of subarctic Atlantic phytoplankton abundance changes occurring since the mid-20 ${ }^{\text {th }}$ century, we use data from the Continuous Phytoplankton Recorder (CPR) survey. As reviewed by Richardson et al. (2006), the CPR remains the most extensive (in spatial scale, taxonomic scope, and time period covered) independent ocean-biological monitoring program in current existence, having recorded the abundance of nearly 700 unique taxa since A.D. 1931. The sampling methodology consists of towing a filtering device at $\sim 10 \mathrm{~m}$ depth along standard shipping routes using ships of opportunity, where each sample corresponds to 10 nautical miles $(\sim 18 \mathrm{~km})$, or $\sim 3 \mathrm{~m}^{3}$ of filtered water. Phytoplankton are collected on a $270 \mu \mathrm{m}$ mesh, a size originally chosen to provide broad representation of planktonic species, including both larger predatorial functional groups (e.g., copepods, pteropods, and small crustaceans) and large-diameter autotrophic phytoplankton. Despite this mesh size, smaller planktonic species - including coccolithophores $(\sim 10 \mu \mathrm{m})$ and diatoms $(\sim 10$ $200 \mu \mathrm{m})$ - are also consistently captured on the silk mesh and recorded for abundance. Importantly, because the sampling methodology has remained relatively unchanged since the survey's inception, consistency of planktonic time series has been correspondingly maintained, and relative changes in planktonic abundance are considered to be generally robust irrespective of size and (or) functional group (Richardson et al., 2006). On the other hand, given the host of complicating factors pertaining to the collection and counting of different sized microorganisms in a given measurement (e.g., planktonic active avoidance or escape, mesh-clogging, cell visibility; see Richardson et al., 2006), as well as the associated challenge therein of converting relative abundance measurements to absolute abundance, CPR measurements must nonetheless be cautioned as semi-quantitative by nature.

Here, we assess CPR products of monthly total diatom (1958-2016), dinoflagellate (19582016), and coccolithophore (1993-2016) abundance within preexisting CPR standard regions situated over the subarctic Atlantic (i.e., $50-65^{\circ} \mathrm{N}, 60-10^{\circ} \mathrm{W}, 14 / 41 \mathrm{CPR}$ standard regions: A6, A8, B5-8, C5-8, D5-8; see Fig. S3-3 or Richardson et al., 2006). We targeted coccolithophore, dinoflagellate, as well as diatom relative abundances as these functional groups share both a known association to DMS production (Stefels et al., 2007) and, collectively, are believed to comprise the bulk-abundance of autotrophic biomass in the subarctic Atlantic regions (e.g., Hátún et al., 2009; Richardson et al., 2006). Towards this latter point, the decision to analyze each group was also of pragmatic intent, with each 
providing adequate CPR spatiotemporal coverage in most subarctic Atlantic regions over recent decades (Richardson et al., 2006; Fig. S3-3). Conversely, since larger-diameter heterotrophs such as copepods and other zooplankton are not directly linked to DMS production (voiding their indirect association via sloppy-grazing and excretion; Stefels et al., 2007), and furthermore raise additional issues of systematic sampling bias due to, e.g., CPR inlet active-avoidance and escape (Richardson et al., 2006), we did not directly consider these higher-order functional groups within our assessments (see also Hátún et al., 2009).

As noted in Richardson et al. (2006), a potential bias in decadal time-series of CPR data arises from the gradual increase in Atlantic shipping speeds since the mid-20 $0^{\text {th }}$ century. This shipping speed increase is believed to have had a systematic, and near-linear, negative effect on the amount of water filtered through CPR devices, thereby (negatively) biasing long term relative abundance trends (Jonas et al., 2004). As such, we correct for this potential bias using conservative (i.e., extreme case) empirical relationships established by Jonas et al. (2004) between increasing mean northeastern-Atlantic shipping speed trends (0.09 knots year ${ }^{-1}$ since 1958) and volume water filtered $\left(-0.26 \mathrm{~m}^{3} \mathrm{knot}^{-1}\right.$; all corrections made relative a mean filtered-water volume of $3.16 \mathrm{~m}^{3}$ in AD 1990). As shown in Fig. S3$3 \mathrm{c}-\mathrm{d}$, this ship-speed bias adjustment imparts only minor adjustments on the "raw" CPR abundance data over the time period considered.

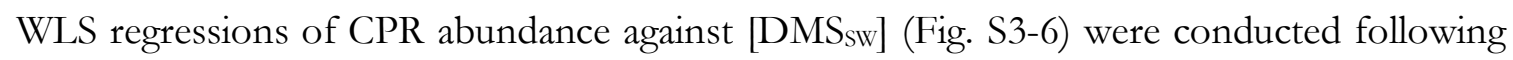
the procedure described for $\left[\mathrm{DMS}_{\mathrm{Sw}}\right]$ vs. NPP (above), the primary difference being that monthly $\left[\mathrm{DMS}_{\mathrm{sw}}\right]$ values were instead averaged within entire CPR standard regions (as opposed to degree latitude-longitude bins), prior to regression. Relationships between [DMS $\left.\mathrm{DW}_{\mathrm{sw}}\right]$ and CPR-abundance were not found to be significantly different when using either the (ship-speed) bias-adjusted or raw CPR data (Fig. S3-3).

Time series of summertime subarctic Atlantic phytoplankton abundance (shown in Fig. 3-4a) were estimated by first calculating annual means in each CPR standard region containing $\geq 8$ months of data (Appendix 2). We report summertime CPR time series as the simple area weighted average of each standard regions' CPR abundance data across the subarctic Atlantic (which vary substantially in size). A comparison of subarctic Atlantic CPR time series - for both summertime- and annual-based measurements - to alternative probabilistic and deterministic data infilling and compositing techniques that better-account for regional-sampling biases are provided in Fig. S3-3 (see also Appendix 2for an extended discussion). 


\subsubsection{Time series statistical significance testing}

Statistical significance levels for all reported time series correlations were computed using the nonparametric Monte Carlo-based method of Ebisuzaki (1997), unless noted otherwise (e.g., see Fig. 3-3b). We created 10,000 pseudo-random surrogate series of the first series by computing its Fourier transform, randomly varying the phase of its Fourier modes between 0 and $2 \pi$, and then computing the inverse transform, thereby retaining the exact autocorrelative properties (i.e., power spectrum preservation) of the original series. Statistical significance was then estimated by computing 10,000 psuedo-random correlations with the original second series, and by calculating the exceedance probability (i.e., inverse percentile) of achieving correlation greater than the original by chance alone.

\subsubsection{Productivity decline onset timing}

The onset timing of the industrial-era productivity decline was estimated using the SiZer (SIgnificant ZERo crossings of derivatives) methodology (Hannig and Marron, 2006), conducted in a manner similar to that described in Abram et al. (2016) and Trusel et al. (2018). Namely, we calculated the median significant $(p<0.1)$ onset of sustained (i.e., requiring the sign of the trend to persist into present) [MSA]-PC1 decline following pre-filtering of the series across a range of Gaussian kernel filters. We assessed 26 filters incrementally distributed from 15-40 year bandwidths. To alleviate edgeeffect biases stemming from our comparably short time series (i.e., relative to Abram et al., 2016; Trusel et al., 2018) we mandated each productivity-decline onset age to be at least one filter-width greater (i.e., more recent than) the oldest age of our time series (i.e., A.D. 1767). As such, our estimated industrial-era productivity-decline onset, A.D. $1816 \pm 11$ years ( \pm 2 median absolute deviations), represents the SiZer solution using a smaller subset (14/26) of the originally-filtered [MSA]-PC1 series. 


\section{Ch. 3 Figures}

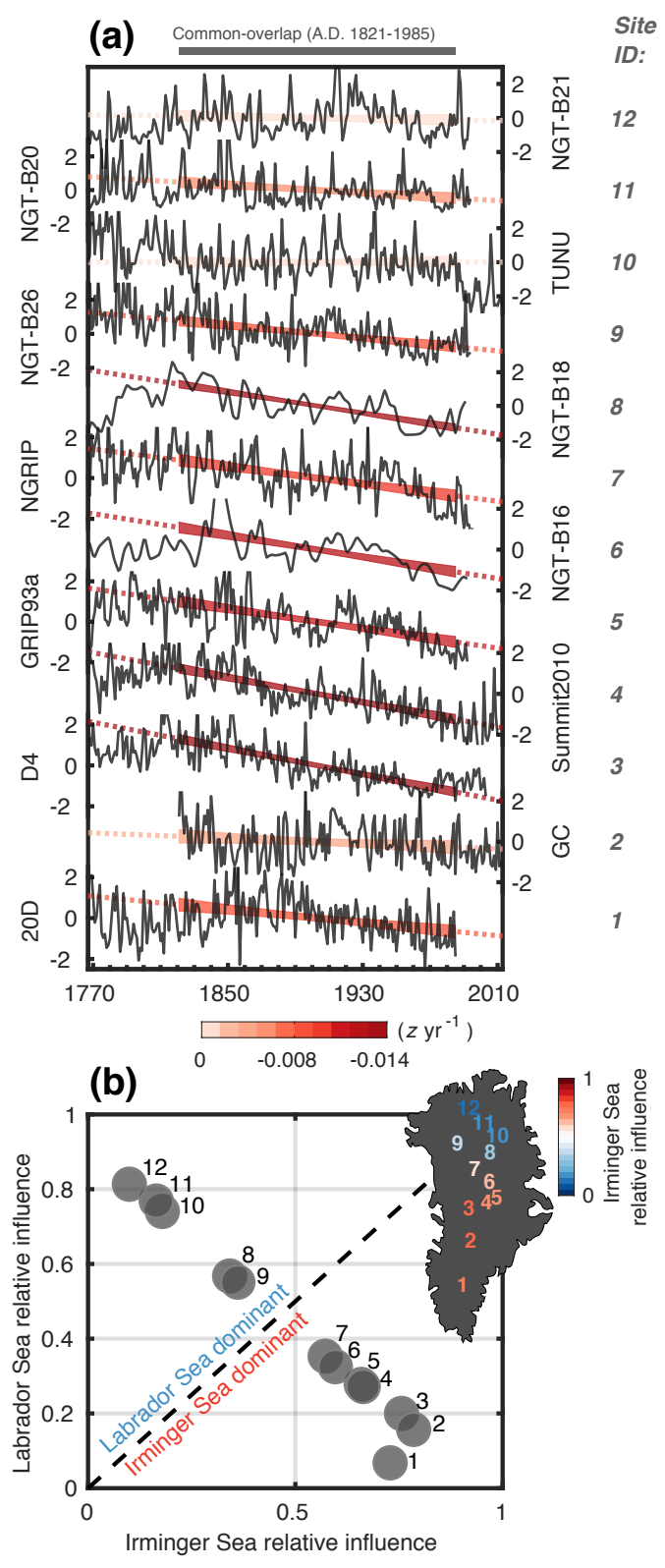

Figure 3-1: Strong covariability between Greenlandic [MSA] records (a) The twelve individual [MSA] time series, plotted from most southerly- (bottom; 20D) to most northerlysituated (top; NGT-B21). All series are standardized relative to A.D. 1821-1985 (period of common overlap; z-units) with linear [MSA] trends computed for the overlapping A.D. 18211985 period. Shaded red envelopes denote the regressions' $90 \%$ confidence intervals during the period of common overlap, while dotted lines show extension of the regressions beyond this period. Note the site identification ("ID") numbers to the right of the time series. (b) Communality scores for the 12 sites" HYSPLIT-derived "airmass transport density" maps (Section 3.2.3; see also Fig. 3-2 and Fig. S3-4) following factor analysis with varimax rotation (Appendix 2). Sites are grouped by whether their incoming marine airmasses are derived predominantly from the Irminger (factor \#1; $\mathrm{x}$-axis) or Labrador Seas (factor \#2; y-axis). All sites' incoming marine airmasses, void one (20D), have $>90 \%$ of their variances explained by a combination of both factors, suggesting sufficiency in limiting the factor analysis to two groupings. Locations of the 12 sites on the GrIS are provided in the inset, with each site-ID color coded with respect to its factor \#1 communality score (i.e., Irminger Sea relative influence). Ice core sites influenced predominantly by airmasses of Irminger Sea origin are denoted using red hues $(n=7)$, while the predominantly Labrador Sea-influenced sites are denoted using blue hues ( $n=5$; see also Fig. S3-6). 

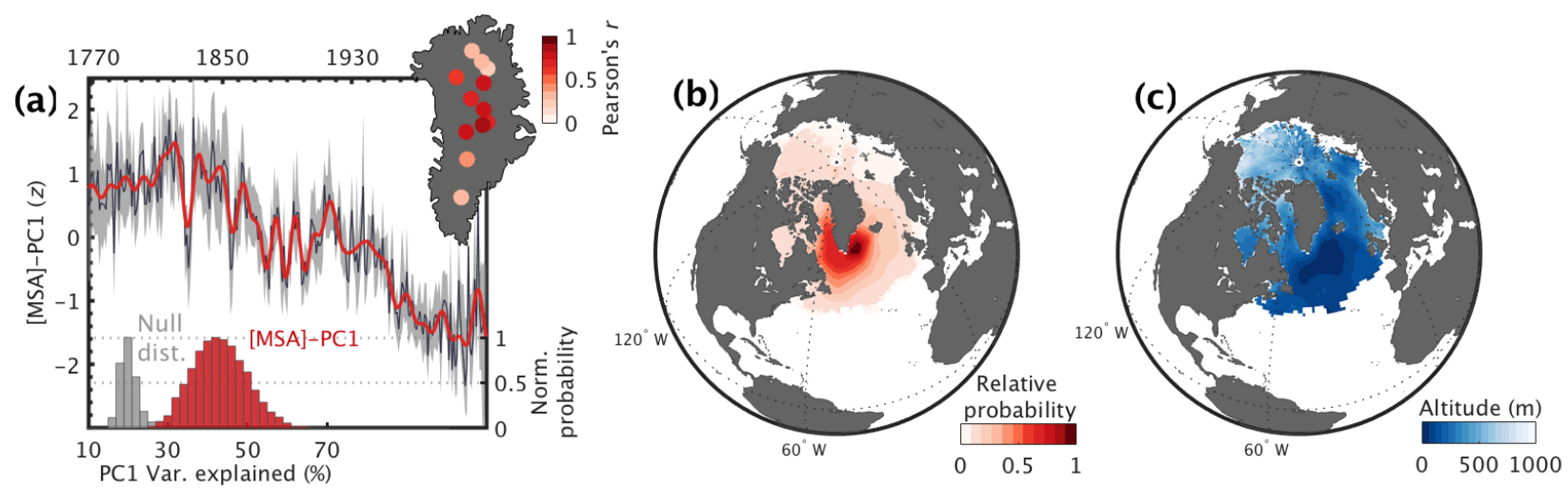

Figure 3-2: [MSA]-PC1 and atmospheric back-trajectory modeling of probable MSA source regions a) Top panel: Time series of [MSA]-PC1 (black (red) line at 1-yr (10-yr lowpass-filtered) resolution with bootstrapbased $95 \%$ confidence interval; $n=10,000$; Section 3.2.6). Units (z) denote standard-variance. Bottom panel: Normalized probability histogram illustrating the variance explained by [MSA]-PC1 following 10,000 bootstrapsampling principal component-tests (red). Also shown is the null-distribution of PC1-explained variance (grey) following 10,000 PCA tests conducted upon pseudo-random surrogate [MSA] datasets, revealing the [MSA]PC1 series to be significantly different from noise at the $p=0.002$ level (two-sample Kolmogorov-Smirnov test). The inset map shows each site's position on the GrIS and its homogenous correlation with [MSA]-PC1 over the period A.D. 1821-1985 (correlation values and significance levels listed in Table S3-1). b) Site-weighted [MSA]-PC1 JJA marine-airmass transport density map (representing the relative probability of an oceanic airmass passing through a given atmospheric column en route to the GrIS; Section 3.2.3), normalized on a 0-1 (least to most probable) scale. c) Site-weighted [MSA]-PC1 median atmospheric altitude for all ocean-situated JJA hourly trajectory locations over the period AD 1948-2013. The primary source of GrIS-[MSA] is assumed to overlap with regions representing high (low) airmass transport densities (atmospheric elevations; see also Fig. S3-4 and Fig. S3-5). 

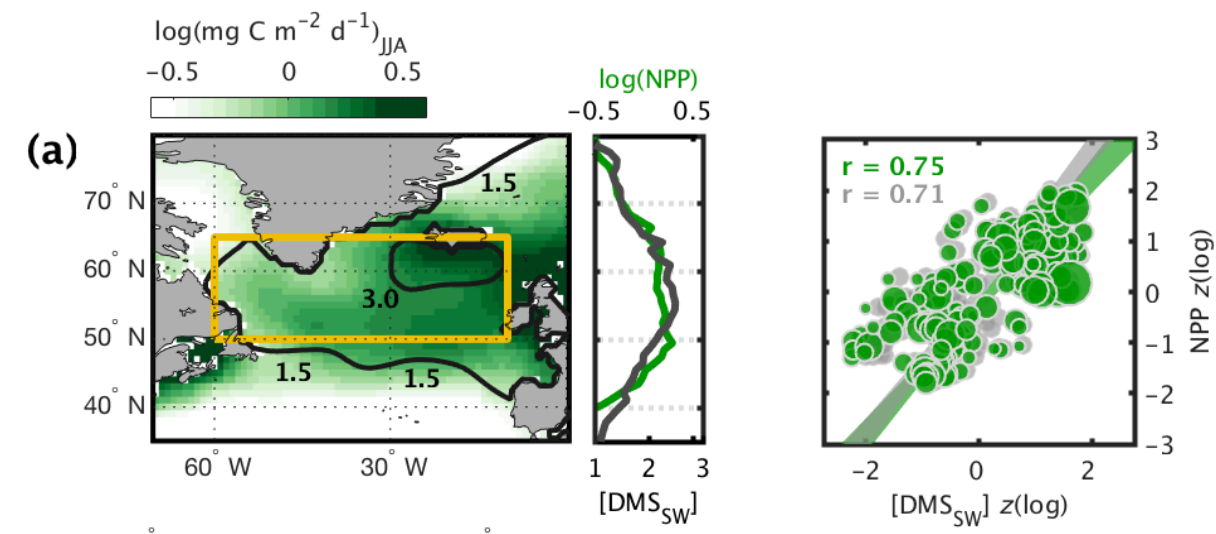

(b)
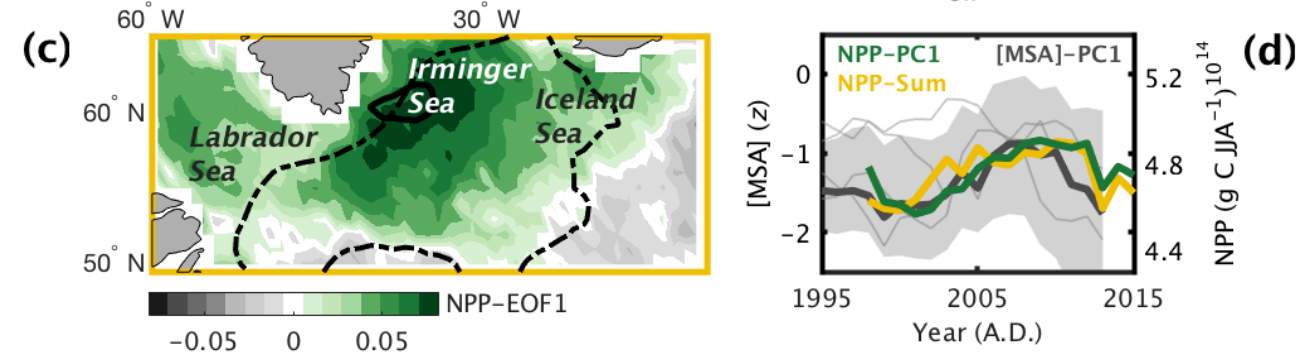

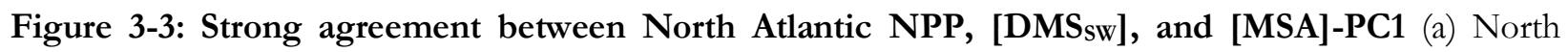
Atlantic mean (log-transformed) satellite JJA VGPM-NPP rates (Section 3.2.4; display data smoothed using a $3^{\circ} \times 3^{\circ}$ boxcar filter). Black contours show JJA [DMS sw]-isopleths (nM) reproduced from Lana et al. (2011). Right panel denotes North Atlantic zonal NPP and [DMS sw $_{\text {] }}$ averages. (b) Weighted (green; $p<0.0001 ; n=$ 184 degrees of freedom) and ordinary (grey; $p<0.0001 ; n=222$ degrees of freedom; Appendix 2) least squares regression analysis of subarctic Atlantic [DMS $\mathrm{Dw}]$ vs. NPP rate. Shaded bands show the $95 \%$ confidence interval of the regression. Green circle diameter represents the relative weighting attributed to [DMS $\mathrm{Dw}_{\mathrm{sw}}$ (Section 3.2.4). (c) Leading EOF (20\% of variance explained) of subarctic Atlantic summertime-integrated VGPM-NPP yields (A.D. $1998-2017 ; 50-65^{\circ} \mathrm{N}, 60^{\circ}-10^{\circ} \mathrm{W}$ ), overlain with the $95^{\text {th }}$-percentile airmass transport density (black bold line; Fig. 3-2b) and 5th-percentile [MSA]-PC1 JJA median trajectory altitude isopleths (black dotted-dashed line; see Fig. 3-2c). (d) PC1-based projection of summertime VGPM-NPP yields (green) alongside the subarctic Atlantic-integrated NPP yield time series (yellow), overlain by [MSA]-PC1 (with grey bootstrap-based 95\% confidence interval); all time-series are smoothed using a 5-year running mean. Individual (5-year smoothed) [MSA] records overlapping the satellite era are shown for comparison as light-grey lines. The yellow box in panel-c indicates the area shown in panel-a. 


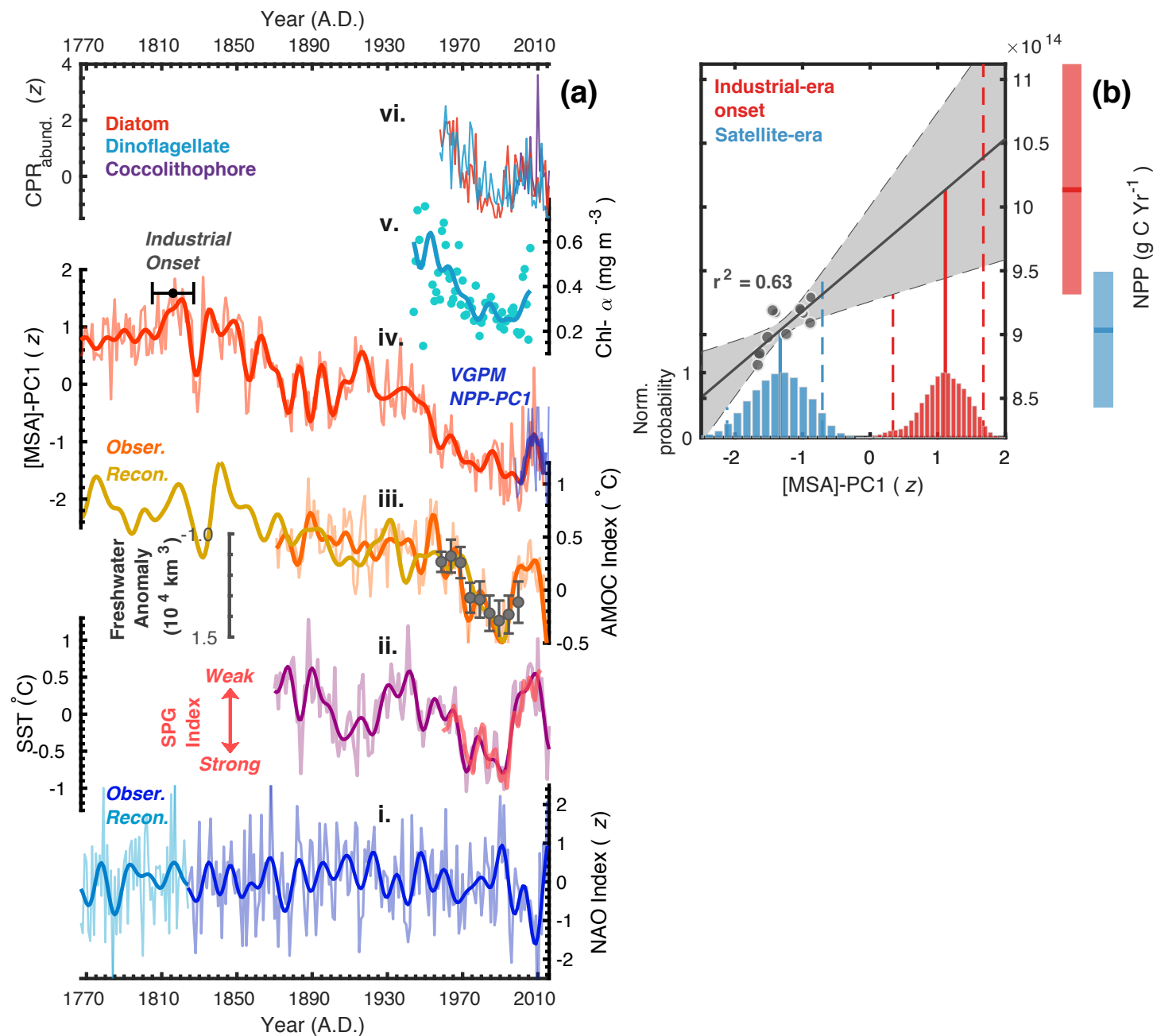

Figure 3-4: Multi-century evolution of subarctic Atlantic productivity. (a) i. Observed (Jones et al., 1997) and reconstructed (Ortega et al., 2015) NAO index. ii. Subarctic Atlantic "warming hole" SST evolution (Huang et al., 2017) (Fig. S3-9) overlain with an extended SPG-index (relative scale; Hátún et al., 2005; Appendix 2). iii. Reconstructed (Rahmstorf et al., 2015) and observed (Caesar et al., 2018) AMOC index, overlain with 5-yr binned subarctic Atlantic freshwater storage anomalies (Curry and Mauritzen, 2005; $\pm 2 \sigma$ ). iv. MSA]-PC1 productivity index (this study) overlain by 5-year smoothed NPP-PC1 (relative scale; Fig. 3-3c). The "Onset" range shows the estimated industrial-era initiation (1816 $\pm 11 \mathrm{yrs;}$ Section 3.2.7) of declining productivity. $v$. North Atlantic [Chl- $\alpha$ ] reconstruction (Boyce et al., 2010; limited to the period of annually-contiguous dataavailability, 1944-2006). vi. Standardized indices of CPR-based diatom, dinoflagellate, and coccolithophore abundance (Section 3.2.5). All thin (bolded) lines shown at 1-yr (10-yr lowpass-filtered) resolution, unless otherwise noted. (b) Weighted least squares calibration of 5-year smoothed [MSA]-PC1 and NPP-PC1 $(n=12$ $\mathrm{yrs} ; r^{2}=0.63 ; p<0.10$ after adjusting for reduced degrees of freedom; Section 3.2.6). The regression weights are the inverse standard deviation of [MSA]-PC1 values (see also Fig. 3-3d). Blue and red distributions show the range of industrial-era onset and satellite-era [MSA]-PC1 values following 10,000 bootstrap tests (both distributions are normalized to their respective modes, with bold (dashed) vertical lines denoting the $50^{\text {th }}$ $\left(2.5 / 97.5^{\text {th }}\right)$ percentiles). The grey-shaded region shows the $95 \%$ confidence interval of the regression parameters. The corresponding 95\% confidence ranges of industrial-era onset and satellite-era annual NPPyields are projected as vertical bands to the right, suggesting a $\sim 10 \pm 7 \%$ NPP decline $( \pm 2 \sigma)$ over the industrialera. 


\section{Ch. 3 Supporting figures}
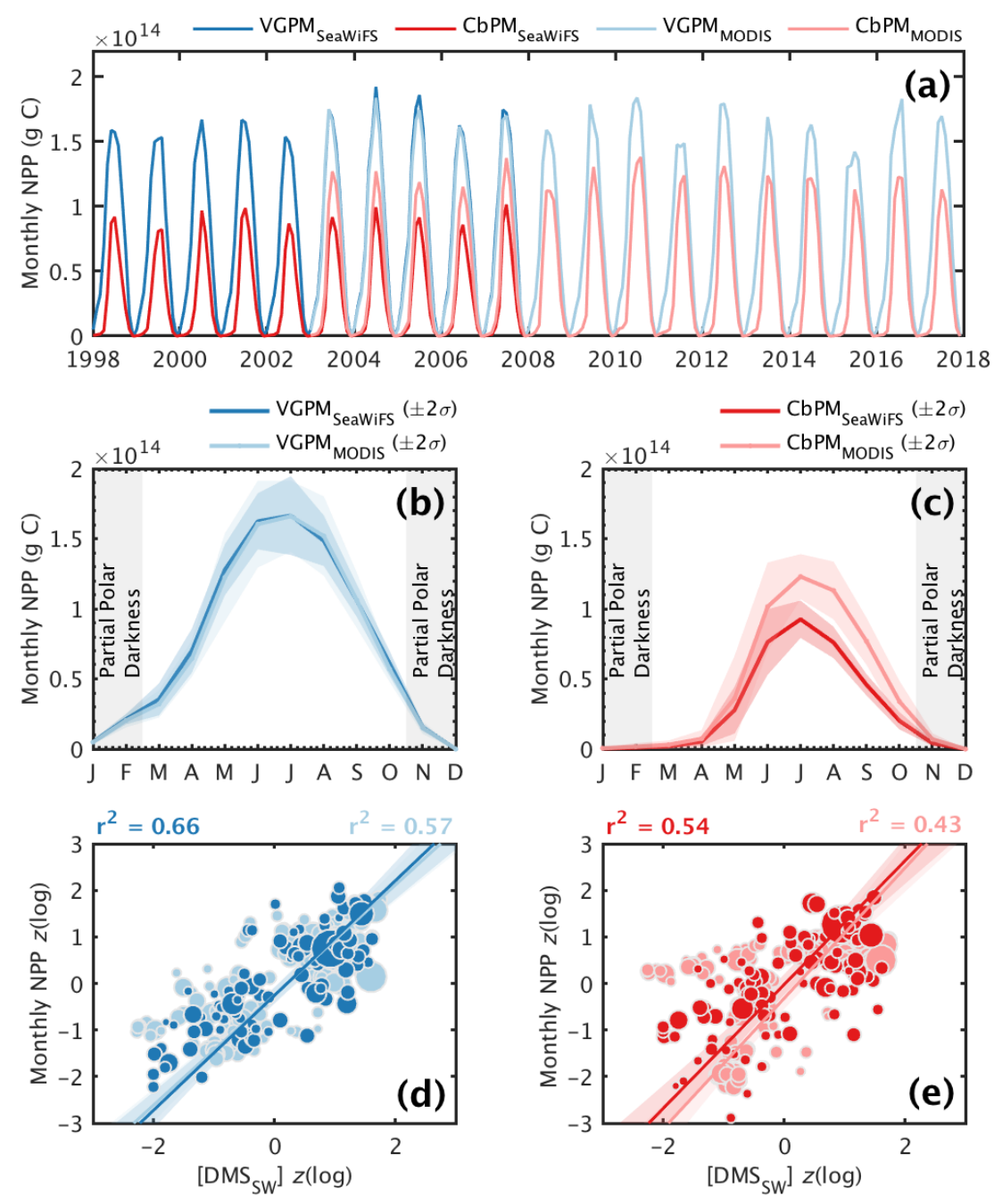

Figure S3-1: Comparison of net primary productivity products. (a) Monthly integrated NPP (g C) across the subarctic Atlantic $\left(50-65^{\circ} \mathrm{N}, 60-10^{\circ} \mathrm{W}\right.$, region highlighted as the yellow boxed region in a-d) for the SeaWiFS-VGPM and MODIS-VGPM NPP products (Behrenfeld et al., 1997; as shown in the main text), as well as independently-derived SeaWiFS- Carbon-based Productivity Model (i.e., CbPM; Westberry et al., 2008; Appendix 2) and MODIS-CbPM NPP products. (b) SeaWiFS and MODIS-derived NPP mean-seasonality $( \pm 2 \sigma$; Jan. 1998- Dec. 2017) for the VGPM and (c) CbPM datasets. Note that four months - Nov-Dec-JanFeb - experience partial polar darkness over the subarctic Atlantic latitude bands $\left(50-65^{\circ} \mathrm{N}\right)$, leading to systematic underestimates of productivity during these months. (d) VGPM and (e) CbPM based linearregressions with ship-based $\left[\mathrm{DMS}_{\mathrm{Sw}}\right]$ measurements (reminiscent of Fig. 3-3b of the main text) using the MODIS- and SeaWiFS-NPP datasets. 

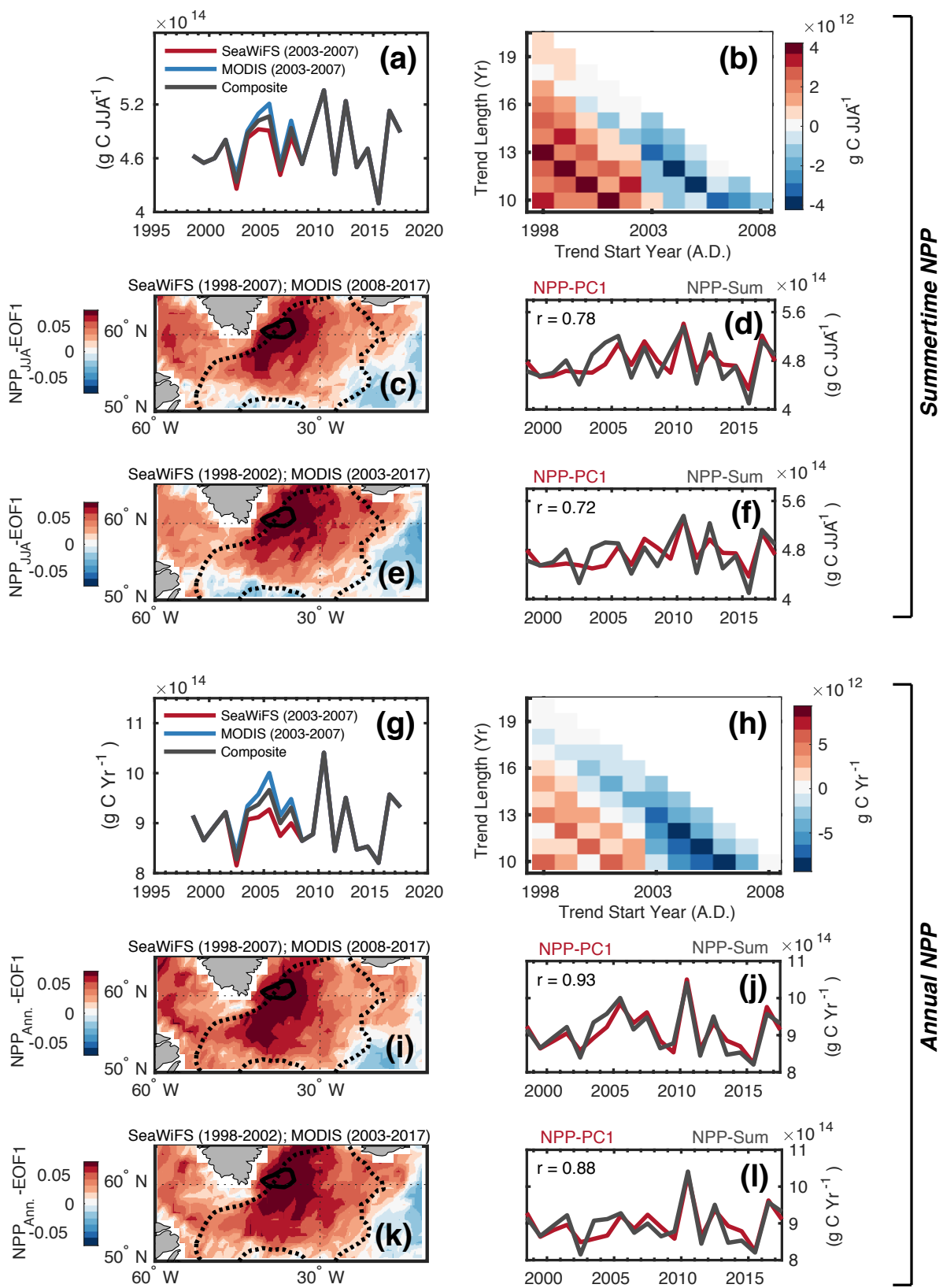

Figure S3-2: Seasonal representativeness of subarctic Atlantic VGPM-NPP satellite-era trends, and sensitivity to satellite sensor used. (a) Comparison of summertime-integrated (JJA) subarctic Atlantic VGPM-NPP yields for three different sensor estimates: a "SeaWiFS-dominant" estimate (red; 1998-2007 NPP estimates derived from the SeaWiFS sensor; 2008-2017 NPP estimates from the MODIS sensor), a MODISdominant estimate (blue; SeaWiFS-based data from 1998-2002, MODIS-based data from 2003-2017) and the composite stack (dark-grey; comprising the average of SeaWiFS- and MODIS-derived summertime VGPMNPP estimates over their period of common annual overlap, 2003-2007). (b) Differential linear trend analysis of the composite summertime subarctic Atlantic NPP time-series from (a). No decadal-scale linear trends were found to be significant at $p<0.05$, using a two-sided Student's t-test with $n$ - 2 degrees of freedom (where $n$ represents the varying trend length in years). (c) EOF1 and (d) PC1 of summertime VGPM-NPP using the MODIS-dominant dataset, reminiscent of Fig. 3-2c,d from the main text. (e-f) as in (c) and (d), but showing EOF-results from the SeaWiFS-dominant summertime VGPM-NPP dataset. (g-l) As in (a-h), but showing annually-integrated VGPM-NPP estimates. 

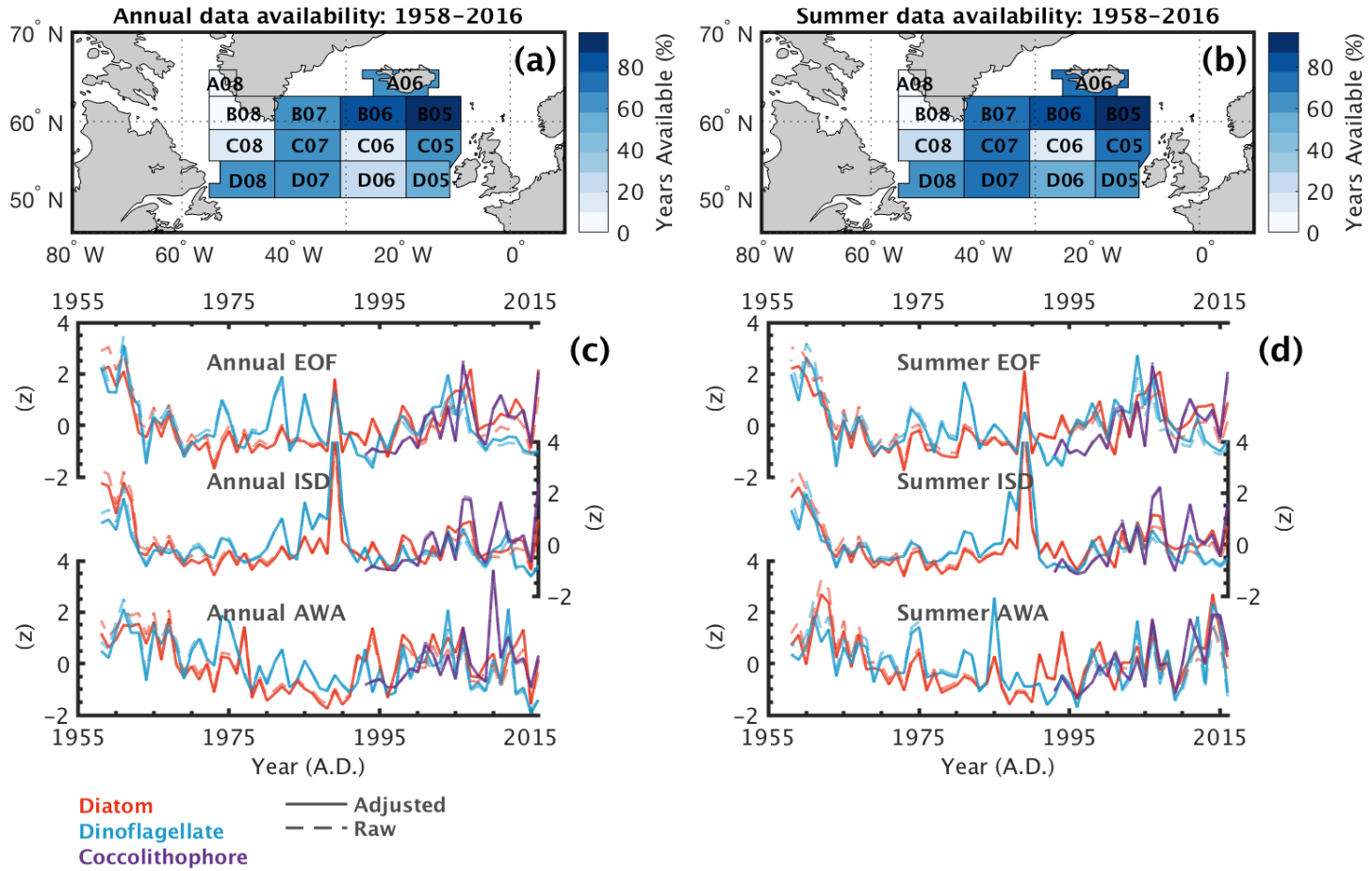

Figure S3-3: Comparison of subarctic Atlantic CPR compositing techniques. (a-b) Data availability (A.D. 1958-2016) by CPR standard region (Section 3.2.5) for (a) annually- ( $\geq 8 / 12$ months/year of data required) and (b) summertime- ( $\geq 4 / 12$ months/year of data during Apr-May-June-Jul-Aug-Sept) considered data. (c-d) Three approaches for compositing time series of CPR-based planktonic abundance, for both (c) annual- and (d) summertime-based data: AWA = Area Weighted Averaging; ISD = Inverse-Squared Distance-based datainfilling; EOF = Empirical Orthogonal Function-based data-infilling (Beckers and Rixon, 2003; see Appendix 2). Thin dashed lines show raw annual relative abundance plankton concentrations, while bolded lines show "adjusted" relative abundances, to correct for potential long-term biases in the volume of water sampled by CPR devices (Richardson et al., 2006; Jonas et al., 2004). Note that the annual AWA series is reproduced from Fig. 3-4a. 

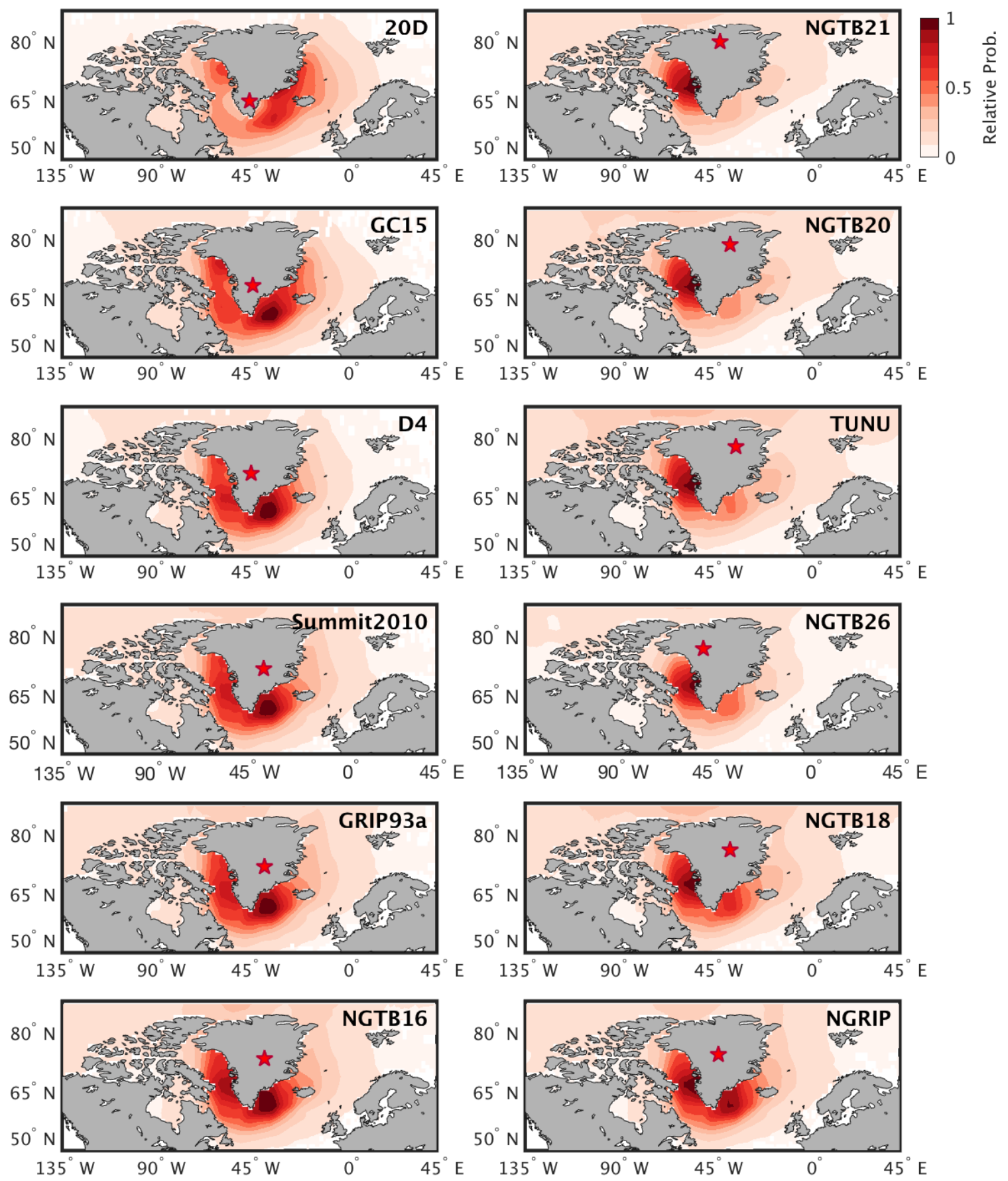

Figure S3-4: HYSPLIT-computed summertime (JJA) airmass transport probability densities for each ice core site. Computed over the period A.D. 1948-2013 (i.e., $6121 \mathrm{JJA}$ trajectories per site), and normalized on a 0-1 relative scale with 1 (0) indicating the most (least) probable airmass trajectory grid-point. Sites are shown counter-clockwise from most southerly- (20D; upper left) to most northerly- (NGT-B21; upper right) situated on the GrIS. 

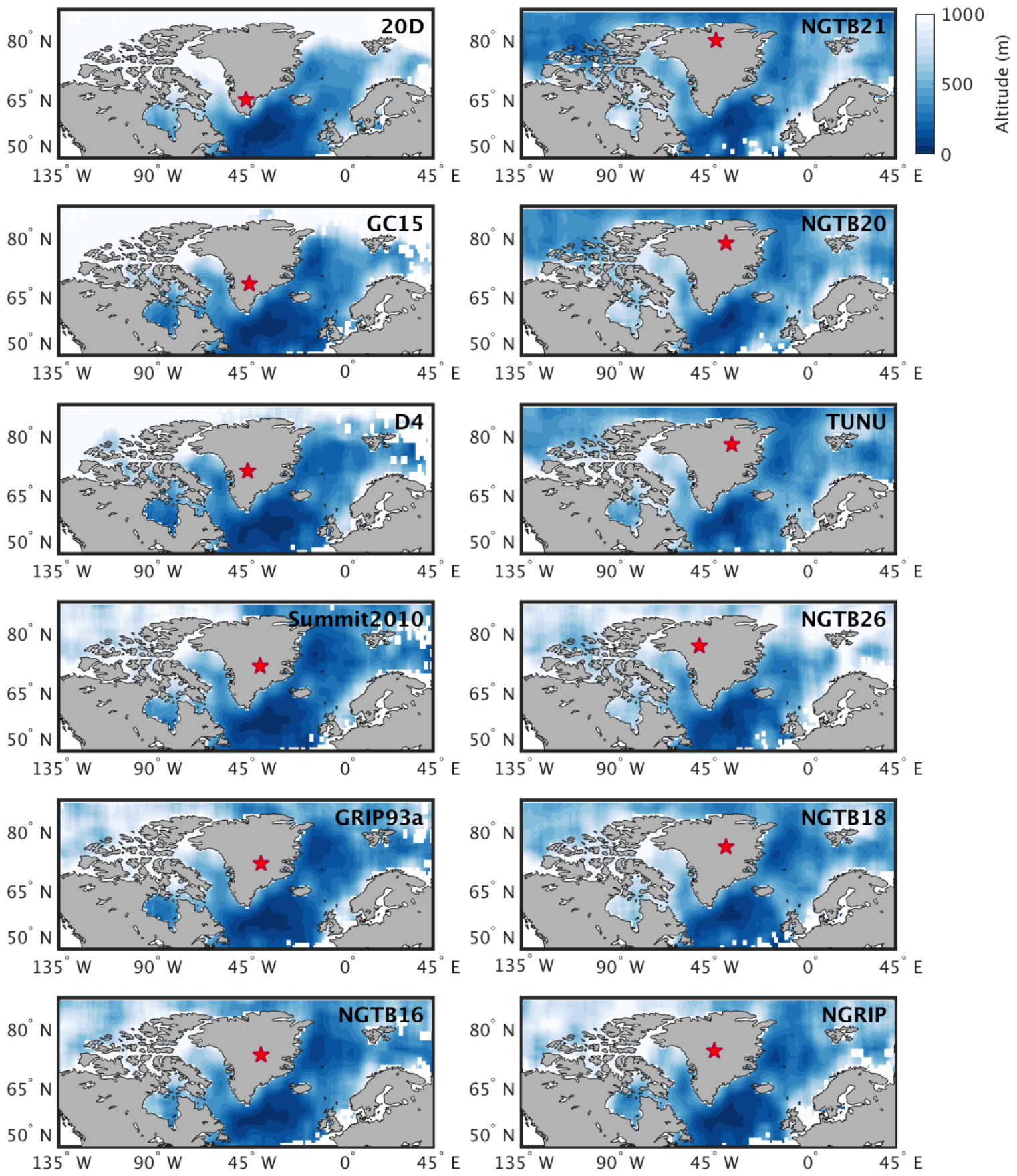

Figure S3-5: HYSPLIT-computed summertime (JJA) airmass median elevation maps for each ice core site. Computed over the period A.D. 1948-2013 (i.e., 6121 JJA trajectories per site). Sites are shown counterclockwise from most southerly- (20D; upper left) to most northerly- (NGT-B21; upper right) situated on the GrIS. 


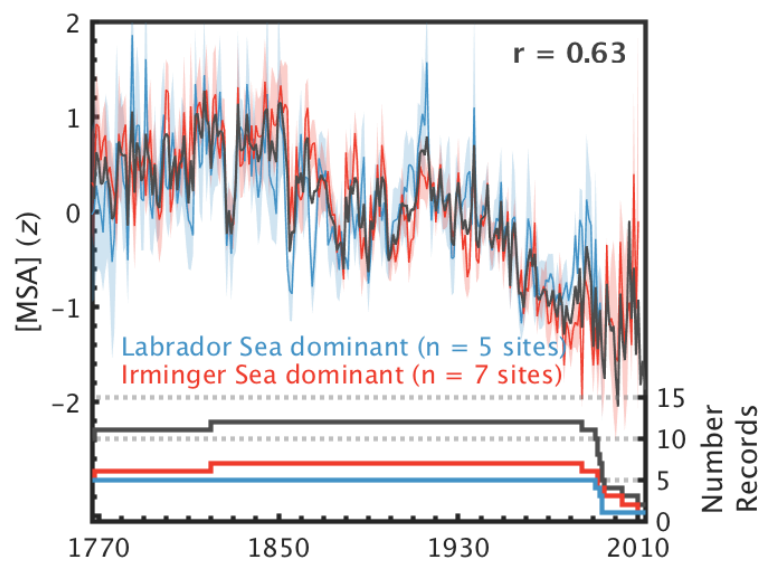

Figure S3-6: Strong covariation between two [MSA] source-trajectory regions. Top panel: The twelve Greenland [MSA] records from Figure 3-1a annually-averaged across the two airmass-trajectory factor analysisgroupings from Figure 3-1b $\left(r=0.63, p<0.0001\right.$; Ebisuzaki, 1997). All records have been standardized ( $z_{-}$ units) relative to their period of common overlap (AD 1821-1985). The shaded bands show \pm 1 standard error about the stack means. The grey line shows the composite (12-site) mean. Bottom panel: [MSA] record availability over time. 

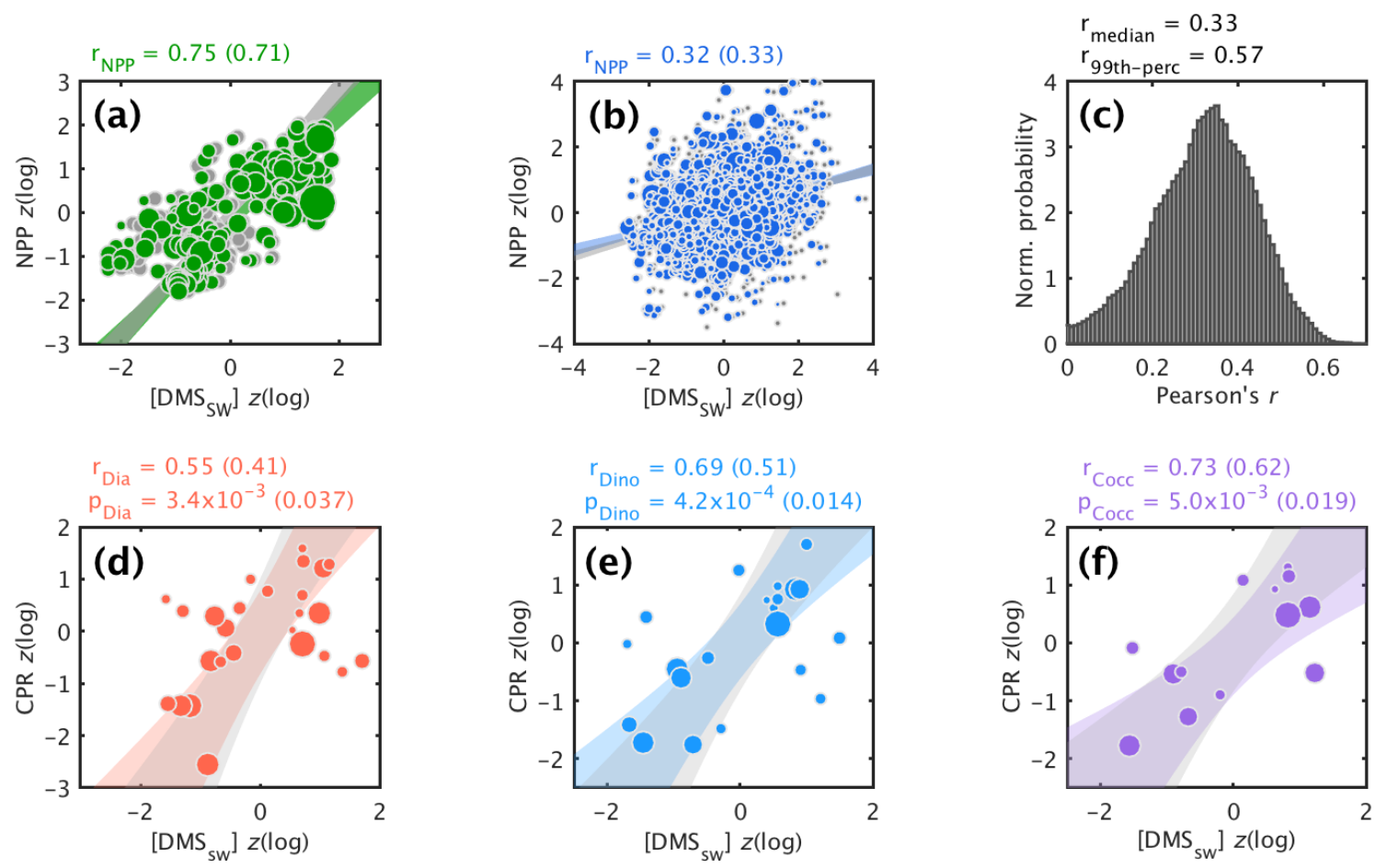

Figure S3-7: Relation between [DMS ${ }_{\mathrm{sw}}$ ], NPP, and CPR planktonic abundance. (a) Reproduced from Fig. 3-3b. (b) As in (a), but for globally regressed values. Diameter of circles represent the root of the relative weighting (inverse standard error of $\left[\mathrm{DMS}_{\mathrm{sw}}\right]$ measurement) used in the weighted least squares (WLS) regressions $\left(n_{W L S, \text { subartic }}=184 ; n_{W L S \text {, global }}=2219\right.$ degrees of freedom). Grey circles represent points used in the ordinary least squares (OLS) regression $\left(n_{O L S, \text { subartic }}=222 ; n_{O L S, \text { global }}=3043\right)$. (c) Probability density of global $r^{2}$ values over $i=1,2, \ldots, 10,000$ degrees-of-freedom preserving (i.e., $n_{\text {iglobal }}=184$ ) bootstrap WLS regressions

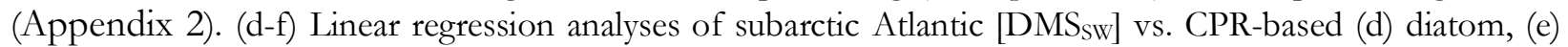
dinoflagellate, and (f) coccolithophore abundance. In all regressions, the colored (grey) shaded region denotes the $95 \%$ confidence interval about the regression parameters for the WLS (OLS) regression. All WLS (OLS) regressions significant at $\mathrm{p}<0.005(<0.05)$. 

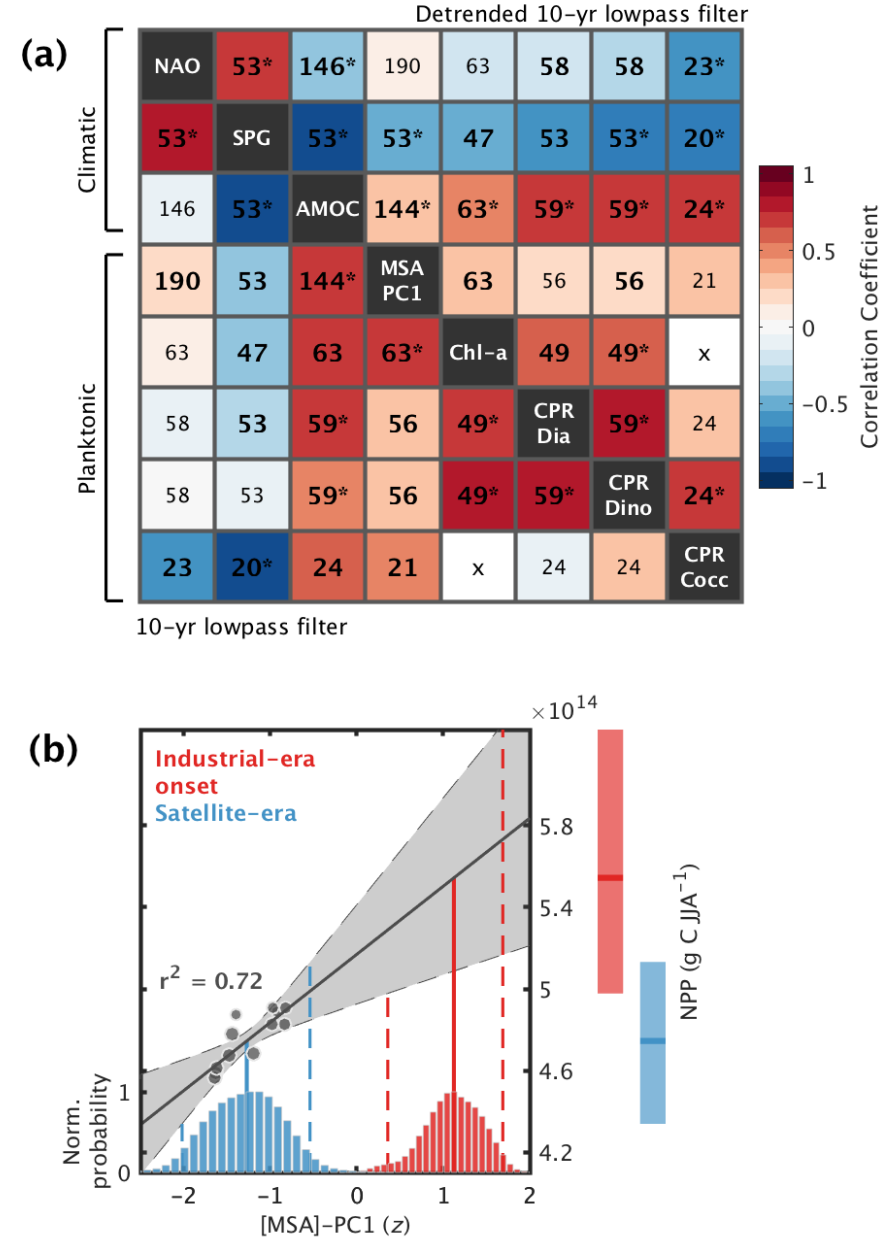

Figure S3-8: Industrial-era decline in subarctic Atlantic NPP and climatic influence. (a) Correlation matrix of planktonic and observed-climatic indices from Fig. 3-4a. Integers represent $n$, the years of overlap between paired series. Bold $n$-values represent significance at the $90 \%$ confidence level $(p<0.1$; assuming a two-tailed Student's $t$-distribution with a $t$-statistic representing $n$ - 2 degrees of freedom). Bold $n$-values with an asterisk represent significance using a Monte Carlo-based Fourier phase-randomization procedure, a more stringent test to account for serial correlation, and hence varying degrees of freedom, amongst paired series (Section 3.2.6). All 10-yr lowpass-filtered (bottom-left of diagonal), and linearly-detrended 10-yr lowpassfiltered (top-right of diagonal), series convolved using a Gaussian filter. Paired series with less than 20 years of overlap are denoted missing by " $x$ ". (b) WLS model of 5-year smoothed [MSA]-PC1 and summertime NPPPC1 $\left(n=12 \mathrm{yrs} ; r^{2}=0.72 ; p<0.05\right.$; significance estimated via the method of Ebisuzaki (1997), to adjust for the reduced degrees of freedom introduced from multiyear averaging). The regression weights are the inverse standard deviation of [MSA]-PC1 values. Histogram distributions denotes the range of industrial-era onset and satellite-era [MSA]-PC1 values following 10,000 bootstrap tests (distributions normalized to their maximum). The shaded band shows the $95 \%$ confidence interval of the WLS-regression parameters. The corresponding 95\% confidence range of NPP ( $\mathrm{g} \mathrm{C} \mathrm{JJA}^{-1}$ ) over the industrial-era onset and satellite-era are shown to the right. The analysis suggests a $\sim 14 \pm 11 \%$ decline $( \pm 2 \sigma)$ in summertime-integrated NPP yields since the industrial-era onset. 

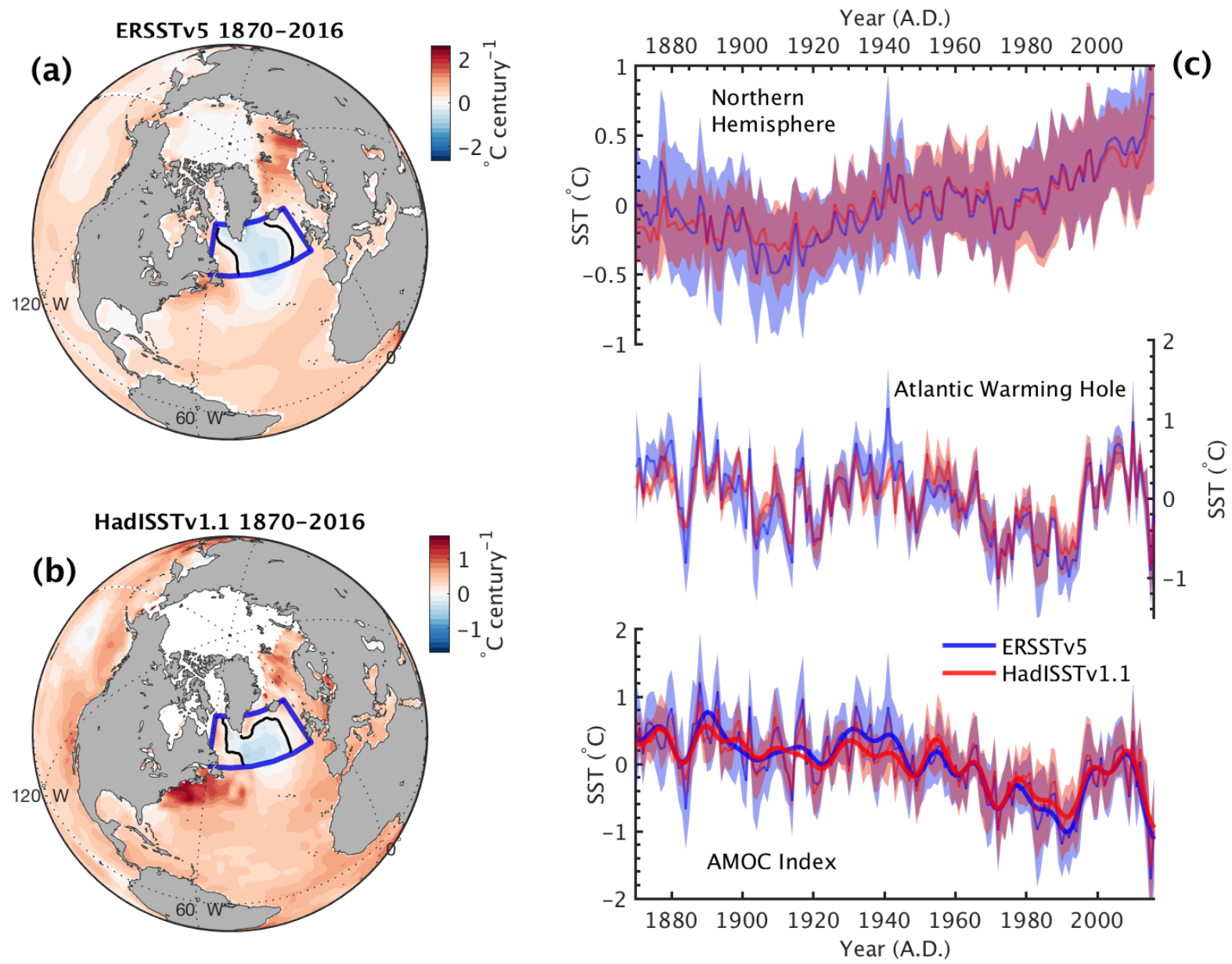

Figure S3-9: Subarctic Atlantic sea-surface temperature (SST) analysis. Annual SST linear-trends in the (a) ERSST (v5; Huang et al., 2017) and (b) HadISST (v1.1; Rayner et al., 2003) reanalyses. Grid points exhibiting a 146-year cooling trend within the subarctic Atlantic $\left(50-65^{\circ} \mathrm{N} ; 60-10^{\circ} \mathrm{W}\right.$; bolded blue outline) are outlined by black isopleths, and defined to encompass the Atlantic "Warming Hole" (Josey et al., 2018). (c) ERSST and HadISST anomalies for the Northern Hemisphere (NH, top; $\pm 1 \sigma$ ), the Atlantic Warming Hole (middle; $\pm 1 \sigma$; top), and the difference between Warming Hole and Northern Hemisphere SSTs, representing the AMOC index as approximately defined in Rahmstorf et al. (2015) and Caesar et al. (2018; bottom; $\pm 1 \sigma)$. Bolded AMOC time series are 10-yr (Butterworth) lowpass-filtered 


\section{Ch. 3 Supporting tables}

\begin{tabular}{|c|c|c|c|c|c|c|c|c|c|c|c|}
\hline $\begin{array}{c}\text { Site } \\
\text { name }\end{array}$ & $\begin{array}{l}\text { Site } \\
\text { ID }\end{array}$ & Lat/Lon & $\begin{array}{l}\text { Elev- } \\
\text { ation } \\
(\mathrm{m})\end{array}$ & $\begin{array}{l}\text { SAT } \\
\left({ }^{\circ} \mathrm{C}\right)\end{array}$ & $\begin{array}{l}\dot{b}(\mathrm{~m} \\
\text { w.e. } \\
\left.\mathrm{yr}^{-1}\right)\end{array}$ & $\begin{array}{l}\text { Core } \\
\text { length } \\
(\mathrm{m})\end{array}$ & $\begin{array}{l}\text { Time } \\
\text { period } \\
\text { (A.D.) }\end{array}$ & $\begin{array}{c}\text { Peak } \\
{[\mathrm{MSA}]} \\
\text { seasonality } \\
(0-10 \mathrm{~m})\end{array}$ & $\begin{array}{c}\text { Mean } \\
{[\text { MSA] }} \\
\pm 1 \sigma ;(\mu \mathrm{g} \\
\left.\mathbf{L}^{-1}\right)\end{array}$ & $\begin{array}{c}n_{[\mathrm{MSA}]-\mathrm{PC} 1} \\
(p)\end{array}$ & Reference \\
\hline $20 \mathrm{D}$ & 1 & $\begin{array}{c}65.01^{\circ} \mathrm{N} \\
-44.87^{\circ} \mathrm{W}\end{array}$ & 2615 & $\mathrm{n} / \mathrm{a}$ & 0.410 & 116 & $\begin{array}{l}1767- \\
1985\end{array}$ & Jun-Aug & $\begin{array}{l}3.30 \\
(2.38)\end{array}$ & $\begin{array}{c}0.300 \\
(0.038)\end{array}$ & $\begin{array}{l}\text { Kinnard et al., } \\
\text { 2011; Whung et } \\
\text { al., } 1994\end{array}$ \\
\hline GC & 2 & $\begin{array}{c}68.91^{\circ} \mathrm{N} \\
-43.39^{\circ} \mathrm{W}\end{array}$ & 2465 & -24 & 0.360 & 104 & $\begin{array}{l}1821- \\
2013\end{array}$ & Jul-Sep & $\begin{array}{c}1.25 \\
(1.25)\end{array}$ & $\begin{array}{c}0.410 \\
(<0.001)\end{array}$ & $\begin{array}{c}\text { Unpublished } \\
\text { MSA data; Trusel } \\
\text { et al., } 2018\end{array}$ \\
\hline D4 & 3 & $\begin{array}{c}71.67^{\circ} \mathrm{N} \\
-44.00^{\circ} \mathrm{W}\end{array}$ & 2715 & -26 & 0.420 & 145 & $\begin{array}{l}1733- \\
2004\end{array}$ & Jun-Jul & $\begin{array}{c}2.44 \\
(1.38)\end{array}$ & $\begin{array}{c}0.766 \\
(<0.001)\end{array}$ & $\begin{array}{c}\text { Unpublished } \\
\text { MSA data; } \\
\text { McConnell et al., } \\
20017 \\
\end{array}$ \\
\hline $\begin{array}{l}\text { Summit } \\
2010\end{array}$ & 4 & $\begin{array}{c}72.33^{\circ} \mathrm{N} \\
-38.29^{\circ} \mathrm{W}\end{array}$ & 3215 & -29.3 & 0.220 & 87 & $\begin{array}{l}1742- \\
2010\end{array}$ & May-Jun & $\begin{array}{c}3.58 \\
(1.49)\end{array}$ & $\begin{array}{c}0.851 \\
(<0.001)\end{array}$ & $\begin{array}{c}\text { Maselli et al., } \\
2017\end{array}$ \\
\hline $\begin{array}{c}\text { GRIP9 } \\
3 \mathrm{a}\end{array}$ & 5 & $\begin{array}{c}72.57^{\circ} \mathrm{N} \\
-37.63^{\circ} \mathrm{W} \\
\end{array}$ & 3240 & -31.5 & $\begin{array}{c}0.200- \\
0.220 \\
\end{array}$ & 73 & $\begin{array}{l}1767- \\
1993\end{array}$ & Jul-Sep & $\begin{array}{c}3.04 \\
(1.40)\end{array}$ & $\begin{array}{c}0.712 \\
(<0.001)\end{array}$ & $\begin{array}{c}\text { Legrand et al., } \\
1997\end{array}$ \\
\hline $\begin{array}{l}\text { NGT- } \\
\text { B16 }\end{array}$ & 6 & $\begin{array}{c}73.94^{\circ} \mathrm{N} \\
-37.63^{\circ} \mathrm{W}\end{array}$ & 3040 & $\begin{array}{c}- \\
32.5 \\
*\end{array}$ & $\begin{array}{c}0.134 \\
- \\
0.148\end{array}$ & 102.4 & $\begin{array}{l}1483- \\
1991\end{array}$ & $\mathrm{n} / \mathrm{a}$ & $\begin{array}{l}2.33 \\
(0.61)\end{array}$ & $\begin{array}{c}0.745 \\
(<0.001)\end{array}$ & $\begin{array}{c}\text { Unpublished } \\
\text { MSA data; } \\
\text { Weißbach et al., } \\
2016 \\
\end{array}$ \\
\hline NGRIP & 7 & $\begin{array}{c}75.1^{\circ} \mathrm{N} \\
-42.32^{\circ} \mathrm{W}\end{array}$ & 2950 & -30.2 & $\sim$ & $\sim$ & $\begin{array}{l}187- \\
1995\end{array}$ & $\mathrm{n} / \mathrm{a}$ & $\begin{array}{l}2.89 \\
(1.43)\end{array}$ & $\begin{array}{c}0.725 \\
(<0.001)\end{array}$ & $\begin{array}{l}\text { Kinnard et al., } \\
\text { 2011; Andersen et } \\
\text { al., } 2004\end{array}$ \\
\hline $\begin{array}{l}\text { NGT- } \\
\text { B18 }\end{array}$ & 8 & $\begin{array}{c}76.62^{\circ} \mathrm{N} \\
-36.40^{\circ} \mathrm{W}\end{array}$ & 2508 & $\begin{array}{c}- \\
32.3 \\
*\end{array}$ & $\begin{array}{c}0.100 \\
- \\
0.110\end{array}$ & 84.4 & $\begin{array}{l}1443- \\
1993\end{array}$ & $\mathrm{n} / \mathrm{a}$ & $\begin{array}{c}1.27 \\
(0.47)\end{array}$ & $\begin{array}{c}0.792 \\
(<0.001)\end{array}$ & $\begin{array}{c}\text { Unpublished } \\
\text { MSA MSA data; } \\
\text { Weißbach et al., } \\
2016 \\
\end{array}$ \\
\hline $\begin{array}{l}\text { NGT- } \\
\text { B26 }\end{array}$ & 9 & $\begin{array}{l}77.25^{\circ} \mathrm{N} \\
-49.22^{\circ} \mathrm{W}\end{array}$ & 2598 & $\begin{array}{c}- \\
30.3 \\
*\end{array}$ & $\begin{array}{c}0.172 \\
- \\
0.190\end{array}$ & 88.2 & $\begin{array}{l}1502- \\
1995\end{array}$ & $\mathrm{n} / \mathrm{a}$ & $\begin{array}{l}1.73 \\
(0.88)\end{array}$ & $\begin{array}{c}0.563 \\
(<0.001)\end{array}$ & $\begin{array}{c}\text { Unpublished } \\
\text { MSA data; } \\
\text { Weißbach et al., } \\
2016\end{array}$ \\
\hline TUNU & 10 & $\begin{array}{c}78.03^{\circ} \mathrm{N} \\
-33.87^{\circ} \mathrm{W} \\
\end{array}$ & 2120 & -27.5 & 0.110 & 213 & $\begin{array}{l}269- \\
2013\end{array}$ & Jul-Aug & $\begin{array}{c}2.16 \\
(1.06)\end{array}$ & $\begin{array}{c}0.273 \\
(<0.001)\end{array}$ & $\begin{array}{c}\text { Maselli et al., } \\
2017\end{array}$ \\
\hline $\begin{array}{l}\text { NGT- } \\
\text { B20 }\end{array}$ & 11 & $\begin{array}{c}78.83^{\circ} \mathrm{N} \\
-36.50^{\circ} \mathrm{W}\end{array}$ & 2147 & $\begin{array}{c}- \\
30.4 \\
*\end{array}$ & $\begin{array}{l}0.90- \\
0.105\end{array}$ & 119.8 & $\begin{array}{l}1066- \\
1994\end{array}$ & $\mathrm{n} / \mathrm{a}$ & $\begin{array}{c}1.31 \\
(0.90)\end{array}$ & $\begin{array}{c}0.315 \\
(0.007)\end{array}$ & $\begin{array}{c}\text { Unpublished } \\
\text { MSA data; } \\
\text { Weißbach et al., } \\
2016\end{array}$ \\
\hline $\begin{array}{l}\text { NGT- } \\
\text { B21 }\end{array}$ & 12 & $\begin{array}{c}80.00^{\circ} \mathrm{N} \\
-41.41^{\circ} \mathrm{W}\end{array}$ & 2185 & $\begin{array}{c}- \\
30.1 \\
*\end{array}$ & $\begin{array}{c}0.105 \\
- \\
0.113\end{array}$ & 93.5 & $\begin{array}{l}1395- \\
1993\end{array}$ & $\mathrm{n} / \mathrm{a}$ & $\begin{array}{l}1.65 \\
(0.73)\end{array}$ & $\begin{array}{c}0.282 \\
(0.091)\end{array}$ & $\begin{array}{c}\text { Unpublished } \\
\text { MSA data; } \\
\text { Weißbach et al., } \\
2016\end{array}$ \\
\hline
\end{tabular}

Table S3-1: Geographical, physical, and glaciological information pertaining to each ice core [MSA] record. The second to last column provides the homogenous correlations (Pearson $r$ ) and significance level ( $p$; Ebisuzaki, 1997) between [MSA]-PC1 and the 12 GrIS-[MSA] records comprising it, computed over the period of common temporal overlap between records, A.D. 1821-1985. Note that correlation values are reproduced from color-coded values shown on the Figure 3-2a inset map. 


\section{Ch. 3 References}

Abram, N. J., McGregor, H. V., Tierney, J. E., Evans, M. N., McKay, N. P., Kaufman, D. S., .. Von Gunten, L. (2016). Early onset of industrial-era warming across the oceans and continents. Nature, 536(7617), 411418. https://doi.org/10.1038/nature19082

Andersen, K. K., Azuma, N., Barnola, J.-M., Bigler, M., Biscaye, P., Caillon, N., ... White, J. W. C. (2004). High-resolution record of Northern Hemisphere climate extending into the last interglacial period. Nature, 431(7005), 147-151. https://doi.org/10.1038/nature02805

Andersen, K. K., Ditlevsen, P. D., Rasmussen, S. O., Clausen, H. B., Vinther, B. M., Johnsen, S. J., \& Steffensen, J. P. (2006). Retrieving a common accumulation record from Greenland ice cores for the past 1800 years. Journal of Geophysical Research Atmospheres, 111(15). https://doi.org/10.1029/2005JD006765

Babamoradi, H., van den Berg, F., \& Rinnan, A. (2013). Bootstrap based confidence limits in principal component analysis - A case study. Chemometrics and Intelligent Laboratory Systems, 120, 97-105. https://doi.org/10.1016/j.chemolab.2012.10.007

Bakker, P. et al. (2016). Fate of the Atlantic Meridional Overturning Circulation: strong decline under continued warming and Greenland melting. Geophys. Res. Lett.43, 12252-12260.

Barton, A. D., Irwin, A. J., Finkel, Z. V, \& Stock, C. A. (2016). Anthropogenic climate change drives shift and shuffle in North Atlantic phytoplankton communities. Proceedings of the National Academy of Sciences, 113(11), 2964-2969. https://doi.org/10.1073/pnas.1519080113

Beckers, J. M., \& Rixen, M. (2003). EOF calculations and data filling from incomplete oceanographic datasets. Journal of Atmospheric and Oceanic Technology, 20(12), 1839-1856. https://doi.org/10.1175/15200426(2003)020<1839:ECADFF>2.0.CO;2

Behrenfeld, M. J., \& Falkowski, P. G. (1997). Photosynthetic rates derived from satellite-based chlorophyll concentration. Limnology and Oceanography, 42(1), 1-20. https://doi.org/10.4319/lo.1997.42.1.0001

Behrenfeld, M. J., \& Boss, E. S. (2014). Resurrecting the Ecological Underpinnings of Ocean Plankton Blooms. Annual Review of Marine Science, 6(1), 167-194. https://doi.org/10.1146/annurev-marine-052913-021325

Born, A., \& Stocker, T. F. (2014). Two Stable Equilibria of the Atlantic Subpolar Gyre. Journal of Physical Oceanography, 44(1), 246-264. https:/ /doi.org/10.1175/JPO-D-13-073.1

Boyce, D. G., Lewis, M. R., \& Worm, B. (2010). Global phytoplankton decline over the past century. Nature, 466(7306), 591-596. https://doi.org/10.1038/nature09268

Caesar, L., Rahmstorf, S., Robinson, A., Feulner, G., \& Saba, V. (2018). Observed fingerprint of a weakening Atlantic Ocean overturning circulation. Nature, 556(7700), 191-196. https://doi.org/10.1038/s41586018-0006-5

Charlson, R. J., Lovelock, J. E., Andreae, M. O., \& Warren, S. G. (1987). Oceanic phytoplankton, atmospheric sulphur, cloud albedo and climate. Nature, 326(6114), 655-661. https://doi.org/10.1038/326655a0

Criscitiello, A. S., Das, S. B., Evans, M. J., Frey, K. E., Conway, H., Joughin, I., .. Steig, E. J. (2013). Ice sheet record of recent sea-ice behavior and polynya variability in the Amundsen Sea, West Antarctica. Journal of Geophysical Research: Oceans, 118(1), 118-130. https://doi.org/10.1029/2012JC008077

Criscitiello, A. S., Marshall, S. J., Evans, M. J., Kinnard, C., Norman, A. L., \& Sharp, M. J. (2016). Marine aerosol source regions to prince of Wales Icefield, Ellesmere Island, and influence from the tropical Pacific, 19792001. Journal of Geophysical Research, 121(16), 9492-9507. https://doi.org/10.1002/2015JD024457

Curry, R. \& Mauritzen, C. (2005). Dilution of the northern North Atlantic Ocean in recent decades. Science, 308, 1772-1774. 
Ebisuzaki, W. (1997). A method to estimate the statistical significance of a correlation when the data are serially correlated. Journal of Climate, 10(9), 2147-2153. https://doi.org/10.1175/15200442(1997)010<2147:AMTETS>2.0.CO;2

Fischer, H., Wagenbach, D., Kipfstuhl, J. (1998) Sulfate and nitrate firn concentrations on the Greenland ice sheet: 1. Large-scale geographical deposition changes. J Geophys Res. 103, 21927-21934.

Hannig, J. \& Marron, J. S. (2006). Advanced distribution theory for SiZer. J. Am. Stat. Assoc. 101, 484-499.

Hátún, H., Payne, M. R., Beaugrand, G., Reid, P. C., Sandø, A. B., Drange, H., .. Bloch, D. (2009). Large biogeographical shifts in the north-eastern Atlantic Ocean: From the subpolar gyre, via plankton, to blue whiting and pilot whales. Progress in Oceanography, 80(3-4), 149-162. https://doi.org/10.1016/j.pocean.2009.03.001

Hátún, H., Sande, A. B., Drange, H., Hansen, B., \& Valdimarsson, H. (2005). Ocean science: Influence of the atlantic subpolar gyre on the thermohaline circulation. Science, 309(5742), 1841-1844. https://doi.org/10.1126/science.1114777

Hezel, P. J., Alexander, B., Bitz, C. M., Steig, E. J., Holmes, C. D., Yang, X., \& Sciare, J. (2011). Modeled methanesulfonic acid (MSA) deposition in Antarctica and its relationship to sea ice. Journal of Geophysical Research Atmospheres, 116(23), 1-18. https://doi.org/10.1029/2011JD016383

Huang, B., Thorne, P. W., Banzon, V. F., Boyer, T., Chepurin, G., Lawrimore, J. H., ... Zhang, H. M. (2017). Extended reconstructed Sea surface temperature, Version 5 (ERSSTv5): Upgrades, validations, and intercomparisons. Journal of Climate, 30(20), 8179-8205. https://doi.org/10.1175/JCLI-D-16-0836.

Jonas T. D (2004) The volume of water filtered by a Continuous Plankton Recorder sample: the effect of ship speed, J. of Phytoplankton Research 26, 1499-1506.

Jones, P. D., Jonsson, T., \& Wheeler, D. (1997). Extension to the North Atlantic oscillation using early instrumental pressure observations from Gibraltar and south-west Iceland. International Journal of Climatology, 17(13), 1433-1450. https://doi.org/10.1002/(SICI)1097-0088(19971115)17:13<1433::AIDJOC203>3.0.CO;2-P

Josey, S. A., Hirschi, J. J.-M., Sinha, B., Duchez, A., Grist, J. P., \& Marsh, R. (2018). The Recent Atlantic Cold Anomaly: Causes, Consequences, and Related Phenomena. Annual Review of Marine Science, 10(1), 475-501. https://doi.org/10.1146/annurev-marine-121916-063102

Kalnay, E., Kanamitsu, M., Kistler, R., Collins, W., Deaven, D., Gandin, L., ... Joseph, D. (1996). The NCEP/NCAR 40-Year Reanalysis Project. Bulletin of the American Meteorological Society, 77(3), 437-471. https://doi.org/10.1175/1520-0477(1996)077<0437:TNYRP>2.0.CO;2

Kamenos, N. A. (2010). North Atlantic summers have warmed more than winters since 1353, and the response of marine zooplankton. Proceedings of the National Academy of Sciences, 107(52), 22442-22447. https://doi.org/10.1073/pnas.1006141107

Keller, M. D., Bellows, W. K., \& Guillard, R. R. L. (1989). Dimethyl sulfide production in marine phytoplankton. In Biogenic Sulfur in the Environment. ACS Symposium Series (Vol. 393, pp. 167-182). https://doi.org/10.1021/bk-1989-0393

Kettle, A. J., Andreae, M. O., Amouroux, D., Andreae, T. W., Bates, T. S., Berresheim, H., ... Uher, G. (1999). A global database of sea surface dimethylsulfide (DMS) measurements and a procedure to predict sea surface DMS as a function of latitude, longitude, and month. Global Biogeochemical Cycles, 13(2), 399-444. https://doi.org/10.1029/1999GB900004

Kinnard, C., Zdanowicz, C. M., Fisher, D. A., Isaksson, E., De Vernal, A., \& Thompson, L. G. (2011). Reconstructed changes in Arctic sea ice over the past 1,450 years. Nature, 479(7374), 509-512. https://doi.org/10.1038/nature10581 
Lana, A., Bell, T. G., Simó, R., Vallina, S. M., Ballabrera-Poy, J., Kettle, A. J., ... Liss, P. S. (2011). An updated climatology of surface dimethlysulfide concentrations and emission fluxes in the global ocean. Global Biogeochemical Cycles, 25(1), 1-17. https://doi.org/10.1029/2010GB003850

Legrand, M., Hammer, C., De Angelis, M., Savarino, J., Delmas, R., Clausen, H., \& Johnsen, S. J. (1997). Sulfurcontaining species (methanesulfonate and SO4) over the last climatic cycle in the Greenland Ice Core Project (central Greenland) ice core. Joumal of Geophysical Research: Oceans, 102(C12), 26663-26679. https://doi.org/10.1029/97JC01436

Maselli, O. J., Chellman, N. J., Grieman, M., Layman, L., McConnell, J. R., Pasteris, D., ... Sigl, M. (2017). Sea ice and pollution-modulated changes in Greenland ice core methanesulfonate and bromine. Climate of the Past, 13(1), 39-59. https://doi.org/10.5194/cp-13-39-2017

McConnell, J. R., Edwards, R., Kok, G. L., Flanner, M. G., Zender, C. S., Saltzman, E. S., ... Kahl, J. D. W. (2007). 20th-Century Industrial Black Carbon Emissions Altered Arctic Climate Forcing. Science, 317(5843), 1381-1384. https://doi.org/10.1126/science.1144856

Mernild, S. H., Hanna, E., Mcconnell, J. R., Sigl, M., Beckerman, A. P., Yde, J. C., ... Steffen, K. (2014). Greenland precipitation trends in a long-term instrumental climate context (1890-2012): Evaluation of coastal and ice core records. International Journal of Climatology, 320(March 2014), 303-320. https://doi.org/10.1002/joc.3986

Moore, J. K., Fu, W., Primeau, F., Britten, G. L., Lindsay, K., Long, M., ... Randerson, J. T. (2018). Sustained climate warming drives declining marine biological productivity. Science, 359(6380), 1139-1143. https://doi.org/10.1126/science.aao6379

Mosley-Thompson, E., Readinger, C. R., Craigmile, P., Thompson, L. G., \& Calder, C. a. (2005). Regional sensitivity of Greenland precipitation to NAO variability. Geophysical Research Letters, 32(December), 1-4. https://doi.org/10.1029/2005GL024776

Ortega, P., Lehner, F., Swingedouw, D., Masson-Delmotte, V., Raible, C. C., Casado, M., \& Yiou, P. (2015). A model-tested North Atlantic Oscillation reconstruction for the past millennium. Nature, 523(7558), 7174. https://doi.org/10.1038/nature14518

Osman, M., Das, S. B., Marchal, O., \& Evans, M. J. (2017). Methanesulfonic acid (MSA) migration in polar ice: Data synthesis and theory. Cryosphere, 11(6), 2439-2462. https://doi.org/10.5194/tc-11-2439-2017

Polashenski, D. J., et al. (2018). Denali ice core methansulfonic acid records North Pacific marine primary production, J. Geophys. Res. Atmos., 123, 4642-4653.

Rahmstorf, S., Box, J. E., Feulner, G., Mann, M. E., Robinson, A., Rutherford, S., \& Schaffernicht, E. J. (2015). Exceptional twentieth-century slowdown in Atlantic Ocean overturning circulation. Nature Climate Change, 5(5), 475-480. https://doi.org/10.1038/nclimate2554

Rayner, N. A., Parker, D. E., Horton, E. B., Folland, C. K., Alexander, L. V., Powell, D. P. (2003). Global analyses of sea surface temperature, sea ice, and night marine air temperature since the late nineteenth century. Joumal of Geophysical Research, 108(D14), 4407. https://doi.org/10.1029/2002JD002670

Reid, P. C., Edwards, M., Hunt, H. G., \& Warner, A. J. (1998). Phytoplankton change in the North Atlantic. Nature, 391(6667), 546. https://doi.org/10.1038/35290

Richardson, A. J., Walne, A. W., John, A. W. G., Jonas, T. D., Lindley, J. A., Sims, D. W., .. Witt, M. (2006). Using continuous plankton recorder data. Progress in Oceanography, 68(1), 27-74. https://doi.org/10.1016/j.pocean.2005.09.011

Saltzman, E. S., Whung, P.-Y., \& Mayewski, P. A. (1997). Methanesulfonate in the Greenland Ice Sheet Project 2 Ice Core. Journal of Geophysical Research: Oceans, 102(C12), 26649-26657. https://doi.org/10.1029/97JC01377 
Scarchilli, C., Frezzotti, M., \& Ruti, P. M. (2011). Snow precipitation at four ice core sites in East Antarctica: Provenance, seasonality and blocking factors. Climate Dynamics, 37(9-10), 2107-2125. https://doi.org/10.1007/s00382-010-0946-4

Schlosser, E., Oerter, H., Masson-Delmotte, V., \& Reijmer, C. (2008). Atmospheric influence on the deuterium excess signal in polar firn: Implication for ice-core interpretation. Journal of Glaciology, 54(184), 117-124. https://doi.org/10.3189/002214308784408991

Schmittner, A. (2005). Decline of the marine ecosystem caused by a reduction in the Atlantic overturning circulation. Nature, 434(7033), 628-633. https://doi.org/10.1038/nature03476

Sharma, S., Chan, E., Ishizawa, M., Gong, S. L., Li, S. M., Tarasick, D. W., .. Maenhaut, W. (2012). Influence of transport and ocean ice extent on biogenic aerosol sulfur in the Arctic atmosphere. 117. https://doi.org/10.1029/2011JD017074

Sinclair, K.E., Bertler, N.A., Trompetter, W.J. (2013). Seasonality of Airmass Pathways to Coastal Antarctica: Ramifications for Interpreting High-Resolution Ice Core Records. J. Climate, 26, 2065-2076.

Sgubin, G., Swingedouw, D., Drijfhout, S., Mary, Y. \& Bennabi, A. (2017). Abrupt cooling over the North Atlantic in modern climate models. Nat. Comm. 8, 14375.

Srokosz, M. A., \& Bryden, H. L. (2015). Observing the Atlantic Meridional Overturning Circulation yields a decade of inevitable surprises. Science, Vol. 348. https://doi.org/10.1126/science.1255575

Stein, A. F., Draxler, R. R., Rolph, G. D., Stunder, B. J. B., Cohen, M. D., \& Ngan, F. (2015). NOAA's hysplit atmospheric transport and dispersion modeling system. Bulletin of the American Meteorological Society, 96(12), 2059-2077. https://doi.org/10.1175/BAMS-D-14-00110.1

Stock, C. A., John, J. G., Rykaczewski, R. R., Asch, R. G., Cheung, W. W. L., Dunne, J. P., ... Watson, R. A. (2017). Reconciling fisheries catch and ocean productivity. Proceedings of the National Academy of Sciences, 114(8), E1441-E1449. https://doi.org/10.1073/pnas.1610238114

Sverdrup, H. U. (1953). On conditions for the vernal blooming of phytoplankton. ICES Journal of Marine Science, 18(3), 287-295. https:// doi.org/10.1093/icesjms/18.3.287

Takahashi, T., et al. (2009). Climatological mean and decadal change in surface ocean pCO2, and net sea-air CO2flux over the global oceans. Deep-Sea Research Part II: Topical Studies in Oceanography, 56(8-10), 554577. https://doi.org/10.1016/j.dsr2.2008.12.009

Thornalley, D. J. R., Oppo, D. W., Ortega, P., Robson, J. I., Brierley, C. M., Davis, R., ... Keigwin, L. D. (2018). Anomalously weak Labrador Sea convection and Atlantic overturning during the past 150 years. Nature, 556(7700), 227-230. https://doi.org/10.1038/s41586-018-0007-4

Trusel, L. et al. (2018). Nonlinear rise in Greenland runoff in response to post-industrial Arctic warming, Nature 564, 104-108.

Weißbach, S., Wegner, A., Opel, T., Oerter, H., Vinther, B. M., \& Kipfstuhl, S. (2016). Spatial and temporal oxygen isotope variability in northern Greenland - implications for a new climate record over the past millennium. Climate of the Past, 12(2), 171-188. https://doi.org/10.5194/cp-12-171-2016

Weller, R., F. et al. Postdepositional losses of methane sulfonate, nitrate, and chloride at the European Project for Ice Coring in Antarctica deep-drilling site in Dronning Maud Land, Antarctica (2004), J. Geophys. Res., 109, D07301.

Westberry, T., Behrenfeld, M. J., Siegel, D. A. \& Boss, E. (2008). Carbon-based primary productivity modeling with vertically resolved photoacclimation. Global Biogeochem. Cycles 22, 1-18.

Whung, P. Y., Saltzman, E. S., Spencer, M. J., Mayewski, P. A., \& Gundestrup, N. (1994). Two-hundred-year record of biogenic sulfur in a south Greenland ice core (20D). Journal of Geophysical Research, 99(D1), 11471156. https://doi.org/10.1029/93JD02732 


\title{
4. Enhanced coastal west Greenland hydroclimate variability during the Common Era
}

\begin{abstract}
Ice cores provide valuable, point-scale archives of past climatic conditions at high latitudes. While extensive effort has centered on records deriving from interior Greenland, low-lying and near-coastal Greenlandic ice core records have remained relatively under-sampled, limiting our long-term understanding of past maritime conditions. Here, we present results from a new, Common Era-scale ( A.D. 79 - 2015) ice core record recently extracted from an ice cap on the Nuussuaq Peninsula in coastal west-central Greenland (CWG). We develop an observationally-constrained glacier-flowline inversion framework, allowing us to both optimally-constrain the NU record age-depth scale while also developing robust insights into the ice cap's accumulation time-history. Our results reveal marked centennial-scale changes in CWG hydroclimate variability during the last millennium: as much as $\sim 20 \%$ decreases in snowfall accumulation rates across the canonical Medieval Warm Period (c. A.D. 950-1250) to Little Ice Age (A.D. 1350-1850) transition, followed by subsequent $\sim 40 \%$ increases into the modern. Both hydroclimatic shifts are drastically larger than those previously observed from inland Greenland records, suggesting an enhanced sensitivity of CWG hydroclimate conditions to large-scale Arctic surface air temperature variability over the last millennium. Moreover, we identify for the first time a rapid hydroclimate deterioration event in the mid-14 ${ }^{\text {th }}$ century CE, conspicuously foreshadowing the disappearance of the Greenlandic Norse by a matter of decades. As such, our findings provide the highest resolution and most coastal ice core data to date in support of a nonnegligible climatic contribution to Norse societal deterioration.
\end{abstract}




\subsection{Introduction}

Observations over recent decades (satellite-era, ca. A.D. 1979) have revealed accelerating surface melt and runoff along the peripheries of the western GrIS (Nöel et al., 2016; Trusel et al., 2018; Bevis et al., 2019), as well as widespread thinning, receding, and speeding-up of coastal-west Greenland (CWG) outlet glaciers (c. 1979; Moon et al., 2012; Moon et al., 2015). Via meltwater forcing, these glaciological changes directly impact future global sea level rise (Mouginot et al., 2019), with downstream impacts on oceanic thermohaline variability (Böning et al., 2016) and marine ecosystems vitality (Arrigo et al., 2017; Osman et al., 2019). Yet, while such observations have unambiguously highlighted the sensitivity of CWG to i) atmospheric warming, ii) ocean circulation variability (Holland et al., 2008, Khazendar et al., 2019), iii) and sea ice cover declines (Liu et al. 2015), little remains known of the long-term (i.e., multidecadal to centennial-scale) response of CWG to large-scale internal and external climate forcing. An improved understanding of the response of CWG across a range of timescales is thus of critical, global-scale interest.

Whereas numerous terrestrial climate proxy records (e.g., moraines, lake sediments, lichens) exist from sites spanning the central to southwestern Greenland seaboard (Fig. 4-1a), these records are of typically low-temporal resolution and (or) dating precision, often suffering from local (i.e., basinscale) biases and (or) aliasing which have rendered their collective interpretation challenging (Lasher and Axford, 2019; Fig. S4-1). In particular, North Atlantic climate variability over the last millennium is conventionally marked by a transition between three major intervals: the Medieval Warm Period (MWP; c. A.D. 950 - 1350), the Little Ice Age (LIA; c. A.D. 1450 - 1850), and contemporary postIndustrial-era warming (c. A.D. 1850). Yet, despite their close proximity, one might aptly infer either consistent (e.g., Axford et al., 2013; Thomas et al., 2016; Lasher and Axford, 2019) or paradoxical climate conditions in CWG (Young et al., 2015, Jamelli 2016; Sha et al., 2017; Schweinsberg et al., 2017) to these conventionally-defined climatic intervals depending on the particular CWG record referenced (Fig. S4-1).

Converse to these coastal-terrestrial proxy records, international efforts conducted over the past half-century have produced a multitude of high-resolution, temporally extensive records from sites spanning the interior Greenland Ice Sheet (GrIS; Fig. 4-1a; Jouzel, 2013). Nonetheless, coastal ice core records, defined as deriving from ice caps geographically- and glaciologically-distinct from the main GrIS, have remained scarce, limiting our understanding of past maritime and coastal climate conditions (Mernild et al., 2014; Wong et al., 2015). To date, coastal ice cores extending beyond the 
last millennium have been recovered from ice caps situated on the northern (Flade Isblink, Lemark, 2014; Hans Tausen, Hammer et al., 2001) and eastern (Renland; Hansson et al., 1994) Greenlandic seaboards; this has left coastal west Greenland (CWG) largely unattended (Fig. 4-1a).

In Spring 2015, we recovered a high-resolution, intermediate depth ice core record - the "NU" record - from an ice cap perched atop the Nuussuaq Peninsula, west Greenland $\left(70.49^{\circ} \mathrm{N}, 52.26^{\circ} \mathrm{W}\right.$, 2010 meters above sea level), the most-coastal ice core to date in CWG (Trusel et al., 2018). Moisture-source modeling (Sodemann et al., 2008; Läderach and Sodemann, 2016; see Section 4.6.2) for the NU ice cap, conducted at high-frequency across a multi-decadal timeframe (c. 1980 - 2013), highlights the locally-biased source of moisture deposited as snow atop this ice cap (Fig. 4-1b,c; Fig. S4-S2), revealing the NU record as well-poised for inferring past hydroclimate conditions along the CWG margin and greater Baffin Bay maritime province. Here, we describe the methodology used to date the NU core, including - principally - the development of a novel, observationally-constrained ice cap flowline inversion method allowing us to infer past NU ice cap accumulation variability. We explore the climatic influences underlying CWG hydroclimate variability, highlighting the first-order influence of regional surface air temperature (SAT) variability. Finally, we conclude by discussing the potential role that a rapid, and newly-identified, $14-15^{\text {th }}$ coastal hydroclimate deterioration event may have played in the demise of the Greenlandic Norse "Vikings".

\subsection{Ice core dating and NU ice-cap flowline inversion}

The NU ice core covers an age range of A.D. 2015 to approximately A.D. 79, based on the identification of 55 tie points identified over the span of the core length. These tie points represent depth-horizons of well-prescribed snow deposition age within the ice column, and reference $20^{\text {th }}$ century radiogenic bomb horizons (2 ties; identified via ${ }^{239} \mathrm{Pu}$; Arienzo et al., 2016), volcanic eruptions (49 ties, identified primarily via non-sea-salt sulfate (nssS) and ECM), as well as several unambiguous heavy-metal horizons ( $\mathrm{Pb}$ and Ti) identified across interior Greenlandic ice cores (4 ties; McConnell et al., 2018; see also see Section 4.6.1 and Table S4-1).

The NU ice core was drilled to a depth of $\sim 138$ meters, shy of bedrock at a location marginally downslope of the ice cap summit (Fig. 4-2; see Section 4.6.1). Estimates of ice cap thickness, derived from a combination of field-team ground penetrating radar (Section 4.6.1) and NASA Operation IceBridge-derived laser altimetry (e.g., Csatho et al., 2014) measurements, suggest the NU ice cap is geometrically-confined atop a smoothly-domed promontory, with an estimated depth at the drill 
location of $\sim 153 \pm 10 \mathrm{~m}$ (142 $\mathrm{m}_{\text {ice}}$; Fig. 4-2a). The physical setting of the NU ice cap is advantageous for understanding past CWG glacial-climatic interactions for the following reasons: first, the steep promontory on which the ice cap rests sets a natural upper limit on its areal coverage, while likely also moderating associated changes in its thickness under variable climate conditions (Cuffey and Patterson, 2010). Second, the smoothness of the underlying bed topography suggests that relatively simple glacial flow-conditions prevail at the NU ice cap (Dansgaard and Johnsen, 1969); such suggestions are supported by borehole temperature measurements showing static cold-based thermal conditions persisting throughout the NU core depth below $\sim 40$ meters (Fig. S4-4).

Provided these considerations, we developed a 1-dimensional, physically-based ice flowline inverse method in order to both i) refine our age-scale and ii) establish an accumulation history of the NU ice cap, relying on the 55 age-tie points identified along the core length (see also Fudge et al., 2014). Our approach sought a core-depth thinning function - representing the ratio between the iceequivalent thickness of a given annual layer to its original thickness when deposited at the surface of the NU ice cap - that produces an accumulation history that is both "simple" (i.e., denoting minimal deviations in accumulation rate from the NU site's climatological mean) and consistent with our observations (tie points; Section 4.6.3). To better-constrain the inversion, we mandated constant accumulation variability between age-constraints. This permitted a median accumulation rate resolution of 27 years (quantile range 15-42 years). In particular, we sought to minimize the cost function $(J)$ :

$$
J\left(\mathbf{m}\left(\dot{b_{0}}, H_{0}\right)\right)=\left\|\frac{G\left(\mathbf{m}\left(\dot{b_{0}}, H_{0}\right)\right)-\mathbf{d}}{\boldsymbol{\sigma}}\right\|^{2}+\lambda\left\|\mathbf{m}\left(\dot{b_{0}}, H_{0}\right)\right\|^{2}
$$

Here, the vector $\mathbf{m}$ includes the snow accumulation rates at different times for the NU ice cap which are the unknowns of the inverse problem, $\dot{b_{0}}$ is a site-representative (climatological) accumulation rate, and $H_{0}$ is a site ice-cap thickness (assumed stationary in time). The nonlinear function $G\left(\mathbf{m}\left(\dot{b_{0}}, H_{0}\right)\right)$ represents a forward 1-dimensional ice flow model (Dansgaard and Johnsen, 1969; Cuffey and Patterson, 2010), mapping our accumulation history onto an idealized depth-age scale that assumes only steady-state $\dot{b_{0}}$ and $H_{0}$ conditions (see Section 4.6.3), whereas the vector $\mathbf{d}$ contains the 55 observed age-constrained depths; the difference between the two are normalized by the observed depth-uncertainties $(\boldsymbol{\sigma})$. The weight value $\lambda$ specifies the relative importance of the layer thicknesses 
and the data misfits in determining $J$, conditioning the ill-constrained problem for uniqueness. All squared brackets denote the standard (Euclidian, or L2) norm. Note that minimizing the first term of Eq. (4.1) improves the match between the time-depth scale at the data points, while minimizing the second term yields a simpler solution; minimizing both terms gives a solution that balances between the two, the exact solution dictated in turn by the choice of $\lambda$.

We used an iterative one-dimensional solver (Fudge et al., 2014) to minimize $J$ across a range of $H_{0}$ (120 to $165 \mathrm{~m}$ ice eq.), and $\dot{b}_{0}\left(0.2\right.$ to $\left.0.45 \mathrm{~m}_{\text {ice }} \mathrm{yr}^{-1}\right)$ reference-values. For each combination, we recorded the value of the cost (Eq. 4.1), revealing a minimum "complexity" (i.e., most simple and consistent $\mathbf{m}$ ) at $H_{\text {opt }}=141 \mathrm{~m}_{\text {ice }}$ and $\dot{b}_{\text {opt }}=0.325 \mathrm{~m}_{\text {ice } \mathrm{yr}^{-1}}$ (Fig. 4-3c and Fig. S4-5 and S4-6). Although we expect that the least-complex accumulation variation should indicate the correct values of the reference accumulation rate and the ice thickness, we have no reason to believe that a model that is slightly more complex than the least-complex model is incorrect. As such, we nominally prescribe the distribution of accumulation models whose complexity was no more than $10 \%$ larger than that of the least-complex model as indicative of the uncertainty in our dating process. These values delineate a skewed ellipse, with acceptable thicknesses between 138 and $144 \mathrm{~m}_{\text {ice, }}$ and acceptable reference accumulation rates between 0.30 and $0.35 \mathrm{~m}_{\text {ice }} \mathrm{yr}^{-1}$ (Fig. 4-3c,d). Remarkably, the leastcomplex ice thickness $\left(141 \mathrm{~m}_{\text {ice }}\right)$ is only $1 \mathrm{~m}$ thinner than the radar-derived value of $142 \mathrm{~m}_{\text {ice, }}$ well within the error bounds for either estimate. The recovered NU accumulation rate histories for all such models are provided in Figure 4-3d, each showing broad agreement albeit with increasing divergence (that is, relative uncertainty) at progressively deeper depths (or, older portions) of the NU core.

Further insight into the sensitivity of our accumulation reconstruction framework under variable $H_{\text {opt }}$ reference values (of which the magnitude of recovered NU accumulation change depends most strongly on; Fig. 4-3c), is provided in Figures 4-3a,b. We compared the idealized depthage models for three reference values of the ice thickness: the least-complex thickness, $H_{\text {opt }}=141$ $\mathrm{m}_{\text {ice, }}$, as well as $H_{\text {opt }} \pm 10 \mathrm{~m}_{\text {ice, }}$, each paired with our least-complex reference accumulation value $\left(\dot{b}_{\text {opt }}\right)$. All corresponding age-scales agree well at shallow depths, but diverge noticeably at depths greater than approximately $100 \mathrm{~m}_{\text {ice }}$ where large variations in depth-ages are increasingly dictated by small variations in ice strain. Fig. 4-3b shows the locally-optimum NU accumulation histories needed to bring the three model age scales into agreement with the picked ages. For $H_{0}=131 \mathrm{~m}_{\text {ice, }}$ accumulation rate must increase over much of the core's time-history to compensate for the added strain implied 
by the thinner ice cap. The converse is true for $H_{0}=151 \mathrm{~m}_{\mathrm{ice}}$, where the annual layers must be relatively thin to compensate for weaker thinning. The deviations from the global optimum accumulation rate for $H_{0}=131 \mathrm{~m}_{\text {ice }}$ and $H_{0}=151 \mathrm{~m}_{\text {ice }}$ each imply enhanced model complexity, with $J$-values (30.59 and 23.35) both larger than the constrained-minimum $J$-value $(J=10.40)$. Importantly, however, the form of variability over the last millennium appears robust across all models.

\subsection{Enhanced CWG hydroclimate variability during the last millennium}

Our reconstructed NU accumulation record reveals marked changes in CWG hydroclimate conditions across the last millennium. Specifically, we observe abrupt decreases in NU ice cap accumulation averaging nearly $14-20 \%$ moving out of the late-MWP (A.D. $14^{\text {th }}$ c.) into the height of the LIA (A.D. $17^{\text {th }}$ century), followed by subsequent $\sim 40 \%$ increases going from the LIA into contemporary “Industrial-era" conditions (A.D. $20^{\text {th }}$ century; Fig.'s 4-3 and 4-4). All changes are substantially larger than last-millennium variability recorded by two interior Greenland ice cores (GRIP and GISP2) collected near the summit of the GrIS (Fig. 4-4a; Dahl-Jensen et al., 1993; Meese et al., 1994), highlighting both the enhanced sensitivity of CWG hydroclimate variability to large-scale climatic shifts during the last millennium, as well as the exceptional ability of CWG ice caps to respond to (and hence record) such variability (Fig. 4-4).

We find remarkable multidecadal- to centennial-scale covariation $(r=0.70 ; p<0.001)$ between our NU accumulation record and a recent Common Era-scale reconstruction of pan-Arctic SAT (McKay and Kaufman, 2014). To better constrain the mechanisms relating NU accumulation to regional changes in SAT and (Baffin Bay) sea-ice extent (SIE), we employ Lagrangian-based estimates of NU precipitation from the state-of-the-art FLEXPART-v9.0 moisture-source (back-trajectory) model (Sodemann et al., 2008; Läderach and Sodemann, 2016; see also Section 4.6.2). In doing so, we presume hereafter that our reconstructed NU accumulation history is most strongly dicated by regional (CWG) changes in annual accumulated precipitation, thus assuming therein that changes in sublimation and (or) melt-induced surface runoff losses have imparted only negligible impacts on NU ice cap annual accumulation during much of the Common Era (see also, Trusel et al., 2018).

FLEXPART-modeled annual accumulated precipitation atop the NU ice cap significantly covaries with contemporaneous station-based CWG observations over decadal ( $p<0.001$; Fig. 4-4; Fig. S4-10i-iii) down to seasonal timescales (Fig. S4-2; Cappelan, 2018), lending confidence in the 
ability of the model to adequately resolve underlying CWG hydroclimate dynamics. Therein, our FLEXPART results corroborate the close association observed between the pan-Arctic SAT reconstruction (McKay and Kaufmann, 2014) and our NU accumulation record (Fig.'s 4-7 and S4-9), suggesting a nominal CWG precipitation sensitivity of $0.032 \pm 0.007 \mathrm{~m}_{\text {ice }} \mathrm{yr}^{-1}$ per degree centigrade moisture-source warming (Fig. S4-8). This sensitivity value is broadly in line with a more spatially intuitive NU-ice core accumulation sensitivity of $0.033 \pm 0.011 \mathrm{~m}_{\text {ice }} \mathrm{yr}^{-1}$ per degree centigrade warming in pan-Arctic SAT, determined from temporal overlap ( 140-160 years) between reconstructed NU accumulation and an ensemble of independent climate-reanalyses (Fig. S4-8; Jones et al., 2012; Compo et al., 2011; Lenssen et al., 2019).

We find the reciprocal condition, however, is not as strongly upheld: FLEXPART-modeled CWG precipitation and Baffin SIE anomalies exhibit only marginal-association (Fig. S4-7b) across recent decades (Methods), notwithstanding coupled SIE-SAT linkages that may be important across longer, multidecadal to centennial timescales (Guillevic et al., 2013). We hypothesize the poor correlative association between CWG-precipitation and regional SIE reflects the underlying summertime seasonal bias in CWG annual accumulated precipitation observed in both model- and station-based measurements (Cappelan, 2018; Fig. S4-2b). In particular, FLEXPART results reveal that changes in CWG annual accumulated precipitation are most-strongly driven by changes in summertime marine evaporation proximal to the NU Peninsula during the months July-AugustSeptember (Fig. S4-9). Given that sea ice cover is typically absent across this region during latesummertime months, interannual changes in near-surface (i.e., boundary layer) saturation vapor pressure and evaporation are most-likely governed predominantly by the (temperature-dependent) Clausius-Claperyon relation (Sodemann et al., 2008), highlighting again the primary role that regional SAT variability plays in dictating changes in CWG precipitation.

Moreover, the significant positive-association we observe between changes in NUaccumulation and pan-Arctic SAT strongly contradicts prior contentions of "paradoxical" CWG climate conditions during the MWP and LIA (Young et al., 2015, Jamelli 2016; Schweinsberg et al., 2017). In particular, Young et al. (2015) and Jomelli et al. (2016) used independent cosmogenicnuclide exposure moraine-dating methods to infer centennial-scale changes in nearby CWG outlet glacier termini positions (that is, $\sim 50 \mathrm{~km}$ and $\sim 140 \mathrm{~km}$ to the southeast and south of NU, respectively), concluding that CWG outlet glaciers reached their most-advanced last-millennium state during the classical peak of the MWP (A.D. 11-12 ${ }^{\text {th }}$ centuries) thereafter receding during the LIA (Fig. 4-4a,i). While both teams (in the prior absence of CWG ice cap accumulation histories) interpreted the 
advanced MWP glacial-termini positions as representing prevailing CWG cold conditions during the MWP, our results imply instead that the advanced MWP termini positions reflect the positive influence of regional SAT's on CWG-precipitation. Specifically, we suggest that enhanced local and far-field moisture-uptake during the MWP markedly increased annual accumulation rates across CWG ice caps, facilitating ice cap growth and expansion, and hence the advancement of CWG ice cap glacial termini.

We caution, however, that the apparent linear relationship between high-latitude SAT and NU accumulation we observe (Fig. 4-4) may not remain stationary provided unabated future warming of the Arctic, but instead become subject to threshold-like (nonlinear) behavior. Indeed, our annuallyresolved NU accumulation estimates hint at a shift towards an anomalous negative correlation with coastal SAT measurements during the most-recent 2-3 decades (Fig. S4-10). This time period coincides with an increase in summertime surface melt to levels unprecedented over the preceding centuries (and possibly millennia; Trusel et al., 2018). We speculate such observations could indicate an ongoing shift from a positive to negative SAT-mass balance regime at NU. Continued monitoring and future work across a range of CWG ice caps will help better-elucidate the relationships between local and regional SAT changes, ice cap melt, and annual mass balance (i.e., accumulation) changes.

\subsection{Potential impacts on the collapse of the Greenlandic Norse}

Due to its close vicinity, precise dating, and strong coherence with regional (Fig. S4-10) and broadscale (Fig. 4-4) SAT variability, our CWG hydroclimate record allows us to establish novel insights into hydroclimatic changes potentially conditioning the colonization - and subsequent disappearance - of Norse Viking society in southwestern Greenland during the early last millennium. As is told in the Greenlandic Sagas (Thorsson, 2001), the Norse colonization of Greenland commenced in A.D. 985, part of a broader pattern of Norse Atlantic-expansion ongoing since the $\sim 7-8^{\text {th }}$ century A.D. (Dugmore et al., 2012; Hartmann et al., 2017). Representing perhaps the most geographically-remote and inhospitable European outpost of the Medieval Period, the underlying socioeconomic, climatic, cultural factors influencing Norse inhabitation of Greenland remains a topic of considerable debate (Dugmore et al., 2012). However, it is the unknown circumstances behind the late $14^{\text {th }}$ to early $15^{\text {th }}$ century disappearance of the Greenlandic Norse in particular that has especially fascinated both scholars and the public alike for centuries (e.g., Dansgaard et al., 1975; Diamond, 2005).

The last known mention in the Icelandic Annals of commerce to or from the Greenlandic colonies references a wedding in A.D. 1408 in the southerly-situated Eastern Settlement, whereas the Western Settlement, situated $\sim 600 \mathrm{~km}$ to the north, is believed to have succumbed some half a century 
prior (Hartmann et al., 2017). Popular contention (e.g., Diamond, 2005) has held that a warmer Atlantic-sector climatic state (i.e., the MWP) likely facilitated the Norse colonization of Greenland, therein encouraging the adoption of a culturally-familiar pastoral-based agricultural patriarchy in CWG, while also allowing marine commerce and trade to be conducted with mainland Europe with relative ease; indeed, both Greenlandic Norse subsistence and economy ultimately relied on both aspects to varying degrees (Dugmore et al., 2012; Frei et al., 2015). Supporting conjecture has thus historically centered on the notion that these basic tenets of Norse society progressively eroded under a gradual, multi-generational shift towards a colder climatic state (i.e., the LIA). However, studies now increasingly recognize the exceptional flexibility and adaptability of the Greenlandic Norse across successive generations, and suggest that societal deterioration more likely originated from the inauspicious confluence of several socioeconomic and climatic factors (Dugmore et al., 2012).

In either case, robust paleoclimatic evidence underpinning a potential link between climate and Norse societal adaptation has thus far remained sparse. Given the low resolution and large uncertainties surrounding extant terrestrial records proximal to the Eastern and Western Settlements (Fig. S4-1), prior studies (Dansgaard et al., 1975; Barlow et al., 1997; Patterson et al., 2010; Dugmore et al., 2012) have most-often invoked climatic insights from interior GrIS ice core water isotopic (primarily reflecting temperature at condensation and atmospheric transport processes) or geochemical (reflecting atmospheric circulation or storminess) records (Meeker et al., 1997). However, notwithstanding the previously-demonstrated relative insensitivity of interior GrIS ice core records to CWG climate variability (Fig. 4-4), such records reveal only moderate multidecadal variability and (or) secular trends during the period of Norse inhabitation, with - by our interpretation - scant evidence of any single climatic precursor predating the Norse collapse (e.g., Fig. 4-4).

In contrast to these prior records, our coastal NU accumulation record shows - for the first time - a conspicuous collapse of moderate coastal west Greenland hydroclimate conditions during the early-mid $13^{\text {th }}$ century, both portending the disappearance of the Western and Eastern Settlements by a matter of decades (Fig. 4-4) and signaling a rapid onset of LIA-like conditions that ensued for a subsequent three to four centuries. Confidence towards the veracity of this abrupt hydroclimate event is provided by both the high-precision and high-density of age-constraint depths in our NU chronology across the $12^{\text {th }}-15^{\text {th }}$ centuries A.D (Fig. 4-2; Fig. S4-3 and S4-6), and an exceptional consistency in the timing and relative magnitude of the event across a broad range of less-thanacceptable recovered NU accumulation histories (Fig. 4-3). 
The abruptness of the mid- $14^{\text {th }}$ century CWG hydroclimate shift, as suggested in our NU accumulation record, represents a notable departure from prior high-resolution multi-proxy-based reconstructions of pan-Arctic SAT's (which in turn actually show an increase in pan-Arctic SAT's prior to the Eastern Settlement collapse; Fig. 4-4), suggesting that the $14^{\text {th }}$ century CWG hydroclimate changes reflected by our record represents a previously-unknown, regionally-confined hydroclimate phenomenon that was potentially dissociated from large-scale SAT changes (Fig. 4-4). The underlying climatic drivers of this event are currently unknown, but may represent regional ice-ocean responses to large-scale volcanic forcing during the late $13^{\text {th }}$ to early $14^{\text {th }}$ century (Miller et al., 2012) or weakening in the Atlantic subpolar gyre to the south (Moreno-Chamarro et al., 2016). One line of evidence linking potential-attempts at Norse adaptation to this hydroclimate event come from the shifting dietary habits of Eastern Settlement Norse inhabitants, as derived from carbon and nitrogen isotopic analyses on excavated skeletal remains (Arneborg et al., 1999). In particular, the timing of a step change in Norse dietary habits, shifting from predominantly terrestrial-based (i.e., $~ 20-50 \%$ marinebased) to nearly $60-80 \%$ marine-based diet over the span of about a generation, is remarkably coeval with that of the mid- $14^{\text {th }}$ century collapse in CWG hydroclimate conditions. We speculate that following this hydroclimate event, rapidly declining precipitation rates and CWG temperatures - in conjunction with population food-shortage pressures - would have necessitated a large-scale dietary shift from predominantly pastoral-based agriculture to predominantly subsistence-based hunting of marine mammals (e.g., seals; Ogilvie et al., 2009), the latter of which the Norse may have been culturally maladapted and (or) ill-equipped to adjust to under a short (i.e., single-generation) timespan (Dugmore et al., 2012).

Moreover, rapidly-deteriorating CWG temperatures, as suggested by the NU accumulation record, would have likely also manifested (either in response to or as a result of) through increases in regional sea ice cover. Concievably, this would have also restricted migration into and out of both Settlements during a broad portion of the year, diminishing maritime accessibility to key trading and hunting routes (the latter centered around dense walrus nesting grounds surrounding Disko Bay; Ogilvie et al., 2009; Dugmore et al., 2012). The Western Settlement, due to its northerly location and close-proximity to the wintertime sea-ice extent maxima (Walsh et al., 2016), would have been particularly susceptible to such changes (Barlow et al., 1997). Collectively, we hypothesize that the relatively abrupt shift from moderate CWG hydroclimate conditions (Fig. 4-4), exacerbated by compounding socioeconomic pressures (e.g., the devaluation of walrus ivory, the primary Norse 
export to Europe, Frei et al., 2015; Star et al., 2018) and increased cultural isolation from Europe, combined to make the continued habitation of CWG untenable by the mid $15^{\text {th }}$ century.

\subsection{Conclusions}

Here, we report on a new high-resolution terrestrial climate record - and first Common Era-scale ice core - from CWG to date. We present a novel glacier flowline inversion framework which, in tandem with high precision estimates of the NU ice core chronology, allow us to reconstruct marked changes in CWG hydroclimate variability over the last millennium with a high degree of confidence. Our results show that, contrary to prior reports, paradoxical climate conditions did not characterize the last millennium in CWG, which were characterized instead by enhanced - often abrupt - changes in temperature and precipitation. Therein, we find that changes in NU ice cap accumulation and panArctic temperature variability are strongly and near-linearly coupled over much of the Common Era, notwithstanding a period of rapidly declining CWG hydroclimate conditions that has new implications for understanding the late-Medieval period collapse of the Greenland Norse settlements.

\subsection{Methods}

\subsubsection{Ice core drilling, processing, and dating}

Drilling was conducted over the span of three days in April 2015 using an 81-mm diameter EclipseBadger Drill provided by the University of Wisconsin's Ice Drilling and Design and Operations (IDDO) program, reaching a (contiguous) bottom depth of $137.97 \mathrm{~m}$ below the surface, shy of bedrock. Borehole temperature measurements were conducted at $\sim 10 \mathrm{~m}$ intervals, indicating an 11.5 $\mathrm{m}$ temperature of $-6.54^{\circ} \mathrm{C}$ and a core-bottom temperature of $-13.38^{\circ} \mathrm{C}$ (Fig. S4-4).

Ice core processing was conducted in June 2015 at the United States Geological Survey's National Ice Core Laboratory (Lakeland, CO) in a Class-100 HEPA-filtered cold room $\left(-24^{\circ} \mathrm{C}\right)$, where the Nuussuaq core was cut into $\sim 3 \times 3 \mathrm{~cm}$ longitudinal sections ("sticks") for subsequent chemical analysis. Several complimentary, non-destructive measurements were conducted at NICL, including replicate core density measurements and 1-mm resolution Electrical Conductivity Measurements (i.e., ECM; both alternating current (AC) and direct current (DC); Taylor et al., 1992) for volcanic layer identification.

The Nuussuaq core was stored for a $\sim$ year at NICL at $-34^{\circ} \mathrm{C}$, prior to being transported to the Desert Research Institute (DRI; University of Nevada, Reno). At DRI, chemical analyses were 
conducted for the entirety of the core over a one-week span in mid-May 2016 using a continuous (icecore) melter system. Technical aspects of the DRI continuous melter system have been previously described, both in original detail by McConnell et al. (2002), with several recent updates noted by Maselli et al. (2017). Measurements conducted at DRI on the Nuussuaq ice core included simultaneous, depth-registered concentration measurements of 10 trace species $(\mathrm{Na}, \mathrm{Mg}, \mathrm{S}, \mathrm{Cl}, \mathrm{Ca}, \mathrm{Br}$, $\mathrm{Sr}, \mathrm{Ce}, \mathrm{Ti}$, and $\mathrm{Pb}$ ) from two Inductively-Coupled Plasma Mass Spectrometers (ICP-MS); water isotope abundances $\left(\delta^{18} \mathrm{O}\right.$ and $\delta \mathrm{D}$ of $\left.\mathrm{H}_{2} \mathrm{O}\right)$ from a Picarro ${ }^{\mathrm{TM}}$ liquid water analyzer, black carbon concentrations from a single particle soot photometer (SP2; Droplet Measurement Technologies ${ }^{\mathrm{TM}}$, Boulder, $\mathrm{CO})$, soluble chemistry $\left(\mathrm{NH}_{4}{ }^{+}, \mathrm{HNO}_{3}{ }^{-}\right)$and conductivity using Continuous Flow Analysis (CFA; see Pasteris et al., 2012 for details), and semi-quantitative particle concentrations using an Abacus $^{\mathrm{TM}}$ particle counter. In total, 17 parameters were measured at continuous $\sim 2 \mathrm{~cm}$ water equivalent resolution over the entire depth of the core. Additionally, 24 low-resolution measurements $(\sim 0.3-0.5 \mathrm{~m})$ of ${ }^{239} \mathrm{Pu}$, a proxy for atmospheric nuclear weapons testing, were conducted over targeted shallow to mid-depth portions of the core (23 - $33 \mathrm{~m}$ depth; Arienzo et al., 2016) for dating purposes.

The shallowest $90.79 \mathrm{~m}$ of the core ( $2 / 3$ of the core depth), down to the Huaynaputina (Peru) volcanic eruption reference horizon at 1601 A.D. (Sigl et al., 2015), contains the best-dated portion of the core ( $<2 \mathrm{yr}$ relative uncertainty), as vertical strain and associated thinning of annual layers have not yet become severe so as to preclude the identification of seasonality in most chemical parameters (Fig. 4-2b and Fig. S4-3). In deeper portions, where seasonality in chemical parameters could no longer be adequately discriminated, dating relied on the synchronization of well-prescribed volcanic (Sigl et al., 2013; Sigl et al., 2015) and heavy metal (McConnell et al., 2018) horizons to alternate well-dated inland GrIS cores (e.g., NGRIP2, NEEM-2011-S1; Fig. S4-3). Although semisubjective by nature, we consider age-constraint depths down to the A.D. 536 mega-eruption horizon (Larsen et al., 2008; $132.64 \mathrm{~m}$ ) to be well-constrained ( $\sigma \leq 5 \mathrm{yr}$ ) given this portion of the NU record's sufficient time-resolution $\left(>1\right.$ sample year ${ }^{-1}$ ) and multi-parameter approach used for tie-point synchronization (Fig. S4-3 and Table S4-1). Due to thinning of annual layers below $132.64 \mathrm{~m}(<1 \mathrm{yr}$ per sample; Fig. 4-2), the identification of tie points in the deepest $\sim 3$ meters of core relied moreintensively on 1-mm resolution alternating-current Electrical Conductivity Measurements (AC-ECM; Fig. S4-3) synchronized to the aforementioned interior GrIS ice core records (McConnell et al., 2018). Below the A.D. 536 horizon, relative uncertainty is estimated to $10 \mathrm{yr}$ at A.D. 424 (Sigl et al., 2015), increasing to $1 \sigma=30$ years at A.D. 169.5, the deepest (volcanic) age-horizon identified (Fig. 4-2b; Fig. S4-3). 


\subsubsection{NU moisture source tracking}

We quantitatively assessed seasonal and interannual variability in the geographic moisture source(s) of precipitating airmasses over the Nuussuaq Peninsula following the method of Sodemann et al. (2008). We incorporated the FLEXPART v9.0 Lagrangian particle dispersion model (Stohl et al., 2005) to advect airmasses backwards in time over the span of 10 days for all airmasses resulting in precipitation over the Nuussauq Peninsula grid cell. Air parcel trajectories were forced by European Center for Medium Range Weather Forecast (ECMWF) ERA-Interim reanalysis velocity fields at $1^{\circ} \times 1^{\circ}$ horizontal resolution over 60 vertical levels (Dee et al., 2011) over the time period AD 1980-2013. Specifically, we inferred moisture gains (diagnosed as evaporation) or losses (presumed to represent precipitation only if losses were $>0.10 \mathrm{~mm} \mathrm{~m}^{-2}$ day ${ }^{-1}$ over a given grid cell) along a given trajectory by tallying the specific humidity content of that air parcel over space in 6-hour time steps. Using this method, the percentage of explained moisture contained in a given air-parcel at each successive time step could be quantified through a mass-weighted summing and differencing of evaporation and precipitation events along that air parcel's trajectory. By using this budgeting approach, over multiple (34) years the relative contribution of precipitated-moisture derived from a given evaporative-source region could be similarly assessed, along with accompanying, spatially-weighted metrics such as time series of moisture-source SAT (e.g., Fig. 4-4; Fig. S4-7).

\subsubsection{NU ice cap glacier flowline inversion}

We formed an initial estimate of the age-depth scale for our core based on a thinning function, $C(t)$, that gives the ratio of the ice-equivalent thickness of a layer deposited in year $t, T_{c}(t)$, to its original thickness when it was deposited at the surface, $T_{0}(t)$. In this model, the thickness of any layer found in the core is:

$$
T_{c}(t)=C(t) T_{0}(t)
$$

The depth for the age-depth scale for time $t$ is found by adding the thicknesses of all layers with ages less than $t$. The thinning function $C(t)$ is estimated based on a one-dimensional flow model for a constant accumulation rate, in which the vertical strain rate, $\dot{\epsilon}(z)$ at any height $z$ above the ice cap bed $0<z \leq H$ (where $H$ is the surface height above the bed) is proportional to the depth- 
dependent horizontal velocity, $u(z)$. If the basal velocity is zero, and if the ice temperature does not vary strongly with depth, then integrating Glen's flow law (Cuffey and Paterson 2010; Dansgaard and Johnsen, 1969) from the bed to height $Z$ gives:

$$
u(z)=u_{H}\left[1-\left(1-\frac{z}{H}\right)^{n+1}\right]
$$

where the creep exponent $n=3$ is prescribed following convention (Cuffey and Paterson, 2010). If $\dot{\epsilon}(z)$ is proportional to $u(z)$, then

$$
\dot{\epsilon}(z)=-\dot{\epsilon}_{H} \frac{u(z)}{u_{H}},
$$

where $\dot{\epsilon}_{H}$ and $u_{H}$ denote the vertical strain rate and horizontal velocity at the ice cap surface, respectively. The integral of the vertical strain rate from the bed to the surface gives the vertical velocity, $w$, at the surface, equal to:

$$
w_{H}=-\dot{\epsilon}_{H}\left(H \frac{n+1}{n+2}\right)
$$

or, solving for $\dot{\epsilon}_{H}$ gives the surface vertical strain rate:

$$
\dot{\epsilon}_{H}=-\frac{w_{H}}{H} \frac{n+2}{n+1}
$$

This expression is similar to that for the mean strain rate (equal to the accumulation rate divided by the ice thickness) but because the strain rate near the bed is small, the surface strain rate must be larger than the mean. The final expression for the vertical strain rate as a function of height above the bed is then:

$$
\dot{\epsilon}(z)=\dot{\epsilon}_{H}\left[1-\left(1-\frac{z}{H}\right)^{n+1}\right]
$$

The vertical velocity at any depth is found by integrating $\dot{\epsilon}(z)$ from the bed to $z$ : 


$$
w(z)=-\dot{\epsilon}_{H} H\left[1-\frac{1}{n+2}-\left(\mu-\frac{1}{n+2} \mu^{n+2}\right)\right]
$$

Here, $\mu=1-\frac{z}{H}$. An idealized steady-state age-depth scale for time $t$ can be found by integrating the position of a particle as it traverses the vertical-velocity field from the surface at time $-t$ to $t=0$ using the vertical-velocity depth profile (Eq. 4.8). The thinning function $C(t)$ is the exponential of $\dot{\epsilon}_{H}$, integrated as a function of time along a layer's path from $H$ to its final depth, $z$ :

$$
C(t)=\exp \left[\int_{-t}^{0} \dot{\epsilon}(z(t)) d t\right]
$$

Age-depth scales calculated using this scheme depend on the initial layer thickness (i.e., accumulation rate or surface vertical velocity) and the total ice thickness. If the accumulation rate varies in time, then during the time between a layer's surface deposition and its recovery in an ice core, the ice thickness will change, and the thinning rate will differ from that given by Eq. 4.9 for constant $w_{H}$. However, as long as the thickness variation over the lifetime of a layer is small, we expect that layer thicknesses calculated with Eq. 4.9 will not differ substantially from those of a steady-state model with $w_{H}$ equal to the site mean "reference" accumulation rate, $\dot{b}_{0}$. Under this assumption, we calculate an age-depth scale from Eq. 4.2 using $C(t)$ (Eq. 4.9) and $w_{H}=-\dot{b}_{0}$ in Eq.'s 4.6 and 4.7. Under this assumption, we expressed the age-depth scale, $\delta(t)$, as a linear function of $\dot{b}(z(t))$ and a non-linear function of $\dot{b}_{0}$ and the ice cap "reference" thickness, $H_{0}$ :

$$
\delta\left(t ; \dot{b}_{0}, H_{0}\right)=\dot{b}_{0} \sum_{i=0}^{t} s_{i} C\left(t_{i} ; \dot{b}_{0}, H_{0}\right)
$$

Here $s_{i}$ represents a set of scalar values that give the ratio between the thickness of the annual layer deposited at year $i=0,1, \ldots t$ and $\dot{b}_{0}$. Age-constraint depths specify a few of the estimated 1935 annual layers in the core, but to calculate $\delta(t)$ we need to find estimates of $s_{i}$ for the remaining layers, under prescribed $\dot{b}_{0}$ and $H_{0}$. Alone, Eq. 4.10 does not allow for a unique solution for these quantities, so we look for a set of solutions that give the least-complex accumulation histories that match the $k$ 
$=1,2, \ldots n$ age-constrained depths, $\delta_{0, k}$, to within their estimated age-constrained depth uncertainties $\left(\sigma_{k}\right)$. These solutions minimize the cost function, $J$ :

$$
J=\sum_{k=1}^{n}\left(\frac{\delta\left(t_{k} ; \dot{b}_{0}, H_{0}\right)-\delta_{0, k}}{\sigma_{k}}\right)^{2}+\lambda \sum_{i=0}^{t}\left(s_{i}-1\right)^{2}
$$

The scalar $\lambda$ is a weight value that specifies the relative importance of the layer thicknesses and the data misfits in determining $J$. Minimizing the first term improves the match between $\delta(t)$ at the $n$ age-constrained depths $\left(\delta_{0, k}\right)$, minimizing the second term yields a simpler solution; minimizing both at the same time gives solutions that balance between the two, the particulars of the solution depending on the choice of $\lambda$ (Lundin, 2012; Fudge et al., 2014).

The $n$ age-constrained depths only provide information about the thickness of groups of layers, not on individual layers, so to further simplify the problem, we assume that $S$ is constant between pairs of depth picks, thus specifying a mean accumulation- rate scale for the interval $t_{k}$ to $t_{k+1}$. With this simplification, Eq. 4.11 becomes:

$$
J=\sum_{k=1}^{n}\left(\frac{\delta\left(t_{k} ; \dot{b}_{0}, H_{0}\right)-\delta_{0, k}}{\sigma_{k}}\right)^{2}+\lambda \sum_{i=0}^{k}\left(t_{k+1}-t_{k}\right)\left(s_{k}-1\right)^{2}
$$

To express this equation as a set of matrix multiplications, we use the notation:

$$
J=\left(\boldsymbol{G} \boldsymbol{s}-\boldsymbol{\delta}_{\mathbf{0}}\right)^{T} \boldsymbol{\Sigma}^{-1}\left(\boldsymbol{G} \boldsymbol{s}-\boldsymbol{\delta}_{\mathbf{0}}\right)^{T}+\lambda(\boldsymbol{s}-\boldsymbol{\gamma})^{T} \boldsymbol{W}(\boldsymbol{s}-\boldsymbol{\gamma})
$$

with bolded-uppercase denoting a matrix, bolded-lowercase a vector, and unbolded-lowercase a scalar. Here,

$$
\boldsymbol{G}=\left[\begin{array}{cccccc}
g_{11} & 0 & \cdots & 0 & \cdots & 0 \\
g_{21} & g_{22} & \cdots & 0 & \cdots & 0 \\
\vdots & \vdots & \ddots & \vdots & \ddots & \vdots \\
g_{k 1} & g_{k 2} & \cdots & g_{k k} & \cdots & 0 \\
\vdots & \vdots & \ddots & \vdots & \ddots & \vdots \\
g_{n 1} & g_{n 2} & \cdots & g_{n k} & \cdots & g_{n n}
\end{array}\right], \text { wherein, }
$$




$$
g_{k}=\dot{b}_{0} \int_{t_{k-1}}^{t_{k}} C\left(t ; \dot{b}_{0}, H_{0}\right) d t
$$

That is, $\boldsymbol{G}$ is a lower-triangular $n \times n$ matrix comprised of idealized ice equivalent thicknesses (predicted ice equivalent thicknesses under some combination of prescribed steady-state $\dot{b}_{0}$ and $H_{0}$ ) between the surface and $n$ age-constrained depths. The $n \times 1$ vector $\boldsymbol{s}$ consists of the mean accumulation rate-scalar values amongst the $k$ corresponding age-intervals, $t_{k}$ to $t_{k+1} . \mathbf{\Sigma}$ is a diagonal matrix consisting of the $n$ squared depth-uncertainty values $\left(\sigma^{2}\right)$. In the second term, $\boldsymbol{W}$ is a diagonal matrix consisting of $\boldsymbol{\gamma}=\left[\left(t_{1}-0\right) \ldots\left(t_{k}-t_{k-1}\right) \ldots\left(t_{n}-t_{n-1}\right)\right]$.

For a given value of $\lambda, J$ is minimized by some $\boldsymbol{S}$ for which $\frac{d J}{d \boldsymbol{s}}=0$, that is, the least-squares solution to Eq. 4.13. We assume that if the error estimates for our layer picks are well-prescribed and the errors Gaussian-normal, the first term of Eq. 4.11 for the true age-depth relationship will exhibit a $\chi^{2}$ distribution consisting of $n-1$ degrees of freedom. Thus, solving Eq. 4.13 for $\boldsymbol{s}$ under different values of $\lambda$ gives a range of $\chi^{2}$. We consider the value of $\boldsymbol{s}$ that corresponds to $\chi^{2}=n-1$ to be the locally optimum model: the simplest model that matches the data to within the specified error tolerances under prescribed $\dot{b}_{0}$ and $H_{0}$. 


\section{Ch. 4 Figures}
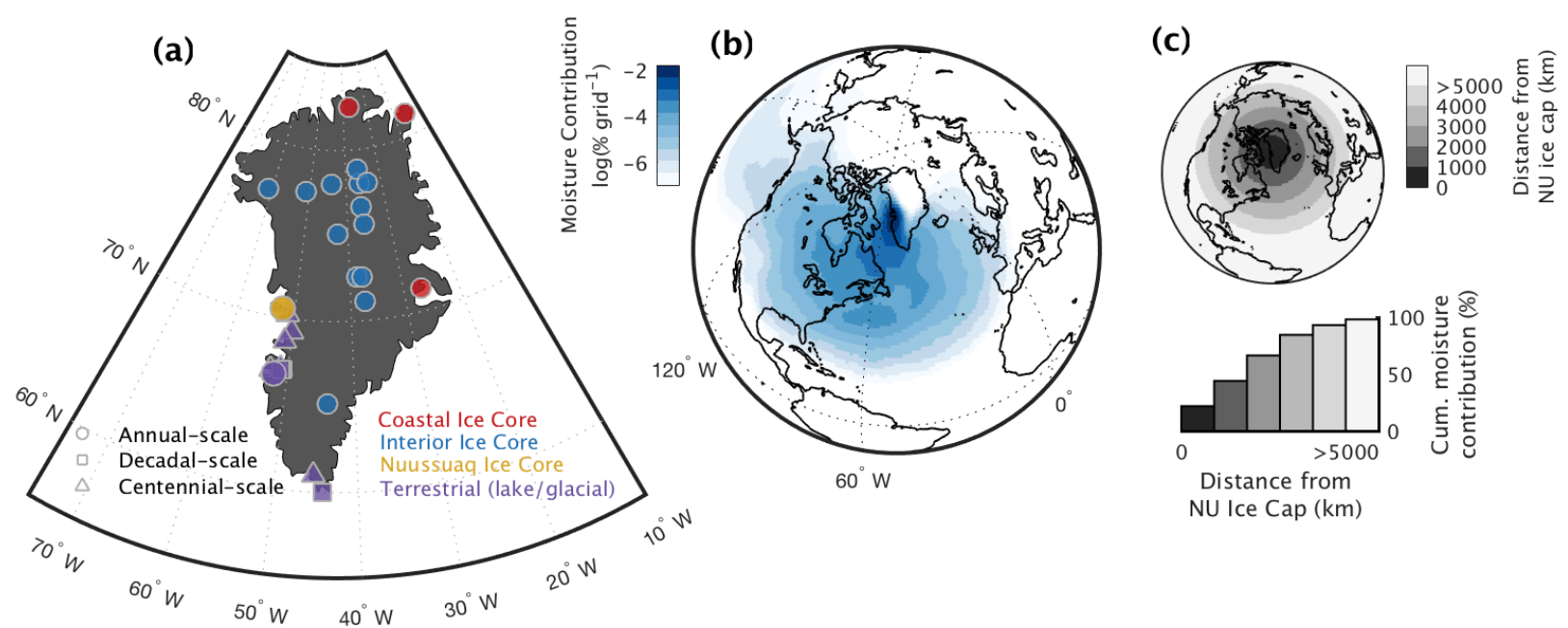

Figure 4-1: (a) Prior ice core sites whose record length extend beyond the last millennium; red sites show ice cores from coastal Greenlandic ice caps, blue sites show ice cores from the interior GrIS, and yellow denotes the Nuussuaq ice cap ice-core location. Locations of terrestrial climate records containing $>10$ data points during the last millennium are also shown in purple (see also Fig. S1). (b) Percent contribution of the NU annual moisture budget per degree latitude-longitude (log-transformed), inferred from Lagrangian atmospheric analyses (see Section 4.6.2) over the satellite-era (c. 1980). (c) Cumulative moisture contribution from (b), now shown as a function of distance from the NU ice core site, further illustrating the localized nature of moisture sources. 

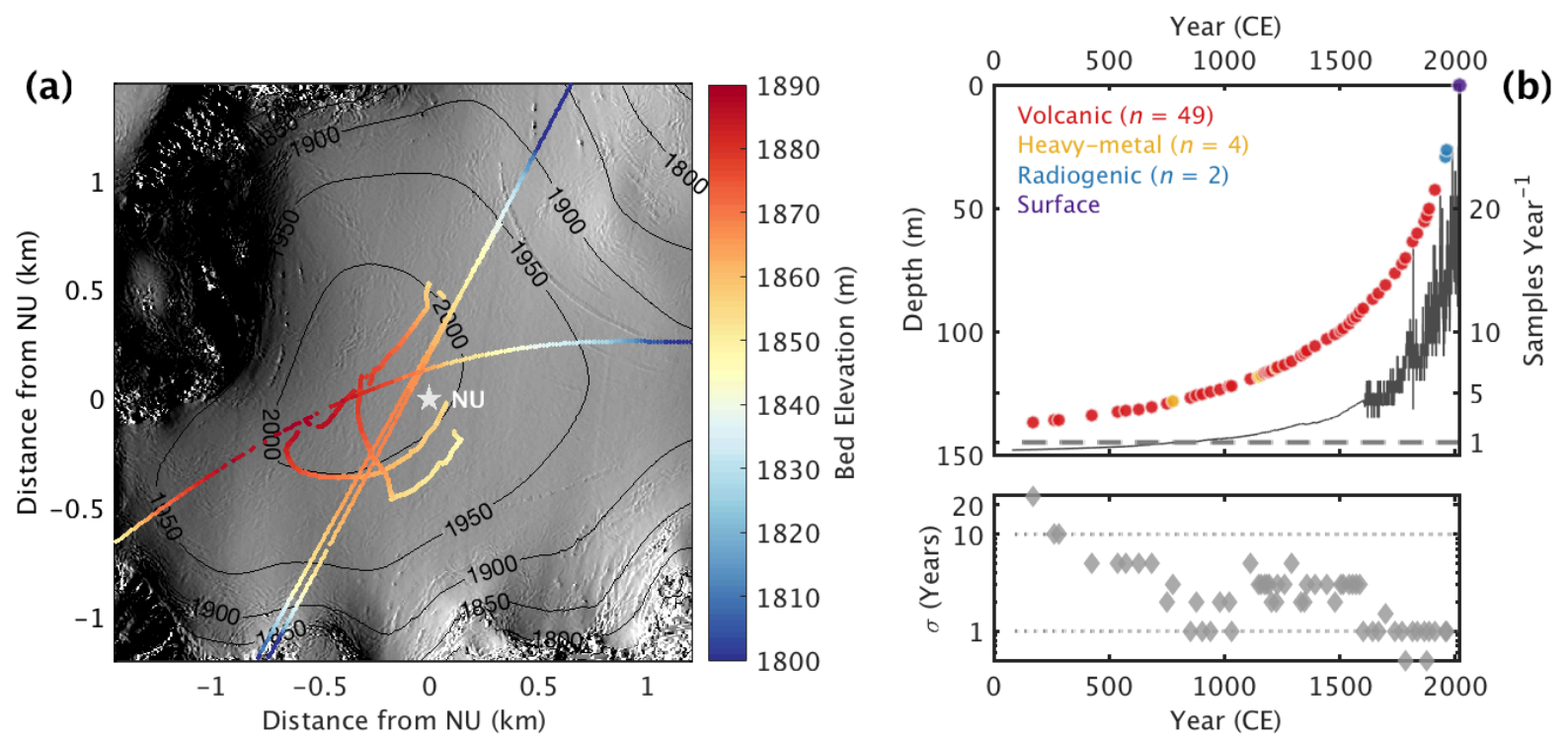

Figure 4-2: (a) Location map showing a digital elevation model (DEM) derived from the Worldview-4 stereo pair satellite-sensor (contours and shaded-relief grayscale), and bed-elevation measurements (meters above sea level) derived from ground-based radar (irregular lines) and three NASA Operation Ice Bridge airborne-radar transects (diagonal lines). The $\mathrm{NU}$ ice core site $\left(70.49^{\circ} \mathrm{N}, 52.26^{\circ} \mathrm{W}\right)$ is shown by a white star. Coordinates are relative to the core site in the Greenland polar stereographic projection. (b) Top panel: Age-constraint depths chosen for the NU core, with chemistry-sampling resolution (dashed line denotes the 1-year resolution sampling limit); annual layer counting was possible to A.D. 1601. Bottom panel: corresponding $1 \sigma$ age-uncertainties in the depth-age constraints. 

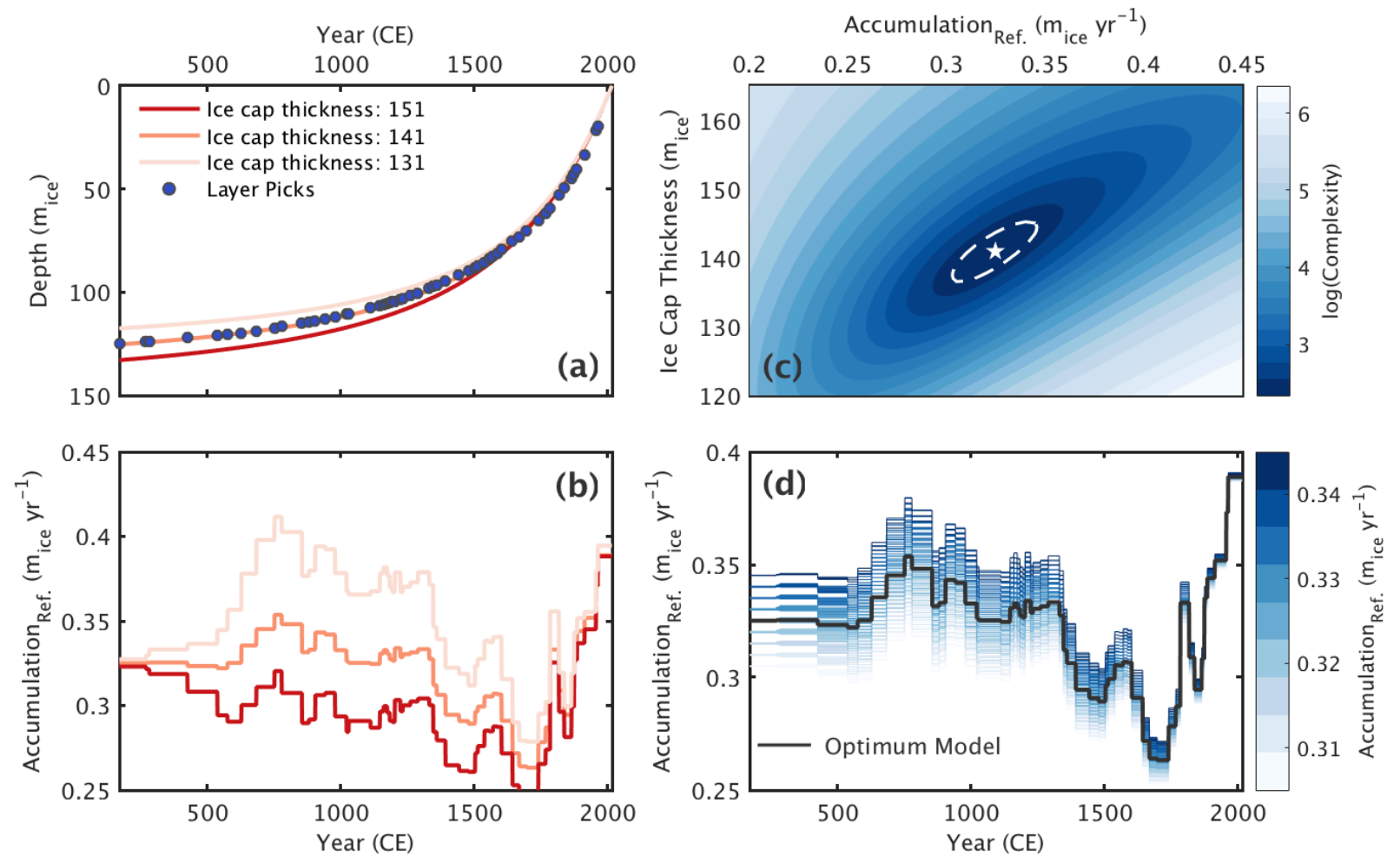

Figure 4-3: (a) Predicted (i.e., forward modeled) age-depth scales under three different reference ice thickness $\left(H_{0}=H_{\text {opt }}=141 \mathrm{~m}_{\text {ice }}\right.$ and $\left.H_{0}=H_{\text {opt }} \pm 10 \mathrm{~m}_{\text {ice }}\right)$ values and a constant reference accumulation $\left(\dot{b}_{0}=\dot{b}_{\text {opt }}=\right.$ $0.325 \mathrm{~m}_{\text {ice }} \mathrm{yr}^{-1}$ ). The depth-age-constraints (Fig. 2b) are shown for comparison. (b) Recovered NU accumulation histories estimates for the predicted age-depth scales shown in (a). (c) Model complexity for refined age-depth scales over a range of $H_{0}$ and $\dot{b}_{0}$ values. The white-dashed contour shows models that are less than $10 \%$ more complex than the optimum model. (d) Recovered NU accumulation histories for all models that are less than $10 \%$ more complex than the optimum (least complex) model. Each history is color coded by its reference accumulation value. 


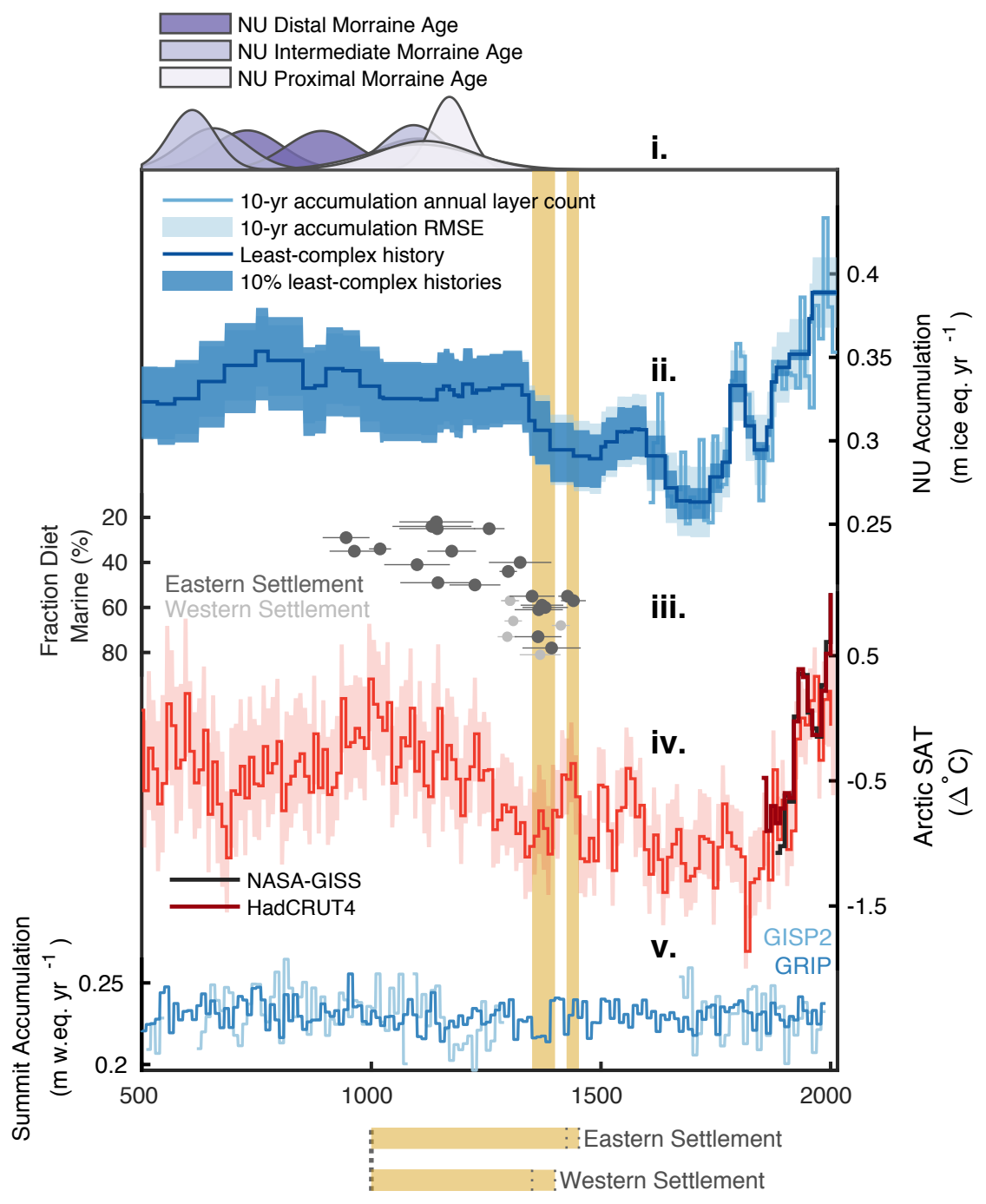

Figure 4-4: From top: (i.) Nuussuaq Peninsula outlet glacier terminal-moraine age probability density functions reproduced from Young et al. (2015). The "distal" moraine dates refer to the most advanced glacier terminus position, "proximal" the most recessed glacier terminus position (albeit advanced relative to the LIA/present day positions), and "intermediate" intermediate between the two. (ii.) The recovered optimum NU accumulation history with the $10 \%$ least complex confidence interval. Also shown superimposed is the 10-yr binned accumulation history for the portion of the core allotting for annual layer counting (ALC), with the 10yr root-mean-square-error offset between the optimum NU accumulation history and the ALC accumulation history. (iii.) Marine-based percentage of Greenland Norse diet over time, derived from carbon-isotopic analysis of Norse bone fragments (Arneborg et al., 1999). (iv.) Multi-proxy 10-yr binned reconstruction of panArctic SAT's from McKay and Kaufman (2014). Overlain in dark red are 10-yr mean-binned pan-Arctic $\left(>60^{\circ} \mathrm{N}\right)$ SAT's from the HadCRUT4 (Jones et al., 2012), against which the Kaufman et al. (2014) reconstruction is calibrated against, and Arctic temperatures in the NASA-GISS (Lenssen et al., 2019) reanalysis product for comparison. Red shading denotes the $\pm 1 \sigma$ uncertainty range in the SAT reconstruction (v.) Previously-published (Dahl-Jensen et al,. 1993; Meese et al, 1994) accumulation histories for Summit, Greenland, shown at mean 10-yr binned resolution (see also Fig S9), illuminating the low precipitation sensitivity at interior, high-elevation GrIS sites to SAT changes. Vertical yellow bands denote the inferred timerange of the Eastern (right band) and Western (left band) Greenlandic Norse settlement collapses. 


\section{Ch. 4 Supporting figures}
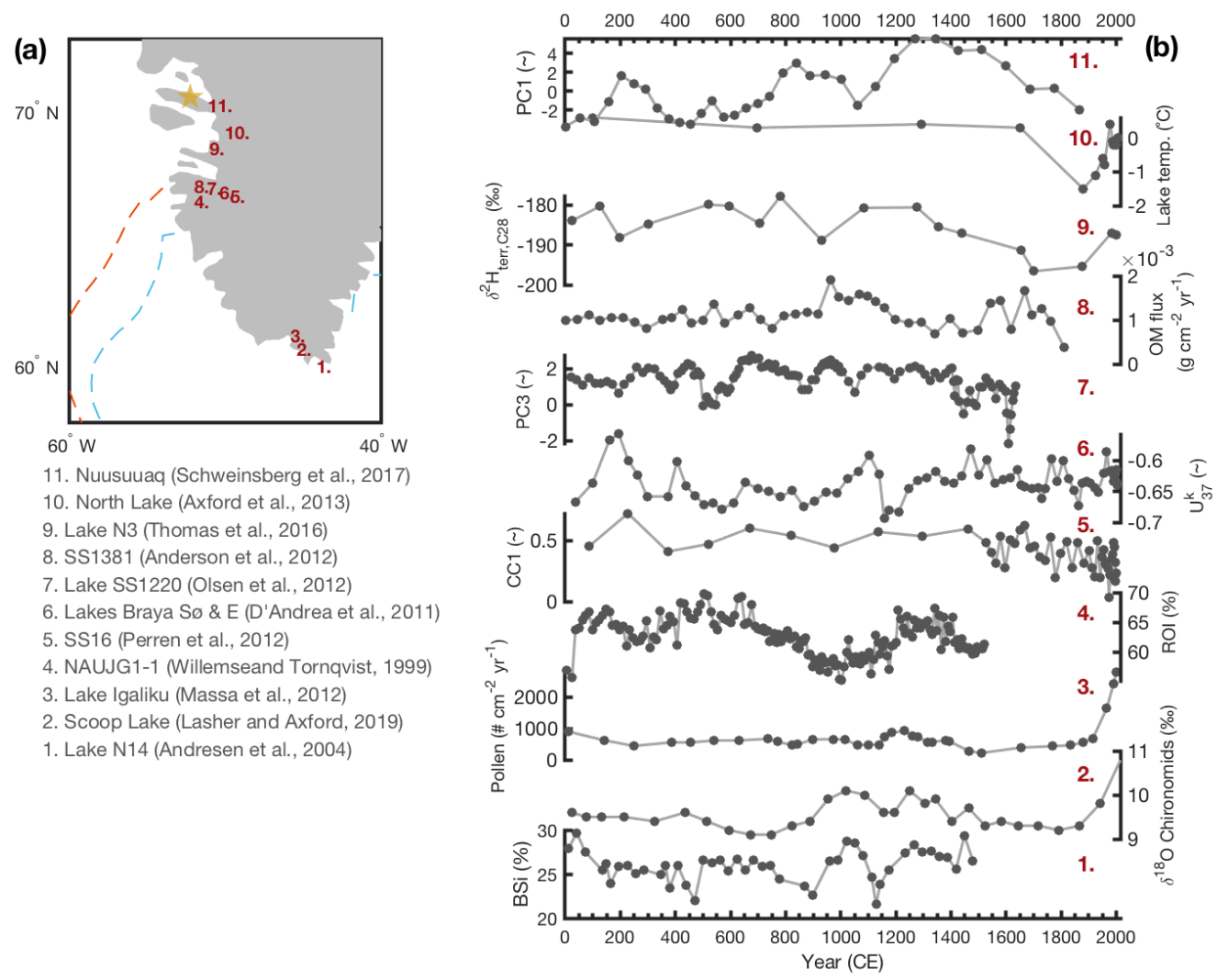

Figure S4-1: (a) Locations of terrestrial CWG temperature proxy records. Records shown are limited to those previously published containing at least 10 data points during the Common Era. Sites are numbered from 1-11, representing most-southerly to most-northerly situated. Dotted lines show the mean wintertime-maxima (blue) and annual average (red) sea ice extent (15\% concentration) over the satellite era (c. 1979). (b) Corresponding time series of the terrestrial temperature-driven proxies, shown from most northerly (top) to southerly-situated (bottom), illustrating the conspicuous lack of consistency amongst the climatic indicators. (11.) First component of Principal Component Analysis ("PC1"; 56\% variance) derived from several physical properties (e.g., magnetic susceptibility, density, organic matter, and metals) measured from Sikuiui Lake sediments, Nuussuaq Peninsula; a higher loading is interpreted to mean enhanced glaciation, or colder summertime temperatures (Schweinsberg et al., 2018). (10.) Reconstructed July lake temperatures derived from chironomidabundance assemblages from North Lake, CWG (Axford et al., 2013). (9.) Lake N-3 $\delta^{2} \mathrm{H}$ of C28 n-alkanoic acids, produced by terrestrial plants, inferred to (positively) reflect changes in summertime temperature. (8.) Organic matter fluxes for SS1381 (Anderson et al., 2012), inferred to relate to temperature via its positive relationship with meltwater (positive response on organic matter flux), wind, and vegetation variability. (7.) PC3 reflects parameters associated with redox conditions in lake $\mathrm{S} 1220$ (Mn, $\mathrm{Mn} / \mathrm{Fe}, \mathrm{Ca} / \mathrm{Ti}$ and grey scale), associated with NAO-like atmospheric circulation (higher PC3 means generally colder CWG temperatures; Olsen et al., 2012). (6.) Alkenone unsaturation $\left(U_{37}^{K}\right)$ from Braya Sø, a proxy (positive relationship) for lake air temperature (D'Andrea et al., 2011). (5.) First canonical correspondence analysis mode (CC1) of SS16 diatom assemblages, with an inferred positive relationship to temperature (Perron et al., 2012). (4.) Residue-on-ignition (ROI) from the NAUJG1.1 lake sediment core, indicating a positive relationship with air-temperature (Willemse and Törnqvist, 1999). (3.) Pollen flux to Lake Igaliku, CWG, inferred to have a positive relationship with temperature. (2.) Lake temperature reconstruction of Scoop Lake using the $\delta^{2} \mathrm{H}$ content of chironomid, showing a positive relationship to temperature (Lasher and Axford, 2019). (1.) Biogenic silica abundances in Lake N14 (Andresen et al., 2004), with an inferred positive relationship to local water temperature. 

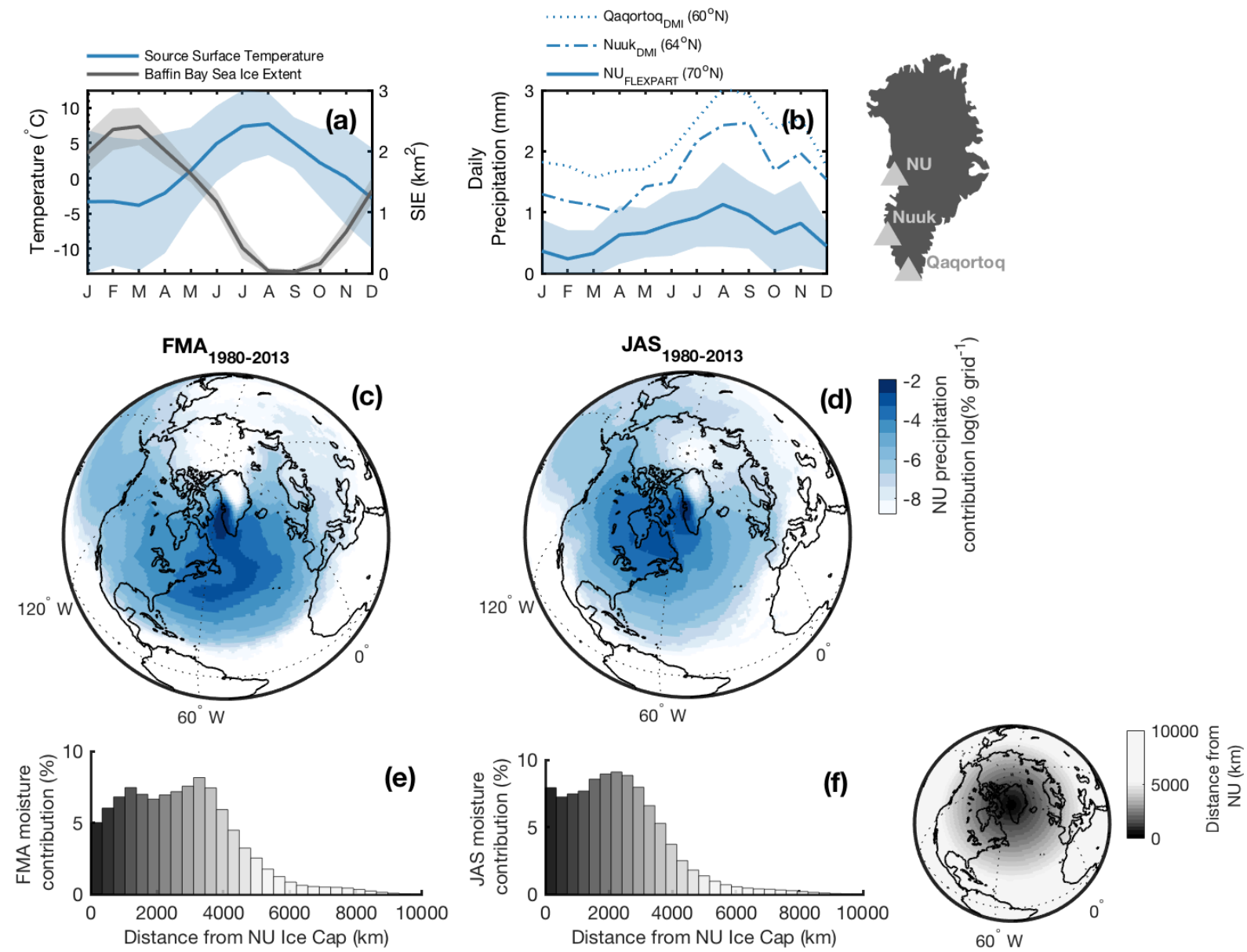

Figure S4-2: (a) The FLEXPART-modeled (A.D. 1980-2013) seasonal cycle of moisture-source surface air temperature (blue), contrasted against the seasonal cycle of Baffin Bay (defined $85-45^{\circ} \mathrm{W}$ and $40-80^{\circ} \mathrm{N}$ ) sea ice extent from ERA-Interim during the same period (SIE; grey). Thick lines denote the mean and shaded bands the $1 \sigma$ range. (b) The FLEXPART-modeled seasonal cycle for NU precipitation. The bold line denotes the median and shaded bands the median absolute deviation range. Also shown in (b) are observed precipitation rates derived from Danish Meteorological Institute (DMI; Cappelen, 2018) weather-stations in Nuuk $\left(64^{\circ} \mathrm{N}\right)$ and Qaqortoq $\left(60^{\circ} \mathrm{N}\right.$; see also inset Greenland map to the right of (b)). (c) Percent contribution of the NU annual moisture budget per degree latitude-longitude (log-transformed), inferred from FLEXPART (Section 4.6.2) during February-March-April (FMA). (d) As in (c), but for July-August-September (JAS). (e) and (f): Percent moisture contribution as a function of distance from the NU ice core site, shown for FMA and JAS, respectively (see also Fig. 1b-c). Bar plots in (e) and (f), and inset globe to the right of (f), are color-coded by distance from the NU ice core site. 


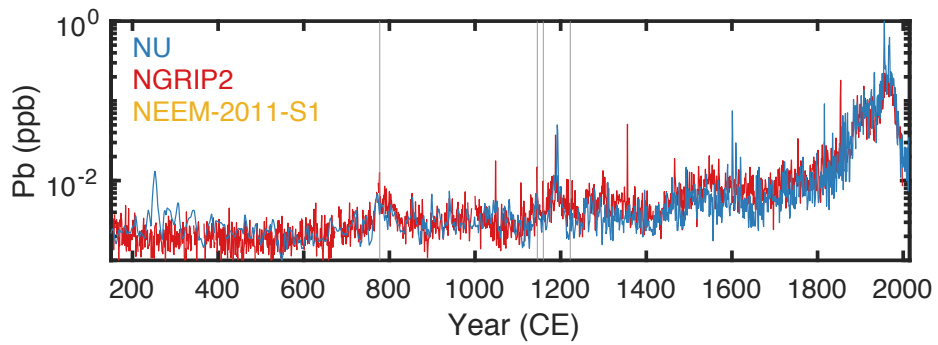

(a)

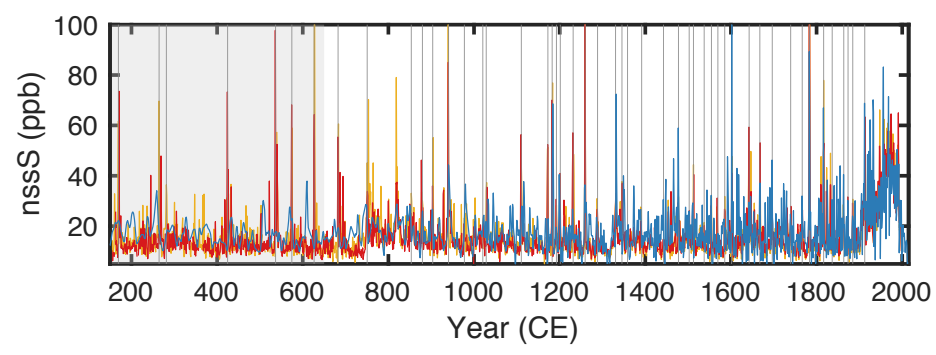

(b)

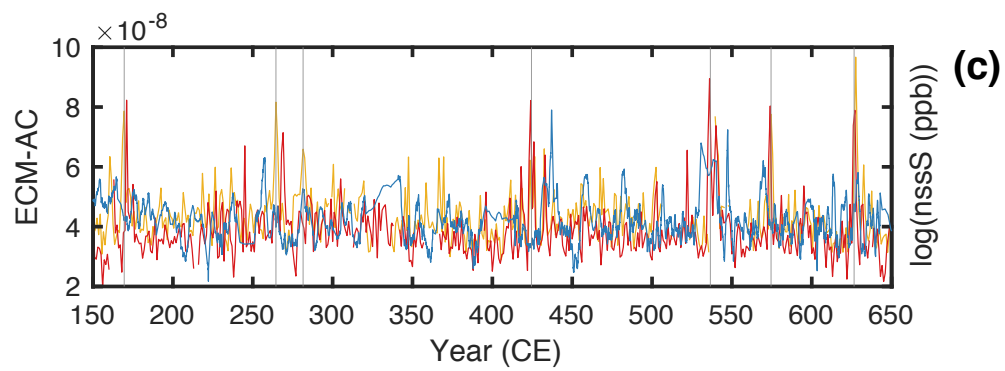

Figure S4-3: Comparison of the NU ice core record with well-dated, interior GrIS NGRIP2 and NEEM-2011$\mathrm{S} 1$ records for (a) $\mathrm{Pb}$, and (b) non-sea-salt-(nss)S. Alternating-current Electrical Conductivity Measurements (AC-ECM), conducted at high-resolution $(1 \mathrm{~mm})$, are shown for the deepest (oldest) portion of the core alongside the NGRIP2 and NEEM-2011-S1 log-transformed nssS records in (c). Tie points identified using the various parameters along the core length are shown as vertical grey bands. 

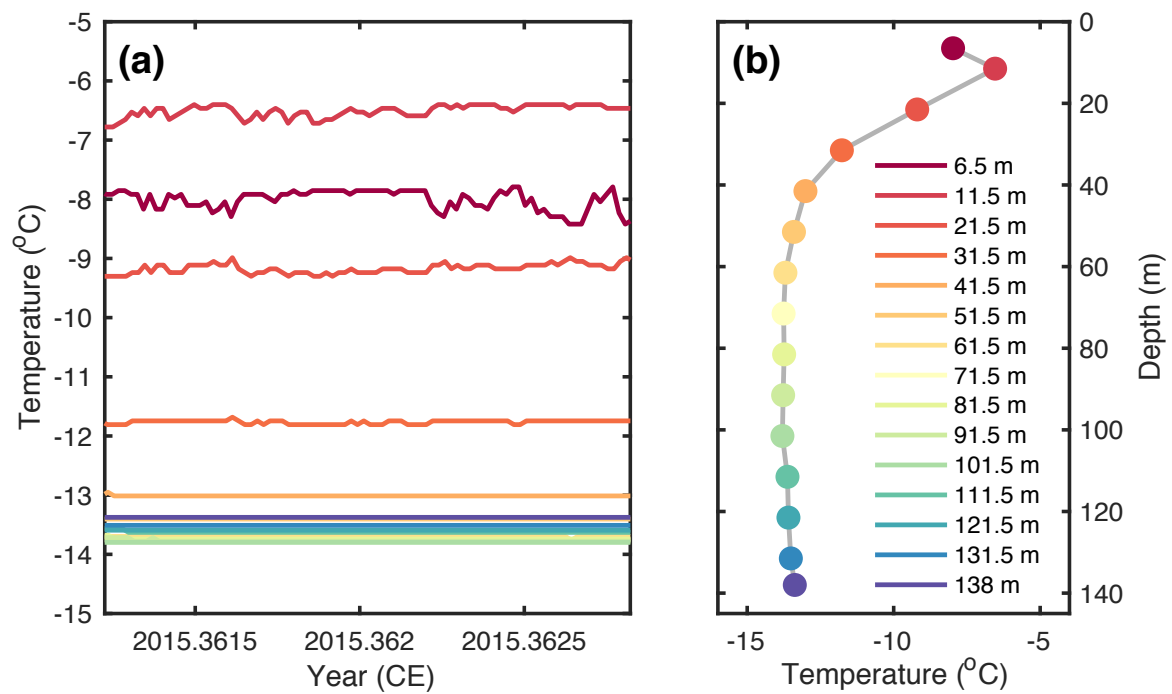

Figure S4-4: Borehole temperatures measured over the span of multiple days at the NU ice core site in April 2015, shown as a function of (b) time and (a) depth. 

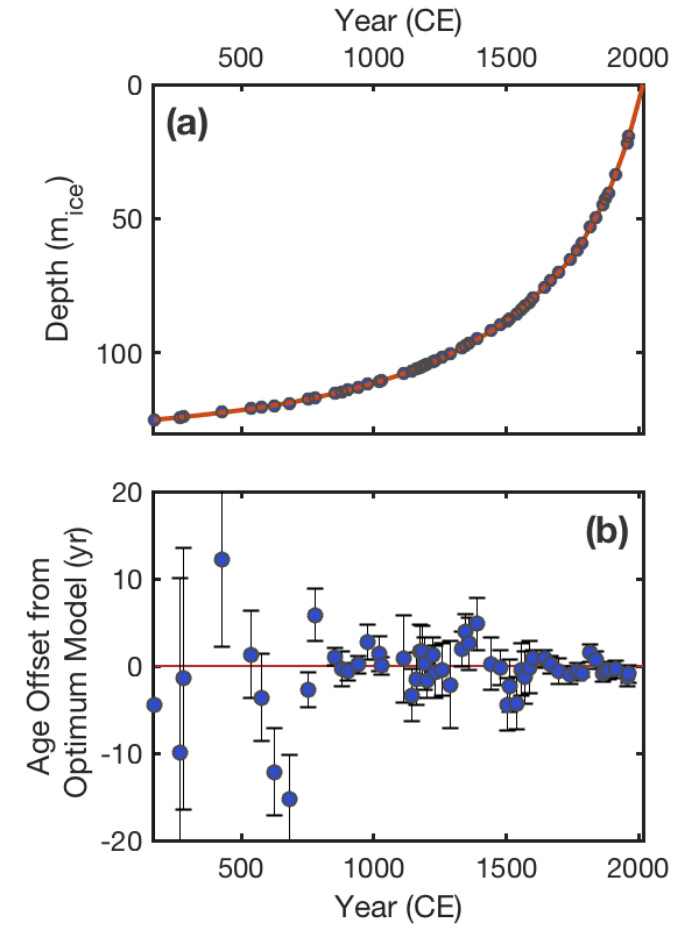

Figure S4-5: (a) Recovered age-depth scale for the optimum accumulation history model, alongside the corresponding age-depth picks. Error bars on the age-depth picks, and differences with the recovered agedepth model, is not visible at this scale. (b) Age differences between the optimum recovered age-depth scale and the age-depth constraints (circles with bars), with the prescriped relative uncertainties shown as the vertical bars. 


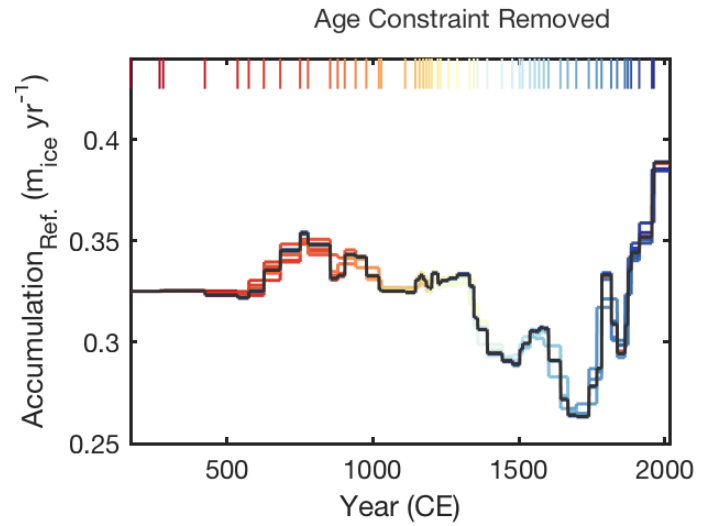

Figure S4-6: Recovered age-depth scales for the optimum accumulation history models with individual ageconstraints removed (i.e., a Jackknife approach). 
(a) Moisture Source Temperature

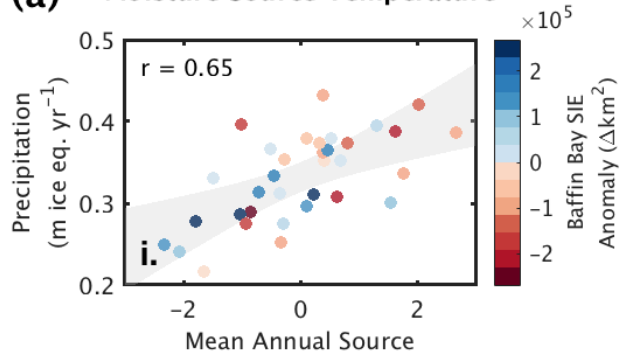

Temperature Anomaly $\left(\Delta^{\circ} \mathrm{C}\right)$

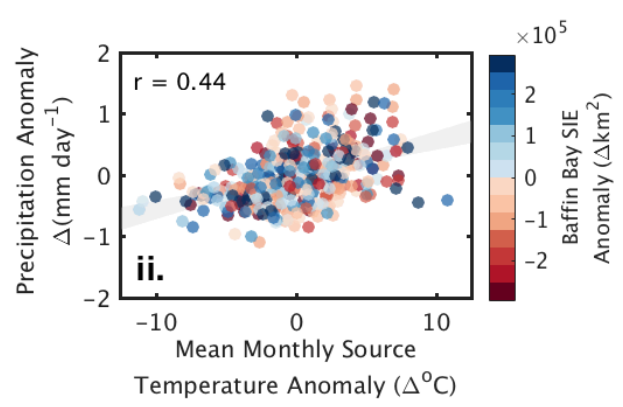

(b) Baffin Bay Sea Ice Extent
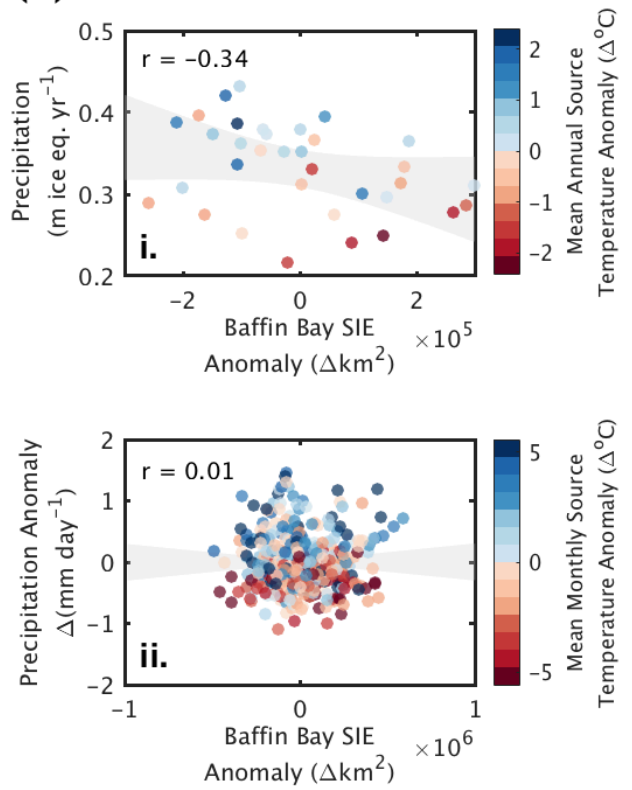

Figure S4-7: Relationships between Lagrangian-modeled NU accumulation and moisture source temperature (a) and Baffin Bay SIE (b) at mean-annual (i.) and mean-monthly (ii.) resolutions. Points in (a) are color-coded with respect to Baffin SIE (A.D. 1980-2013), and in (b) with respect to moisture source SAT (A.D. 1980-2013). All values shown in (ii.) have been seasonally-detrended. Both linear correlations shown in (a) are significant at $p<0.0001$ (Ebisuzaki, 1997). 


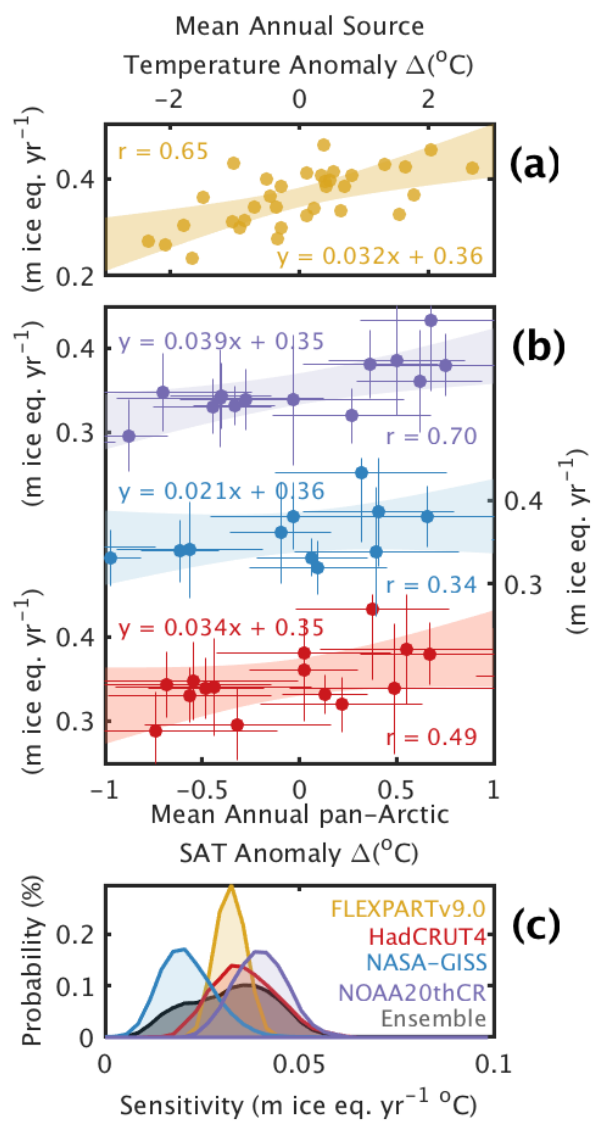

Figure S4-8: Sensitivity of modelled NU accumulation from the (top panel) FLEXPART v9.0 model (reproduced from Fig. 4b) as well as the sensitivity of observed NU accumulation to (middle panel) three different SAT reanalysis products: the NOAA 20th Century Reanalysis (NOAA20thCR), the NASA-GISS product, and the HadCRUT4 product. All three reanalysis correlations with NU accumulation are shown at 10 -yr mean-binned resolution, with $\mathrm{x}$ and y-uncertainties representing $\pm 1 \sigma(n=10)$ and the shaded bands the $95 \%$ confidence intervals of the weighted bilinear-least squares regression parameters. The bottom panel shows the bootstrap-derived $(n=1,000)$ sensitivity of NU accumulation per degree SAT warming. 

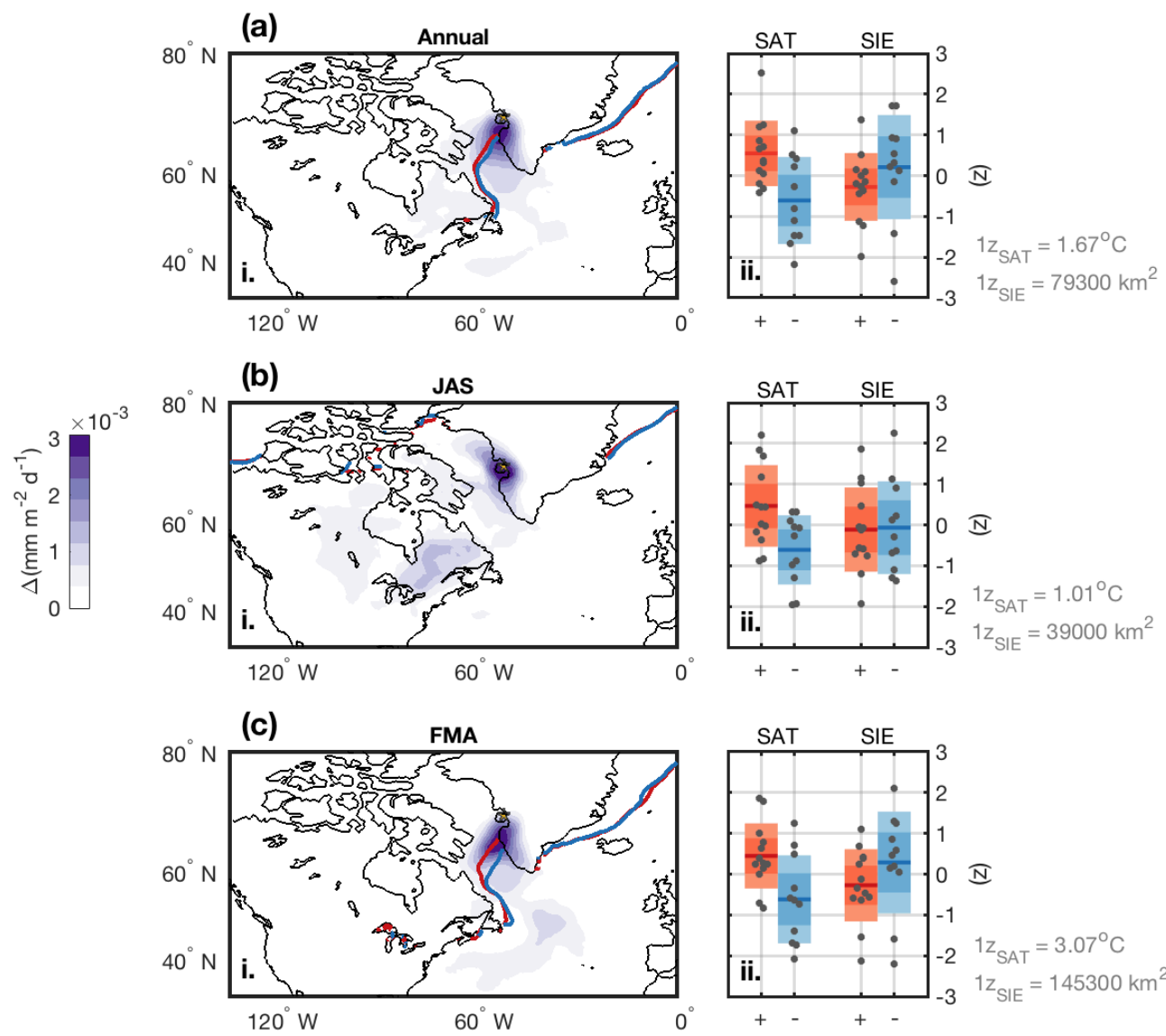

Figure S4-9: Summertime (July-August-September, JAS) vs. wintertime (February-March-April; FMA) precipitation sensitivity. (i.) FLEXPART-modeled mean-annual (a), mean-JAS (b) and mean-FMA (c) NU moisture-source atmospheric uptake rate (i.e., evaporation) differencing maps for positive- minus negativeanomaly annual snow-accumulation years. Anomalous snow-accumulation years are defined as years where annual snow-accumulation deviates greater than $0.5 \sigma$ and less than $-0.5 \sigma$, respectively, following unit-variance standardization of all NU annual snow-accumulation values for the period A.D. 1980-2013. Note anomalous years are the same for (a), (b), and (c). Red and blue lines shown in (i.) denote the corresponding mean sea ice edge position (defined as the 15\% sea ice concentration isopleth) for anomalously-high and -low NU snowaccumulation years, respectively. (ii.) Distributions of SW Greenland SAT (Vinther et al., 2006) and Baffin Bay (defined $40-80^{\circ} \mathrm{N}, 80-45^{\circ} \mathrm{W}$ ) SIE values for anomalous $\mathrm{NU}$ snow-accumulation years shown in (i.). Anomalously-positive and negative NU snow-accumulation years are represented using red and blue ("+" and "-") box plots, respectively. In each box plot the center line represents the mean, the dark shading the $\pm 1 \sigma$ range, and the light shading the $95 \%$ confidence interval (assuming normality). The results collectively suggest that while SAT is most important in dictating NU snow accumulation on a year-round basis, Baffin Bay SIE also plays a non-negligible secondary role in dictating wintertime NU snow-accumulation. 


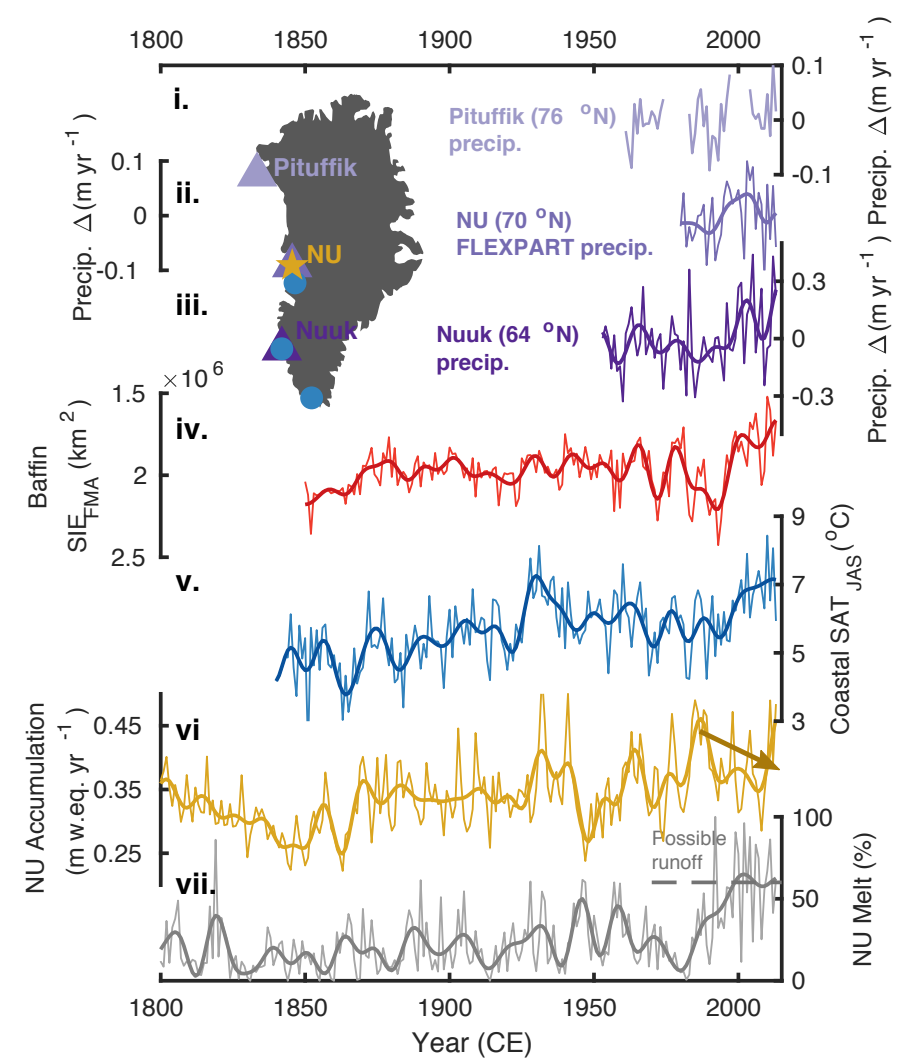

Figure S4-10: Industrial-era analysis of NU accumulation at annual (thin lines) and 10-yr lowpass filtered (bold, thick lines) scale resolution. $i$. DMI-derived precipitation anomalies (mean-centered annual sums) at Pituffik (Thule) Greenland $\left(77.47^{\circ} \mathrm{N}\right)$ and iii. Nuuk $\left(64.18^{\circ} \mathrm{N}\right)$, compared against the $i i$. FLEXPART-modeled CWG precipitation annual sums. Both Nuuk and Pituffik show significant correlations with FLEXPART-predicted precipitation variability at the NU site ( $\not<0.001$; Ebisuzaki, 1997), suggesting FLEXPART adequately captures underlying regional hydroclimate dynamics and its drivers. $i v$. Baffin Bay wintertime (FMA) SIE $\left(40-80^{\circ} \mathrm{N}, 80-\right.$ $\left.45^{\circ} \mathrm{W}\right)$. v. Danish Meteorological Institute-derived mean-annual summertime southwest-Greenland SAT (Vinther et al., 2006; sites used to compute this time series are shown as blue dots in the inset Greenland map). $v i$. The NU annual-resolution accumulation history and vii. annual layer melt percent history. The downwards arrow in vi. denotes an apparent sign-change in the relationship between CWG temperature and NU accumulation over recent decades, coinciding with enhanced NU melt and possible surface runoff (Trusel et al., 2018). 


\section{Ch. 4 Supporting tables}

Table S4-1: Age-constraint depths identified for the NU core, with attribution to the event horizon, and parameters used to identify it.

\begin{tabular}{|c|c|c|c|c|c|}
\hline $\begin{array}{l}\text { Year } \\
(\mathrm{CE})\end{array}$ & $\begin{array}{l}\text { Depth } \\
\text { (m w. } \\
\text { eq.) }\end{array}$ & $\begin{array}{l}\text { Uncertain } \\
\text { ty }(1 \sigma \text { yrs })\end{array}$ & Tie attribution & $\begin{array}{c}\text { Parameter(s } \\
\text { ) used }\end{array}$ & Citation \\
\hline 169.5 & 114.63 & 30 & $\begin{array}{l}\text { Volcanic } \\
\text { eruption - ? }\end{array}$ & ECM, Cond. & Sigl et al., 2015 \\
\hline 269.5 & 113.83 & 10 & $\begin{array}{l}\text { Volcanic } \\
\text { eruption - ? }\end{array}$ & $\begin{array}{l}\text { ECM, S, } \\
\text { Cond. }\end{array}$ & $\begin{array}{l}\text { Sigl et al., 2015; } \\
\text { McConnell et al. } \\
2018\end{array}$ \\
\hline 281.5 & 113.62 & 10 & $\begin{array}{l}\text { Volcanic } \\
\text { eruption - ? }\end{array}$ & ECM, Cond. & Sigl et al., 2015 \\
\hline 424.5 & 112 & 5 & $\begin{array}{l}\text { Volcanic } \\
\text { eruption - ? }\end{array}$ & $\begin{array}{l}\text { ECM, S, } \\
\text { Cond. }\end{array}$ & $\begin{array}{l}\text { Sigl et al., 2015; } \\
\text { McConnell et al. } \\
2018\end{array}$ \\
\hline 536.5 & 110.8 & 5 & $\begin{array}{c}\text { Volcanic } \\
\text { eruption - El } \\
\text { Chichon, } \\
\text { Mexico }\end{array}$ & $\begin{array}{l}\text { ECM, Cond., } \\
\text { S, Pb }\end{array}$ & $\begin{array}{l}\text { Sigl et al., 2015; } \\
\text { McConnell et al. } \\
2018\end{array}$ \\
\hline 574.5 & 110.37 & 5 & $\begin{array}{c}\text { Volcanic } \\
\text { eruption - El } \\
\text { Salvador }\end{array}$ & Cond., S, Pb & Sigl et al., 2015 \\
\hline 626.5 & 109.77 & 5 & $\begin{array}{c}\text { Volcanic } \\
\text { eruption - ? }\end{array}$ & $\begin{array}{l}\text { ECM, Cond., } \\
\text { S, Pb }\end{array}$ & Sigl et al., 2015 \\
\hline 682.5 & 108.97 & 5 & $\begin{array}{c}\text { Volcanic } \\
\text { eruption - } \\
\text { Jombolok, } \\
\text { Central Asia }\end{array}$ & $\begin{array}{l}\text { ECM, Cond., } \\
\text { S, Pb }\end{array}$ & Sigl et al., 2015 \\
\hline 750.5 & 107.59 & 2 & $\begin{array}{l}\text { Volcanic } \\
\text { eruption - ? }\end{array}$ & & Sigl et al., 2015 \\
\hline 777.5 & 106.91 & 3 & $\begin{array}{l}\mathrm{Pb}-\text { step } \\
\text { function }\end{array}$ & $\mathrm{Pb}$ & $\begin{array}{l}\text { McConnell et al. } \\
2018\end{array}$ \\
\hline 853.5 & 105.45 & 1 & $\begin{array}{c}\text { Volcanic } \\
\text { eruption - ? }\end{array}$ & $\mathrm{Pb}$ & Sigl et al., 2015 \\
\hline 879.5 & 104.93 & 2 & $\begin{array}{c}\text { Volcanic } \\
\text { eruption - ? }\end{array}$ & S & Sigl et al., 2015 \\
\hline 903.5 & 104.41 & 1 & $\begin{array}{c}\text { Volcanic } \\
\text { eruption - ? }\end{array}$ & S & Sigl et al., 2015 \\
\hline 940.5 & 103.51 & 1 & $\begin{array}{c}\text { Volcanic } \\
\text { eruption - } \\
\text { Eldgjá, Iceland }\end{array}$ & $\begin{array}{l}\mathrm{S}, \mathrm{Pb}, \mathrm{Ti} \\
\text { Cond. }\end{array}$ & Sigl et al., 2015 \\
\hline 977.5 & 102.51 & 2 & $\begin{array}{c}\text { Volcanic } \\
\text { eruption(s) - ? }\end{array}$ & $\mathrm{S}, \mathrm{Pb}$ & $\begin{array}{l}\text { Sigl et al., 2015; } \\
\text { McConnell et al. } \\
2018\end{array}$ \\
\hline 1020.5 & 101.41 & 2 & $\begin{array}{c}\text { volcanic } \\
\text { eruption - ? }\end{array}$ & $\begin{array}{l}\mathrm{S}, \mathrm{Pb}, \mathrm{Ti} \\
\text { Cond. }\end{array}$ & Sigl et al., 2015 \\
\hline 1028.5 & 101.23 & 1 & $\begin{array}{l}\text { Volcanic } \\
\text { eruption - ? }\end{array}$ & $\begin{array}{c}\text { Part (prev. } \\
\text { year), S, Pb, } \\
\text { Ti, Cond. }\end{array}$ & Sigl et al., 2015 \\
\hline 1110.5 & 98.81 & 5 & $\begin{array}{c}\text { Volcanic } \\
\text { eruption - Mt. } \\
\text { Asama, Japan }\end{array}$ & S & $\begin{array}{l}\text { Sigl et al., 2015; } \\
\text { McConnell et al. } \\
2018\end{array}$ \\
\hline 1145.5 & 97.815 & 3 & $\begin{array}{l}\mathrm{Pb}-\text { step } \\
\text { function }\end{array}$ & $\mathrm{Pb}, \mathrm{Ti}$ & $\begin{array}{l}\text { McConnell et al. } \\
2018\end{array}$ \\
\hline 1159.5 & 97.27 & 3 & $\begin{array}{l}\mathrm{Pb} \text { - step } \\
\text { function }\end{array}$ & $\mathrm{Pb}$ & $\begin{array}{l}\text { McConnell et al. } \\
2018\end{array}$ \\
\hline
\end{tabular}




\begin{tabular}{|c|c|c|c|c|c|}
\hline 1172.5 & 96.69 & 3 & $\begin{array}{l}\text { Volcanic } \\
\text { eruption - ? }\end{array}$ & S & Sigl et al., 2015 \\
\hline 1182.5 & 96.33 & 3 & $\begin{array}{c}\text { Volcanic } \\
\text { eruption - ? }\end{array}$ & $\begin{array}{l}\text { S, Cond, Ti, } \\
\mathrm{Pb}\end{array}$ & Sigl et al., 2015 \\
\hline 1192.5 & 96.01 & 3 & $\begin{array}{c}\text { Volcanic } \\
\text { eruption - ? }\end{array}$ & S, Ti, (Pb), S & Sigl et al., 2015 \\
\hline 1201.5 & 95.75 & 2 & $\begin{array}{c}\text { Volcanic } \\
\text { eruption - ? }\end{array}$ & $\mathrm{S}, \mathrm{Pb}, \mathrm{Ti}$, Cond & Sigl et al., 2015 \\
\hline 1222.5 & 94.81 & 2 & $\begin{array}{l}\text { Ti - step } \\
\text { function }\end{array}$ & $\mathrm{Ti}$ & $\begin{array}{c}\text { McConnell et al. } \\
2018\end{array}$ \\
\hline 1231.5 & 94.53 & 3 & $\begin{array}{l}\text { Volcanic } \\
\text { eruption - } \\
\text { Lipari, Italy } \\
\end{array}$ & S & $\begin{array}{l}\text { Sigl et al., 2015; } \\
\text { McConnell et al. } \\
2018\end{array}$ \\
\hline 1259.5 & 93.353 & 3 & $\begin{array}{l}\text { Volcanic } \\
\text { eruption - } \\
\text { Samalas, } \\
\text { Indonesia } \\
\end{array}$ & S & Sigl et al., 2015 \\
\hline 1288.5 & 92.15 & 5 & $\begin{array}{c}\text { Volcanic } \\
\text { eruption - ? }\end{array}$ & $\mathrm{S}, \mathrm{Pb}$ & $\begin{array}{l}\text { Sigl et al., 2015; } \\
\text { McConnell et al. } \\
2018\end{array}$ \\
\hline 1330.5 & 89.938 & 2 & $\begin{array}{c}\text { Volcanic } \\
\text { eruption - Mt. } \\
\text { Etna, Italy }\end{array}$ & $\begin{array}{c}\text { S, Pb, Cond., } \\
\text { Ti }\end{array}$ & Sigl et al., 2015 \\
\hline 1345.5 & 89.09 & 2 & $\begin{array}{c}\text { Volcanic } \\
\text { eruption - } \\
\text { Popocatepetl, } \\
\text { Mexico }\end{array}$ & $\begin{array}{c}\text { S, Pb, Cond., } \\
\text { Ti }\end{array}$ & Sigl et al., 2015 \\
\hline 1358.5 & 88.51 & 3 & $\begin{array}{l}\text { Volcanic } \\
\text { eruption - ? }\end{array}$ & $\mathrm{Pb}, \mathrm{S}$ & $\begin{array}{l}\text { Sigl et al., 2015; } \\
\text { McConnell et al. } \\
2018\end{array}$ \\
\hline 1391.5 & 86.71 & 3 & $\begin{array}{c}\text { Volcanic } \\
\text { eruption - } \\
\text { Hekla, Iceland }\end{array}$ & $\mathrm{Pb}, \mathrm{S}$ & $\begin{array}{l}\text { Sigl et al., 2015; } \\
\text { McConnell et al. } \\
2018\end{array}$ \\
\hline 1442.5 & 84.19 & 3 & $\begin{array}{c}\text { Volcanic } \\
\text { eruption - ? }\end{array}$ & $\mathrm{Ti}, \mathrm{S}$ & $\begin{array}{c}\text { McConnell et al. } \\
2018 \\
\end{array}$ \\
\hline 1477.5 & 82.15 & 2 & $\begin{array}{c}\text { Volcanic } \\
\text { eruption - } \\
\text { Sangeang Api, } \\
\text { Indonesia }\end{array}$ & $\begin{array}{l}\text { Pb, S, Ti., } \\
\text { Cond. }\end{array}$ & Sigl et al., 2015 \\
\hline 1502.5 & 80.85 & 3 & $\begin{array}{c}\text { Volcanic } \\
\text { eruption - ? }\end{array}$ & Ti, Cond., & Sigl et al., 2015 \\
\hline 1512.5 & 80.05 & 3 & $\begin{array}{c}\text { Volcanic } \\
\text { eruption - ? }\end{array}$ & $\begin{array}{l}\mathrm{S}, \mathrm{Pb}, \mathrm{Ti} \\
\text { Cond. }\end{array}$ & Sigl et al., 2015 \\
\hline 1537.5 & 78.43 & 3 & $\begin{array}{c}\text { Volcanic } \\
\text { eruption - ? }\end{array}$ & Ti, Cond, S & Sigl et al., 2015 \\
\hline 1554.5 & 76.85 & 3 & $\begin{array}{c}\text { Volcanic } \\
\text { eruption - ? }\end{array}$ & S, Pb, Cond. & Sigl et al., 2015 \\
\hline 1569.5 & 75.73 & 3 & $\begin{array}{l}\text { Volcanic } \\
\text { eruption - } \\
\text { Tambora, } \\
\text { Indonesia(?) }\end{array}$ & $\mathrm{Pb}, \mathrm{S}$ & $\begin{array}{l}\text { Sigl et al., 2015; } \\
\text { McConnell et al., } \\
2018\end{array}$ \\
\hline 1585.5 & 74.31 & 3 & $\begin{array}{c}\text { Volcanic } \\
\text { eruption - (?) }\end{array}$ & S, Pb, Cond. & Sigl et al., 2015 \\
\hline 1601.5 & 72.838 & 1 & $\begin{array}{c}\text { Volcanic } \\
\text { eruption - } \\
\text { Huaynaputina, } \\
\text { Peru }\end{array}$ & $\begin{array}{l}\text { S, Pb, Ti, } \\
\text { Part., Cond. }\end{array}$ & Sigl et al., 2015 \\
\hline 1642.5 & 69.21 & 1 & $\begin{array}{c}\text { Volcanic } \\
\text { eruption - } \\
\text { Parker, } \\
\text { Phillipines } \\
\end{array}$ & S, Pb, Ti, Part. & Sigl et al., 2015 \\
\hline
\end{tabular}




\begin{tabular}{|c|c|c|c|c|c|}
\hline 1667.5 & 67.01 & 1 & $\begin{array}{c}\text { Volcanic } \\
\text { eruption - Mt } \\
\text { Tarumae, Japan }\end{array}$ & $\begin{array}{l}\text { S, Pb, Ti, } \\
\text { Part., Cond. }\end{array}$ & Sigl et al., 2015 \\
\hline 1696.5 & 64.35 & 1.5 & $\begin{array}{c}\text { Volcanic } \\
\text { eruption - } \\
\text { Sabancaya, Peru } \\
\end{array}$ & $\begin{array}{l}\text { S, Pb, Ti, } \\
\text { Part., Cond. }\end{array}$ & Sigl et al., 2015 \\
\hline 1739.5 & 59.95 & 1 & $\begin{array}{c}\text { Volcanic } \\
\text { eruption - Mt. } \\
\text { Tarumae, Japan }\end{array}$ & $\begin{array}{l}\text { S, Pb, Ti, } \\
\text { Part., Cond. }\end{array}$ & Sigl et al., 2015 \\
\hline 1766.5 & 56.65 & 1 & $\begin{array}{c}\text { Volcanic } \\
\text { eruption - } \\
\text { Hekla, Iceland }\end{array}$ & $\begin{array}{l}\text { S, Pb, Ti, } \\
\text { Part., Cond. }\end{array}$ & Sigl et al., 2015 \\
\hline 1783.5 & 54.43 & 0.5 & $\begin{array}{c}\text { Volcanic } \\
\text { eruption - Laki, } \\
\text { Iceland }\end{array}$ & $\begin{array}{l}\text { S, Pb, Ti, } \\
\text { Part., Cond. }\end{array}$ & Sigl et al., 2015 \\
\hline 1816.5 & 48.634 & 1 & $\begin{array}{l}\text { Volcanic } \\
\text { eruption - } \\
\text { Tambora, } \\
\text { Indonesia }\end{array}$ & $\begin{array}{l}\text { S, Pb, Ti, } \\
\text { Part., Cond. }\end{array}$ & Sigl et al., 2015 \\
\hline 1836.5 & 45.47 & 1 & $\begin{array}{l}\text { Volcanic } \\
\text { eruption - } \\
\text { Cosigüina, } \\
\text { Nicaragua }\end{array}$ & $\begin{array}{l}\text { S, Pb, Ti, } \\
\text { Part., Cond. }\end{array}$ & Sigl et al., 2015 \\
\hline 1863.5 & 41.19 & 1 & $\begin{array}{l}\text { Volcanic } \\
\text { eruption - } \\
\text { Makian, } \\
\text { Indonesia } \\
\end{array}$ & $\begin{array}{l}\text { S, Pb, Ti, } \\
\text { Part., Cond. }\end{array}$ & Sigl et al., 2015 \\
\hline 1873.5 & 39.27 & 0.5 & $\begin{array}{l}\text { Volcanic } \\
\text { eruption - } \\
\text { Grímsvötn, } \\
\text { Iceland }\end{array}$ & $\begin{array}{l}\text { S, Pb, Ti, } \\
\text { Part., Cond. }\end{array}$ & Sigl et al., 2015 \\
\hline 1884.5 & 37.01 & 1 & $\begin{array}{c}\text { Volcanic } \\
\text { eruption - } \\
\text { Krakatoa, } \\
\text { Indonesia }\end{array}$ & $\begin{array}{l}\text { S, Pb, Ti, } \\
\text { Part., Cond. }\end{array}$ & Sigl et al., 2015 \\
\hline 1912.5 & 30.67 & 1 & $\begin{array}{c}\text { Volcanic } \\
\text { eruption - } \\
\text { Novarupta, AK } \\
\end{array}$ & $\begin{array}{l}\text { S, Pb, Ti, } \\
\text { Part., Cond. }\end{array}$ & Sigl et al., 2015 \\
\hline 1955.5 & 19.95 & 1 & $\begin{array}{c}\text { Radiogenic } \\
\text { (bomb horizon) }\end{array}$ & ${ }^{239} \mathrm{Pu}$ & $\begin{array}{c}\text { Arienzo et al., } \\
2016\end{array}$ \\
\hline 1962.5 & 17.81 & 1 & $\begin{array}{c}\text { Radiogenic } \\
\text { (bomb horizon) }\end{array}$ & ${ }^{239} \mathrm{Pu}$ & $\begin{array}{c}\text { Arienzo et al., } \\
2016 \\
\end{array}$ \\
\hline $\begin{array}{c}2015.4 \\
2\end{array}$ & 0 & 0 & Core top & $\mathrm{N} / \mathrm{a}$ & $\sim$ \\
\hline
\end{tabular}




\section{Ch. 4 References}

Andersen, K. K., Azuma, N., Barnola, J.-M., Bigler, M., Biscaye, P., Caillon, N., White, J. W. C. (2004). Highresolution record of Northern Hemisphere climate extending into the last interglacial period. Nature, 431(7005), 147-151. https://doi.org/10.1038/nature02805

Anderson, N. J., Liversidge, A. C., McGowan, S., \& Jones, M. D. (2012). Lake and catchment response to Holocene environmental change: spatial variability along a climate gradient in southwest Greenland. Journal of Paleolimnology, 48(1), 209-222. https://doi.org/10.1007/s10933-012-9616-3

Andresen, C. S., Björck, S., Bennike, O., \& Bond, G. (2004). Holocene climate changes in southern Greenland: evidence from lake sediments. Journal of Quaternary Science, 19(8), 783-795. https://doi.org/10.1002/jqs.886

Arienzo, M. M., McConnell, J. R., Chellman, N., Criscitiello, A. S., Curran, M., Fritzsche, D., Steffensen, J. P. (2016). A Method for Continuous 239Pu Determinations in Arctic and Antarctic Ice Cores. Environmental Science \& Technology, 50(13), 7066-7073. https://doi.org/10.1021/acs.est.6b01108

Arneborg, J., Heinemeier, J., Lynnerup, N., Nielsen, H. L., Rud, N., \& Sveinbjörnsdóttir, Á. E. (1999). Change of Diet of the Greenland Vikings Determined from Stable Carbon Isotope Analysis and 14C Dating of Their Bones. Radiocarbon, 41(2), 157-168. https://doi.org/DOI: 10.1017/S0033822200019512

Arrigo, K. R., van Dijken, G. L., Castelao, R. M., Luo, H., Rennermalm, Å. K., Tedesco, M., Yager, P. L. (2017). Melting glaciers stimulate large summer phytoplankton blooms in southwest Greenland waters. Geophysical Research Letters, 44(12), 6278-6285. https://doi.org/10.1002/2017GL073583

Axford, Y., Losee, S., Briner, J. P., Francis, D. R., Langdon, P. G., \& Walker, I. R. (2013). Holocene temperature history at the western Greenland Ice Sheet margin reconstructed from lake sediments. Quaternary Science Reviews, 59, 87-100. https://doi.org/https://doi.org/10.1016/j.quascirev.2012.10.024

Bastiaan, S., H., B. J., T., G. A., \& Sanne, B. (2018). Ancient DNA reveals the chronology of walrus ivory trade from Norse Greenland. Proceedings of the Royal Society B: Biological Sciences, 285(1884), 20180978. https://doi.org/10.1098/rspb.2018.0978

Böning, C. W., Behrens, E., Biastoch, A., Getzlaff, K., \& Bamber, J. L. (2016). Emerging impact of Greenland meltwater on deepwater formation in the North Atlantic Ocean. Nature Geoscience, 9, 523. Retrieved from https://doi.org/10.1038/ngeo2740

Compo, G. P., Whitaker, J. S., Sardeshmukh, P. D., Matsui, N., Allan, R. J., Yin, X., .. Worley, S. J. (2011). The Twentieth Century Reanalysis Project. Quarterly Journal of the Royal Meteorological Society, 137(654), 128. https://doi.org/10.1002/qj.776

Crowley, T. J., Criste, T. A., \& Smith, N. R. (1993). Reassessment of Crete (Greenland) ice core acidity/volcanism link to climate change. Geophysical Research Letters, 20(3), 209-212. https://doi.org/10.1029/93GL00207

Csatho, B. M., Schenk, A. F., van der Veen, C. J., Babonis, G., Duncan, K., Rezvanbehbahani, S., van den Broeke, M. R., Simonsen, S. B., Nagarajan, S., and van Andgelen, J. H. (2014). Greenland ice dynamics from laser altimetry, Proceedings of the National Academy of Sciences, 111(52), 18478-18483, https://doi.org/10.1073/pnas.1411680112

Cuffey, K. M. and Paterson, W. S. B. (2010). The Physics of Glaciers, Butterworth-Heinemann/Elsevier, Burlington, MA, USA.

D’Andrea, W. J., Huang, Y., Fritz, S. C., \& Anderson, N. J. (2011). Abrupt Holocene climate change as an important factor for human migration in West Greenland. Proceedings of the National Academy of Sciences, 108(24), 9765 LP - 9769. https://doi.org/10.1073/pnas.1101708108 
Dahl-Jensen, D. Johnsen, S. J., Hammer, C. U., Clausen, H. B., Jouzel, J. (1993). Past accumulation rates derived from observed annual layers in the GRIP ice core from Summit, central Greenland. In: Peltier, W R (ed.), Ice in the Climate System,Springer-Verlag, Berlin-Heidelberg, Germany, 517-532.

Dansgaard, W., \& Johnsen, S. J. (1969). A Flow Model and a Time Scale for the Ice Core from Camp Century, Greenland. Journal of Glaciology, 8(53), 215-223. https://doi.org/DOI: 10.3189/S0022143000031208

Dansgaard, W., Johnsen, S. J., Møller, J., \& Langway, C. C. (1969). One Thousand Centuries of Climatic Record from Camp Century on the Greenland Ice Sheet. Science, 166(3903), 377 LP - 380. https://doi.org/10.1126/science.166.3903.377

Ebisuzaki, W. (1997). A Method to Estimate the Statistical Significance of a Correlation When the Data Are Serially Correlated. Journal of Climate, 10(9), 2147-2153. https://doi.org/10.1175/15200442(1997)010<2147:AMTETS>2.0.CO;2

Emile-Geay, J., McKay, N. P., Kaufman, D. S., von Gunten, L., Wang, J., Anchukaitis, K. J., Zinke, J. (2017). A global multiproxy database for temperature reconstructions of the Common Era. Scientific Data, 4, 170088. https://doi.org/10.1038/sdata.2017.88

Fudge, T. J., Waddington, E. D., Conway, H., Lundin, J. M. D., \& Taylor, K. (2014). Interpolation methods for Antarctic ice-core timescales: application to Byrd, Siple Dome and Law Dome ice cores. Clim. Past, 10(3), 1195-1209. https://doi.org/10.5194/cp-10-1195-2014

Grootes, P. M., \& Stuiver, M. (1997). Oxygen 18/16 variability in Greenland snow and ice with 10-3- to 105year time resolution. Journal of Geophysical Research: Oceans, 102(C12), 26455-26470. https://doi.org/10.1029/97JC00880

Guillevic, M., Bazin, L., Landais, A., Kindler, P., Orsi, A., Masson-Delmotte, V., Vinther, B. M. (2013). Spatial gradients of temperature, accumulation and \&delta; ${ }^{18} \mathrm{O}$-ice in Greenland over a series of Dansgaard\&ndash;Oeschger events. Clim. Past, 9(3), 1029-1051. https://doi.org/10.5194/cp-9-10292013

Hammer, C.U., Johnsen, S.J., Clausen, H.B., Dahl-Jensen, D., Gundestrup, NN., Steffensen, J.P., The paleoclimatic record from a $345 \mathrm{~m}$ long ice core from the Hans Tuasen Iskappe. Meddelelser Om. Grønl. Geosci. 39, 87-95, 2001.

Hansson, M. E. (1994). The Renland ice core. A Northern Hemisphere record of aerosol composition over 120,000 years. Tellus B: Chemical and Physical Meteorology, 46(5), 390-418. https://doi.org/10.3402/tellusb.v46i5.15813

Hartman, S., Ogilvie, A. E. J., Ingimundarson, J. H., Dugmore, A. J., Hambrecht, G., \& McGovern, T. H. (2017). Medieval Iceland, Greenland, and the New Human Condition: A case study in integrated environmental humanities. Global and Planetary Change, 156, 123-139. https://doi.org/https://doi.org/10.1016/j.gloplacha.2017.04.007

Herron, M. M., Herron, S. L., \& Langway, C. C. (1981). Climatic signal of ice melt features in southern Greenland. Nature, 293(5831), 389-391. https://doi.org/10.1038/293389a0

Holland, D. M., Thomas, R. H., de Young, B., Ribergaard, M. H., \& Lyberth, B. (2008). Acceleration of Jakobshavn Isbræ triggered by warm subsurface ocean waters. Nature Geoscience, 1, 659. Retrieved from https://doi.org/10.1038/ngeo316

Jensen, J. The Stone Age of Qeqertarsuup Tunua (Disko Bugt) (2006). A regional analysis of the Saqqaq and Dorset cultures of Central West Greenland. Meddelelser om Grønland, Man \& Society 32:1-245.

Jomelli, V., Lane, T., Favier, V., Masson-Delmotte, V., Swingedouw, D., Rinterknecht, V. Keddadouche, K. (2016). Paradoxical cold conditions during the medieval climate anomaly in the Western Arctic. Scientific Reports, 6, 32984. Retrieved from https://doi.org/10.1038/srep32984 
Jones, P. D., Lister, D. H., Osborn, T. J., Harpham, C., Salmon, M., \& Morice, C. P. (2012). Hemispheric and large-scale land-surface air temperature variations: An extensive revision and an update to 2010. Journal of Geophysical Research: Atmospheres, 117(D5). https://doi.org/10.1029/2011JD017139

Jouzel, J. (2013). A brief history of ice core science over the last 50 yr. Clim. Past, 9(6), 2525-2547. https://doi.org/10.5194/cp-9-2525-2013

Khazendar, A., Fenty, I. G., Carroll, D., Gardner, A., Lee, C. M., Fukumori, I., Willis, J. (2019). Interruption of two decades of Jakobshavn Isbrae acceleration and thinning as regional ocean cools. Nature Geoscience, 12(4), 277-283. https:// doi.org/10.1038/s41561-019-0329-3

Läderach, A., \& Sodemann, H. (2016). A revised picture of the atmospheric moisture residence time. Geophysical Research Letters, 43(2), 924-933. https://doi.org/10.1002/2015GL067449

Larsen, L. B., Vinther, B. M., Briffa, K. R., Melvin, T. M., Clausen, H. B., Jones, P. D., Nicolussi, K. (2008). New ice core evidence for a volcanic cause of the A.D. 536 dust veil. Geophysical Research Letters, 35(4). https://doi.org/10.1029/2007GL032450

Lasher, G. E., \& Axford, Y. (2019). Medieval warmth confirmed at the Norse Eastern Settlement in Greenland. Geology, 47(3), 267-270. https://doi.org/10.1130/G45833.1

Lemark, A. (2006). A study of the Flade Isblink ice cap using a simpe ice flow model, Master's thesis, Centre for Ice and Climate, U. Of Copenhagen.

Lenssen, N. J. L., Schmidt, G. A., Hansen, J. E., Menne, M. J., Persin, A., Ruedy, R., \& Zyss, D. (2019). Improvements in the uncertainty model in the Goddard Institute for Space Studies Surface Temperature (GISTEMP) analysis. Journal of Geophysical Research: Atmospheres, $O(\mathrm{ja})$. https://doi.org/10.1029/2018JD029522

Liu, J., Chen, Z., Francis, J., Song, M., Mote, T., \& Hu, Y. (2016). Has Arctic Sea Ice Loss Contributed to Increased Surface Melting of the Greenland Ice Sheet? Journal of Climate, 29(9), 3373-3386. https://doi.org/10.1175/JCLI-D-15-0391.1

Maselli, O. J., Chellman, N. J., Grieman, M., Layman, L., McConnell, J. R., Pasteris, D., Sigl, M. (2017). Sea ice and pollution-modulated changes in Greenland ice core methanesulfonate and bromine. Clim. Past, 13(1), 39-59. https://doi.org/10.5194/cp-13-39-2017

Maselli, O. J., Chellman, N. J., Grieman, M., Layman, L., McConnell, J. R., Pasteris, D., Sigl, M. (2017). Sea ice and pollution-modulated changes in Greenland ice core methanesulfonate and bromine. Climate of the Past, 13(1), 39-59. https://doi.org/10.5194/cp-13-39-2017

Massa, C., Perren, B. B., Gauthier, É., Bichet, V., Petit, C., \& Richard, H. (2012). A multiproxy evaluation of Holocene environmental change from Lake Igaliku, South Greenland. Journal of Paleolimnology, 48(1), $241-$ 258. https://doi.org/10.1007/s10933-012-9594-5

McConnell, J. R., Lamorey, G. W., Lambert, S. W., \& Taylor, K. C. (2002). Continuous Ice-Core Chemical Analyses Using Inductively Coupled Plasma Mass Spectrometry. Environmental Science \& Technology, 36(1), 7-11. https://doi.org/10.1021/es011088z

McConnell, J. R., Wilson, A. I., Stohl, A., Arienzo, M. M., Chellman, N. J., Eckhardt, S., Steffensen, J. P. (2018). Lead pollution recorded in Greenland ice indicates European emissions tracked plagues, wars, and imperial expansion during antiquity. Proceedings of the National Academy of Sciences, 115(22), 5726 LP - 5731. https://doi.org/10.1073/pnas.1721818115

McKay, N. P., \& Kaufman, D. S. (2014). An extended Arctic proxy temperature database for the past 2,000 years. Scientific Data, 1, 140026. Retrieved from https://doi.org/10.1038/sdata.2014.26

Meeker, L. D., \& Mayewski, P. A. (2002). A 1400-year high-resolution record of atmospheric circulation over the North Atlantic and Asia. The Holocene, 12(3), 257-266. https://doi.org/10.1191/0959683602hl542ft 
Meese, D. A., Gow, A. J., Grootes, P., Stuiver, M., Mayewski, P. A., Zielinski, G. A., Waddington, E. D. (1994). The Accumulation Record from the GISP2 Core as an Indicator of Climate Change Throughout the Holocene. Science, 266(5191), 1680 LP - 1682. https://doi.org/10.1126/science.266.5191.1680

Mernild, S. H., Hanna, E., McConnell, J. R., Sigl, M., Beckerman, A. P., Yde, J. C., Steffen, K. (2015). Greenland precipitation trends in a long-term instrumental climate context (1890-2012): evaluation of coastal and ice core records. International Journal of Climatology, 35(2), 303-320. https://doi.org/10.1002/joc.3986

Miller, G. H., Geirsdóttir, Á., Zhong, Y., Larsen, D. J., Otto-Bliesner, B. L., Holland, M. M., Thordarson, T. (2012). Abrupt onset of the Little Ice Age triggered by volcanism and sustained by sea-ice/ocean feedbacks. Geophysical Research Letters, 39(2). https:// doi.org/10.1029/2011GL050168

Moon, T., Joughin, I., Smith, B., \& Howat, I. (2012). 21st-Century Evolution of Greenland Outlet Glacier Velocities. Science, 336(6081), 576 LP - 578. https://doi.org/10.1126/science.1219985

Moon, T., Joughin, I., \& Smith, B. (2015). Seasonal to multiyear variability of glacier surface velocity, terminus position, and sea ice/ice mélange in northwest Greenland. Journal of Geophysical Research: Earth Surface, 120(5), 818-833. https://doi.org/10.1002/2015JF003494

Moreno-Chamarro, E., Zanchettin, E. D., Lohmann, K., and Jungclaus, J. H. (2015). Internally generated decadal cold events in the northern North Atlantic and their possible implications for the demise of the Norse settlements in Greenland, Geophys. Res. Lett., 42, 908-915, https://doi:10.1002/2014GL062741

Mouginot, J., Rignot, E., Bjørk, A. A., van den Broeke, M., Millan, R., Morlighem, M., Wood, M. (2019). Fortysix years of Greenland Ice Sheet mass balance from 1972 to 2018. Proceedings of the National Academy of Sciences, 116(19), 9239 LP - 9244. https://doi.org/10.1073/pnas.1904242116

Noël, B., van de Berg, W. J., Lhermitte, S., Wouters, B., Machguth, H., Howat, I., van den Broeke, M. R. (2017). A tipping point in refreezing accelerates mass loss of Greenland's glaciers and ice caps. Nature Communications, 8, 14730. Retrieved from https://doi.org/10.1038/ncomms14730

Ogilvie, A. E. J., Woollett, J. M., Smiarowski, K., Arneborg, J., Troelstra, S., Kuijpers, A., McGovern, T. H. (2009). Seals and Sea Ice in Medieval Greenland. Journal of the North Atlantic, 2(1), 60-80. Retrieved from https://doi.org/10.3721/037.002.0107

Olsen, J., Anderson, N. J., \& Knudsen, M. F. (2012). Variability of the North Atlantic Oscillation over the past 5,200 years. Nature Geoscience, 5, 808. Retrieved from https://doi.org/10.1038/ngeo1589

Osman, M. B., Das, S. B., Trusel, L. D., Evans, M. J., Fischer, H., Grieman, M. M., Saltzman, E. S. (2019). Industrial-era decline in subarctic Atlantic productivity. Nature, 569(7757), 551-555. https://doi.org/10.1038/s41586-019-1181-8

Pasteris, D. R., McConnell, J. R., \& Edwards, R. (2012). High-Resolution, Continuous Method for Measurement of Acidity in Ice Cores. Environmental Science \& Technology, 46(3), 1659-1666. https://doi.org/10.1021/es202668n

Perren, B. B., Anderson, N. J., Douglas, M. S. V, \& Fritz, S. C. (2012). The influence of temperature, moisture, and eolian activity on Holocene lake development in West Greenland. Journal of Paleolimnology, 48(1), 223 239. https://doi.org/10.1007/s10933-012-9613-6

Rasmussen, S. O., Abbott, P. M., Blunier, T., Bourne, A. J., Brook, E., Buchardt, S. L., Winstrup, M. (2013). A first chronology for the North Greenland Eemian Ice Drilling (NEEM) ice core. Clim. Past, 9(6), 27132730. https://doi.org/10.5194/cp-9-2713-2013

Schweinsberg, A. D., Briner, J. P., Miller, G. H., Bennike, O., \& Thomas, E. K. (2017). Local glaciation in West Greenland linked to North Atlantic Ocean circulation during the Holocene. Geology, 45(3), 195-198. https://doi.org/10.1130/G38114.1 
Sigl, M., Winstrup, M., McConnell, J. R., Welten, K. C., Plunkett, G., Ludlow, F., Woodruff, T. E. (2015). Timing and climate forcing of volcanic eruptions for the past 2,500 years. Nature, 523, 543. Retrieved from https:// doi.org/10.1038/nature14565

Sigl, M., McConnell, J. R., Layman, L., Maselli, O., McGwire, K., Pasteris, D., Kipfstuhl, S. (2013). A new bipolar ice core record of volcanism from WAIS Divide and NEEM and implications for climate forcing of the last 2000 years. Journal of Geophysical Research: Atmospheres, 118(3), 1151-1169. https://doi.org/10.1029/2012JD018603

Sodemann, H., Schwierz, C., \& Wernli, H. (2008). Interannual variability of Greenland winter precipitation sources: Lagrangian moisture diagnostic and North Atlantic Oscillation influence. Journal of Geophysical Research: Atmospheres, 113(D3). https://doi.org/10.1029/2007JD008503

Stohl, A., \& James, P. (2005). A Lagrangian Analysis of the Atmospheric Branch of the Global Water Cycle. Part II: Moisture Transports between Earth's Ocean Basins and River Catchments. Journal of Hydrometeorology, 6(6), 961-984. https://doi.org/10.1175/JHM470.1

Taylor, K., Alley, R., Fiacco, J., Grootes, P., Lamorey, G., Mayewski, P., \& Spencer, M. J. (1992). Ice-core dating and chemistry by direct-current electrical conductivity. Journal of Glaciology, 38(130), 325-332. https://doi.org/DOI: 10.3189/S0022143000002215

Thomas, E. K., Briner, J. P., Ryan-Henry, J. J., \& Huang, Y. (2016). A major increase in winter snowfall during the middle Holocene on western Greenland caused by reduced sea ice in Baffin Bay and the Labrador Sea. Geophysical Research Letters, 43(10), 5302-5308. https://doi.org/10.1002/2016GL068513

Thorsson, Ö. The Sagas of Icelanders: A Selection, Penguin Books, USA. ed.1, 2001.

Trusel, L. D., Das, S. B., Osman, M. B., Evans, M. J., Smith, B. E., Fettweis, X., van den Broeke, M. R. (2018). Nonlinear rise in Greenland runoff in response to post-industrial Arctic warming. Nature, 564 (7734), 104 108. https://doi.org/10.1038/s41586-018-0752-4

Vinther, B. M., Andersen, K. K., Jones, P. D., Briffa, K. R., \& Cappelen, J. (2006). Extending Greenland temperature records into the late eighteenth century. Journal of Geophysical Research: Atmospheres, 111(D11). https://doi.org/10.1029/2005JD006810

Vinther, B. M., Jones, P. D., Briffa, K. R., Clausen, H. B., Andersen, K. K., Dahl-Jensen, D., \& Johnsen, S. J. (2010). Climatic signals in multiple highly resolved stable isotope records from Greenland. Quaternary Science Reviews, 29(3), 522-538. https://doi.org/https://doi.org/10.1016/j.quascirev.2009.11.002

Walsh, J. E., Fetterer, F., Scott Stewart, J., \& Chapman, W. L. (2017). A database for depicting Arctic sea ice variations back to 1850. Geographical Review, 107(1), 89-107. https://doi.org/10.1111/j.19310846.2016.12195.x

Weißbach, S., Wegner, A., Opel, T., Oerter, H., Vinther, B. M., \& Kipfstuhl, S. (2016). Spatial and temporal oxygen isotope variability in northern Greenland - implications for a new climate record over the past millennium. Climate of the Past, 12(2), 171-188. https://doi.org/10.5194/cp-12-171-2016

Willemse, N. W., \& Törnqvist, T. E. (1999). Holocene century-scale temperature variability from West Greenland lake records. Geology, 27(7), 580-584. https://doi.org/10.1130/00917613(1999)027<0580:HCSTVF>2.3.CO;2

Wong, G. J., Osterberg, E. C., Hawley, R. L., Courville, Z. R., Ferris, D. G., \& Howley, J. A. (2015). Coast-tointerior gradient in recent northwest Greenland precipitation trends (1952-2012). Environmental Research Letters, 10(11), 114008. https:// doi.org/10.1088/1748-9326/10/11/114008

Young, N. E., Schweinsberg, A. D., Briner, J. P., \& Schaefer, J. M. (2015). Glacier maxima in Baffin Bay during the Medieval Warm Period coeval with Norse settlement. Science Advances, 1(11), e1500806. https://doi.org/10.1126/sciadv.150080 


\title{
5. Enhanced North Atlantic jet-stream variability coeval with Arctic warming during the last millennium
}

\begin{abstract}
Model projections suggest enhanced variability and northward migration in the Atlantic eddy driven jet stream under $21^{\text {st }}$ century warming scenarios, but assessing the significance of these changes is difficult given the lack of long-term observations. Skillful reconstruction of the North Atlantic eddydriven jet stream from the proxy-archive thus presents a critical, albeit largely-unconstrained, paleoclimatic target. Here, we compile the largest annual-resolution Greenland Ice Sheet water isotope $\left(\delta^{18} \mathrm{O}\right)$ ice core array to date, allowing us to robustly isolate two unique (i.e., orthogonal) signatures of atmospheric variability, both of which strongly project onto the two (independently-derived) leadingmodes of observed Atlantic jet stream variability. In tandem with a new ensemble of water isotopeenabled, millennium-long global climate model simulations, we illuminate the underlying influence of the well-known North Atlantic Oscillation (NAO) and East Atlantic (EA) patterns (the leading two modes of Atlantic-sector atmospheric variability) on these Greenlandic $\delta^{18} \mathrm{O}$ depositional-signatures, further revealing that both atmospheric modes are necessary for discerning past variations in the Atlantic jet stream. Following conceptual and statistical validation using a novel, model-based pseudoproxy framework, we reconstruct changes in the Atlantic jet latitude, as well as the leading two modes of (NAO and EA-modulated) Atlantic jet stream variability over the last millennium using our $\delta^{18} \mathrm{O}$ compilation. We demonstrate our reconstructed leading mode of jet variability improves upon a recent, model-tested reconstruction of the NAO, whereas our jet latitude reconstruction shows little coherence against a recent biproxy tree-ring-based jet latitude reconstruction. Moreover, we provide the first evidence of progressively-enhanced Atlantic jet latitude variability during the past twocenturies, marking a jet variability regime change that is coeval with the onset of amplified Industrialera Arctic warming. Our results thus provide improved temporal context for understanding Atlantic jet variability, and highlight the enhanced long-term sensitivity of mid-latitude atmospheric dynamics to polar warming.
\end{abstract}




\subsection{Introduction}

Variations in the intensity and positioning of the North Atlantic jet stream - currents of strong prevailing westerly-winds situated over the mid-latitudes - play an important role in modulating eastern North American and European synoptic-scale weather variability, economics (Coumou and Rahmstorf, 2012, transport and commerce (Williams et al., 2013), and fisheries and ecosystems functioning (Chen et al., 2014; Belchemeri et al., 2017). Models predict that under future "business as usual" greenhouse warming scenarios the Atlantic jet will shift progressively poleward - as much as $1-2^{\circ}$ by the end of the $21^{\text {st }}$ century (Yin et al., 2005; Barnes et al., 2013). However, apart from a recent study comprising limited proxy data and temporal extent (Trouet et al., 2018), little is known about changes in the positioning, intensity, and potential long-term drivers of Atlantic jet variability prior to the $20^{\text {th }}$ century. This lack of understanding hinders our ability to contextualize historical $\left(20^{\text {th }}-21^{\text {st }}\right.$ century) observations (Compo et al., 2011; Woollings et al., 2014) and model-derived predictions (Yin et al., 2005; Barnes et al., 2013).

Here, we focus on the low-lying component (850-700 millibar, mB) of the Atlantic eddy-driven jet stream (e.g., Woollings et al., 2010), because of its i. intimate relationship to the Atlantic storm track and hence North American and European societies (Coumou and Rahmstorf, 2012); ii. nearhomogenous vertical imprint throughout the tropospheric column (Woollings et al., 2008, Woollings et al., 2010), and iii. readily-interpretable comparison to large-scale Atlantic-sector climatic indicators (Woollings et al., 2011, Woollings et al., 2014). Albeit spatially displaced, we illustrate that measurements of the abundance of the water isotope $\mathrm{H}_{2}{ }^{18} \mathrm{O}$ relative to $\mathrm{H}_{2}{ }^{16} \mathrm{O}$ deposited across Greenland (where the superscript represents the atomic mass of oxygen, conventionally expressed relative to global mean seawater in "delta"-notation: $\delta^{18} \mathrm{O}$; see Section 5.6.1; Dansgaard,1964) provide an ideal proxy of past Atlantic jet-variations via their association to mid- and high-latitude blocking (see also Rimbu et al., 2011, Rimbu et al., 2017). In particular, whereas robust conceptual grounding has illustrated the first-order correspondence between $\delta^{18} \mathrm{O}$ in precipitation and ambient temperature at condensation (Dansgaard,1964), the isotopic content of meteoric waters represent, in their entirety, an integrated signal of atmospheric transport and dynamics from evaporation to precipitation. Indeed, meteoric waters precipitated as snow atop Greenland are near-entirely derived from evaporativeuptake of Atlantic surface waters situated to the south (Sodemann et al., 2008; Rhines and Huybers 2014) while interannual changes in mid-tropospheric (condensation) temperatures over Greenland are, in turn, strongly predicated upon broader-scale variations in Atlantic atmospheric circulation 
(Mellado-Cano et al., 2019). Together, both facts allude towards a strong atmospheric circulation signal embedded across Greenlandic $\delta^{18} \mathrm{O}$ variations.

\subsection{Identification of leading modes of $\delta^{18} \mathrm{O}$ covariability}

We combine twenty-nine (29) annual mean $\delta^{18} \mathrm{O}$ records from sites spanning the Greenland Ice Sheet (GrIS) - the largest annual-resolution last-millennium-scale $\delta^{18} \mathrm{O}$ compilation to date - in order to examine the dynamical linkages between GrIS $\delta^{18} \mathrm{O}$ deposition and Atlantic-sector jet stream variability (Fig. 5-1). To isolate coherent modes of GrIS $\delta^{18} \mathrm{O}$-covariability during the mid-19th to late 20th centuries (A.D. 1851 - 2000; Section 5.6.1), we conduct a probabilistic principal component analysis (pPCA), permitting the decomposition of our $\delta^{18} \mathrm{O}$ stack despite the presence of missing late20th century data in some records (Fig. 5-1; see Section 5.6.2, Tipping and Bishop, 1999; Section 5.6.23). The leading temporal mode of GrIS- $\delta^{18} \mathrm{O}$ variability, $\delta^{18} \mathrm{O}-\mathrm{PC} 1$, loads positively across all Greenland sites, while explaining $19-29 \%$ of the GrIS-wide $\delta^{18} \mathrm{O}$ variability (Fig. 5-2). This dominant mode of variability has been identified in prior work (albeit incorporating compilations considerably less extensive, e.g., Vinther et al., 2003, 2010; Ortega et al., 2014, 2015), wherein it has been interpreted in the context of temperature (Dansgaard et al., 1964; Holme et al., 2019) and (or) variability in the North Atlantic Oscillation (NAO; Vinther et al., 2006; Ortega et al., 2014), the primary mode of Atlantic-sector atmospheric variability (Hurrell et al., 1995). In addition, our pPCA reveals a second and third mode of GrIS- $\delta^{18} \mathrm{O}$ variability, $\delta^{18} \mathrm{O}-\mathrm{PC} 2\left(\sim 9-15 \%\right.$ variance explained) and $\delta^{18} \mathrm{O}-\mathrm{PC} 3(\sim 7$ $11 \%$ variance explained), each statistically distinct from red noise (Fig. 5-2) at the $p<0.05$ level. Both

modes, to our knowledge, have been so far unidentified by prior GrIS- $\delta^{18} \mathrm{O}$ compilations (Vinther et al., 2003, 2010; Ortega et al., 2014; Weißbach et al., 2016; Rimbu et al., 2017): $\delta^{18}$ O-PC2 illuminates a southern to northern-trending positive-negative dipole in GrIS- $\delta^{18} \mathrm{O}$ deposition that stands in contrast to the near-homogenous loading pattern of $\delta^{18} \mathrm{O}$-PC1 (Fig. 5-2), whereas $\delta^{18} \mathrm{O}$-PC3 hints at a spatially-homogenous positive loading signal across the northeast sector of the GrIS.

We confirm the strong correlation between $(p<0.0001) \delta^{18} \mathrm{O}-\mathrm{PC} 1$ and annually-averaged GrIS near-surface/coastal temperatures (Vinther et al., 2006; Kobashi et al., 2011), several observational-indices of the NAO (Jones et al., 1997; Hurrell, 2003), as well as a recently-defined index of blocking variability over Greenland (GBI; Fig. S5-1; Hanna et al., 2016, 2018). The latter index in particular - defined as the area-weighted mean $500 \mathrm{mB}$ geopotential height anomaly (hereafter, “Z500”) over Greenland (60-80 N; 80-20 W; Hanna et al, 2016, 2018) - represents an advantageous 
dynamical target: we find $\sim 80 \%$ of our GrIS- $\delta^{18} \mathrm{O}$ records are significantly $(p<0.10)$ and positively correlated with GBI (Ebisuzaki, 1997) during their period of common-overlap (A.D. 1851-1967; $n=$ 117), thus highlighting both the sensitivity and spatially-coherent response of GrIS- $\delta^{18} \mathrm{O}$ deposition to localized mid-tropospheric pressure loading (Fig. S5-2). The strong covariability between this index of regional blocking and the primary mode of GrIS- $\delta^{18} \mathrm{O}$ (Fig. S5-2) variability represents a salient aspect of our compilation: Quasi-stationary anti-cyclonic high-pressure blocking systems are wellknown to preferentially form over Greenland as a result of atmospheric ridging, surface cooling, and the raising of geopotential-heights aloft. Once formed, these blocking systems are characterized by enhanced occurrences of upper-level Rossby wave-breaking events, whose frequency in turn exhibit a strong, negatively-correlated statistical association to low-frequency (i.e., monthly to interannual) perturbations in both the NAO (Woollings et al., 2008; Hanna et al., 2016, 2018) as well as meridional shifting of the mid-Atlantic jet-stream (Woollings et al., 2010; Hanna et al., 2018). Given this firstorder association between localized $500 \mathrm{mB}$-height anomalies and $\delta^{18} \mathrm{O}$-deposition over Greenland, we thus target this index for prefiltering $\delta^{18} \mathrm{O}$ records by their fidelity to both localized and broadscale atmospheric-circulation variability, as well as - implicitly - data-quality. Notably, if removing $\delta^{18} \mathrm{O}$-records not significantly correlated to GBI at the $p<0.10$ level prior to pPCA-computation (Section 5.6.8), we find $\delta^{18} \mathrm{O}-\mathrm{PC} 1$ and $\delta^{18} \mathrm{O}-\mathrm{PC} 2$ are nearly unchanged from their unfiltered pPCArealizations, both in terms of their spatial and temporal imprints. Conversely, $\delta^{18} \mathrm{O}-\mathrm{PC} 3$ - previously loading highest at sites now removed from the northeast-GrIS sector - manifests indistinctly from noise $(p>0.05)$.

\subsection{Atlantic jet stream latitude proxy development and verification}

Having isolated two robust modes of GrIS- $\delta^{18} \mathrm{O}$ variability, we next illustrate how $\mathrm{GrIS}-\delta^{18} \mathrm{O}$ can be used to infer changes in Atlantic jet variability to the south. For simplicity, we invoke a diagnostic one-dimensional (meridional) representation of the Atlantic jet stream by zonally-averaging the annual-average lower-tropospheric zonal-wind from the NOAA $20^{\text {th }}$ Century Reanalysis v.2c (NOAA20thCRv2c; Compo et al., 2011; pressure-weighted over the 850-700 mB levels) over 60 $\mathrm{W}$ $0^{\circ} \mathrm{E}$ and $16-76^{\circ} \mathrm{N}$, following prior convention (Woollings et al., 2010; Barnes et al., 2013). In this representation, the Atlantic jet manifests simply as a wind speed "bulge" broadly centered over the Atlantic mid-latitudes, wherein variability can be reasonably transcribed geometrically through year- 
to-year changes in jet speed (i.e., the maximum bulge speed), jet width (i.e., the latitudinal spread of the bulge at half its max speed), and jet latitude (the latitudinal position of the jet speed; Barnes et al., 2013; Fig. 5-3a,b). Conversely, a more statistically integrative, albeit less physically intuitive, approach comes via decomposing the Atlantic jet into orthogonal modes using PCA (Section 5.6.2). The leading two modes in this latter approach - explaining 40 and $32 \%$ of the annual jet stream variability, respectively - are well-characterized across synoptic ( $\sim$ daily-weekly) timescales (Lorenz and Hartmann, 2003; Barnes et al., 2012, 2013): geometrically, Jet-PC1can be interpreted as a north-south "wobbling" of the Atlantic jet (correlation of $r=0.76$ with the mean-annual Atlantic jet-latitude position; Thompson and Wallace, 2000; Barnes et al., 2013), and Jet-PC2 as a characteristic protracting-contracting of the bulge half-width (correlation of $r=0.76$ with the mean-annual Atlantic jet-width; Fig. 5-3c,d). The corresponding spatial loading patterns for both orthogonal modes (i.e., the empirical orthogonal functions, EOF's), shown in Figure 5-4, further reveal two distinct wave-like patterns qualitatively similar to those described by Barnes et al. (2013): Jet-EOF1 shows a maximum at $\sim 51-53^{\circ} \mathrm{N}$ centered (i.e., 0-loading intercept) at the mean-jet latitude approximately $10^{\circ}$ equatorward. This latter latitude is the same where, by construction, Jet-EOF2 exhibits its maxima. Moreover, both jet patterns' corresponding PC's are significantly correlated at the $p<0.05$ level to $\delta^{18} \mathrm{O}-\mathrm{PC} 1$ and $\delta^{18} \mathrm{O}-\mathrm{PC} 2$ (Fig. 5-4), an important observation whose relevance we expound upon shortly.

Whereas Jet-PC1 can indeed be significantly $(p<0.0001)$ and linearly related to meridional shifting of the Atlantic jet (Barnes et al., 2013), our results suggest that jet latitude can be betterconstrained by projection of the jet speed parameter-space onto a second dimension. Naïve evidence towards this suggestion comes from Fig. 5-3c, which reveals clear demarcations in the linear association between Jet-PC1 and jet-latitude as a function of jet-speed (or, near-equivalently, jetwidth). Since Jet-PC1 and Jet-PC2 are by definition orthogonal, an improved approach thus expresses the Atlantic jet latitude using bilinear least-squares. In this view, the Atlantic jet-latitude appears to lie robustly $\left(r^{2}=0.84\right)$ along a hyperbolic paraboloid (a "saddle"; Fig. 5-3), suggesting that both Jet-PC1 and PC2 are necessary (albeit not necessarily sufficient) for geometrically constraining meridional shifts in the Atlantic zonal-mean zonal jet.

Critically, the statistically significant correlations we observed previously between both JetPC1/2 and $\delta^{18} \mathrm{O}-\mathrm{PC} 1 / 2$ (Fig. 5-4a) imply the potential to robustly-constrain past meridional shifts in the Atlantic jet from our GrIS- $\delta^{18} \mathrm{O}$ compilation. However, from this suggestion arises questions surrounding the climatological linkage(s) underpinning such covariability. To explore this, we conduct 
a truncated Canonical Correlation Analysis (CCA; see Section 5.6.10; Barnett and Preisendorfer, 1987; Bretherton et al., 1992) between Northern Hemisphere NOAA20thCRv2 Z500 anomalies (Compo et al., 2011) and the Atlantic zonally averaged zonal jet between A.D. 1851 to present. We find the leading two modes of covariance robustly reproduce the aforementioned Jet-EOF1 and -EOF2 patterns (Fig. 5-5c), confirming the climatological veracity of the leading two modes of Northern Hemisphere Z500-covariability we incidentally recover from the CCA (i.e., Z500-CC1 and -CC2). Therein, Z500-CC1 illuminates a strong negative-positive dipole over Greenland-Azores corresponding to the well-known Z500 pattern associated with the NAO (Fig. 5-5a), whereas Z500CC2 reveals a southerly-shifted dipole in Z500 reminiscent of the East Atlantic (EA) pattern (Woollings et al., 2010; Fig. 5-5b); both patterns are well-characterized as the two leading modes of atmospheric variability over the Atlantic sector, and have been suggested by prior authors' as important diagnostics for predicting synoptic-scale ( $\sim$ daily-weekly) jet-variability (Woolings et al., 2010; 2012; Hall et al., 2015; Mellano-Cano et al., 2019).

Figure 5-5a,b,c,d confirms that the NAO and the EA pattern govern the meridional positioning of the mid-Atlantic jet stream across interannual timescales (see also, Woollings et al., 2010). This suggests, by virtue of the strong temporal association between $\delta^{18} \mathrm{O}-\mathrm{PC} 1$ and -PC2 and the corresponding Jet-PC's (Fig. 2), that a substantial fraction of the North Atlantic water isotopic variability can also be explained by both climatic modes (Fig. 5-2). To explore this contention more explicitly, we employ an ensemble of eight different last-millennium model runs from the isotopeenabled Community Earth System Model (iCESM; Section 5.6.9; Otto-Bleisner et al., 2016; Nusbaumer et al., 2017). To test the ability of the iCESM to constrain NAO- and EA-modulated Atlantic jet dynamics, a second set of CCA's is performed in an identical manner to that described above (Section 5.6.10). Our results show the iCESM reliably reproduces the same two spatial-modes of covariance observed in the NOAA20thCRv2 reanalysis data across all ensemble members (Fig. 5-

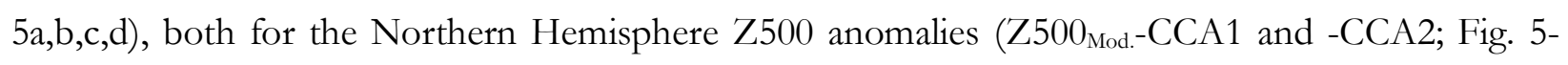

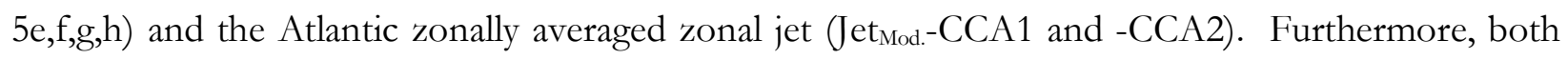
corresponding Z500-temporal modes show robust $(p<0.0001)$ correlations with iCESM-modeled GrIS- $\delta^{18} \mathrm{O}$ (i.e., $\delta^{18} \mathrm{O}_{\text {Mod. }}$ PC1 and -PC2) for all unique grid-cells underlying the locations of our ice core sites (i.e., 24 unique grid cells representing 29 ice core sites). Together, both findings thus establish confidence in the ability of the iCESM to adequately capture real underlying Atlantic jet stream and GrIS- $\delta^{18} \mathrm{O}$ dynamics. 
Provided these results, we thus extend our iCESM-CCA approach to explicitly investigate coupling between Northern Hemisphere precipitation-weighted $\delta^{18} \mathrm{O}$ and the Atlantic zonallyaveraged zonal jet. Remarkably, the $\delta^{18} \mathrm{O} /$ jet-derived CCA once again broadly reproduces the meridional structure of Jet-EOF1 and -EOF2 (Fig. 5-4b), while also recovering the associated spatial pattern of Northern Hemisphere $\delta^{18} \mathrm{O}$-deposition. From Figure 5-5i,j,k,1 we see the first (i.e., NAOmodulated) mode of coupled jet- $\delta^{18} \mathrm{O}$ variability invokes a largely homogenous, negatively-correlated $\delta^{18} \mathrm{O}$ imprint over Greenland (Fig. 5-5i), with the exception of the northeastern GrIS as suggested previously by GBI-prefiltering (e.g., see Fig. 5-1c, Fig. S5-5 and S5-6). The second mode, albeit lessrobustly constrained over Greenland than its peripheries, nonetheless reveals a positive-negative dipole in $\delta^{18} \mathrm{O}$ deposition over southern and northern Greenland mirroring the actual spatial loading pattern of $\delta^{18} \mathrm{O}-\mathrm{PC} 2$ (Fig.'s 5-1 and S5-7). While further experiments conducted using the iCESM suggest that extraction of Jet-PC2 (EA, i.e., jet-speed, width) might yet be improved by the future addition of ice core accumulation records in southern GrIS, or precipitation proxies in northern Britain (Fig. S5-3), our analyses nonetheless suggest, overwhelmingly, that GrIS water isotopes are ideal proxies for discerning past jet changes.

\section{4 iCESM pseudoproxy experiments}

Given the ability of the iCESM to robustly constrain the leading two modes of Atlantic jet-variability and their corresponding GrIS-wide $\delta^{18} \mathrm{O}$-imprints, we next exploit the iCESM as a testbed for reconstructing the Atlantic jet-latitude using GrIS- $\delta^{18} \mathrm{O}$ records. We incorporate a Partial Least Squares regression (PLSr) method (Section 5.6.4; Kinnard et al., 2011) to extract both the dominantas well as lower-order embedded - climatic signals within our $\delta^{18} \mathrm{O}$-compilation (e.g., Fig. 5-2) for use as jet-latitude predictors. Our pseudoproxy experiments, which incorporate as synthetic proxy time series the mean-annual precipitation-weighted $\delta^{18} \mathrm{O}$ iCESM-output at the grid cells underlying our ice core sites, reveals the PLSr-methodology to skillfully reconstruct changes in the modeled Atlantic jetlatitude on an annual basis, both during the calibration interval (A.D. 1851-2000) and prior; indeed, the skillfulness of the pseudoproxy reconstruction extends to model-surrogate $\delta^{18} \mathrm{O}$ compilations entailing noise-to-signal ratios doubling that of our observed data (Fig. S5-4 and Table S5-2; Section 5.6.11). Notwithstanding the additional age-model uncertainties that reconstructions incorporating real ice core data must contend with (Section 5.6.1), the robust predictability under the pseudoproxy approach underscore the robustness of GrIS- $\delta^{18} \mathrm{O}$ for reconstructing past variability in the Atlantic 
jet-latitude. Moreover, we find that the reconstructions are near-equivalently robust whether incorporating a direct calibration to the Atlantic jet-latitude, or a hierarchical approach (e.g., Fig. 5-3e) requiring independent reconstructions of the Jet-PC1 and Jet-PC2 series as precursor jet-latitude (bilinear-regression) predictors (Table S5-2). Due to its simpler implementation and inherent-ability to embed multiple modes of $\delta^{18} \mathrm{O}$ variability as jet-predictors, we report only (the former) PLSrderived reconstructions of the Atlantic jet-latitude (as well as Jet-PC1 and Jet-PC2) henceforth.

\subsection{Enhanced Atlantic jet variability during the last millennium}

In Figure 5-6a, we show the reconstructed annual-mean Atlantic jet-latitude, Jet-PC1, and Jet-PC2 time series for the last millennium, calibrated to jet-diagnostics derived from the NOAA20thCRv2c reanalysis (A.D. 1851-2000; see also Fig. 5-3). Extensive calibration-validation efforts for all three reconstructions, tested upon several PSLr-methods designed to iteratively select for optimal $\delta^{18} \mathrm{O}$ predictors (Section 5.6.6), show skillful jet-reconstructions are possible back to A.D. 1022 (Fig. S5-5 and S5-7), beyond which point a coherent $\delta^{18} \mathrm{O}-\mathrm{PC} 2$ signal can no longer be independently isolated due to increasingly limited $(<11 / 29) \delta^{18} \mathrm{O}$ record availability (Section 5.6.3; Fig. S5-5). Interestingly, we find a slight improvement in reconstruction skill across all three calibration targets when each is first detrended using a 100-year high-pass filter, hence removing a slight positive-trending bias in the Atlantic jet-latitude and Jet-PC1 observed across the 20th century reanalysis data (Figure S5-5a). Although both the resultant detrended and non-detrended reconstructions remain closely correlated over the full reconstruction interval $\left(r_{\text {Lat }}=0.98 ; r_{P C 1}=0.99 ; r_{P C 2}=0.95\right)$, the improvements we observe across the calibration-verification metrics (Fig. S5-8 vs. S5-9; Section 5.6.5) suggest interannual- to multidecadal Atlantic jet-variability may be especially well-resolved by GrIS-deposited $\delta^{18} \mathrm{O}$. We speculate this may be due, in part, to the contradictory influence of thermal vs. atmospheric dynamical processes on GrIS- $\delta^{18} \mathrm{O}$ deposition: whereas increasing local air-temperatures during the last two centuries are believed to increase the precipitation-weighted $\delta^{18} \mathrm{O}$ signal across the GrIS, it may be that such temperature-driven positive GrIS- $\delta^{18} \mathrm{O}$ trends have, in part, been dampened by the negative relationship between GrIS- $\delta^{18} \mathrm{O}$ and the (also positive-trending) Atlantic jet latitude (Fig. S5-7).

Despite these potential limitations, our reconstruction markedly widens the temporal coverage of pre-observational jet-stream records and, to our knowledge, provides the first quantitative lastmillennium-scale Atlantic jet-reconstruction to date. Therein, our reconstruction substantially extends 
a recent Atlantic jet-latitude reconstruction by Trouet et al. (2018; hereafter T18), who reported "unprecedented" eastern Atlantic (10-30 W) jet-latitude variance during recent decades across a threecentury context. However, despite notable spatiotemporal overlap with our reconstruction, we find the T18 Atlantic jet-latitude reconstruction to show only weak correlation to our own $(r=0.03 ; n=$ 254; Fig. 5-6). This weak-coherence could stem from several factors, including the limited proxy data (i.e., relying on two tree ring chronologies, one from the United Kingdom and the other from the eastern Mediterranean, both averaged and scaled to the overlapping jet-latitude variance), the summertime-proxy bias (despite jet-variability being a winter-dominated phenomenon), and smaller spatial scope this reconstruction employed. We suggest an additional, fundamental shortcoming of the T18 reconstruction: both proxy locations - argued by the authors to entrain a temperature "seesaw" signal from the British Isles down to the northeastern Mediterranean region - denote the centers of action for the EA temperature/pressure dipole pattern as opposed to the NAO, despite the latter being of primary importance in modulating east-Atlantic jet-latitude variability (e.g., Fig. S5-3c,d; Woollings et al., 2012). Indeed, these authors report their bi-proxy jet-latitude reconstruction to be more strongly correlated with the EA index than the NAO, and is similarly more strongly correlated to our $\delta^{18} \mathrm{O}-\mathrm{PC} 2$ than $\delta^{18} \mathrm{O}-\mathrm{PC} 1$ signal.

Conversely, our 29-record $\delta^{18} \mathrm{O}$-compilation robustly embeds signals of both the NAO and EA patterns, each necessary for robust reconstruction of the North Atlantic jet-latitude (Fig.'s 5-2, 53, and 5-4; Woollings et al., 2010, 2012). The strong association of our $\delta^{18} \mathrm{O}$-compilation to the NAOmodulated Jet-PC1 signal is particularly remarkable. For example, although indirectly calibrated, we find our Jet-PC1 index provides a more-strongly coherent annual-NAO signal than does a recent, multi-proxy (comprising predominantly tree ring, but also speleothem, lake sediment, and ice core data) and model-tested annual-resolution reconstruction by Ortega et al. (2015), as suggested by crosscorrelation with several observationally-constrained 19-20th century NAO indices (Fig. 5-6). Whereas both the Ortega et al. (2015) and Jet-PC1 reconstruction negate prior contentions of a "persistent" positive NAO during the Medieval Warm Period (c. A.D. 950-1350; Trouet et al., 2009), the stronger association to observed NAO variations exhibited by our Jet-PC1 index further calls into the question the veracity of the associated enhanced multi-decadal to centennial-scale variability this aforementioned model-tested NAO reconstruction exhibits across the Common Era (Fig. 5-6). Contrary to the findings of Ortega et al. (2015) and T18, respectively, neither our Jet-PC1 nor jetlatitude reconstruction reveals evidence of statistically-meaningful $\mathrm{NAO} /$ jet-anomalies associated 
with large eruptions during the last millennium (results not shown; note analyses here were conducted identically to those described in Ortega et al. (2015)).

Further compounding differences with the Ortega et al. (2015) NAO reconstruction, our North Atlantic jet-latitude and Jet-PC1 reconstructions reveal evidence of moderate energy concentrated in the $11 \mathrm{yr}^{-1}$ frequency band, hence supporting several observation-based studies suggesting modulation of the NAO/North Atlantic jet by the 11-yr solar irradiance cycle (Huth et al., 2007; Gray et al., 2013, 2016; Fig. S5-10). Spectral decomposition of our jet-latitude and Jet-PC2 ( $\sim$ EA) reconstructions also suggest substantial multidecadal variability concentrated in the $\sim 50-60 \mathrm{yr}^{-}$ ${ }^{1}$ spectral bands (Fig. S5-10), suggestive of dynamical interaction between the Atlantic Multidecadal Oscillation (i.e., AMO) and North Atlantic eddy-driven jet. In particular, the apparent multidecadal correspondence between Jet-PC2 and AMO supports the findings of Hakkinen et al. (2011) who, using 20th century reanalysis data, showed positive decadal-scale covariation between blocking intensity/frequency over the eastern-Atlantic/western European sector (i.e., East Atlantic atmospheric blocking) and sea-surface temperatures across the North Atlantic (as mediated by stormtrack driven wind-stress curl and air-sea heat exchange changes).

Whereas there exists generally low multicentennial-scale variability in Atlantic jet-latitude positioning, Jet-PC1 (NAO), and Jet-PC2 (EA) during the last millennium, our reconstruction suggests alarming increases in the occurrence of North Atlantic mean-annual jet-latitude anomalies (defined as $>\operatorname{abs}(1 \sigma)$ per century) following the Industrial-era onset (c. $19^{\text {th }}$ century; Fig. 5-6c). This finding revealing a remarkable two-fold increase in mean-annual jet-anomalies over the last two centuries relative to a pre-industrial context - appears independent of PLSr variable-selection algorithm used (e.g., Fig. S5-7, S5-8, and S5-9), and is robust when calibrating to either the 100-year high-pass filtered or non-filtered jet-latitude observations (Fig. S5-8 and S5-9). Moreover, contrary to findings reported by T18, directionality of jet-latitude anomalies during the last two-centuries are not consistent, but primarily accounted for by negatively-shifted jet stream anomalies. Conversely, the frequency of northerly jet stream anomalies during the Industrial-era remains indistinct from the pre-Industrial background state (Fig. S5-6d).

Importantly, the evolution of North Atlantic jet latitude anomalies closely aligns with the century-scale evolution of reconstructed pan-Arctic surface-air-temperature (SAT) anomalies during the last millennium (Kaufman et al., 2009). Provided time-independence in $\delta^{18} \mathrm{O}$ data fidelity and dating (e.g., Fig. 5-1), this finding supports a prior notion that anomalous Industrial-era warming of the Arctic relative the low- to midlatitudes (i.e., Arctic amplification) - believed to reduce the low- 
level poleward temperature gradient and zonal wind speed in the upper atmosphere, as suggested by the thermal wind relationship - has led to a progressively-more sinuous, and hence more variable (less predictable), Atlantic jet stream (Francis et al., 2012, 2015; Cohen et al., 2014). As suggested by our data, we hypothesize this Industrial-era long decrease in poleward temperature gradients has thus led to increased frequency of southerly jet-meanders over the zonally-averaged Atlantic sector (i.e., 60$\left.0^{\circ} \mathrm{W}\right)$, albeit not a negative-shift in the Atlantic jet-latitude mean-state.

The increased frequency in jet-latitude anomalies over the Industrial-era has implications for better-contextualizing past and future-projected climatic, economic, and ecosystems changes across the North American- and European-based Atlantic sectors. Increased Industrial-era Atlantic jetlatitude variability is likely underpinned by enhanced blocking-occurrence and (or) high-amplitude quasi-stationary atmospheric Rossby wave breaking over the Atlantic sector (Coumou et al., 2012, 2018; Mann et al., 2018), each manifested through increased mid-latitude weather extremes on both sides of the Atlantic (Cohen et al., 2014; Coumou et al., 2018). Given the ongoing rapid decline in Arctic sea ice, seasonal snow cover, and glacial-melt extent/cover, collectively believed to contribute to Arctic amplification (Stroeve et al., 2012; albeit notwithstanding non-negligible, associated cloud and water-vapor feedbacks; Goosse et al., 2018), we suspect enhanced Atlantic jet-variability (and associated mid-latitude weather extremes therein, including North American and European heat waves, droughts, fires, and flooding; Cohen et al., 2014) will be exacerbated over the 21st century provided unabated greenhouse gas emissions (Martin and Diffenbaugh, 2018). Continued observations, and independently-derived Common Era jet-reconstructions extending across a muchbroader spatial and temporal scope, will help to constrain such speculations.

\subsection{Methods}

\subsubsection{Proxy record selection and preprocessing}

Atmospheric measurements of the abundance of the stable isotope of water $\mathrm{H}_{2}{ }^{18} \mathrm{O}$ relative to $\mathrm{H}_{2}{ }^{16} \mathrm{O}$ (where superscripts denote the atomic mass of the oxygen atom, "16" being the "normal", or most isotopically-abundant, case) provide an integrated signal of meteoric moisture-cycling. Specifically, one expresses the isotopic ratio in $\delta$-notation: 


$$
\delta^{18} O=\frac{\frac{\left[\mathrm{H}_{2}^{18} \mathrm{O}\right]}{\left[\mathrm{H}_{2}^{16} \mathrm{O}\right]} \text { samp. }}{{\frac{\left[\mathrm{H}_{2}^{18} \mathrm{O}\right]}{\left[\mathrm{H}_{2}^{16} \mathrm{O}\right]}}_{\text {std }}} \cdot 1000
$$

where brackets denote concentrations, such that $\delta^{18} \mathrm{O}$ represents a deviation in the ratio of atomicallyheavy to light water molecules within a sample ("samp.") from that measured in a standard ("std."; conventionally, Vienna Standard mean ocean water), relative to that same standard's ratio. The 1000xscaling of this "ratio of a ratio" implies the deviations are typically small (parts per thousand), and is again made following convention out of convenience.

From a pragmatic sense alone, the climatic delineation of $\delta^{18} \mathrm{O}$ ice core measurements represents a useful target: often considered the centerpiece (Dansgaard, 1969) of Greenland ice core studies, the measurement of $\delta^{18} \mathrm{O}$ from Greenlandic ice samples - traditionally conducted using isotope mass spectrometry or, more recently, laser-based spectrometry - are well established (Dansgaard et al., 1969; Jones et al., 2017). Six decades removed since the first recovered deepGreenlandic ice cores (Dansgaard et al., 1969; Jouzel et al., 2013), $\delta^{18} \mathrm{O}$ remains perhaps the mostcommonly measured climate proxy in Greenland ice core records. Exploiting this prevalence, we compiled twenty nine (29) $\delta^{18}$ O-records from sites spanning the Greenland Ice Sheet $(\mathrm{GrIS})$ and nearby ice caps - the largest compilation to date (e.g., Vinther et al., 2003, 2010; Ortega et al., 2014). Records were included in our compilation on the basis that each $i$. be of at least annual scale resolution (i.e., $\leq 1$ year per sample), $i i$. be well dated ( $<5$ year relative uncertainty at the deepest portions of the record considered), and iii. contain both $>100$ years overlap within the calibration period (A.D. 1851 - 2010) and extend beyond the calibration period (i.e., prior to A.D. 1851, the time period covered by the NOAA 20th Century Reanalysis v.2c product; Compo et al., 2011); note that the most recent year covered by all records within our compilation varies broadly, spanning the late 1960's to early 2010's. Aspects of all ice core records, including ice core extraction and development of their respective agescales, are previously published, with specific details confined to original references listed in Table S51. Twenty-three out of twenty-nine $(23 / 29) \delta^{18}$ O-records represent previously published data. All remaining (6) records: the ACT11d, NU, D4, Summit2010-combined, NEEM-2001-S1, and TUNU $\delta^{18} \mathrm{O}$-records, were analyzed at the Desert Research Institute at high- (2-cm water-equivalent) resolution following well-established methods (e.g., McConnell et al., 2002; Gkinis et al., 2011). 
Prior to the analysis of all records, each was linearly-interpolated (when necessary) to a resolution of one year (Jan-Dec averaging period). The period of common overlap for each record (accounting for intermittently-missing years of data in the NEEM-2011-S1 record) is A.D. 1775-1967. The oldest year retained for analysis is A.D. 1. Given the lack of seasonal-resolution data for all sites, or targeting of seasonally-dependent climatic signals, no artificial corrections for isotopic-diffusion (i.e., "back-diffusion"; Jones et al., 2016) were performed. Moreover, we expect that any isotopic skewing of the annual signals is largely minimized during data-reduction (and effectively removed following lowpass filtering of the records thereafter). Similarly, given the lack of evidence for a systematic long-term or spatially-synchronous change in accumulation during the last-millennium across interior Greenland (Andersen et al., 2006; Box et al., 2013), no water-isotopic "amount-effect" corrections were performed.

\subsubsection{Probabilistic Principal Component Analysis (pPCA) and missing data imputation}

Since naive estimates of the proxy covariance structure cannot be adequately achieved in the presence of missing data, a probabilistic principal component analysis was conducted, allowing estimation of latent GrIS- $\delta^{18} \mathrm{O}$ structure and covariability. Consider the following latent variable model, relating $\boldsymbol{x}_{\boldsymbol{i}}$ ), the $i^{\text {th }}$ row (time dimension) of a $p$-dimensional (i.e., $p=$ number of proxy records) matrix consisting of $n$ centered observations $\left(\boldsymbol{X}_{\mathbf{0}}\right)$ to some (a priori unknown) $q$ dimensional vector of latent variables $(\boldsymbol{Z})$, where $p>q$ :

$$
x_{i}=C z_{i}+v_{i}
$$

Here, $\boldsymbol{C}$ is a $p$ × $q$ rotation matrix mapping $\boldsymbol{z}_{\boldsymbol{i}}$ onto $\boldsymbol{x}_{\boldsymbol{i}}$, and $\boldsymbol{v}_{\boldsymbol{i}}$ is a vector consisting of Gaussian-

distributed noise with variance $\sigma_{i}^{2}$ (i.e., $\boldsymbol{v}_{\boldsymbol{i}} \sim \mathcal{N}\left(0, \sigma_{i}^{2} \boldsymbol{I}\right)$ ). Each vector of latent variables $\left(\boldsymbol{z}_{\boldsymbol{i}}\right)$ is assumed independent and identically distributed according to an underlying unit variance model. Provided both the latent variables and noise are conjugate normal, Eq. 5.2 thus reduces to a single Gaussian distribution model:

$$
\boldsymbol{x}_{\boldsymbol{i}}=\mathcal{N}\left(0, \boldsymbol{C} \boldsymbol{C}^{\prime}+\sigma_{i}^{2} \boldsymbol{I}\right)
$$


where, $\sigma_{i}^{2} \boldsymbol{I}$ explains the variability unique to a given $\boldsymbol{x}_{\boldsymbol{i}}$ and $\boldsymbol{C} \boldsymbol{C}^{\prime}$ explains the covariability between the $p$ variables $\boldsymbol{x}$

Probabilistic PCA seeks a probabilistic estimate of the parameters $\boldsymbol{C}$ and $\sigma_{i}^{2}$. As discussed by Roweiss (1998), the problem can be readily transcribed into a Bayesian framework:

$$
\begin{aligned}
& \operatorname{Pr}\left(\boldsymbol{z}_{\boldsymbol{i}} \mid \boldsymbol{x}_{\boldsymbol{i}}\right)=\frac{\operatorname{Pr}\left(\boldsymbol{x}_{\boldsymbol{i}} \mid \boldsymbol{z}_{\boldsymbol{i}}\right) \operatorname{Pr}\left(\boldsymbol{z}_{\boldsymbol{i}}\right)}{\operatorname{Pr}\left(\boldsymbol{x}_{\boldsymbol{i}}\right)}, \text { where, } \\
& \operatorname{Pr}\left(\boldsymbol{x}_{\boldsymbol{i}} \mid \boldsymbol{z}_{\boldsymbol{i}}\right)=\mathcal{N}\left(\boldsymbol{C} \boldsymbol{z}_{\boldsymbol{i}}, \sigma_{i}^{2} \boldsymbol{I}\right) \\
& \operatorname{Pr}\left(\boldsymbol{z}_{\boldsymbol{i}}\right)=\mathcal{N}(\mathbf{0}, \boldsymbol{I}) \\
& \operatorname{Pr}\left(\boldsymbol{x}_{\boldsymbol{i}}\right)=\mathcal{N}\left(\mathbf{0}, \boldsymbol{C} \boldsymbol{C}^{\prime}+\sigma_{i}^{2} \boldsymbol{I}\right)
\end{aligned}
$$

Conventionally, pPCA uses Expectation-Maximization (EM; Dempster, 1977) to maximize the likelihood function $\mathcal{N}\left(\boldsymbol{C}_{\boldsymbol{i}}, \sigma_{i}^{2} \boldsymbol{I}\right)$ for a given set of proxy observations $\boldsymbol{X}_{\mathbf{0}}$ by iteratively estimating $\boldsymbol{C}$ and $\sigma_{i}^{2}$, even in the absence of missing data, $\boldsymbol{X}_{\boldsymbol{h}}$. Here we marginalize $\operatorname{Pr}\left(\mathbf{z}_{\boldsymbol{i}} \mid \boldsymbol{x}_{\boldsymbol{i}}\right)$ following the EMalgorithm presented in Appendix B of Tipping and Bishop (1999). Once $\boldsymbol{C}$ and $\sigma_{i}^{2}$ are estimated within a given tolerance, $\boldsymbol{X}_{\boldsymbol{h}}$ can be estimated via

$$
X_{h}=C\left(C^{\prime} C\right)^{-1}\left(C^{\prime} C+\sigma^{2} I\right) X_{0}
$$

\subsection{3 $\delta^{18} \mathrm{O}-\mathrm{PC} 1$ and -PC2 signal extraction and uncertainty attribution}

Extraction of the $\delta^{18} \mathrm{O}-\mathrm{PC} 1$ and -PC2 time series during the last millennium, including signal uncertainty-attribution (Fig. S5-5), was conducted broadly following the methodology outlined in Osman et al. (2019). In brief, we computed an initial probabilistic principal component analysis (pPCA) on the data during the period A.D. 1775-2000 where all 29 records are available (note common overlap of A.D. 1775-1967). Bootstrap-based random $\delta^{18} \mathrm{O}$-record re-sampling with replacement of all 29 records over $n=1000$ iterations, tested against a pseudo-random (power-spectrum-preserving; Ebisuzaki, 1997) null, revealed the first two components (defined here after as $m_{1}=\delta^{18} \mathrm{O}-\mathrm{PC} 1$ and $m_{2}$ $=\delta^{18} \mathrm{O}$-PC2) to provide both spatially-meaningful and statistically-distinct modes of GrIS- $\delta^{18} \mathrm{O}$ variability (Fig. 5-2). 
In order to extend the $\delta^{18} \mathrm{O}-\mathrm{PC} 1$ and -PC2 signals beyond the period of common overlap, the following procedure was taken: $i$. For each new nest (i.e., each representing, in general, progressively fewer available $\delta^{18} \mathrm{O}$ records and a longer temporal domain), an initial pPCA was conducted. $i i$. The first two modes of variability were then correlated against $m_{1}$ and $m_{2}$ over the original period of common overlap (i.e., A.D. 1775-2000) using the non-parametric Monte Carlo-based method of Ebisuzaki (1997; $n=1000$ iterations) as a test of statistical-signficance. iii. Provided significance at the $p<0.01$ level (and, when necessary, correcting for potential PCA-sign-changes), bootstrap-based random $\delta^{18} \mathrm{O}$-record sampling with replacement was conducted on the nest $\mathrm{n}$-times, with all $\mathrm{n}$ principal-component "score" matrices adjusted to the reference pPCA principal-component score matrix from $i$. using a Procrustes transform to correct for rotational ambiguity (Osman et al., 2019; Babamoradi, 2012). Following the $\mathrm{n}$ tests, the $2.5^{\text {th }}$ and $97.5^{\text {th }}$ percentiles of the resultant $n \delta^{18} \mathrm{O}-\mathrm{PC} 1$ and -PC2 realizations were then stored as 95\% confidence intervals, with the median was taken as the optimal $\delta^{18} \mathrm{O}-\mathrm{PC} 1$ and -PC2 signals. For each new nest, only the new temporal information not available from the prior nest was appended to the $\delta^{18} \mathrm{O}$-PC1 and -PC2 signal. (iv.) Steps $i .-i i i$. were then repeated for new nests until $i$. was not passed (Fig. S5-5).

\subsubsection{Partial Least Squares regression (PLSr)}

One problem suffered by reconstructions of climate indices from climate proxies is over-fitting of the regression. In such multivariate regression problems, proxy records are often highly collinear or linearly-dependent, leading to problems that manifest during model calibration/learning. This can result in, for example, a loss of independence and (or) precision in the regression coefficients and, by consequence, a loss of certainty and (or) consistency (i.e., depending on which parameters are included) in the resulting predictions.

Several methods have been developed to deal with collinearity in multiple regression-based learning. These have included (but are not limited to) simple proxy compositing and variance scaling to the predictand (“composite-plus-scaling; Mann et al., 2008; Trouet et al., 2018), shrinkage-based and (or) regularization methods (Mann et al. 2009), and Eigen-based decomposition and regression methods (e.g., Kinnard et al., 2011; Ortega et al., 2015; Wang et al., 2017). Here we use a specific class of biased (see below) regression methods, Partial Least Squares regression (PLSr), to reconstruct Atlantic jet variability over the last millennium using a compilation of water isotope ice core records from the GrIS. 
There are many representations of, and a great deal of underlying research comprising, PLSr (see, e.g., Rosipal and Krämer (2005), for a review). Two widely-used algorithms, however, warrant mention. These are the Nonlinear Iterative PArtial Least Squares (NIPALS) algorithm (Wold et al., 2001) - often termed the "standard" algorithm - and the SIMPLS algorithm of de Jong (1994). The overarching goal of both algorithms is the same; namely, one attempts to refine a matrix of proxy predictors, $\boldsymbol{X}=\left[\boldsymbol{x}_{\mathbf{1}}, \boldsymbol{x}_{\mathbf{2}}, \ldots, \boldsymbol{x}_{\boldsymbol{p}}\right]$, representing $n$ years of data for $p$ proxy records, into a truncated set of $A$ latent variables (also known as factor scores), $\boldsymbol{T}=\left[\boldsymbol{t}_{\mathbf{1}}, \boldsymbol{t}_{\mathbf{2}}, \ldots, \boldsymbol{t}_{\boldsymbol{p}}\right]$, where $A \leq p . \boldsymbol{X}$ is related to $\boldsymbol{T}$ via,

$$
X=T P^{\prime}+\epsilon_{X}
$$

where $\boldsymbol{P}$ is the $p$ x $A$ loading matrix of $\boldsymbol{X}, \boldsymbol{\epsilon}_{\boldsymbol{X}}$ is an $n \times p$ matrix of misfits $\left(\boldsymbol{\epsilon}_{\boldsymbol{X}}\right.$ is degenerate when $p$ $=A$ ), and prime denotes a matrix transpose hereafter. If assuming a (multi)linear relationship between $\boldsymbol{X}$ and a set of $m$ predictand (i.e., response) variables $\boldsymbol{Y}$, i.e., $\boldsymbol{Y}=\left[\boldsymbol{y}_{1}, \boldsymbol{y}_{2}, \ldots, \boldsymbol{y}_{\boldsymbol{m}}\right]$, we prescribe

$$
\boldsymbol{Y}=\boldsymbol{X} \boldsymbol{\beta}+\boldsymbol{F}
$$

where $\boldsymbol{\beta}$ and $\boldsymbol{F}$ are $p \times m$ and $n \times m$ vectors of mapping coefficients and intercepts, respectively. Thus, the resultant linear calibration of $\boldsymbol{\beta}$ and $\boldsymbol{F}$ can be used to predict $\boldsymbol{Y}$ from $\boldsymbol{X}$. Given that the columns of $\boldsymbol{T}$ successively describe the maximum amount of covariance between $\boldsymbol{X}$ and $\boldsymbol{Y}$ (each orthogonal to the next), without loss of generality one can also describe $\boldsymbol{Y}$ by,

$$
Y=T Q^{\prime}+\epsilon_{Y}
$$

where $\boldsymbol{Q}$ is the $m \times A$ loading matrix of $\boldsymbol{Y}$, and $\boldsymbol{\epsilon}_{\boldsymbol{Y}}$ is an $n \times m$ matrix of misfits $\left(\boldsymbol{\epsilon}_{\boldsymbol{Y}}\right.$ being degenerate when $m=A$ ). As next shown, $\boldsymbol{P}$ and $\boldsymbol{Q}$ can be used to generate $\boldsymbol{\beta}$. Thus, PLSr models are distinguished by their being both biased and parsimonious, where the optimal predictive model of $\boldsymbol{Y}$ underlying $\boldsymbol{T}$ often exists when $A<p$ (provided collinearity in $\boldsymbol{X}$ ). Indeed, choosing the correct number of latent variables constitutes a major underlying concern when implementing PLSr (e.g., Faber and Rajko, 2007), an issue we subsequently return. 
Importantly, when $m=1$ as in our case (i.e., $\boldsymbol{Y}=\boldsymbol{y}_{\mathbf{1}}$ ), both NIPALS and SIMPLS produce indistinguishable results (de Jong, 1994; Andersson, 2009). As such, we implement the standard (NIPALS) algorithm in this study. This gives us the following predictive model we aim to prescribe:

$$
\boldsymbol{y}=\boldsymbol{X} \boldsymbol{b}+f+\boldsymbol{\epsilon}
$$

where $\boldsymbol{b}$ is a $p \times 1$ vector of regression coefficients, $f$ is an intercept, and $\boldsymbol{\epsilon}$ is an $n \times 1$ vector of misfits. To prescribe $\boldsymbol{b}$, the NIPALS algorithm (see also, Wald et al., 2001, de Jong, 1994) first centers (standardizing optional) $\boldsymbol{X}$ and $\boldsymbol{y}$ to give $\boldsymbol{X}_{\mathbf{0}}$ and $\boldsymbol{y}_{\mathbf{0}}$, hence allotting $f=0$ (within machine precision). The orthogonal PLSr factors and loadings for $\boldsymbol{X}_{\mathbf{0}}$ and $\boldsymbol{y}_{\mathbf{0}}$ are then computed iteratively, for $\boldsymbol{a}=1,2$, $\ldots, A$, by,

1. Computing a $p \times 1$ vector of loading weights $\boldsymbol{w}_{\boldsymbol{a}}=\boldsymbol{X}_{\boldsymbol{a}-\mathbf{1}}^{\prime} \boldsymbol{y}_{\boldsymbol{a}-\mathbf{1}}$, and then normalizing these weights (i.e., its Euclidian norm) $\boldsymbol{w}_{\boldsymbol{a}}=\boldsymbol{w}_{\boldsymbol{a}}\left\|\boldsymbol{w}_{-} \boldsymbol{a}\right\|^{-1}$;

2. Computing the $n \times 1$ score vector $\boldsymbol{t}_{\boldsymbol{a}}=\boldsymbol{X}_{\boldsymbol{a}-\mathbf{1}} \boldsymbol{w}_{\boldsymbol{a}}$;

3. Computing the $\boldsymbol{X}$ and $\boldsymbol{y}$ loadings via $\boldsymbol{p}_{\boldsymbol{a}}=\boldsymbol{X}_{\boldsymbol{a}-\mathbf{1}}^{\prime} \boldsymbol{t}_{\boldsymbol{a}}\left(\boldsymbol{t}_{\boldsymbol{a}}^{\prime} \boldsymbol{t}_{\boldsymbol{a}}\right)^{-\mathbf{1}}$ and $q_{\boldsymbol{a}}=\boldsymbol{y}_{\boldsymbol{a}-\mathbf{1}}^{\prime} \boldsymbol{t}_{\boldsymbol{a}}\left(\boldsymbol{t}_{\boldsymbol{a}}^{\prime} \boldsymbol{t}_{\boldsymbol{a}}\right)^{\mathbf{- 1}}(p \times 1$ and 1 x 1 , respectively);

4. Subtracting variance from $\boldsymbol{X}_{\boldsymbol{a}-\mathbf{1}}$ and $\boldsymbol{y}_{\boldsymbol{a}-\mathbf{1}}$ via $\boldsymbol{X}_{\boldsymbol{a}}=\boldsymbol{X}_{\boldsymbol{a}-\mathbf{1}}-\boldsymbol{t}_{\boldsymbol{a}} \boldsymbol{p}_{\boldsymbol{a}}^{\prime}$ and $\boldsymbol{y}_{\boldsymbol{a}}=\boldsymbol{y}_{\boldsymbol{a}-\mathbf{1}}-\boldsymbol{t}_{\boldsymbol{a}} q_{\boldsymbol{a}}$; and 5. Storing results from steps 1., 2., and 3. as $\boldsymbol{W}=\left[\boldsymbol{w}_{\mathbf{1}}, \boldsymbol{w}_{\mathbf{2}}, \ldots, \boldsymbol{w}_{\boldsymbol{A}}\right], \boldsymbol{P}=\left[\boldsymbol{p}_{\mathbf{1}}, \boldsymbol{p}_{2}, \ldots, \boldsymbol{p}_{\boldsymbol{A}}\right], q=\left[q_{1}\right.$, $\left.q_{2}, \ldots, q_{A}\right]$.

Following completion of iteration $A$, the model coefficients and intercepts are then computed as

$$
b=W\left(P^{\prime} W\right)^{-1} q
$$

For the full model reconstruction, a step-wise PLSr was conducted following prior authors (e.g., Mann et al., 2009, Kinnard et al., 2011), in which new model calibrations were constructed using Eq. 5.9 and Eq. 5.10 to accommodate the changing (i.e., declining with age) number of proxy-predictors over the reconstruction interval. Due to changing losses in variance associated with the nested regression approach, we re-standardized each reconstructed nest and uncertainty-interval with respect to the calibration interval, following prior convention (Mann et al., 2008, 2009; Ortega et al., 2015; Trouet et al., 2018). 


\subsubsection{PLSr model dimensionality and significance testing}

A primary concern when implementing PLSr is adequately prescribing the model dimensionality; that is, choosing the correct number of latent variables, $A$, to include in the ultimate prediction model. Choosing too few $A$ would lead to underfitting (i.e., an erroneously low-variance, high-bias jet reconstruction), whilst choosing too many $A$ overfitting (i.e., an erroneously high-variance (or, noisy), low-variance reconstruction). To determine $A$, two independent methods were employed for comparison. The first method, following from Faber and Rajko (2007), assesses the probability, or "risk", of overfitting $\left(p_{\text {risk }}\right)$ by testing the exceedance probability (inverse likelihood) of achieving greater covariance between successive columns of $\boldsymbol{t}_{\boldsymbol{a}}$ and $\boldsymbol{y}$ than that actually observed by chance alone. The corresponding null distribution for which the observed value was tested against was determined empirically by conducting 1,000 pseudorandomized tests (i.e., $p_{\text {risk }}$ precision of 0.001). In each test, $\boldsymbol{y}^{\prime}$ s Fourier phase was uniformly varied between 0 and $2 \pi$, thus retaining the exact autocorrelative properties, or power spectrum of $\boldsymbol{y}$ while effectively removing any underlying mechanistic coherency between $\boldsymbol{t}_{\boldsymbol{a}}$ and and $\boldsymbol{y}$ prior to covariance computation. A relativelyconservative significance threshhold of $p_{\text {risk }}<0.10$ was adopted for retention of model components.

The second method considered was a more-conventional cross-validation (Hastie, Tibshirani, and Friedman, 2009) approach. In this case, the full model calibration period (i.e., AD 1851-2000) was split into two contiguous sub-groups: a new calibration interval (2/3 of full calibration interval), and a withheld "validation interval" sub-group (1/3 of full calibration interval). Within the calibration sub-group, a new sub-calibration was derived following Eq. 1 and Eq. 2. For each $a=a_{1}, a_{2}, \ldots, A$, the resultant model calibration was then used to predict withheld $\boldsymbol{y}$-values within the validation interval subgroup. This procedure was repeated $K$ times, whereby for each successive test the calibration and validation intervals were stepped uniformly by $b$ years, where $h$ corresponds to the integral timescale of $\boldsymbol{y}$ (i.e., the approximate number of years between independent observations of $\boldsymbol{y}$ when accounting for serial correlation; von Storch, 1999) and $K$ represents the quotient of the full calibration length and $h$. This stepping-procedure helps to avoid potential user-subjectivity or underlying systemic biases arising from arbitrarily defining a calibration/validation interval.

For each of the $K$ tests, three primary metrics were used for assessing the model dimensionality: First, we computed the average of the $k$ Root Mean Square Error of Prediction (RMSEP) values for the validation interval datasets. Specifically, the RMSEP value was calculated as 


$$
R M S E P=\frac{1}{K} \sum_{k=1}^{K} \sqrt{\frac{1}{N} \sum_{n=1}^{N}\left(y_{n}^{o}-y_{n}^{p}\right)^{2}},
$$

where $y_{n}^{p}$ and $y_{n}^{o}$ are the predicted and observed $y$ values, respectively, summed over $n=n_{1}$, $n_{2}, \ldots, N$ withheld validation samples. For each model dimension $A$ where RMSEP was computed, the global minima in prediction error was sought. Similarly, for each model $A$ we computed the Reduction of Error (RE) and Coefficient of Error (CE) statistics (Cook et al., 1994, Trusel et al., 2018), defined (respectively) as

$$
\begin{aligned}
& R E=\frac{1}{K} \sum_{k=1}^{K}\left(1-\frac{\sum_{n=1}^{N}\left(y_{n}^{o}-y_{n}^{p}\right)^{2}}{\sum_{n=1}^{N}\left(y_{n}^{o}-\overline{y_{C}}\right)^{2}}\right), \text { and, } \\
& C E=\frac{1}{K} \sum_{k=1}^{K}\left(1-\frac{\sum_{n=1}^{N}\left(y_{n}^{o}-y_{n}^{p}\right)^{2}}{\sum_{n=1}^{N}\left(y_{n}^{o}-\overline{y_{V}}\right)^{2}}\right),
\end{aligned}
$$

where $\overline{y_{C}}$ and $\overline{y_{V}}$ are the mean $y$-values over the calibration and validation interval, respectively. Both $\mathrm{RE}$ and $\mathrm{CE}$ vary from 1 to $-\infty$, where $\mathrm{RE}$ and $\mathrm{CE}>0$ indicate predictive power above simple mean during the calibration interval. In this case we wish to maximize RE and CE across the various model dimensions. As a rule of thumb, CE is typically harder to pass (i.e., CE or RE $>0$ ), and hence often lower, than RE.

Tests suggested the number of retained model components $A$ (risk, RMSEP, RE, CE) to robustly agree within \pm 1 across the four tests, during all reconstruction intervals. In general, however, the "risk" assessment metric tended towards more-conservative estimates of $A$. In order to automate model learning across an entire nested-reconstruction, the most-conservative estimate was chosen in all instances.

\subsubsection{PLSr variable selection}

Following calibration of each of the stepped reconstruction models, all included variables were assessed for their robustness, and hence model-inclusion, using a backwards PLSr variable selection routine (Mehmood et al., 2012) similar to that described by Martens and Martens (2000), i.e., the 'Martens Uncertainty Test'. The variation upon the Martens Uncertainty Test employed here was conducted in an iterative fashion, by first assessing all variables' $\boldsymbol{b}$ (i.e., PLSr coefficient) values for significance against empirical (power-spectrum preserving) null-distributions of $\boldsymbol{b}$ (1,000 tests; see 
below). The lowest-probability variable was then removed (provided $p<0.05$ or $p>0.95$ ), and the calibration, cross-validation, and $\boldsymbol{b}$ empirical null-distributions recomputed using the truncated number of predictors. The former two steps were conducted in an iterative fashion (as for all stepwise regressions) until all retained variables' $\boldsymbol{b}$ values were observed to be significantly distinct from their null. Importantly, whereas the above-described backwards variable selection routine is computationally slower than the more-traditional Martens Uncertainty Test (which tests the $\boldsymbol{b}$ coefficients against a null t-distribution containing $n$, the number of samples in $\boldsymbol{X}$, degrees of freedom; Martens and Marten, 2000, Kinnard et al., 2011), this algorithm guards against potentially ill-defined assumptions concerning the underlying statistical distributions (and hence significance) of associated $\boldsymbol{b}$-values. Hence, the above test provides a much more conservative estimate of variable inclusion across the reconstruction models. For comparison, in Figures S5-7, S5-8, and S5-9, we compare reconstructions both including (using the above described, as well as traditional, Martens Uncertainty Tests) and excluding the variable selection routine.

\subsubsection{PLSr reconstruction significance}

Reconstruction uncertainty was prescribed as $95 \%$ confidence intervals, derived using the RMSEP estimates generated from model cross-validation after assessing for residual-normality, i.e., $\mathcal{N}\left(y_{n^{-}}^{o}\right.$ $\left.y_{n}^{p}\right)$. Similarly, model significance for all stepwise calibrations was assessed using the cross-validated $\mathrm{RE}$ and $\mathrm{CE}$ statistics. Whereas $\mathrm{RE}$ and $\mathrm{CE}>0$ does indicate some predictive power in the transfer function over mean-climatology, it does not necessarily indicate statistical significance, provided underlying autocorrelation amongst the predictor/predictand series (Macias-Fauria et al., 2011). Thus, in order to estimate whether the observed calibration statistics are statistically significant, a Monte Carlo methodology was employed. Namely 1,000 pseudo-random (i.e., power-spectrum preserving) $\boldsymbol{X}$ and $\boldsymbol{y}$ surrogate pairings (Ebisuzaki, 1997) were developed over the full calibration-interval, and reassessed using the cross-validation procedure described above. This allowed empirical probability density functions for the RMSEP, RE, and CE statistics to be derived, each tuned to the exact autocorrelative properties and length of the observed predictor/predictand series. Using these distributions, we then assessed the exceedance probability of measuring a RMSEP/RE/CE statistic greater than (or, in the RMSEP case, less than) or equal to that actually observed (i.e., the likelihood of committing a Type-I error). 


\subsubsection{Time series correlation statistical significance testing}

Significance estimates for time series correlations (Pearson's $r$ in all instances) were computed using a nonparametric Monte Carlo-based method (Ebisuzaki, 1997), as described in Osman et al. (2019). Namely, we created $n=10,000$ pseudo-random surrogate series of the first series by computing its Fourier transform, randomly varying the Fourier mode phases between 0 and $2 \pi$, and computing the inverse transform, thus preserving the power spectrum of the original series. Statistical significance was then estimated by computing $n$ pseudo-random correlations with the original second series and by calculating the probability of achieving a correlation magnitude greater than the original correlation.

\subsubsection{Global climate model (iCESM) output}

For conceptual and statistical validation, we use a recent ensemble of water isotope $\delta^{18} \mathrm{O}$ and deuterium, $\delta \mathrm{D})$-enabled global climate simulations conducted with the Community Earth System Model (v.1.2) Last Millennium Ensemble (iCESM-LME; Otto-Bleisner et al., 2016). The LME incorporates a 2-degree atmosphere and 1-degree ocean version of the CESM-Community Atmospheric Model v.5 (CAM5) model, ran from A.D. 850 to 2006. In addition to the regular hydrologic cycle, iCESM can explicitly simulate the transport and transformation of water isotopes (e.g., $\mathrm{H}_{2}{ }^{18} \mathrm{O}$ ) in the atmosphere, land, ocean, sea ice, and river runoff. The description of the individual components including the isotope-enabled atmosphere, land, and ocean models are documented elsewhere (Nusbaumer et al., 2017). In this study we explore all currently-available monthly ensemble members, which consist of the following: one control run, two full-forcing runs, two greenhouse-gasonly forcing runs, one orbital-only forcing run, one solar-intensity-only forcing run, and two volcanicforcing only runs. Note the only post-processing performed on the original iCESM output was annually-averaging of the monthly-fields.

\subsubsection{Canonical Correlation Analysis (CCA)}

Inter-comparison of coupled climatic fields (i.e., modelled/observed Z500, modelled/observed Atlantic zonally-averaged zonal jet, iCESM-modelled isotopes, iCESM-modelled precipitation) were computed using pre-truncated Canonical Correlation Analysis following the method of Barnett and Preisendorfer (1987; see also Bretherton et al., 1992 and von Storch, 1999) in order to reduce noise in our projection. In CCA, one aims to find the spatial partitioning of climatic modes that maximize the temporal cross-correlation matrix between two climatic fields, $\boldsymbol{X}$ and $\boldsymbol{Y}$, where each mode is 
orthogonal to the next while explaining progressively less of the original cross-correlation structure. Due to rapid convergence of the leading modes' percent variance explained towards unity in all fields described above, we took a conservative approach, retaining $99 \%$ of the original variance in $\boldsymbol{X}$ and $\boldsymbol{Y}$ prior to decomposition.

Notably, whereas we have only one realization of "reality" (i.e., here taken as the NOAA20thCRv2c product), we find the iCESM robustly reproduces the first two modes of (NAO and EA-modulated) Atlantic co-variability across all 8 model ensembles during the last millennium (A.D. 850-2006; Fig. 5-3). In order to develop explicit confidence bands about this observed crossensemble uniformity, we used a bootstrap resampling with replacement approach for all iCESMderived CCA-spatial patterns shown in Figure 5-3d to 5-31, wherein 1000 CCA's were conducted on randomly-sampled (with replacement) iCESM ensemble members. Using the distribution of spatial patterns, we developed $95 \%$ confidence intervals using the $2.5^{\text {th }}$ and $97.5^{\text {th }}$ percentiles, barely distinguishable by eye in Figures 5-5g and 5-51, and Fig. S5-5c. The spatial patterns of Z500, $\delta^{18} \mathrm{O}$, and precipitation (Fig. 5-5e,f and 5-5i,j, and Fig. S5-5a,b) are the median of the distribution.

\subsubsection{1 iCESM pseudoproxy experiments}

As a means of testing the viability, and veracity, of skillfully-reconstructing the annual-mean Atlantic jet-stream latitude, we take advantage of model-output from the iCESM experiments (see "Global climate model (iCESM) output", above). The pseudoproxy experiments were conducted so as to mimic the pre-processing procedure of our actual GrIS- $\delta^{18} \mathrm{O}$ records as closely as possible. Therein, for a given last-millennium ensemble-member, 29 temporal records of monthly precipitation-weighted $\delta^{18} \mathrm{O}$ surface deposition were extracted from grid-cells overlying the locations all ice core records in our $\delta^{18} \mathrm{O}$-compilation (Table S5-1); despite the close proximity of several records, this resulted in 24/29 unique model-grid cells. Following the extraction of the 29 records, each was annually averaged (Jan-Dec) to produce a mean-annual $\delta^{18} \mathrm{O}$ "model-surrogate" compilation over A.D. 1000-2000. Years where data were missing/unavailable in each original record were then also removed from their corresponding surrogate.

The pseudoproxy experiment provides a unique opportunity for synthetically-controlling, and testing, the statistical-model design from the bottom-up. A crucial concept to observe during any pseudoproxy experiment-design is the "signal-to-noise" ratio (SNR), representing the ratio between 
the standard deviation $(\sigma)$ in a unit variance-standardized predictand $(\sigma=1)$ and the standard deviation of a pure white noise nominally existing on top of (in the cumulative-sense) any proxy-based predictor,

$$
S N R=\frac{1}{\sqrt{\sigma_{\text {noise }}^{2}}} .
$$

As such, greater variance in the white noise added to the signal (reminder, $\sigma=1$ ) results in a lower SNR. As described by Smerdon (2012), this definition can also be used interchangeably with the correlation between the signal and the signal-plus-noise time series, which purports:

$$
r=\frac{1}{\sqrt{1+\sigma_{\text {noise }}^{2}}}
$$

which, by relation, suggests the SNR between any proxy and its predictand can be readily computed as,

$$
S N R=\frac{1}{\sqrt{\frac{1}{r^{2}}-1}},
$$

where $r$ is the correlation between that proxy record and the predictand.

In most pseudoproxy experiments conducted to date ( $\mathrm{Li}$ et al., 2010; Smerdon et al., 2010; Ortega et al., 2015), the pseudoproxy (i.e., predictor) network can be developed by simply isolating the model-derived predictand-variable (e.g., temperature) at the grid cells underlying a given set of (typically-sparse) proxy locations, and adding to these grid cells' (standardized) temperature time series some amount of white noise, as pre-specified by Eq.'s 5.14-5.16, above. In our case, however, time series of precipitation-weighted $\delta^{18} \mathrm{O}$ are already prespecified explicitly vis-á-vis the model-output. Whereas this ultimately comes as a convenience, via Eq. 5.15 it is also apparent that our modelspecified $\delta^{18} \mathrm{O}$ surrogate time series most-often entail SNR's (with, e.g., Atlantic jet-latitude) that are appreciably higher than those of our observed $\delta^{18} \mathrm{O}$ records (e.g., Fig.'s 5-3d,h,l). As such, using the principal of the variance-summation (i.e., variances of two independent time series add, or subtract), we include in Eq. 5.14 a white-noise adjustment term $\left(\sigma_{a d j}^{2}\right)$, 


$$
S N R=\frac{1}{\sqrt{\sigma_{\text {noise }}^{2}+\sigma_{a d j}^{2}}}
$$

which, by Eq. 5.15, can be readily solved for and added as white noise to our surrogate $\delta^{18} \mathrm{O}$ time series to prespecify SNR. In our case, we analyzed three realizations of pseudoproxy SNR's: 'best', representing the modeled precipitation-weighted $\delta^{18} \mathrm{O}$ output; "1", representing a given pseudoproxy's SNR that has been adjusted to the corresponding observed proxy-records' SNR; and "0.5", representing a pseudoproxy with twice as much noise as the level observed.

Once each surrogate $\delta^{18} \mathrm{O}$ record was SNR-adjusted, data availability for each record was made to match the data-availability of the corresponding observed record, and missing values imputed over the calibration-interval using inverted pPCA. Following removal and imputation of missing years, pseudoproxy-based PLSr-reconstructions were conducted in a manner identical to that described above. 


\section{Ch. 5 Figures}

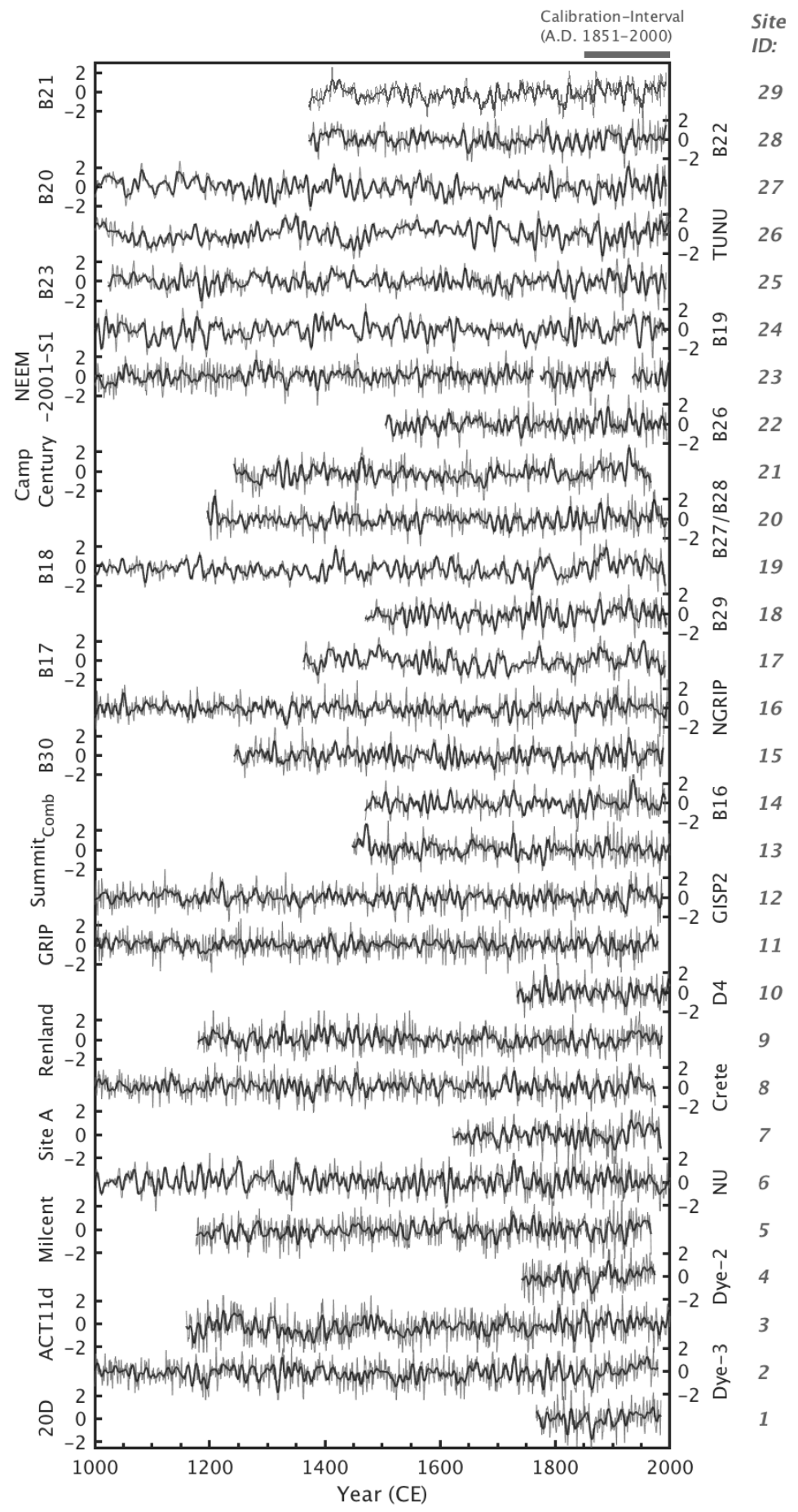

Figure 5-1: Compilation of $29 \mathrm{GrIS}$ annual-resolution ice core water isotope $\left(\delta^{18} \mathrm{O}\right)$ time series, plotted from most southerly situated (bottom; 20D) to most northerly situated (top; NGT-B21). All series are standardized (₹-units) relative to A.D. 1775-2000 (the former representing the oldest year of common overlap, the latter chosen to maximize overlap with the observational-era and reasonable ( $50 \%$ records available) data coverage). Thin lines denote annual resolution, and bolded lines the 10-year lowpass-filtered series. Note the site identification ("Site-ID") numbers to the right of the time series. 

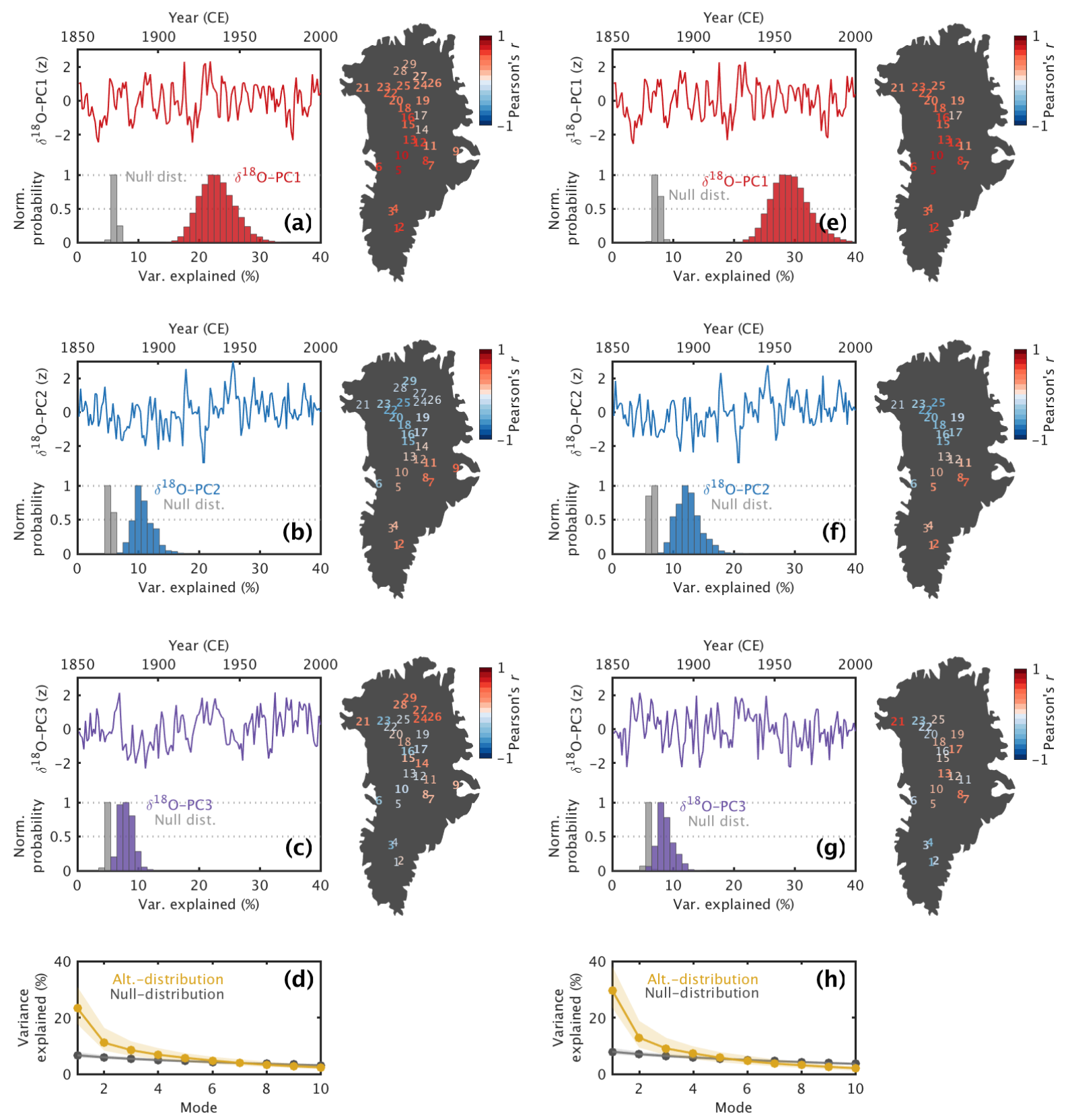

Figure 5-2: Probabilistic principal component analysis (pPCA) of the GrIS- $\delta^{18} \mathrm{O}$ compilation. (a) $\delta^{18} \mathrm{O}-\mathrm{PC} 1$ time series for the "observational" period (based on temporal overlap with the NOAA20thCRv2 reanalysis (Compo et al., 2011); A.D. 1851-2000). Histograms shown at the bottom of the panel denote the null distribution of PC1-explained variance (grey) following 10,000 PCA's conducted upon pseudo-random surrogate $\delta^{18} \mathrm{O}$ datasets (Methods), revealing the $\delta^{18} \mathrm{O}-\mathrm{PC} 1$ series to be significantly different from noise at the $p<0.0001$ level (one-sided, two-sample Kolmogorov-Smirnov test) based on bootstrap resampling with replacement. Inset map shows the homogeneous linear correlation (Pearson's $r$ ) of each site (site-ID's in Fig. 5-1) with $\delta^{18} \mathrm{O}-\mathrm{PC} 1$. (b) and (c) as in (a), but for $\delta^{18} \mathrm{O}-\mathrm{PC} 2$ and $\delta^{18} \mathrm{O}-\mathrm{PC} 3$, each shown to be significantly distinct from pseudo-random noise. (d) Monte Carlo-derived $95 \%$ confidence intervals of variance explained by each mode of $\delta^{18} \mathrm{O}$-variance relative to a pseudo-random null (Methods). (e-h) as in (a-d), but with prefiltering of the sites performed to remove records not significantly correlated (i.e., $p>0.10$; Ebisuzaki, 1997) with the GBI. 
(a)

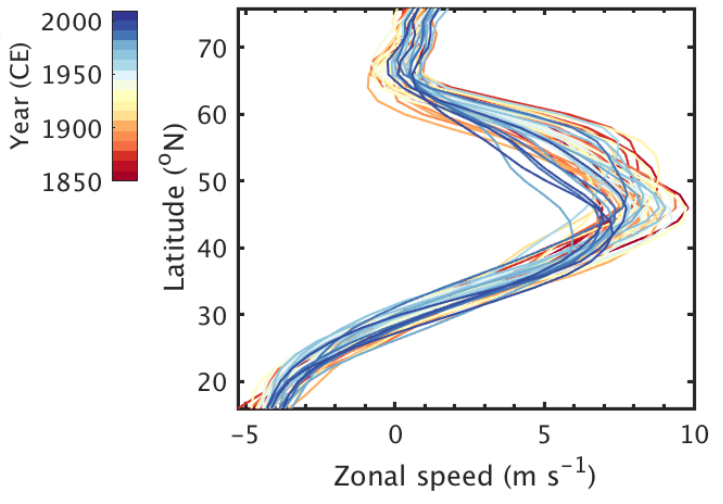

(c)

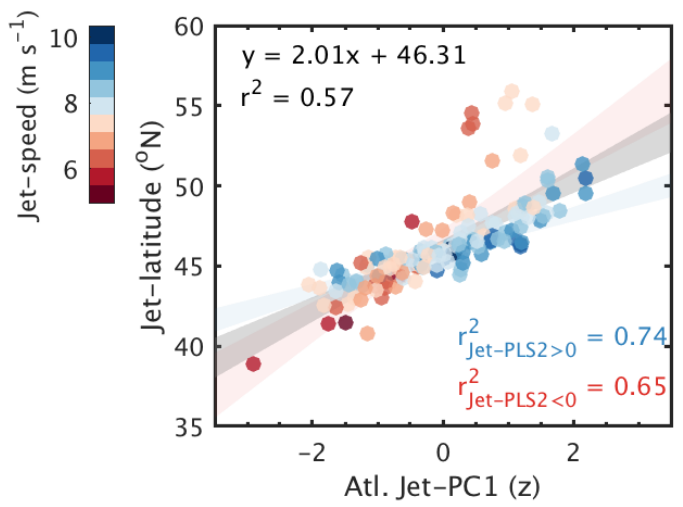

(e)

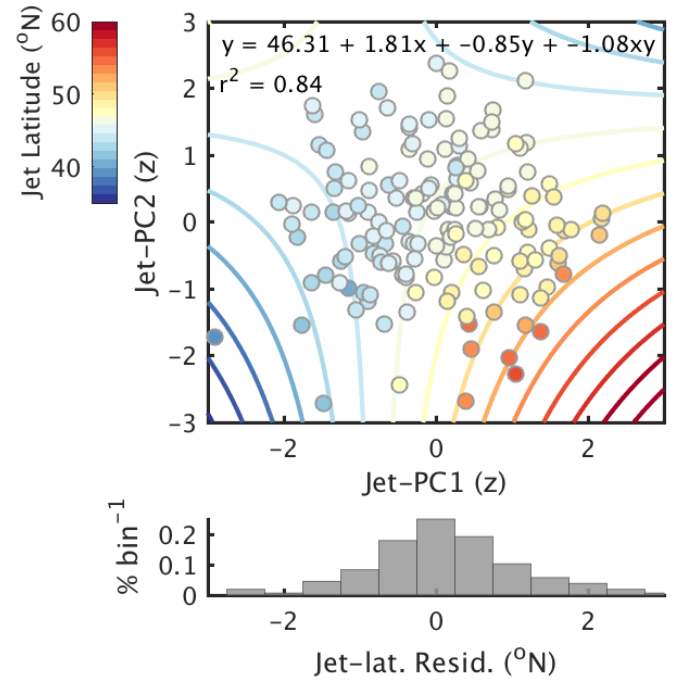

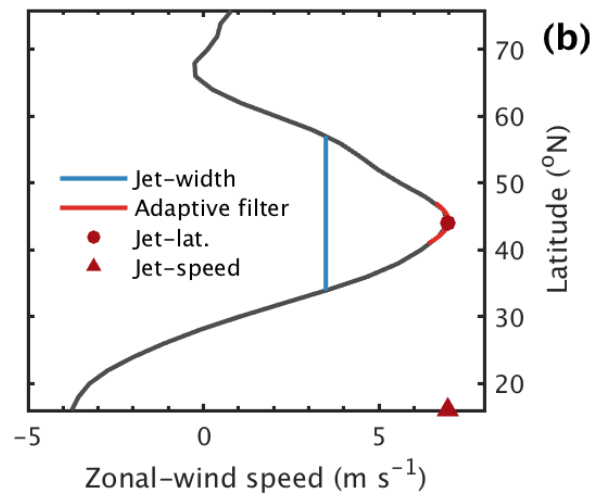

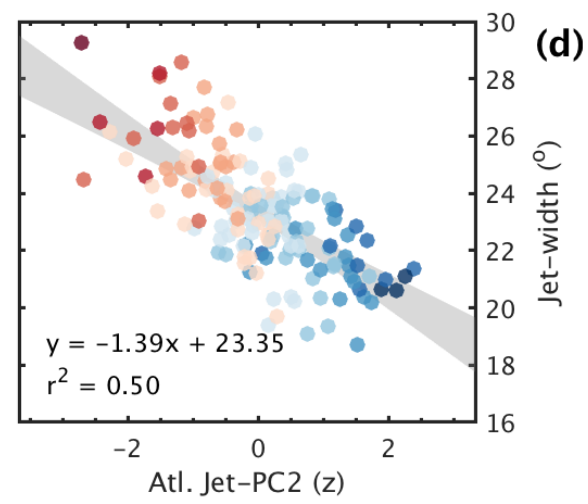

(d)

Figure 5-3: Diagnostic 1-dimensional representations of the Atlantic jet stream, and robust predictability of the Atlantic jet stream latitude. (a) Several $(n=3)$ randomly chosen years for each decade of the NOAA20thCRv2 dataset, illustrating annual-variability in the Atlantic zonally averaged zonal jet profile. (b) Geometric characterization of the Atlantic zonal jet width, jet latitude, and jet speed. Following prior convention (Barnes et al., 2013), an adaptive filter was used to discretize the $2^{\circ}$-resolution zonally-averaged jet speeds onto a finer $0.001^{\circ}$-grid by fitting a $2^{\text {nd }}$-order polynomial centered $\pm 3^{\circ}$ over the course-gridded jet latitude. Jet width was defined as the meridional-extent of the jet profile at half jet-speed. (c) Relationship between the NOAA20thCRv2 Jet-PC1 and Atlantic jet latitude, color-coded with respect to jet speed. (d) As in (c), but showing Jet-PC2 vs. jet width. (e) Relationship between Jet-PC1, Jet-PC2, and the Atlantic jet-latitude from the NOAA20thCRv2 dataset, fitted along a hyperbolic paraboloid. Lower panel: histogram showing the distribution of residual values from (e). 

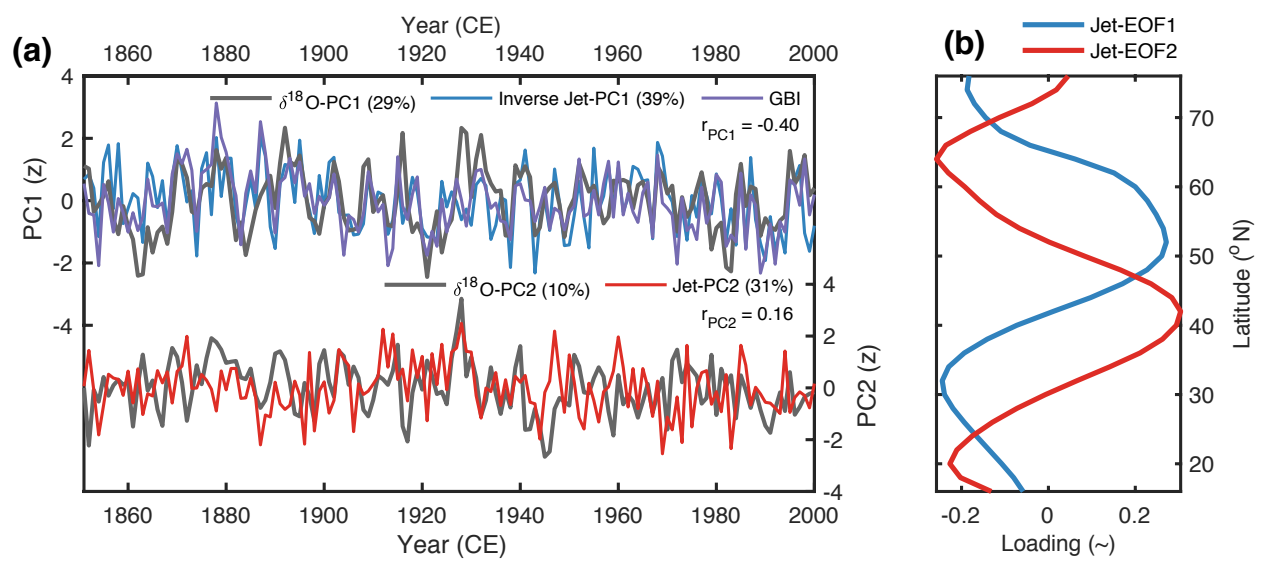

Figure 5-4: Strong coherence between the leading two modes GrIS- $\delta{ }^{18} \mathrm{O}$ and Atlantic jet variability over the "observational" interval. (a) Top panel: $\delta^{18} \mathrm{O}-\mathrm{PC} 1$ alongside the NOAA20thCRv2-derived GBI, and the JetPC1 index. Bottom panel: $\delta{ }^{18} \mathrm{O}-\mathrm{PC} 2$ alongside the NOAA20thCRv2-derived Jet-PC2 index. Correlation values represent Pearson's $r$-value for the both corresponding PC1/2 series. Values in parentheses in the legends denote the percent variance explained by each mode. (b) Corresponding EOF-patterns for Jet-PC1 and -PC2 modes. 

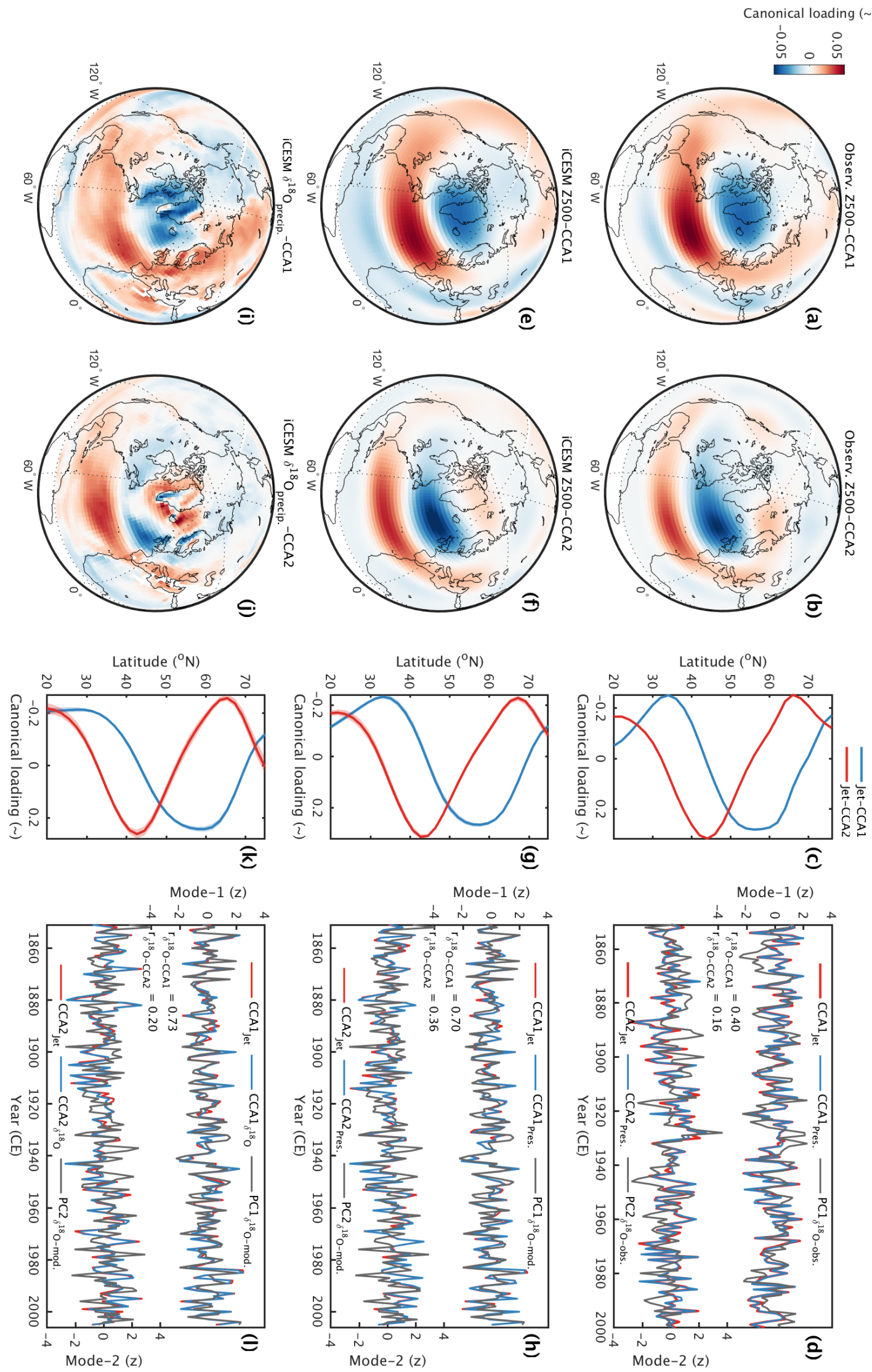
Figure 5-5: Spatial-temporal descriptions of Atlantic jet, $500 \mathrm{mB}$ geopotential height (Z500), and $\delta^{18} \mathrm{O}$ covariability using Canonical Correlation Analysis (CCA). (a) and (b) First two spatial modes of covariability of $500 \mathrm{mB}$ geopotential height with the Atlantic zonally-averaged zonal jet. (c) First two spatial modes of covariability of the Atlantic zonally-averaged zonal jet with Z500; note the strong qualitative similarity between both spatial-modes to Fig. 5-3b). (d) Corresponding temporal variability of the orthogonal modes of covariability for the Atlantic jet, Z500, the GBI, and $\delta^{18} \mathrm{O}-\mathrm{PC} 1$. (e-h) As in (a-d), but using climatological output from isotope-enabled Community Earth Systems Model (iCESM) last-millennium simulations. Note the $\delta^{18} \mathrm{O}$-PC1 and $\delta^{18} \mathrm{O}-\mathrm{PC} 2$ data shown in (h) are derived using annual-average $\delta^{18} \mathrm{O}$ depositional data from all 29 GrIS grid cells (24/29 unique). (i-l) As in (a-d) and (e-h), but instead representing the leading modes of covariability between the iCESM-derived Atlantic zonally-averaged zonal jet and annual precipitation-weighted average of $\delta^{18} \mathrm{O}$ deposition. 

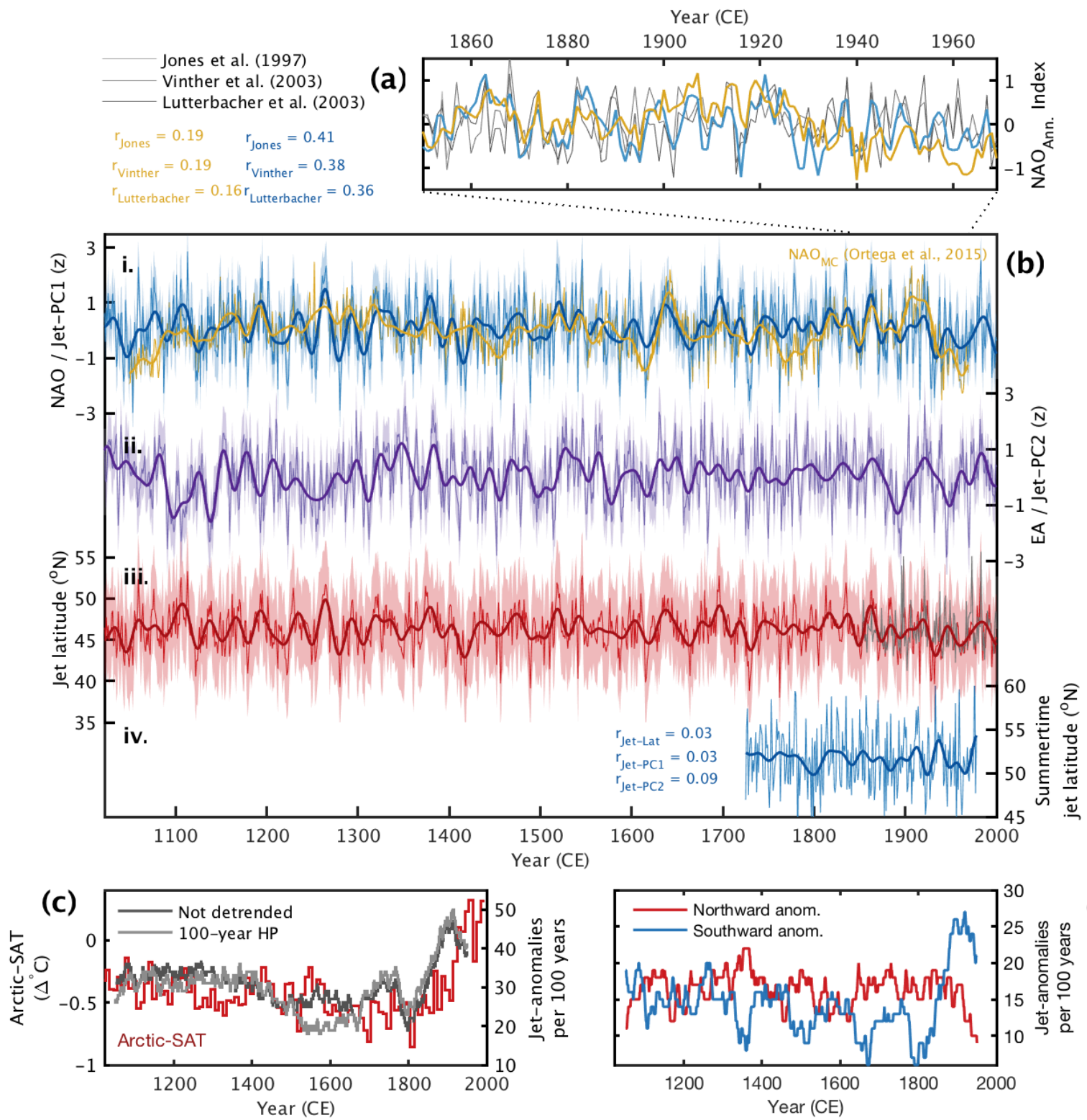

(d)

Figure 5-6: Reconstructed Atlantic jet-stream diagnostics during the last millennium CE. (a) Comparison of a recent proxy-based NAO reconstruction (yellow; Ortega et al., 2015) and our $\delta^{18} \mathrm{O}$-reconstructed Jet-PC1 index (blue), highlighting the stronger coherence of our Jet-PC1 index across several observationally-derived $\mathrm{NAO}$ indices (grey). (b) Time series of $\delta^{18} \mathrm{O}$-reconstructed mean-annual (i.) Jet-PC1 (blue; $\mathrm{NAO}$-modulated), (ii.) Jet-PC2 (purple), (iii.) the Atlantic jet latitude ( $\pm 2 \sigma$; red), and (iv.) a recent tree ring-based Atlantic jetlatitude reconstruction (blue; Trouet et al., 2018). The observed jet latitude index from the NOAA20thCR is shown in grey in (iii.). All bold lines in (b) are 20-yr lowpass Butterworth filtered. (c) Number of Atlantic jetlatitude anomalies per 101 years (defined as $>\mathrm{abs}(1 \sigma)$ centered \pm 50 years), compared against reconstructions of Northern Hemisphere (NH) surface temperature (decadal means; McKay and Kaufman, 2014). (d) Partitioning of Atlantic jet latitude anomalies from (c) into northward $(>1 \sigma)$ and southward $(<1 \sigma)$ shifted anomalies. 


\section{Ch. 5 Supporting figures}

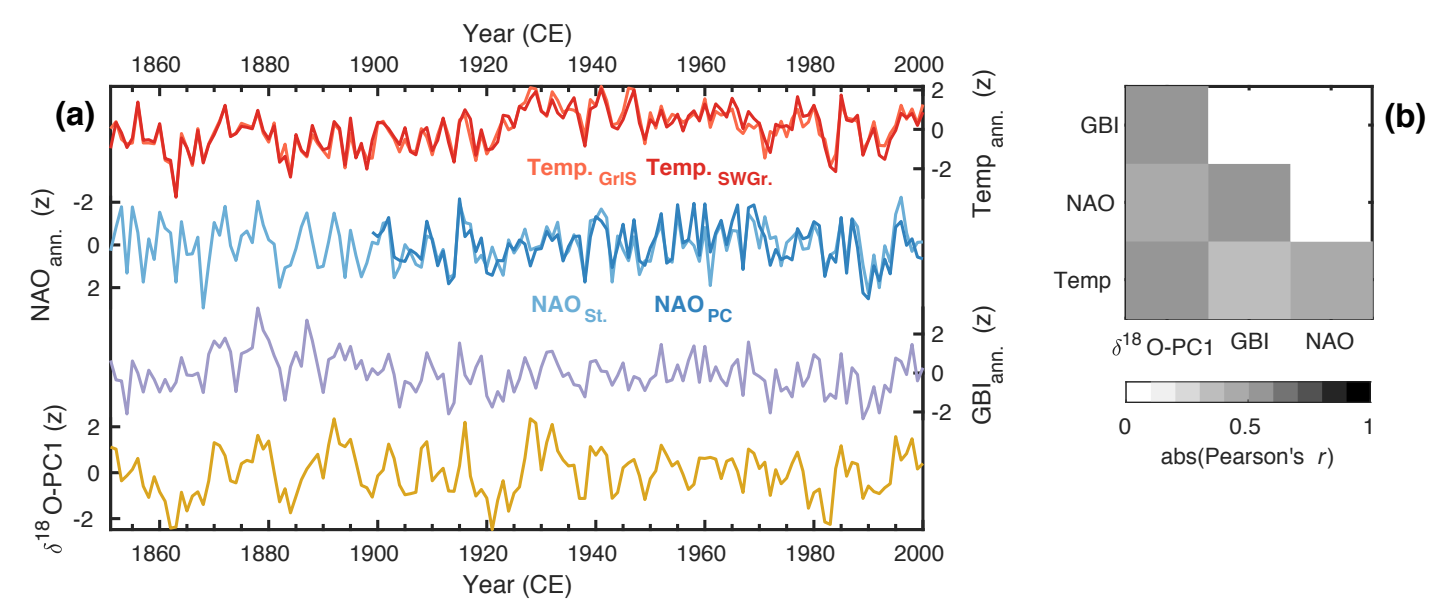

Figure S5-1: Comparison of $\delta^{18} \mathrm{O}$ with several climatic indices. (a) From bottom to top: $\delta^{18} \mathrm{O}-\mathrm{PC} 1$ (this study); annual-GBI (Hanna et al., 2016); station-based ("NAOst."; Jones et al., 1997) and PCA-based ("NAOpC"; Hurrell, 2003) index of NAO (note the inverted y-axis), and area-averaged GrIS temperatures ("TempGrI"; Kobashi et al., 2011) and Danish Meteorological Institute station-derived compilation of coastal-southwest Greenland temperatures ("TempswGr."; Vinther et al., 2006). All time series represent 12-month-averaged (JanDec) annual resolution data, unit-variance standardized relative to AD 1851 to 2000. (b) Absolute linear correlation coefficient (Pearson's $r$ ) of the time series shown in (a). All correlations are significant at the $p<$ 0.0001 level, and insensitive to which NAO and temperature series is used. 

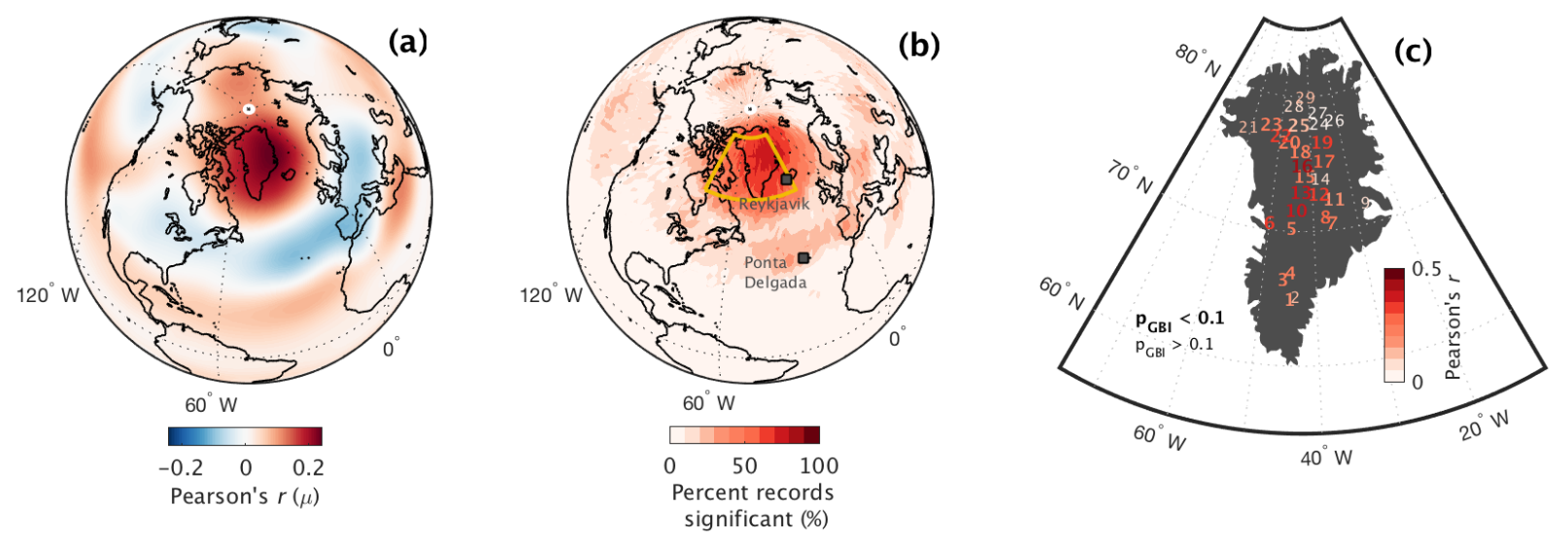

Figure S5-2: Localized covariation between $500 \mathrm{mB}$ geopotential height anomalies and GrIS- $\delta^{18} \mathrm{O}$. (a) Spatial (i.e., grid-by-grid) correlation (A.D. 1851-2000) between NOAA20thCRv2 $500 \mathrm{mB}$ geopotential height and GrIS $\delta^{18} \mathrm{O}$, averaged across all $n=29$ sites. (b) Percent records significant at the $p<0.10$ level (Ebisuzaki et al., 1997). (c). Pearson's r correlation-value of each GrIS- $\delta^{18} \mathrm{O}$ record vs. annually-averaged GBI (A.D. 1851 2000; Hanna et al., 2016). 

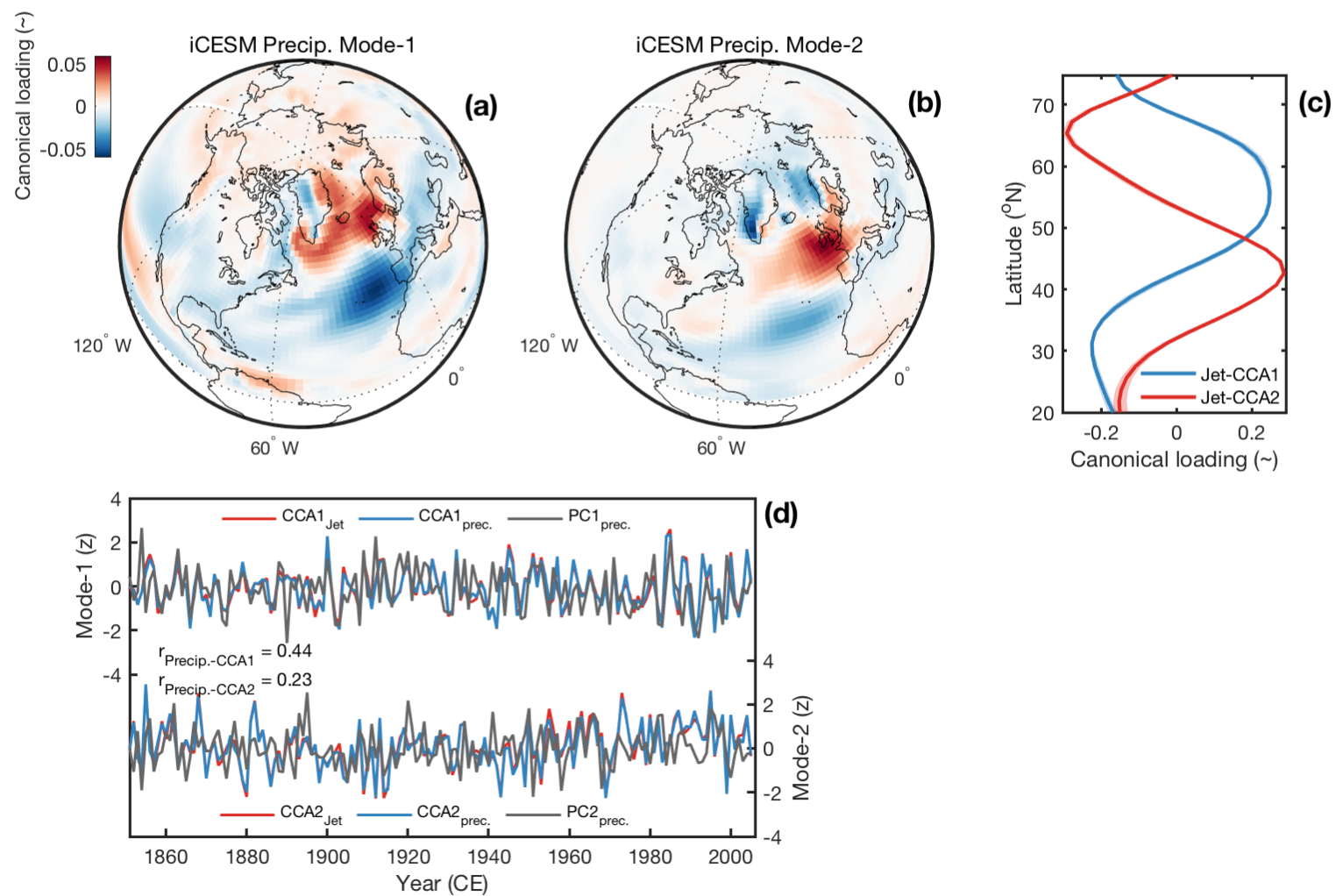

Figure S5-3: Spatial-temporal descriptions of Atlantic jet and precipitation covariability using Canonical Correlation Analysis (CCA). (a) and (b) First two spatial modes of covariability of precipitation variability with the Atlantic zonally-averaged zonal jet. (c) First two spatial modes of covariability of the Atlantic zonallyaveraged zonal jet with precipitation; note the strong qualitative similarity between both spatial-modes to Fig. 5-3b). (d) Corresponding temporal variability of the orthogonal modes of covariability for the Atlantic jet, precipitation, the GBI, and $\delta^{18} \mathrm{O}-\mathrm{PC} 1$. Note the $\delta^{18} \mathrm{O}-\mathrm{PC} 2$ and $\delta^{18} \mathrm{O}-\mathrm{PC} 2$ data shown in (d) are derived using annual-average GrIS $\delta^{18} \mathrm{O}$ depositional data from all overlapping $29 \mathrm{GrIS}$ grid cells (24/29 unique) 

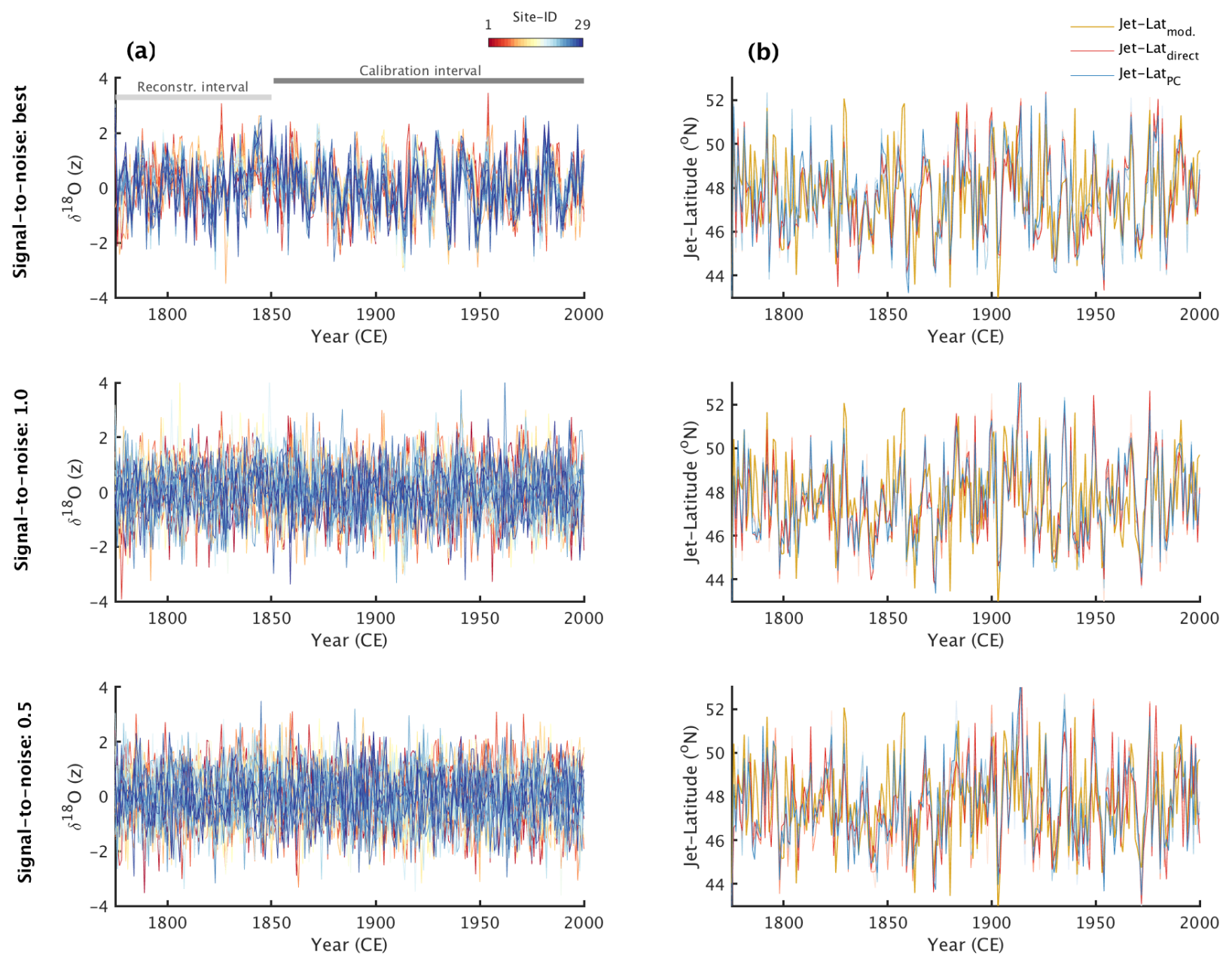

Figure S5-4: Comparison of three iCESM-pseudoproxy experiments for reconstructing the annual-mean Atlantic jet-latitude. (a, from top) $\delta^{18} \mathrm{O}$ surrogate predictor data, comprising raw ("best") iCESM $\delta^{18} \mathrm{O}$ output; adjusted $\delta^{18} \mathrm{O}$ surrogate data mimicking the signal-to-noise ratio of the observed $\delta^{18} \mathrm{O}$-data ("1"); and surrogate $\delta^{18} \mathrm{O}$-data adjusted to be twice as noisy as the observed adjusted $\delta^{18} \mathrm{O}$ data (" 0.5 "). (b) iCESM-Atlantic jetlatitude reconstructions for using the time series shown in (a) as predictors. Two reconstruction methods are shown for comparison, one calibrated directly to the Atlantic jet latitude using PLSr ("Jet-Lat direct"), and the other a bilinear-based reconstruction (e.g. Fig. 5-3e) requiring underlying Jet-PC1 and -PC2 reconstructions to first be computed in a hierarchical approach. Note the calibration and reconstruction intervals in the top-panel graphs, extending from A.D. 1851-2000 and A.D. 1775-1850, respectively. Calibration/reconstruction statistics for this figure are provided in Table S5-2. 

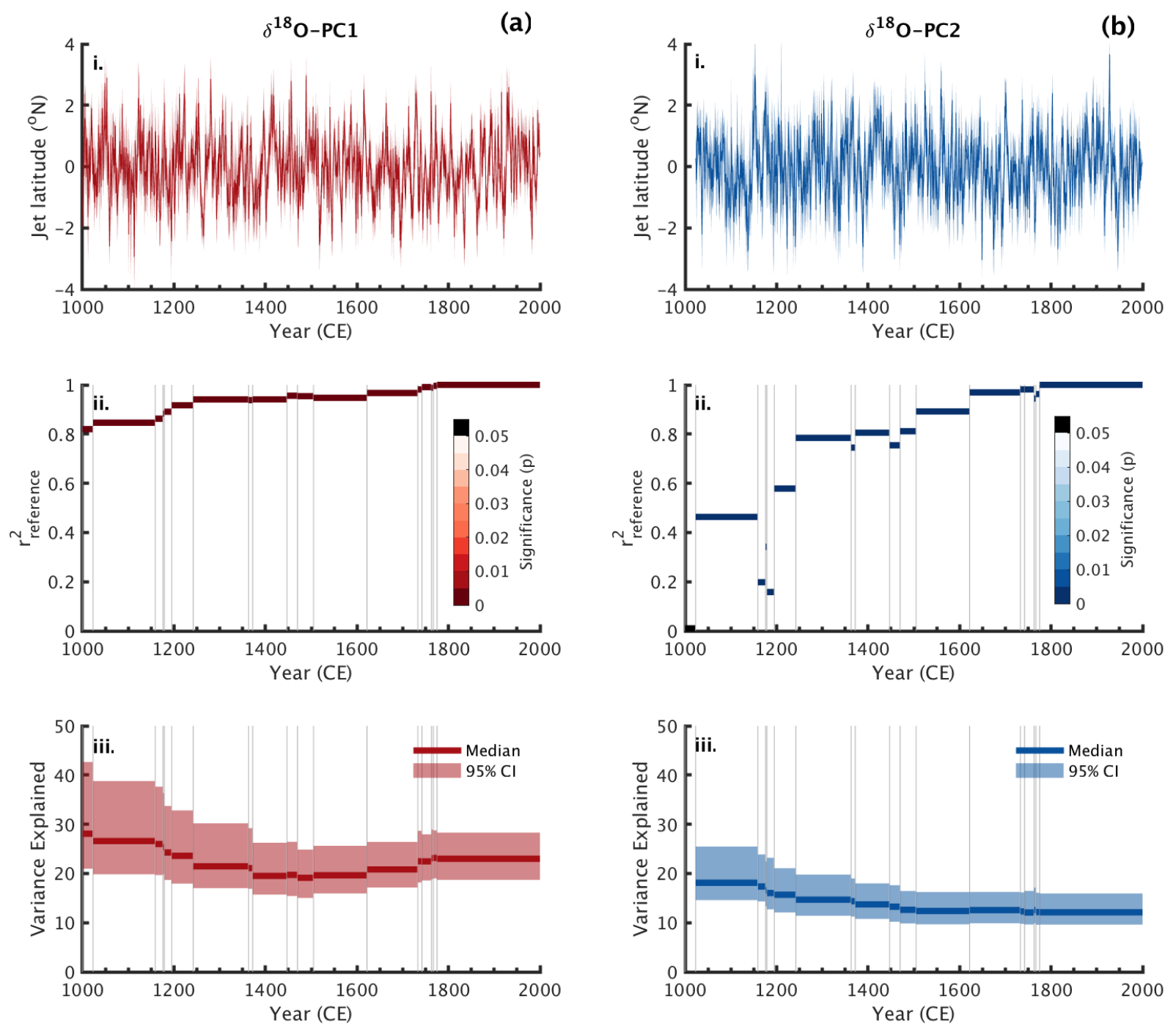

Figure S5-5: (i.) Time series of last-millennium (a) $\delta^{18} \mathrm{O}-\mathrm{PC} 1$ and (b) $\delta^{18} \mathrm{O}-\mathrm{PC} 2$, derived using a nested bootstrap methodology (shaded regions denoting the 95\% confidence intervals; Methods). Row (ii.) shows the correlation of each new nested PCA-derived PC1 and PC2-time series against the reference PC1 and PC2 time series (i.e., the raw PCA generated during the period of maximum record-overlap, A.D. 1775-2000), color coded with respect to each correlation's Monte Carlo-derived significance level (Ebisuzaki, 1997; Methods). Row (iii.) shows the range of percent variance explained for each new PCA-nest following 1000 bootstrap (i.e., random available $\delta^{18} \mathrm{O}$ record sampling with replacement) iterations. Note that $\delta^{18} \mathrm{O}-\mathrm{PC} 2$ becomes significantlyuncorrelated (i.e., $p>0.05 ; n=1000$ ) to the reference $\delta^{18} \mathrm{O}-\mathrm{PC} 2$ time series prior to A.D. 1022. 

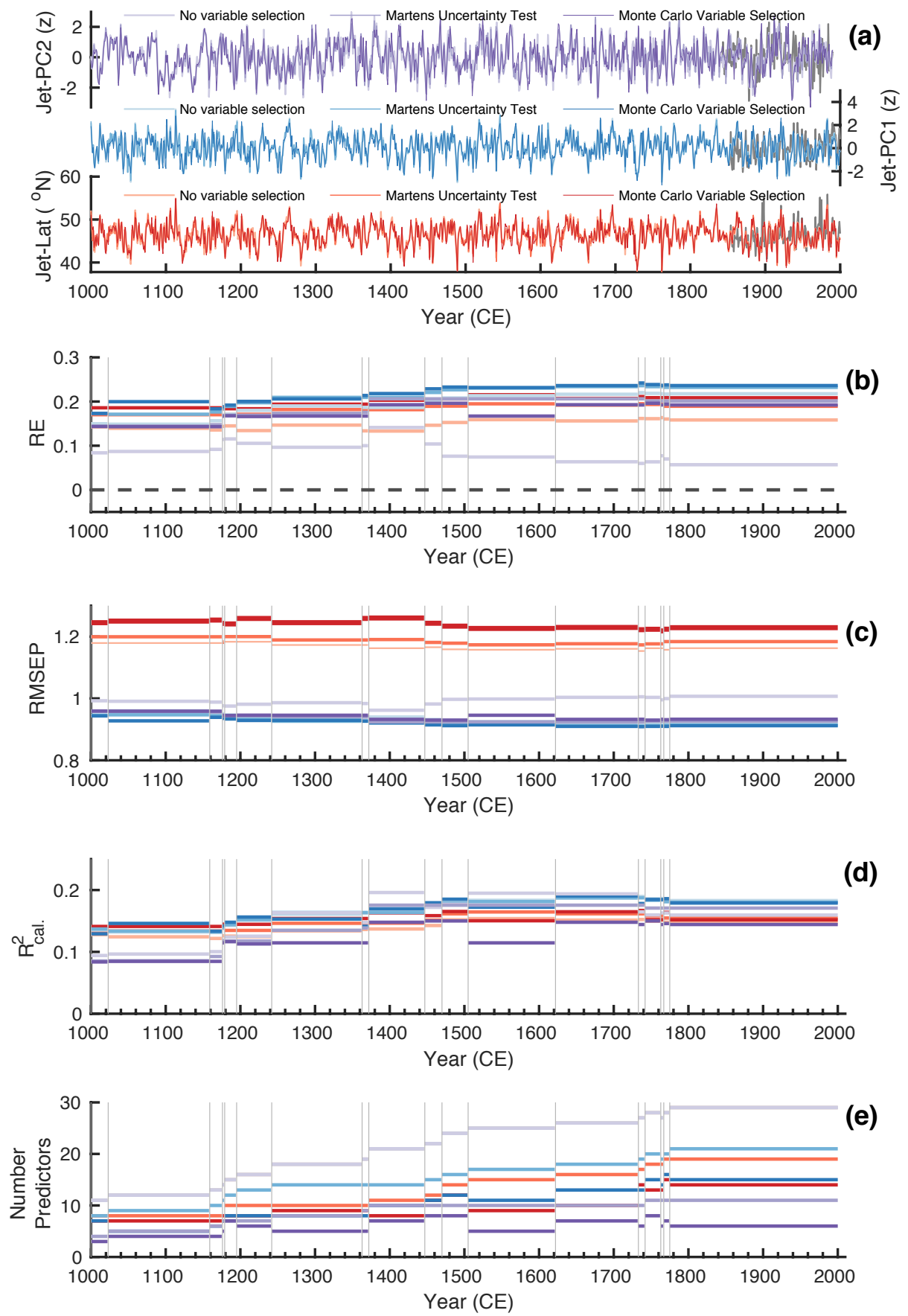

Figure S5-6: Comparison of Atlantic jet-latitude, Jet-PC1, and Jet-PC2 calibration-validation statistics for three different PLS1-variable selection methodologies. (a) One thousand-year reconstructions of (from bottom) mean annual jet-latitude, Jet-PC1, and Jet-PC2; note that three time series are shown for each reconstruction, each in close qualitative agreement. Shown in (b-d) are the corresponding (b) Reduction of Error (RE), (c) Root Mean Square Error of Prediction (RMSEP), and (d) squared Pearson-correlation coefficient calibration statistics for each nested calibration interval (each interval separated by vertical thin-grey lines). (e) The number of $\delta^{18} \mathrm{O}$ records used as predictors in each PLS1 regression-nest for the three variable selection methodologies. 
(a)

Site Location
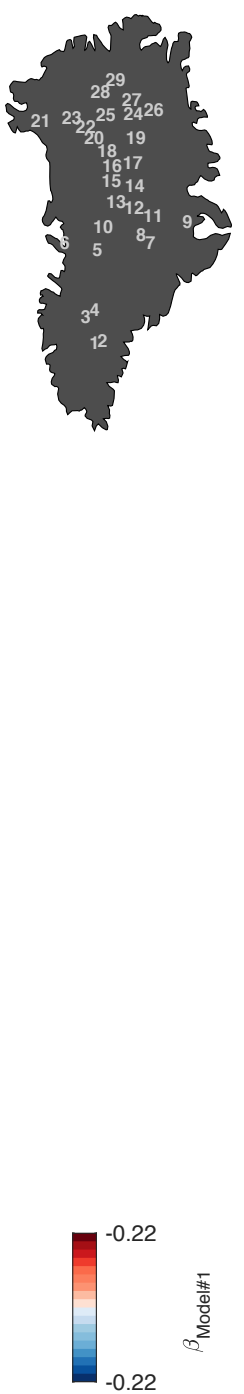

(b)

Jet-Latitude

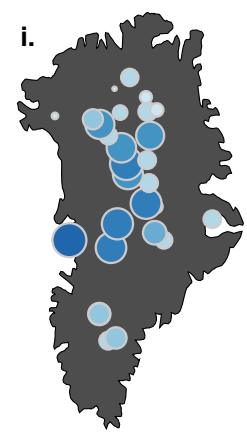

ii.
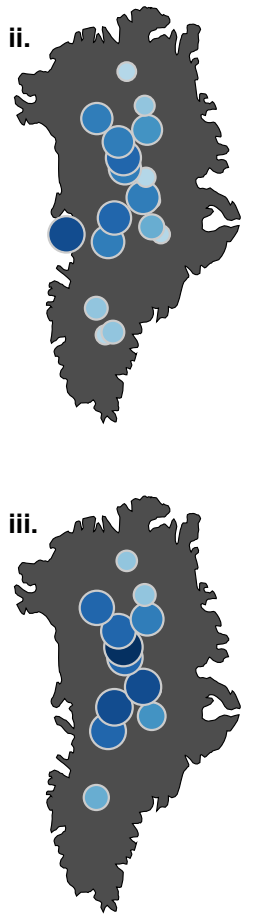

(c)

Jet-PC1
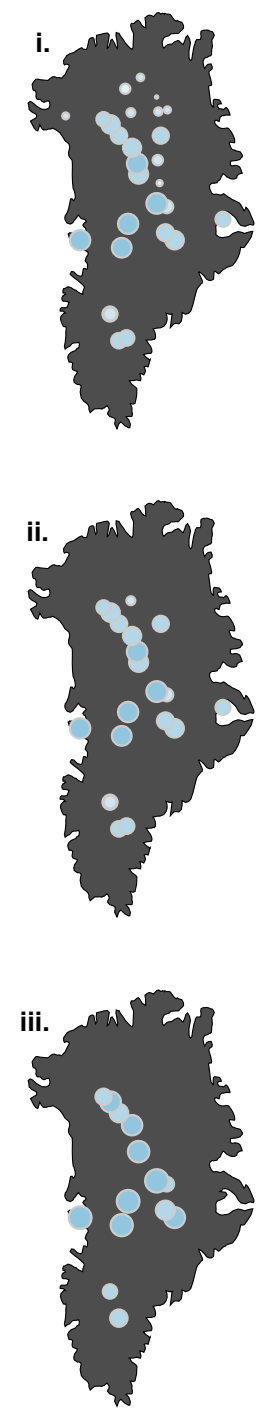

(d)
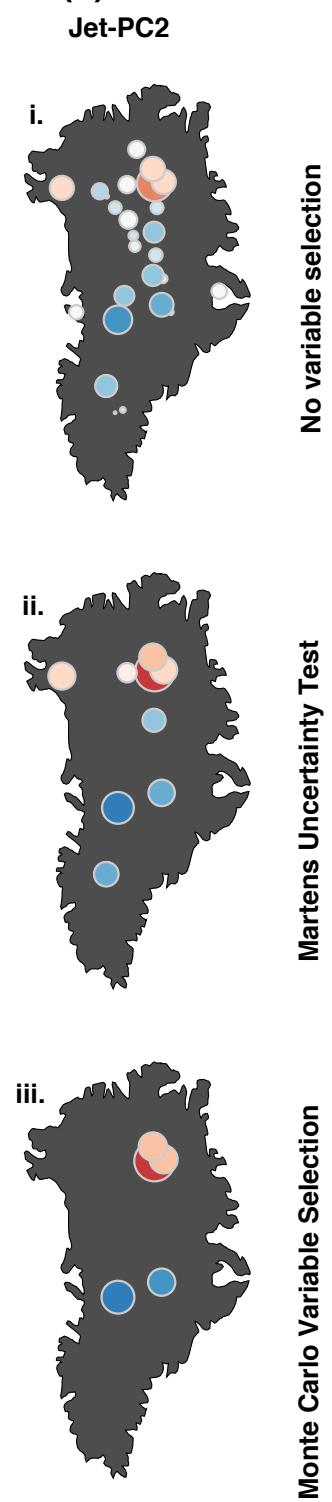

Figure S5-7: Spatial distribution of PLSr $\beta$-regression coefficients for the first nested reconstruction model (A.D. 1775-2000) of last-millennium mean-annual (b) Atlantic jet-latitude, (c) Jet-PC1, and (d) Jet-PC2. For improved visualization, bubble diameter is made proportional to the absolute-value of the $\beta$-value (also colorcoded). The associated site-ID's on the GrIS are shown in panel (a); see Fig. 5-1 or Table S5-1 for each ID's corresponding site-name. 

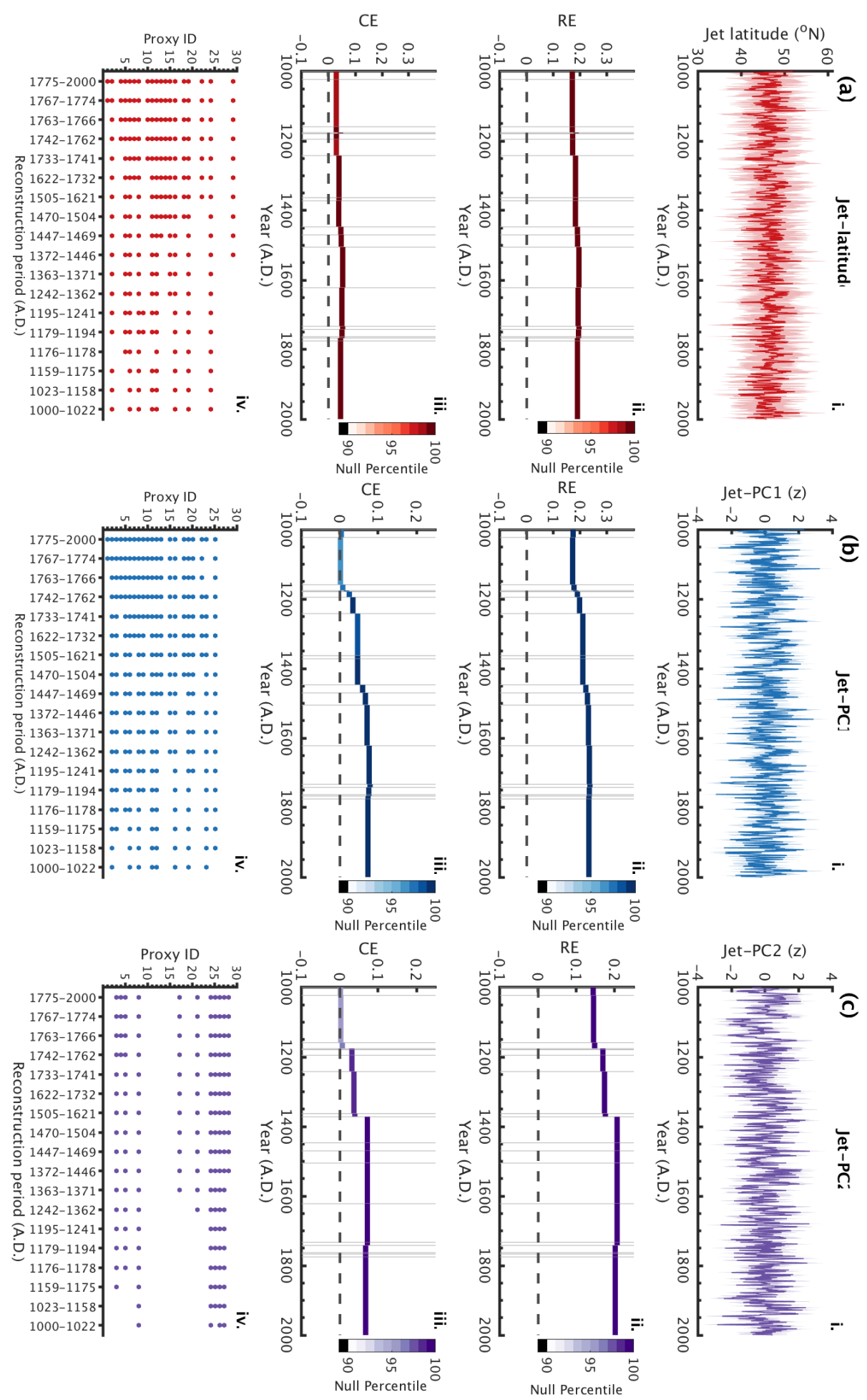

Figure S5-8: Robust reconstruction of the Atlantic (a) jet-latitude, (b) Jet-PC1, and (c) Jet-PC2. Top row depicts the reconstructed time series ( \pm 1 standard deviation); middle two-rows show the corresponding RE and $\mathrm{CE}$ validation-values for each nested calibration interval of the reconstruction, along with their Monte Carlo-derived null percentile placement for each nest ( $n=10000$ nest $^{-1}$; Methods) - note all RE/CE intervals shown are significant at the $99^{\text {th }}$ percentile level; bottom row shows the records used for reconstruction following the PLS-variable selection algorithm of Martens and Martens (2003). 

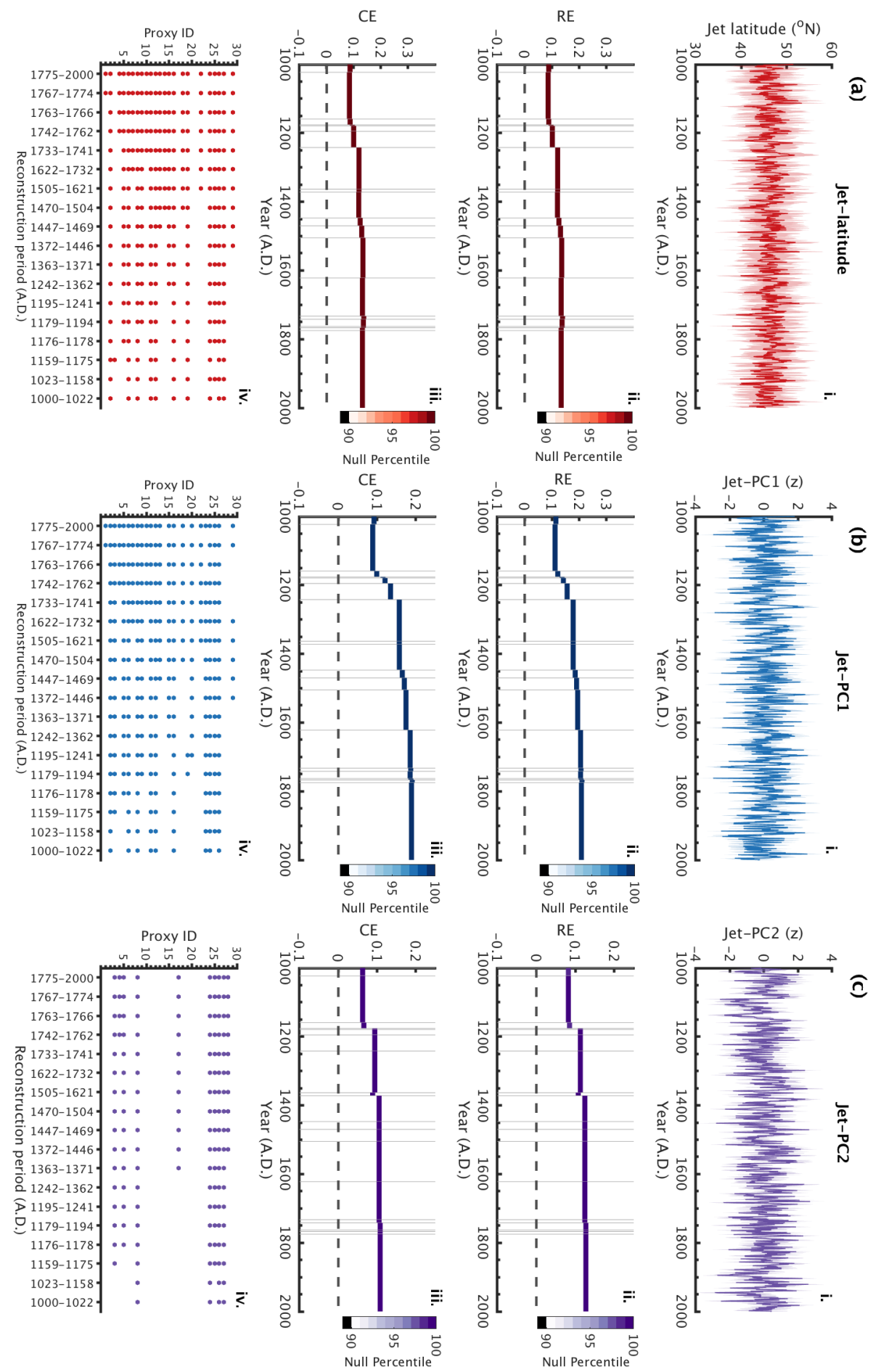

Figure S5-9. As in Figure S5-8, but showing instead the calibration-interval 100-year high-pass filtered jetlatitude (a), Jet-PC1 (b), and Jet-PC2 (c) reconstructions. 

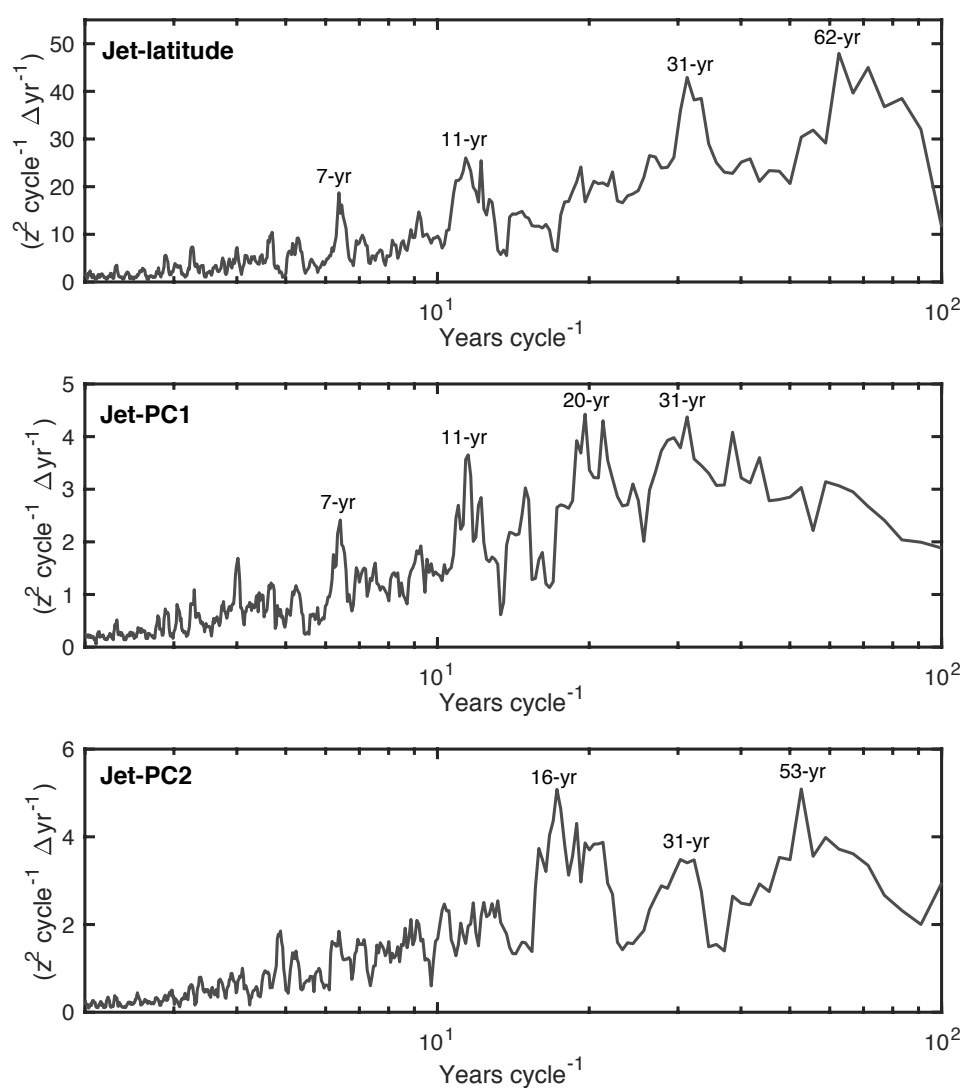

Figure S5-10. Spectral analysis of last millennium Atlantic jet variability, using the multi-taper method with four Slepian tapers (Percival and Walden, 1993). Years corresponding to notable spectral peaks are denoted by numbers. Note the log-scaled $\mathrm{x}$-axis. 


\section{Ch. 5 Supporting tables}

Table S5-1: Geographical and site-identification information pertaining to each GrIS- $\delta^{18} \mathrm{O}$ ice core record.

\begin{tabular}{|c|c|c|c|c|c|c|}
\hline Site name & $\begin{array}{l}\text { Site- } \\
\text { ID }\end{array}$ & $\begin{array}{l}\text { Time-period } \\
\text { covered (CE) }\end{array}$ & $\begin{array}{l}\text { Lat } \\
\left({ }^{\circ} \mathrm{N}\right)\end{array}$ & $\begin{array}{l}\text { Lon. } \\
\left({ }^{\circ} \mathrm{E}\right)\end{array}$ & $\begin{array}{c}\text { rGBI }\left({ }^{*} p<0.10 ;\right. \\
\text { A.D. 1851-1967) }\end{array}$ & Citation \\
\hline $20 \mathrm{D}$ & 1 & 1767-1984 CE & 65.01 & -44.87 & $0.189^{*}$ & Kinnard et al. (2011); Anderson et al. (2004) \\
\hline Dye-3 & 2 & 1-1979 CE & 65.2 & -43.8 & $0.186^{*}$ & Kinnard et al. (2011); Vinther et al. (2009) \\
\hline ACT11d & 3 & 1159-2011 CE & 66.5 & -46.3 & $0.154^{*}$ & Unpublished; Mernild et al. (2015) \\
\hline Dye-2 & 4 & 1742-1974 CE & 66.5 & -46.3 & $0.191 *$ & Kinnard et al. (2011); Anderson et al. (2004) \\
\hline Milcent & 5 & 1176-1967 CE & 70.3 & -45 & $0.339^{*}$ & Dansgaard, et al. (1975); Clausen et al. (1988) \\
\hline NU & 6 & 536-2013 CE & 70.49 & -52.26 & $0.266^{*}$ & Unpublished; Trusel et al. (2018) \\
\hline Site A & 7 & 1622-1984 CE & 70.63 & -35.82 & $0.169^{*}$ & Kinnard et al. (2011) \\
\hline Crete & 8 & 553-1974 CE & 71.1 & -37.3 & $0.231 *$ & Kinnard et al. (2011) \\
\hline Renland & 9 & 1179-1986 CE & 71.3 & -26.7 & -0.057 & Kinnard et al. (2011) \\
\hline D4 & 10 & 1733-2003 CE & 71.67 & -44 & $0.327 *$ & Unpublished; McConnell et al. (2007) \\
\hline GRIP & 11 & 1-1979 CE & 72.57 & -36.63 & $0.115^{*}$ & Emile-Geay et al. (2017) \\
\hline GISP2 & 12 & 818-1987 CE & 72.8 & -38.5 & $0.253^{*}$ & Grootes et al. (1997); Emile-Geay et al. (2017) \\
\hline Summit_\{Comb $\}$ & 13 & 1447-2009 CE & 72.8 & -38.5 & $0.344^{*}$ & Unpublished; Maselli et al. (2017) \\
\hline $\mathrm{B} 16$ & 14 & 1470-1992 CE & 73.94 & -37.63 & 0.093 & Weißbach et al. (2016) \\
\hline $\mathrm{B} 30$ & 15 & 1242-1988 CE & 74.5 & -42 & $0.312^{*}$ & Weißbach et al. (2016) \\
\hline NGRIP & 16 & 1-1995 CE & 75.1 & -42.32 & $0.290^{*}$ & Kinnard et al. (2011) \\
\hline B17 & 17 & 1363-1992 CE & 75.25 & -37.63 & $0.217^{*}$ & Weißbach et al. (2016) \\
\hline B29 & 18 & 1471-1994 CE & 76 & -43.5 & $0.312^{*}$ & Weißbach et al. (2016) \\
\hline B18 & 19 & 874-1992 CE & 76.62 & -36.4 & $0.230^{*}$ & Weißbach et al. (2016) \\
\hline B27/B28 & 20 & 1195-1994 CE & 76.66 & -46.82 & $0.287^{*}$ & Weißbach et al. (2016) \\
\hline Camp Century & 21 & 1242-1967 CE & 77.2 & -61.1 & $0.192^{*}$ & Dansgaard et al. (1967) \\
\hline $\mathrm{B} 26$ & 22 & 1505-1994 CE & 77.25 & -49.22 & $0.366^{*}$ & Weißbach et al. (2016) \\
\hline NEEM-2001-S1 & 23 & 88-2007 CE & 77.49 & -51.2 & $0.313^{*}$ & Unpublished; Sigl et al. (2015) \\
\hline B19 & 24 & 753-1993 CE & 78 & -36.4 & -0.062 & Weißbach et al. (2016) \\
\hline B23 & 25 & 1023-1993 CE & 78 & -44 & $0.122^{*}$ & Weißbach et al. (2016) \\
\hline TUNU & 26 & 269-2013 CE & 78.03 & -33.87 & 0.070 & Unpublished; Maselli et al. (2017) \\
\hline $\mathrm{B} 20$ & 27 & 775-1993 CE & 78.83 & -36.5 & -0.130 & Weißbach et al. (2016) \\
\hline B22 & 28 & 1372-1993 CE & 79.34 & -45.91 & $0.216^{*}$ & Weißbach et al. (2016) \\
\hline B21 & 29 & 1372-1993 CE & 80 & -41.14 & $0.167^{*}$ & Weißbach et al. (2016) \\
\hline
\end{tabular}


Table S5-2: Calibration-validation statistics for the pseudoproxy-based (i.e., iCESM-derived surrogate $\delta^{18} \mathrm{O}$ records) jet-latitude reconstructions for the first nested-model reconstruction interval (A.D. 1775-2000). (a) Coefficient of Efficiency (CE) and $\mathrm{R}^{2}$ verif. PLSr variable selection methods tested are as follows: $a$. without variable selection; $b$. iterative-PLS using the "Martens Uncertainty Test"-variable selection algorithm (Martens and Martens, 2003); c. iterative-PLS using a Monte Carlo-based variable selection method novel to this study (see Sect. 5.6.6). (b) As in (a), but reconstruction-validation statistics (i.e., Root-Mean-Squared-Error-ofPrediction (RMSEP) and the squared Pearson's correlation between the reconstructed and model-generated jet-latitude) outside the calibration-interval (i.e., A.D. 1775-1850). CE/R $2 / R M S E P$ values and their superscripts and subscripts denote the mean, max, and min across 10 pseudoproxy reconstructions. Maximum $\mathrm{CE} / \mathrm{R}^{2}$ values and minimum RMSEP values are bolded for each signal-to-noise ratio test (see Sect. 5.6.11).

\begin{tabular}{|c|c|c|c|c|}
\hline \multirow{2}{*}{\multicolumn{2}{|c|}{$\begin{array}{c}\text { (a) } \\
\mathbf{R}_{\text {verif. }}^{2} / \mathrm{CE}\end{array}$}} & \multicolumn{3}{|c|}{ Predictand signal-to-noise ratio } \\
\hline & & Best & 1 & 0.5 \\
\hline \multirow{12}{*}{$\begin{array}{l}\text { Variable- } \\
\text { selection } \\
\text { method }\end{array}$} & & \multicolumn{3}{|c|}{ Predictor: Jet-latitude (direct calibration) } \\
\hline & a & $0.35 / 0.31$ & $0.22_{0.20}^{0.25} / 0.18_{0.15}^{0.22}$ & $0.09_{0.03}^{0.18} / 0.05_{-0.07}^{0.17}$ \\
\hline & $b$ & $0.41 / 0.39$ & $0.24_{0.20}^{0.32} / 0.20_{0.15}^{0.30}$ & $0.16_{0.10}^{0.23} / 0.14_{0.07}^{0.21}$ \\
\hline & $c$ & $0.42 / 0.39$ & $0.25_{0.21}^{0.28} / 0.22_{0.18}^{0.25}$ & 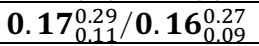 \\
\hline & & \multicolumn{3}{|c|}{ Predictor: Jet-PC1 } \\
\hline & $a$ & $0.54 / 0.53$ & $0.27_{0.21}^{0.37} / 0.24_{0.16}^{0.35}$ & $0.11_{j 0.03}^{0.19} / 0.06_{-0.07}^{0.18}$ \\
\hline & $b$ & $0.56 / 0.55$ & $0.39_{0.33}^{0.47} / 0.38_{0.32}^{0.46}$ & $0.15_{0.10}^{0.23} / 0.13_{0.08}^{0.21}$ \\
\hline & $c$ & $0.57 / 0.56$ & $\mathbf{0 . 3 9 _ { 0 . 2 6 } ^ { 0 . 4 8 } / \mathbf { 0 . 3 8 }} 8_{0.25}^{0.48}$ & $0.18_{0.08}^{0.25} / \mathbf{0 . 1 5} 5_{0.05}^{0.24}$ \\
\hline & & \multicolumn{3}{|c|}{ Predictor: Jet-PC2 } \\
\hline & a & $0.13 / 0.11$ & $0.06_{0.02}^{0.13} / 0.00_{-0.13}^{0.12}$ & $0.05_{0.02}^{0.09} / 0.01_{-0.12}^{0.06}$ \\
\hline & $b$ & $0.24 / 0.23$ & $0.11_{0.08}^{0.15} / 0.10_{0.06}^{0.14}$ & $\mathbf{0 . 1 0 _ { 0 . 0 8 } ^ { 0 . 1 3 } / 0 . 0 9 _ { 0 . 0 6 } ^ { 0 . 1 2 }}$ \\
\hline & $c$ & $0.27 / 0.26$ & $\mathbf{0 1 2} 2_{0.06}^{0.19} / \mathbf{0 . 1 0} \mathbf{1 0}_{0.03}^{0.18}$ & $0.08_{0.05}^{0.12} / 0.07_{0}^{0.12}$ \\
\hline
\end{tabular}

\begin{tabular}{|c|c|c|c|c|}
\hline \multirow{2}{*}{\multicolumn{2}{|c|}{$\begin{array}{c}\text { (b) } \\
\mathrm{R}_{\text {recon. }} / \mathrm{RMSEP}\end{array}$}} & \multicolumn{3}{|c|}{ Predictand signal-to-noise ratio } \\
\hline & & Best & 1 & 0.5 \\
\hline \multirow{8}{*}{$\begin{array}{l}\text { Variable- } \\
\text { selection } \\
\text { method }\end{array}$} & & \multicolumn{3}{|c|}{ Predictor: Jet-latitude (Direct) } \\
\hline & a & $0.31 / 1.45$ & $0.28_{0.23}^{0.33} / 1.49_{1.45}^{1.57}$ & $0.11_{0.06}^{0.19} / 1.65_{1.59}^{1.70}$ \\
\hline & $b$ & $0.27 / 1.50$ & $0.23_{0.06}^{0.34} / 1.55_{1.43}^{1.74}$ & $0.11_{0.01}^{0.20} / 1.65_{1.54}^{1.83}$ \\
\hline & $c$ & $0.30 / 1.45$ & $0.23_{0.17}^{0.26} / 1.62_{1.58}^{1.67}$ & $0.13_{0.06}^{0.24} / 1.63_{1.50}^{1.73}$ \\
\hline & & \multicolumn{3}{|c|}{ Predictor: Jet-latitude (PC-derived) } \\
\hline & $a$ & $0.32 / 1.45$ & $0.27_{0.18}^{0.31} / 1.57_{1.48}^{1.71}$ & $0.14_{0.04}^{0.20} / 1.63_{1.55}^{1.74}$ \\
\hline & $b$ & $0.34 / 1.43$ & $0.24_{0.19}^{0.29} / 1.57_{1.48}^{1.65}$ & $0.14_{0.06}^{0.20} / 1.62_{1.56}^{1.72}$ \\
\hline & $c$ & $0.31 / 1.45$ & $0.23_{0.18}^{0.25} / 1.63_{1.62}^{1.65}$ & $0.11_{0.02}^{0.22} / 1.58_{1.53}^{1.77}$ \\
\hline
\end{tabular}




\section{Ch. 5 References}

Andersen, K. K., Ditlevsen, P. D., Rasmussen, S. O., Clausen, H. B., Vinther, B. M., Johnsen, S. J., \& Steffensen, J. P. (2006). Retrieving a common accumulation record from Greenland ice cores for the past 1800 years. Journal of Geophysical Research: Atmospheres, 111(D15). https://doi.org/10.1029/2005JD006765

Andersson, M. (2009). A comparison of nine PLS1 algorithms. In Journal of Chemometrics (Vol. 23). https://doi.org/10.1002/cem.1248

Babamoradi, H., van den Berg, F., \& Rinnan, A. (2013). Bootstrap based confidence limits in principal component analysis - A case study. Chemometrics and Intelligent Laboratory Systems, 120, 97-105. https://doi.org/https://doi.org/10.1016/j.chemolab.2012.10.007

Barnes, E. A., \& Polvani, L. (2013). Response of the Midlatitude Jets, and of Their Variability, to Increased Greenhouse Gases in the CMIP5 Models. Journal of Climate, 26(18), 7117-7135. https://doi.org/10.1175/JCLI-D-12-00536.1

Barnes, E. A., \& Polvani, L. M. (2015). CMIP5 Projections of Arctic Amplification, of the North American/North Atlantic Circulation, and of Their Relationship. Joumal of Climate, 28(13), 5254-5271. https://doi.org/10.1175/JCLI-D-14-00589.1

Barnett, T. P., \& Preisendorfer, R. (1987). Origins and Levels of Monthly and Seasonal Forecast Skill for United States Surface Air Temperatures Determined by Canonical Correlation Analysis. Monthly Weather Review, 115(9), 1825-1850. https://doi.org/10.1175/1520-0493(1987)115<1825:OALOMA>2.0.CO;2

Belmecheri, S., Babst, F., Hudson, A. R., Betancourt, J., \& Trouet, V. (2017). Northern Hemisphere Jet Stream Position Indices as Diagnostic Tools for Climate and Ecosystem Dynamics. Earth Interactions, 21 (8), 1-23. https://doi.org/10.1175/EI-D-16-0023.1

Box, J. E., Cressie, N., Bromwich, D. H., Jung, J.-H., van den Broeke, M., van Angelen, J. H., ... McConnell, J. R. (2012). Greenland Ice Sheet Mass Balance Reconstruction. Part I: Net Snow Accumulation (16002009). Journal of Climate, 26(11), 3919-3934. https://doi.org/10.1175/JCLI-D-12-00373.1

Bretherton, C. S., Smith, C., \& Wallace, J. M. (1992). An Intercomparison of Methods for Finding Coupled Patterns in Climate Data. Journal of Climate, 5(6), 541-560. https://doi.org/10.1175/15200442(1992)005<0541:AIOMFF>2.0.CO;2

Chen, K., Gawarkiewicz, G. G., Lentz, S. J., \& Bane, J. M. (2014). Diagnosing the warming of the Northeastern U.S. Coastal Ocean in 2012: A linkage between the atmospheric jet stream variability and ocean response. Journal of Geophysical Research: Oceans, 119(1), 218-227. https://doi.org/10.1002/2013JC009393

Cohen, J., Screen, J. A., Furtado, J. C., Barlow, M., Whittleston, D., Coumou, D., ... Jones, J. (2014). Recent Arctic amplification and extreme mid-latitude weather. Nature Geoscience, 7, 627. Retrieved from https://doi.org/10.1038/ngeo2234

Cohen, J., Screen, J. A., Furtado, J. C., Barlow, M., Whittleston, D., Coumou, D., .. Jones, J. (2014). Recent Arctic amplification and extreme mid-latitude weather. Nature Geoscience, 7, 627. Retrieved from https://doi.org/10.1038/ngeo2234 
Compo, G. P., Whitaker, J. S., Sardeshmukh, P. D., Matsui, N., Allan, R. J., Yin, X., ... Worley, S. J. (2011). The Twentieth Century Reanalysis Project. Quarterly Joumal of the Royal Meteorological Society, 137(654), 128. https://doi.org/10.1002/qj.776

Cook, E. R., Briffa, K. R., \& Jones, P. D. (1994). Spatial regression methods in dendroclimatology: A review and comparison of two techniques. International Journal of Climatology, 14(4), 379-402. https://doi.org/10.1002/joc.3370140404

Coumou, D., Di Capua, G., Vavrus, S., Wang, L., \& Wang, S. (2018). The influence of Arctic amplification on mid-latitude summer circulation. Nature Communications, 9(1), 2959. https://doi.org/10.1038/s41467-01805256-8

Coumou, D., \& Rahmstorf, S. (2012). A decade of weather extremes. Nature Climate Change, 2, 491. Retrieved from https://doi.org/10.1038/nclimate1452

Dansgaard, W. (1964). Stable isotopes in precipitation. Tellus, 16(4), 436-468. https://doi.org/10.1111/j.21533490.1964.tb00181.x

de Jong, S. (1993). SIMPLS: An alternative approach to partial least squares regression. Chemometrics and Intelligent Laboratory Systems, 18(3), 251-263. https://doi.org/https://doi.org/10.1016/0169-7439(93)85002-X

Dempster, A. P., Laird, N. M., \& Rubin, D. B. (1977). Maximum likelihood from incomplete data via the EM algorithm. Journal of the Royal Statistical Society Series B Methodological, 39(1), 1-38. https://doi.org/http://dx.doi.org/10.2307/2984875

Dempster, A., Laird, N., \& B. Rubin, D. (1977). Maximum Likelihood From Incomplete Data Via The EM algorithm. In Journal of the Royal Statistical Society. Series B (Methodological) (Vol. 39).

Diffenbaugh, N. S., Singh, D., \& Mankin, J. S. (2018). Unprecedented climate events: Historical changes, aspirational targets, and national commitments. Science Advances, 4(2), eaao3354. https://doi.org/10.1126/sciadv.aao3354

Ebisuzaki, W. (1997). A method to estimate the statistical significance of a correlation when the data are serially correlated. Journal of Climate, 10(9), 2147-2153. https://doi.org/10.1175/15200442(1997)010<2147:AMTETS>2.0.CO;2

Faber, N. M., \& Rajkó, R. (2007). How to avoid over-fitting in multivariate calibration-The conventional validation approach and an alternative. Analytica Cbimica Acta, 595(1), 98-106. https://doi.org/https://doi.org/10.1016/j.aca.2007.05.030

Francis, J. A., \& Vavrus, S. J. (2012). Evidence linking Arctic amplification to extreme weather in mid-latitudes. Geophysical Research Letters, 39(6). https://doi.org/10.1029/2012GL051000

Francis, J., \& Skific, N. (2015). Evidence linking rapid Arctic warming to mid-latitude weather patterns. Philosophical Transactions. Series A, Mathematical, Physical, and Engineering Sciences, 373(2045), 20140170. https://doi.org/10.1098/rsta.2014.0170

Gkinis, V., Popp, T. J., Blunier, T., Bigler, M., Schüpbach, S., Kettner, E., \& Johnsen, S. J. (2011). Water isotopic ratios from a continuously melted ice core sample. Atmos. Meas. Tech., 4(11), 2531-2542. https://doi.org/10.5194/amt-4-2531-2011 
Goosse, H., Kay, J. E., Armour, K. C., Bodas-Salcedo, A., Chepfer, H., Docquier, D., ... Vancoppenolle, M. (2018). Quantifying climate feedbacks in polar regions. Nature Communications, 9(1), 1919. https://doi.org/10.1038/s41467-018-04173-0

Gray, L. J., Woollings, T. J., Andrews, M., \& Knight, J. (2016). Eleven-year solar cycle signal in the NAO and Atlantic/European blocking. Quarterly Journal of the Royal Meteorological Society, 142(698), 1890-1903. https://doi.org/10.1002/qj.2782

Gray, L. J., Scaife, A. A., Mitchell, D. M., Osprey, S., Ineson, S., Hardiman, S., .. Kodera, K. (2013). A lagged response to the 11 year solar cycle in observed winter Atlantic/European weather patterns. Journal of Geophysical Research: Atmospheres, 118(24), 13, 405-413, 420. https://doi.org/10.1002/2013JD020062

Häkkinen, S., Rhines, P. B., \& Worthen, D. L. (2011). Atmospheric Blocking and Atlantic Multidecadal Ocean Variability. Science, 334(6056), 655 LP - 659. https://doi.org/10.1126/science.1205683

Hall, R., Erdélyi, R., Hanna, E., Jones, J. M., \& Scaife, A. A. (2015). Drivers of North Atlantic Polar Front jet stream variability. International Joumal of Climatology, 35(8), 1697-1720. https://doi.org/10.1002/joc.4121

Hanna, E., Cropper, T. E., Hall, R. J., \& Cappelen, J. (2016). Greenland Blocking Index 1851-2015: a regional climate change signal. International Journal of Climatology, 36(15), 4847-4861. https://doi.org/10.1002/joc.4673

Hanna, E., Hall, R. J., Cropper, T. E., Ballinger, T. J., Wake, L., Mote, T., \& Cappelen, J. (2018). Greenland blocking index daily series 1851-2015: Analysis of changes in extremes and links with North Atlantic and UK climate variability and change. International Journal of Climatology, 38(9), 3546-3564. https://doi.org/10.1002/joc.5516

Hastie, T., Tibshirani, R., Friedman, J., \& Franklin, J. (2004). The Elements of Statistical Learning: Data Mining, Inference, and Prediction. In Math. Intell. (Vol. 27). https://doi.org/10.1007/BF02985802

Holme, C., Gkinis, V., Lanzky, M., Morris, V., Olesen, M., Thayer, A., ... Vinther, B. M. (2019). Varying regional $\delta 18 \mathrm{O}-$ temperature relationship in high-resolution stable water isotopes from east Greenland. Clim. Past, 15(3), 893-912. https://doi.org/10.5194/cp-15-893-2019

Hurrell, J. W. (1995). Decadal Trends in the North Atlantic Oscillation: Regional Temperatures and Precipitation. Science, 269(5224), 676 LP - 679. https://doi.org/10.1126/science.269.5224.676

Hurrell, J. W., Kushnir, Y., Ottersen, G., \& Visbeck, M. (2003, January). An Overview of the North Atlantic Oscillation. The North Atlantic Oscillation: Climatic Significance and Environmental Impact, pp. 1-35. https://doi.org/doi:10.1029/134GM01

Huth, R., Bochníček, J., \& Hejda, P. (2007). The 11-year solar cycle affects the intensity and annularity of the Arctic Oscillation. In Journal of Atmospheric and Solar-Terrestrial Physics (Vol. 69). https://doi.org/10.1016/j.jastp.2007.03.006

Jones, P. D., Jonsson, T., \& Wheeler, D. (1997). Extension to the North Atlantic oscillation using early instrumental pressure observations from Gibraltar and south-west Iceland. International Journal of Climatology, 17(13), 1433-1450. https://doi.org/10.1002/(SICI)1097-0088(19971115)17:13<1433::AIDJOC203>3.0.CO;2-P 
Jones, T. R., Cuffey, K. M., White, J. W. C., Steig, E. J., Buizert, C., Markle, B. R., ... Sigl, M. (2017). Water isotope diffusion in the WAIS Divide ice core during the Holocene and last glacial. Journal of Geophysical Research: Earth Surface, 122(1), 290-309. https://doi.org/10.1002/2016JF003938

Jones, T. R., White, J. W. C., Steig, E. J., Vaughn, B. H., Morris, V., Gkinis, V., ... Schoenemann, S. W. (2017). Improved methodologies for continuous-flow analysis of stable water isotopes in ice cores. Atmos. Meas. Tech., 10(2), 617-632. https://doi.org/10.5194/amt-10-617-2017

Jouzel, J. (2013). A brief history of ice core science over the last 50 yr. Clim. Past, 9(6), 2525-2547. https://doi.org/10.5194/cp-9-2525-2013

Kaufman, D. S., Schneider, D. P., McKay, N. P., Ammann, C. M., Bradley, R. S., Briffa, K. R., ... Vinther, B. M. (2009). Recent Warming Reverses Long-Term Arctic Cooling. Science, 325(5945), 1236 LP - 1239. https://doi.org/10.1126/science.1173983

Kinnard, C., Zdanowicz, C. M., Fisher, D. A., Isaksson, E., de Vernal, A., \& Thompson, L. G. (2011). Reconstructed changes in Arctic sea ice over the past 1,450 years. Nature, 479, 509. Retrieved from https://doi.org/10.1038/nature10581

Kobashi, T., Kawamura, K., Severinghaus, J. P., Barnola, J.-M., Nakaegawa, T., Vinther, B. M., ... Box, J. E. (2011). High variability of Greenland surface temperature over the past 4000 years estimated from trapped air in an ice core. Geophysical Research Letters, 38(21). https://doi.org/10.1029/2011GL049444

Li, B., Nychka, D. W., \& Ammann, C. M. (2010). The Value of Multiproxy Reconstruction of Past Climate. Journal of the American Statistical Association, 105(491), 883-895. Retrieved from http://www.jstor.org/stable/27920111

Lorenz, D. J., \& Hartmann, D. L. (2003). Eddy-Zonal Flow Feedback in the Northern Hemisphere Winter. Journal of Climate, 16(8), 1212-1227. https://doi.org/10.1175/15200442(2003)16<1212:EFFITN>2.0.CO;2

Macias-Fauria, M., Grinsted, A., Helama, S., \& Holopainen, J. (2012). Persistence matters: Estimation of the statistical significance of paleoclimatic reconstruction statistics from autocorrelated time series. Dendrochronologia, 30(2), 179-187. https://doi.org/https://doi.org/10.1016/j.dendro.2011.08.003

Mann, M. E., Rahmstorf, S., Kornhuber, K., Steinman, B. A., Miller, S. K., Petri, S., \& Coumou, D. (2018). Projected changes in persistent extreme summer weather events: The role of quasi-resonant amplification. Science Advances, 4(10), eaat3272. https://doi.org/10.1126/sciadv.aat3272

Mann, M. E., Zhang, Z., Hughes, M. K., Bradley, R. S., Miller, S. K., Rutherford, S., \& Ni, F. (2008). Proxybased reconstructions of hemispheric and global surface temperature variations over the past two millennia. Proceedings of the National Academy of Sciences, 105(36), 13252 LP -13257. https://doi.org/10.1073/pnas.0805721105

Mann, M. E., Zhang, Z., Rutherford, S., Bradley, R. S., Hughes, M. K., Shindell, D., .. Ni, F. (2009). Global Signatures and Dynamical Origins of the Little Ice Age and Medieval Climate Anomaly. Science, 326(5957), 1256 LP - 1260. https://doi.org/10.1126/science.1177303 
Mann, M. E., Zhang, Z., Rutherford, S., Bradley, R. S., Hughes, M. K., Shindell, D., ... Ni, F. (2009). Global Signatures and Dynamical Origins of the Little Ice Age and Medieval Climate Anomaly. Science, 326(5957), 1256 LP - 1260. https://doi.org/10.1126/science.1177303

Martens, H., \& Martens, M. (2000). Modified Jack-knife estimation of parameter uncertainty in bilinear modelling by partial least squares regression (PLSR). In Food Quality and Preference (Vol. 11). https://doi.org/10.1016/S0950-3293(99)00039-7

Mehmood, T., Liland, K. H., Snipen, L., \& Sæbø, S. (2012). A review of variable selection methods in Partial Least Squares Regression. Chemometrics and Intelligent Laboratory Systems, 118, 62-69. https://doi.org/https://doi.org/10.1016/j.chemolab.2012.07.010

Mellado-Cano, J., Barriopedro, D., García-Herrera, R., Trigo, R. M., \& Hernández, A. (2019). Examining the North Atlantic Oscillation, East Atlantic pattern and jet variability since 1685. Journal of Climate. https://doi.org/10.1175/JCLI-D-19-0135.1

Nusbaumer, J., Wong, T. E., Bardeen, C., \& Noone, D. (2017). Evaluating hydrological processes in the Community Atmosphere Model Version 5 (CAM5) using stable isotope ratios of water. Journal of Advances in Modeling Earth Systems, 9(2), 949-977. https://doi.org/10.1002/2016MS000839

Ortega, P., Lehner, F., Swingedouw, D., Masson-Delmotte, V., Raible, C. C., Casado, M., \& Yiou, P. (2015). A model-tested North Atlantic Oscillation reconstruction for the past millennium. Nature, 523, 71. Retrieved from https://doi.org/10.1038/nature14518

Ortega, P., Swingedouw, D., Masson-Delmotte, V., Risi, C., Vinther, B., Yiou, P., ... Yoshimura, K. (2014). Characterizing atmospheric circulation signals in Greenland ice cores: insights from a weather regime approach. Climate Dynamics, 43(9), 2585-2605. https://doi.org/10.1007/s00382-014-2074-z

Osman, M. B., Das, S. B., Trusel, L. D., Evans, M. J., Fischer, H., Grieman, M. M., ... Saltzman, E. S. (2019). Industrial-era decline in subarctic Atlantic productivity. Nature, 569(7757), 551-555. https://doi.org/10.1038/s41586-019-1181-8

Otto-Bliesner, B. L., Brady, E. C., Fasullo, J., Jahn, A., Landrum, L., Stevenson, S., ... Strand, G. (2015). Climate Variability and Change since $850 \mathrm{CE}$ : An Ensemble Approach with the Community Earth System Model. Bulletin of the American Meteorological Society, 97(5), 735-754. https://doi.org/10.1175/BAMS-D-14-00233.1

Pohjola, V. A., Moore, J. C., Isaksson, E., Jauhiainen, T., van de Wal, R. S. W., Martma, T., ... Vaikmäe, R. (2002). Effect of periodic melting on geochemical and isotopic signals in an ice core from Lomonosovfonna, Svalbard. Journal of Geophysical Research: Atmospheres, 107(D4), ACL 1-1-ACL 1-14. https://doi.org/10.1029/2000JD000149

Rhines, A., \& Huybers, P. J. (2014). Sea Ice and Dynamical Controls on Preindustrial and Last Glacial Maximum Accumulation in Central Greenland. Journal of Climate, 27(23), 8902-8917. https:/ / doi.org/10.1175/JCLID-14-00075.1

Rimbu, N., \& Lohmann, G. (2011). Winter and summer blocking variability in the North Atlantic region evidence from long-term observational and proxy data from southwestern Greenland. Clim. Past, 7(2), 543-555. https://doi.org/10.5194/cp-7-543-2011 
Rimbu, N., Lohmann, G., Werner, M., \& Ionita, M. (2017). Links between central Greenland stable isotopes, blocking and extreme climate variability over Europe at decadal to multidecadal time scales. Climate Dynamics, 49(1), 649-663. https://doi.org/10.1007/s00382-016-3365-3

Rosipal, R., \& Krämer, N. (2006). Overview and Recent Advances in Partial Least Squares BT - Subspace, Latent Structure and Feature Selection (C. Saunders, M. Grobelnik, S. Gunn, \& J. Shawe-Taylor, eds.). Berlin, Heidelberg: Springer Berlin Heidelberg.

Roweis, S. (1999). Em algorithms for pca and spca. In Advances in Neural Information Processing Systems (Vol. 10).

Smerdon, J. E. (2012). Climate models as a test bed for climate reconstruction methods: pseudoproxy experiments. Wiley Interdisciplinary Reviews: Climate Change, 3(1), 63-77. https://doi.org/10.1002/wcc.149

Smerdon, J. E., Kaplan, A., Chang, D., \& Evans, M. N. (2010). A Pseudoproxy Evaluation of the CCA and RegEM Methods for Reconstructing Climate Fields of the Last Millennium. Journal of Climate, 23(18), 4856-4880. https://doi.org/10.1175/2010JCLI3328.1

Sodemann, H., Schwierz, C., \& Wernli, H. (2008). Interannual variability of Greenland winter precipitation sources: Lagrangian moisture diagnostic and North Atlantic Oscillation influence. Journal of Geophysical Research: Atmospheres, 113(D3). https://doi.org/10.1029/2007JD008503

Storch, H. Von, \& Zwiers, F. W. (1999). Statistical Analysis in Climate Research. Journal of the American Statistical Association, 95, 1375. https://doi.org/10.1017/CBO9780511612336

Stroeve, J. C., Serreze, M. C., Holland, M. M., Kay, J. E., Malanik, J., \& Barrett, A. P. (2012). The Arctic's rapidly shrinking sea ice cover: a research synthesis. Climatic Change, 110(3), 1005-1027. https://doi.org/10.1007/s10584-011-0101-1

Thompson, D. W. J., \& Wallace, J. M. (2000). Annular Modes in the Extratropical Circulation. Part I: Monthto-Month Variability. Joumal of Climate, 13(5), 1000-1016. https://doi.org/10.1175/15200442(2000)013<1000:AMITEC>2.0.CO;2

Tipping, M. E., \& Bishop, C. M. (1999). Probabilistic Principal Component Analysis. Journal of the Royal Statistical Society. Series B (Statistical Methodology), 61(3), 611-622. Retrieved from http://www.jstor.org/stable/2680726

Trouet, V., Esper, J., Graham, N. E., Baker, A., Scourse, J. D., \& Frank, D. C. (2009). Persistent Positive North Atlantic Oscillation Mode Dominated the Medieval Climate Anomaly. Science, 324(5923), 78 LP - 80. https://doi.org/10.1126/science.1166349

Trusel, L. D., Das, S. B., Osman, M. B., Evans, M. J., Smith, B. E., Fettweis, X., ... van den Broeke, M. R. (2018). Nonlinear rise in Greenland runoff in response to post-industrial Arctic warming. Nature, 564(7734), 104-108. https://doi.org/10.1038/s41586-018-0752-4

Vinther, B. M., Andersen, K. K., Hansen, A. W., Schmith, T., \& Jones, P. D. (2003). Improving the Gibraltar/Reykjavik NAO index. Geophysical Research Letters, $30(23)$. https://doi.org/10.1029/2003GL018220 
Vinther, B. M., Andersen, K. K., Jones, P. D., Briffa, K. R., \& Cappelen, J. (2006). Extending Greenland temperature records into the late eighteenth century. Journal of Geophysical Research: Atmospheres, 111(D11). https://doi.org/10.1029/2005JD006810

Vinther, B. M., Johnsen, S. J., Andersen, K. K., Clausen, H. B., \& Hansen, A. W. (2003). NAO signal recorded in the stable isotopes of Greenland ice cores. Geophysical Research Letters, 30(7). https://doi.org/10.1029/2002GL016193

Vinther, B. M., Jones, P. D., Briffa, K. R., Clausen, H. B., Andersen, K. K., Dahl-Jensen, D., \& Johnsen, S. J. (2010). Climatic signals in multiple highly resolved stable isotope records from Greenland. Quaternary Science Reviews, 29(3), 522-538. https://doi.org/https://doi.org/10.1016/j.quascirev.2009.11.002

Wahl, E. R., Zorita, E., Trouet, V., \& Taylor, A. H. (2019). Jet stream dynamics, hydroclimate, and fire in California from 1600 CE to present. Proceedings of the National Academy of Sciences, 116(12), 5393 LP - 5398. https://doi.org/10.1073/pnas.1815292116

Wang, J., Yang, B., Ljungqvist, F. C., Luterbacher, J., Osborn, T. J., Briffa, K. R., \& Zorita, E. (2017). Internal and external forcing of multidecadal Atlantic climate variability over the past 1,200 years. Nature Geoscience, 10, 512. Retrieved from https://doi.org/10.1038/ngeo2962

Weißbach, S., Wegner, A., Opel, T., Oerter, H., Vinther, B. M., \& Kipfstuhl, S. (2016). Spatial and temporal oxygen isotope variability in northern Greenland - implications for a new climate record over the past millennium. Climate of the Past, 12(2), 171-188. https://doi.org/10.5194/cp-12-171-2016

Williams, P. D., \& Joshi, M. M. (2013). Intensification of winter transatlantic aviation turbulence in response to climate change. Nature Climate Change, 3, 644. Retrieved from https://doi.org/10.1038/nclimate1866

Wold, S., Sjöström, M., \& Eriksson, L. (2001). PLS-regression: a basic tool of chemometrics. Chemometrics and Intelligent Laboratory Systems, 58(2), 109-130. https://doi.org/https://doi.org/10.1016/S01697439(01)00155-1

Woollings, T., \& Blackburn, M. (2011). The North Atlantic Jet Stream under Climate Change and Its Relation to the NAO and EA Patterns. Journal of Climate, 25(3), 886-902. https://doi.org/10.1175/JCLI-D-1100087.1

Woollings, T., Czuchnicki, C., \& Franzke, C. (2014). Twentieth century North Atlantic jet variability. Quarterly Journal of the Royal Meteorological Society, 140(680), 783-791. https:// doi.org/10.1002/qj.2197

Woollings, T., Hannachi, A., \& Hoskins, B. (2010). Variability of the North Atlantic eddy-driven jet stream. Quarterly Journal of the Royal Meteorological Society, 136(649), 856-868. https://doi.org/10.1002/qj.625

Woollings, T., Hoskins, B., Blackburn, M., \& Berrisford, P. (2008). A New Rossby Wave-Breaking Interpretation of the North Atlantic Oscillation. Joumal of the Atmospheric Sciences, 65(2), 609-626. https://doi.org/10.1175/2007JAS2347.1

Yin, J. H. (2005). A consistent poleward shift of the storm tracks in simulations of 21st century climate. Geophysical Research Letters, 32(18). https:/ / doi.org/10.1029/2005GL023684 


\section{Ch. 6 Summary and conclusions}

Having reached the concluding chapter of this thesis, I now summarize - in successive order - the main results of this thesis, and provide recommendations for future research directions:

Chapter [2] investigates the fidelity of ice core glaciochemical climate proxies at the microphysical scale. I compile the largest array of ice core glaciochemistry to date, and develop empirical and theoretical models describing the post-depositional transport of routinely-analyzed soluble, marine-derived chemical species in cold, polar ice. I illustrate that one routinely-analyzed soluble chemical species, methanesulfonic acid, or "MSA", undergoes particularly rapid vertical movement along super-cooled ice columns through an advection-diffusion process occurring at the liquid grain-boundaries of individual ice crystals, curiously migrating out of summers to form welldefined, winter concentration peaks. By modeling the migration process over varying physicochemical boundary-conditions, I show that - contrary to assumptions commonly made in the literature (e.g., Curran et al., 2002; Thomas et al., 2016) - such post-depositional migration may be fairly ubiquitous, particularly at coastal and (or) high accumulation regions across Greenland and Antarctica. Importantly, however, because significant multi-year changes in MSA tend to occur only under low snow-accumulation and high-impurity-content conditions, this phenomenon appears to be mitigated over much of the Greenland Ice Sheet.

The insights developed in Chapter [2] illuminate the potential for future research that might significantly improve upon the paleoclimatic potential of ice core glaciochemical proxies such as MSA. In particular, whereas the physicochemical models presented in Chapter [2] provide an important mechanistic framework for both understanding and testing the sensitivity chemical migration in polar ice, such models remain nonetheless limited by uncertainties in several key model parameters. These parameters include, most importantly, the diffusivities of the various migrating chemical species under super-cooled ambient conditions, as well as the partitioning of impurities between the ice-grain boundaries and crystalline lattice. Targeted laboratory studies will help to better constrain such uncertainties, and raise the potential for integration of these migration models into "back-diffusion" inverse frameworks that could, in turn, correct for post-depositional chemical migration (e.g., Jones et al., 2017). Such models would improve upon the robustness and utility of ice core glaciochemical records, and the ability of such records to constrain subannual-scale climatic variability. 
In Chapter [3], I investigate the origin of declining Greenland Ice Sheet MSA concentrations spanning the $19^{\text {th }}$ and $20^{\text {th }}$ centuries. Incorporating a broad array of ship- and satellite-derived planktonic measurements, I show that Greenlandic MSA records provide a valuable new proxy for regional ocean-atmosphere fluxes of oceanic dimethylsulfide (DMS) gas emissions which, in turn, are tightly coupled to multiannual-scale changes in planktonic production across the subarctic Atlantic basin. My results provide the first continuous multi-century and area-integrated record of productivity variability spanning the pre- to post-Industrial-era (c. 1850), revealing the following major insights: (i) subarctic Atlantic marine productivity has declined significantly over the industrial-era, by $10 \pm 7 \%$; (ii) the early $19^{\text {th }}$ century onset of declining productivity coincides with the onset of regional surface warming, and also strongly co-varies with regional sea surface temperatures and basin-scale gyre circulation strength; (iii) there exists significant decadal- to centennial-scale coherence between northern Atlantic productivity and declining Atlantic Meridional Overturning Circulation (AMOC) strength. Nonetheless, while the AMOC offers one plausible (Schmittner, 2005) and stasticallytestable driver of declining northern Atlantic planktonic stocks (that is, given the availability of recent proxy-based AMOC reconstructions, e.g., Rahmstorf et al., 2015), this thesis also recognizes that myriad other environmental factors (occurring either as a result of or in lieu of AMOC) could moredirectly influence North Atlantic productivity. Such factors - of which few long-term and continuous obvervational time series currently exist - include potential long-term changes in North Atlantic upper ocean cloudiness, stratification, mixed layer depth, and nutrient-availability.

More broadly, the use of Greenland ice core MSA as a robust indicator of North Atlantic marine productivity, as presented in Chapter [3], represents a paradigm shift from the reigning presupposition that ice core MSA represents predominantly a sea-ice proxy (e.g., Curran et al., 2002; Abram et al., 2013; Maselli et al., 2017). It is anticipated that these findings - illustrating a remarkably intimate (and previously unappreciated) sensitivity in North Atlantic marine ecosystems to Industrialera forcing - will thus spur future proxy development efforts using measurements of MSA from Greenlandic ice. In addition, a greater number of temporally-extensive Greenlandic MSA ice core records will help us to better constrain variations in North Atlantic productivity prior to the mid-1 ${ }^{\text {th }}$ century. Such records would also improve temporal overlap with contemporary satellite era and shipbased observations, providing further insight into potential environmental drivers (or mitigators) of declining North Atlantic marine productivity. 
Chapter [4] develops and presents a new climate record from an ice cap on the Nuussuaq Peninsula in west-central Greenland - the most coastal ice core to date along the west-Greenlandic seaboard. Results show enhanced hydroclimate variability in coastal west Greenland (CWG) ] during three major climatic intervals of the last millennium: the Medieval Warm Period (MWP; A.D. 9501250), Little Ice Age (LIA; 1350-1850), and post-industrial period (c. $\sim 1850$-). Using a newly developed, physically- and observationally-constrained ice cap flowline inversion, I identify marked centennial-scale changes in CWG precipitation during the last millennium: a nearly $\sim 20 \%$ decrease in annual snowfall accumulation across the MWP to LIA transition, followed by a subsequent $\sim 40 \%$ increase in accumulation from the LIA into the modern. Both changes are drastically larger than those observed from inland Greenland records, suggesting a strong sensitivity in west Greenlandic hydroclimate conditions to regional surface air temperature (SAT) variations. Furthermore, these coastal ice core-derived insights strongly contradict recent contentions of "paradoxical" climate conditions in coastal west Greenland during the last millennium (that is, of paradoxically cold MWP and warm LIA conditions; Young et al., 2015; Jomelli et al., 2016), instead illuminating the key role that SAT variability plays in near-linearly governing local evaporation, coastal precipitation, and ice cap growth/glacier expansion. Nonetheless, it is noted that a negative SAT - ice cap accumulation relationship observed during recent decades aligns conspicuously with the shift towards "unprecedented" coastal west Greenland glacial melt reported by Trusel et al. (2018; see also Appendix 3). Speculatively, this negative relationshiop might hint at an ongoing shift from a positive to negative Nuussuaq ice cap mass balance state under $21^{\text {st }}$ century warming trends. This thesis thus recommends continued, careful monitoring be conducted across a range of coastal west Greenland ice caps.

Moreover, I identify for the first time a rapid hydroclimate deterioration event in the mid- $14^{\text {th }}$ century CE, foreshadowing the disappearance of the Greenlandic Norse settlements by only a matter of decades. The timing and magnitude of this hydroclimate event appears robust across a broad range of sensitivity experiments using the ice cap flowline inversion. This finding thus suggests deteriorating hydroclimate-conditions may have played a larger role in the demise of Greenland Norse societies in the $14^{\text {th }}$ and $15^{\text {th }}$ centuries than previously recognized. The climatic driving mechanism(s), as well as spatial extent, of this hydroclimate event are currently unknown. New coastal west Greenland ice core records would, however, help to better constrain insights into coastal climate variability and its drivers during this key time interval. 
Finally, in Chapter [5] I compile the largest annual-resolution Greenland Ice Sheet water isotope $\left(\delta^{18} \mathrm{O}\right)$ ice core array to date, permitting the extraction of two unique (and previously unidentified) modes of Greenlandic $\delta^{18} \mathrm{O}$-covariability. I illustrate that both temporal modes of $\delta^{18} \mathrm{O}$ covariability reflect temporally overlapping changes in Atlantic jet variability during the observational era, interpreted as shifts in the jet-stream meridional positioning (mode 1) and jet-stream pulsation/width (mode 2). To explore the climatological underpinning(s) of this covariability, a new ensemble of water isotope-enabled, millennium-length global climate model simulations is employed. Results illuminate the underlying influence of the well-known North Atlantic Oscillation (NAO) and East Atlantic (EA) pattern on both Greenlandic $\delta^{18} \mathrm{O}$-depositional- and Atlantic jet stream-variability, revealing both atmospheric modes are necessary for discerning past variations in the Atlantic jetstream. A skillful reconstruction of the mean-annual Atlantic jet latitude, as well as the leading two modes of (NAO and EA-modulated) Atlantic jet variability, is thus established over the last millennium using our $\delta^{18} \mathrm{O}$ compilation. I show that the first mode of jet variability markedly improves upon a recent NAO reconstruction (Ortega et al., 2015), though shows little coherence when compared against a recent biproxy tree-ring-based jet-latitude reconstruction (Trouet et al., 2018). Furthermore, I show evidence of both solar- (11-yr recurrence interval) and ocean- (50-70-yr recurrence interval) modulated changes in jet speed positioning and intensity during the last millennium, in contrast to these prior reconstructions.

Perhaps most alarming, my results also suggest progressively-enhanced Atlantic jet-latitude variability during the past two centuries, marking an ongoing Atlantic jet-stream regime shift that appears coeval with the onset of amplified Industrial-era Arctic warming (e.g., Kaufman et al., 2009). This result suggests a strong sensitivity of mid-latitude dynamics to polar-latitude thermal forcing, and alludes towards prior hypotheses (e.g., Francis et al., 2012, 2015) that anomalous Industrial-era warming of the Arctic has led to a reduced poleward temperature gradient and midlatitude zonal windiness during recent decades of the $20^{\text {th }}$ and $21^{\text {st }}$ centuries (Trouet et al., 2018). Speculatively, this (purported) long-term reduction in upper-atmosphere zonal wind speeds may have increased the frequency of anomalous southerly jet-meanders over the zonally-averaged Atlantic sector, albeit not necessarily the Atlantic jet-latitude mean-state. Future improvements in reconstructing the jet-latitude - as suggested by pseudoproxy experiments using isotope-enabled global climate model output - may be achieved by inclusion of well-sited North Atlantic precipitation (or snow accumulation) proxies into the Greenland $\delta^{18} \mathrm{O}$-array. 


\section{Coda}

The Greenlandic ice archive embeds a rich array of climatic insights ranging from monthly to millennial timescales. Through the development of new coastal and interior Greenlandic ice core records (e.g., the Disko Bay ice core array; see Ch. [1.3] and Ch. [4]) and an extensive (re)analysis of those preexisting (see Chapters [2], [3], and [5]), this thesis has illuminated several previouslyunrecognized Common Era climatic and ecologic changes, and has expanded the scope of the Greenlandic ice archive as quantitative proxies of the coupled North Atlantic climate system. However, much work remains. In particular, this dissertation has illustrated, recurrently, that meaningful climatic signals can be more readily isolated from noise when more ice core records become available for analysis. The findings of this thesis thus invoke a recognition that more paleoclimatic records, covering a broader range of time and spatial scales, are needed. Such records will, in turn, improve our ability to both contextualize contemporary climatic and ecologic observations against those of the near- and distant-past, as well as better inform predictions of climate change into the future. 


\section{Ch. 6 References}

Abram, N. J., Mulvaney, R., Wolff, E. W., \& Mudelsee, M. (2007). Ice core records as sea ice proxies: An evaluation from the Weddell Sea region of Antarctica. Journal of Geophysical Research Atmospheres, 112(15), 1-13. https://doi.org/10.1029/2006JD008139

Curran, M. a J., van Ommen, T. D., Morgan, V. I., Phillips, K. L., \& Palmer, A. S. (2003). Ice core evidence for Antarctic sea ice decline since the 1950s. Science, 302(5648), 1203-1206. https://doi.org/10.1126/science.1087888

Francis, J., \& Skific, N. (2015). Evidence linking rapid Arctic warming to mid-latitude weather patterns. Philosophical Transactions. Series A, Mathematical, Physical, and Engineering Sciences, 373(2045), 20140170. https://doi.org/10.1098/rsta.2014.0170

Francis, J. A., \& Vavrus, S. J. (2012). Evidence linking Arctic amplification to extreme weather in mid-latitudes. Geophysical Research Letters, 39(6). https://doi.org/10.1029/2012GL051000

Jomelli, V., Lane, T., Favier, V., Masson-Delmotte, V., Swingedouw, D., Rinterknecht, V., ... Keddadouche, K. (2016). Paradoxical cold conditions during the medieval climate anomaly in the Western Arctic. Scientific Reports, 6, 32984. Retrieved from https://doi.org/10.1038/srep32984

Jones, T. R., Cuffey, K. M., White, J. W. C., Steig, E. J., Buizert, C., Markle, B. R., ... Sigl, M. (2017). Water isotope diffusion in the WAIS Divide ice core during the Holocene and last glacial. Journal of Geophysical Research: Earth Surface, 122(1), 290-309. https:// doi.org/10.1002/2016JF003938

Kaufman, D. S., Schneider, D. P., McKay, N. P., Ammann, C. M., Bradley, R. S., Briffa, K. R., ... Vinther, B. M. (2009). Recent Warming Reverses Long-Term Arctic Cooling. Science, 325(5945), 1236 LP - 1239. https://doi.org/10.1126/science.1173983

Ortega, P., Swingedouw, D., Masson-Delmotte, V., Risi, C., Vinther, B., Yiou, P., ... Yoshimura, K. (2014). Characterizing atmospheric circulation signals in Greenland ice cores: insights from a weather regime approach. Climate Dynamics, 43(9), 2585-2605. https://doi.org/10.1007/s00382-014-2074-z

Rahmstorf, S., Box, J. E., Feulner, G., Mann, M. E., Robinson, A., Rutherford, S., \& Schaffernicht, E. J. (2015). Exceptional twentieth-century slowdown in Atlantic Ocean overturning circulation. Nature Climate Change, 5(5), 475-480. https://doi.org/10.1038/nclimate2554

Schmittner, A. (2005). Decline of the marine ecosystem caused by a reduction in the Atlantic overturning circulation. Nature, 434(7033), 628-633. https://doi.org/10.1038/nature03476

Thomas, E. R., \& Abram, N. (2016). Ice core reconstruction of sea ice change in the Amundsen-Ross Seas since 1702 AD. Geophysical Research Letters. https://doi.org/10.1002/2016GL068130

Trouet, V., Babst, F., \& Meko, M. (2018). Recent enhanced high-summer North Atlantic Jet variability emerges from three-century context. Nature Communications, 9(1), 180. https://doi.org/10.1038/s41467-01702699-3

Trusel, L. D., Das, S. B., Osman, M. B., Evans, M. J., Smith, B. E., Fettweis, X., ... van den Broeke, M. R. (2018). Nonlinear rise in Greenland runoff in response to post-industrial Arctic warming. Nature, 564(7734), 104-108. https://doi.org/10.1038/s41586-018-0752-4

Young, N. E., Schweinsberg, A. D., Briner, J. P., \& Schaefer, J. M. (2015). Glacier maxima in Baffin Bay during the Medieval Warm Period coeval with Norse settlement. Science Advances, 1(11), e1500806. https://doi.org/10.1126/sciadv.1500806 


\section{Appendix 1: Supplementary to Chapter 2}

\section{A1.1 Defining the shallowest depth of MSA migration, with emphasis on the Greenland sites D4 and Summit2010}

In this section, we provide further details about how the shallowest depth at which MSA occurs $\left(z_{f o}\right)$ is determined in this study. Such a determination involves some subjectivity. As noted in the main text (Section 2.2), we broadly define $z_{f o}$ as the depth where [MS] shows its annual peak within a winter layer. This definition appears consistent with previous descriptions of the phenomenon, i.e., the loss of clear summer [MS'] maxima and depressed annual [MS] amplitudes relative to those in the shallow portion of the core (Mulvaney et al., 1992; Pasteur and Mulvaney, 2000; Curran et al., 2002). In all but five of the sites considered in our compilation (Table 2-1), we use values of $z_{f o}$ as reported in prior studies. At two sites (Dolleman Island sites (1) and (2)), we redefine the values of $z_{f o}$ from those suggested in the original publications (Pasteur and Mulvaney, 2000) to be consistent within our broader definition (Table A1-1). At the three remaining sites - DIV2010, and the Greenland sites D4 and Summit2010 - no prior estimate of $z_{f o}$ appears to be available in the literature. Details on the determination of $z_{f o}$ in DIV2010 are provided in the main text; below we clarify the criteria used to define $z_{f o}$ at both D4 and Summit2010.

At both D4 and Summit2010, MSA migration appears progressive down-core. As such, for the purposes of our study, $z_{f o}$ is defined at each site by calculating monthly averages of [MS ] for each decade all along the core. The monthly [MS] averages are normalized so as to range from 0 to 1 , and the month of maximum [MS] $(=1)$ for each decade is recorded. We assume that the youngest (shallowest) decade contains the "true" (i.e., unaffected by migration) month of maximum [MS"]. Hence, we define $z_{f o}$ at both sites as the shallowest depth where the month of the annual [MS] maximum differs from the "true" month of maximum [MS] by more than 3 months. The results are provided in Table A1-1, and illustrated in Figures A1-2 and A1-3 for D4 and Summit2010, respectively.

\section{A1.2 Calculation of the slopes of the liquidus curves}


The slope of the liquidus curve, $\Gamma$, as introduced in Rempel et al. (2002), approximates the dependence of super-cooling on the mass fraction ( $\mathrm{wt} \%$ ) of a given impurity species dissolved in $\mathrm{H}_{2} \mathrm{O}$ (Figure A14), such that

$$
\Gamma_{i} \approx \frac{T_{m}-T}{c_{i}}
$$

Here, $T_{m}$ is the melting point of pure water $(273.15 \mathrm{~K}), T$ is the temperature at the eutectic point, and $c_{i}$ is the intergranular concentration of species $i$ at the eutectic point $\left(\mathrm{mol} \mathrm{L}^{-1}\right)$. The liquidus curve slope is calculated here by linearly interpolating between the eutectic composition (see Table 2.2 and references therein) and zero mass fraction $\left(\mathrm{H}_{2} \mathrm{O}=100 \mathrm{wt} \%\right.$ ) (Figure A1-4). We note that alternative approaches, e.g. a linear regression of all data between these two points, are possible. As noted by Rempel et al. (2002), the values of $\Gamma_{i}$ are typically most similar between impurity species when the concentration of the solute is expressed in units of molarity $\left(\mathrm{mol} \mathrm{L}^{-1}\right)$.

To illustrate how the $\Gamma$ values reported in Table 2.2 are calculated, we provide an example below using the $\mathrm{NaCl}-\mathrm{H}_{2} \mathrm{O}$ binary system. For this system, the eutectic point is characterized by a solution containing $23.3 \% \mathrm{NaCl}$ by mass $\left(76.7 \% \mathrm{H}_{2} \mathrm{O}\right)$ and a temperature of $-21.3^{\circ} \mathrm{C}(251.85 \mathrm{~K})$. The molarity of $\mathrm{NaCl}$ in the solution at the eutectic point, $C_{N a C l}$, is

$$
c_{N a C l}=\frac{m_{N a C l} \cdot \rho_{N a C l}}{M_{N a C l}}
$$

where $m_{\mathrm{NaCl}}=0.233$ is the mass fraction (23.3 g NaCl per $100 \mathrm{~g} \mathrm{NaCl}-\mathrm{H}_{2} \mathrm{O}$ solution), $M_{\mathrm{NaCl}}=58.44 \mathrm{~g}$ $\mathrm{NaCl} \mathrm{mol}{ }^{-1}$ is the molar mass of $\mathrm{NaCl}$, and $\rho_{\mathrm{NaCl}}=1160 \mathrm{~g} \mathrm{NaCl}_{-} \mathrm{H}_{2} \mathrm{O} \mathrm{L}^{-1}$ is the density of the NaCl$\mathrm{H}_{2} \mathrm{O}$ solution at the eutectic composition, such that $c_{N a C l}=4.6 \mathrm{~mol} \mathrm{NaCl} \mathrm{L}{ }^{-1}$. Thus, by eq. (A1-1),

$$
\Gamma_{\mathrm{NaCl}}=\frac{T_{m}-T}{c_{N a C l}}=\frac{(273.15-251.85) K}{(4.6) M}=4.6 \frac{K}{M}
$$

\section{A1.3 Discretization of the MSA migration models}

\section{A1.3.1 Linearized model}

Equation (2-13) is solved numerically using finite differences. The model grid is staggered, with $c_{M S}$ defined at equally spaced points and the effective velocity $w_{*}$ defined at points located midway 
between the $C_{M S^{-}}$-carrier points. Both the upper and lower boundaries of the model domain coincide with $w_{*}$-carrier points. Equation (2-13) is discretized using an upstream scheme and a centered difference scheme for the diffusion term. With the grid point index $i=1,2, \ldots N$, increasing with depth in the core, the discrete analogue of $(2-13)$ is

$$
\begin{gathered}
c_{i}^{t+1}=c_{i}^{t}-\frac{\Delta t}{\Delta z}\left\{\left(\left(\frac{w_{i+\frac{1}{2}}+\left|w_{i+\frac{1}{2}}\right|}{2}\right) c_{i}^{t}+\left(\frac{w_{i+\frac{1}{2}}-\left|w_{i+\frac{1}{2}}\right|}{2}\right) c_{i+1}^{t}\right]-\left[\left(\frac{w_{i-\frac{1}{2}}+\left|w_{i-\frac{1}{2}}\right|}{2}\right) c_{i-1}^{t}+\right.\right. \\
\left.\left.\left.\left(\frac{w_{i-\frac{1}{2}}-\left|w_{i-\frac{1}{2}}\right|}{2}\right) c_{i}^{t}\right]\right\}+\frac{D \Delta t}{(\Delta z)^{2}} \cdot\left(c_{i-1}^{t}-2 c_{i}^{t}+c_{i+1}^{t}\right)\right) .
\end{gathered}
$$

Here $c=c_{M S}, w=w_{*}, D=D_{M S}, \Delta t=2.5 \cdot 10^{6} \mathrm{~s}$ ( $\sim 29$ days $)$ is the time step chosen so as to satisfy the CFL criterion, and $\Delta z=0.05 \mathrm{~m}$, corresponding to the sampling interval for the DIV2010 core. The effective velocity $w$ is calculated from the profile of $\bar{c}=\left[\mathrm{Na}^{+}\right]$,

$$
w_{i+\frac{1}{2}}=\frac{D}{\Delta z} \ln \left(\frac{\overline{c_{l+1}}}{\overline{c_{l}}}\right) .
$$

Equation (A1-3) can be written in the more compact form

$$
c_{i}^{t+1}=\alpha_{i} c_{i-1}^{t}+\beta_{i} c_{i}^{t}+\gamma_{i} c_{i+1}^{t}
$$

where $\alpha_{i}, \beta_{i}$, and $\gamma_{i}$ are dimensionless coefficients given by

$$
\begin{aligned}
& \alpha_{i}=\frac{\Delta t}{\Delta z}\left(\frac{w_{i-\frac{1}{2}}+\left|w_{i-\frac{1}{2}}\right|}{2}\right)+\frac{D \Delta t}{(\Delta z)^{2}} \\
& \beta_{i}=1-\frac{\Delta t}{\Delta z}\left(\frac{w_{i+\frac{1}{2}}+\left|w_{i+\frac{1}{2}}\right|}{2}\right)+\frac{\Delta t}{\Delta z}\left(\frac{w_{i-\frac{1}{2}}-\left|w_{i-\frac{1}{2}}\right|}{2}\right)-2 \frac{D \Delta t}{(\Delta z)^{2}},
\end{aligned}
$$




$$
\gamma_{i}=-\frac{\Delta t}{\Delta z}\left(\frac{w_{i+\frac{1}{2}}-\left|w_{i+\frac{1}{2}}\right|}{2}\right)+\frac{D \Delta t}{(\Delta z)^{2}} .
$$

Equation (A1-5) is used to calculate $c$ at the grid points $i=2,3, \ldots, N-1$. For the shallowest grid point $(i=1)$, the following equation is used,

$$
c_{1}^{t+1}=\beta_{1} c_{1}^{t}+\gamma_{1} c_{2}^{t}
$$

which implicitly satisfies the condition of no $c$ flux at the upper boundary. Likewise, at the deepest grid point $(i=N)$, the following equation is used,

$$
c_{N}^{t+1}=\alpha_{N} c_{N-1}^{t}+\beta_{N} c_{N}^{t}
$$

which implicitly satisfies the condition of no $c$ flux at the lower boundary.

\section{A1.3.2 Model of Rempel et al. (2002)}

The method of solution of the RWW model follows largely that for the linearized model. Equations (2-6a-b) are solved using finite differences and a staggered grid. The concentrations of $\mathrm{MS}^{-}$and $\mathrm{Na}^{+}$,

$c_{M S}$ and $c_{N a}$, are defined at equally spaced points, and the effective velocity $w_{*}$ is defined at points located midway between the concentration-carrier points. The upper and lower boundaries of the model domain coincide with $w_{*}$-carrier points. The discrete analogue of equation (2-6a) is,

$$
\begin{gathered}
c_{M S, i}^{t+1}=c_{M S, i}^{t}-\frac{\Delta t}{\Delta z}\left[\left(\frac{w_{M S, i+\frac{1}{2}}^{t}+w_{M S, i+\frac{1}{2}}^{t} \mid}{2}\right) c_{M S, i}^{t}+\left(\frac{w_{M S, i+\frac{1}{2}}^{t}-\left|w_{M S, i+\frac{1}{2}}^{t}\right|}{2}\right) c_{M S, i+1}^{t}\right]- \\
\frac{\Delta t}{\Delta z}\left[\left(\frac{w_{M S, i-\frac{1}{2}}^{t}+\left|w_{M S, i-\frac{1}{2}}^{t}\right|}{2}\right) c_{M S, i-1}^{t}+\left(\frac{w_{M S, i-\frac{1}{2}}^{t}-\left|w_{M S, i-\frac{1}{2}}^{t}\right|}{2}\right) c_{M S, i}^{t}\right],
\end{gathered}
$$

where 


$$
\begin{aligned}
& w_{M S, i+\frac{1}{2}}^{t}=\left(D_{M S} \frac{\Gamma_{N a}}{\Gamma_{M S} \cdot c_{M S, i+\frac{1}{2}}^{t}+\Gamma_{N a} \cdot c_{N a, i+\frac{1}{2}}^{t}} \cdot\left[\frac{c_{N a, i+1}^{t}-c_{N a, i}^{t}}{\Delta z}-\frac{c_{N a, i+\frac{1}{2}}^{t}}{c_{M S, i+\frac{1}{2}}^{t}} \cdot \frac{c_{M S, i+1}^{t}-c_{M S, i}^{t}}{\Delta z}\right]\right), \\
& w_{M S, i-\frac{1}{2}}^{t}=\left(D_{M S} \frac{\Gamma_{N a}}{\Gamma_{M S} \cdot c_{M S, i-\frac{1}{2}}^{t}+\Gamma_{N a} \cdot c_{N a, i-\frac{1}{2}}^{t}} \cdot\left[\frac{c_{N a, i}^{t}-c_{N a, i-1}^{t}}{\Delta z}-\frac{c_{N a, i-\frac{1}{2}}^{t}}{c_{M S, i-\frac{1}{2}}^{t}} \cdot \frac{c_{M S, i}^{t}-c_{M S, i-1}^{t}}{\Delta z}\right]\right),
\end{aligned}
$$

Expressions similar to (A1-9 and A1-10) are used for equation (2-6b). Note that the ionic concentrations at the $w_{*}$-carrier points are obtained by linear interpolation from the two neighboring values. As for the linearized model, $\Delta t$ is set to $2 \cdot 5 \cdot 10^{6} \mathrm{~s}$ ( $\sim 29$ days) and $\Delta z$ is set equal to $0.05 \mathrm{~m}$.

At the upper and lower boundaries, a condition of no flux is prescribed for both ions. Thus, at the grid point nearest to the upper boundary, the concentration of $\mathrm{MS}^{-}$is computed from

$$
c_{M S, 1}^{t+1}=c_{M S, 1}^{t}-\frac{\Delta t}{\Delta z}\left[\left(\frac{w_{M S, \frac{3}{2}}^{t}+w_{M S, \frac{3}{2}}^{t} \mid}{2}\right) c_{M S, 1}^{t}+\left(\frac{w_{M S, \frac{3}{2}}^{t}-\left|w_{M S, \frac{3}{2}}^{t}\right|}{2}\right) c_{M S, 2}^{t}\right],
$$

where

$$
w_{M S, \frac{3}{2}}^{t}=\left(D_{M S} \frac{\Gamma_{N a}}{\Gamma_{M S} \cdot c_{M S, \frac{3}{2}}^{t}+\Gamma_{N a} \cdot c_{N a, \frac{3}{2}}^{t}} \cdot\left[\frac{c_{N a, 2}^{t}-c_{N a, 1}^{t}}{\Delta z}-\frac{c_{N a, \frac{3}{2}}^{t}}{c_{M S, \frac{3}{2}}^{t}} \cdot \frac{c_{M S, 2}^{t}-c_{M S, 1}^{t}}{\Delta z}\right]\right)
$$

Likewise, the concentration of $\mathrm{MS}^{-}$at the grid point nearest to the lower boundary is computed from

$$
c_{M S, N}^{t+1}=c_{M S, N}^{t}-\frac{\Delta t}{\Delta z}\left[\left(\frac{w_{M S, N-\frac{1}{2}}^{t}+w_{M S, N-\frac{1}{2}}^{t} \mid}{2}\right) c_{M S, N-1}^{t}+\left(\frac{w_{M S, N-\frac{1}{2}}^{t}-\left|w_{M S, N-\frac{1}{2}}^{t}\right|}{2}\right) c_{M S, N}^{t}\right],
$$

where

$$
w_{M S, N-\frac{1}{2}}^{t}=\left(D_{M S} \frac{\Gamma_{N a}}{\Gamma_{M S} \cdot c_{M S, N-\frac{1}{2}}^{t}+\Gamma_{N a} \cdot c_{N a, N-\frac{1}{2}}^{t}} \cdot\left[\frac{c_{N a, N}^{t}-c_{N a, N-1}^{t}}{\Delta z}-\frac{c_{N a, N-\frac{1}{2}}^{t}}{c_{M S, N-\frac{1}{2}}^{t}} \cdot \frac{c_{M S, N}^{t}-c_{M S, N-1}^{t}}{\Delta z}\right]\right),
$$


(A1-14)

Equations (A1-11) and (A1-13) implicitly satisfy the condition of no flux at the upper boundary and lower boundary, respectively. Expressions similar to (A1-11 and A1-12) and (A1-13 and A1-14) are used to compute the concentration of $\mathrm{Na}^{+}$at grid points nearest to the upper and lower boundaries.

\section{A1.3.3 Modeling MSA migration at DIV2010}

Simulating the [MS] record for DIV2010, as described in Sections 2.4.4 and 2.5.2, requires accounting for the variable amplitude of MSA migration along the core. We assume that MSA migration takes place only below a critical depth $z_{\text {crit }}$, which is set equal to $9.1 \mathrm{~m}$ for the DIV2010 core (section 3). At depths shallower than $Z_{\text {crit }}$ migration is thus assumed not to occur due, e.g., to too low ice densities (section 2.4). From the DIV2010 core chronology, we infer the amount of time migration has occurred at each core depth where [MS] has been measured. This time interval is denoted as $\Delta t_{i}$, where subscript $i$ refers to a particular depth level, and calculated from $\Delta t_{i}=a_{i}-a_{\text {crit }}$, where $a_{i}$ is the calendar age at depth level $i$ and $a_{\text {crit }}$ is the calendar age at the critical depth. The model domain extends from $z=$ $9.1 \mathrm{~m}$ to $Z=60.4 \mathrm{~m}$, and the model grid is set up such that each grid point coincides with a depth where [MS $]$ has been measured, i.e., $i=1,2, \ldots, N$, where $i=1$ denotes the shallowest grid point and $i=N$ the deepest grid point.

The migration of MSA is then incorporated as follows in the model. The model is integrated over a time interval equal to $\Delta t_{N}=a_{N}-a_{c r i t} \approx 95$ years, which is the estimated time interval during which migration has affected the deepest sample of DIV2010. At each model iteration $n$, where $n=$ $1,2, \ldots, \Delta t_{N} / \Delta \mathrm{t}$ and $\Delta \mathrm{t} \approx 0.08 \mathrm{yr}$ is the model time step, the integration time $n \Delta \mathrm{t}$ is compared to the migration time $\Delta t_{i}$ at each grid point. If $\Delta t_{i} \leq \Delta t_{N}-n \Delta \mathrm{t} n$, then migration at the $i$ th grid point is inactivated: the effective velocities $w_{M S}$ and $w_{N a}$ are set to 0 , so that $[\mathrm{MS}-]$ and $\left[\mathrm{Na}^{+}\right]$remain unaltered at this point. Conversely, if $\Delta t_{i}>\Delta t_{N}-n \Delta \mathrm{t}$, then migration at the $i$ th grid point is activated: $w_{M S}$ and $w_{N a}$ are calculated according to equations $(\mathrm{A} 1-7 \mathrm{a}, \mathrm{b})$, so that $[\mathrm{MS}]$ and $\left[\mathrm{Na}^{+}\right]$suffer convergence or divergence at this point. Hence, [MS] and $\left[\mathrm{Na}^{+}\right]$at shallow grid points are subjected to transport over a smaller amount of time than $[\mathrm{MS}]$ and $\left[\mathrm{Na}^{+}\right]$at deeper grid points. In Figures A1-5 and A1-6, the activation of the migration process at progressively shallower grid points can be visualized by the variable position of the vertical yellow bar, which separates the region where migration is allowed to take place from the region where migration is not allowed to take place in the model domain. 


\section{A1.3.4 Sensitivity experiments with the RWW Model}

Calculation of a predicted MSA migration time was implemented by creating two idealized and out of phase sinusoidal curves of identical wavelength, $\lambda$, representing an [MS] annual cycle and an $\left[\mathrm{Na}^{+}\right]$ annual cycle. In each test, the model grid comprises the same number of model grid points $(n=101)$, so that truncation errors due to spatial differencing are of comparable magnitude between experiments. The initial profile of [MS $]$ is given by

$$
\left[M S^{-}\right]=a_{M S} \cdot \sin \left(\frac{2 \pi}{\lambda} z\right)+b_{M S}
$$

while the initial profile of $\left[\mathrm{Na}^{+}\right]$was additionally varied by a scalar $\overline{\mathrm{Na}^{+}}$relative to the $\mathrm{MS}^{-}$ concentration,

$$
\left[N a^{+}\right]=\left(\overline{N a^{+}} \cdot \frac{a_{N a}}{b_{N a}}\right) \cdot \sin \left(\frac{2 \pi}{\lambda} z+\pi\right)+\overline{N a^{+}}
$$

In our tests, we considered 17 values of $\overline{\mathrm{Na}^{+}}$between 16 and $400 \mu \mathrm{g} \mathrm{L}{ }^{-1}$, and 19 values of $\lambda$ between 0.1 and $1.0 \mathrm{~m}$, for a total of 323 tests. The coefficients $a_{M S}, b_{M S}, a_{\mathrm{Na}}$, and $b_{\mathrm{Na} a}$ are determined from a least squares fit of equations (A1-15) and (A1-16) to the mean monthly profiles of [MS] and $\left[\mathrm{Na}^{+}\right]$observed in the DIV2010 shallow zone (Fig. 2-8), which yield $a_{M S}=5.1 \mu \mathrm{g} \mathrm{L} \mathrm{L}^{-1}, b_{M S}=6.2 \mu \mathrm{g} \mathrm{L}{ }^{-1}, a_{N a}=15.0 \mu \mathrm{g}$ $\mathrm{L}^{-1}$, and $b_{N a}=39.2 \mu \mathrm{g} \mathrm{L}{ }^{-1}$. As a result, in our tests, the product $\overline{N a^{+}} \cdot \frac{a_{N a}}{b_{N a}}$ ranges from $\sim 9.6$ and 153.3 $\mu g L^{-1}$. 


\section{Appendix 1 Figures}
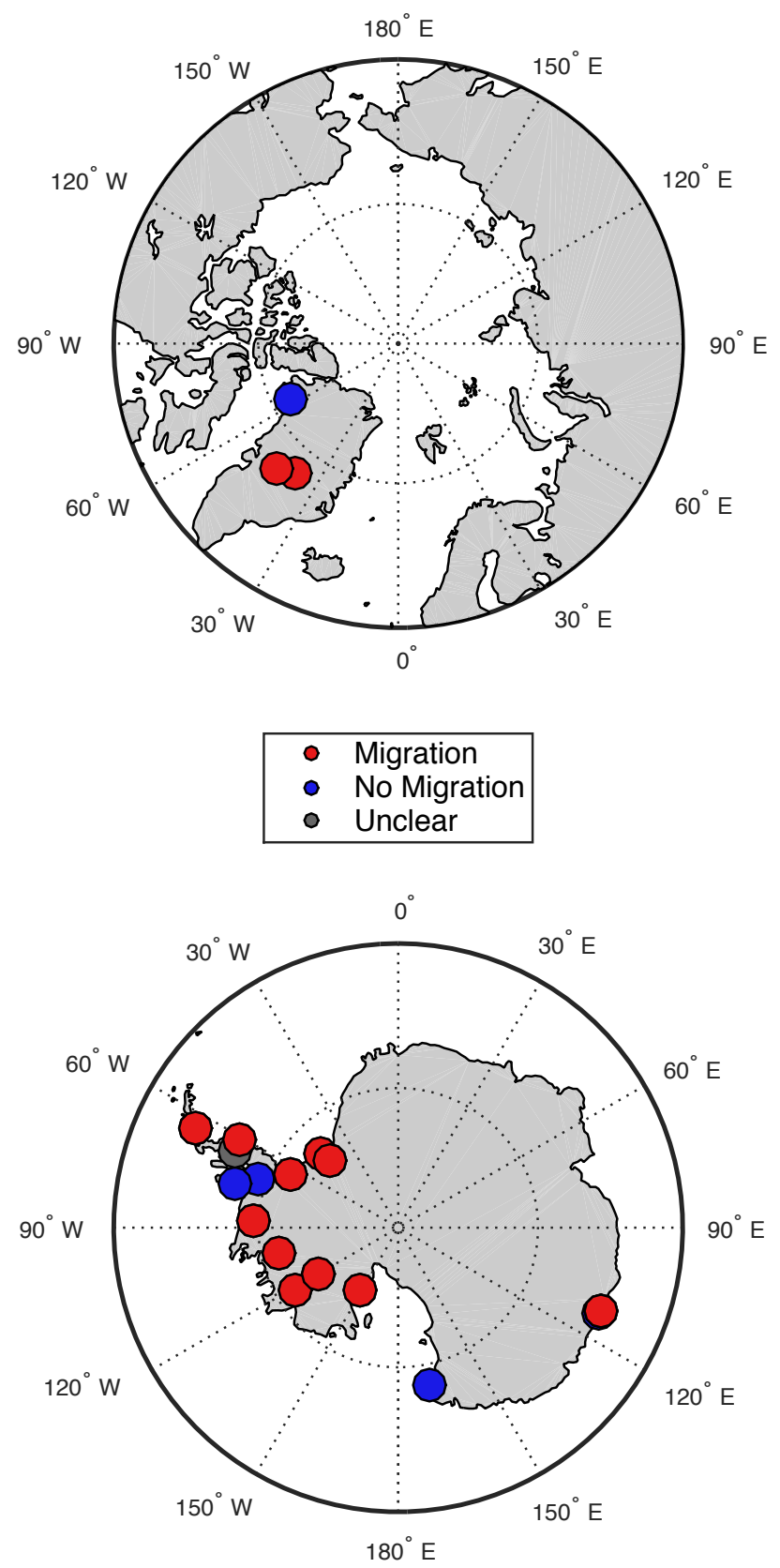

Figure A1-1: Distribution of the 20 sites considered in this study, located in Greenland (top) and Antarctica (bottom). Note that all three Law Dome sites (DSS, DE08, W20k, all at $\sim 66^{\circ} \mathrm{S}, \sim 113^{\circ} \mathrm{E}$ ) are each within $35 \mathrm{~km}$ of each other (Curran et al., 2002) and that only W20k (where MSA migration was observed) is visible in the map. Not visible are Law Dome DSS, where MSA migration was found to be unclear, and DE08, where MSA migration was not found. 


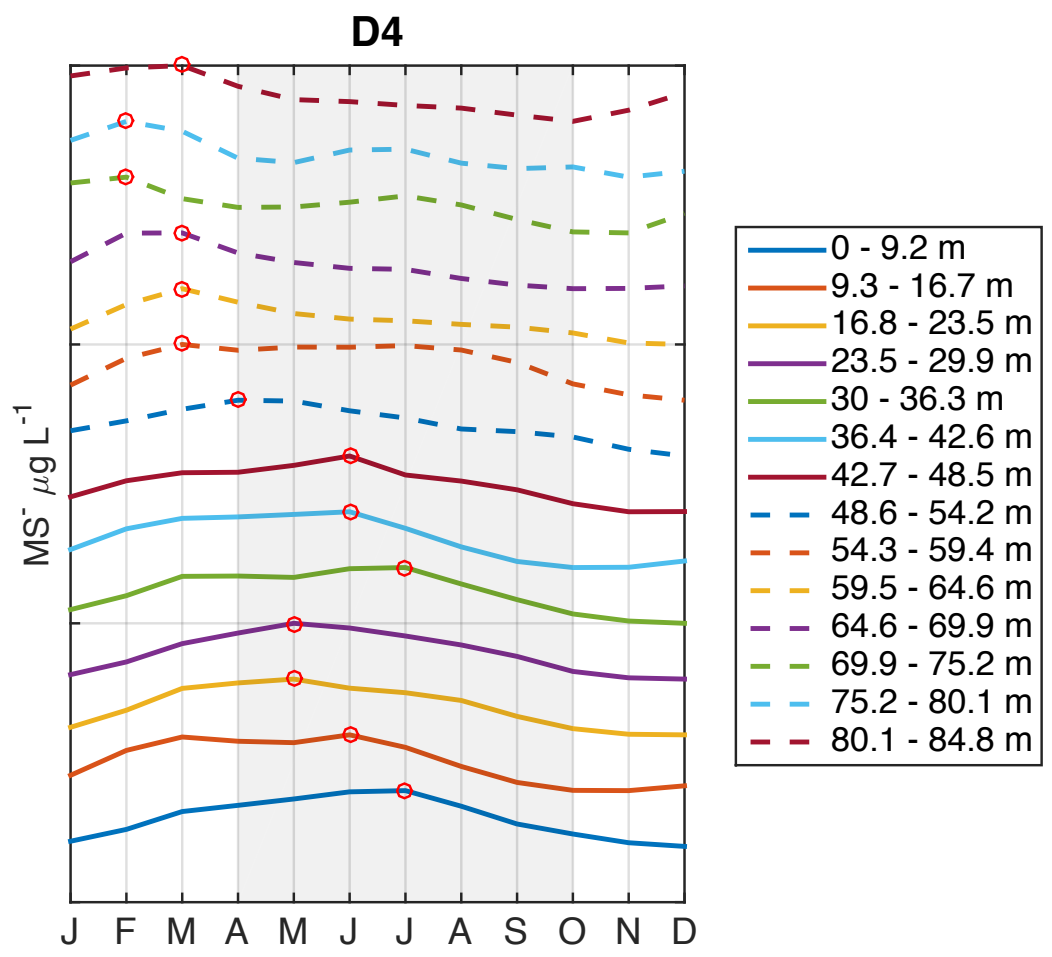

Figure A1-2: Monthly averages of [MS-] for different decades (corresponding to different depth intervals in the core and different colors in the figure) at the D4 core site, Greenland. The averages are normalized so as to range from 0 to 1 and plotted on top of each other for better visualization. The shallowest depth interval from 0 to 9.2 m represents the decade from Dec-Jan 2003 to Dec-Jan 1994. All other depth intervals represent older and contiguous decades. The red circle on each curve denotes the month of the annual maximum [MS] for the corresponding decade. The grey shaded region represents the \pm 3 -month range of the "true" month of annual maximum [MS-], taken to be July at D4 (the month of annual maximum [MS-] for the 0-9.2 $\mathrm{m}$ interval). At D4, $z_{f o}$ is estimated to $54.3-59.4 \mathrm{~m}$, the shallowest depth range where the annual [MS-] maximum peaks in a month outside of the shaded region. 


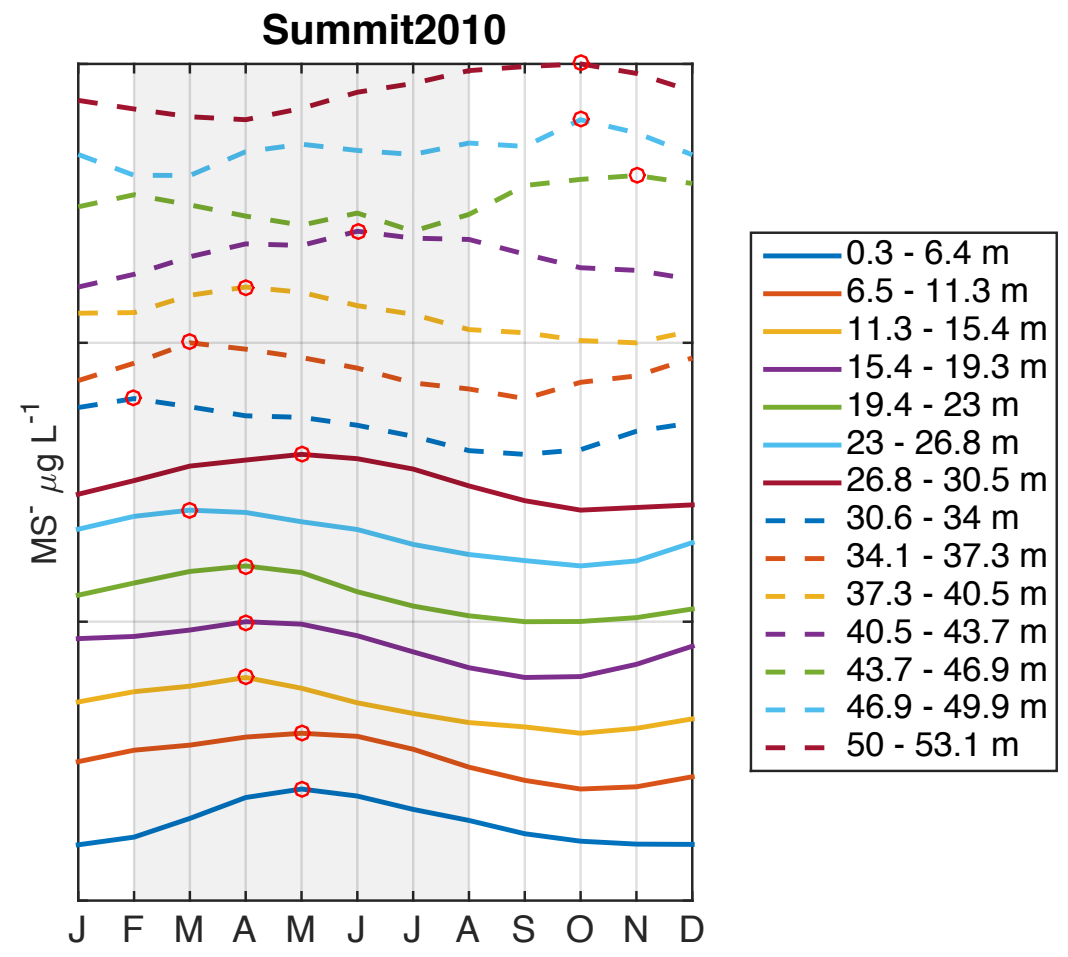

Figure A1-3: Same as Fig. A1-2 but for the Summit2010 ice core, Greenland. The shallowest depth interval (0.3-6.4 m) represents the decade from Dec-Jan 2009 to Dec-Jan 2000. The "true" month of annual maximum [MS-] is estimated to be May (the month of annual maximum [MS] for the 0.3-6.4 m interval). At Summit2010, $Z_{f o}$ is estimated to $43.7-46.9 \mathrm{~m}$. 


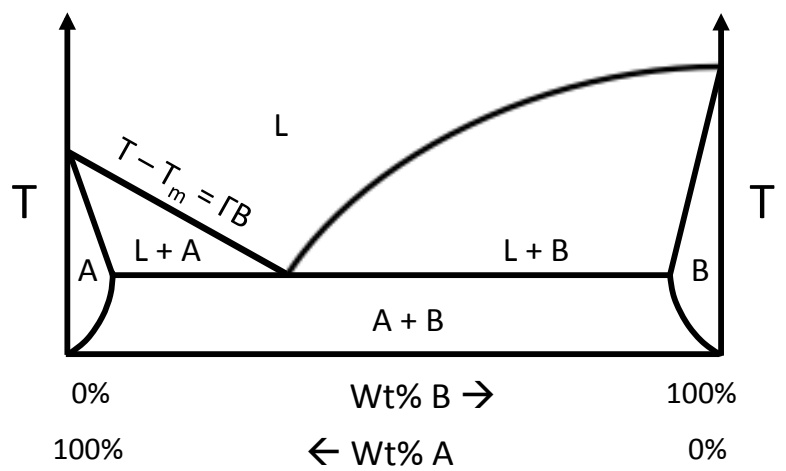

Figure A1-4: Schematic of a phase diagram for a hypothetical binary mixture. The dependence of supercooling, $T$ - $T_{m}$, on solute concentration $c$ is approximated by $T-T_{\mathrm{m}}=\Gamma c$, where $\Gamma$, assumed constant, is the slope of the liquidus curve. 


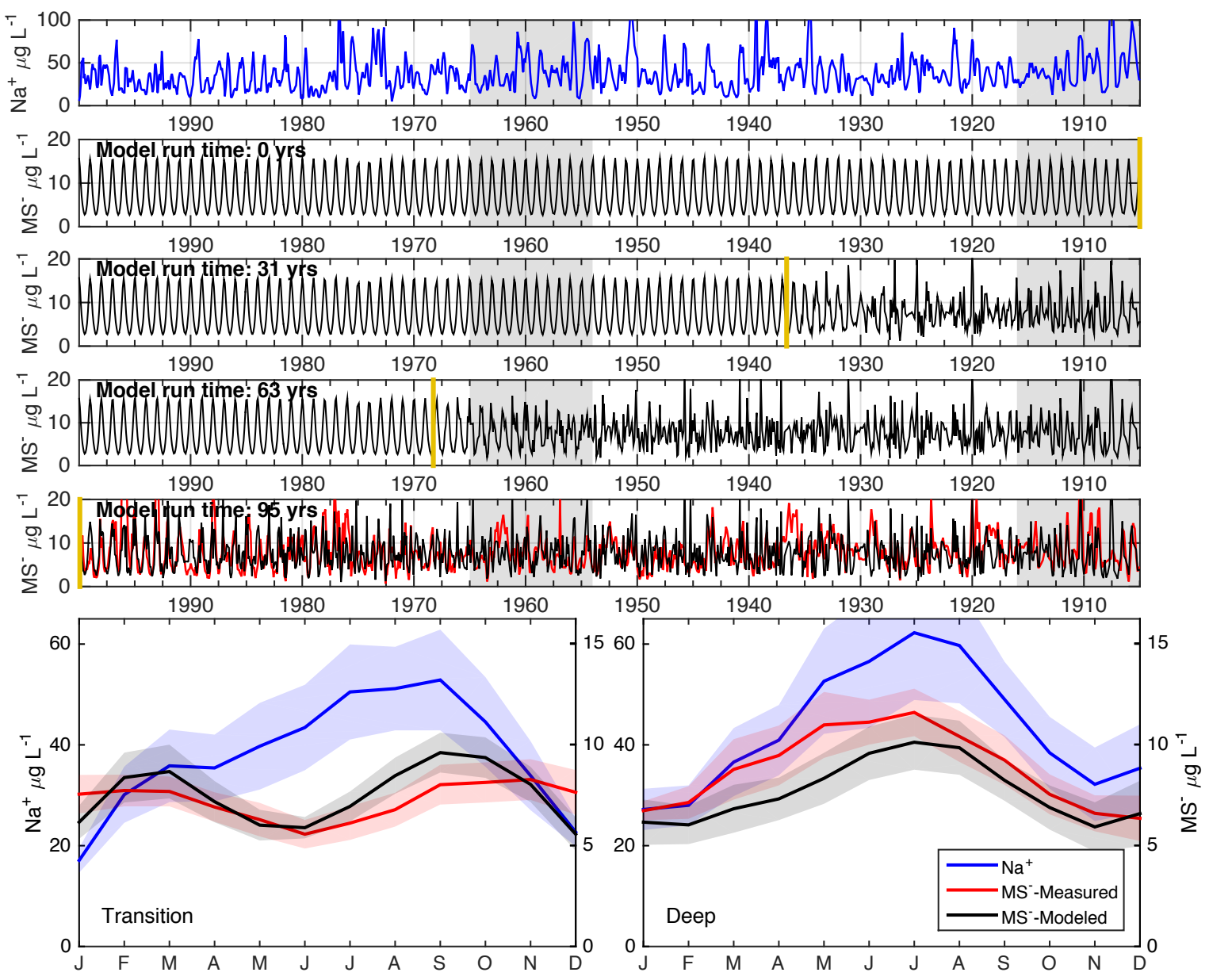

Figure A1-5: Profiles $\left[\mathrm{Na}^{+}\right]$and [MS-] measured along the DIV2010 core, and profiles of [MS-] simulated with the linearized migration model with $D_{M S}=10^{-11} \mathrm{~m}^{2} \mathrm{~s}^{-1}$. Top panel: measured $\left[\mathrm{Na}^{+}\right]$profile (3-pt running average). The shaded bands depict the transition zone (left band) and the deep zone (right band). Middle panels (4 panels): simulated [MS-] profiles at different times $(0,31,63,95 \mathrm{yr})$. The shaded bands depict the transition zone (left band) and the deep zone (right band) in DIV2010. The yellow bar separates the region unaffected by migration on the left from the region affected by migration on the right. In the bottommost of the middle panels, the red (black) line shows the measured (simulated) [MS-] profile. Bottom panels (2 panels): monthly mean values of $\left[\mathrm{Na}^{+}\right]$and [MS] measured in DIV2010, and monthly mean values of [MS] simulated by the model, in the transition zone (left panel) and the deep zone (right panel). In both panels, the shaded regions indicate \pm 1 standard error of the mean. 


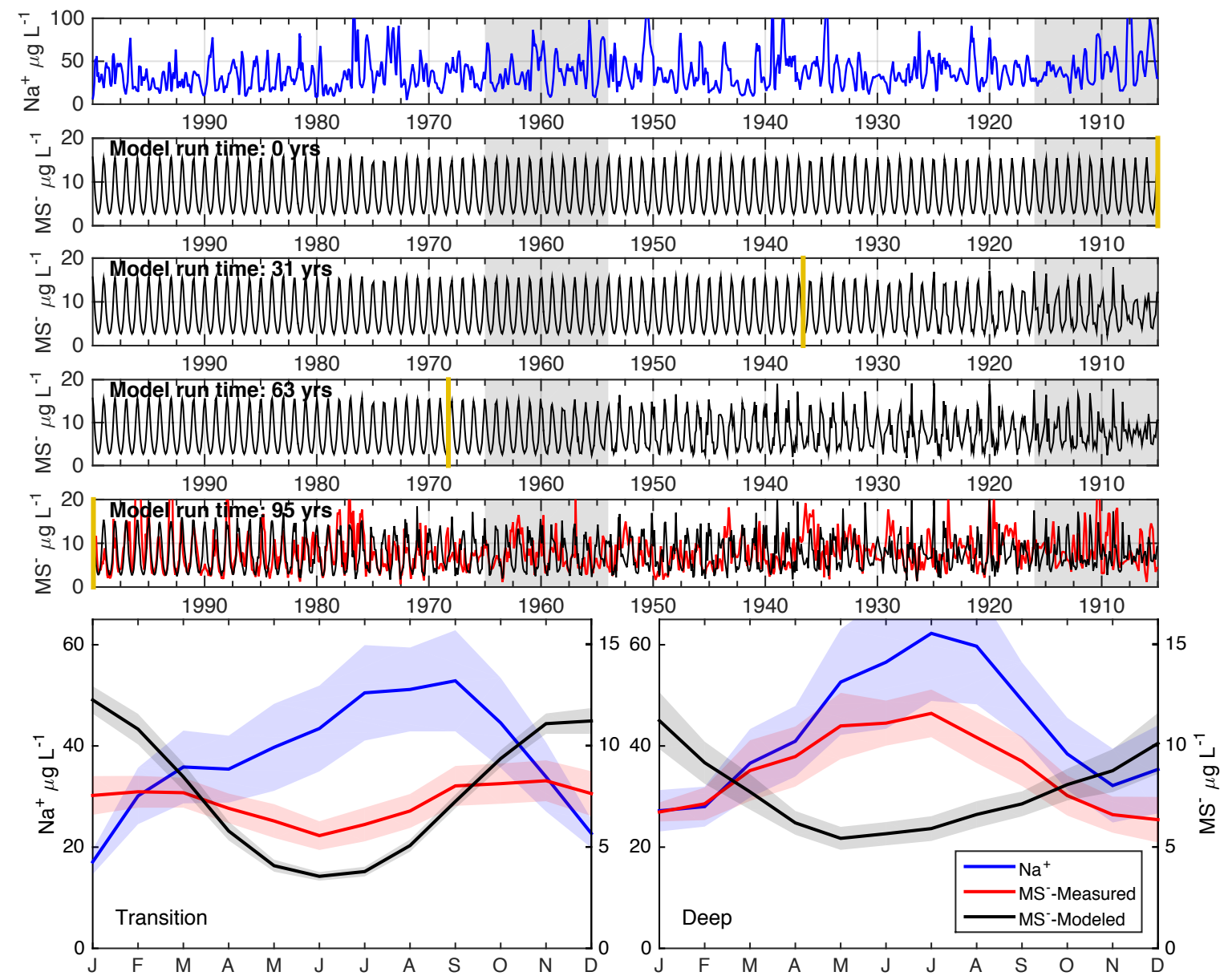

Figure A1-6: Same as Figure A1-5, but for $D_{M S}=10^{-12} \mathrm{~m}^{2} \mathrm{~s}^{-1}$. 


\section{Appendix 1 Tables}

Table A1-1. Notes and references for defining $z_{f o}$.

\begin{tabular}{|c|c|c|c|}
\hline Core & $z_{f o}(\mathrm{~m})$ & Notes on defining $z_{f o}$ & Citation \\
\hline Dolleman Island (1) & 10 & $\begin{array}{l}\text { Redefined in this study. Our estimate appears to differ slightly from Pasteur } \\
\text { and Mulvaney (2000), who suggested a depth of } 1.9 \mathrm{~m} \text { w.eq (corresponding to } \\
\text { the annual cycle for } 1981 ; 1.9 \mathrm{~m} \text { w. eq. also corresponds to an estimated depth } \\
\text { of } \sim 6.5-7 \mathrm{~m} \text { by peak matching with Mulvaney et al.'s(1992) Figure } 3 \mathrm{a} \text { ). We } \\
\text { find that Pasteur and Mulvaney's (2000) estimate of } z_{f o}=1.9 \mathrm{~m} \text { w.eq. (1981) } \\
\text { appears to an anomalous/inconsistent case, as annual [MS-] maxima in the } \\
\text { neighboring } \pm 2-3 \text { years consistently occur in summer layers. Our contention } \\
\text { is verified by the 5-year monthly-averaged values binned for the years } 1979- \\
\text { 1984, shown in Figure } 9 \text { of Pasteur and Mulvaney (2000), which shows the } \\
\text { monthly mean maximum of [MS-] clearly in summer months. Based on the } \\
\text { binned five-year monthly mean [MS-] profiles for } 1969-1974 \text { also shown in } \\
\text { Figure } 9 \text { of Pasteur and Mulvaney, } 2000 \text {, as well as visual verification from the } \\
\text { depth }+ \text { time-series provided in Figure } 8 \text { of Pasteur and Mulvaney, } 2000 \text {, we } \\
\text { suggest that at depths deeper than } \sim 5 \text { m w.eq. }(\sim 10 \mathrm{~m} \text { via estimates from } \\
\text { Mulvaney et al. (2000), or } 1973), \text { the maximum [MS-] is consistently in the } \\
\text { winter layer. As such an estimate of } z_{f o}=\sim 10 \mathrm{~m} \text { is more consistent with the } \\
\text { definition of } z_{f o} \text { provided in } \mathrm{S} 1 \text {. }\end{array}$ & $\begin{array}{l}\text { Mulvaney et } \\
\text { al., } 1992 \text {; } \\
\text { Pasteur and } \\
\text { Mulvaney } \\
2000\end{array}$ \\
\hline Dolleman Island (2) & $\begin{array}{l}8.5 \mathrm{~m} \\
\text { w.eq. }\end{array}$ & $\begin{array}{l}\text { Redefined in this study. Our estimate differs from Pasteur and Mulvaney's } \\
\text { (2000) estimate of } 5.4 \mathrm{~m} \text { w.eq. (1981), where the [MS-] maximum in the } \\
\text { neighboring 2-3 annual layers remains in the summer layers (additionally, we } \\
\text { find that the local [MS-] maxima for the annual layer at } 5.4 \mathrm{~m} \text { w. eq. also } \\
\text { remains in the summer layer, as visually verifiable by the time/depth-series } \\
\text { provided in Figure } 8 \text { of Pasteur and Mulvaney, 2000). This contention is } \\
\text { further supported by analysis of the binned five-year monthly mean [MS-] for } \\
\text { the period } 1979-1984 \text { (containing the } 5.4 \mathrm{~m} \text { w.eq. annual cycle), as provided in } \\
\text { Figure } 9 \text { of Pasteur and Mulvaney, } 2000 \text {, which clearly shows the } 5 \text {-yr mean } \\
\text { annual [MS-] maxima in summer layers. On the other hand, at depths deeper } \\
\text { than } \sim 8.5 \mathrm{~m} \text { w.eq. (corresponding to the annual cycle for 1973), it appears } \\
\text { that [MS-] consistently shows its annual maximum in the winter layer, as } \\
\text { supported by the 5-year binned monthly [MS-] averages for the period 1969- } \\
1974 \text { of Figure } 8 \text {. }\end{array}$ & $\begin{array}{c}\text { Pasteur and } \\
\text { Mulvaney, } \\
2000\end{array}$ \\
\hline $\begin{array}{l}\text { Berkner Island } \\
\text { North (1) }\end{array}$ & $\begin{array}{l}9(4.2 \mathrm{~m} \\
\text { w.eq.) }\end{array}$ & $\begin{array}{l}\text { Estimate based on Figure } 2 \text { of Wagenbach et al., } 1994 \text { (available in depth units } \\
\text { of meters of water equivalent), and supporting data available online (where } \\
\text { data is available in depth units of meters): } \\
\text { https:// doi.pangaea.de/10.1594/PANGAEA.548653. At depths greater than } \\
9 \mathrm{~m} \text { ( } 4.2 \text { m w.eq.; Fig } 2 \text { of Wagenbach et al., 1994), MSA annual maxima } \\
\text { clearly switch from being consistently in summer to consistently in winter. }\end{array}$ & $\begin{array}{l}\text { Wagenbach } \\
\text { et al., } 1994\end{array}$ \\
\hline $\begin{array}{l}\text { Berkner Island } \\
\quad \text { South }\end{array}$ & $\begin{array}{l}6(2.8 \mathrm{~m} \\
\text { w.eq. })\end{array}$ & $\begin{array}{l}\text { Estimate based on Figure } 2 \text { of Wagenbach et al., } 1994 \text { (where data is available } \\
\text { in depth units of meters of water equivalent), and supporting data available } \\
\text { online (available in depth units of meters): } \\
\text { https://doi.pangaea.de/10.1594/PANGAEA.548654. At depths greater than } \\
6 \mathrm{~m}(2.8 \mathrm{~m} \text { w.eq.; Fig } 2 \text { of Wagenbach et al., 1994), MSA annual maxima } \\
\text { clearly switch from being consistently in summer to consistently in winter. }\end{array}$ & $\begin{array}{l}\text { Wagenbach } \\
\text { et al., } 1994\end{array}$ \\
\hline DIV2010 & $26 \pm 3$ & $\begin{array}{l}\text { Defined in this study; although the phasing of maximum annual [MS-] at } \\
\text { DIV2010 appears to be progressive (Fig. } 6 \text { of this study), a conspicuous and } \\
\text { distinctive shift in the seasonal integrity of the annual [MS-] cycle, and a }\end{array}$ & $\begin{array}{l}\text { This study; } \\
\text { see also }\end{array}$ \\
\hline
\end{tabular}




\begin{tabular}{|c|c|c|c|}
\hline & & $\begin{array}{l}\text { corresponding shift towards winter phasing of [MS-] first becomes prominent } \\
\text { at } \sim 26+/-3 \mathrm{~m} \text { depth, as also noted by Criscitiello, } 2014 \text {. }\end{array}$ & $\begin{array}{l}\text { Criscitiello, } \\
2014\end{array}$ \\
\hline THW2010 & $17 \pm 3$ & $\begin{array}{c}\text { Defined by Criscitiello, 2014; below } \sim 17 \mathrm{~m},[\mathrm{MS} \text { ] peaks near-consistently in } \\
\text { winter layers. }\end{array}$ & $\begin{array}{l}\text { Criscitiello, } \\
2014\end{array}$ \\
\hline Bruce Plateau & 395 & $\begin{array}{l}\text { As reported in the supplementary material of Porter et al., 2016. [MS-] } \\
\text { migration onset appears first apparent at } \sim 380 \mathrm{~m} \text {, and prominent winter-layer } \\
\text { maxima occur by depths of } 395 \mathrm{~m} \text {. }\end{array}$ & $\begin{array}{l}\text { Porter et al., } \\
2016\end{array}$ \\
\hline NBY-2 (Byrd) & 2.6 & As reported by Langway et al., 1994 & $\begin{array}{l}\text { Langway et } \\
\text { al., } 1994\end{array}$ \\
\hline 94-1 Siple Dome & 2 & As reported by Kreutz et al., 1998; see Kreutz et al., Figures 2 and 3 & $\begin{array}{l}\text { Kreutz et al., } \\
1998\end{array}$ \\
\hline $\begin{array}{l}\text { D235: Filchner } \\
\text { Ronne Ice Shelf }\end{array}$ & $\begin{array}{c}1.8 \mathrm{~m} \\
\text { w.eq. }(3- \\
4 \mathrm{~m} ; \mu= \\
3.5)\end{array}$ & $\begin{array}{c}\text { As reported (in the abstract) of Minikin et al., 1994. Can be visually verified in } \\
\text { Fig. } 2 \text { of Minikin et al., 1994, where below } 1.8 \mathrm{~m} \text { w.eq. [MS-] is consistently } \\
\text { peaking in winter layers. }\end{array}$ & $\begin{array}{l}\text { Minikin et al., } \\
1994\end{array}$ \\
\hline Ferrigno & 25 & $\begin{array}{l}\text { As reported by Thomas and Abram, } 2016 \text { (see also Thomas and Abram, } 2016 \\
\text { Supporting Information) }\end{array}$ & $\begin{array}{l}\text { Thomas and } \\
\text { Abram, } 2016\end{array}$ \\
\hline Summit2010 & $\begin{array}{c}43.7- \\
46.9(\mu= \\
45.3)\end{array}$ & Defined in this study; See section S1 and Figure SF3. & $\begin{array}{l}\text { Maselli et al., } \\
2017 \text { and J. } \\
\text { McConnell } \\
\text { (DRI) pers. } \\
\text { comm. }\end{array}$ \\
\hline D4 & $\begin{array}{c}54.3- \\
59.4(\mu= \\
56.9)\end{array}$ & Defined in this study. See section S1 and Figure SF2. & $\begin{array}{l}\text { J. McConnell } \\
\text { (DRI) pers. } \\
\text { comm. }\end{array}$ \\
\hline
\end{tabular}




\section{Appendix 1 References}

Criscitiello, A. S (2014). Amundsen Sea sea-ice variability, atmospheric circulation, and spatial variations in snow isotopic composition from new West Antarctic firn cores. Ph.D. Thesis. The Massachusetts Institute of Technology - Woods Hole Oceanographic Institution Joint Program in Oceanography/Applied Science and Engineering.

Kreutz, K. J., Mayewski, P. A., Whitlow, S. I., and Twickler, M. S., Limited migration of soluble ionic species in a Siple Dome, Antarctica, ice core, Ann. Glaciol., 27, 371-377, 1998.

Langway, C.C., Jr., Osada, K., Clausen, H. B., Hammer, C.U, Shoji, H., and Mitani, A (1994). New chemical stratigraphy over the last millennium for Byrd Station, Antarctica, Tellus, 46B, 40-51.

Maselli, O. J., Chellman, N. J., Grieman, M., Layman, L., McConnell, J. R., Pasteris, D., Rhodes, R. H., Saltzman, E., and Sigl, M. (2017). Sea ice and pollution-modulated changes in Greenland ice core methanesulfonate and bromine, Clim. Past., 13, 39-59, doi:10.5194/cp-2016-49

Minikin, A., Wagenbach, D., Graf, W., and Kipfstuhl, J. (1994). Spatial and seasonal variations of the snow chemistry at the Filchner-Ronne Ice Shelf, Antarctica, Annals of. Glac. 20, 283-290.

Mulvaney, R., Pasteur, E. C., Peel, D. A., Saltzman, E. S., and Whung, P. Y. (1992). The ratio of MSA to nonsea-salt sulphate in Antarctic Peninsula ice cores, Tellus B, 44(4), doi:10.3402/tellusb.v44i4.15457

Pasteur, E. C., and Mulvaney, R. (2000). Migration of methane sulphonate in Antarctic firn and ice, J. Geophys. Res.,105, 11525-11534, doi:10.1029/2000JD900006.

Porter, S. E., Parkinson, C. L., and Mosley-Thompson, E. (2016). Bellinghausen Sea ice extent recorded in an Antarctic Peninsula ice core, J. Geophys. Res. Atmos., 121, 13886-13900, doi:10.1002/2016JD025626..

Thomas, E. R., and Abram, N. (2016). Ice core reconstruction of sea ice change in the Amundsen-Ross Seas since 1702 AD, Geophys. Res. Lett., doi:10.1002/2016GL068130.

Wagenbach, D., Graf, W., Minikin, A., Trefzer, U., Kipestuhl, J., Oerter, H., and Blindow, N. (1994). Reconnaissance of chemical and isotopic firn properties on top of Berkner Island, Antarctica, Annals of Glaciology, 20, 307-312. 


\section{Appendix 2: Supplementary to Chapter 3}

\section{A2.1 Marine airmass source and covariation in Greenland [MSA] records}

\section{A2.1.1 Site-wise marine airmass source attribution}

A notable degree of low-frequency covariability is observed amongst preexisting methanesulfonic acid-concentration ([MSA]) records from Greenland (Fig. S3-4). Prior authors have independently identified a c. 150-200 year decline in [MSA] in the $19^{\text {th }}-20^{\text {th }}$ centuries across several ice core [MSA] records (Whung et al., 1994; Legrand et al., 1997; Maselli et al., 2017), though its attribution has thus far remained uncertain. Due to i) the particularly short atmospheric residence time of MSA ( $~ 7$ days, a function of the species' high hygroscopicity and susceptibility to particle scavenging; Hezel et al., 2011), and ii) known differences in the primary moisture source of airmasses arriving to Greenland (Kahl et al., 1997; Schuenemann and Cassano, 2010), broad covariation of [MSA] across Greenland is not necessarily expected (e.g., Abram et al., 2013).

In order to better understand the physical basis behind the observed [MSA] covariation, we analyzed summertime (JJA) trajectory patterns of atmospheric air parcels arriving at each ice core site in our Greenland array using the Hybrid Single-Particle Lagrangian Integrated Trajectory model (HYSPLIT), version 4.9 (Stein et al., 2015). We assumed the primary source region of Greenlandicdeposited MSA to be commensurate with the most-probable summertime (JJA) trajectory path(s) taken by low-lying, oceanic (i.e., existing within the marine boundary layer) air parcels traveling en route to each ice core site. Due to positioning errors of individual trajectories, which increase with distance from the particle receptor $\operatorname{sites}^{46}$, we adopted a probabilistic approach here, in which a largenumber of 7-day back-trajectories were computed (one particle released each day at 12:00:00 PM from AD 1948-2013) for each site and integrated into probabilistic marine airmass transport density maps. These maps, normalized on a $0-1$ relative scale, provide an index of the relative probability $(0-1=$ least to most probable, respectively) that a given atmospheric particle would travel over a given oceanic grid box at a given time. Using information of atmospheric height (above sea level) recorded for each particle, we similarly computed mean trajectory elevations for each latitude-longitude bin.

The JJA marine-airmass transport density maps for each site can be viewed in Fig. S3-5.

Qualitatively, the sites appear to lie along a spectrum, whereby sites situated more southerly in Greenland receive predominantly easterly- to southeasterly-sourced (the Irminger Sea and Subarctic Gyre (SPG) regions) trajectories, while sites situated further north on the GrIS exhibit a predominantly 
westerly-sourced trajectory pattern.

To more-objectively differentiate the sites by their varying airmass transport densities (Fig. S34), we performed factor analysis with varimax rotation (Richman, 1986) on each site's airmass transport density field under the a priori assumption of two underlying airmass source regions, or "factors". The two inferred factors, as qualitatively identified above, are assumed to represent either 1) the Irminger Sea/SPG or 2) Baffin Bay/Labrador Sea as primary airmass sources. The results of the experiment are summarized by analysis of the squared loadings, or communalities, shown in Fig. 3-1b, which represent the fraction of the variance explained by each factor (columns) at each site (rows). For $11 / 12$ sites, over $90 \%$ of the variance is explained, indicating our a priori assumption of retaining two primary MSA source regions to be sufficient (the remaining site, $20 \mathrm{D}$, has $>80 \%$ of its variability explained). As expected, the factor analysis correctly identifies the most southerly GrIS sites (20D and GC; Fig. S3-4) as having the highest Factor \#1 scores, while the most northerly GrIS sites (e.g., NGTB20, NGTB26, TUNU) score highest on the Factor \#2 loading. Grouping the sites as either Factor \#1 or \#2 sites based on the highest communality score achieved by each site indicates the seven most-southerly GrIS sites - 20D, GC, D4, Summit2010, GRIP93a, NGRIP, and B16 - are primarily derived from the Irminger Sea/SPG, while airmasses arriving at the five most-northerly GrIS sites - NGTB18, NGTB20, NGTB21, NGTB26, and TUNU - may be of predominantly Baffin Bay/Labrador Sea origin (notwithstanding notable similarities in all sites' median atmospheric elevation grids; Fig. S3-5).

Importantly, analysis of the Factor \#1 and Factor \#2 communalities also indicate that airmass sources across GrIS sites are not wholly independent, but instead represent variable mixtures of easterly (Factor 1) vs. westerly (Factor 2) sourced airmasses. As summarized by Figure 3-1b, a Factor \#1 score of 1 roughly represents $100 \%$ of airmass trajectories sourced from the Irminger Sea, while a Factor \#2 score of 1 roughly indicates 100\% of airmass trajectories sourced from Baffin Bay/Labrador Sea. Since no sites displayed a communality score as high as 1 , this - in combination with similarities found between the median particle elevation maps - suggests a common [MSA] signal should be embedded within all Greenlandic sites. In the following section, we explore this prediction more explicitly by analyzing the [MSA] records produced for each site.

\section{A2.1.2 Exploratory principal component analysis of Greenland [MSA] records}

To explore the degree of similarity amongst the Factor \#1 and Factor \#2 sites' [MSA] records, we plot in Fig. S3-6 the unit-variance standardized and mean-centered [MSA] time series (relative to A.D. 
1821- 1985) for all 12 sites over the time period A.D. 1767 - 2013, the oldest year still containing $\geq 75 \%$ (at least 9/12) of the original records. If composited into either Factor \#1 or Factor \#2 sites, remarkably high coherence, even at interannual-scales, is found in the two time series $\left(r^{2}=0.40, p<\right.$ 0.0001; Ebisuzaki, 1997). A notable feature amongst records from both airmass source regions is the conspicuous $\sim 150-200$ year decline in [MSA], beginning at c. A.D. 1800-1850, and occurring into the late $20^{\text {th }}$ century.

To better extract mode(s) of covariability amongst individual records, we performed an exploratory principal component analysis (PCA) using records from both airmass source regions. PCA is a commonly used Eigen decomposition technique, which allows one to linearly re-project a dataset as a new set of basis vectors, whereby each new projection represents a mutually-orthogonal representation of the former while representing a progressively smaller variance fraction of the original dataset (Storch and Zwiers, 1999). We again limited the analysis from the most-recently available data (i.e., A.D. 2013) until A.D. 1767. As some records have missing data at their extremities, a statistical data-infilling procedure was used for the PCA analysis (Beckers and Rixon, 2003) as elaborated in the Methods portion of Chapter 3.

Results of the PCA for the Factor \#1 and Factor \#2 [MSA] records, revealed a slightly improved degree of similarity (not shown; $r^{2}=0.43, p<0.0001$; Ebisuzaki, 1997) amongst each factor's first principal components (PC1), which capture $\sim 50$ and 33\% of the variability, respectively. The significant correlation found between the two PC1's is also impervious to linear detrending $(p<$ 0.001; Ebisuzaki, 1997), underscoring the high degree of interannual-decadal scale covariability captured by the Eigen decomposition. Conversely, no tailing modes of [MSA]-variability (including permutations therein) were significantly correlated, suggesting these modes represent locally confined bioproductivity signals, or "noise", amongst the records. The analysis provides robust evidence that PC1 successfully captures a common mode of Greenlandic-wide MSA variability, as independently predicted by the joint distributions of each Factor's airmass transport probability densities. As such, using the combined Greenlandic PC1 signal (capturing a median/mode of $\sim 44 \%$ of the variability amongst the 12 records) we consider the Greenlandic sites as a single "MSA receptor" (Fig. 3-2).

\section{A2.1.3 Spatiotemporal stability of marine-airmass trajectories \& Arctic influence}

While recent reconstructions have suggested more frequent and intense intrusions of upperatmosphere Arctic "jet stream" meanders into the mid-latitudes since the mid 1960's (e.g., Trouet et al., 2018), current evidence does not suggest such changes have had a discernable effect on the 
background state of subarctic Atlantic-derived bioaerosol deposition over the GrIS during our 250year study period. We explored this argument explicitly over the period AD 1948 to 2013 by systematically cataloguing the annual percentage of hourly oceanic trajectory-endpoints situated at latitudes further north than each ice core site's location. We found no sites showing long-term trends in northern-derived trajectories significantly different than zero $(p<0.05)$, nor evidence of shifting intensities in Arctic-derived airmasses, despite the existence of multidecadal trends in GrIS-[MSA] over the same time period. More broadly, our results underscore prior studies that have analyzed the source of precipitating Greenland airmasses in equable (Sodemann et al., 2008; Schüpbach et al., 2018), as well as substantially varied, background climate states (Rhines and Huybers, 2014) in that each show consistency in the North Atlantic as a stable source of marine aerosols and moisture to Greenland.

\section{A2.2 Comparison of data infilling methodologies for [MSA]-PC1 computation}

Prior to computing the PCA of the 12 Greenland [MSA] records over the period A.D. 1767-2013, multiple records required data infilling at their extremities. The method for data infilling used is described at length in the Methods portion of the main text. Here, we compare two additional methods for data infilling in order to test the veracity of [MSA]-PC1: 1) a Probabilistic PCA ("PPCA") algorithm is tested, which relies on the expectation maximization (EM) algorithm (Dempster et al., 1977), as well as 2) a nested PCA-compositing approach, a hybrid methodology incorporating the EOF-based imputation algorithm (Beckers and Rixon, 2003) discussed in the main text.

We briefly describe the steps taken in applying the two methodologies for computation of [MSA]-PC1 and its uncertainty:

PPCA: Details on the PPCA algorithm (including its derivation and technical considerations for implementation) are described at length in multiple previous studies (Roweis, 2004). In general, PPCA can be viewed as a probabilistic extension of classical PCA, one that iteratively seeks the principal $q$ axes of an observed $d$-dimensional dataset (where $q<d$ ) that maximizes variance within a projected subspace, by explicitly incorporating maximum likelihood estimates of an isotropic (Gaussian) error model (Tipping and Bishop, 1999). We take advantage of the MATLABTM function "ppca.m" (available since R2013a in the Statistics and Machine Learning Toolbox) for implementation of the PPCA algorithm. As described in the Methods, we use a PCA-bootstrap routine $(n=10,000$ realizations of [MSA]-PC1 based on random sampling with replacement of the 12 [MSA] records; Babamoradi et al., 2013) to estimate confidence limits from the PPCA-derived [MSA]-PC1 signal. 
Nested EOF: The nested PCA approach combines classical PCA, and the EOF data infilling routine. Specifically, we take an approach identical to that described in the main text for the imputation of missing values (Beckers and Rixon, 2003) since A.D. 1821, the oldest year represented by all 12 records (as such, the infilled data represents the leading modes of variance for the period A.D. 1821-2013). Following infilling of missing values (for which $m=1,000$ realizations were conducted, see Methods), we conducted PCA analysis within a nested loop, in which for each nest a PCA was conducted using a successively smaller number of records, based on temporal availability of the records. Following computation of the principal components in each nest, each PC1 was checked for qualitative and statistical consistency during periods of common overlap with the former nest's PC1. Provided consistency, the PC1 components were then spliced together. In total, our criterion of $>75 \%$ record retention for computation of [MSA]-PC1 required only 4 nests to be computed. We again use the PCA-bootstrap routine (random sampling with replacement of $n$ [MSA] records, where $n=12,11,10$, and 9 for successive nests; Babamoradi et al., 2013) for confidence level estimation.

All three methods for PCA with missing data are essentially identical $(r>0.99)$, although PPCA generally tends to produce slightly more conservative uncertainty estimates (not shown). While we ultimately chose to use the EOF-based infilling routine (Beckers and Rixon, 2003) for its slightly more transparent methodology and interpretation (relying, at its core, only on fundamental concepts of linear algebra), conclusions of the study do not appear overly sensitive to which PCA-method is used in calculating [MSA]-PC1.

\section{A2.3 Satellite-derived net primary productivity (NPP) and temporal trends (A.D. 1998-2016)}

In this section, we provide a brief overview, including a model- and satellite-based inter-comparison, of NPP trends in the subarctic Atlantic. NPP is the rate of photosynthetic derived carbon fixation minus the rate of (bioavailable) carbon respiration by autotrophic communities. It has been estimated using satellite observations ( $\sim 8$ day reoccurring) for nearly $\sim 2$ decades, though is by itself not a property that can be measured directly from satellite platforms. Rather, estimates of NPP are based on empirically derived algorithms incorporating satellite-retrieved estimates of ocean physical properties such as (albeit not necessarily including or limited to) temperature, color (reflected wavelength), and (or) incident (photosynthetically-active) radiation.

We compared NPP using output from two independent algorithms: i) the (standard) Vertically Generalized Production Model (VGPM, Berhenfeld et al., 1997), and ii) the Carbon-based Production 
Model (CbPM; Westberry et al., 2008). Both products include overlapping estimates of (monthlycontiguous) NPP estimates (SeaWiFS: Oct 1997 - Dec 2007; MODIS-Aqua: Jul 2002 - Dec 2017), and are available at mean-monthly $1 / 6^{\circ} \times 1 / 6^{\circ}$ gridded resolution. Models i) and ii), and variants therein, are among the most commonly used models of NPP (Berhenfeld et al., 1997; Carr et al., 2006). The VGPM model is primarily chlorophyll- $\alpha$ based and temperature dependent (parameterization of photosynthetic efficiency with sea-surface temperature based on a polynomial relationship (Behrenfeld et al., 1997); for a comparison of VGPM variants incorporating different parameterizations, see Carr et al., 2006). Model ii) represents a complimentary, chlorophyllindependent description of NPP. The CbPM relates satellite-retrieved particle back-scattering variations to planktonic biomass concentration, which is in turn related to planktonic growth rate (i.e., NPP) via chlorophyll-carbon (planktonic biomass) ratios (Westberry et al., 2008). More details on the intercomparison of the models, and additional references therein, can be found linked via the URL in Table A2-3, or in the supplementary of Behrenfeld et al. (2006).

We assessed trends in subarctic Atlantic $\left(50-65^{\circ} \mathrm{N}, 60-10^{\circ} \mathrm{W}\right) \mathrm{NPP}$ using both models (VGPM and CbPM) and satellite sensors (SeaWiFS and MODIS-Aqua). The results are encapsulated in Fig. S3-1. All models and satellite sensors show peak subarctic Atlantic productivity occurring during the summer months, Jun-Aug; note that partial polar darkness occurs over the subarctic Atlantic during the months Nov-Dec-Jan-Feb, which results in underestimates of NPP during those months. Inconsistencies between MODIS and SeaWiFS-derived NPP estimates (temporal overlap c. 20032007) are greatest for the CbPM-based NPP estimates, which show substantially higher NPP yields in the MODIS-based estimates. Note however, that although discrepancies between SeaWiFS and MODIS are comparatively minor for the VGPM-based NPP estimates, SeaWiFS-based annual NPP yields are systematically $\sim 2-7 \%$ higher than MODIS-derived yields during all years of overlap. In Fig. S3-1 we also show alternate realizations of the weighted-least squares regression analysis of Fig. 3-3b (see methods of main text), comparing the SeaWiFS-VGPM, MODIS-VGPM, SeaWiFS-CbPM and MODIS-CbPM against contemporaneous $\left[\mathrm{DMS}_{\mathrm{sw}}\right]$ measurements. Our results show that VGPMNPP estimates are more closely related to $\left[\mathrm{DMS}_{\mathrm{sw}}\right]$ than CbPM-NPP estimates, and SeaWiFS-based NPP estimates are more closely related to $\left[\mathrm{DMS}_{\mathrm{sw}}\right]$ than MODIS-based NPP estimates. All four regressions, however, show statistical significance at the $p<0.001$ level.

Due to superior inter-satellite sensor comparisons and improved covariation with [DMS $\left.\mathrm{Dw}_{\mathrm{sw}}\right]$ (Fig. S3-1), we report NPP trends deriving from the standard VGPM product within the main text. Due to the strong spatiotemporal consistency in both SeaWiFS and MODIS-derived subarctic Atlantic 
VGPM NPP estimates (Fig. S3-1), we spatially-composited (via averaging) monthly SeaWiFS and MODIS-Aqua sensor data over their years of common overlap (A.D. 2003-2007) to produce a single satellite VGPM-NPP product. Using this composited product we find generally positive trends in subarctic Atlantic NPP over the first decade of satellite monitoring, and generally negative trends over the subsequent (most-recent) decade (Fig. S3-2). However, it is noted that substantial spatial heterogeneity does occur. Note that sensitivity analyses pertaining to our decision to composite SeaWiFS and MODIS-Aqua derived VGPM estimates can be found in Fig. S3-2.

\section{A2.4 Processing of Continuous Plankton Recorder (CPR) survey data}

A brief overview of the CPR survey, including the survey's data-collection methodology, potential biases (and associated adjustments), as well as limitations, can be found in the Methods portion of the main text (for an extensive review see Richardson et al., 2006). Here, we provide specific details on i) the availability of CPR survey data within the subarctic Atlantic (A.D. 1958-2016) and an intercomparison of summertime vs. annual averaging of CPR data, as well as ii) a comparison of data reduction techniques for estimating (spatially-integrated) subarctic Atlantic planktonic abundance trends from CPR data.

\section{A2.4.1 Record availability by standard CPR region: summer vs. annual}

We only considered data from CPR standard regions situated over the subarctic Atlantic $\left(50-65^{\circ} \mathrm{N}\right.$, $60-10^{\circ} \mathrm{W}$ ), limiting our analysis to the following 14 (out of the 41) standard CPR regions: A6, A8, B58, C5-8, D5-8 (Richardson et al., 2006).

Because few years have data for all months out of the year in most subarctic Atlantic-situated standard regions, the convention for estimating interannual variability using CPR data is to average across years with $\geq 8$ months of data (i.e., $\geq 2 / 3$ of a year), though annual estimates can typically be improved when the remaining $\leq 4$ months (i.e., $\leq 1 / 3$ of a year) are first estimated prior to annual averaging $^{53}$. Richardson et al. (2006) suggests the following method for estimating a missing month $(M)$ of data:

$$
M=\bar{M} * \frac{Y}{\bar{Y}}
$$


where $\bar{M}$ is the climatological monthly mean, and $Y$ is the annual mean which is normalized by $\bar{Y}$, the climatological annual mean. In Fig. S3-3, we show the data availability in the subarctic Atlantic for the annual averaged CPR data (i.e., the percentage of years per standard region where number of months were $\geq 8$ ) over the period A.D. 1958-2016.

We compare CPR data representing (conventionally) annually-averaged data to summertimeaveraged data, that is, the mean for CPR data collected in the months (Apr-May-June-July-AugustSept). Following Richardson et al. (2006), in this case we required $\geq 4$ months (i.e., $\geq 2 / 3$ of a summer) to compute the summertime average, whereby the missing summer months are estimated via Eq. A21 (such that $Y$ now represents the annual summer mean and $\bar{Y}$ the climatological summer mean) prior to averaging. As can be seen in Fig. S3-3a,b, withholding wintertime data facilitates marginal increases in the number of available years of data for most standard regions, particularly across the relatively poorly-sampled (albeit less-productive; Fig. 3-3a) central to western subarctic Atlantic.

We explore correlations of summertime- and annually-averaged CPR data to alternate subarctic Atlantic bioproductivity and climatological indices, reminiscent to the procedure highlighted in Fig. S3-8a. The results of the correlation analysis (not shown) reveal that the CPR correlations using annual-averages are highly similar to summertime averages, suggesting both approaches are reasonable for estimating long-term variability in CPR abundance data. In the following section, we extend our comparison of annually- vs. summertime averaged CPR time series to also compare methods of compositing time series between CPR standard regions.

\section{A2.4.2 Comparison of methods for determining CPR temporal variation}

The availability of 14 CPR standard regions for the subarctic Atlantic necessitated a spatially-and statistically- representative dimensional reduction technique to compute annual indices of PCI, diatom, dinoflagellate, and coccolithophore abundance, respectively. We considered three approaches: area-weighted averaging (AWA), inverse squared distance-infilling (ISD) averaging (Hátún et al., 2009), and an empirical orthogonal function (EOF)-based statistical infilling method (Beckers and Rixon, 2003).

The AWA method provides the simplest approach, incorporating an area-weighted mean planktonic abundance estimate of all available CPR regions in a given year. Given that each CPR region entails varying amounts of missing data (e.g., due to year-to-year differences in shipping route coverage; see above section or Richardson et al., 2003), some underlying (non-stationary) spatial bias may be introduced when estimating annual planktonic abundance with the AWA method. To help 
alleviate these potential biases, we explored ISD-infilling to first estimate missing years of data (e.g., Hátún et al., 2009) prior to area-weighting averaging of the CPR regions' abundances. This approach relies on the physical rationale that planktonic abundances in CPR regions of closer proximity are, ostensibly, more closely-related than CPR regions farther afield. This deterministic data-infilling approach (i.e., ISD averaging) is contrasted by a probabilistic EOF-based infilling methodology (Beckers and Rixon, 2003). Following Hátún et al. (2009), for this procedure we first omitted CPR standard regions missing $\geq 20$ years of data from the analysis, in order to remove spurious signals and thus improve convergence of the EOF-algorithm (Beckers and Rixon, 2003). For the remaining CPR regions, EOF-based imputation of missing years of data (Beckers and Rixon, 2003) was conducted in a manner identical to that described in Methods (i.e., for the infilling of missing [MSA] data), prior to area weighted averaging.

A qualitative comparison of the annual time series resulting from all three compositing procedures can be found in Fig. S3-3. Correlation analysis of both the summertime vs. annually time series for all three compositing techniques suggests that, in general, the EOF-data infilling technique provides the most internally consistent results (Table A2-2). Nonetheless, all three techniques show a notable degree of similarity across multidecadal timescales, suggesting that decadal-scale and longer productivity trends measured by the CPR survey are robust independent of which compositing approach is used. Due to its simplistic and intuitive approach, we highlight in Figure 3-4a and Fig. S3$8 \mathrm{a}$ of the main text CPR abundance time series using AWA.

\section{A2.5 Comparison of [MSA]-PC1 to regional sea-ice behavior}

Due to the reigning presupposition behind the use of ice core [MSA] as a proxy for sea ice extent (Maselli et al., 2017; Abram et al., 2013), we compared trends in near-Greenlandic sea ice extent (SIE; defined as the summed area of sea-ice concentration grids that are $\geq 15 \%$ ) against the [MSA]-PC1 time series. We used the updated National Snow and Ice Data Center (NSIDC) Historical Arctic Sea Ice gridded sea ice concentration product (Walsh et al., 2017), which extends from A.D. 1850 to present and is available at monthly temporal resolution. We explored trends in SIE for both March and September, typically the months of maximum and minimum SIE in the Arctic, and across four distinct regions listed subsequently in order of decreasing presumed association to Greenland MSA deposition. Region $1\left(60-70^{\circ} \mathrm{N}, 315-340^{\circ} \mathrm{E}\right)$ encompasses the vicinity of the Denmark Strait/Icelandic Basin, and is situated over the southeast margin of Greenland. This is the region over which the 
highest [MSA]-PC1 airmass transport probability density is situated (Fig. 3-1). Region 2 (60-85 N, 315$\left.15^{\circ} \mathrm{E}\right)$ defines the entire eastern margin of Greenland extending west to Svalbard. Region $3\left(45-85^{\circ} \mathrm{N}\right.$, $280-315^{\circ} \mathrm{E}$ ) covers Baffin Bay, extending southward into the Labrador Sea beyond the southernmost mean SIE maximum reached over the period A.D. 1900-2013. Region 4 comprises the sum of Region 2 and 3, capturing both eastern and western Greenlandic sea-ice behavior.

As a rough test of causality (i.e., assuming a priori that annual production and the ease of subsequent airborne deposition of MSA onto the Greenland Ice Sheet is in some way modulated by the extent of sea ice proximal to Greenland; Abram et al., 2013), we computed the lag-0 ordinary least squares linear regression of annual [MSA]-PC1 to regional SIE in both September and March over four different tests: Test 1) the satellite-era correlations (1979-2009; $n=31$ years; representing the best-resolved period of satellite sea-ice observation); Test 2) the long term non-detrended annual-scale correlations (1850-2009; $n=160)$; Test 3) the long term linearly-detrended annual-scale correlations (1850-2009; $n=160$; note that both [MSA]-PC1 and regional SIE were linearly-detrended prior to regression analysis); Test 4) correlations following 10-yr lowpass (Butterworth) filtering of the time series (1850-2009; $n=160$ decades). Results of the four tests, provided in full in Table A2-1, show that only 2/32 tests, both for Region 3 in September, resulted in a significant [MSA]-PC1 - SIE correlation $(\phi \leq 0.05)$ when adjusting for serial correlation amongst the paired time series (Ebisuzaki, 1997).

In addition to the correlation analyses, we point out two additional qualitative discrepancies between [MSA]-PC1 and SIE (not shown). First, multidecadal-scale phasing between [MSA]-PC1 and SIE does not appear stationary for any of the four SIE regions. For example, the generally positive association between SIE and [MSA]-PC1 trends during the earlier half of the sea-ice satelliteobservational period (1979 to mid-1990's) is not preserved into present. For example, since A.D. 1979, summertime and wintertime SIE has declined at an accelerating rate (Walsh et al., 2017), while the [MSA]-PC1 series shows a generally-increasing trend. Second, a conspicuous increase in SIE found across all four regions during the late 1960's to early 1970's (reflecting the Great Salinity Anomaly, a period of elevated Arctic-basin sea ice export into the Barents/Greenlandic Seas; Zhang et al., 2006), does not have an appropriate analogue in the [MSA]-PC1 series.

Overall, our analysis suggests SIE variability is not the primary signal captured by [MSA] variations across interior Greenland, in contrast to prior suggestions (e.g., Maselli et al., 2017). While the use of [MSA] as a sea ice proxy appears to be robust for records from low-lying ice caps in Svalbard (O'Dwyer et al., 2000), situated at the summertime ice marginal extent of the Barents Sea, we argue 
that the leading mode of interior-Greenlandic [MSA] variability more likely reflects spatially-integrated variations in DMS production centered around the central to northeastern subarctic Atlantic, a region largely removed from the summertime sea ice margin.

\section{A2.6 NOAA Global Surface Seawater DMS Database measurements}

In Fig. S3-S7b, we plot a global comparison of [DMS $\left.\mathrm{DW}_{\mathrm{sw}}\right]$ to VGPM-derived NPP. The binning and regression methodology is described in the Methods of the main text. The results clearly show that $\left[\mathrm{DMS}_{\mathrm{Sw}}\right]$ variations within the subarctic Atlantic (Fig. S3-7a reproduced from Fig. 3-3b in the main text) capture a much larger fraction of NPP variability (51\% using an OLS regression with $n=224$ points; $57 \%$ using a WLS regression with $n=186$ points (where the difference in $n$ between the two regressions discriminates between $1^{\circ} \times 1^{\circ} \times 1$-month binned $\left[\mathrm{DMS}_{\mathrm{SW}}\right]$ values representing $>1$ measurement) than exhibited on a global scale ( $r=0.32$ and $r=0.33$ for the WLS and OLS, respectively).

Due to the large number data used in the global regression $(n=3045$ observations for OLS, $n$

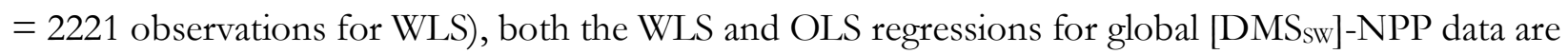
highly significant $(p<<0.0001)$ despite the substantially smaller Pearson $r$ values. To adjust for this potential statistical artifact, a large number $(10,000)$ of global $\left[\mathrm{DMS}_{\mathrm{sw}}\right]-\mathrm{NPP}$ WLS regressions were conducted, whereby for each iteration $n=186$ samples were randomly drawn (with replacement) from the $n=2221$ global WLS [DMS $\left.S_{\mathrm{Sw}}\right]-\mathrm{NPP}$ pairings in order to approximate the degrees of freedom used in the subarctic Atlantic WLS regression. The results of this procedure indicated a median $r=0.33$, and $99^{\text {th }}$ percentile of $r=0.56$, indicating the globally-integrated [DMS $\mathrm{Sw}_{\mathrm{sw}}$-NPP relationship to be less robust than in the subarctic (Fig. S3-7c).

\section{A2.7 Defining the subarctic Atlantic "warming hole" and AMOC index}

Broad portions of the observational subarctic Atlantic SST (or, near-equivalently, SAT) record are characterized by long term cooling in spite of global long-term warming (Rahmstorf et al., 2015; de Jong et al., 2016; Caesar et al., 2018; Josey et al., 2018). Due to the conspicuous nature of this so-called Atlantic "warming hole" and its relationship to both atmospheric forcing (de Jong et al., 2016), lateral convection (Hátún et al., 2005), and, across longer timescales, thermohaline overturning strength (Rahmstorf et al., 2015), we target this region as an indicator for linking primary productivity trends within the context of subarctic Atlantic climate dynamics. Trends in sea-surface temperatures (SST) 
were first analyzed using the ERSST (v5; Huang et al., 2017) and HadISST- (v1.1; Raynor et al., 2003) mean-monthly reanalysis datasets over the period A.D. 1870-2016. We defined grid cells showing a linear decrease over this $146-\mathrm{yr}$ period within the subarctic Atlantic $\left(50-65^{\circ} \mathrm{N}, 60-10^{\circ} \mathrm{W}\right)$ as the Atlantic warming hole region. Despite some discrepancies between the spatial extent of the warming hole between the two datasets - likely a result of differences in grid-cell resolution $\left(2^{\circ} \times 2^{\circ}\right.$ for ERSSTv5; $1^{\circ} \times 1^{\circ}$ for HadISSTv1.1) - both area-weighted mean annual SST anomalies reveal a high degree of consistency (bottom panel; $r=0.91$; Fig. S3-9), indicating temperature covariability across the subarctic Atlantic is generally coherent between datasets.

Following Rahmstorf et al. (2015) and Caesar et al. (2018), we used the Atlantic warming hole region to calculate the observational AMOC index from A.D. 1870-2016 as the difference between the mean annual warming hole SST anomaly and the mean annual northern hemisphere SST anomaly. As shown in the supplementary information of Rahmstorf et al. (2015), primary features of the AMOC index are preserved when using either SST (i.e., only oceanic grid points) or SAT (i.e., both oceanic and continental grid points) as the base unit. Similar to the warming hole comparison above, we find minor differences between the ERSSTv5 derived- and the HadISSTv1.1 derived AMOC indices. Further, both indices - following 10-yr lowpass filtering - show strong correlation with the (10-yr lowpass filtered) reconstructed AMOC index of Rahmstorf et al. (2015; A.D. 1870-1995.; $r_{E R S S T}=0.81$; $r_{\text {HadISST }}=0.82$; Fig. S3-9). Due to differences in base unit (SAT vs. SST) and reference datasets used, small magnitudinal offsets between the observed SST AMOC index and the reconstructed SAT AMOC index of Rahmstorf et al. (2015) do exist. As such, the observational ERSSTv5 AMOC index provided in Figure 3-3a of the main text was bias corrected and adjusted to the reconstructed SAT AMOC index of Rahmstorf et al. (2015) to improve visual clarity. The adjustment does not affect the correlation analyses listed above or within the main text. 


\section{Appendix 2 Tables}

Table A2-1. Explorative correlation analysis of [MSA]-PC1 to SIE in regions proximal to Greenland (see Section A2.5 for region definitions). Values are the correlation values (Pearson $r$ ) of [MSA]-PC1 with March SIE ( $\sim$ maximum extent), while values in parentheses represent September ( $\sim$ minimum extent) SIE correlations. Bolded values represent significance at the $p<5 \%$ confidence level following a Monte Carlo Fourier-phase randomization procedure ( $N=10,000$ tests per pairing), used to empirically account for serial correlation amongst paired time series (Ebisuzaki, 1997).

\begin{tabular}{|c|c|c|c|c|}
\hline & Region 1 & Region 2 & Region 3 & Region 4 \\
\hline $\begin{array}{c}\text { Test 1: Annual satellite period } \\
\text { (A.D. 1979-2009; } \boldsymbol{n}=\mathbf{3 1 )}\end{array}$ & $0.03(-0.23)$ & $-0.05(-0.08)$ & $-0.08(-0.02)$ & $-0.09(-0.06)$ \\
\hline $\begin{array}{c}\text { Test 2: Annual reanalysis period } \\
\text { (A.D. 1850-2009; } \boldsymbol{n}=\mathbf{1 6 0})\end{array}$ & $0.06(0.04)$ & $0.25(0.17)$ & $0.03(\mathbf{0 . 3 7})$ & $0.21(0.31)$ \\
\hline $\begin{array}{c}\text { Test 3: Annual, linearly detrended } \\
\text { (A.D. 1850-2009; } \boldsymbol{n}=\mathbf{1 6 0})\end{array}$ & $-0.11(-0.07)$ & $-0.11(-0.06)$ & $0.05(-0.00)$ & $0.06(-0.04)$ \\
\hline $\begin{array}{c}\text { Test 4: 10-yr lowpass filtered } \\
\text { (A.D. 1850-2009; } \boldsymbol{n}=\mathbf{1 6})\end{array}$ & $0.08(0.11)$ & $0.31(0.29)$ & $-0.04(\mathbf{0 . 5 8})$ & $0.28(0.46)$ \\
\hline
\end{tabular}


Table A2-2. Linear correlation analysis of three methods of CPR-based compositing for i) diatom, ii) dinoflagellate, and iii) coccolithophore abundances, comparing both summer vs. annual averaging. Numbers represent Pearson product-moment correlations (r, A.D. 1958-2016), with Monte Carlo-based (Ebisuzaki, 1997) significance level in parentheses. A significance level of " $<10^{-4}$ " represents an observed $r$-value whose magnitude is greater than all $(10,000)$ correlations using pseudo-random surrogate data (see Methods).

\begin{tabular}{|c|c|c|c|c|c|c|c|c|c|}
\hline & \multicolumn{3}{|c|}{ i) Diatom } & \multicolumn{3}{|c|}{ ii) Dinoflagellate } & \multicolumn{3}{|c|}{ iii) Coccolithophore } \\
\hline $\begin{array}{c}\text { Summer } \\
\text { AWA }\end{array}$ & $\begin{array}{c}0.91 \\
\left(2.1 \times 10^{-4}\right)\end{array}$ & $\begin{array}{c}0.30 \\
(0.19)\end{array}$ & $\begin{array}{c}0.68 \\
\left(1.5 \times 10^{-2}\right)\end{array}$ & $\begin{array}{c}0.83 \\
\left(4.7 \times 10^{-4}\right)\end{array}$ & $\begin{array}{c}0.06 \\
(0.40)\end{array}$ & $\begin{array}{c}0.66 \\
\left(6.0 \times 10^{-4}\right)\end{array}$ & $\begin{array}{c}0.63 \\
(0.10)\end{array}$ & $\begin{array}{c}0.77 \\
\left(5.4 \times 10^{-2}\right)\end{array}$ & $\begin{array}{c}0.74 \\
\left(7.5 \times 10^{-2}\right)\end{array}$ \\
\hline $\begin{array}{c}\text { Summer } \\
\text { ISD }\end{array}$ & $\begin{array}{c}0.50 \\
\left(2.4 \times 10^{-2}\right)\end{array}$ & $\begin{array}{c}0.96 \\
\left(<10^{-4}\right)\end{array}$ & $\begin{array}{c}0.84 \\
\left(<10^{-4}\right)\end{array}$ & $\begin{array}{c}0.17 \\
(0.28)\end{array}$ & $\begin{array}{c}0.94 \\
\left(<10^{-4}\right)\end{array}$ & $\begin{array}{c}0.38 \\
\left(6.6 \times 10^{-2}\right)\end{array}$ & $\begin{array}{c}0.69 \\
\left(7.2 \times 10^{-2}\right)\end{array}$ & $\begin{array}{c}0.82 \\
\left(2.8 \times 10^{-2}\right)\end{array}$ & $\begin{array}{c}0.80 \\
\left(4.6 \times 10^{-2}\right)\end{array}$ \\
\hline $\begin{array}{l}\text { Summer } \\
\text { EOF }\end{array}$ & $\begin{array}{c}0.77 \\
\left(4.6 \times 10^{-3}\right)\end{array}$ & $\begin{array}{c}0.78 \\
\left(<10^{-4}\right)\end{array}$ & $\begin{array}{c}0.98 \\
\left(<10^{-4}\right)\end{array}$ & $\begin{array}{c}0.69 \\
\left(2.9 \times 10^{-4}\right)\end{array}$ & $\begin{array}{c}0.42 \\
\left(4.0 \times 10^{-2}\right)\end{array}$ & $\begin{array}{c}0.96 \\
\left(<10^{-4}\right)\end{array}$ & $\begin{array}{c}0.81 \\
\left(2.9 \times 10^{-2}\right)\end{array}$ & $\begin{array}{c}0.89 \\
\left(1.0 \times 10^{-2}\right)\end{array}$ & $\begin{array}{c}0.99 \\
\left(<10^{-4}\right)\end{array}$ \\
\hline & $\begin{array}{c}\text { Annual } \\
\text { AWA }\end{array}$ & $\begin{array}{c}\text { Annual } \\
\text { ISD }\end{array}$ & $\begin{array}{c}\text { Annual } \\
\text { EOF }\end{array}$ & $\begin{array}{c}\text { Annual } \\
\text { AWA }\end{array}$ & $\begin{array}{c}\text { Annual } \\
\text { ISD }\end{array}$ & $\begin{array}{c}\text { Annual } \\
\text { EOF }\end{array}$ & $\begin{array}{c}\text { Annual } \\
\text { AWA }\end{array}$ & $\begin{array}{c}\text { Annual } \\
\text { ISD }\end{array}$ & $\begin{array}{c}\text { Annual } \\
\text { EOF }\end{array}$ \\
\hline
\end{tabular}


Table A2-3. Overview of climatic indices, reanalysis, and biological data used.

\begin{tabular}{|c|c|c|c|c|c|c|}
\hline Variable & Dataset name & URL (as of Feb. 2018) & Time period covered & $\begin{array}{c}\text { Resol- } \\
\text { ution }\end{array}$ & $\begin{array}{l}\text { Regridding } \\
\text { performed? }\end{array}$ & Citation \\
\hline \multirow[t]{2}{*}{$\begin{array}{l}\text { Sea surface } \\
\text { temperature (SST) }\end{array}$} & $\begin{array}{c}\text { NOAA } \\
\text { ERSST (v5) }\end{array}$ & $\begin{array}{c}\text { https://www.esrl.noaa.go } \\
\text { v/psd/data/gridded/data } \\
\text {.noaa.ersst.html }\end{array}$ & Jan 1854 - (monthly) & $2^{\circ}$ & $\mathrm{N}$ & $\begin{array}{l}\text { Huang et } \\
\text { al., } 2017\end{array}$ \\
\hline & $\begin{array}{c}\text { HadISST } \\
(\mathrm{v} 1.1) \\
\end{array}$ & $\begin{array}{l}\text { https://www.metoffice.g } \\
\text { ov.uk/hadobs/hadisst/ }\end{array}$ & Jan 1870 - (monthly) & $1^{\circ}$ & $\mathrm{N}$ & $\begin{array}{c}\text { Rayner et } \\
\text { al., } 2003 \\
\end{array}$ \\
\hline $\begin{array}{l}\text { Sea-ice extent } \\
\quad \text { (SIE) }\end{array}$ & $\begin{array}{c}\text { NSIDC } \\
\text { Gridded } \\
\text { Historical Sea } \\
\text { Ice (v1) }\end{array}$ & $\begin{array}{c}\text { https://nsidc.org/data/g } \\
10010\end{array}$ & $\begin{array}{l}\text { Jan } 1850 \text { - Dec. } 2013 \\
\text { (monthly) }\end{array}$ & $0.25^{\circ}$ & $\mathrm{N}$ & $\begin{array}{l}\text { Walsh et } \\
\text { al., } 2017\end{array}$ \\
\hline $\begin{array}{l}\text { Dimethylsulfide } \\
\text { sea-surface } \\
\text { concentration }\end{array}$ & $\begin{array}{l}\text { NOAA Global } \\
\text { Surface } \\
\text { Seawater DMS } \\
\text { Database } \\
\end{array}$ & $\begin{array}{c}\text { https://saga.pmel.noaa.g } \\
\text { ov/dms/ }\end{array}$ & $\begin{array}{l}1972 \text { - (Inconsistent } \\
\text { sampling) }\end{array}$ & $\mathrm{n} / \mathrm{a}$ & $\begin{array}{l}\mathrm{Y}\left(1^{\circ} \mathrm{CPR}\right. \\
\text { standard } \\
\text { region-wise } \\
\text { binning }) \\
\end{array}$ & $\begin{array}{l}\text { Lana et } \\
\text { al., 2011; } \\
\text { Kettle et } \\
\text { al., } 1999 \\
\end{array}$ \\
\hline $\begin{array}{c}\text { Phytoplankton } \\
\text { Color Index } \\
\text { (PCI), Diatom, } \\
\text { Dinoflagellate, \& } \\
\text { Coccolithophore } \\
\text { abundance } \\
\end{array}$ & $\begin{array}{l}\text { SAHFOS } \\
\text { Continuous } \\
\text { Plankton } \\
\text { Recorder } \\
\text { (CPR) survey }\end{array}$ & $\begin{array}{c}\text { https://www.sahfos.ac.u } \\
\text { k/ }\end{array}$ & 1958 - (monthly) & $\mathrm{n} / \mathrm{a}$ & $\mathrm{n} / \mathrm{a}$ & $\begin{array}{l}\text { Richards } \\
\text { on et al., } \\
2006\end{array}$ \\
\hline \multirow[t]{2}{*}{$\begin{array}{l}\text { North Atlantic } \\
\text { Oscillation } \\
(\mathrm{NAO}) \text { index } \\
\end{array}$} & $\begin{array}{l}\text { CRU Station- } \\
\text { based }\end{array}$ & $\begin{array}{c}\text { https://crudata.uea.ac.uk } \\
\text { /cru/data/nao/ }\end{array}$ & $\mathrm{n} / \mathrm{a}$ & $\mathrm{n} / \mathrm{a}$ & $\mathrm{n} / \mathrm{a}$ & $\begin{array}{l}\text { Jones et } \\
\text { al., } 1997\end{array}$ \\
\hline & $\begin{array}{l}\mathrm{NAO}-\text { proxy- } \\
\text { based } \\
\text { reconstruction }\end{array}$ & $\begin{array}{c}\text { https://www1.ncdc.noaa. } \\
\text { gov/pub/data/paleo/co } \\
\text { ntributions_by_author/o } \\
\text { rtega2015/ortega2015nao } \\
\text {.txt } \\
\end{array}$ & $1767-1969$ & $\mathrm{n} / \mathrm{a}$ & $\mathrm{n} / \mathrm{a}$ & $\begin{array}{l}\text { Ortega et } \\
\text { al., } 2015\end{array}$ \\
\hline $\begin{array}{l}\text { Subpolar Gyre } \\
\text { (SPG) Index }\end{array}$ & $\begin{array}{l}\text { Merged } \\
\text { MICAM } \\
\text { (model) and } \\
\text { AVISO SSH } \\
\text { (observed) }\end{array}$ & $\begin{array}{c}\text { Observed: } \\
\text { https://data.marine.gov.s } \\
\text { cot/dataset/sub-polar- } \\
\text { gyre-index; model: } \\
\text { received upon request } \\
\text { from H. Hatun, Feb. } \\
2018\end{array}$ & $\begin{array}{l}\text { 1960-2003 (modeled; Hátún } \\
\text { et al., 2005); 1993-2012 } \\
\text { (observed; Berx et al., 2018); } \\
r=0.96 \text { for } 11 \text { years of } \\
\text { overlap; A.D. 1993-2003). } \\
\text { Note that the observed series } \\
\text { was truncated due to recent, } \\
\text { ongoing discussion on } \\
\text { defining the SPG index } \\
\text { across recent years (Hátún et } \\
\text { al., 2018). }\end{array}$ & $\mathrm{n} / \mathrm{a}$ & $\mathrm{n} / \mathrm{a}$ & $\begin{array}{l}\text { Hátún et } \\
\text { al., 2005; } \\
\text { Hátún et } \\
\text { al., } 2018\end{array}$ \\
\hline AMOC Index & $\begin{array}{c}\text { AMOC - } \\
\text { proxy-based } \\
\text { reconstruction }\end{array}$ & $\begin{array}{c}\text { http://www.pik- } \\
\text { potsdam.de/\%7Estefan/ } \\
\text { amoc_index_data.html }\end{array}$ & $1767-1995$ & $\mathrm{n} / \mathrm{a}$ & $\mathrm{n} / \mathrm{a}$ & $\begin{array}{l}\text { Rahmsto } \\
\text { rf et al., } \\
2015 \\
\end{array}$ \\
\hline $\begin{array}{l}\text { Dimethylsulfide } \\
\text { monthly } \\
\text { climatology }\end{array}$ & $\begin{array}{l}\text { SOLAS } \\
\text { Project }\end{array}$ & $\begin{array}{l}\text { https://www.bodc.ac.uk } \\
\text { /solas_integration/imple } \\
\text { mentation_products/gro } \\
\text { up1/dms/ }\end{array}$ & n/a (monthly climatology) & $1^{\circ}$ & $\mathrm{N}$ & $\begin{array}{l}\text { Lana et } \\
\text { al., } 2011\end{array}$ \\
\hline \multirow[t]{3}{*}{$\begin{array}{l}\text { Ocean Net } \\
\text { Primary } \\
\text { Productivity }\end{array}$} & $\begin{array}{l}\text { Vertically } \\
\text { Generalized } \\
\text { Production } \\
\text { Model } \\
\text { (VGPM) using } \\
\text { SeaWiFS- } \\
\text { r2018 } \\
\text { reprocessing } \\
\end{array}$ & $\begin{array}{c}\text { http://orca.science.orego } \\
\text { nstate.edu/1080.by.2160. } \\
\text { monthly.hdf.vgpm.s.chl.a. } \\
\text { sst.php }\end{array}$ & $\begin{array}{l}\text { Oct. } 1997 \text { - Dec. } 2007 \\
\text { (monthly) }\end{array}$ & $1 / 6^{\circ}$ & $\mathrm{Y}\left(1^{\circ}\right)$ & $\begin{array}{c}\text { Berhenfel } \\
\text { d et al., } \\
1997\end{array}$ \\
\hline & $\begin{array}{l}\text { Vertically } \\
\text { Generalized } \\
\text { Production } \\
\text { Model } \\
\text { (VGPM) using } \\
\text { MODIS- } \\
\text { r2018.0 (GSM) } \\
\text { reprocessing } \\
\end{array}$ & $\begin{array}{c}\text { http://orca.science.orego } \\
\text { nstate.edu/1080.by. } 2160 \text {. } \\
\text { monthly.hdf.vgpm.m.chl. } \\
\text { m.sst.php }\end{array}$ & $\begin{array}{l}\text { Jul. } 2002-\text { Dec. } 2017 \\
\text { (monthly) }\end{array}$ & $1 / 6^{\circ}$ & $Y\left(1^{\circ}\right)$ & $\begin{array}{c}\text { Berhenfel } \\
\text { d et al., } \\
1997\end{array}$ \\
\hline & $\begin{array}{l}\text { Carbon-based } \\
\text { Productivity } \\
\text { Model using } \\
\text { GSM-v8; } \\
\text { SeaWiFS- } \\
\end{array}$ & $\begin{array}{l}\text { http://orca.science.orego } \\
\text { nstate.edu/1080.by.2160. } \\
\text { monthly.hdf.cbpm2.s.ph } \\
\text { p }\end{array}$ & $\begin{array}{l}\text { Oct. } 1997 \text { - Dec. } 2007 \\
\text { (monthly) }\end{array}$ & $1 / 6^{\circ}$ & $\mathrm{Y}\left(1^{\circ}\right)$ & $\begin{array}{l}\text { Westberr } \\
\text { y et al., } \\
2008\end{array}$ \\
\hline
\end{tabular}




\begin{tabular}{|c|c|c|c|c|c|c|}
\hline & $\begin{array}{c}\mathrm{r} 2018 \\
\text { reprocessing }\end{array}$ & & & & & \\
\hline & $\begin{array}{l}\text { Carbon-based } \\
\text { Productivity } \\
\text { Model using } \\
\text { MODIS- } \\
\text { r2018.0 } \\
\text { reprocessing } \\
\text { (GSM) }\end{array}$ & $\begin{array}{l}\text { http://orca.science.orego } \\
\text { nstate.edu/1080.by.2160. } \\
\text { monthly.hdf.cbpm2.m.ph } \\
\text { p }\end{array}$ & $\begin{array}{c}\text { Jul. } 2002 \text { - Dec. } 2017 \\
\text { (monthly) }\end{array}$ & $1 / 6^{\circ}$ & $\mathrm{Y}\left(1^{\circ}\right)$ & $\begin{array}{l}\text { Westberr } \\
\text { y et al., } \\
2008\end{array}$ \\
\hline
\end{tabular}




\section{Appendix 2 References}

Abram, N. J., Wolff, E. W. \& Curran, M. a J. (2013). A review of sea ice proxy information from polar ice cores. Quat. Sci. Rev. 79, 168-183.

Beckers, J. M., \& Rixen, M. (2003). EOF calculations and data filling from incomplete oceanographic datasets. Journal of Atmospheric and Oceanic Technology, 20(12), 1839-1856. https://doi.org/10.1175/15200426(2003)020<1839:ECADFF>2.0.CO;2

Behrenfeld, M. J., \& Falkowski, P. G. (1997). Photosynthetic rates derived from satellite-based chlorophyll concentration. Limnology and Oceanography, 42(1), 1-20. https://doi.org/10.4319/lo.1997.42.1.0001

Behrenfeld, M. J. et al. (2006). Climate-driven trends in contemporary ocean productivity. Nature, 444, 752 755.

Berx, B. \& Payne, M. R. (2017). The Sub-Polar Gyre Index - A community data set for application in fisheries and environment research. Earth Syst. Sci. Data 9, 259-266.

Caesar, L., Rahmstorf, S., Robinson, A., Feulner, G., \& Saba, V. (2018). Observed fingerprint of a weakening Atlantic Ocean overturning circulation. Nature, 556(7700), 191-196. https://doi.org/10.1038/s41586018-0006-5

Carr, M. E. et al. (2006). A comparison of global estimates of marine primary production from ocean color. Deep. Res. Part II Top. Stud. Oceanogr. 53, 741-770.

Dempster, A. P., Laird, N. M. \& Rubin, D. B. (1977). Maximum likelihood from incomplete data via the EM algorithm. J. R. Stat. Soc. Ser. B Methodol. 39, 1-38.

Ebisuzaki, W. (1997). A method to estimate the statistical significance of a correlation when the data are serially correlated. Journal of Climate, 10(9), 2147-2153. https://doi.org/10.1175/15200442(1997)010<2147:AMTETS > 2.0.CO;2

Hátún, H., Payne, M. R., Beaugrand, G., Reid, P. C., Sandø, A. B., Drange, H., .. Bloch, D. (2009). Large biogeographical shifts in the north-eastern Atlantic Ocean: From the subpolar gyre, via plankton, to blue whiting and pilot whales. Progress in Oceanography, 80(3-4), 149-162. https://doi.org/10.1016/j.pocean.2009.03.001

Hátún, H., Sande, A. B., Drange, H., Hansen, B., \& Valdimarsson, H. (2005). Ocean science: Influence of the atlantic subpolar gyre on the thermohaline circulation. Science, 309(5742), 1841-1844. https://doi.org/10.1126/science.1114777

Hátún, H., \& Chafik, L. (2018). On the recent ambiguity of the North Atlantic subpolar gyre index. J. of Geophys. Res., 123.

Hezel, P. J. et al. (2011). Modeled methanesulfonic acid (MSA) deposition in Antarctica and its relationship to sea ice. J. Geophys. Res. Atmos. 116, 1-18.

Huang, B., Thorne, P. W., Banzon, V. F., Boyer, T., Chepurin, G., Lawrimore, J. H., ... Zhang, H. M. (2017). Extended reconstructed Sea surface temperature, Version 5 (ERSSTv5): Upgrades, validations, and intercomparisons. Journal of Climate, 30(20), 8179-8205. https://doi.org/10.1175/JCLI-D-16-0836.

Jones, P. D., Jonsson, T., \& Wheeler, D. (1997). Extension to the North Atlantic oscillation using early instrumental pressure observations from Gibraltar and south-west Iceland. International Journal of Climatology, 17(13), 1433-1450. https://doi.org/10.1002/(SICI)1097-0088(19971115)17:13<1433::AIDJOC203>3.0.CO;2-P

de Jong, M. F. \& de Steur, L. (2016). Strong winter cooling over the Irminger Sea in winter 2014-2015, exceptional deep convection, and the emergence of anomalously low SST. Geophys. Res. Lett., 43, 71067113. 
Josey, S. A. et al. (2018). The Recent Atlantic Cold Anomaly: Causes, Consequences, and Related Phenomena. Ann. Rev. Mar. Sci. 10, 475-501.

Kahl, D. W. et al. (1997). Air mass trajectories to Summit, Greenland: A 44-year climatology and some episodic events, J. Geophys. Res. 102, 26,861 - 26,875.

Kettle, A. J., Andreae, M. O., Amouroux, D., Andreae, T. W., Bates, T. S., Berresheim, H., ... Uher, G. (1999). A global database of sea surface dimethylsulfide (DMS) measurements and a procedure to predict sea surface DMS as a function of latitude, longitude, and month. Global Biogeochemical Cycles, 13(2), 399-444. https://doi.org/10.1029/1999GB900004

Lana, A., Bell, T. G., Simó, R., Vallina, S. M., Ballabrera-Poy, J., Kettle, A. J., .. Liss, P. S. (2011). An updated climatology of surface dimethlysulfide concentrations and emission fluxes in the global ocean. Global Biogeochemical Cycles, 25(1), 1-17. https://doi.org/10.1029/2010GB003850

O'Dwyer, J. et al. (2000). Methanesulfonic acid in a Svalbard Ice Core as an indicator of ocean climate. Geophys. Res. Lett. 27, 1159-1162.

Ortega, P., Lehner, F., Swingedouw, D., Masson-Delmotte, V., Raible, C. C., Casado, M., \& Yiou, P. (2015). A model-tested North Atlantic Oscillation reconstruction for the past millennium. Nature, 523(7558), 7174. https://doi.org/10.1038/nature14518

Rahmstorf, S., Box, J. E., Feulner, G., Mann, M. E., Robinson, A., Rutherford, S., \& Schaffernicht, E. J. (2015). Exceptional twentieth-century slowdown in Atlantic Ocean overturning circulation. Nature Climate Change, 5(5), 475-480. https://doi.org/10.1038/nclimate2554

Rayner, N. A., Parker, D. E., Horton, E. B., Folland, C. K., Alexander, L. V., Powell, D. P. (2003). Global analyses of sea surface temperature, sea ice, and night marine air temperature since the late nineteenth century. Journal of Geophysical Research, 108(D14), 4407. https://doi.org/10.1029/2002JD002670

Rhines, A. \& Huybers, P. J. (2014). Sea Ice and Dynamical Controls on Preindustrial and Last Glacial Maximum Accumulation in Central Greenland, J. of Clim., 27, 8902-8917.

Richardson, A. J., Walne, A. W., John, A. W. G., Jonas, T. D., Lindley, J. A., Sims, D. W., ... Witt, M. (2006). Using continuous plankton recorder data. Progress in Oceanography, 68(1), 27-74. https://doi.org/10.1016/j.pocean.2005.09.011

Richman, M. B. (1986). Rotation of principal components. J. Climatol., 6, 293-335.

Roweis, S. (1997). EM Algorithms for PCA and SPCA. Computing 10, 626-632.

Schuenemann, K. C. \& Cassano, J. J. (2010). Changes in synoptic weather patterns and Greenland precipitation in the 20th and 21st centuries: 2 . Analysis of 21 st century atmospheric changes using self-organizing maps. J. Geophys. Res. Atmos., 115, 1-18.

Schüpbach, S., et al. (2018). Greenland records of aerosol source and atmospheric lifetime changes from the Eemian to the Holocene, Nat. Comm., 9, 1476.

Sodemann, H., Schwierz, C., \& Wernli, H. (2008). Interannual variability of Greenland winter precipitation sources: Lagrangian moisture diagnostic and North Atlantic Oscillation influence, J. Geophys. Res. 113 D03107.

Stein, A. F., Draxler, R. R., Rolph, G. D., Stunder, B. J. B., Cohen, M. D., \& Ngan, F. (2015). NOAA’s hysplit atmospheric transport and dispersion modeling system. Bulletin of the American Meteorological Society, 96(12), 2059-2077. https://doi.org/10.1175/BAMS-D-14-00110.1

Storch, H. Von \& Zwiers, F. W. Statistical Analysis in Climate Research. J. Am. Stat. Assoc., 95, 1375 (1999).

Tipping M. E, and Bishop, C. M. (1999). Probabilistic Principal Component Analysis. J. R. Stat. Soc. Ser. B, 61, 611-622. 
Trouet, V., Babst, F., \& Meko, M (2018). Recent enhanced high-summer North Atlantic Jet variability emerges from three-century context, Nature Comm. 9.

Walsh, J. E., Fetterer, F., Stewart, J. S., \& Chapman, W. L. A database for depicting Arctic sea ice variations back to 1850. Geogr. Rev. 107, 89-107 (2017).

Westberry, T., Behrenfeld, M. J., Siegel, D. A. \& Boss, E. (2008). Carbon-based primary productivity modeling with vertically resolved photoacclimation. Global Biogeochem. Cycles 22, 1-18.

Zhang, R. \& Vallis, G. K. (2006). Impact of great salinity anomalies on the low-frequency variability of the North Atlantic climate. J. Clim. 19, 470-482. 


\section{Appendix 3: Disko Bay ice core array data}

\section{A3.1 Greenland Central (GC) ice core [MSA] measurements (A.D. 1821 - 2013)}

GC [MSA] data used in Ch. [3] are archived via the National Science Foundation (NSF) Arctic Data

Center (http:/ / arcticdata.io; Indentifier: urn:uuid:05735a2b-576d-40d9-8d4d-30491c89e0af).

\section{A3.2 Nuussuaq (NU) ice core accumulation history (A.D. 79-2015)}

Table A3.1. Reconstructed accumulation (“Accum.”) history for the NU ice core.

\begin{tabular}{|c|c|c|c|}
\hline $\begin{array}{c}\text { Year range } \\
(\mathbf{C E})\end{array}$ & $\begin{array}{c}\text { Accum. } \\
\mathbf{( - 1 0 \% )}\end{array}$ & $\begin{array}{c}\text { Accum. (least } \\
\text { complex) }\end{array}$ & $\begin{array}{c}\text { Accum. } \\
\mathbf{( + 1 0} \mathbf{)}\end{array}$ \\
\hline $1962.5-2015.42$ & 0.387 & 0.389 & 0.390 \\
\hline $1955.5-1962.5$ & 0.370 & 0.373 & 0.376 \\
\hline $1912.5-1955.5$ & 0.348 & 0.352 & 0.355 \\
\hline $1884.5-1912.5$ & 0.339 & 0.344 & 0.348 \\
\hline $1873.5-1884.5$ & 0.329 & 0.335 & 0.340 \\
\hline $1863.5-1873.5$ & 0.302 & 0.308 & 0.313 \\
\hline $1836.5-1863.5$ & 0.288 & 0.295 & 0.299 \\
\hline $1816.5-1836.5$ & 0.301 & 0.309 & 0.315 \\
\hline $1783.5-1816.5$ & 0.323 & 0.333 & 0.342 \\
\hline $1766.5-1783.5$ & 0.278 & 0.287 & 0.295 \\
\hline $1739.5-1766.5$ & 0.269 & 0.278 & 0.286 \\
\hline $1696.5-1739.5$ & 0.253 & 0.263 & 0.272 \\
\hline $1667.5-1696.5$ & 0.253 & 0.264 & 0.273 \\
\hline $1642.5-1667.5$ & 0.259 & 0.272 & 0.282 \\
\hline $1601.5-1642.5$ & 0.277 & 0.291 & 0.303 \\
\hline $1585.5-1601.5$ & 0.290 & 0.307 & 0.321 \\
\hline $1569.5-1585.5$ & 0.291 & 0.307 & 0.321 \\
\hline $1554.5-1569.5$ & 0.289 & 0.305 & 0.320 \\
\hline $1537.5-1554.5$ & 0.288 & 0.305 & 0.320 \\
\hline $1512.5-1537.5$ & 0.282 & 0.299 & 0.314 \\
\hline $1502.5-1512.5$ & 0.279 & 0.296 & 0.311 \\
\hline $1477.5-1502.5$ & 0.272 & 0.289 & 0.304 \\
\hline $1442.5-1477.5$ & 0.272 & 0.291 & 0.306 \\
\hline $1391.5-1442.5$ & 0.275 & 0.295 & 0.311 \\
\hline $1358.5-1391.5$ & 0.286 & 0.306 & 0.324 \\
\hline $1345.5-1358.5$ & 0.291 & 0.312 & 0.330 \\
\hline $1330.5-1345.5$ & 0.305 & 0.327 & 0.347 \\
\hline $1288.5-1330.5$ & 0.310 & 0.333 & 0.354 \\
\hline $1259.5-1288.5$ & 0.308 & 0.331 & 0.352 \\
\hline $1231.5-1259.5$ & 0.307 & 0.330 & 0.351 \\
\hline $1222.5-1231.5$ & 0.305 & 0.329 & 0.349 \\
\hline $1201.5-1222.5$ & 0.309 & 0.334 & 0.355 \\
\hline $1192.5-1201.5$ & 0.302 & 0.327 & 0.348 \\
\hline $1182.5-1192.5$ & 0.302 & 0.327 & 0.349 \\
\hline $1172.5-1182.5$ & 0.305 & 0.331 & 0.353 \\
\hline $1159.5-1172.5$ & 0.307 & 0.333 & 0.355 \\
\hline
\end{tabular}




\begin{tabular}{|c|c|c|c|}
\hline $1145.5-1159.5$ & 0.305 & 0.331 & 0.353 \\
\hline $1110.5-1145.5$ & 0.299 & 0.325 & 0.347 \\
\hline $1028.5-1110.5$ & 0.300 & 0.325 & 0.347 \\
\hline $1020.5-1028.5$ & 0.299 & 0.326 & 0.349 \\
\hline $977.5-1020.5$ & 0.305 & 0.333 & 0.356 \\
\hline $940.5-977.5$ & 0.314 & 0.342 & 0.366 \\
\hline $903.5-940.5$ & 0.315 & 0.343 & 0.368 \\
\hline $879.5-903.5$ & 0.304 & 0.333 & 0.358 \\
\hline $853.5-879.5$ & 0.303 & 0.332 & 0.356 \\
\hline $777.5-853.5$ & 0.318 & 0.348 & 0.374 \\
\hline $750.5-777.5$ & 0.324 & 0.354 & 0.380 \\
\hline $682.5-750.5$ & 0.317 & 0.345 & 0.371 \\
\hline $626.5-682.5$ & 0.308 & 0.335 & 0.360 \\
\hline $574.5-626.5$ & 0.299 & 0.325 & 0.348 \\
\hline $536.5-574.5$ & 0.298 & 0.322 & 0.344 \\
\hline $424.5-536.5$ & 0.301 & 0.323 & 0.344 \\
\hline $281.5-424.5$ & 0.304 & 0.325 & 0.346 \\
\hline $269.5-281.5$ & 0.305 & 0.325 & 0.346 \\
\hline $79.5-269.5$ & 0.305 & 0.325 & 0.345 \\
\hline
\end{tabular}

\section{A3.3 NU ice core mean-annual $\delta^{18} O$ (A.D. $\left.1001-2000\right)$}

Table A3.2. Mean-annual NU $\delta^{18} \mathrm{O}$ over the last millennium (A.D. 1001 - 2000; note data are listed columnwise in 200-year segments, and span multiple pages).

\begin{tabular}{|c|c|c|c|c|c|c|c|c|c|}
\hline $\begin{array}{l}\text { Year } \\
\text { (CE) }\end{array}$ & $\begin{array}{l}\delta^{18} \mathbf{O} \\
(\% 0)\end{array}$ & $\begin{array}{l}\text { Year } \\
(C E)\end{array}$ & $\begin{array}{l}\delta^{18} \mathbf{O} \\
(\% 0)\end{array}$ & $\begin{array}{l}\text { Year } \\
\text { (CE) }\end{array}$ & $\begin{array}{l}\delta^{18} \mathrm{O} \\
(\% 0)\end{array}$ & $\begin{array}{l}\text { Year } \\
\text { (CE) }\end{array}$ & $\begin{array}{l}\delta^{18} \mathrm{O} \\
(\% 0)\end{array}$ & $\begin{array}{l}\text { Year } \\
\text { (CE) }\end{array}$ & $\begin{array}{l}\delta^{18} \mathrm{O} \\
(\% 0)\end{array}$ \\
\hline 2000 & -21.69 & 1800 & -20.48 & 1600 & -21.48 & 1400 & -22.53 & 1200 & -19.47 \\
\hline 1999 & -22.52 & 1799 & -21.87 & 1599 & -22.03 & 1399 & -22.33 & 1199 & -20.64 \\
\hline 1998 & -22.30 & 1798 & -23.90 & 1598 & -21.48 & 1398 & -21.45 & 1198 & -21.57 \\
\hline 1997 & -22.37 & 1797 & -23.53 & 1597 & -21.39 & 1397 & -21.45 & 1197 & -21.68 \\
\hline 1996 & -22.31 & 1796 & -23.80 & 1596 & -21.11 & 1396 & -21.32 & 1196 & -21.83 \\
\hline 1995 & -20.53 & 1795 & -24.17 & 1595 & -21.31 & 1395 & -22.93 & 1195 & -21.60 \\
\hline 1994 & -22.05 & 1794 & -22.26 & 1594 & -21.78 & 1394 & -22.76 & 1194 & -22.09 \\
\hline 1993 & -23.01 & 1793 & -22.65 & 1593 & -22.30 & 1393 & -21.72 & 1193 & -23.17 \\
\hline 1992 & -22.55 & 1792 & -21.34 & 1592 & -22.13 & 1392 & -22.41 & 1192 & -23.36 \\
\hline 1991 & -21.98 & 1791 & -22.74 & 1591 & -23.16 & 1391 & -23.00 & 1191 & -22.51 \\
\hline 1990 & -23.02 & 1790 & -23.82 & 1590 & -22.31 & 1390 & -22.55 & 1190 & -21.34 \\
\hline 1989 & -23.35 & 1789 & -22.58 & 1589 & -21.67 & 1389 & -22.37 & 1189 & -21.73 \\
\hline 1988 & -23.19 & 1788 & -21.84 & 1588 & -21.79 & 1388 & -22.64 & 1188 & -22.81 \\
\hline 1987 & -22.36 & 1787 & -21.95 & 1587 & -21.06 & 1387 & -22.69 & 1187 & -22.00 \\
\hline 1986 & -21.96 & 1786 & -21.30 & 1586 & -21.82 & 1386 & -21.97 & 1186 & -20.90 \\
\hline 1985 & -21.49 & 1785 & -22.67 & 1585 & -22.09 & 1385 & -21.10 & 1185 & -20.50 \\
\hline 1984 & -22.08 & 1784 & -23.25 & 1584 & -22.50 & 1384 & -20.82 & 1184 & -20.51 \\
\hline 1983 & -24.83 & 1783 & -23.04 & 1583 & -22.49 & 1383 & -20.78 & 1183 & -20.83 \\
\hline 1982 & -24.23 & 1782 & -21.42 & 1582 & -21.58 & 1382 & -20.74 & 1182 & -21.24 \\
\hline 1981 & -22.57 & 1781 & -23.13 & 1581 & -21.11 & 1381 & -21.31 & 1181 & -21.43 \\
\hline 1980 & -22.58 & 1780 & -23.23 & 1580 & -21.45 & 1380 & -21.98 & 1180 & -20.69 \\
\hline 1979 & -22.26 & 1779 & -22.49 & 1579 & -22.23 & 1379 & -22.23 & 1179 & -20.59 \\
\hline 1978 & -22.46 & 1778 & -23.54 & 1578 & -23.11 & 1378 & -21.96 & 1178 & -21.86 \\
\hline 1977 & -21.99 & 1777 & -22.75 & 1577 & -22.55 & 1377 & -22.01 & 1177 & -22.34 \\
\hline
\end{tabular}




\begin{tabular}{|c|c|c|c|c|c|c|c|c|c|}
\hline 1976 & -22.49 & 1776 & -20.49 & 1576 & -23.50 & 1376 & -22.13 & 1176 & -22.38 \\
\hline 1975 & -23.11 & 1775 & -20.68 & 1575 & -22.84 & 1375 & -22.91 & 1175 & -22.79 \\
\hline 1974 & -21.74 & 1774 & -23.01 & 1574 & -22.38 & 1374 & -23.12 & 1174 & -23.10 \\
\hline 1973 & -21.44 & 1773 & -21.61 & 1573 & -21.71 & 1373 & -22.54 & 1173 & -22.62 \\
\hline 1972 & -22.56 & 1772 & -22.40 & 1572 & -21.56 & 1372 & -22.09 & 1172 & -22.46 \\
\hline 1971 & -23.38 & 1771 & -21.94 & 1571 & -21.76 & 1371 & -22.40 & 1171 & -22.30 \\
\hline 1970 & -21.62 & 1770 & -22.57 & 1570 & -22.43 & 1370 & -21.52 & 1170 & -21.17 \\
\hline 1969 & -21.39 & 1769 & -21.04 & 1569 & -21.94 & 1369 & -21.75 & 1169 & -21.11 \\
\hline 1968 & -20.62 & 1768 & -22.44 & 1568 & -20.14 & 1368 & -22.06 & 1168 & -22.31 \\
\hline 1967 & -21.89 & 1767 & -22.83 & 1567 & -20.63 & 1367 & -21.64 & 1167 & -22.80 \\
\hline 1966 & -22.12 & 1766 & -22.07 & 1566 & -21.68 & 1366 & -21.55 & 1166 & -22.65 \\
\hline 1965 & -22.22 & 1765 & -21.24 & 1565 & -21.75 & 1365 & -22.22 & 1165 & -22.75 \\
\hline 1964 & -21.42 & 1764 & -21.49 & 1564 & -22.21 & 1364 & -22.33 & 1164 & -23.01 \\
\hline 1963 & -21.61 & 1763 & -20.42 & 1563 & -22.82 & 1363 & -22.89 & 1163 & -22.52 \\
\hline 1962 & -20.03 & 1762 & -20.81 & 1562 & -23.31 & 1362 & -22.05 & 1162 & -22.73 \\
\hline 1961 & -22.74 & 1761 & -22.26 & 1561 & -23.67 & 1361 & -21.61 & 1161 & -22.23 \\
\hline 1960 & -22.18 & 1760 & -22.76 & 1560 & -23.15 & 1360 & -21.67 & 1160 & -21.93 \\
\hline 1959 & -21.84 & 1759 & -21.76 & 1559 & -23.10 & 1359 & -21.78 & 1159 & -22.00 \\
\hline 1958 & -22.93 & 1758 & -21.94 & 1558 & -21.62 & 1358 & -22.20 & 1158 & -22.07 \\
\hline 1957 & -22.01 & 1757 & -22.71 & 1557 & -20.98 & 1357 & -21.37 & 1157 & -22.06 \\
\hline 1956 & -21.88 & 1756 & -23.32 & 1556 & -20.65 & 1356 & -20.64 & 1156 & -21.39 \\
\hline 1955 & -21.19 & 1755 & -22.56 & 1555 & -21.43 & 1355 & -20.70 & 1155 & -20.48 \\
\hline 1954 & -22.14 & 1754 & -21.68 & 1554 & -22.44 & 1354 & -20.49 & 1154 & -20.73 \\
\hline 1953 & -22.59 & 1753 & -22.17 & 1553 & -22.04 & 1353 & -21.88 & 1153 & -20.95 \\
\hline 1952 & -21.73 & 1752 & -23.72 & 1552 & -21.74 & 1352 & -21.64 & 1152 & -20.81 \\
\hline 1951 & -22.48 & 1751 & -22.50 & 1551 & -22.01 & 1351 & -20.49 & 1151 & -20.87 \\
\hline 1950 & -22.16 & 1750 & -21.66 & 1550 & -22.61 & 1350 & -20.10 & 1150 & -21.91 \\
\hline 1949 & -21.50 & 1749 & -22.11 & 1549 & -22.60 & 1349 & -20.16 & 1149 & -22.64 \\
\hline 1948 & -21.30 & 1748 & -23.69 & 1548 & -21.63 & 1348 & -20.69 & 1148 & -23.11 \\
\hline 1947 & -21.72 & 1747 & -22.67 & 1547 & -22.28 & 1347 & -21.70 & 1147 & -22.85 \\
\hline 1946 & -22.57 & 1746 & -21.87 & 1546 & -23.35 & 1346 & -21.85 & 1146 & -22.54 \\
\hline 1945 & -23.65 & 1745 & -22.10 & 1545 & -22.36 & 1345 & -22.34 & 1145 & -22.19 \\
\hline 1944 & -23.61 & 1744 & -21.54 & 1544 & -21.48 & 1344 & -22.86 & 1144 & -21.68 \\
\hline 1943 & -21.97 & 1743 & -21.39 & 1543 & -21.78 & 1343 & -23.21 & 1143 & -21.02 \\
\hline 1942 & -21.03 & 1742 & -20.86 & 1542 & -21.34 & 1342 & -24.56 & 1142 & -21.30 \\
\hline 1941 & -22.40 & 1741 & -21.15 & 1541 & -20.83 & 1341 & -22.79 & 1141 & -21.72 \\
\hline 1940 & -21.25 & 1740 & -21.29 & 1540 & -22.23 & 1340 & -21.15 & 1140 & -21.94 \\
\hline 1939 & -21.03 & 1739 & -21.21 & 1539 & -22.73 & 1339 & -22.42 & 1139 & -22.20 \\
\hline 1938 & -22.73 & 1738 & -21.08 & 1538 & -22.52 & 1338 & -23.03 & 1138 & -22.68 \\
\hline 1937 & -22.70 & 1737 & -21.51 & 1537 & -21.62 & 1337 & -21.47 & 1137 & -22.96 \\
\hline 1936 & -22.62 & 1736 & -20.89 & 1536 & -21.72 & 1336 & -21.79 & 1136 & -22.41 \\
\hline 1935 & -22.73 & 1735 & -20.92 & 1535 & -22.04 & 1335 & -22.83 & 1135 & -22.27 \\
\hline 1934 & -22.65 & 1734 & -22.25 & 1534 & -23.56 & 1334 & -23.45 & 1134 & -22.31 \\
\hline 1933 & -22.83 & 1733 & -23.10 & 1533 & -23.46 & 1333 & -23.02 & 1133 & -22.35 \\
\hline 1932 & -20.72 & 1732 & -22.26 & 1532 & -22.83 & 1332 & -22.95 & 1132 & -22.39 \\
\hline 1931 & -21.00 & 1731 & -20.26 & 1531 & -22.33 & 1331 & -22.65 & 1131 & -22.43 \\
\hline 1930 & -21.85 & 1730 & -20.98 & 1530 & -21.73 & 1330 & -22.18 & 1130 & -22.47 \\
\hline 1929 & -20.45 & 1729 & -19.95 & 1529 & -21.76 & 1329 & -21.21 & 1129 & -22.50 \\
\hline 1928 & -20.57 & 1728 & -19.05 & 1528 & -22.26 & 1328 & -21.21 & 1128 & -22.29 \\
\hline 1927 & -22.54 & 1727 & -20.48 & 1527 & -22.19 & 1327 & -21.61 & 1127 & -22.00 \\
\hline 1926 & -22.25 & 1726 & -22.11 & 1526 & -21.61 & 1326 & -22.67 & 1126 & -21.71 \\
\hline 1925 & -22.68 & 1725 & -20.81 & 1525 & -21.28 & 1325 & -22.93 & 1125 & -21.41 \\
\hline 1924 & -21.80 & 1724 & -21.90 & 1524 & -21.40 & 1324 & -22.95 & 1124 & -21.13 \\
\hline 1923 & -21.03 & 1723 & -22.53 & 1523 & -22.68 & 1323 & -22.71 & 1123 & -21.02 \\
\hline 1922 & -22.45 & 1722 & -22.81 & 1522 & -22.68 & 1322 & -22.97 & 1122 & -20.90 \\
\hline
\end{tabular}




\begin{tabular}{|c|c|c|c|c|c|c|c|c|c|}
\hline 1921 & -23.23 & 1721 & -22.17 & 1521 & -22.80 & 1321 & -21.83 & 1121 & -20.97 \\
\hline 1920 & -23.35 & 1720 & -21.22 & 1520 & -23.38 & 1320 & -22.27 & 1120 & -21.37 \\
\hline 1919 & -22.85 & 1719 & -22.16 & 1519 & -22.03 & 1319 & -23.13 & 1119 & -21.75 \\
\hline 1918 & -23.57 & 1718 & -22.84 & 1518 & -22.59 & 1318 & -22.70 & 1118 & -21.98 \\
\hline 1917 & -21.53 & 1717 & -21.82 & 1517 & -22.22 & 1317 & -22.34 & 1117 & -22.32 \\
\hline 1916 & -20.19 & 1716 & -22.34 & 1516 & -21.67 & 1316 & -22.30 & 1116 & -22.67 \\
\hline 1915 & -21.23 & 1715 & -23.19 & 1515 & -22.13 & 1315 & -22.77 & 1115 & -22.44 \\
\hline 1914 & -23.05 & 1714 & -22.25 & 1514 & -22.84 & 1314 & -22.77 & 1114 & -22.23 \\
\hline 1913 & -21.86 & 1713 & -22.75 & 1513 & -22.50 & 1313 & -21.50 & 1113 & -23.14 \\
\hline 1912 & -21.01 & 1712 & -23.75 & 1512 & -23.98 & 1312 & -21.71 & 1112 & -22.17 \\
\hline 1911 & -22.53 & 1711 & -22.92 & 1511 & -22.45 & 1311 & -21.30 & 1111 & -21.19 \\
\hline 1910 & -23.30 & 1710 & -22.07 & 1510 & -22.38 & 1310 & -20.30 & 1110 & -21.05 \\
\hline 1909 & -21.33 & 1709 & -21.25 & 1509 & -22.65 & 1309 & -21.28 & 1109 & -21.43 \\
\hline 1908 & -20.56 & 1708 & -20.95 & 1508 & -21.57 & 1308 & -22.46 & 1108 & -22.01 \\
\hline 1907 & -22.09 & 1707 & -20.69 & 1507 & -21.82 & 1307 & -21.47 & 1107 & -23.53 \\
\hline 1906 & -22.56 & 1706 & -21.42 & 1506 & -21.71 & 1306 & -20.32 & 1106 & -24.92 \\
\hline 1905 & -22.94 & 1705 & -22.49 & 1505 & -22.11 & 1305 & -20.47 & 1105 & -23.06 \\
\hline 1904 & -21.17 & 1704 & -21.94 & 1504 & -22.53 & 1304 & -21.81 & 1104 & -22.29 \\
\hline 1903 & -20.02 & 1703 & -21.65 & 1503 & -22.71 & 1303 & -22.15 & 1103 & -22.35 \\
\hline 1902 & -22.26 & 1702 & -22.33 & 1502 & -22.17 & 1302 & -22.19 & 1102 & -22.39 \\
\hline 1901 & -21.76 & 1701 & -20.59 & 1501 & -21.76 & 1301 & -21.57 & 1101 & -21.93 \\
\hline 1900 & -21.62 & 1700 & -20.64 & 1500 & -22.22 & 1300 & -21.10 & 1100 & -21.23 \\
\hline 1899 & -22.42 & 1699 & -20.92 & 1499 & -21.12 & 1299 & -21.27 & 1099 & -21.45 \\
\hline 1898 & -23.13 & 1698 & -21.39 & 1498 & -20.45 & 1298 & -21.61 & 1098 & -22.42 \\
\hline 1897 & -21.14 & 1697 & -21.94 & 1497 & -20.87 & 1297 & -22.07 & 1097 & -22.27 \\
\hline 1896 & -21.42 & 1696 & -22.95 & 1496 & -21.94 & 1296 & -22.71 & 1096 & -21.30 \\
\hline 1895 & -21.11 & 1695 & -22.49 & 1495 & -22.03 & 1295 & -21.91 & 1095 & -21.09 \\
\hline 1894 & -21.74 & 1694 & -21.98 & 1494 & -21.35 & 1294 & -21.76 & 1094 & -22.32 \\
\hline 1893 & -21.00 & 1693 & -22.75 & 1493 & -21.92 & 1293 & -21.70 & 1093 & -22.28 \\
\hline 1892 & -20.58 & 1692 & -23.15 & 1492 & -23.14 & 1292 & -21.99 & 1092 & -21.06 \\
\hline 1891 & -20.96 & 1691 & -22.74 & 1491 & -23.75 & 1291 & -22.42 & 1091 & -20.45 \\
\hline 1890 & -21.80 & 1690 & -22.33 & 1490 & -22.87 & 1290 & -21.46 & 1090 & -21.24 \\
\hline 1889 & -21.31 & 1689 & -21.20 & 1489 & -20.86 & 1289 & -20.77 & 1089 & -21.36 \\
\hline 1888 & -21.47 & 1688 & -21.29 & 1488 & -21.20 & 1288 & -21.74 & 1088 & -21.37 \\
\hline 1887 & -22.50 & 1687 & -22.18 & 1487 & -21.72 & 1287 & -21.98 & 1087 & -22.11 \\
\hline 1886 & -22.02 & 1686 & -22.44 & 1486 & -21.87 & 1286 & -22.28 & 1086 & -22.79 \\
\hline 1885 & -21.67 & 1685 & -21.64 & 1485 & -22.85 & 1285 & -21.59 & 1085 & -21.85 \\
\hline 1884 & -24.17 & 1684 & -21.46 & 1484 & -21.84 & 1284 & -21.28 & 1084 & -21.90 \\
\hline 1883 & -21.28 & 1683 & -22.72 & 1483 & -22.23 & 1283 & -21.09 & 1083 & -22.42 \\
\hline 1882 & -22.28 & 1682 & -23.34 & 1482 & -22.31 & 1282 & -21.96 & 1082 & -23.18 \\
\hline 1881 & -21.14 & 1681 & -23.30 & 1481 & -21.01 & 1281 & -21.44 & 1081 & -23.53 \\
\hline 1880 & -20.66 & 1680 & -23.02 & 1480 & -22.69 & 1280 & -21.41 & 1080 & -22.43 \\
\hline 1879 & -20.87 & 1679 & -21.82 & 1479 & -22.88 & 1279 & -21.77 & 1079 & -22.62 \\
\hline 1878 & -21.00 & 1678 & -22.28 & 1478 & -22.53 & 1278 & -21.56 & 1078 & -22.83 \\
\hline 1877 & -21.71 & 1677 & -22.20 & 1477 & -21.56 & 1277 & -21.12 & 1077 & -22.77 \\
\hline 1876 & -22.66 & 1676 & -22.11 & 1476 & -21.71 & 1276 & -21.67 & 1076 & -23.04 \\
\hline 1875 & -23.05 & 1675 & -22.00 & 1475 & -21.07 & 1275 & -22.23 & 1075 & -22.75 \\
\hline 1874 & -22.43 & 1674 & -22.35 & 1474 & -21.63 & 1274 & -22.50 & 1074 & -22.97 \\
\hline 1873 & -21.02 & 1673 & -22.00 & 1473 & -22.24 & 1273 & -22.23 & 1073 & -22.55 \\
\hline 1872 & -21.52 & 1672 & -22.16 & 1472 & -23.08 & 1272 & -21.51 & 1072 & -22.00 \\
\hline 1871 & -20.38 & 1671 & -20.71 & 1471 & -23.43 & 1271 & -21.63 & 1071 & -20.95 \\
\hline 1870 & -21.66 & 1670 & -21.46 & 1470 & -21.82 & 1270 & -22.59 & 1070 & -20.45 \\
\hline 1869 & -21.95 & 1669 & -21.78 & 1469 & -21.87 & 1269 & -22.88 & 1069 & -20.81 \\
\hline 1868 & -22.23 & 1668 & -21.87 & 1468 & -22.40 & 1268 & -21.98 & 1068 & -21.19 \\
\hline 1867 & -22.08 & 1667 & -22.57 & 1467 & -21.82 & 1267 & -21.83 & 1067 & -21.47 \\
\hline
\end{tabular}




\begin{tabular}{|c|c|c|c|c|c|c|c|c|c|}
\hline 1866 & -22.27 & 1666 & -22.57 & 1466 & -22.97 & 1266 & -22.92 & 1066 & -21.77 \\
\hline 1865 & -22.54 & 1665 & -22.06 & 1465 & -22.61 & 1265 & -23.37 & 1065 & -21.94 \\
\hline 1864 & -22.17 & 1664 & -20.71 & 1464 & -22.08 & 1264 & -23.22 & 1064 & -21.43 \\
\hline 1863 & -24.09 & 1663 & -21.01 & 1463 & -21.33 & 1263 & -22.67 & 1063 & -21.16 \\
\hline 1862 & -23.00 & 1662 & -21.68 & 1462 & -20.37 & 1262 & -22.75 & 1062 & -21.84 \\
\hline 1861 & -22.29 & 1661 & -21.16 & 1461 & -21.77 & 1261 & -22.62 & 1061 & -22.14 \\
\hline 1860 & -22.02 & 1660 & -22.78 & 1460 & -21.96 & 1260 & -22.37 & 1060 & -21.86 \\
\hline 1859 & -20.86 & 1659 & -22.55 & 1459 & -21.38 & 1259 & -22.16 & 1059 & -21.17 \\
\hline 1858 & -22.75 & 1658 & -21.82 & 1458 & -22.63 & 1258 & -22.34 & 1058 & -21.17 \\
\hline 1857 & -23.46 & 1657 & -23.60 & 1457 & -21.30 & 1257 & -22.17 & 1057 & -21.45 \\
\hline 1856 & -21.38 & 1656 & -21.77 & 1456 & -21.87 & 1256 & -21.10 & 1056 & -21.68 \\
\hline 1855 & -21.77 & 1655 & -21.08 & 1455 & -21.91 & 1255 & -20.43 & 1055 & -21.93 \\
\hline 1854 & -22.19 & 1654 & -20.48 & 1454 & -22.65 & 1254 & -20.89 & 1054 & -21.81 \\
\hline 1853 & -22.69 & 1653 & -21.90 & 1453 & -22.21 & 1253 & -20.84 & 1053 & -21.63 \\
\hline 1852 & -22.36 & 1652 & -22.13 & 1452 & -21.66 & 1252 & -20.68 & 1052 & -21.58 \\
\hline 1851 & -20.37 & 1651 & -21.75 & 1451 & -21.54 & 1251 & -20.51 & 1051 & -21.88 \\
\hline 1850 & -23.00 & 1650 & -21.93 & 1450 & -21.89 & 1250 & -20.34 & 1050 & -21.89 \\
\hline 1849 & -22.93 & 1649 & -22.47 & 1449 & -21.40 & 1249 & -20.16 & 1049 & -22.28 \\
\hline 1848 & -22.13 & 1648 & -22.84 & 1448 & -20.78 & 1248 & -19.99 & 1048 & -23.17 \\
\hline 1847 & -20.65 & 1647 & -21.88 & 1447 & -21.75 & 1247 & -20.74 & 1047 & -23.29 \\
\hline 1846 & -22.19 & 1646 & -22.32 & 1446 & -21.84 & 1246 & -22.46 & 1046 & -23.06 \\
\hline 1845 & -21.11 & 1645 & -22.34 & 1445 & -21.78 & 1245 & -21.51 & 1045 & -22.27 \\
\hline 1844 & -21.65 & 1644 & -22.85 & 1444 & -21.40 & 1244 & -21.48 & 1044 & -21.60 \\
\hline 1843 & -21.23 & 1643 & -22.62 & 1443 & -22.47 & 1243 & -21.31 & 1043 & -20.97 \\
\hline 1842 & -22.24 & 1642 & -21.76 & 1442 & -22.93 & 1242 & -20.99 & 1042 & -20.96 \\
\hline 1841 & -21.41 & 1641 & -22.39 & 1441 & -23.34 & 1241 & -20.86 & 1041 & -21.39 \\
\hline 1840 & -21.94 & 1640 & -22.58 & 1440 & -23.33 & 1240 & -21.77 & 1040 & -22.10 \\
\hline 1839 & -21.39 & 1639 & -22.18 & 1439 & -22.32 & 1239 & -21.93 & 1039 & -22.49 \\
\hline 1838 & -22.27 & 1638 & -22.66 & 1438 & -21.60 & 1238 & -21.38 & 1038 & -22.47 \\
\hline 1837 & -22.62 & 1637 & -22.67 & 1437 & -22.38 & 1237 & -22.29 & 1037 & -22.36 \\
\hline 1836 & -22.00 & 1636 & -22.61 & 1436 & -22.06 & 1236 & -22.06 & 1036 & -21.96 \\
\hline 1835 & -20.39 & 1635 & -23.16 & 1435 & -22.41 & 1235 & -21.72 & 1035 & -21.74 \\
\hline 1834 & -21.49 & 1634 & -22.16 & 1434 & -22.37 & 1234 & -22.38 & 1034 & -21.92 \\
\hline 1833 & -21.07 & 1633 & -21.17 & 1433 & -21.22 & 1233 & -22.10 & 1033 & -22.08 \\
\hline 1832 & -21.13 & 1632 & -21.64 & 1432 & -21.53 & 1232 & -21.65 & 1032 & -22.13 \\
\hline 1831 & -19.86 & 1631 & -22.58 & 1431 & -22.14 & 1231 & -21.93 & 1031 & -22.02 \\
\hline 1830 & -21.15 & 1630 & -21.31 & 1430 & -22.18 & 1230 & -22.85 & 1030 & -22.00 \\
\hline 1829 & -21.91 & 1629 & -22.52 & 1429 & -21.59 & 1229 & -23.07 & 1029 & -21.92 \\
\hline 1828 & -23.13 & 1628 & -22.20 & 1428 & -21.56 & 1228 & -22.85 & 1028 & -22.04 \\
\hline 1827 & -22.67 & 1627 & -21.63 & 1427 & -22.36 & 1227 & -22.05 & 1027 & -21.85 \\
\hline 1826 & -22.49 & 1626 & -21.85 & 1426 & -22.10 & 1226 & -21.92 & 1026 & -21.76 \\
\hline 1825 & -22.65 & 1625 & -21.93 & 1425 & -23.02 & 1225 & -22.04 & 1025 & -22.10 \\
\hline 1824 & -21.88 & 1624 & -23.65 & 1424 & -22.56 & 1224 & -21.83 & 1024 & -22.44 \\
\hline 1823 & -19.93 & 1623 & -23.00 & 1423 & -21.64 & 1223 & -20.86 & 1023 & -22.29 \\
\hline 1822 & -21.91 & 1622 & -21.77 & 1422 & -20.76 & 1222 & -20.17 & 1022 & -21.88 \\
\hline 1821 & -22.35 & 1621 & -20.88 & 1421 & -22.00 & 1221 & -21.00 & 1021 & -21.84 \\
\hline 1820 & -20.95 & 1620 & -21.47 & 1420 & -22.02 & 1220 & -21.52 & 1020 & -22.18 \\
\hline 1819 & -21.48 & 1619 & -21.76 & 1419 & -21.46 & 1219 & -21.90 & 1019 & -22.39 \\
\hline 1818 & -21.12 & 1618 & -21.80 & 1418 & -21.32 & 1218 & -22.30 & 1018 & -22.21 \\
\hline 1817 & -21.46 & 1617 & -21.22 & 1417 & -20.18 & 1217 & -21.72 & 1017 & -22.03 \\
\hline 1816 & -21.93 & 1616 & -20.04 & 1416 & -21.31 & 1216 & -22.32 & 1016 & -22.20 \\
\hline 1815 & -21.69 & 1615 & -21.69 & 1415 & -22.69 & 1215 & -22.32 & 1015 & -22.83 \\
\hline 1814 & -22.55 & 1614 & -22.29 & 1414 & -22.54 & 1214 & -22.84 & 1014 & -22.87 \\
\hline 1813 & -23.35 & 1613 & -23.97 & 1413 & -21.54 & 1213 & -22.04 & 1013 & -22.78 \\
\hline 1812 & -22.67 & 1612 & -23.86 & 1412 & -21.30 & 1212 & -21.41 & 1012 & -23.10 \\
\hline
\end{tabular}




\begin{tabular}{|l|l|l|l|l|l|l|l|l|l|}
\hline 1811 & -22.70 & 1611 & -24.06 & 1411 & -21.97 & 1211 & -21.22 & 1011 & -22.83 \\
\hline 1810 & -22.82 & 1610 & -24.09 & 1410 & -21.36 & 1210 & -21.48 & 1010 & -22.45 \\
\hline 1809 & -22.04 & 1609 & -22.05 & 1409 & -20.59 & 1209 & -22.08 & 1009 & -22.41 \\
\hline 1808 & -21.43 & 1608 & -23.18 & 1408 & -21.04 & 1208 & -22.05 & 1008 & -22.31 \\
\hline 1807 & -22.56 & 1607 & -21.90 & 1407 & -22.06 & 1207 & -22.02 & 1007 & -21.97 \\
\hline 1806 & -20.87 & 1606 & -20.41 & 1406 & -21.91 & 1206 & -21.98 & 1006 & -21.81 \\
\hline 1805 & -22.76 & 1605 & -20.70 & 1405 & -22.46 & 1205 & -22.06 & 1005 & -21.58 \\
\hline 1804 & -21.81 & 1604 & -22.40 & 1404 & -22.56 & 1204 & -21.67 & 1004 & -21.53 \\
\hline 1803 & -21.21 & 1603 & -21.55 & 1403 & -22.97 & 1203 & -21.55 & 1003 & -21.02 \\
\hline 1802 & -21.68 & 1602 & -20.99 & 1402 & -21.86 & 1202 & -22.51 & 1002 & -21.38 \\
\hline 1801 & -21.49 & 1601 & -22.60 & 1401 & -21.10 & 1201 & -22.36 & 1001 & -22.14 \\
\hline
\end{tabular}




\title{
Appendix 4. Trusel et al. (2018) - Nonlinear rise in Greenland runoff in response to post-industrial Arctic warming
}

This chapter was originally published as: Trusel, L. D., Das, S. B., Osman, M. B., Evans, M. J., Smith, B. E., Fettweis, X., van den Broeke, M. R. (2018). Nonlinear rise in Greenland runoff in response to post-industrial Arctic warming. Nature, 564(7734), 104-108. https://doi.org/10.1038/s41586-0180752-4. Used with permission as granted in the original copyright agreement.

\begin{abstract}
The Greenland ice sheet (GrIS) is a growing contributor to global sea-level rise, with recent ice mass loss dominated by surface meltwater runoff. Satellite observations reveal positive trends in GrIS surface melt extent, but melt variability, intensity and runoff remain uncertain before the satellite era. Here we present the first continuous, multi-century and observationally constrained record of GrIS surface melt intensity and runoff, revealing that the magnitude of recent GrIS melting is exceptional over at least the last 350 years. We develop this record through stratigraphic analysis of central west Greenland ice cores, and demonstrate that measurements of refrozen melt layers in percolation zone ice cores can be used to quantifiably, and reproducibly, reconstruct past melt rates. We show significant $(p<0.01)$ and spatially extensive correlations between these ice-core-derived melt records and modelled melt rates and satellite-derived melt duration across Greenland more broadly, enabling the reconstruction of past ice-sheet-scale surface melt intensity and runoff. We find that the initiation of increases in GrIS melting closely follow the onset of industrial-era Arctic warming in the mid-1800s, but that the magnitude of GrIS melting has only recently emerged beyond the range of natural variability. Owing to a nonlinear response of surface melting to increasing summer air temperatures, continued atmospheric warming will lead to rapid increases in GrIS runoff and sea-level contributions.
\end{abstract}




\section{Nonlinear rise in Greenland runoff in response to post-industrial Arctic warming}

Luke D. Trusel ${ }^{1,2 *}$, Sarah B. Das ${ }^{2}$, Matthew B. Osman ${ }^{3}$, Matthew J. Evans ${ }^{4}$, Ben E. Smith ${ }^{5}$, Xavier Fettweis ${ }^{6}$, Joseph R. McConnell ${ }^{7}$, Brice P. Y. Noël $1^{8}$ \& Michiel R. van den Broeke ${ }^{8}$

The Greenland ice sheet (GrIS) is a growing contributor to global sea-level rise ${ }^{1}$, with recent ice mass loss dominated by surface meltwater runoff ${ }^{2,3}$. Satellite observations reveal positive trends in GrIS surface melt extent ${ }^{4}$, but melt variability, intensity and runoff remain uncertain before the satellite era. Here we present the first continuous, multi-century and observationally constrained record of GrIS surface melt intensity and runoff, revealing that the magnitude of recent GrIS melting is exceptional over at least the last 350 years. We develop this record through stratigraphic analysis of central west Greenland ice cores, and demonstrate that measurements of refrozen melt layers in percolation zone ice cores can be used to quantifiably, and reproducibly, reconstruct past melt rates. We show significant $(P<0.01)$ and spatially extensive correlations between these ice-core-derived melt records and modelled melt rates ${ }^{5,6}$ and satellite-derived melt duration ${ }^{4}$ across Greenland more broadly, enabling the reconstruction of past ice-sheet-scale surface melt intensity and runoff. We find that the initiation of increases in GrIS melting closely follow the onset of industrial-era Arctic warming in the mid-1800s, but that the magnitude of GrIS melting has only recently emerged beyond the range of natural variability. Owing to a nonlinear response of surface melting to increasing summer air temperatures, continued atmospheric warming will lead to rapid increases in GrIS runoff and sea-level contributions.

Melting across higher elevations of the GrIS results in liquid water infiltration, percolation, and either refreezing or storage within the porous firn layer. Such processes reduce ice-sheet surface albedo, increase firn temperatures ${ }^{7}$, and may generate impermeable ice layers that exacerbate ice-sheet runoff ${ }^{8}$, the proportion of surface melt leaving the ice sheet. Runoff across the margins of the GrIS is presently the leading source of mass loss from the ice sheet ${ }^{2,3,6}$, and has been implicated in the centennial-scale slowdown of the overturning circulation in the North Atlantic Ocean ${ }^{9}$.

GrIS surface melting in 2012 was more expansive than at any time over the 40 years since we started measuring melt using satellites (in 1978) ${ }^{4}$. Proposed mechanisms driving melt in 2012 include contributions from anomalous radiative ${ }^{10-12}$ and non-radiative ${ }^{13}$ energy fluxes, and anticyclonic atmospheric circulation favouring advection of warm, dry air and clear sky conditions ${ }^{14}$. An ice core record from Summit Station (Fig. 1) demonstrated the exceptional nature of 2012 melt at high elevation (about 3,200 m), revealing ${ }^{15}$ that it last occurred at this site in 1889. At lower elevations, where melt occurs more frequently and at greater rates, there exist only limited ice-core-derived reconstructions of melt variability ${ }^{16-18}$ and no quantifiable ice-core-based reconstructions of melt intensity or runoff. Furthermore, large discrepancies among reanalysis products over Greenland before the midtwentieth century ${ }^{6,19}$ limit their utility over longer timescales. Consequently, the true anomaly of recent melt intensity and runoff, and the longer-term evolution of these processes in response to climate forcing, remain poorly constrained.
Here we analyse refrozen melt layer stratigraphy in ice cores from central west Greenland (CWG) drilled between 2003 and 2015 to quantify annual melting over the last several centuries (Methods; Extended Data Fig. 1a). Significant co-variability between records from two cores separated by about $40 \mathrm{~km}$ in the western GrIS accumulation area (cores GC and D5; Fig. 1) indicates that regional melt, percolation and refreezing are well preserved and represented in these multi-century cores (Fig. 2 inset; Methods). We combine records from cores GC and D5 with a shallower core (core GW; Fig. 1, Extended Data Fig. 1b) to create a single 339-year stacked CWG record (Methods). CWG reveals frequent, but generally low-magnitude, melting during the last three centuries, with approximately 13-year periodicity and a marked departure from low-melt conditions over the last two decades (Fig. 2). We develop a complementary 364-year melt record using a fourth core (core NU) recovered from an ice cap on Nuussuaq Peninsula (Fig. 1) in 2015. The NU core record contains a greater overall magnitude of melt than the CWG combined core record owing to its lower elevation and coastal location (Extended Data Table 1), similar 13-16-year oscillations, and a distinct departure from baseline conditions in recent decades (Fig. 2). Common periodicities in the CWG and NU melt records suggest the influence of multiple known climate modes on melt variability (Extended Data Fig. 2; Methods). In all cores, there is also a clear pattern towards more frequent, thicker (and thus more intense) melt layers towards the present day (Extended Data Fig. 1c).

Our results show a pronounced $250 \%$ to $575 \%$ increase in melt intensity over the last 20 years, relative to a pre-industrial baseline period (eighteenth century) for cores NU and CWG, respectively (Fig. 2). Furthermore, the most recent decade contained in the cores (20042013) experienced a more sustained and greater magnitude of melt than any other 10-year period in the ice-core records. For GrIS cores, 2012 melt is unambiguously the strongest melt season on record. Both NU and CWG annual ice-core-derived melt records significantly $(P<0.01)$ correlate with one another over their 339 years of overlap, and both also with summer air temperatures from the Ilulissat region (Extended Data Table 2; Methods), relationships that improve after applying a 5-year moving average, probably reflecting the noise inherent to melt records owing to variability in meltwater percolation and refreezing ${ }^{8,16}$. These empirically derived results revealing coherence between independent melt and temperature records emphasize broad-scale GrIS melt forcing, and suggest that summer warming (see Fig. 2) is an important component of the observed regional melt intensification.

GrIS ice cores provide a valuable point-scale view of melt history within the percolation zone, but records of past melt variability within the GrIS saturation and bare ice zones, where melt is more directly tied to mass loss and runoff, have remained elusive. To assess whether our ice-core-derived melt records also serve as quantitative archives of past regional-scale melt variability and intensity, we examine correlations between the CWG stack and recent modelled and observed melt parameters across the entire GrIS (Fig. 3; Methods). We find

\footnotetext{
${ }^{1}$ Department of Geology, Rowan University, Glassboro, NJ, USA. ${ }^{2}$ Department of Geology and Geophysics, Woods Hole Oceanographic Institution, Woods Hole, MA, USA. ${ }^{3}$ Joint Program in Oceanography, Massachusetts Institute of Technology/Woods Hole Oceanographic Institution, Woods Hole, MA, USA. ${ }^{4}$ Department of Chemistry, Wheaton College, Norton, MA, USA. ${ }^{5}$ Polar Science Center, Applied Physics Laboratory, University of Washington, Seattle, WA, USA. ${ }^{6}$ Department of Geography, University of Liège, Liège, Belgium. ${ }^{7}$ Division of Hydrologic Sciences, Desert Research
} Institute, Reno, NV, USA. ${ }^{8}$ Institute for Marine and Atmospheric Research, Utrecht University, Utrecht, Netherlands. *e-mail: trusel@rowan.edu 
a

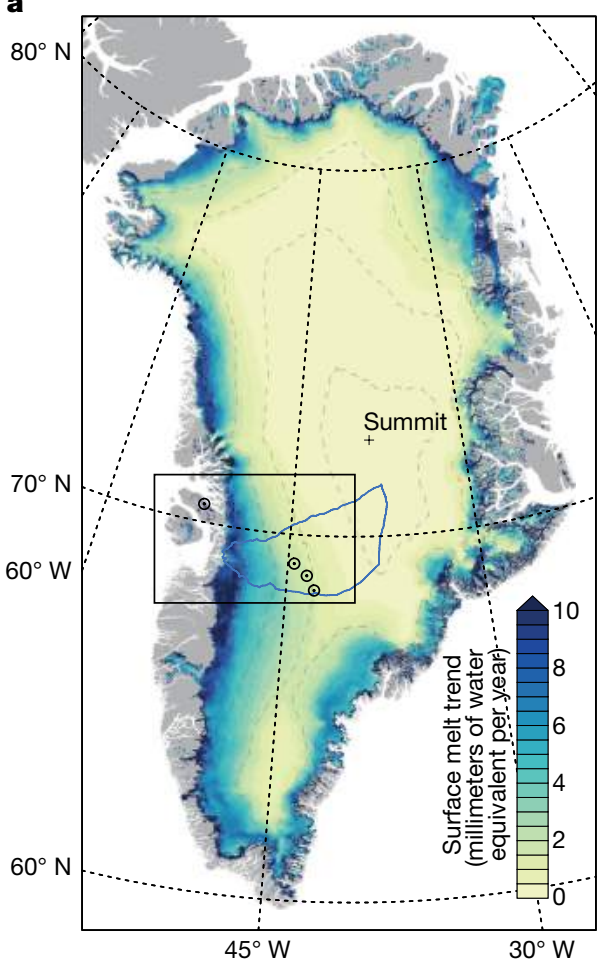

Fig. 1 Positive trends in Greenland surface melt and locations of ice cores used to reconstruct past surface melt variability. a, Positive trends in annual surface meltwater production over 1958-2016, as simulated by RACMO2.3p $2^{5}$. b, Locations of our ice cores situated within the Jakobshavn drainage basin (blue outline; basin 7.1) of CWG and on the

wide-ranging significant $(P<0.01)$ positive correlations between the CWG melt record and RACMO2-modelled ${ }^{5}$ melt (Fig. 3a) and refreezing (Fig. 3b), as well as satellite-observed melt duration ${ }^{4}$ (Fig. 3d). Further supporting these results are significant $(P<0.01)$ relationships between our NU and CWG melt records and long-term pan-Greenland air temperature observations (Extended Data Table 3; Methods). Moreover, we find significant $(P<0.01)$ and wide-ranging correlations
Nuussuaq Peninsula, as well as air-temperature observations integrated into a composite Ilulissat air-temperature record (Methods; Extended Data Table 2). The satellite image in $\mathbf{b}$ was obtained with the NASA MODIS instrument (from the NASA Rapid Response data archive).

between the ice-core-derived melt record and RACMO2-simulated meltwater runoff across the ice-sheet margins (Fig. 3c). These ice-core model relationships indicate that rates of meltwater production, refreezing and runoff across much of Greenland are all at multi-century highs, assuming that the spatial character of melt and high correlations between modelled GrIS-integrated melt, refreezing, and runoff are robust and have remained stationary through time (Extended Data Fig. 4).

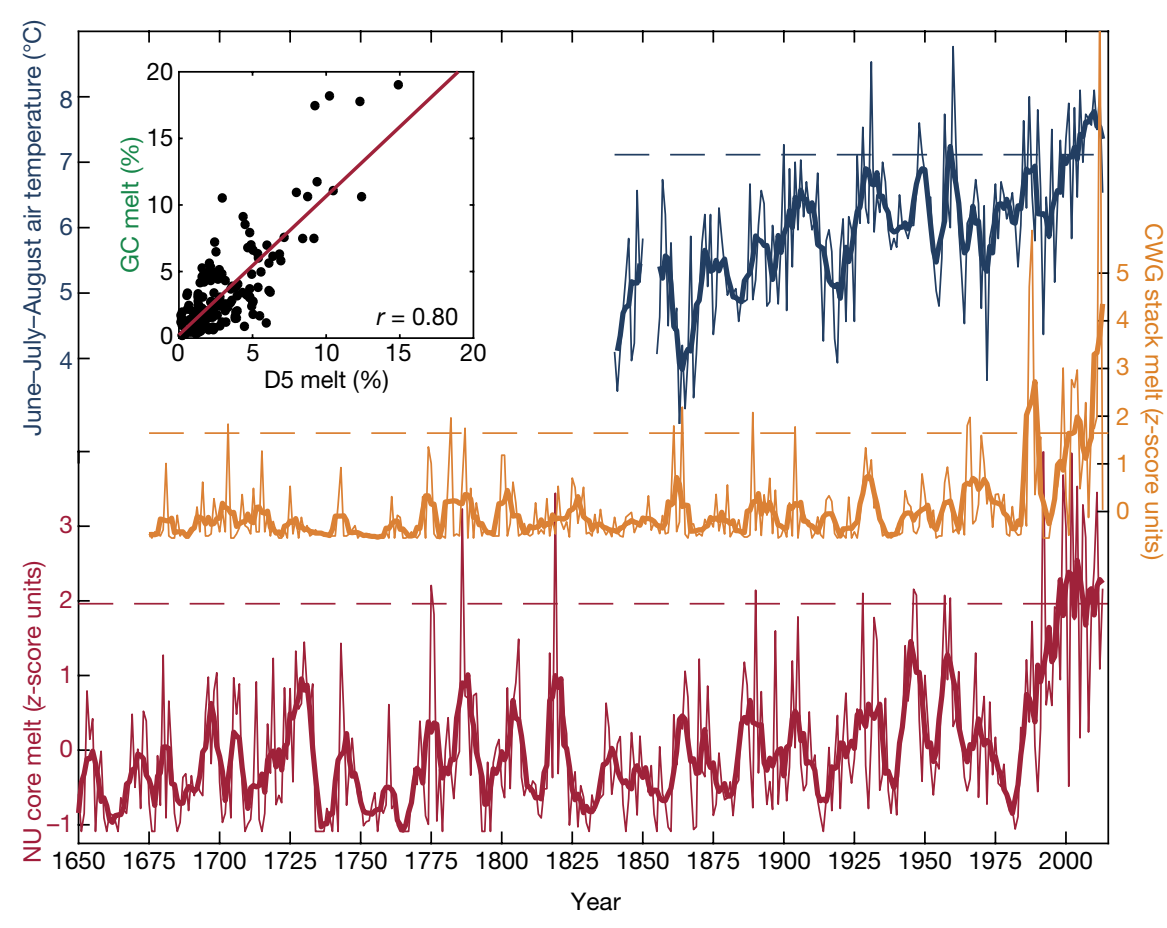

Fig. $2 \mid$ Multi-century evolution of CWG surface melt from ice cores. Observed summer (June-August) air temperatures from the Ilulissat area and melt intensity (in standardized $z$-score units) from the CWG ice-core-derived melt stack and from the NU core on Nuussuaq Peninsula (see Methods). Horizontal dashed lines show means over the last twenty years of the ice-core records (1994-2013). Bold lines show 5-year smoothed time series. Significant correlation $\left(P<0.01 ; n^{*}=106\right)$ between 5 -year running means of GC and D5 melt per cent (inset) reveals that variability in total annual surface melt, as well as broader regional melt variability, is well captured by our ice cores. 

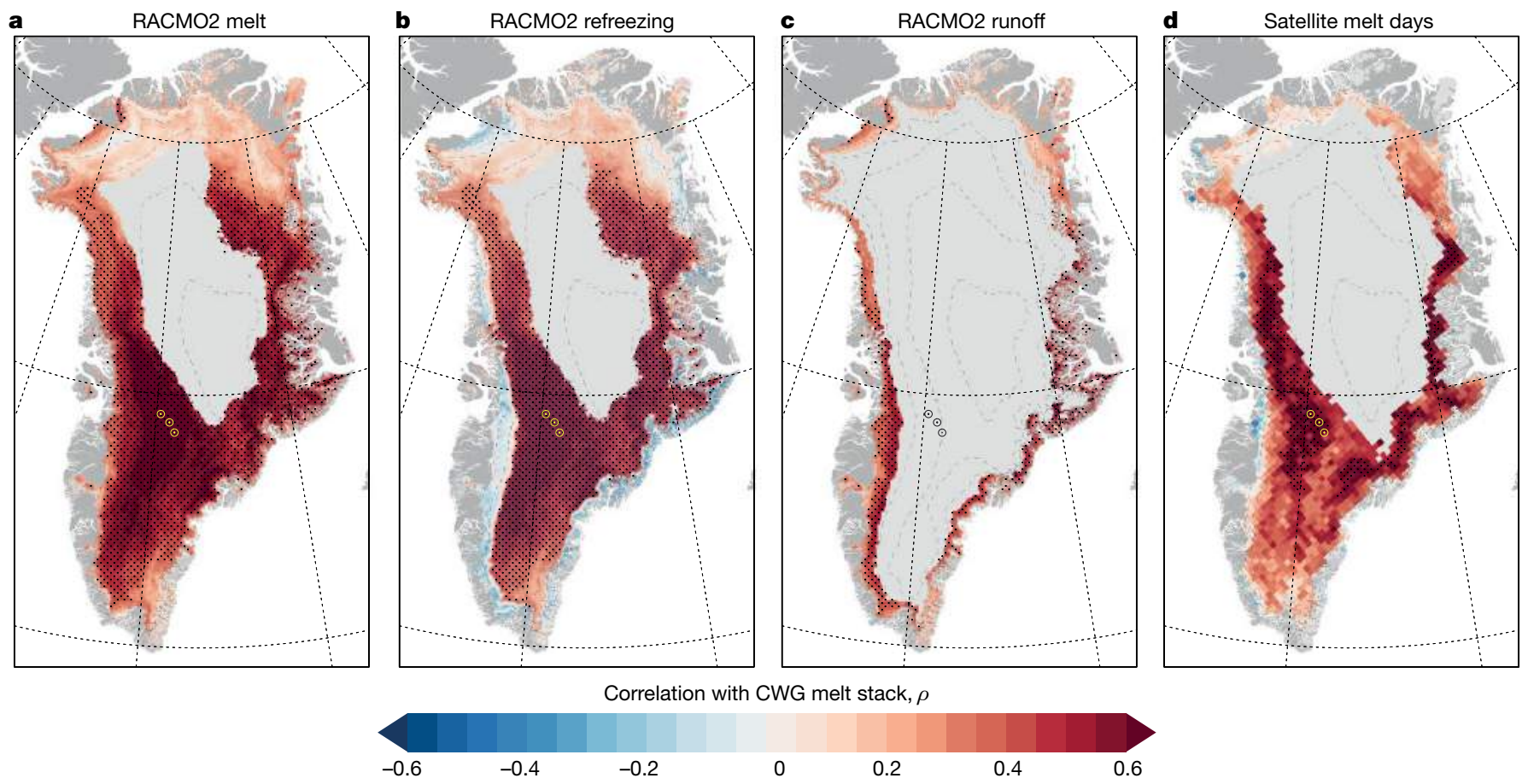

Fig. 3 | Spatially broad representation of melt processes captured by CWG ice cores. a-d, Spearman rank order correlations between the CWG melt stack and RACMO2-modelled annual melt (a), refreezing (b) and runoff (c) over 1958-2013 ${ }^{5}$, and with satellite-observed melt over $1988-2013^{4}$ (d; Methods). Areas of significant correlation $(P<0.01)$ are

Given the strong correlations between modern percolation zone melt and ice-sheet meltwater runoff, we produce the first observationally constrained record of ice-sheet runoff variability using a stepwise calibration/validation procedure between our ice-core melt records and RACMO2 runoff (Methods). Performing this analysis against integrated runoff from each GrIS surface drainage basin (Extended Data Fig. 5), as well as total GrIS runoff (Fig. 4a), we find that the combined CWG and NU melt records possess high predictive skill in reconstructing runoff over 1958-2013 across much of the GrIS (Extended Data Figs. 5, 6). Our results show that relatively stable and low runoff occurred before the 1990s in all individual basins (Extended Data Fig. 5) as well as across the broader ice sheet. Our reconstructions are consistent with modern model-based runoff estimates (Fig. 4a) and limited direct runoff measurements ${ }^{20}$. Divergence in past runoff estimates derived from longer reanalyses ${ }^{6,19}$ hinders centennial-scale comparisons, but also highlights in particular the value of our new observationally based reconstruction farther back in time. We show that an exceptional rise in runoff has occurred over the last two decades, equating to an approximately $50 \%$ increase in GrIS-integrated runoff compared to pre-industrial runoff, and a $33 \%$ increase over the twentieth century alone (Fig. 4a).

The onset of industrial-era Arctic warming occurred in the mid-nineteenth century ${ }^{21}$ and differential smoothing analysis likewise indicates increases in GrIS runoff initiated shortly thereafter (Fig. 4b; Methods). The median onset of positive trends in GrIS runoff are also coincident with the median onset of weakening Atlantic meridional overturning circulation ${ }^{9}$. Emergence of runoff beyond the natural range of variability, however, has only very recently occurred (Fig. $4 \mathrm{~b}$ ). Although the precise mechanisms behind these rapid recent changes remain underconstrained, the high temporal resolution of our reconstruction allows us to explore a range of possibilities. Runoff emergence timing follows the emergence (that is, steep decline) of pan-Arctic summer sea ice (Methods; Fig. 4b, Extended Data Table 4), supporting prior hypotheses that Arctic sea ice loss may amplify GrIS melt and runoff ${ }^{22}$. The pronounced sea ice and runoff changes are also roughly coincident with a negative shift in the summer North Atlantic Oscillation, marking denoted by the black stipple pattern. Correlations are calculated only for years where the gridded data indicated melt for $>50 \%$ of the years $(28$ years in $\mathbf{a}-\mathbf{c}$; 13 years in d). The location of cores used in the CWG stack is denoted by yellow $(\mathbf{a}, \mathbf{b}, \mathbf{d})$ or black (c) points. Contour interval, $500 \mathrm{~m}$.

enhanced summertime anticyclonic conditions over Greenland known to contribute to warming ${ }^{23}$ and a positive melt-albedo feedback ${ }^{12}$. Sea-ice loss is also suggested to be more directly responsible for atmospheric blocking over Greenland, thus contributing to recent North Atlantic Oscillation trends ${ }^{22}$. Regional atmospheric ${ }^{24}$ and sea-ice ${ }^{25}$ trends may also represent a teleconnected pan-Arctic response to tropical Pacific sea surface temperature forcing.

Our reconstruction quantifies the exceptional magnitude of presentday melt and runoff relative to the last several centuries. Their rapid intensification over the last two decades also illustrates a clear nonlinear melt-temperature relationship (Fig. 4c; Methods). Similar late-twentieth-century melt acceleration was found using records from an Antarctic Peninsula ice core ${ }^{26}$, and attributed to a nonlinear response of melting to climate warming more broadly across Antarctica, owing largely to the melt-albedo positive feedback ${ }^{27}$. At all of our core sites, 2012 melt was more intense than any other year according to two distinct reanalysis-forced regional climate models that extend back to $1958^{5}$ and $1979^{6}$ (Fig. 4c). Our ice-core results provide further context and reveal that these 2012 melt rates are exceptional highs for at least the past 350 years. If an air-temperature reconstruction from the nearby Canadian Arctic is regionally representative, GrIS melt and runoff experienced in the last decade is likely also to be unprecedented over the last $6,800-7,800$ years ${ }^{28}$. The nonlinear melt-temperature sensitivity also helps explain why episodes of mid-twentieth-century warmth resulted in less intense and less sustained melting compared to the last two decades, despite being only marginally cooler (Fig. 2). Additional factors, such as recent sea-ice losses, as well as regional and teleconnected general circulation changes, may also play a part in amplifying the melt response. Moreover, this melt-temperature nonlinearity indicates that only limited additional warming will greatly enhance the area of the ice sheet subject to meltwater runoff. Indeed, even high-elevation regions of the percolation zone, such as at our CWG core sites, have already warmed enough to induce the melt intensification and firn densification necessary to generate meltwater runoff in some years, as opposed to full melt refreezing and retention (Fig. 4c). 

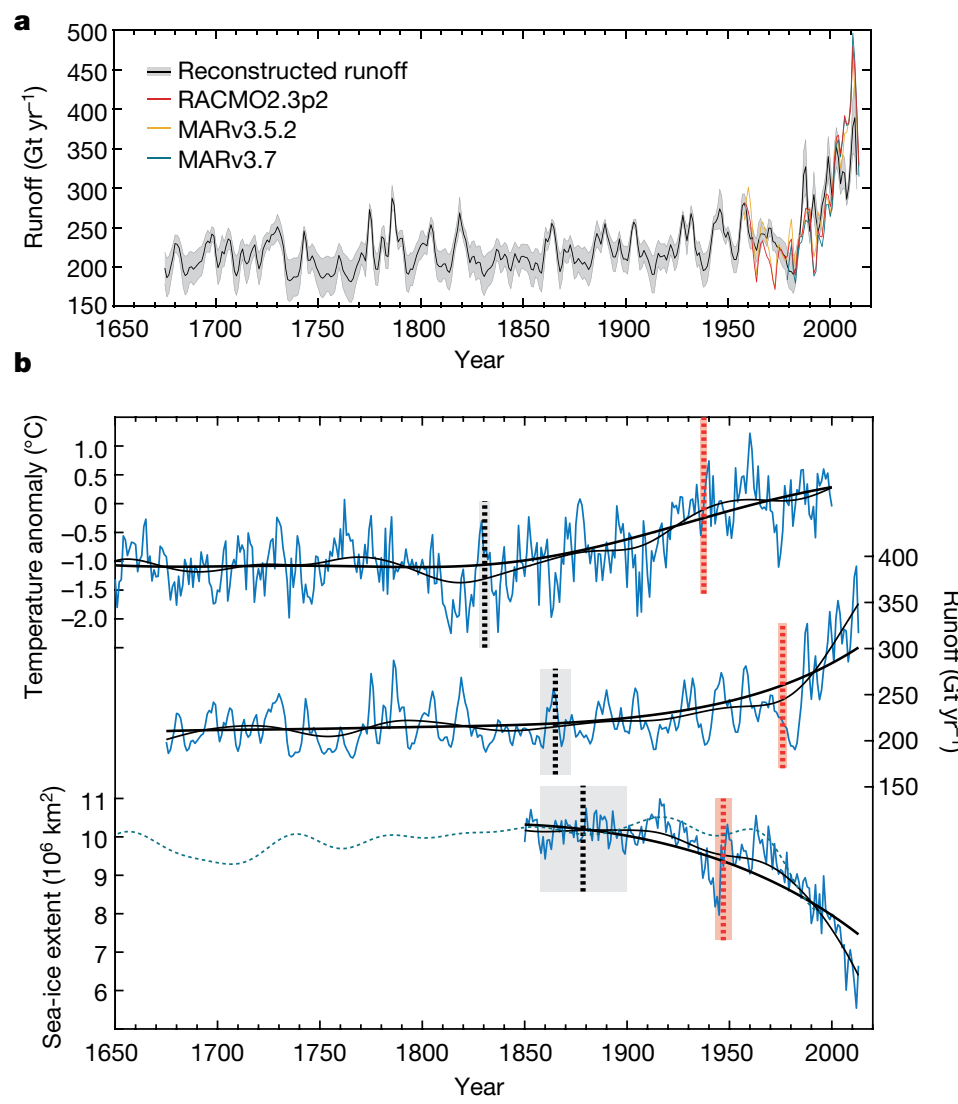

Fig. 4 | Exceptional rise in Greenland ice-sheet runoff and climate warming context. a, GrIS-integrated meltwater runoff, as simulated by regional climate models ${ }^{5,6}$ (coloured lines; 5 -year smoothed) and reconstructed using the NU and CWG ice-core-derived melt records (black line; 95\% confidence interval shaded; see Methods). b, Median onset of significant trends (vertical black dotted lines) and climate emergence above pre-industrial (vertical red dotted lines) for mean Arctic temperatures ${ }^{21}$ (top), our ice-core-derived runoff reconstruction (middle) and two summer Arctic sea-ice extent datasets ${ }^{29,30}$ (bottom; Methods). Median absolute deviations of trend onsets and climate emergence shown as shaded boxes. Thin and bold black lines denote 15-year and 50-year Gaussian smoothed series. c, Recent modelled evolution of mean summer (JJA) near-surface air temperature and surface

Our GrIS melt and runoff reconstructions highlight how icecore-based surface mass balance reconstructions add important additional in situ context to the relatively brief instrumental, satellite and climate reanalysis eras. Today, surface melting and melt-induced runoff in Greenland occur at magnitudes not previously experienced over at least the last several centuries, if not millennia. Melt-temperature nonlinearity and general circulation changes mean that further twenty-first-century warming has important implications for the ice-sheet mass balance, by accelerating the intensity of surface melting and amplifying GrIS contributions to global sea-level rise.

\section{Online content}

Any methods, additional references, Nature Research reporting summaries, source data, statements of data availability and associated accession codes are available at https://doi.org/10.1038/s41586-018-0752-4.

Received: 4 May; Accepted: 18 September 2018;

Published online 5 December 2018.

1. Hanna, E. et al. Ice-sheet mass balance and climate change. Nature 498, 51-59 (2013).

2. Enderlin, E. M. et al. An improved mass budget for the Greenland ice sheet. Geophys. Res. Lett. 41, 2013GL059010 (2014).

3. van den Broeke, M. R. et al. On the recent contribution of the Greenland ice sheet to sea level change. Cryosphere 10, 1933-1946 (2016). c

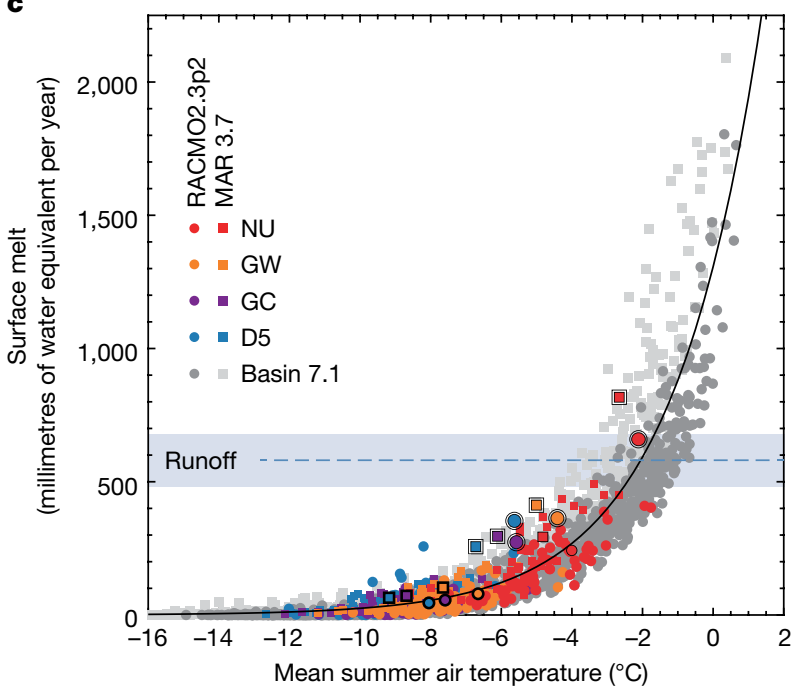

melt (in millimetres of water equivalent per year) across CWG. Ice core sites are shown as coloured points, and a Jakobshavn basin (basin 7.1; Fig. 1) elevational transect as grey points from RACMO2.3p2 (circles) and MARv3.7 (squares). Means over the past 20 years of the ice-core records (1994-2013) at core sites are denoted by points with single black border, and peak melting in 2012 by double black borders. The evolution of CWG ice-sheet melt in response to a warming climate is well represented by an exponential function (black curve). Recent melt rates at our percolation zone core sites approach conditions where the models have recently begun to simulate meltwater runoff (blue dashed line indicates mean runoff-linked melt rate and the shaded region corresponds to \pm 1 s.d.; see Methods for details).

4. Tedesco, M. et al. Evidence and analysis of 2012 Greenland records from spaceborne observations, a regional climate model and reanalysis data. Cryosphere 7, 615-630 (2013).

5. Noël, B. et al. Modelling the climate and surface mass balance of polar ice sheets using RACMO2-Part 1: Greenland (1958-2016). Cryosphere 12, 811-831 (2018).

6. Fettweis, X. et al. Reconstructions of the 1900-2015 Greenland ice sheet surface mass balance using the regional climate MAR model. Cryosphere 11, 1015-1033 (2017).

7. Humphrey, N. F., Harper, J. T. \& Pfeffer, W. T. Thermal tracking of meltwater retention in Greenland's accumulation area. J. Geophys. Res. 117, F01010 (2012).

8. Machguth, H. et al. Greenland meltwater storage in firn limited by near-surface ice formation. Nat Clim. Chang. 6, 390-393 (2016).

9. Thornalley, D. J. R. et al. Anomalously weak Labrador Sea convection and Atlantic overturning during the past 150 years. Nature 556, 227-230 (2018).

10. Bennartz, R. et al. July 2012 Greenland melt extent enhanced by low-level liquid clouds. Nature 496, 83-86 (2013).

11. Van Tricht, K. et al. Clouds enhance Greenland ice sheet meltwater runoff. Nat. Commun. 7, 10266 (2016)

12. Hofer, S., Tedstone, A. J., Fettweis, X. \& Bamber, J. L. Decreasing cloud cover drives the recent mass loss on the Greenland Ice Sheet. Sci. Adv. 3, e1700584 (2017).

13. Fausto, R. S. et al. The implication of nonradiative energy fluxes dominating Greenland ice sheet exceptional ablation area surface melt in 2012. Geophys. Res. Lett. 43, 2649-2658 (2016).

14. Hanna, E. et al. Atmospheric and oceanic climate forcing of the exceptional Greenland ice sheet surface melt in summer 2012. Int. J. Climatol. 34, 1022-1037 (2014). 
15. Keegan, K. M., Albert, M. R., McConnell, J. R. \& Baker, I. Climate change and forest fires synergistically drive widespread melt events of the Greenland Ice Sheet. Proc. Natl Acad. Sci. USA 111, 7964-7967 (2014).

16. Graeter, K. A. et al. Ice core records of West Greenland melt and climate forcing. Geophys. Res. Lett. 45, 3164-3172 (2018).

17. Herron, M. M., Herron, S. L. \& Langway, C. C. Climatic signal of ice melt features in southern Greenland. Nature 293, 389-391 (1981).

18. Kameda, T. et al. Melt features in ice cores from Site J, southern Greenland: some implications for summer climate since AD 1550. Ann. Glaciol. 21, 51-58 (1995).

19. van den Broeke, M. et al. Greenland ice sheet surface mass loss: recent developments in observation and modeling. Curr. Clim. Change Rep. 3, 345-356 (2017).

20. Ahlstrøm, A. P., Petersen, D., Langen, P. L., Citterio, M. \& Box, J. E. Abrupt shift in the observed runoff from the southwestern Greenland ice sheet. Sci. Adv. 3, e1701169 (2017)

21. Abram, N. J. et al. Early onset of industrial-era warming across the oceans and continents. Nature 536, 411-418 (2016)

22. Liu, J. et al. Has Arctic sea-ice loss contributed to increased surface melting of the Greenland ice sheet? J. Clim. 29, 3373-3386 (2016).

23. Fettweis, $X$. et al. Brief communication 'Important role of the mid-tropospheric atmospheric circulation in the recent surface melt increase over the Greenland ice sheet'. Cryosphere 7, 241-248 (2013).

24. Ding, Q. et al. Tropical forcing of the recent rapid Arctic warming in northeastern Canada and Greenland. Nature 509, 209-212 (2014)

25. Ding, Q. et al. Influence of high-latitude atmospheric circulation changes on summertime Arctic sea ice. Nat. Clim. Chang. 7, 289-295 (2017).

26. Abram, N. J. et al. Acceleration of snow melt in an Antarctic Peninsula ice core during the twentieth century. Nat. Geosci. 6, 404-411 (2013).

27. Trusel, L. D. et al. Divergent trajectories of Antarctic surface melt under two twenty-first-century climate scenarios. Nat. Geosci. 8, 927-932 (2015).

28. Lecavalier, B. S. et al. High Arctic Holocene temperature record from the Agassiz ice cap and Greenland ice sheet evolution. Proc. Natl Acad. Sci. USA 114, 5952-5957 (2017).

29. Walsh, J. E., Fetterer, F., Scott Stewart, J. \& Chapman, W. L. A database for depicting Arctic sea ice variations back to 1850. Geogr. Rev. 107, 89-107 (2017).

30. Kinnard, C. et al. Reconstructed changes in Arctic sea ice over the past 1,450 years. Nature 479, 509-512 (2011).

Acknowledgements Funding was provided by US National Science Foundation (NSF) awards OPP-1205196 and PLR-1418256 to S.B.D., ARC-1205062 to B.E.S. and OPP-1205008 to M.J.E. L.D.T. acknowledges institutional support from Rowan University and the Doherty Postdoctoral Scholarship at Woods Hole Oceanographic Institution. M.B.O. acknowledges support from the Department of Defense Office of Naval Research, National Defense Science and Engineering Graduate (NDSEG) Fellowship, 32 CFR 168a. Collection, analysis and interpretation of core D5 was supported by NSF grant 0352511 to J.R.McC. B.P.Y.N. and M.R.v.d.B. acknowledge support from the Polar Program of the Netherlands Organization for Scientific Research (NWO/NPP) and the Netherlands Earth System Science Centre (NESSC). For running the MAR model, computational resources have been provided by the Consortium des Équipements de Calcul Intensif (CÉCl), funded by the Fonds de la Recherche Scientifique de Belgique (FRS-FNRS) under grant number 2.5020.11 and the Tier-1 supercomputer (Zenobe) of the Fédération Wallonie Bruxelles infrastructure funded by the Walloon Region under grant agreement number 1117545. We thank M. Waszkiewicz and IDPO/IDDO for ice core drilling support. We thank the NSF Ice Core Facility (formerly NICL), A. York, M. Bingham, M. Hatch, S. Zarfos, Z. Li, and Milton Academy students for ice core sampling and processing support. We thank R. Banta for help with the D5 core, and A. Arienzo and N. Chellman for help in analysing the NU core. We thank M. Tedesco for providing the satellite melt duration data used in Fig. 3d. Maps in Figs. 1a, 3 and Extended Data Figs. 3, 4 were created with the NCAR Command Language (https://www.ncl.ucar.edu), and maps in Fig. 1b and Extended Data Fig. 6 were created with Esri ArcGIS. We acknowledge the use of Rapid Response imagery in Fig. $1 \mathrm{~b}$ from the Land, Atmosphere Near real-time Capability for EOS (LANCE) system operated by the NASA/GSFC/Earth Science Data and Information System (ESDIS) with funding provided by NASA/HQ.

Reviewer information Nature thanks J. Briner and B. Vinther for their contribution to the peer review of this work.

Author contributions L.D.T. and S.B.D. conceived of and designed the study with input from M.B.O. B.E.S., S.B.D., M.J.E. and L.D.T. determined the ice core siting. S.B.D., L.D.T., M.B.O. and M.J.E. collected the ice cores. L.D.T. analysed melt stratigraphy for cores NU, GC and GW. S.B.D., J.R.McC. and L.D.T. analysed core D5. M.J.E. and J.R.McC. analysed ice core chemistry. Ice core chronology was led by M.B.O. with input from B.E.S., S.B.D., J.R.McC. and L.D.T. M.B.O. developed melt reconstruction code with input from L.D.T. B.P.Y.N. and M.R.v.d.B. provided RACMO2 model output and expertise. X.F. provided MAR model output and expertise. L.D.T. led the data analyses and interpretation, and wrote the manuscript, with input from S.B.D. and M.B.O. All authors read and commented on the manuscript.

Competing interests The authors declare no competing interests.

Additional information

Extended data is available for this paper at https://doi.org/10.1038/s41586018-0752-4.

Reprints and permissions information is available at http://www.nature.com/ reprints.

Correspondence and requests for materials should be addressed to L.D.T. Publisher's note: Springer Nature remains neutral with regard to jurisdictional claims in published maps and institutional affiliations. 


\section{METHODS}

Ice-core melt analyses. Surface melt histories were developed from an array of percolation-zone firn and ice cores collected in CWG (Figs. 1, 2, Extended Data Table 1). Core chronology was achieved through annual layer counting of seasonal ice-core chemistry (including the summertime species $\delta^{18} \mathrm{O}, \mathrm{NO}_{3}{ }^{-}$and $\mathrm{SO}_{4}{ }_{4}^{2-}$, and the winter/springtime species $\mathrm{Mg}^{2+}, \mathrm{Ca}^{2+}$ and $\mathrm{Na}^{+}$) for cores $\mathrm{GC}$ and GW. Soluble chemistry measurements were conducted on discrete, $5-\mathrm{cm}$-long longitudinal cuts for both cores using suppressed ion chomoatography ${ }^{31}$. The relative dating uncertainty in the GW and GC cores is estimated at a year or less, based on validation of the annual layer counts with absolute-dated volcanic horizons $s^{32}$. In the NU core, simultaneous and depth-registered measurements of trace metallic species ( $\mathrm{Na}, \mathrm{Mg}, \mathrm{S}, \mathrm{Cl}, \mathrm{Ca}, \mathrm{Br}, \mathrm{Sr}, \mathrm{Ce}, \mathrm{Ti}$ and $\mathrm{Pb}$ ), black carbon, water isotopic abundance $\left(\delta^{18} \mathrm{O}\right.$ and $\delta \mathrm{D}$ of $\left.\mathrm{H}_{2} \mathrm{O}\right)$, as well as semiquantitative particle counts, were conducted at a continuous resolution of about $2 \mathrm{~cm}$ (water equivalent) following established methods $\mathrm{s}^{33,34}$. Annual layer counts were similarly determined in the NU core down to the Huaynaputina (Peru) volcanic horizon ${ }^{32}$ at AD 1601, via identification of winter-springtime seasonality in $\mathrm{Na}, \mathrm{Mg}, \mathrm{Ca}$ and particulates ${ }^{35}$, and summertime seasonality in $\mathrm{S}, \delta^{18} \mathrm{O}$, black carbon and heavy metals ${ }^{34}$. The relative uncertainty down to AD 1601 is estimated at two year or less using validation of annual layer counts with 15 absolute-dated tie points (13 volcanic, 2 radiogenic; following ref. ${ }^{36}$ ). Reference ${ }^{34}$ details the establishment of the depth-age scale for core D5.

All cores were latitudinally cut, cleaned and analysed for visible refrozen stratigraphic horizons at the US National Science Foundation Ice Core Facility, formerly the National Ice Core Laboratory (NICL). Cores GC, GW and NU were scanned with the NICL high-resolution (sub-millimetre) optical imaging system ${ }^{37}$. Resulting images allowed for manual identification of refrozen melt layers using digitally registered core depths (see, for example, Extended Data Fig. 1a). Following established melt layer identification ${ }^{38}$ and classification ${ }^{26}$ methods, we characterized only horizontally continuous refrozen melt layers with discrete upper and lower bounds identifiable based on their optical contrast with surrounding undisturbed firn or ice, while excluding vertical percolation features or layers extending $<50 \%$ of the total ice-core width. For core D5, we applied the same methodology to detailed stratigraphic logs produced from analysis of the ice core on a back-lit table at NICL. We report results of these analyses for the full length of the GC, GW and D5 records, and for the upper $86 \mathrm{~m}$ of the NU core (corresponding to the year AD 1650), beyond which refrozen melt horizons become ambiguous owing to layer thinning and reduced visible contrast between refrozen layers and surrounding ice. As annual accumulation and melt layers advect downward, thinning of both annual accumulation and melt layers occurs ${ }^{26,39}$. It is therefore necessary to account for this thinning as a function of increasing depth, and following previous studies ${ }^{18,26}$, we characterize melt as a percentage of annual snow accumulation after converting each to water equivalent lengths using density measurements along the core and assuming a density of ice $\left(0.917 \mathrm{~g} \mathrm{~cm}^{-3}\right)$ for refrozen melt layers. After converting melt thicknesses to melt per cent, cores GC, GW and D5 were composited to form the CWG stack by averaging and standardizing (mean set to 0 and standard deviation set to 1) the records. To facilitate comparison, the NU melt per cent record was also standardized based on its full time series (1650-2013). Melt intensity increases were calculated before standardizing.

Broader spatial representation of ice-core melt histories. To assess the potential of our ice-core melt records to indicate wider ice-sheet melt variability, we calculated correlations across space between the annual CWG melt stack and gridded model and satellite melt datasets (Fig. 3). To quantify these relationships across space, we assessed Spearman rank order correlations owing to the nonparametric distributions of the datasets as a result of nonlinear melt evolution ${ }^{26,27}$ and tested significance (at the $P<0.01$ level) using a two-tailed Student's $t$-test. Two sophisticated reanalysis-driven regional climate-snowpack models were used in our anal$\mathrm{ysis}$, as well as satellite-derived estimates of annual surface melt duration. First, the most recent version of RACMO2, RACMO2.3p2, forced by the ECMWF ERA-40 and ERA-Interim reanalyses over 1958-2013 and statistically downscaled to $1 \mathrm{~km}$ spatial resolution from $11 \mathrm{~km}$ native outputs ${ }^{5,40}$, was used to assess correlations with melt magnitude, refreezing, and runoff (Fig. $3 \mathrm{a}-\mathrm{c}$ ). As an assessment of the sensitivity of these correlations to model selection, we also calculated correlations against the MARv3.7 model forced by ERA-Interim over 1979-2013 and similarly downscaled to $1 \mathrm{~km}$ from $7.5 \mathrm{~km}$ native outputs ${ }^{6}$. Despite incorporating a unique snow model, results using MARv3.7 show broadly similar results to those from RACMO2.3p2, including wide-ranging significant correlations between the CWG ice-core composite and simulated melt and runoff (Extended Data Fig. 3). We also quantified spatial correlations with observed melting from satellite passive microwave radiometers at $25 \mathrm{~km}$ resolution ${ }^{4,41}$ over the time period of common overlap with full daily satellite observations (1988-2013), and note similarly high spatial correlations between satellite-observed summer melt duration and melt variability from the ice cores (Fig. 3d). Finally, we report correlations only where the gridded dataset indicated that the respective melt variable occurred in at least $50 \%$ of the years of common overlap (that is, 28 years for the 1958-2013 RACMO2 and 13 years for the 1988-2013 satellite time series).

Runoff reconstruction. Ice core-derived runoff reconstructions were performed through multilinear regression of the CWG and NU melt records as predictor (independent) variables against RACMO2-modelled annual runoff as the predictand (dependent variable) over the period of common overlap between the two datasets (1958-2013). This procedure allows us to develop a transfer function by calibrating the ice-core melt records to the RACMO2-simulated runoff, and thus extend the runoff record back in time using only the ice-core melt records. We used a nonparametric Monte Carlo approach to generate 95\% confidence intervals to the reconstructions. Namely, we developed 10,000 surrogate pseudo-random predictor/predictand pairings over the full calibration interval (1958-2013) using the frequency-domain method ${ }^{42}$, following established methods ${ }^{43}$. To test reconstruction skill, we calculated the coefficient of determination $\left(r^{2}\right)$, reduction of error (RE), and coefficient of efficiency (CE) statistics ${ }^{44}$. Both RE and CE may vary from 1 to $-\infty$, where $\mathrm{RE}>0$ and $\mathrm{CE}>0$ indicate a predictive power above the simple mean estimate of RACMO2-simulated runoff during the calibration interval. Indeed, positive RE and CE values are commonly invoked to demonstrate skillful reconstructions ${ }^{45,46}$. Any positive value of RE and CE, however, does not necessarily signify statistical significance provided the predictor/predictand series represent varying degrees of autocorrelation. Thus, to estimate whether a calibration statistic is significant for the ice-core and RACMO2 data, we additionally used 10,000 Monte Carlo iterations to develop empirical probability density functions for the reconstruction statistics $\left(r^{2}, \mathrm{RE}, \mathrm{CE}\right)$ tuned to the exact autocorrelative properties and length of the observed predictor/predictand series, and against which significance was tested ${ }^{43}$. Next, to test the sensitivity of the reconstruction to calibration period, we performed stepwise cross-validation tests ${ }^{45}$. This was done by initially defining the calibration interval as the most recent contiguous two-thirds of years in the period of common overlap between the ice-core and RACMO2 datasets (1977-2013), such that the validation interval initially represented the oldest one-third of available years (1958-1976). The cross-validation calibration interval was then stepped to one year older (1976-2012), while the verification interval was defined as all remaining years $(1958-1975,2013)$. This was progressively repeated until the calibration interval represented the oldest two-thirds of the period of common overlap (1958-1994) and the verification interval represented the youngest contiguous one-third of years (1995-2013). After each iteration, validation statistics $\left(r^{2}, \mathrm{RE}, \mathrm{CE}\right)$ were calculated and significance levels were determined using the Monte Carlo approach described above.

We performed this procedure of multilinear regression between ice-core melt records and RACMO2-modelled runoff, estimation of reconstruction confidence intervals, and iterative calibration period and statistic assessment to reconstruct runoff across each of the 19 ICESat elevation-defined GrIS surface drainage basins ${ }^{47}$ and for the ice sheet as a whole (Extended Data Fig. 5). For this analysis, we first smoothed all data series using a 5 -year centred moving average, as this allows for the possibility of meltwater percolation to deeper layers (potentially important for the higher-melt NU core) while also remaining consistent with the approximate integral timescale in melt and its climatic drivers across the GrIS. In each case, area-integrated RACMO 2 runoff (that is, across a specific basin or entire ice sheet) was used as the predictand and the NU and CWG melt records as predictors.

For most individual basins and for GrIS-integrated runoff (the focus of our study), the majority of calibration intervals produced CE and RE values much greater than zero and significant validation statistics, indicating broad and skillful runoff reconstructions (Extended Data Fig. 6). The northernmost GrIS basins, in particular basins 1 and 8 , overall had the fewest calibration/validation intervals where validation statistics $\left(r^{2}, \mathrm{RE}, \mathrm{CE}\right)$ were found to be significant, indicating comparatively low skill in reconstructing RACMO2 runoff in this region (Extended Data Fig. 6). However, our ice-core melt records and derived reconstruction of basin 8.2 runoff moderately agree with observed air temperatures from the nearby Pituffik site since 1948 (Extended Data Table 3; also see next section), and our reconstructed late twentieth-century increases in melt across northern Greenland (Extended Data Fig. 5) are consistent with recently rapid warming and melting reported in the Canadian Arctic ${ }^{28,48}$. Robust reconstruction of GrIS-integrated runoff, despite a relatively poor fit with RACMO2 across northern basins is probably the result of little runoff originating from northern Greenland (about $8 \%-13 \%$ on average annually according to RACMO2 and MAR, respectively), and because GrIS-integrated runoff is dominated by runoff from the central-southwestern and southern basins (Extended Data Fig. 5). In these more southerly regions, our runoff reconstruction (Extended Data Figs. 5, 6), relationships between our ice core-derived melt and modelled and satelliteobserved melt (Fig. 3, Extended Data Fig. 3), and relationships between point-scale melt processes and GrIS-integrated melt and runoff (Extended Data Fig. 4) are all particularly strong. Nevertheless, collection and integration of compatible ice-core melt records from regions currently under-represented in our reconstruction could 
provide an opportunity to improve upon basin-level reconstructions of GrIS melt and runoff.

As an additional check on our runoff reconstruction, we also compared ice-core-reconstructed runoff calibrated using RACMO2 against two versions of the MAR model ${ }^{6}$ (v3.5.2 and v3.7), forced by ECMWF reanalyses and downscaled to $5 \mathrm{~km}$ and $1 \mathrm{~km}$ resolution, respectively. We note strong agreement at the ice-sheet scale among the models and reconstruction (Fig. 4a). Similar methodological agreement is found across most individual drainage basins, although it is also clear there are biases among the magnitudes of runoff simulated by models in some basins that compensate when integrated over the full GrIS (Extended Data Fig. 5), a feature that has persisted since previous versions of the models $s^{49}$. Comparisons with observed air temperatures. As a further assessment of our ice-core melt time series and the derived runoff reconstruction, we quantified relationships between these variables and observed air temperatures across coastal Greenland (Extended Data Table 3). We used data ${ }^{50,51}$ compiled and archived by the Danish Meteorological Institute (DMI) for all sites with near-continuous summer (JJA) observations that predate the onset of the ERA-40 reanalysis (1958) used to drive RACMO2 and which extend to at least 2013, the most recent year in the ice core records. As in our runoff reconstruction, we use the CWG and NU melt time series as predictor variables in a multilinear regression against observed air temperatures after calculating 5-year moving averages of the time series. We find overwhelmingly significant (see next section) relationships between the temperature time series and the combined CWG and NU melt records, as well as between reconstructed runoff integrated across surface drainage basins adjacent to the location of air-temperature observations (Extended Data Table 3). We do note, however, that in general stronger peak correlations exist between the ice-core melt records and melt simulated directly on the ice sheet from RACMO2 (Extended Data Fig. 5), suggesting that coastal temperature observations (some of which are far removed from the ice sheet) may poorly or only partially represent climatic and surface energy balance conditions over the ice sheet. Owing to observational paucity on the ice sheet proper, especially before the last two decades ${ }^{19}$, ice-core-derived melt records that directly capture melt processes are therefore of particularly high value.

Quantifying significance of paired time series. Statistical significance of correlations among air temperatures, melt records, and runoff reconstructions was assessed with a two-tailed Student's $t$-test (Fig. 2 inset; Extended Data Tables 2, 3). For analyses between paired time series smoothed with 5-year moving averages, we accounted for autocorrelation in the smoothed data using two distinct methods. First, following ref. ${ }^{52}$, we calculated reduced effective sample sizes, $n^{*}$, and thus reduced effective degrees of freedom (d.o.f. $\left.*=n^{*}-2\right)$, given inherent lag-1 autocorrelation. As a secondary test of statistical significance given the presence of sample autocorrelation in the paired 5-year smoothed series, and following our reconstruction methods above, we also implemented a nonparametric Monte Carlo-based method ${ }^{42}$ to generate 10,000 pseudo-random series with the exact length and autocorrelative properties of each time series. We then quantified correlations using these surrogate datasets against the original second time series, and estimated significance by calculating the exceedance probability of generating a stronger correlation by chance alone.

Trend onset and emergence timing. We examined the timing of the onset of the most recent phase of increasing GrIS meltwater runoff, as well as the emergence of GrIS runoff beyond a pre-industrial baseline, and compared these timings to those of reconstructed Arctic temperatures (that is, 'Arctic $2 \mathrm{k}$ ' in ref. ${ }^{21}$ ) and summer (July-September) sea ice extent ${ }^{29}$ (Fig. 4b; Extended Data Table 4). For these analyses, we used the SiZer (SIgnificant ZERo crossings of derivatives) method ${ }^{53}$ following recent studies ${ }^{21,45}$, to calculate the median onset of sustained, significant $(P<0.1)$ trends from smoothed time series of the original datasets using a suite of Gaussian kernel filters from 15 years to 50 years. Uncertainty in trend changepoint timing is expressed here as the median absolute deviation of the change points determined using each of the 36 synthetic data series (smoothed using the 15-50-year filters). Next, we tested whether GrIS runoff has surpassed natural variability, commonly defined as $+2 \sigma$ beyond a pre-industrial period ${ }^{21,54}$. As in our assessments of the magnitude of melt increases, we defined the pre-industrial period for the Arctic temperature and runoff reconstruction datasets as the eighteenth century (1700-1799), which has been identified as a period predating the onset of industrial-era Arctic warming ${ }^{21}$. Emergence is defined here as the median timing at which the 15-50-year smoothed time series surpass and remain above the pre-industrial $+2 \sigma$ level. As with trend onset timing, we estimated uncertainty in emergence timing as the median absolute deviation in the emergence timings determined using the various filter widths. Timing and uncertainty range in trend onset and emergence timing for these and other data series are shown as the vertical lines and shaded regions in Fig. 4b, and expressed numerically in Extended Data Table 4.

We also evaluated the trend onset and emergence timing from an observationally derived sea-ice reconstruction by Walsh et al. ${ }^{29}$ and compare this dataset with a longer, proxy-derived summer sea ice reconstruction from Kinnard et al. ${ }^{30}$ To facilitate comparison, we performed a minor adjustment (that is, bias correction) by matching the mean of the Kinnard time series to the mean of the Walsh dataset over 1850-1899, a period of common overlap and of little sea-ice change, by subtracting $0.22 \times 10^{6} \mathrm{~km}^{2}$ from the full Kinnard dataset. Likewise, we note that the lower temporal resolution (40-yr low-pass filtered) of the Kinnard dataset precluded accurate assessment of change points and emergence from this longer dataset. Owing to the shorter length (1850-present) of the observationally derived Walsh sea-ice reconstruction, it was necessary to define the baseline period for this dataset as 1850-1899. Nevertheless, we have confidence in our estimated timing of summer sea-ice decline and its forced emergence given the clear similarity of the observationally based and proxy-based sea-ice datasets (Fig. 4b). Because the Kinnard data show relatively stable summer sea ice before 1850, but with a slight decrease during the baseline period used for the other datasets (1700-1799), we believe our calculated climate emergence from the Walsh dataset to be a conservative estimate (that is, early in time). Indeed, if we utilize the bias-adjusted summer sea-ice extent from Kinnard over the earlier baseline of 1700-1799 with the standard deviation of the annual-resolution Walsh data (over 1850-1899), the median emergence is moved forward in time to $1966 \pm 3$ years, still predating the median emergence of GrIS runoff by $10 \mathrm{yr}$.

Nonlinear melt-temperature relationship. We extracted profiles of melt and temperature at our coring sites and from an accumulation zone $(>1,200 \mathrm{~m})$ elevational transect spaced every $100 \mathrm{~m}$ down the centreline of basin 7.1 , containing our three cores forming the CWG stack (outline shown in Fig. 1a; also Extended Data Fig. 6). Because RACMO2.3p2 and MARv3.7 represent different time spans and incorporate unique snow models, we used both in our assessment of melt-temperature sensitivity (Fig. 4c). For RACMO2.3p2, simulated melt at the NU core site was determined to be implausibly low (26.5 millimetres of water equivalent per year over 1994-2013) despite a relatively high air temperature over this time period $\left(-1.52^{\circ} \mathrm{C}\right)$, and so we did not utilize this model at this site. In comparison, MARv3.7 simulates much greater melt (898 millimetres of water equivalent per year) and higher air temperature $\left(-0.92^{\circ} \mathrm{C}\right)$ averaged over $1994-2013$. These values align with the expected melt-temperature relationship derived from basin 7.1, but also greatly exceed accumulation rate determined from the NU core (around 300 millimetres of water equivalent per year). Because our analysis of the ice core chemistry and resulting dating do not indicate missing years (that is, net annual ablation), we believe MARv3.7 simulates unrealistically high melt at this site. We speculate that these discrepancies are at least partially due to the small size of the NU ice cap (about $4 \mathrm{~km} \times 4 \mathrm{~km}$ ), its more maritime climate, and the relatively coarse grid scale of the native climate model simulations $(11 \mathrm{~km}$ and $7.5 \mathrm{~km}$ for RACMO2 and MAR, respectively). Because our in situ observations reveal that the NU site experiences higher melt than our GrIS cores (and thus it more closely represents conditions along the margins of the GrIS where runoff is prevalent), we include surrogate melt and temperature points from RACMO2.3p2 and MARv3.7 for the NU core site. As a potential analogue for conditions at the NU core site, we plot in Fig. 4c values derived from 1,900 m along the centerline of basin 7.1, where simulated melt rates are consistent with those derived from our NU core. From these data, we find that an exponential function well represents the nonlinear relationship between surface melting and near-surface air temperature. This result is consistent with previous ice-core melt reconstructions ${ }^{26}$ and model-based studies in Greenland ${ }^{55}$ and Antarctica ${ }^{27}$.

To assess melt conditions associated with runoff initiation, using both RACMO2.3p2 and MARv3.7 we isolated melt flux values for the three highest-elevation sampling sites along the basin 7.1 centreline with multiple years of runoff simulated at $>10$ millimetres of water equivalent per year. From these runoff-associated melt fluxes, we calculated the mean melt associated with initial runoff and the standard deviation among the mean melt fluxes (shown as dashed runoff line and shaded area in Fig. 4c). This level of melt linked to initial onset of runoff in recent years is a function of more frequent or sustained high-intensity melt that leads to formation of thicker refrozen melt layers before favouring runoff over retention ${ }^{8,56,57}$.

Analysis of periodicities in ice-core melt records. Semi-periodic oscillations are apparent in our primary ice-core-derived melt records (Fig. 2). To explore this variability more quantitatively, and to discern potential signatures of climate modes known to affect Greenland, we performed analyses to identify spectral signatures and coherence between our melt records and climate indicators including the North Atlantic Oscillation ${ }^{58}$, the Atlantic Multidecadal Oscillation, the Greenland Blocking Index ${ }^{59}$, and air temperatures. Extended Data Fig. 2 displays a subset of these analyses. The upper four plots show power spectral density using the multi-taper method ${ }^{60}$ for our two main melt records and the summertime North Atlantic Oscillation and the Greenland Blocking Index, two atmospheric modes known to influence Greenland climate and melt ${ }^{14,23,59}$. We find relatively high spectral power in the 13-16-year range common to NU and CWG. This periodicity appears consistent with the North Atlantic Oscillation, which shows 
moderate evidence of spectral energy centred around a periodicity of about 13 years, although the summertime North Atlantic Oscillation is characteristically noisy (Extended Data Fig. 2d). We also note a periodicity of about 8 years in CWG corresponding to moderately high power in the Greenland Blocking Index, and also previously described for the winter North Atlantic Oscillation ${ }^{59}$ but not apparent here in the summertime North Atlantic Oscillation. Finally, we find strong, high spectral power at 60-year periodicity in our coastal ice cap record, $\mathrm{NU}$, consistent with the known 60-80-year periodicity of Atlantic Multidecadal Oscillation ${ }^{61,62}$. Cross-wavelet analysis ${ }^{63}$ reveals the greatest coherence and stationarity between the NU melt record and the southwest Greenland JJA air-temperature composite s1 $^{51}$ (Extended Data Fig. 2e). This analysis reveals high common power in the $\sim 10-25$-yr range and generally in phase relationships, with periods of melt partially leading temperature that probably reflect meltwater percolation in this high-melt core.

Our finding of strongest temporal coherence between NU and air temperature (as opposed to an individual climate mode) potentially indicates the combined influence of multiple climate modes on Greenland melt that are well represented by air temperature. Indeed, it is a confluence of processes that impact Greenland climate, combined with ice-sheet-climate interactions including the melt-albedo feedback, that govern the melt variability archived in ice cores. Given noise inherent to the relatively short time series, further analysis is warranted to better discern the varied factors responsible for the longer-term evolution of Greenland melt, and the representation of these processes in ice-core melt records.

Code availability. Code used for runoff reconstructions is available from L.D.T. upon request. Codes used for SiZer analysis were modified from ref. ${ }^{23}$ (https:// www.nature.com/articles/nature19082) and available from L.D.T. upon request.

\section{Data availability}

Ice-core melt records, the derived runoff reconstructions, and other records from cores NU, GC and GW are available via the NSF Arctic Data Center (http:// arcticdata.io) and from the corresponding author upon request. Additionally, source data for Figs. 2, 4 are provided in the online version of this paper. RACMO2 model outputs ${ }^{5}$ as well as downscaled $1-\mathrm{km}$ surface mass balance data are available from B.P.Y.N. and M.R.v.d.B. upon request. MAR model outputs ${ }^{6}$ are available from X.F. upon request. Greenland air-temperature dat $\mathrm{a}^{51}$ are available from http://www. dmi.dk/laer-om/generelt/dmi-publikationer/tekniske-rapporter/. Sea-ice data ${ }^{29,30}$ are available from https://nsidc.org/data/g10010and https://www.nature.com/ articles/nature10581. Arctic air-temperature reconstruction data ${ }^{21}$ are available from https://www.nature.com/articles/nature19082. Satellite melt data ${ }^{4,41}$ are available from http://www.cryocity.org.

31. Curran, M. A. \& Palmer, A. S. Suppressed ion chromatography methods for the routine determination of ultra low level anions and cations in ice cores. J. Chromatogr. A 919, 107-113(2001).

32. Sigl, M. et al. Timing and climate forcing of volcanic eruptions for the past 2,500 years. Nature $\mathbf{5 2 3}, 543-549$ (2015).

33. McConnell, J. R., Lamorey, G. W., Lambert, S. W. \& Taylor, K. C. Continuous ice-core chemical analyses using inductively coupled plasma mass spectrometry. Environ. Sci. Technol. 36, 7-11 (2002).

34. McConnell, J. R. et al. 20th-century industrial black carbon emissions altered Arctic climate forcing. Science 317, 1381-1384 (2007)

35. Gfeller, G. et al. Representativeness and seasonality of major ion records derived from NEEM firn cores. Cryosphere 8, 1855-1870 (2014).

36. Arienzo, M. M. et al. A method for continuous ${ }^{239} \mathrm{Pu}$ determinations in Arctic and Antarctic ice cores. Environ. Sci. Technol. 50, 7066-7073 (2016).

37. McGwire, K. C. et al. An integrated system for optical imaging of ice cores. Cold Reg. Sci. Technol. 53, 216-228 (2008)

38. Das, S. B. \& Alley, R. B. Characterization and formation of melt layers in polar snow: observations and experiments from West Antarctica. J. Glaciol. 51, 307-312 (2005).
39. Das, S. B. \& Alley, R. B. Rise in frequency of surface melting at Siple Dome through the Holocene: evidence for increasing marine influence on the climate of West Antarctica. J. Geophys. Res. 113, D02112 (2008).

40. Noël, B. et al. A daily, $1 \mathrm{~km}$ resolution data set of downscaled Greenland ice sheet surface mass balance (1958-2015). Cryosphere 10, 2361-2377 (2016).

41. Tedesco, M. Greenland Daily Surface Melt 25km EASE-Grid [1988-2013] http://www.cryocity.org/data.html (City University of New York, New York, 2014).

42. Ebisuzaki, W. A method to estimate the statistical significance of a correlation when the data are serially correlated. J. Clim. 10, 2147-2153 (1997).

43. Macias-Fauria, M., Grinsted, A., Helama, S. \& Holopainen, J. Persistence matters: estimation of the statistical significance of paleoclimatic reconstruction statistics from autocorrelated time series. Dendrochronologia 30, 179-187 (2012).

44. Cook, E. R., Briffa, K. R. \& Jones, P. D. Spatial regression methods in dendroclimatology: a review and comparison of two techniques. Int. J. Climatol. 14, 379-402 (1994).

45. Tierney, J. E. et al. Tropical sea surface temperatures for the past four centuries reconstructed from coral archives. Paleoceanography 30, 2014PA002717 (2015).

46. Anchukaitis, K. J. et al. Last millennium Northern Hemisphere summer temperatures from tree rings. Part II, spatially resolved reconstructions. Quat. Sci. Rev. 163, 1-22 (2017).

47. Zwally, H. J., Giovinetto, M. B., Beckley, M. A. \& Saba, J. L. Antarctic and Greenland Drainage Systems http://icesat4.gsfc.nasa.gov/cryo_data/ant_grn_drainage_ systems.php (GSFC Cryospheric Sciences Laboratory, NASA 2012).

48. Fisher, D. et al. Recent melt rates of Canadian arctic ice caps are the highest in four millennia. Glob. Planet. Change 84, 3-7 (2012).

49. Vernon, C. L. et al. Surface mass balance model intercomparison for the Greenland ice sheet. Cryosphere 7, 599-614 (2013).

50. Vinther, B. M., Andersen, K. K., Jones, P. D., Briffa, K. R. \& Cappelen, J. Extending Greenland temperature records into the late eighteenth century. J. Geophys. Res. 111, D11105 (2006).

51. Cappelen, J. (ed) Greenland-DMI Historical Climate Data Collection 1784-2017 DMI Report 18-04 (DMI, Copenhagen, 2018).

52. Bretherton, C. S., Widmann, M., Dymnikov, V. P., Wallace, J. M. \& Bladé, I. The effective number of spatial degrees of freedom of a time-varying field. J. Clim. 12, 1990-2009 (1999).

53. Hannig, J. \& Marron, J. S. Advanced distribution theory for SiZer. J. Am. Stat Assoc. 101, 484-499 (2006).

54. Hawkins, E. \& Sutton, R. Time of emergence of climate signals. Geophys. Res. Lett. 39, L01702 (2012).

55. Fettweis, X. et al. Estimating the Greenland ice sheet surface mass balance contribution to future sea level rise using the regional atmospheric climate model MAR. Cryosphere 7, 469-489 (2013).

56. de la Peña, S. et al. Changes in the firn structure of the western Greenland Ice Sheet caused by recent warming. Cryosphere 9, 1203-1211 (2015).

57. Noël, B. et al. A tipping point in refreezing accelerates mass loss of Greenland's glaciers and ice caps. Nature Commun. 8, 14730 (2017)

58. Hurrell, J. \& National Center for Atmospheric Research Staff (eds) The Climate Data Guide: Hurrell North Atlantic Oscillation (NAO) Index (station-based). https:// climatedataguide.ucar.edu/climate-data/hurrell-north-atlantic-oscillation-naoindex-station-based (NCAR, Boulder, 2003).

59. Hanna, E., Cropper, T. E., Hall, R. J. \& Cappelen, J. Greenland Blocking Index 1851-2015: a regional climate change signal. Int. J. Climatol. 36, 4847-4861 (2016).

60. Mann, M. E. \& Lees, J. M. Robust estimation of background noise and signal detection in climatic time series. Clim. Change 33, 409-445 (1996).

61. Schlesinger, M. E. \& Ramankutty, N. An oscillation in the global climate system of period 65-70 years. Nature 367, 723-726 (1994).

62. Trenberth, K. E. \& Shea, D. J. Atlantic hurricanes and natural variability in 2005. Geophys. Res. Lett. 33, L12704 (2006).

63. Grinsted, A., Moore, J. C. \& Jevrejeva, S. Application of the cross wavelet transform and wavelet coherence to geophysical time series. Nonlinear Process. Geophys. 11, 561-566 (2004). 
a
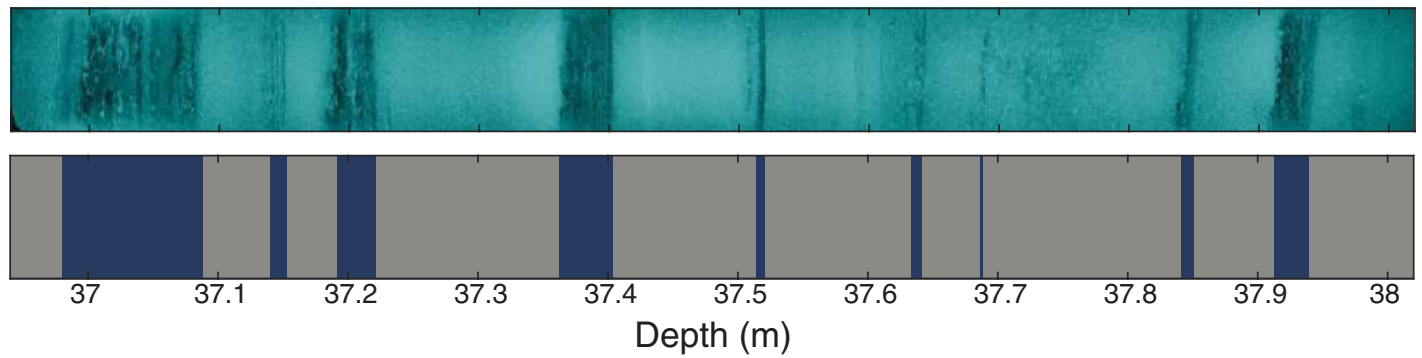

b

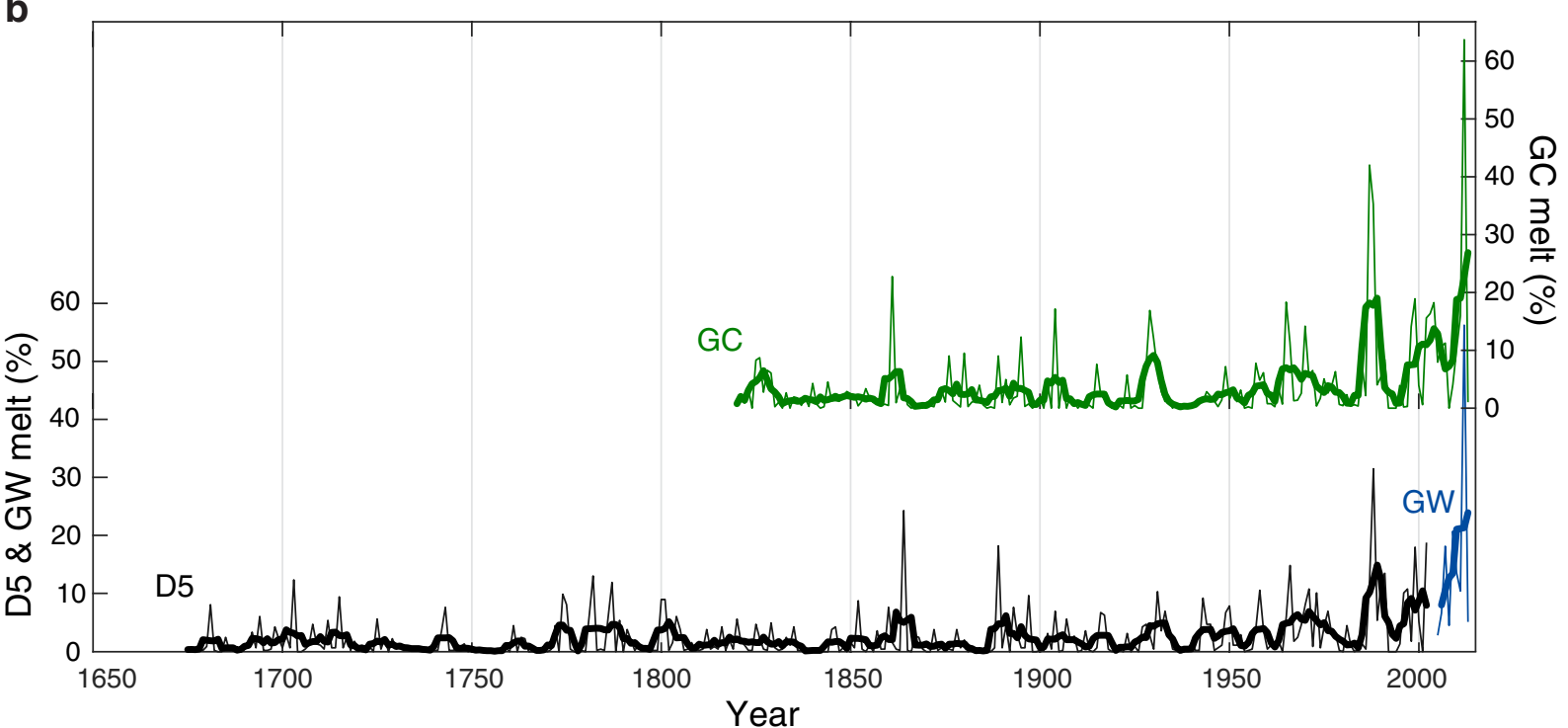

C
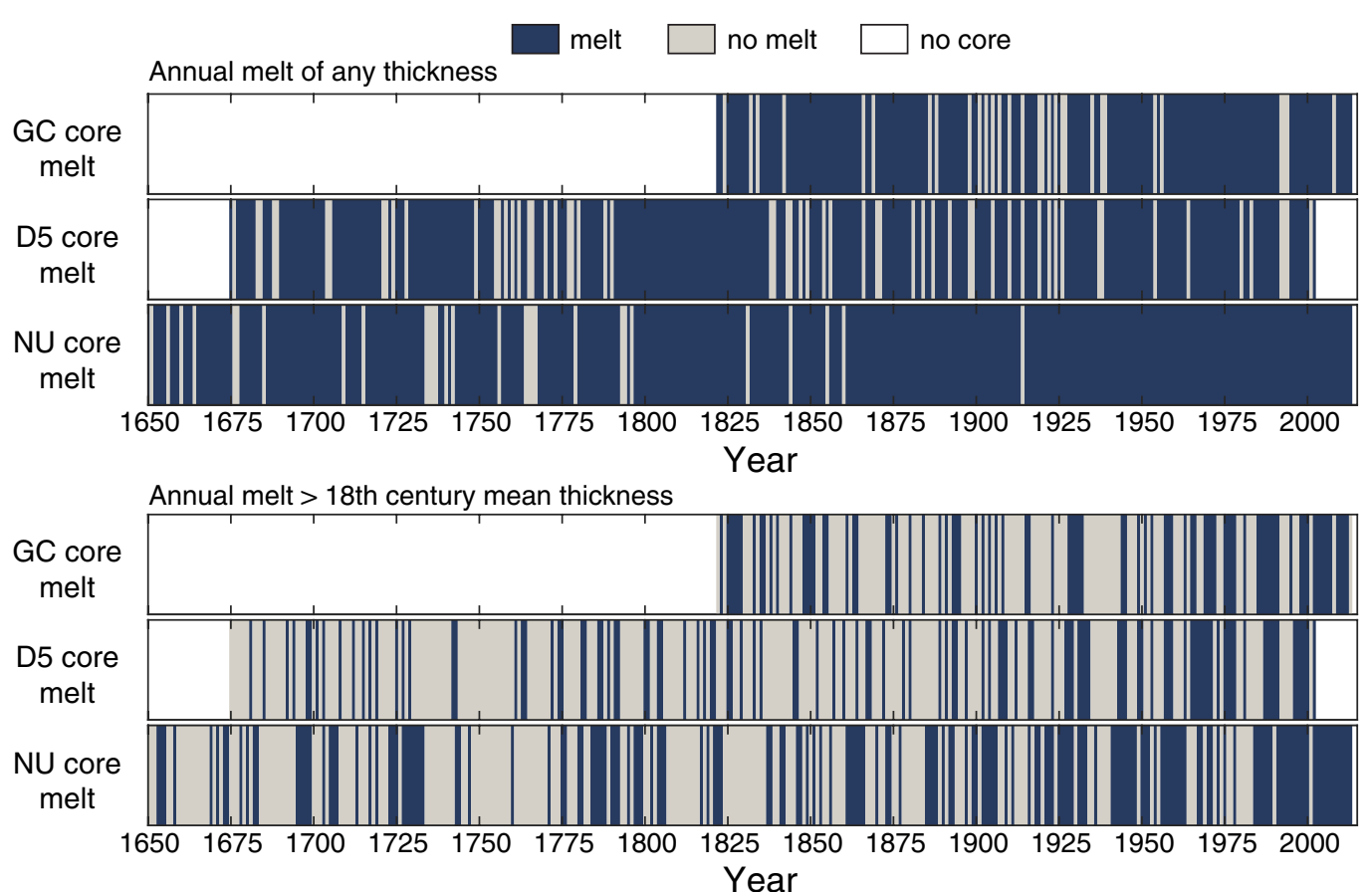

Extended Data Fig. 1 | Example core section and additional annual melt records. a, Example core scan image (top) and resulting digitized melt layers in blue (bottom). b, Annual melt per cent time series for cores in the CWG stack. Bold lines show 5-year moving averages. See Fig. 1 for locations. c, The top panel shows the presence (blue) or absence (grey) of any amount of refrozen surface melt within a particular year in our three longest ice cores, showing regular annual occurrence of melt at each location. The bottom panel shows that, when filtered to show only years with melt percentages greater than the eighteenth-century mean melt at each site, a pattern towards recently more frequent, thicker (and thus more intense) melt emerges. As core GC does not span the eighteenth century, the mean eighteenth-century melt from the nearby D5 core was used as a baseline for GC as well. 

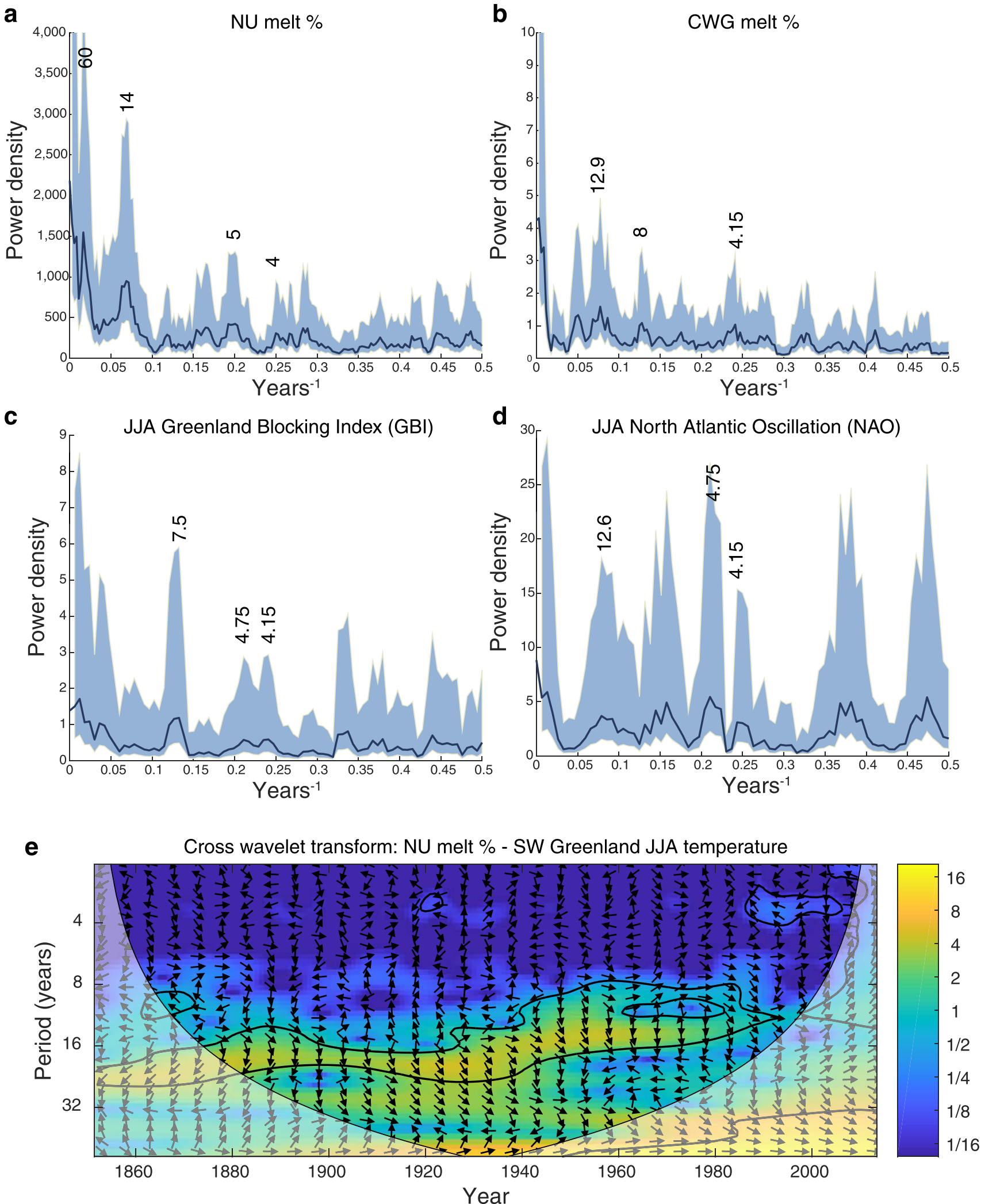

Extended Data Fig. $2 \mid$ Analysis of spectral signatures in melt and climate records. a-d, Multi-taper method spectral power plots for our ice cores, the Greenland Blocking Index ${ }^{59}$ and the North Atlantic Oscillation $^{58}$. e, Cross-wavelet transform plot between NU melt and southwest Greenland temperatures ${ }^{51}$. In the spectral plots $(\mathbf{a}-\mathbf{d})$, years corresponding to specific peaks in spectral power are indicated by numbers, although many peaks are surrounded by a range of years with elevated spectral power. Shaded areas represent $95 \%$ confidence bounds, and we note that many peaks do not show up significantly ( $5 \%$ confidence) above a white-noise threshold. In the cross-wavelet plot in $\mathbf{e}$, areas of significant $(P<0.05)$ coherence are surrounded by a black line. The whiteshaded areas represent regions where coherence cannot be confidently established owing to edge effects. Arrows indicate phase relationships: rightward (leftward) arrows indicate in-phase (out-of-phase) relationships, while downward (upward) arrows indicate melt leading (lagging) temperature. Our analyses found the strongest, and generally in-phase, coherence between NU and air temperature, as opposed to a single climate index, suggestive of the combined influence of multiple climate modes on GrIS melt that are well represented by air temperature (Methods). 
a

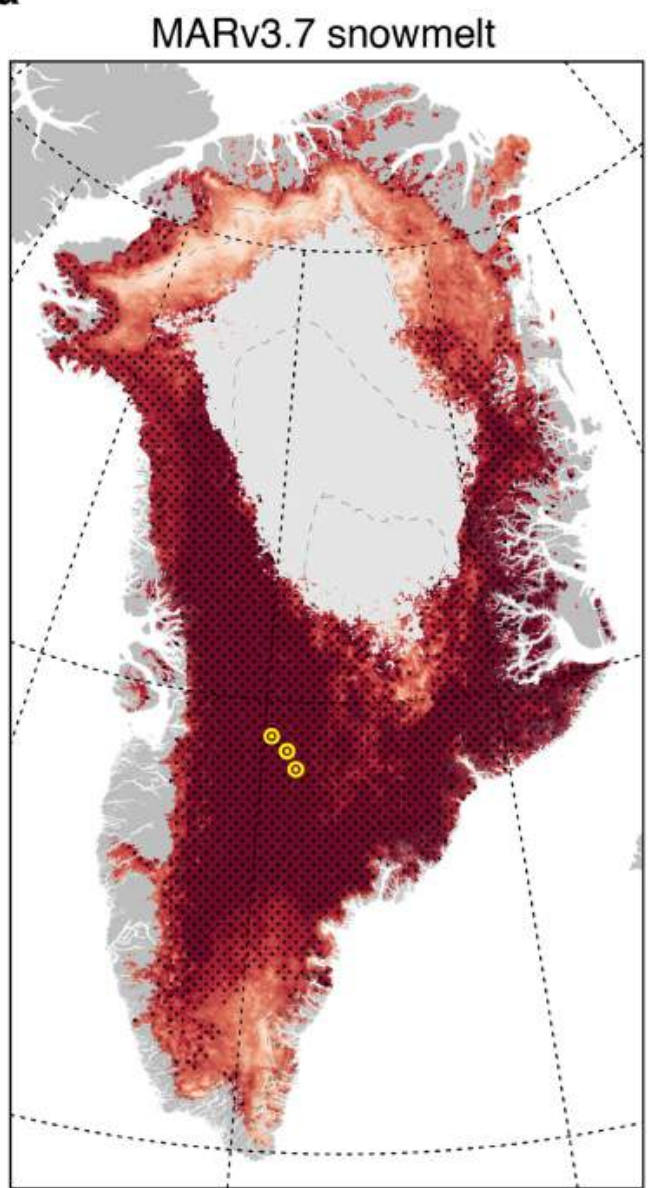

b

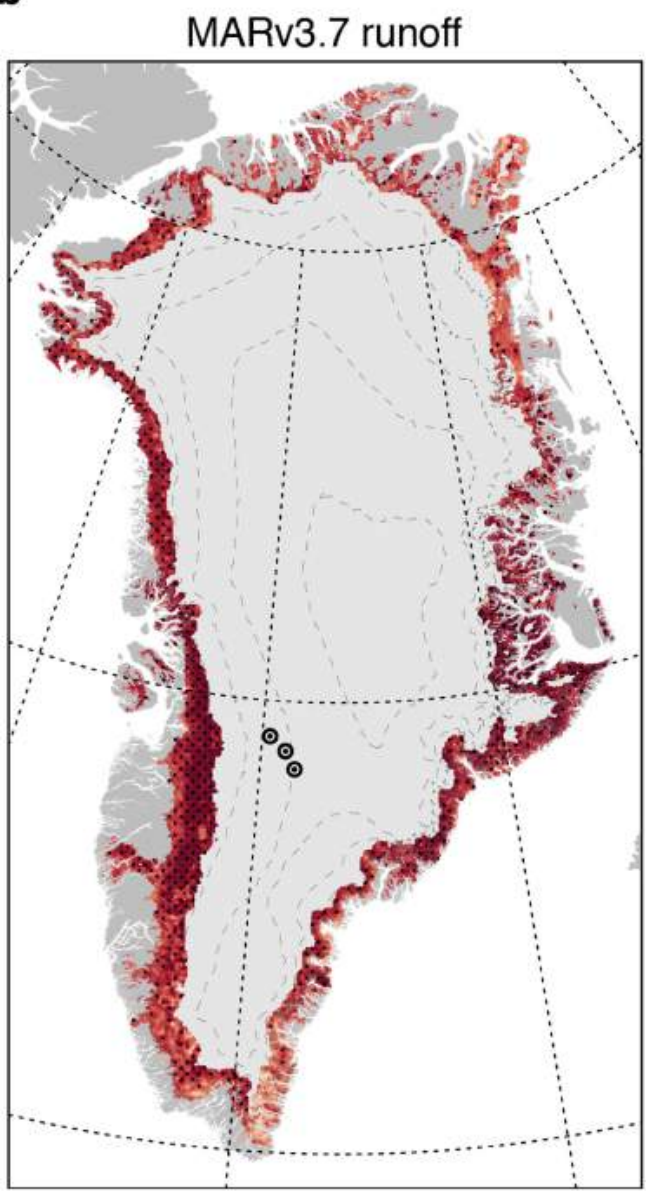

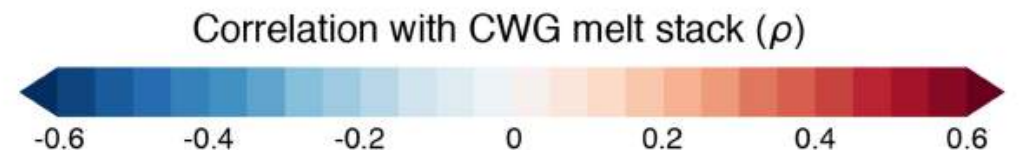

Extended Data Fig. 3 Further evidence of spatially broad

representation of melt processes in CWG cores. Spearman rank order correlations between the CWG melt stack and MARv3.7-modelled annual snowmelt (a) and snowmelt runoff (b) over the period 1978-2013. As in correlations against RACMO2 and satellite melt (Fig. 3), correlations here are shown only for areas where MAR-simulated melt or runoff in at least $50 \%$ of the years of common overlap between the core and modelled datasets $(18$ years). Areas of significant correlation $(P<0.01)$ are denoted by a stipple pattern. Locations of cores used in the CWG stack are denoted by yellow (a) or black (b) points. 
a
RACMO2.3p2

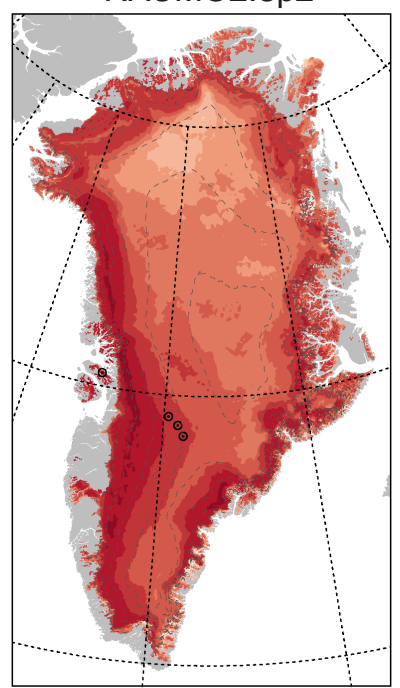

b

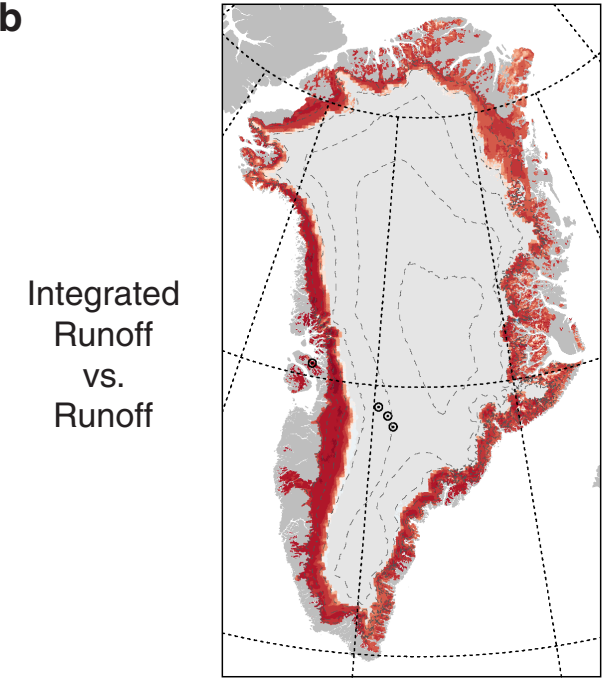

C

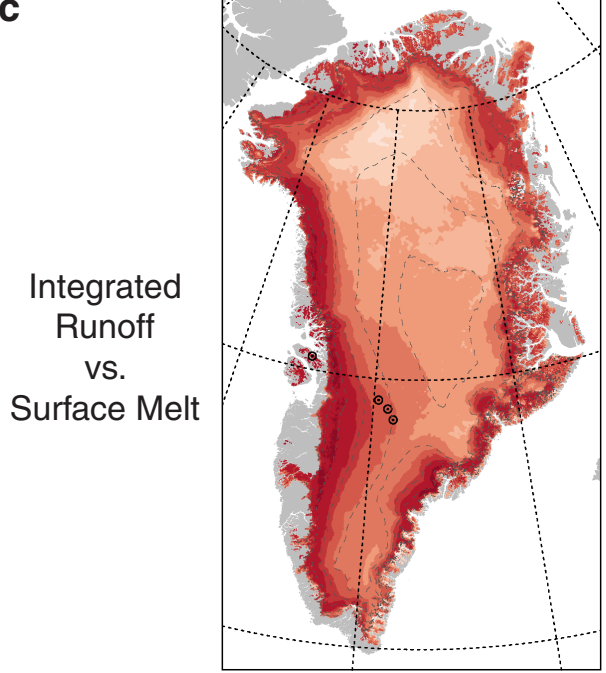

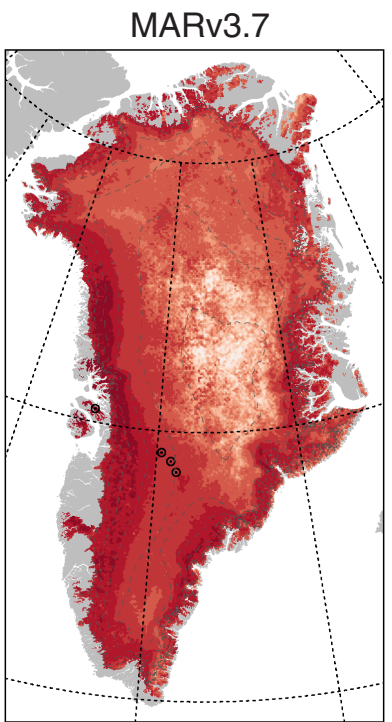
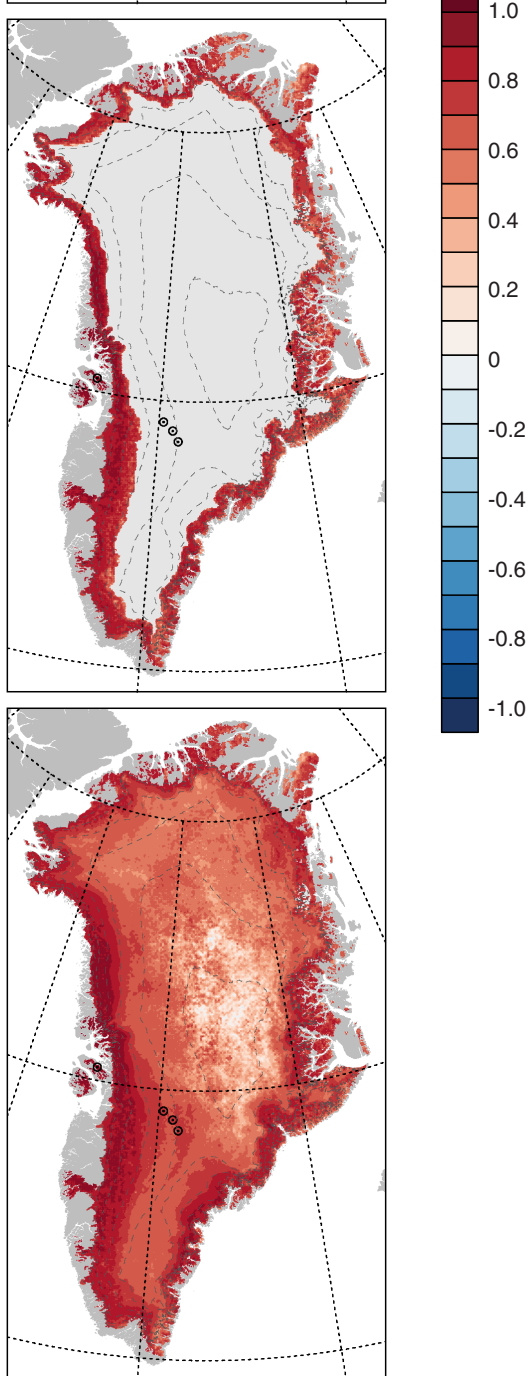

MARv3.7 over 1979-2013 (right-hand plots). Interannual variability in GrIS-integrated melt/runoff is well represented by local-scale interannual variability in melt/runoff. In situ melt records (for example, from well sited percolation-zone ice cores that are able to capture interannual melt variability) can therefore be used to quantify GrIS-integrated melt and runoff.

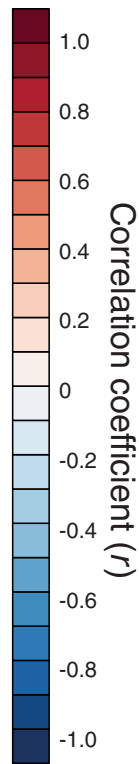

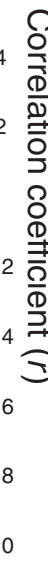

Extended Data Fig. 4 | Relationships between local and ice-sheetintegrated melt processes. Pearson correlation coefficients $(r)$ between GrIS-integrated surface melt and surface melt in each grid cell (a), GrIS-integrated runoff and runoff in each grid cell (b), and GrISintegrated runoff and surface melt in each grid cell (c). Correlations calculated for RACMO2.3p2 over 1958-2013 (left-hand plots) and 

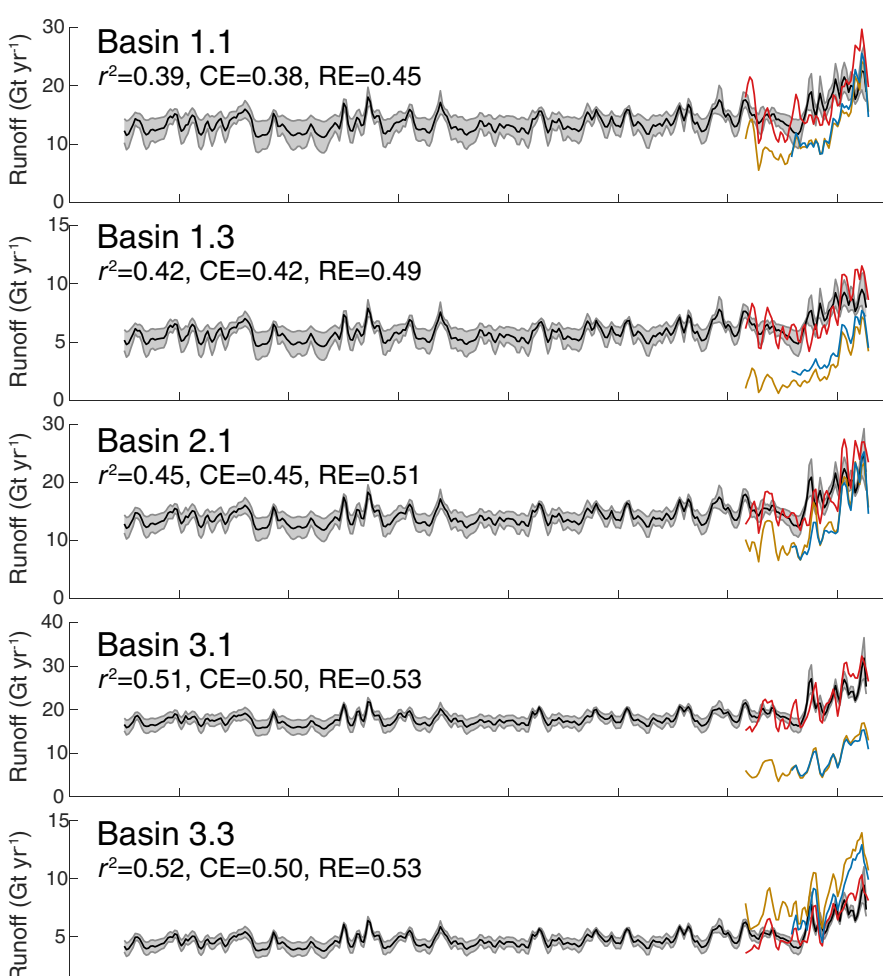$$
\text { 定 }
$$

\section{Basin 4.2}

$r^{2}=0.51, \mathrm{CE}=0.47, \mathrm{RE}=0.51$

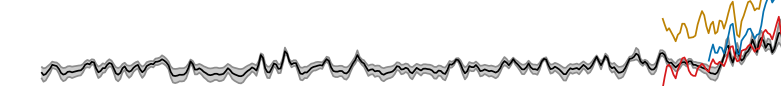

$\widehat{I}^{60}[$ Basin 5

这 $40-r^{2}=0.59, \mathrm{CE}=0.54, \mathrm{RE}=0.59$

弯

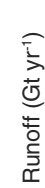

Basin 6.2

$\sum_{0} 100-r^{2}=0.54, \mathrm{CE}=0.54, \mathrm{RE}=0.55$

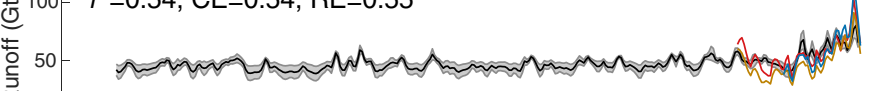
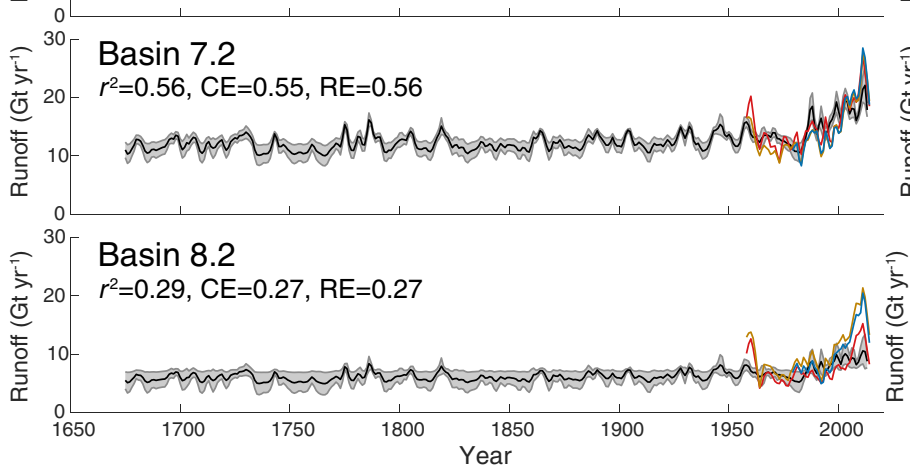

Extended Data Fig. 5 | Basin-specific runoff reconstructions.

Reconstructed runoff using the NU and CWG ice-core melt records calibrated to RACMO2.3p2 for 19 surface drainage basins ${ }^{47}$ and for the full GrIS by summing each basin (lower right; as in Fig. 4). Note unique vertical axes. Reconstruction statistics shown are the maximum
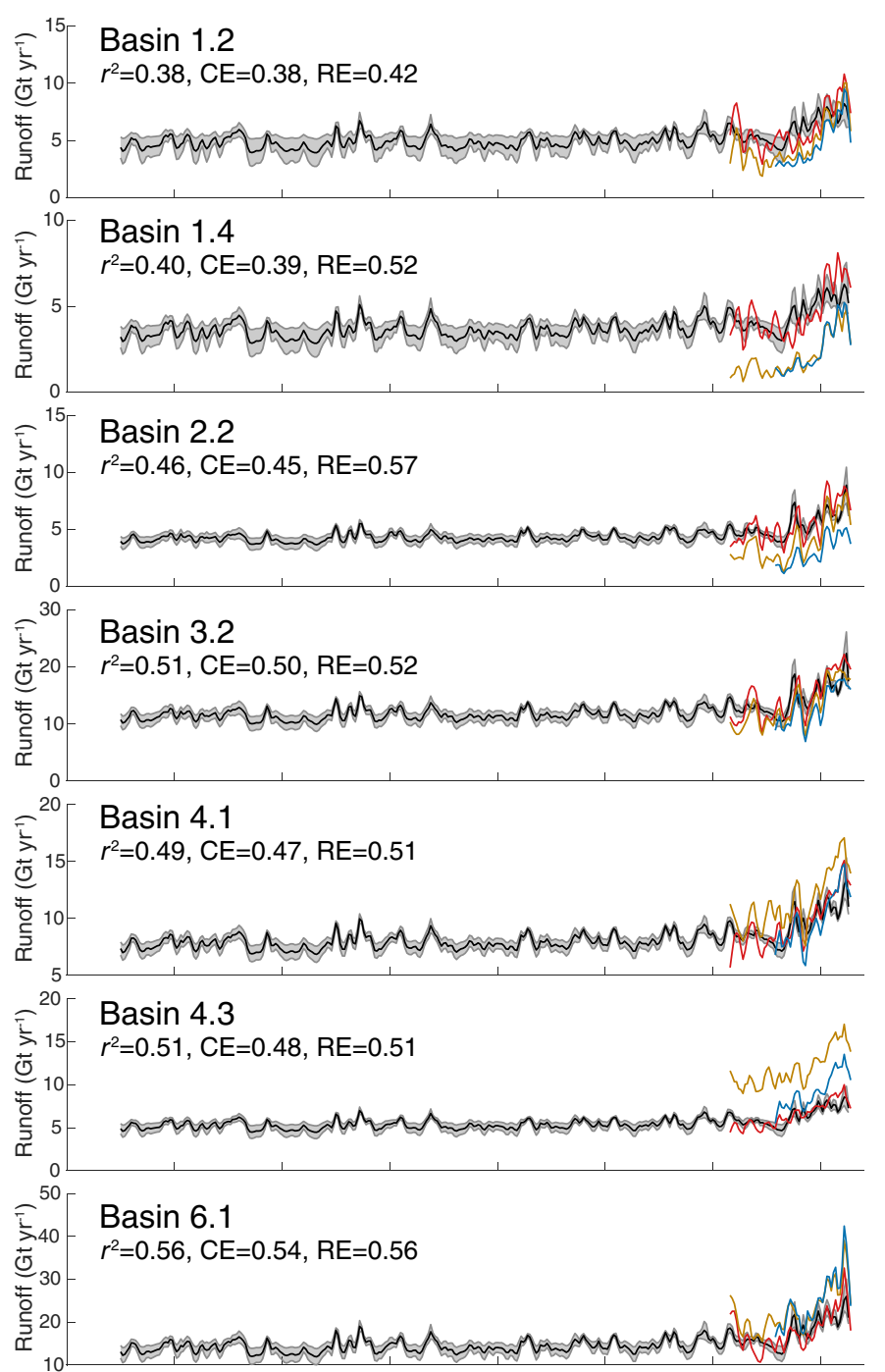

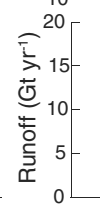

Basin 7.1

$r^{2}=0.56, \mathrm{CE}=0.55, \mathrm{RE}=0.56$

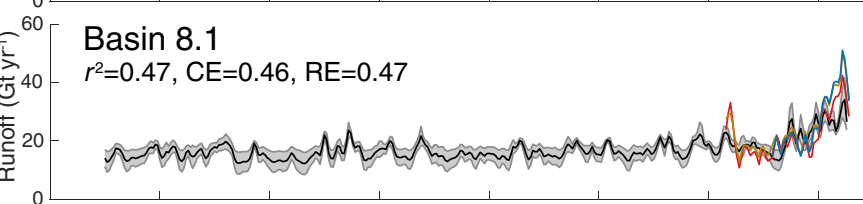

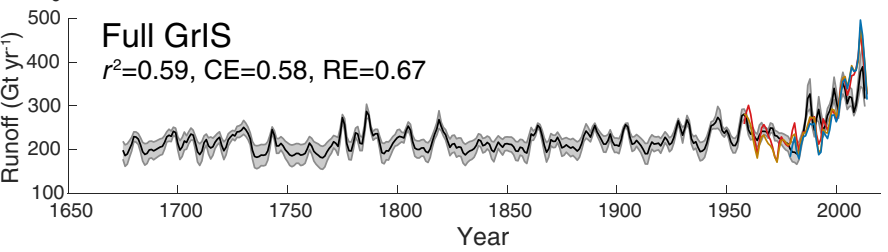

values achieved for each metric across 20 stepwise calibration/validation intervals. Shaded regions around runoff reconstruction represent $95 \%$ confidence bounds. Modelled datasets smoothed using a 5-year Lowess filter. For details on reconstruction see Methods and see Extended Data Fig. 6 for basin location and further statistical assessment. 

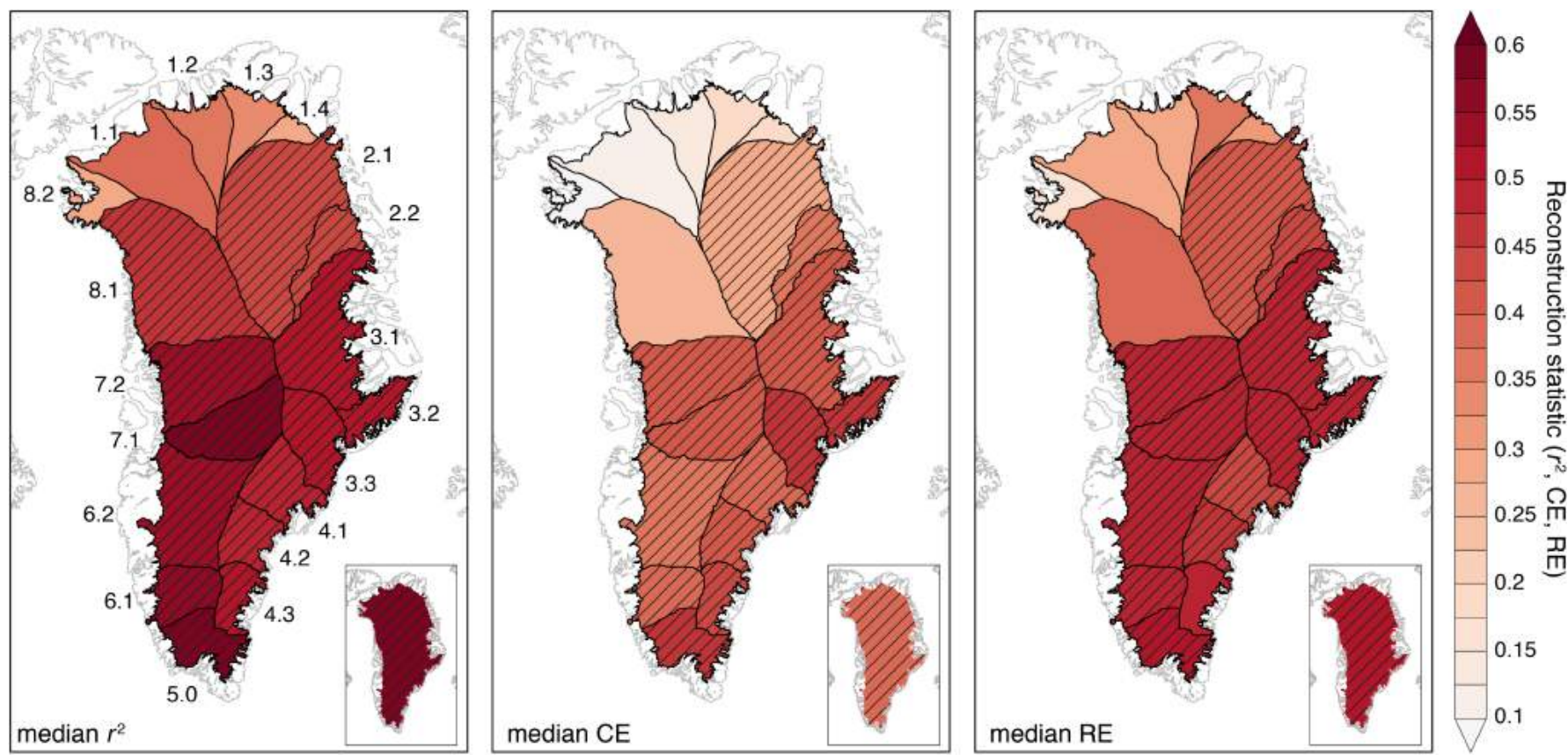

Extended Data Fig. 6 | Basin-specific and GrIS-integrated

reconstruction statistics. Median values of runoff reconstruction skill statistics $\left(r^{2}, \mathrm{CE}, \mathrm{RE}\right)$ over 20 stepwise calibration/validation intervals, calculated for each surface drainage basin (basin numbers in left-hand plot), and for the GrIS as a whole (inset plots). Hatching denotes areas where at least half of the calibration/validation intervals were found to be statistically significant at the $P<0.1$ level, determined using 10,000 Monte Carlo simulations (see Methods). All basins had at least one calibration/ validation interval where at least one of the three validation statistics was significant. See Methods for details on reconstruction methods. 
RESEARCH LETTER

Extended Data Table 1 | Details of firn and ice cores used in this study

\begin{tabular}{lllllll}
\hline Core & $\begin{array}{l}\text { Year } \\
\text { collected }\end{array}$ & Longitude & Latitude & Elevation (m a.s.l.) & Length (m) & Reference \\
\hline GC & 2015 & -43.5025 & 68.892 & 2436 & 104 & This study \\
GW & 2014 & -44.5198 & 69.2028 & 2291 & 140 & This study \\
NU & 2015 & -52.2641 & 70.4865 & 1950 & This study & 148 \\
D5 & 2003 & -42.9 & 68.5 & 2515 & McConnell et al., 2007 (ref. 34)
\end{tabular}

m.a.s.l., metres above sea level. The core source is from ref. ${ }^{34}$. 
Extended Data Table 2 | Statistical relationships among ice cores and CWG air temperature

\begin{tabular}{lll}
\hline Correlation series & Annual/seasonal data & 5-yr moving averages \\
\hline CWG melt versus JJA air temperature ${ }^{50}$ & $r=0.331(n=170)$ & $r=0.581\left(n^{*}=95\right)$ \\
NU melt versus JJA air temperature ${ }^{50}$ & $r=0.259(n=170)$ & $r=0.639\left(n^{*}=91\right)$ \\
CWG melt versus NU melt & $r=0.308(n=339)$ & $r=0.660\left(n^{*}=188\right)$ \\
\hline
\end{tabular}

All correlations are significant at $P<0.01$ level. For 5 -year moving average time series, statistical significance was tested using reduced effective number of observations ( $n *$ ), as well as with a Monte Carlo-based procedure, to account for sample autocorrelation (Methods). Temperature data are from ref. ${ }^{50}$ as shown. 
RESEARCH LETTER

Extended Data Table 3 | Statistical relationships among ice cores, reconstructed runoff and pan-Greenland air temperatures

\begin{tabular}{|c|c|c|}
\hline & Combined CWG and NU melt time series & Reconstructed runoff from adjacent basin(s) \\
\hline Ilulissat $^{\dagger}(1850-2013)$ & $0.665(n=174)$ & $0.641\left(n^{*}=96\right) / \operatorname{Basin} 7.1$ \\
\hline Ittoqqortoormiit (1949-2013) & $0.767(n=65)$ & $0.701\left(n^{*}=36\right) /$ Basin 3.2 \\
\hline Nuuk $^{\dagger}(1866-2013)$ & $0.543(n=148)$ & $0.520\left(n^{*}=82\right) /$ Basin 6.1 \\
\hline Pituffik (1948-2013) & $0.545(n=66)$ & $0.482\left(n^{*}=37\right) / \operatorname{Basin} 8.2$ \\
\hline Tasiilaq (1895-2013) & $0.348(n=119)$ & $0.261^{\S}\left(n^{*}=64\right) / \operatorname{Basin} 4.2$ \\
\hline Upernavik (1871-2013) & $0.690(n=141)$ & $0.643\left(n^{*}=77\right) /$ Basin 8.1 \\
\hline
\end{tabular}

All series smoothed using a 5-year moving average to account for noise inherent to ice-core melt records. The second column shows correlations (multiple $r$ values) using CWG and NU melt records as

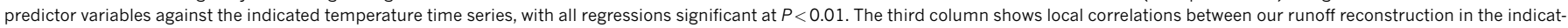

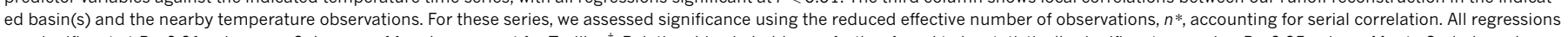
are significant at $P<0.01$ using $n *-2$ degrees of freedom, except for Tasiilaq ${ }^{\ddagger}$. Relationships in bold were further found to be statistically significant assuming $P<0.05$ using a Monte Carlo-based approach (see Methods for details).

tIncludes infilled and regressed observations from regional stations ${ }^{50,51}$

¥Synthesis of llulissat, Nuuk and Qaqortoq master records ${ }^{50,51}$.

$\S P=0.037$ (using $n *-2$ degrees of freedom; see Methods). 
Extended Data Table 4 | Timing of trend initiation and climate emergence

\begin{tabular}{|c|c|c|}
\hline Climate record & Trend onset & Climate emergence \\
\hline Greenland runoff (full GrIS) & $1865(1857.5-1872.5)$ & 1976 (1974-1978) \\
\hline Arctic summer (JAS) sea ice (ref. 29) & $1878.5(1857.5-1899.5)$ & $1947(1943-1951)$ \\
\hline Basin 1.1 reconstructed runoff & $1865(1858.5-1871.5)$ & $1980.5(1979-1982)$ \\
\hline Basin 1.3 reconstructed runoff & $1865(1858.5-1871.5)$ & $1984(1984-1984)$ \\
\hline Basin 1.4 reconstructed runoff & $1865(1858.5-1871.5)$ & $1984(1983-1985)$ \\
\hline Basin 2.1 reconstructed runoff & $1865(1857.5-1872.5)$ & 1976 (1974-1978) \\
\hline Basin 2.2 reconstructed runoff & $1870(1857-1883)$ & $1969.5(1966-1973)$ \\
\hline Basin 3.3 reconstructed runoff & $1866(1858-1874)$ & $1974(1971.5-1976.5)$ \\
\hline Basin 4.1 reconstructed runoff & $1866(1858-1874)$ & $1975(1972-1978)$ \\
\hline Basin 4.2 reconstructed runoff & $1865(1858.5-1871.5)$ & $1979(1977-1981)$ \\
\hline Basin 4.3 reconstructed runoff & $1865(1858.5-1871.5)$ & $1981(1980-1982)$ \\
\hline Basin 5.0 reconstructed runoff & $1865(1858.5-1871.5)$ & $1977.5(1975-1980)$ \\
\hline Basin 6.1 reconstructed runoff & $1865(1857.5-1872.5)$ & $1976(1974-1978)$ \\
\hline Basin 6.2 reconstructed runoff & $1865(1857.5-1872.5)$ & $1975.5(1973-1978)$ \\
\hline
\end{tabular}

Onset of significant trends and climate emergence above pre-industrial levels is defined as 1700-1799 (median and range expressed as \pm median absolute deviation) for datasets shown in Fig. $4 \mathrm{~b}$ (first three records) and for basin-level runoff reconstructions shown in Extended Data Fig. 5. Temperature and sea-ice data are from refs ${ }^{23,29}$. 